
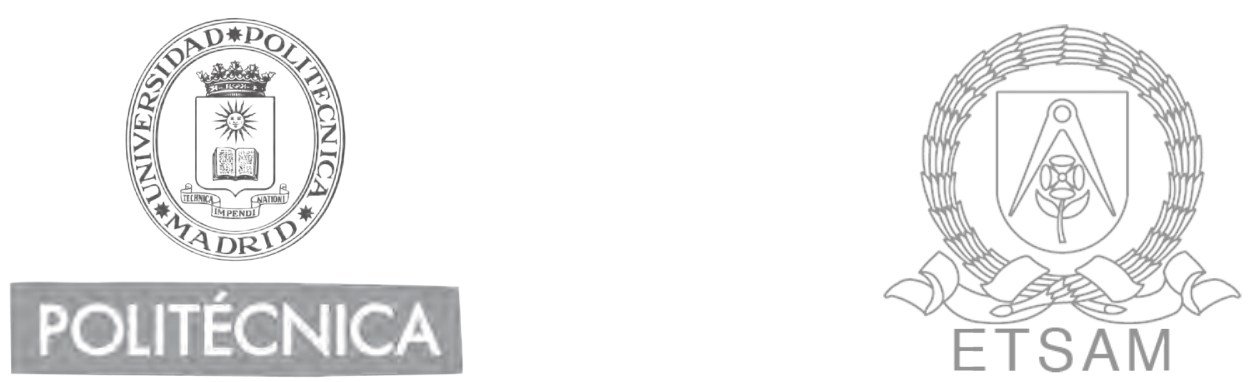

UNIVERSIDAD POLITÉCNICA DE MADRID

Escuela Técnica Superior de Arquitectura de Madrid

Grupo de Investigación Hypermedia

Programa de Doctorado en Comunicación Arquitectónica

\title{
PLAYSPACE | GAMESPACE. \\ ENTRE EL ESPACIO MATERIAL DE LA \\ ARQUITECTURA Y EL ESPACIO VIRTUAL \\ DE LOS VIDEOJUEGOS
}

TESIS DOCTORAL

Autora:

Aida Navarro Redón

Arquitecta

Directorxs:

Atxu Amann Alcocer

Federico Soriano Peláez 



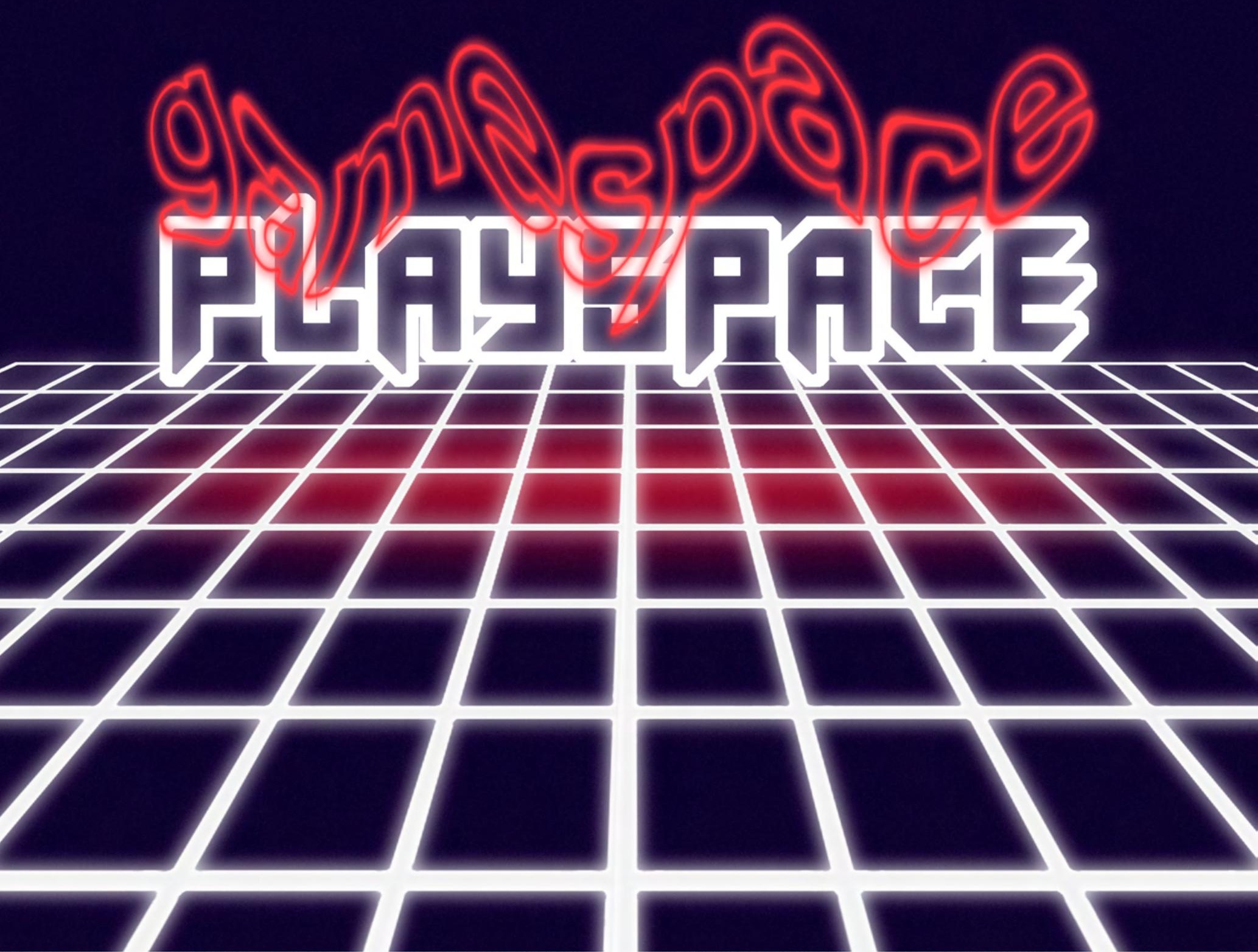



Desde su nacimiento (en los años 60) la creación de videojuegos ha implicado la creación de espacios virtuales donde estos se dieran. Esta investigación enlaza el diseño de esos escenarios lúdicosvirtuales, donde se da el juego, con la arquitectura. Se trazan así las conexiones que se establecen entre ambos campos, el espacio virtual de los videojuegos y el espacio material de la arquitectura.

Por una parte, se analiza como los espacios virtuales han tomado como referencia el espacio arquitectónico, utilizando modos de representación, de interacción, de guía, de organización espacial y hasta de relación con el habitante-jugador, propios de la arquitectura.

Pero, por otra pate, recorre el camino de vuelta, tratando como, posteriormente, ha sido la arquitectura la que se ha valido de los videojuegos, empleando sus herramientas y dejándose afectar por ellos, modificando sus usos y sus propia organización espacial.

Since its beginnings in the 60s, the creation of video games has implied the creation of virtual spaces where they take place. This research connects the design of those virtual playful scenarios, where the game takes place, with architecture. Tracing the connections established between both fields: the virtual space of video games and the material space of architecture.

On one side, the analysis of how virtual spaces have taken architectural space as a reference, using modes of representation, interaction, guidance, spatial organization, and even the relationship of the inhabitant-player, typical of architecture.

And on the other side, it goes the other way and exposes how later the architecture has used video games tools. And therefore, how architecture is been affected by them, modifying the uses of these tools, and the spatial organization. 
Esta tesis está especialmente dedicada a Alan Turing:

Se declaró culpable y no se defendió.

Propuso los juegos como un campo de investigación.

Y así; abrió caminos que yo he podido recorrer. 
Esta tesis no habría existido nunca si una mañana de noviembre de hace cinco años yo no me hubiera encontrado con una mujer en el despacho 40 de la tercera planta y ella, sin saber nada de mi, se hubiera ofrecido a ayudarme. Pasará el tiempo pero yo nunca olvidaré ese momento en que me tendió la mano a cambio de nada (y se pensó que estaba loca, esto también). Esa mujer era Atxu Amann, mi directora de tesis, amiga, asesora espiritual y madre intelectual a la que un día espero parecerme más.

Tampoco habría sido posible hacerla sin el profesor Federico Soriano, ojalá más cerebros brillantes como el suyo en la universidad española (y más camisas fabulosas y más conversaciones en el patio de su estudio).

Por supuesto, darles las gracias a todos los que han querido valorar este trabajo. Tanto a los miembros del tribunal de pre-lectura: Milla Hernández Pezzi, Eduardo Roig y Federico Blanco; como a los que han aceptado formar parte de la lectura de la tesis: Javier Echeverría, Lucía Jalón, Andrés Jaque, Carlos León y Eurídice Cabañes (y también Liana Grigoriadou e Irma Arribas). Es para mi un honor.

Durante todo este tiempo he compartido aventuras y desventuras de arquitectura, investigación y docencia con un puñado de personas geniales: compañeros de universidad (de la ETSA de Valencia y la de Madrid), amigos del Máster de Proyectos y del de Diseño de Videojuegos, del grupo de investigación Hypermedia, alumnos que ahora son amigos de MACA y aliados en proyectos varios.

Paula Jiménez, compañera de docencia de MACA, me ha asesorado y ayudado a dar forma a la tesis con una paciencia y sensibilidad infinitas.

Investigar en España es muy difícil. En este caso, le debo mucho a algunas empresas que me contrataron e hiceron posible continuar investigando. De entre todos ellos estoy profundamente agradecida al estudio Daniel Canogar y mis compañeros allí.

He podido completar este trabajo gracias a multitud de personas en librerías, bibliotecas, colecciones y universidades (como la genial Eloisa Granodeoro) que me han ayudado desinteresadamente. Carlos Molinero de The Barlett School of Architecture me ayudó cuando estaba muy perdida en Londres. Warren Robinnet, María Elisa Navarro y Juan Delcán (entre otros muchos) contestaron a mis preguntas y me permitieron construir esta investigación con sus respuestas.

Sin Natalia García y Javier Quintero nunca habría acabado esta tesis, ellos le pusieron 'el collar al perro'.

Bea, Anna, Carlos, Nuria, Aza, Ele, Josep, Ana, Cani, Héctor y el resto de mi familia y amigos que han estado siempre conmigo.

Isabel Recubenis, mi amiga y socia, a quien conocí el primer día que pise una universidad, con su extraordinaria sensibilidad me hace mejor.

Por encima de todo, mi agradecimiento a quienes me transmitieron la pasión por aprender; mis padres y mi abuelo. Gracias a mi Abu por enseñarme que si no sabía algo siempre podría inventármelo; a mi padre por los libros y tanto tiempo invertido en mí (tantísimo que hasta ha mecanografiado esta tesis conmigo) y a mi madre por ser la persona más valiente. Por haberme enseñado todo lo importante, la pasión por las matemáticas, la lucidez, la bondad y la capacidad de no rendirse.

Alex - antes de acabar - incansable lectora, revisora y animadora de esta tesis, que está cada día a mi lado y vendría conmigo (y yo con ella) allí donde se nos ocurriera vivir una aventura. Es mi paz después de la guerra. Antes de conocerla decía que el amor de mi vida era la arquitectura. Ahora ya no lo digo, ni lo pienso. 
Capítulo 1. Introducción, definición y planteamiento de la investigación.

1.1 Background: experiencia previa y la guerra.

1.2 Construcción del contexto

1.2.1 En relación al análisis histórico

1.2.2 En relación al desarrollo tecnológico y gráfico. El gamespace

1.2.3 En relación a la evolución social. El playspace

1.2.4 Entorno contemporáneo de investigación.

1.3 Definición del tema, hipótesis y objetivos

1.4 Metodología

\section{*terminología para esta tesis*}

Capítulo 2. Del espacio arquitectónico al espacio del videojuego

2.0 Los orígenes. Las palabras y las cosas.

2.1 La construcción del escenario. Del gamespace.

2.1.1 Referencias de diseño: de la realidad a la abstracción

2.1.2 Referencias de representación

2.2 Las estrategias de guía e interacción espacial.

2.3 El papel del jugador en el espacio

2.3.1 Del jugador espectador al jugador constructor.

2.3.2 Los límites del espacio de juego para el jugador

2.4 Conclusiones parciales del capítulo

Capítulo 3. Análisis gráfico

3.1 Introducción al análisis

3.2 Generación 01

3.3 Generación 02

3.4 Generación 03

3.5 Generación 04

3.6 Generación 05

3.7 Generación 06

3.8 Generación 07

3.9 Generación 08

3.10 Conclusiones parciales del capítulo 
Capítulo 4. Del espacio del videojuego al espacio arquitectónico.

4.1 El mundo en tres dimensiones

4.1.1 Software para un mundo en 3D.

4.1.2 Del mundo virtual al mundo material.

4.2 El espacio arquitectónico material del videojuego. El playspace.

4.2.1 El cambio en el modelo de ocio colectivo.

4.2.2 El espacio doméstico del videojuego.

4.2.3 El juego en cualquier parte.

4.3 Los efectos del videojuego en el espacio a gran escala

4.3.1 La disolución del límite virtual-material.

4.3.2 Los límites del jugador en el espacio.

4.4 Conclusiones parciales del capítulo

Capítulo 5. Conclusiones: un camino de ida y vuelta

- Bibliografía. Fuentes y archivos consultados.

- Ludografía.

- Apéndice $1^{1}$ : Registro completo de cartografías de dispositivos

- Apéndice 2 : Avances de resultados.

\footnotetext{
${ }^{1}$ Este apéndice es exclusivo a la versión digital, en la versión física las cartografías se colocan como desplegables transparentes sobre las propias del Capítulo 3. Esto era imposible de mostrar en digital para que fuera cómodo de leer, por lo que se adjuntan al final.
} 


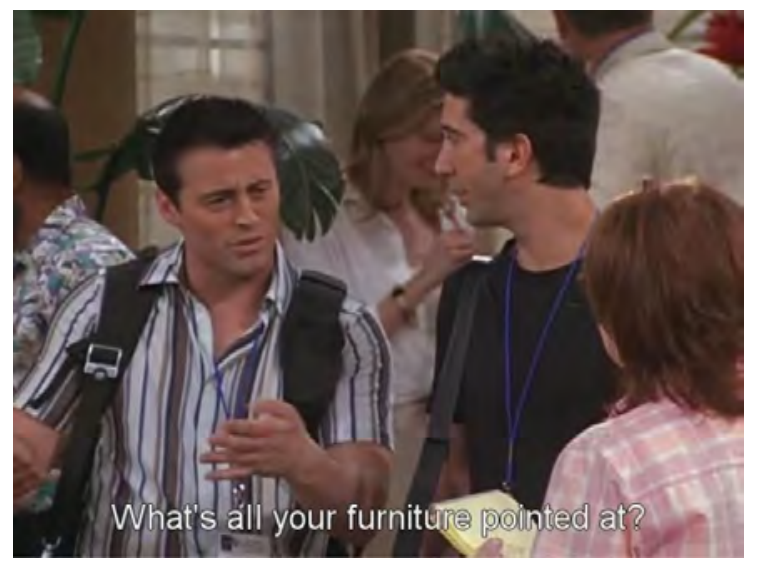

Joey: Me conocerás de televisión. Actúo en el papel del doctor Drake Ramoney

[en la telenovela Días de nuestra vida]

Fan de Ross: No tengo televisor

Joey: Entonces ¿hacia donde apuntan los muebles de tu salón?

Capítulo 23. Temporada 09 'El primero de Barbados'. Serie sitcom Friends (emitida 1994-2004) 
INTRODUCCIÓN, DEFINICIÓN Y PLANTEAMIENTO DE LA INVESTIGACIÓN 
'[...]Not limiting their activities to the earthly realm, American and British spies have infiltrated the fantasy worlds of World of Warcraft and Second Life, conducting surveillance and scooping up data in the online games played by millions of people across the globe, according to newly disclosed classified documents [...] Online games might seem innocuous, a top-secret 2008 NSA document warned, but they had the potential to be a "target-rich communication network" allowing intelligence suspects "a way to hide in plain sight." Virtual games "are a space opportunity!" another 2008 NSA document declared.'

Artículo publicado por ProPublica en colaboración con The Guardian, y The New York Times el 9 de diciembre de 2013 tras salir a la luz los documentos filtrados por Edward Snowden. 


\section{BACKGROUND Y EXPERIENCIA PREVIA, LA GUERRA}

1.1

La investigación que se desarrolla en esta tesis nace-principalmente - a partir de dos puntos enlazados echando la vista atrás: un interés personal por los juegos (tanto virtuales como analógicos) que desembocó en un Trabajo Fin de Máster ${ }^{2}$ sobre la relación juego-espacio público y una serie de noticias (leídas sobre todo entre 2013 y 2014) que permitían entrever un campo de investigación relevante en torno a los juegos en el espacio virtual.

Del primero cabe señalar 'algo' que no suele reseñarse en las investigaciones ortodoxas, pero que, sin duda, resulta vital. A ello hace referencia el cardiólogo Valentín Fuster al repasar su propia experiencia como director del Centro de Cardiología de Nueva York ${ }^{3}$ como base para construir ciertas ideas. Ese 'algo' es, por supuesto, la propia experiencia y entusiasmo de cada investigador, que en este caso concreto se centraba en el juego.

No tendría sentido obviar el interés propio, derivado de haber crecido entre matemáticas, puzles, acertijos, construcciones y juegos de lógica como una cuestión clave a la hora de elegir un camino de investigación. $\mathrm{Ni}$ obviar tampoco los finales de los años 90 consiguiendo disquetes para copiar juegos que aún no habían salido en España y que, en el mejor de los casos, estaban en inglés. También especialmente interesante fue aprender a programar en un - muy básico - HTML y dar en la primera década de los 2000 con juegos a mitad camino entre el mundo virtual y el real (como los desarrollados por la Sociedad Española de Matemáticas en sus olimpiadas ${ }^{4}$ ) o aquellos que disolvían la idea de 'juego' y entraban más en el terreno de los rompecabezas de soluciones múltiples como Notpron ${ }^{5}$.

Este entusiasmo propio - esta deformación personal - por la idea de juego fue, sin duda, el detonador que permitió fijar la atención en ese tema cuando en 2013 se publicó el anteproyecto de Ley de Seguridad Ciudadana ${ }^{6}$. La propuesta estaba en todos los medios de comunicación por

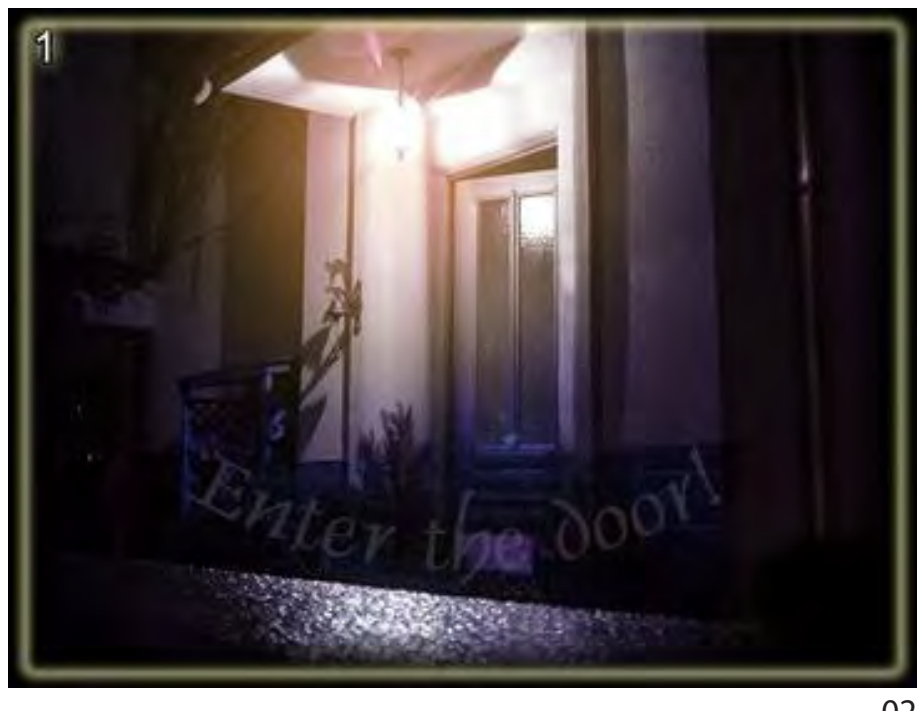

2 El espacio público como tablero de juego. TFM. Máster en Proyectos Arquitectónicos Avanzados. 2014. charla TEDx. 2016

${ }^{3}$ Fuster, Valentí. El circulo de la motivación. Planeta. 2013

${ }^{4}$ Las olimpiadas de la Real Sociedad Española de Matemáticas tienen tres partes: una prueba teórica en papel, una prueba de velocidad por equipos y una última considerada prueba de campo que no es más que un juego que permite combinar reglas lúdicas con los recorridos a través de una ciudad.

${ }^{5}$ Notpron, juego de puzzles online creado en 2004 por David Münnich con 140 niveles de soluciones diversas (incluyendo consultar el código fuente o usar herramientas como editores de sonido). En octubre de 2019 había recibido 19 millones de visitas y solo 66 personas habían completado el juego.

${ }^{6}$ Ley de Seguridad Ciudadana (anteproyecto de 2013, ley en firme 2016). Congreso de los Diputados de España. 
muchos motivos, pero casi ninguno se detenía en el artículo 63; en el que se indicaba el castigo mediante penas expresas - por primera vez - para el acto de jugar cuando este sucediera en lugares no acotados para ello.

Este apunte sirvió como punto de partida para llevar a cabo una serie de investigaciones y lecturas que, centradas en Aldo van Eyck, Cedric Price, Giorgio Agamben, Walter Benjamin, Johan Huizinga o Ernst Bloch, permitieron construir una base en torno a conceptos teóricos del juego y su relación con el espacio y concluyeron con la elaboración de la investigación 'El espacio público como tablero de juego' al finalizar el año de máster en octubre de 2014.

El segundo punto en que se apoya el origen de esta investigación tiene mucho que ver con el comienzo del ensayo 'Pornotopía'.

"Este proyecto surgió de una noche de insomnio. Veía la televisión, mientras intentaba dormir sin éxito en mi apartamento de Brooklyn, cuando, de repente, escuché a Hugh Hefner, el director de Playboy, la más influyente revista para adultos del mundo, vestido con pijama, batín y zapatillas de estar en casa, hablando sobre la importancia de la arquitectura en el imperio que él mismo había creado en 1953: palabras como «domesticidad», «liberación espacial» o "ático de soltero» tenían una resonancia especial en el discurso de Hefner. [...] Así fue como Playboy acabó siendo un laboratorio crítico para explorar la emergencia de un nuevo discurso sobre el género, la sexualidad, la pornografía, la domesticidad y el espacio público durante la guerra fría."

Preciado, 2010

En diciembre de 2013, justo a mitad del año del Máster de Proyectos Arquitectónicos Avanzados se hicieron públicos gran cantidad de documentos clasificados ${ }^{7}$ relativos al espionaje y el control informático a través de la filtración de Edward Snowden. Entre ellos uno en concreto titulado 'NSA files: games and virtual environments paper'8 , escrito en 2008 y publicado el 9 de diciembre de aquel año, mostraba el interés de los servicios de espionaje tanto británico como estadounidense por los juegos virtuales entendiendo que podían constituir un espacio de oportunidad. Alertaban de la importancia de desarrollar medidas que aplicar a estos lugares virtuales, donde al darse la comunicación entre jugadores e incluso los traspasos económicos, podían desencadenarse tramas de variable cuestionamiento legal y/o ético.

Por aquel entonces la investigación de máster sobre el juego estaba centrada más en una fase de documentación teórica y no abarcaba el juego virtual. Sin embargo, la idea de que el espacio virtual fuera considerado espacio de oportunidad, y que con ese término se le igualara de algún modo y se introdujera la necesidad de que la ley, las personas, el control o la vigilancia actuaran sobre él como actúan sobre el espacio material, resultó tan cautivadora como las palabras de Hefner para Preciado. Medio año después, ya en 2014, con el trabajo de Máster entregado, esa idea lanzada en el documento de la $\mathrm{NSA}^{9}$ fue el principal apoyo para hacer virar la investigación hacia el espacio virtual, y determinar que el juego en él sería el tema siguiente que investigar. Ello se vio alimentado durante

\footnotetext{
${ }^{7}$ En 2013 el exconsultor tecnológico de la CIA Edward Snowden dio a conocer información clasificada.

8 'NSA files: games and virtual environments paper' 2008. Adjunto en Anexo 1.

${ }^{9}$ Siglas de National Security Agencia (NSA) de Estados Unidos.
} 
los siguientes meses con la lectura de numerosos artículos sobre las relaciones de los videojuegos con cuerpos de espionaje, inteligencia o militarización como el ejército de ESTADOS UNIDOS o el ISIS ${ }^{10}$.

Este último tema, la relación del denominado Estado Islámico con el espacio virtual estaba siendo ampliamente reseñado en aquel momento, en artículos como 'Video games, terrorism, and ISIS's Jihad 3.0' (Al-Rawi, 2016) o 'The Media Strategy of ISIS' (Farwell, 2014) dada su contemporaneidad, sin ser innovador en sí mismo. Ya en los años 80 y 90 , se analizó el uso militar que daba a los videojuegos el ejército de Estados Unidos (Barlow M, 2005).

Poco después, ese verano de 2014, se publicó en la BBC una entrevista con un joven soldado de ISIS que expresó que 'mi vida es mejor que Call of Duty'11. Esta comparación con el videojuego bélico en primera persona reflejaba que la línea que separa el espacio virtual del espacio material - si es que existía - estaba tendiendo a una disolución que llevaba a una mezcla entre ambos.

Esta serie de noticias acerca del uso de los videojuegos como estrategia bélica se enriqueció con la lectura de 'War Play: Video Games and the Future of Armed Conflict' (Mead, 2013) y 'Joystick Soldiers. The Politics of Play in Military Video Games' (Huntemann, Payne, 2009) lo que permitió conformar una línea de investigación primitiva, que se centraba en el uso de videojuegos por parte de la industria bélica en torno a dos grandes bloques.

Por una parte, la utilización del espacio virtual como campo de pruebas y entrenamiento del espacio material. Estos juegos son considerados la sucesión lógica de los poblados y escenarios de entrenamiento construidos con dicho objetivo desde el final de la II Guerra Mundial (Fernández-Muro, 2013). En el caso de España el propio Ministerio de Defensa explica:

"De gran importancia durante el proceso de adiestramiento es la simulación en ejercicios con espacios y actores reales, pero estos son difíciles y costosos puesto que requieren de personal con profundos conocimientos de la forma de actuar de la población y del ambiente en el que se va a mover la unidad, y en cantidad suficiente para que sea eficaz [...] por ello se propone como alternativa recurrir a programas de simulación informatizados".

Las nuevas guerras: globalización y sociedad ${ }^{12}$.

Este uso, denota, además, la importancia que toman los planos y mapas virtuales, hasta tal punto de emplearse como anticipo de un espacio real que representan ${ }^{13}$.

Por otra parte, la utilización del juego y su narrativa como forma de

\footnotetext{
10 Siglas del Estado Islámico (ISIS/DAESH)

10 'British jihadi compares Syria war to Call of Duty'. 13 Jun 2014. BBC. Consultado online 03/01/2017 en http://www.bbc.co.uk/newsbeat/article/27838978/british-jihadi-compares-syria-war-to-call-of-duty

12 Monografías del CESEN. Centro Superior de Estudios de la Defensa Nacional. Ministerio de Defensa. Octubre 2011

${ }^{13}$ Russ Shilling, Michael Zyda and E. Casey Wardynski, "Introducing Emotion into Military Simulation and Videogame Design: America's Army Operations and VIRTE," in the Proceedings of the GameOn Conference, London, 30 November 2002, pp. 151-154.
} 
promover una visión concreta de la realidad y, por tanto, captar la atención de los jugadores hacia un punto de vista concreto. Sucede así en títulos como American Army ${ }^{14}$, que fue pionero como juego de captación, cuando en 1999 el propio ejército de Estados Unidos lo desarrolló para emplearlo frente a la crisis de alistamientos. El uso de videojuegos como estrategia de comunicación y llamada de atención ha suscitado desde sus inicios interés y ha sido protagonista de multitud de estudios e investigaciones académicas. Resulta especialmente significativa la

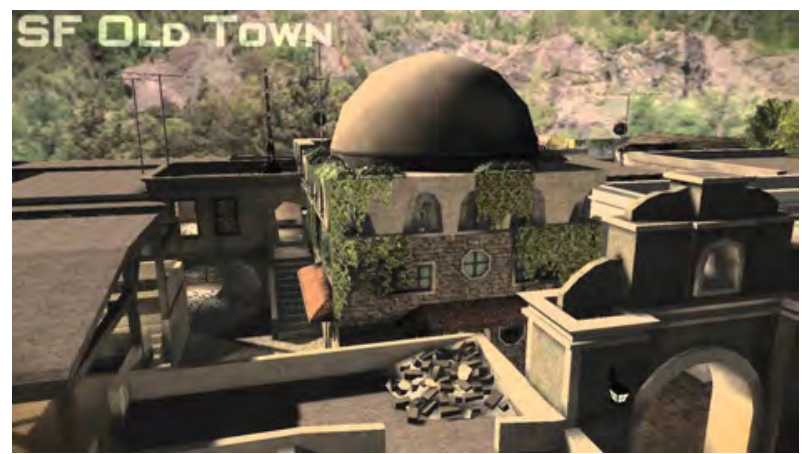

03 reflexión del antropólogo Allen Robertson $(2010,2012)$ que trabajó durante dos años en el equipo de desarrollo de American Army - al referirse al juego como un sistema que genera 'guerras sin fronteras' ya que éstas quedan diluidas en el espacio virtual. Estados Unidos deja de poder reclutar a miembros exclusivamente en su territorio extendiéndose por todos los lugares a los que llegue la conexión y los archivos del juego: es la conexión al juego la que constituye un límite y no la dimensión geográfica.

Esta línea de investigación primigenia en torno a los videojuegos y la guerra mostró claros puntos de contacto y posible análisis sobre la relación espacio material/espacio virtual en el juego y sirvió como punto de partida. Sin embargo, entraba en muchos temas que se alejaban del campo arquitectónico y espacial que ocupa y centra este trabajo. Además de tratarse de un tema ya desarrollado por especialistas de otras áreas. Por ello, y tomando como inicio muchas de las conexiones conseguidas con la guerra, se decidió que esta investigación se centraría en el espacio material y el espacio virtual del videojuego, y la relación entre ambos.

${ }^{14}$ American Army, (2002). United States Army. 


\section{2}

Una vez determinado el campo de interés y la relación del espacio virtual de los videojuegos y del espacio material de la arquitectura, se comienza la investigación tratando de determinar el estado del tema sobre el que se asienta la relación a estudiar: espacio material-espacio virtual. Destacando desde un inicio la falta de análisis que relacionen ambos campos.

En una comparativa con otro arte también ligado al espacio y la narrativa como es el cine, existe una notable diferencia en cuanto a la cantidad y extensión de investigaciones y estructuras de investigación desde la arquitectura. En el caso del cine, existen numerosas investigaciones tanto informales como académicas. Solo en la Escuela de Arquitectura de Madrid constan $6^{15}$, siendo un área en que muchas universidades disponen de su propia línea de trabajo. Architecture and The Moving Image en University of Cambridge, The Bartlett Film, place Architecture Network en UCL o the Interactive Cinema en el Medialab del MIT son algunos ejemplos.

Cabe señalar que el cine como espectáculo data de finales del siglo XIX mientras que los videojuegos no alcanzaron esta posición hasta pasado el ecuador del siglo XX (70 años de diferencia). Sumado esto a la concepción histórica de que los videojuegos no eran (al menos inicialmente) un sistema para adultos ni más allá del entretenimiento, ha perpetuado la imagen de arte menor (Villalobos, 2014).

\subsubsection{En relación al análisis histórico}

Los espacios virtuales de los videojuegos son recorridos y habitados por, prácticamente, la mitad de la población ${ }^{16}$. En 2018 jugaban el 47\% de las personas en datos globales ${ }^{17}$. Por franjas de edades se alcanza el $70 \%$ de video jugadores por debajo de 24 años y el $50 \%$ por debajo de $40^{4}$. Así, en España hay más de 14 millones de jugadores que pasan una media de 6 horas semanales en el mundo virtual ${ }^{5}$. Sin embargo, el videojuego como producto de una industria que ha alcanzado un elevado consumo (mueve más dinero que los libros, el cine y la televisión juntos ${ }^{6}$ ), comenzó hace tan solo 50 años.

Esta rápida evolución ha sido ampliamente estudiada por Steven L. Kent, periodista estadounidense de videojuegos que ha analizado gran cantidad de títulos. En su libro 'The Ultimate History of Video Games. The story behind the craze that touched our lives and changed the world' (2001) realiza detallado recorrido por la historia de los videojuegos, destacando un

\footnotetext{
15 Lista completa en la bibliografía completa en Anexo 1.

164 Estudio 'La industria del Videojuego en España. Anuario 2018'. Elaborado por
}

Asociación Española de videojuegos. Consultado el 01/04/2020 en http://www.aevi.org.es/ web/wp-content/uploads/2019/05/AEVI_Anuario_2018.pdf

17 Estudio 'La industria del Videojuego en el Mundo' Consultado el 01/04/2020 en http:// www.aevi.org.es/la-industria-del-videojuego/en-el-mundo/

${ }^{5}$ Estudio «Videojuegos y Adultos» - Elaborado por AEVI \& Sigma Dos.

Consultado el 01/04/2020 en http://www.aevi.org.es/web/wp-content/uploads/2015/12/Estudio-Videojuegos-y-adultos_presentaci\%C3\%B3n.pdf

6 Turing, Alan. 'Digital Computers applied to Games' Bowden's Faster than Thought. 
contexto de varios capítulos iniciales en los que analiza el nacimiento de los videojuegos y la situación de los juegos recreativos hasta el momento. Punto que comparte con 'History of Digital Games: Developments in Art, Design and Interaction' (2017) de Andrew Williams de Art \& Art History Department, University of Wisconsin-South que reseña gran cantidad de dispositivos mecánicos previos a la aparición de los juegos digitales. La obra de Kent es especialmente importante por su extensa recopilación de entrevistas y testimonios de fuentes primarias - principalmente creadores y desarrolladores de juegos de la propia industria, que permite acercarse al momento en que sucedieron los hechos y las razones que los desencadenaron. Del mismo modo que el libro 'Sensei. Diálogos con maestros del videojuego japonés' (en dos volúmenes 2017 y 2019) y las series de entrevistas publicadas por Nintendo 'Iwata pregunta' (online entre 2006 y 2015) que han documentado las ideas iniciales de juegos y consolas que, muchas veces, partían de supuestos puramente espaciales y arquitectónicos.

Por otra parte, y de mayor actualidad en comparación con el trabajo de Kent (2001), es el trabajo también histórico del periodista británico Tristan Donovan 'Replay: The history of Video games' (2010). Cuyo principal valor para esta investigación es la que el propio autor indica como su principal intención: centrarse en los juegos como producciones propias de la cultura de cada tiempo, relacionándolos en muchas ocasiones con otros campos como el cine, la música o la arquitectura, y no tanto en las consolas o empresas y personas.

Para la construcción completa de la relación histórica del espacio virtual y el espacio material es necesario consultar, por una parte, libros que no estén centrados exclusivamente en videojuegos. En el campo de la informática general destacan 'A history of modern computing' (2003) y 'Computing: A Concise History' (2012), ambos de Paul E. Ceruzzi, 'Computer: A History of the Information Machine' de Martin Campbell-Kelly y William Aspray así como 'Alan Turing. El pionero de la era de la informática' (2013) de Jack Copeland (el director del archivo Turing). Este último libro muestra que las primeras aproximaciones a los videojuegos nacieron del matemático británico. Fue él quien, tras la Segunda Guerra Mundial, sugirió usar los juegos en computadoras como campo de investigación para analizar la lógica que podría implementarse en las máquinas. Por estas sugerencias recibió críticas de la comunidad científica que lo consideró un campo poco serio e inútil (Copeland, 2013).

No se ha detectado ninguna investigación centrada propiamente en la relación cronológica entre la arquitectura y los videojuegos. Por lo que, para profundizar en ello, es necesario valerse también de estudios que recogen la evolución de los dispositivos y de los juegos.

En cuando a los dispositivos destacar, 'The encyclopedia of Game Machines. Consoles, Handhelds \& Home Computers 1972-2005' (2006) del periodista alemán de videojuegos Winnie Forster y 'The Game Console: A Photographic History from Atari to Xbox' (2016) del fotógrafo de videojuegos Evan Amos. Todos los libros mencionados carecen del aspecto gráfico de los análisis históricos de dispositivos hardware, ya que este se limita a fotografías y no aparecen planos que permitan saber la dimensión de éstas o su afección al entorno ${ }^{18}$.

En cuanto a la evolución histórica de los videojuegos destacan varios títulos. '1001 video games you have to play before die'(2015) que incluye imágenes del $80 \%$ de los juegos analizados - y 'High Score!

\footnotetext{
${ }^{18}$ En 2019 se creó dimensiones.guide iniciativa de University of Arizona donde aparecen medidas 16 consolas.
} 
Expanded: The Illustrated History of Electronic Games' (2018, se trata de la tercera edición, pues el autor sigue actualizándolo). Estos libros tratan de abarcar la historia de los videojuegos al completo, sin embargo, no pueden analizarla de manera completa y exhaustiva. Por lo que, también se requiere consultar otros que analizan juegos de forma específica, clasificándolos por empresas o modelos de consola. Cabe citar 'The History of Nintendo' (en 3 volúmenes, 1889-1980, 1980-1991 y 1983-2016), 'The NES Encyclopedia' (2019), 'A Compendium of Atari 2600 Games' (2019), 'La bible de Game Boy' (2013), 'The A-Z of Commodore 64 Games' (2018), 'The Encyclopedia of Arcade Video Games' (2003), etc ${ }^{19}$.

Tanto en el análisis de los dispositivos como en el de los juegos, se hace necesario consultar archivos tanto físicos como digitalizados 20

Finalmente, dentro de la documentación histórica de la construcción del tema se consultan libros que recogen la evolución de los videojuegos narrando los acontecimientos y las historias personales que envolvieron cada nuevo juego o dispositivo. Así 'Console Wars'(2014) analiza la guerra entre Sega y Nintendo y 'Blood, sweat and pixels' (2017) destapa la realidad tras el desarrollo de algunos de los juegos más conocidos. Estos libros, del mismo modo que los ya citados de entrevistas con desarrolladores, ayudan particularmente a detectar puntos de contacto para la investigación, tales como la presencia de problemas espaciales propios de la representación arquitectónica o la necesidad de contar con arquitectos en los equipos de diseño de espacios virtuales.

El desarrollo de la industria del videojuego analizado históricamente muestra que la relación entre el espacio arquitectónico y el espacio lúdicovirtual, pese a no estar prácticamente reseñada, ha estado de un modo u otro, siempre presente. Viéndose afectada esta relación por una serie de cambios tecnológicos, sociales y espaciales.

\subsubsection{En relación al desarrollo tecnológico y gráfico. El gamespace.}

Estas primeras plataformas - consolas primitivas, máquinas arcade y ordenadores únicos - permitían jugar a juegos muy básicos. Hasta el punto de que en el caso de Tennis for two ${ }^{21}$, junto al ordenador se utilizó un osciloscopio para visualizar el juego en una pantalla circular de $12 \mathrm{~cm}$ de diámetro.

Sin embargo, desde los primeros juegos existía un componente espacial indisoluble de su condición lúdica. Tal y como desgranó Huizinga en 'Homo Ludens' (1938) el tablero de juego es el espacio sobre el que actúan una serie de normas o leyes conocidas como reglas del juego.

Al generar un juego en un entorno que no es el mundo material, debe necesariamente diseñarse un entorno nuevo que llamamos mundo virtual.

Aunque, inicialmente, fuera solo un color sólido con paredes y una línea central - como es el caso de Pong (1972) - se estaba diseñando un lugar donde se diera ese juego. Estos lugares virtuales fueron al comienzo representaciones abstractas de la realidad en dos dimensiones. La mayoría empleaban sistemas conocidos en dibujo técnico para mostrar

\footnotetext{
${ }^{19}$ Consultar bibliografía completa en Anexo 1.

${ }^{20}$ Consultar listado de archivos, museos y fondos completos en Anexo 1.

${ }^{21}$ Tennis for Two. Videojuego de deporte visualizado en alzado. Creado en el Laboratorio Nacional de en 1958.
} 
el juego. A esta conclusión llega Martínez de Salazar Muñoz al plantear los paralelismos entre los modelos de representación de juegos en 2D y los sistemas de dibujo existentes en su investigación 'Los sistemas de representación en los videojuegos bidimensionales. Análisis de su evolución histórica' (2016). Similar a las ideas de Aarseth en 'Allegories fo the space; the question of the spaciality' (2000).

A partir de 1974 aparecieron una serie de juegos, empezando por Maze $\mathrm{War}^{22}$, que trataron de simular un mundo en 3 dimensiones recurriendo a perspectivas cónicas dibujadas como escenario del juego. Sin embargo, esto no constituía un espacio real en 3D, sino que lo simulaba. El lanzamiento del primer juego basado en microprocesadores ${ }^{23}$, Gun Fight en 1975 (Donovan, 2010), permitió evitar que la posición física de los elementos del circuito determinara el juego, cuestión que había sucedido hasta el momento en las primeras arcades y en la consola Magnavox Odissey.

El uso de cartuchos de mayor capacidad para almacenar los juegos permitió crear espacios en dos dimensiones más extensos, pudiendo referirse a ellos como mundos virtuales (Bartle, 2003). También chips como el DSP-1 de la Super Nintendo (SNES, 1990) o el Mode 7 de la misma consola acercaron la posibilidad de mostrar estos mundos en 3D. No obstante, no fue hasta el año 1992 cuando Sega lanzó Virtua Racing ${ }^{24}$ para recreativas y consiguió construir un mundo en 3D virtual propiamente dicho (Donovan, 2010). Este desarrollo tecnológico, ligado a la aparición del formato CD que goza de más almacenamiento que un cartucho, permitió la proliferación de escenarios tridimensionales que podían alcanzan dimensiones territoriales.

Estos mundos o lugares 2D y 3D - a los que denominaremos gamespaces virtuales - han sido ampliamente analizados en la investigación 'Video Games Spaces. Image, Play and Structure in 3d Game Worlds' (Nitsche, 2008) e incluso - muy recientemente - catalogados por su extensión y complejidad en 'Ludotopia: Spaces, Places and Territories in Computer' (Aarseth \& Gunzel, 2019) y 'Virtual Cities; An Atlas \& Exploration of Video Game Cities' (Dimopoulos, 2020).

Al igual que sucede en la arquitectura, el diseño y creación de juegos implica la creación y diseño de un espacio. Esta analogía ha sido tratada en trabajos académicos como 'An architectural approach to level design' (W. Totten, 2014), 'Videogames and architecture: An extensive account on video game theory and the possible application of this theory in architectural design' (Tiemersma, 2014), ¿'What Makes a House? Approaching Architectural Design in Virtual Worlds' (Jakobsson, Skog, 2000) y 'Computer Architectures. Constructing the Common Ground' (Vardouli \& Touloumi, 2019). Todos ellos centrados en diferentes puntos de vista del análisis del espacio dentro del mundo virtual.

El espacio virtual que los avances tecnológicos han hecho posible no es, sin embargo, el único espacio del juego. Tal y como hemos indicado, este juego virtual se inspira, pero a su vez afecta al espacio material que le rodea y a la construcción social de este.

\footnotetext{
22 Maze War. Videojuego de disparos en primera persona publicado en 1973.

${ }^{23}$ Los microprocesadores tal y como se entienden hoy en día aparecieron a principios de los 70 .

24 Virtua Racing. Videojuego de conducción visualizado en perspectiva 3d. Creado por el grupo de desarrollo de Sega AM-2.
} 


\subsubsection{En relación a la evolución social. El playspace.}

Del mismo modo que el espacio virtual del videojuego que existe en la actualidad no ha sido siempre así, tampoco el espacio del mundo material donde se da este juego. Ambos han evolucionado ligados entre sí.

\section{a. El inicio de los videojuegos: arcades y consolas de salón.}

En varios de los libros citados sobre la construcción histórica del contexto se analiza el salto de los juegos de ser un pequeño experimento académico a ser un producto de consumo masivo. Este salto se produjo de una forma casi simultánea, por dos vías: la transformación de las máquinas recreativas electromecánicas en juegos virtuales y la transformación del televisor doméstico en un elemento con el que era posible interactuar.

La primera de ellas se centra en la evolución que algunas empresas como SEGA - Service Games - imprimieron a los juegos mecánicos de los años 60 (Pettus, 2012). Pero, sobre todo, en el convencimiento del ingeniero Nolan Bushnell de poder unificar las ideas que había recogido trabajando en un parque temático con los avances técnicos que ya mostraban que era posible jugar con los ordenadores (Kent, 2001). Es por ello por lo que, en el origen de los videojuegos como producto de consumo, se encuentran múltiples conexiones con los parques temáticos que llegan hasta hoy. Así por ejemplo los elementos referenciales de los parques Disney - the weenies - son empleados en diseño de niveles (Rogers, 2010). Por ello se recurre a la consulta de diversos volúmenes que analizan la construcción y diseño de este modelo de ocio 'Designing Disney's Theme Parks: The Architecture of Reassurance' (Marling, 1997), 'The global theme park industry' (Anton Clavé, 2007), 'Building a dream: the art of Disney Architecture' (Dunlop, 1996) y 'Disneyland: A Utopian Urban Space' (Gottdiener, 1982). Permitiendo trazar con nitidez la línea entre el espacio material y el virtual. Este campo de desarrollo dio lugar, inicialmente, a los arcades o recreativas (Fernández, Relinque-Pérez, 2017).

La segunda de ellas se centra en el momento en que la televisión doméstica se pudo emplear como dispositivo de juego interactivo. Esta línea partió de las ideas a las que entre 1951 y 1956 llegó un ingeniero llamado Ralph Baer sobre permitir a las personas jugar por medios electrónicos a través de las televisiones que el $90 \%$ de las familias estadounidenses ya tenía en sus casas $^{25}$. Baer comenzó a dar formas a sus ideas algunos años después ${ }^{26}$, en 1970 (Baer, 2005) y un año más tarde, alcanzó un prototipo de dispositivo que se conectaba a la TV y disponía de controladores con botones de sintonizador y una pistola de luz. Este modelo fue adquirido por Magnavox, rediseñado exteriormente y lanzado al mercado bajo el nombre de Magnavox Odissey en 1972. Siendo la primera consola doméstica de la historia (Kent, 2001). Esta línea entronca con toda una serie de investigaciones que han analizado el papel de la televisión en el espacio doméstico - ilustrado en la imagen con la que comienza este capítulo de la serie Friends - destacando 'Los Señores

\footnotetext{
25 Consultado online https://www.nielsen.com/us/en/insights/article/2010/u-s-homes-addeven-more-tv-sets-in-2010/ consultado por última vez el 16 de junio de 2020

${ }^{26}$ Baer trabajaba como ingeniero en una empresa de electrónica llamada Loral Corporation primero y posteriormente para Sanders Associates. Disponía del conocimiento necesario para poder intervenir y modificar un TV y, en Sanders como ingeniero senior, también del equipo humano y técnico para desarrollar la idea.
} 
del Aire: Telépolis y el tercer entorno.' (Echevarria, 1999) o 'Sales Oddity: Milano 2 and the Politics of Direct-to-Home TV Urbanism' (Jaque, 2018). Sin embargo, existen notables diferencias entre el espacio doméstico de la TV y el espacio doméstico de la consola, como se señala en 'The domestic spaces of Digital Media' (Whalen, 2018), observando que se trata éste de un tema poco tratado, especialmente en su perspectiva gráfica. A esta área del mundo material donde se da el juego virtual es al que denominaremos playspace.

\section{b. La expansión de los playspaces.}

Si el espacio del interior del videojuego ha sido analizado y estudiado desde una perspectiva arquitectónica - tal y como se ha indicado - la afección que los videojuegos generan en el espacio material ha sido reseñada de manera superficial y puntual.

En el caso del espacio doméstico, además del estudio de Whalen (2018) destacan otros como 'The social construction of space in a computerized environment' (Kociatkiewicz, Czarniawska, 2004) y el trabajo 'Technospaces' (Munt, 2001) que abarcan diversos espacios influidos por el mundo virtual incluidos los playspaces de los videojuegos.

Pero, en su mayoría, los análisis han estado ligados a los diferentes avances que han modificado la interactividad en relación al espacio material. Así, el lanzamiento del controlador en forma de guante Nintendo Power Glove (1989) propició el análisis de la relación entre los gestos de los jugadores en el espacio y los controles del juego, como se trata en 'Hand Talk-Implementation of a Gesture Recognizing Glove' (2013). En el mismo sentido, el lanzamiento de los controles de la Nintendo Wii (2010) supuso una revolución al levantar por completo al jugador del sofá y al retomar la idea de una consola de entretenimiento familiar en torno a la TV, por lo que generó ciertos análisis sobre el tema; 'An Analysis of the Preference for Physical Interactive Game Console by Domestic Game Users. Focus on Nintendo Wii (Chang, 2010), "Wii play as a family: the rise in familycentred video gaming' (Chambers, 2010) y 'The Nintendo Wii, virtualisation and gestural analogics' (Crogan, 2010).

El espacio de juego pronto escapó del ámbito doméstico. La versión de la historia según Nintendo ${ }^{27}$ fue que en 1979 el ingeniero y diseñador de Nintendo Gunpei Yokoi observó a un hombre aburrido esperando el autobús que usaba su calculadora para entretenerse (Gorgues, 2012) y, con esta premisa, ideó una consola portátil que empleaba el mismo sistema de pantallas que las calculadoras LCD (no tenía, por tanto, píxeles) permitíendo jugar sin cables ni pantallas adicionales. Esta consola portable usaba como batería una pila de botón que ofrecía 6 meses de juego y no ocupaba - físicamente - más que un par de CD juntos. Su diseño permitía jugar allí donde se quisiera. Game\&Watch no fue la primera consola portable. Mattel ya intentó diseñar unos años antes (Autorace, 1976) y también MB (MB Microvisión, 1979) pero ambas, al contrario que Game\&Watch, estaban pensadas, exclusivamente, para un público infantil, siguiendo la estela de otros juegos portables no digitales. La concepción de Game\&Watch, sin embargo, abrió el camino al juego en cualquier parte. Un camino que consolidó en 1989 la Game Boy al convertirse en un fenómeno de masas y jugadores de todas las edades al separarles de la necesidad de estar frente al TV.

${ }^{27}$ En esta parte se profundiza en el capítulo 4. 
Tanto la Game Boy como sus sucesoras llevaron el juego virtual a cualquier parte, y enlazaron con otro dispositivo que comenzaba a abrirse camino, el teléfono móvil. A partir de 1994, con el modelo Hagenuk MT2000, los móviles incluyeron juegos. Entre los que destacó el juego del que Nokia compró los derechos, Snake (originalmente Blockade, 1976). Si bien las consolas portables no han sido muy reseñadas en su relación con el espacio, los teléfonos móviles sí han sido fuertemente analizados. Esto se debe a su mayor rango de usuarios y al hecho de haberse consolidado los juegos para móviles como un género propio a raíz del lanzamiento del iPhone en 2007. Como análisis que traten el espacio destacan 'Activitycentric streaming of virtual environments and games to mobile devices' (Rahimi, Nazari Shirehjini y Shirmohammadi, 2011), 'Social Media \& Mobile Internet Use among Teens and Young Adults. Millennials' (Lenhart, Purcell, Smith y Zickuhr, 2010) y 'Social, Casual and Mobile Games: The Changing Gaming Landscape' (Willson, Leaver, 2016).

Sin embargo, el gran salto de los dispositivos móviles como plataformas de juego llegó con la realidad aumentada, Ingress (2012) - 'Playing With Portals: Rethinking Urban Play with Ingress (Moore, 2015) - primero y Pokemon Go (2016) después.

Con la publicación en exclusiva para móviles de Pokemon Go tuvo lugar un punto de inflexión que mereció una enorme atención de los medios en general - al convertirse en un juego con más usuarios que Twitter y con más búsquedas que porno ${ }^{28}$ - y de la comunidad científica en particular. En ámbitos tan dispares como la medicina - 'Influence of Pokémon Go on Physical Activity: Study and Implications' (Althoff, White, Horvitz, 2016) o 'Pokémon GO May Increase Physical Activity and Decrease Sedentary Behaviors' (Nigg, Joi Mateo, y An, 2017) o el urbanismo - 'Where to catch 'em all? - a geographic analysis of Pokémon Go locations, Geo-spatial Information Science' (Levente Juhász \& Hartwig H. Hochmair, 2017), "Diseño ludológico y realidad aumentada. ¡La experiencia de juego en Pokémon Go!' (Rodríguez Serrano, Martín-Núñez, Gil-Soldevila, 2017), 'Gamifying the city: Pervasive game elements in the urban environment' (Calafiore, Rapp, 2016) - destacando siempre su papel e influencia espacial. Pokemon Go supuso la visibilización de la cima del iceberg que hizo percibir a gran parte de la sociedad las dimensiones de los videojuegos y dejó entrever que están estrechamente ligados con el espacio material que habitamos.

c. De la sala de juegos a la sala online.

Si la expansión de las consolas - convertidas en portables e hibridando con otros dispositivos móviles - permitió la ampliación de los playspaces fuera del espacio doméstico, la otra cara de los playspaces fueron las salas de juegos arcade o recreativas. Estos lugares alcanzaron un gran protagonismo a principios de los años 80 , hasta el punto de formar parte del movimiento cultural asociado a los videojuegos que transcendía más allá de éstos, generando por ejemplo éxitos como el disco Pac-man Fever de Buckner\&García que vendió más de un millón de copias con canciones inspiradas en juegos y compuestas en salones de recreativas (Donovan, 2010).

Las salas de juegos ya existían previamente a los videojuegos, sobre

\footnotetext{
28 Según las tablas analíticas de Google Trends, el término "pokemon go" se ha buscado más que "porn" (2016)
} 
todo en espacios lúdicos como el pier de Brighton (1889) en Reino Unido, el de Santa Monica en California (1909) o Conney Island (1870-1900) en Nueva York. Sin embargo, a partir de los diferentes avances tecnológicos ya citados y de su explosión económica - según Kent (2001), se ha reseñado de la escasez de monedas en Japón tras el lanzamiento de Space Invaders - ganaron un protagonismo que hizo que proliferaran en locales dedicados íntegramente a ellas. Ciertos estudios analizaron el papel social de estos playspaces, 'The amusement arcade as a social space for adolescents' (Fisher, 1995) así como Munt en Technospaces (2001) analizan desde una perspectiva teórica la afección de los juegos en estos espacios. También en 'The Themed Space: Locating Culture, Nation, and Self' (Lukas, 2007) se citan en parte los arcades. El éxito de las salas recreativas propició el nacimiento de modelos mixtos de negocio como la cadena de restaurantesarcade Chuck E. Cheese's Pizza Time Theatre fundada por Bushnell a partir de 1977. Hacia 1982 había una máquina arcade en casi cualquier negocio que pudiera permitírselo. Según el documental Atari: Game Over (2014) la saturación del mercado (tanto de cartuchos como de arcades) fue una de las causas del Crack de los videojuegos de 1983. Así como también, en gran medida, la facilidad de la que disponía la piratería para lanzar productos de muy baja calidad (Donovan, 2010).

Tras la crisis de los videojuegos, multitud de salas recreativas cerraron. En los países occidentales, las máquinas arcade tuvieron sentido mientras los ordenadores y videoconsolas no podrían alcanzar la calidad de una recreativa. A raíz del trabajo del grupo de investigación Sega AM-2, que permitió igualar la calidad, el modelo de espacio de videojuegos social desapareció. No así en ciertos países orientales como Japón o Korea donde actualmente siguen existiendo, lo que ha propiciado que se continúen elaborando análisis sobre el tema como 'The Role of Onlookers in Arcade Gaming: Frame Analysis of Public Behaviours' (Lin y Sun, 2011), que trata la importancia de los observadores durante las partidas sociales y que enlaza con los grandes torneos seguidos de forma multitudinaria con miles de espectadores que contemplan a videojugadores desarrollar sus partidas $^{29}$.

De este modo, el espacio social del juego virtual no desapareció, sino que comenzó a trasladarse, paulatinamente, al ciberespacio (Morningstar, C. and Farmer, F.R, 1991) gracias a la extensión de Internet. Estas relaciones o interacciones que se dan en espacios sociales virtuales han sido a su vez ampliamente analizadas, también con relación al espacio arquitectónico donde se dan. Así 'Activity Flow Architecture - environment design in Active Worlds and EverQuest' (Jakobsson, 2007), 'Living Digitally: Embodiment in Virtual Worlds' (T.L. Taylor, 2002), 'Virtual worlds and social interaction design (Jakobsson, 2006), 'Half-Real. Video Games between Real Rules and Fictional Worlds' (Juul, 2005), 'A virtual realist primer to virtual world design' (Jakobsson, 2003), 'Play Anything: The Pleasure of Limits, the Uses of Boredom, and the Secret of Games' (Bogost, 2013), 'Social interactions: A first-person perspective' (A. Fathi, Hodgins y Rehg, 2012) y 'Online Games, Social Narratives' ( MacCallum-Stewart 2014).

Señalar el papel de las ligas profesionales de videojuegos ${ }^{30}$ esports - que permiten que los jugadores se enfrenten en partidas online y sean seguidos como deportistas de elite en el espacio material, generando

\footnotetext{
${ }^{29}$ Consultado online https://esports.as.com/league-of-legends/Calendario-horarios-Mundial-League-Legends-2019_0_1284171571.htm/ consultado por última vez el 4 de Julio de 2020

${ }^{30}$ Web de la Liga Profesional de Videojuegos https://lvp.global/consultada por última vez el 4 de junio de 2020.
} 
una construcción social en torno al videojuego.

Hay que destacar también juegos online múltiples ligados a redes sociales como Facebook. En estos casos, la red social supone el propio espacio virtual donde se dan el juego y sus relaciones, así es analizado en 'Platforms for mediated sociability and online social capital: the role of Facebook and massively multiplayer online games' (Marko, Skoric y Grace, 2011).

En conjunto, los juegos online con un componente social han adquirido paulatinamente mayor protagonismo y son, en la actualidad, uno de los principales grupos en los que los jugadores se comunican hablando mientras interactúan en un escenario virtual común al que tienen acceso desde sus playspaces independientes en el mundo material. Como por ejemplo el exitoso Fortnite (2017) que es el videojuego más jugado con 126 millones de jugadores.

\subsubsection{Entorno contemporáneo de investigación.}

Esta construcción del estado de la cuestión muestra además que la investigación formal en juegos - Game Studies - es un tema novedoso y actual como campo de estudio, pero no muy desarrollado por tratarse de un área relativamente reciente. $\mathrm{Y}$, en el caso de su relación con la arquitectura, no muy analizado. Así, en 2015, cuando se aprobó este tema de tesis, no existía el $50 \%$ de la bibliografía que se cita y el $90 \%$ es posterior al año 2000.

En un ámbito internacional existen referentes claros para la investigación. El Medialab del MIT fundado por el arquitecto Nicholas Negroponte en 1985 posee desde 2010 un Gamelab (muchos de los artículos citados proceden de allí). En multitud de universidades europeas, como Bartlett School of Architecture, TU Delft o ETH Zurich, los grupos de investigación sobre dibujo asistido (CAAD), arquitectura computacional (Computer Advance spatial Analisys y Space Syntax) y Serious Games han desarrollado incipientes líneas de trabajo sobre juegos. Así el ETH ha sido el núcleo de dos títulos que han tenido especial relevancia en esta tesis: 'Toward a Ludic Architecture: The Space of Play and Games' (P. Walz, 2010) y 'Space. Time. Play' (von Borries, P. Walz, Böttger. 2007), que si bien no se centran en juegos virtuales ni analizan estrictamente la repercusión entre el espacio material y el virtual, aportan gran cantidad de información a la relación arquitectura-espacio lúdico. El organismo internacional más reconocido en Game Studies es DIGRA, Digital Games Research Association.

A nivel nacional, sin embargo, España presenta una posición más retrasada ${ }^{31}$ con respecto a los ejemplos citados. Es uno de los pocos países europeos que aún no tiene una representación constituida en DIGRA, y la investigación académica en juegos es un campo en crecimiento, pero

\footnotetext{
${ }^{31}$ Esta posición rezagada que ocupa España no es casual y se refleja también en la industria del videojuego español. A diferencia de los países vecinos, la edad dorada del videojuego de los años 80 no se ha mantenido durante las últimas décadas y nos encontramos ante una industria que, aunque genera 1.163 millones de euros anuales (más que cine, televisión, radio y literatura juntos) está muy lejos de Japón, Reino Unido, Alemania o Francia y a una distancia inalcanzable de las potencias mundiales, China y Estados Unidos con 22.000 millones de dólares recaudados en el mismo periodo. Los análisis de la Asociación Española de Videojuegos (AEVI) y de DEV, Desarrollo Español de Videojuegos coinciden en la dificultad de acceso a la financiación como responsable de esta situación, tanto en el campo del desarrollo como de la investigación.
} 
aún de reducido tamaño. La mayoría de las líneas de investigación se encuentran en la Red Española de Excelencia sobre I+D+i y Ciencia para videojuegos (RIDIVI), a la que se asocian multitud de grupos, ninguno de ellos de arquitectura 0 análisis espacial. Priman los de componente informático y tecnológico o comunicativo y audiovisual. En lo que a esta investigación atañe destacan:

- Cátedra Estratégica de Videojuegos, Gamificación y Juegos Serios. Universidad de Málaga.

- Graphics \& Imaging Laboratory (GILAB). Universitat de Girona.

- Centre de Visualització Interactiva (CEVI). Instituto de Nuevas Tecnologías de la Imagen. Universitat Jaume I.

- Arsgames, grupo independiente. Editores de la revista Bit y aparte.

- Grupo Género, Estética y Cultura Audiovisual (GECA). Grupo de Investigaciones de Inteligencia Artificial (GAIA). Universidad Complutense de Madrid

- Grupo de Investigación en Comunicación, Arte y Videojuegos. Universidad de Sevilla.

Existen, al mismo tiempo, investigaciones más significativas que se han desarrollado fuera de estos grupos como 'Videojuegos y mundos de Ciencia Ficción' (Planells, 2015) obra de referencia en el aspecto narrativo del espacio desarrollado en la Universidad Carlos III; 'Arte y Videojuegos: mecánicas, estéticas y diseño de juegos en prácticas de creación contemporánea' (Coterón, 2012) de la Facultad de Bellas Artes de la Universidad Complutense o el propio grupo de investigación Hypermedia donde se enmarca esta tesis. En él destacan 'La infancia en casa. La transformación de los dispositivos domésticos espaciales vinculados a la niñez desde la Edad Media hasta la actualidad' (de Benito, 2018), 'El Entorno Aumentado: Imperativo informacional para una ecología digital de lo arquitectónico' (Roig, 2014) y 'Habitar lo irreal. Aproximaciones a una arquitectónica de los mundos virtuales' (López-Galiacho, 2014). 
1.3

Definición del tema.

Tras la construcción del Estado de la Cuestión se concluye la pertinencia de centrar la investigación en la relación entre el espacio material de la arquitectura y el espacio virtual de los videojuegos. Concretamente en la relación entre el denominado playspace (el lugar del juego del espacio material) y el gamescape (el lugar del juego del espacio virtual).

La investigación se focalizará en: el estudio y la producción gráfica de documentos que permitan un análisis no solo teórico y en la afección del espacio virtual sobre el material. Se dejará a un lado el estudio exclusivo del espacio virtual, que se encuentra fuertemente documentado, y se incidirá en la relación histórica entre ambos espacios lúdicos, virtual y material, de forma que se puedan reconstruir los puntos de contacto que les unen.

\section{Hipótesis general de la tesis.}

Desde la aparición de los videojuegos a mediados del siglo $X X$, estos han generado una serie de acciones-afecciones en el espacio material arquitectónico. Este efecto se ha visto incrementado con la paulatina extensión del alcance de dispositivos y redes, así como el desarrollo de mundos en 3D más complejos, sobre todo a partir de los años 90. En la actualidad los espacios virtuales de los videojuegos tienen una relación cada vez más estrecha con el mundo material, lo recubren, interfieren, funden con él sus límites, compartiendo habitantes, estrategias e incluso leyes.

A

\section{Hipótesis primera}

Tal y como se ha analizado en el estado de la cuestión - en 1.2.1 En relación al análisis histórico y 1.2.2 En relación al desarrollo tecnológico y gráfico - se intuyen evidentes conexiones entre el origen de los videojuegos y la arquitectura.

Por lo que se propone la hipótesis de que el espacio virtual de los videojuegos - al ser un espacio en cierta medida como lo es el material - se basa, nace e inspira en este arquitectónico. Y es por ello que presentan desde sus inicios múltiples puntos de contacto, estrategias comunes para desarrollarse, dibujarse, crearse y habitarse.

\section{Objetivo primero}

Mostrar que - desde su mismo origen - el espacio virtual de los videojuegos y el espacio material arquitectónico tienen conexiones fundamentales, ya que el segundo ha servido de base y referencia para el primero. 


\section{B}

\section{Hipótesis segunda}

De nuevo tal y como se ha apunta al realizar el estado de la cuestión - 1.2.3 En relación a la evolución social - se han entrevisto las afecciones/conexiones que, una vez aparece, genera el espacio de los videojuegos con el material de la arquitectura.

Por lo que se pone la hipótesis de que el espacio virtual de los videojuegos produce, también una serie de conexiones con el espacio material, siendo la arquitectura la que, a partir de un momento, emplea de referencia como parte de su evolución los videojuegos, sus procesos, usos y realidades.

\section{Objetivo segundo}

Mostrar que - desde el momento en que aparece y por su origen común - el espacio virtual de los videojuegos genera conexiones y afecta al espacio arquitectónico, hasta ser, en cierta medida, una referencia de éste en ciertos aspectos.

Para llevar a cabo estos objetivos se requerirá de una investigación histórica que, empleando epígrafes similares a los del estado de la cuestión, profundice en cómo se ha producido el espacio de los videojuegos y qué referencias ha tenido. Además, este análisis deberá incluir un estudio gráfico que busque el origen de los principales juegos, dispositivos y entornos con implicaciones espaciales (ver metodología). Ello responde a una serie de objetivos extra que persiguen producir y organizar una información hasta ahora inexistente y dispersa:

- Elaborar una compilación tanto gráfica como teórica de dispositivos de juego virtual y su relación con el espacio material.

- Elaborar una compilación tanto gráfica como teórica de juegos virtuales en relación a cuanto a su relevancia y afección espacial desde la perspectiva arquitectónica.

- Cartografiar el espacio de la relación espacio material y espacio virtual. 
La investigación contenida en este documento se ha desarrollado siguiendo una metodología en tres partes: construcción de una base de datos, análisis de la base de datos y extracción de la información del análisis en relación con la hipótesis planteada.

Sin embargo, esta metodología ha ido construyéndose según avanzaba la investigación, por lo que no se trata de un proceso lineal. Se destaca el volumen 'Research Methodology in Gaming: An Overview' (Mäyrä, Holopainen, Jakobsson, 2012) como base para entender el punto de partida de la investigación.

\section{a. Elaboración de una estructura inicial}

La elección del tema, la construcción del estado de la materia y la decisión de elaborar un glosario de terminología específica permitieron crear una agrupación inicial en dos bloques.

Por una parte, se decidió analizar la influencia del mundo virtual sobre el mundo material y, por otra, la opuesta, la influencia del mundo material sobre el virtual. Para ello se optó, en primer lugar, por recoger la información de las principales plataformas-dispositivos empleados en el espacio material para generar espacio virtual, con el objetivo de poder establecer estas relaciones a diferentes escalas.

Tras una búsqueda inicial, se detectó la ya citada ausencia de una catalogación desde el punto de vista espacial de estas plataformas. No existían planos o dibujos con dimensiones, ni en 2D ni 3D (solo a partir de 2019 unas pocas consolas se han publicado en dimensions.guide). Tampoco gráficos o tablas con datos como la longitud de los cables de los controladores o las horas de duración de las baterías. Características necesarias para analizar el impacto del espacio virtual, al que dan lugar, sobre el espacio material. Por lo que, en primer lugar, se decidió construir una base de datos sobre estas plataformas y sus características.

\section{b. Construcción de la base de datos.}

\section{Parte 1. Plataformas.}

La ausencia de datos sobre estas plataformas que, situándose en el espacio material dan lugar al espacio virtual, requiere de varias acciones combinadas:

- En primer lugar, el contacto (tanto físico como virtual) con museos y colecciones de historia de la informática y los videojuegos.

- En segundo lugar, la consulta de bases de datos colaborativas de modelos y asociaciones de coleccionistas o entusiastas de diferentes plataformas. 
- Y, en tercer lugar, en numerosas ocasiones con la oficina de patentes de Estados Unidos y su equivalente en Japón.

Esto permite elaborar una primera aproximación de base de datos que incluye: datos básicos de cada plataforma (año de publicación, unidades vendidas y empresa creadora), dibujos en proyección diédrica ${ }^{32}$ de cada una a escala (1:1 consolas portables, 1:2 consolas domésticas, 1:5 ordenadores, $1: 10$ arcades y algunos casos de ordenadores especiales a $1: 20)$, alcance del cableado y de las conexiones inalámbricas (Ud. metros) y alcance de las áreas de juego (Ud. metros cuadrados).

Se concluye con el análisis de 146 plataformas de juego: 27 ordenadores, 53 arcades, 39 consolas y 27 dispositivos portátiles (y las variaciones de diseño de cada una de ellas).

Esta primera base de datos muestra la necesidad de analizar, además del dispositivo material, el lugar virtual que crea, es decir, los juegos.

\section{Parte 2. Juegos y accesorios.}

Se procede a la recopilación e indexación de los juegos más significativos en cuanto al espacio se refiere (sea por su uso, representación, modo de interacción, narrativa espacial u otro motivo) a través, sobre todo, de los libros que forman la Bibliografía ${ }^{33}$.

Esta base de datos de juegos con relación a las consolas incluye: una imagen de cada juego, género, año de publicación, modelo de visualización del espacio, el mundo en que se sitúa, además del aporte en cada caso en relación al espacio.

Se concluye con el análisis de 656 juegos, y, en este mismo bloque, se incluyen ciertos accesorios que, empleados como elementos de juego, ampliaban la interacción y relación mundo material-mundo virtual.

\section{c. Análisis de la base de datos.}

Finalizada la base de datos se dispone de una muestra de suficiente amplitud para proceder a contrastar la información obtenida con la hipótesis y objetivos propuestos. Al tratarse de un análisis en referencia al espacio y a la relación con este, se divide el proceso en dos partes:

\section{Parte 1. Análisis gráfico.}

Toda la base de datos al completo se organiza por las denominadas 'generaciones'. Cada una de ellas abarca un periodo de tiempo con unas determinadas características de la historia de los videojuegos. Hasta la actualidad han existido 8 generaciones ${ }^{34}$. Antes de cada bloque de datos

\footnotetext{
${ }^{32}$ Al pretender estudiar la afección de un espacio sobre el otro se recurre a un sistema de representación que permita medir, por lo que se descartan perspectivas.

33 Consultar bibliografía completa en Anexo 3.

${ }^{34}$ Se toman de referencia las generaciones históricas de las consolas y arcades. Ya que,
} 
de una generación se adjuntan una serie de dibujos que permiten analizar la relación espacio material - espacio virtual de forma gráfica. Estos dibujos contienen:

- Consolas domésticas: plano de una vivienda contemporánea a cada generación sobre la que se superponen las diferentes consolas y sus áreas de juego. Estos planos permiten dar orden de magnitud de la afección del espacio virtual sobre el material en cada momento.

- Consolas portables/dispositivos portables: plano/esquema de la relación espacio/pasos y tiempo de batería. En él se refleja la cantidad de espacio material (en pasos) que puede recorrerse con cada una de las consolas portátiles de cada generación.

- Arcade: plano de un salón recreativo con la afección que recibe el espacio material del juego virtual.

- Ordenadores: plano del espacio de trabajo/juego con la afección del espacio material.

\section{Parte 2. Análisis teórico.}

La base de datos construida y su análisis gráfico da paso un análisis teórico estructurado en los dos grandes bloques ideados inicialmente: del espacio material al espacio virtual y del espacio virtual al espacio material.

- Del espacio material arquitectónico al espacio virtual del juego (capítulo 2): se analizan las estrategias espaciales, modelos de representación, roles del jugador e incluso modos de interacción que los juegos virtuales han tomado de la arquitectura material.

- Del espacio virtual del juego al espacio material de la arquitectura (capítulo 4): se analizan cómo determinadas herramientas, estrategias, modelos de representación e incluso espacialidades que nacieron en los videojuegos, ahora alimentan el proyecto arquitectónico y lo modifican e intervienen.

pese a no coincidir exactamente con las generaciones de los ordenadores, se considera que son estos los dispositivos clave que permiten la evolución del videojuego para saltar a ser un producto de arte y consumo. 
$\Xi \Xi$ 
$\sqrt{3}$ 

Al introducirse esta investigación en un campo, en principio, ajeno al arquitectónico, ha sido necesario construir un glosario inicial, en el que, a imagen y semejanza de un debate medieval, se detallen los términos que se usan y el sentido en que se entienden, discerniendo - si fuera necesario - entre las diferentes acepciones de los mismos.

- Juego: el concepto de juego tiene una amplia gama de significados. Según la RAE el principal es 'acción y efecto de jugar por entretenimiento' (2019), pero en 'Homo ludens' Huizinga (1938) analiza en su capítulo 'El juego en el lenguaje' la extensión del concepto y su origen mostrando que se trata de un concepto polisémico ${ }^{1}$. Para lo que a esta investigación respecta el juego define al acto de desarrollar una actividad lúdica durante un tiempo (partida) y en un lugar (tablero). Si bien es muy diferente el acto que afecta al espacio material y el que tiene lugar dentro del videojuego, en el espacio virtual. Para ambos basta recurrir al dualismo entre los conceptos ingleses play/game.

- Play: concepto inglés que denomina al juego, la interacción, la actuación y determinadas acciones como tocar ciertos instrumentos musicales o la práctica de deporte en equipo (Huizinga, 1938) y que se emplea en general para referirse a toda esta serie de actividades ligadas a lo lúdico y el entretenimiento sin ser exclusivamente 'juegos'.

Es el concepto que suele emplearse para definir los lugares de juego en el espacio material, como las áreas playgrounds (van Eyck, 1962/2008). En relación al espacio destaca el análisis de Price (2001) cuando propone el play ${ }^{2}$ como el término con el que referirse a la interacción más o menos libre que se da sobre el espacio cuando este puede activarse como un dispositivo (Easterling, 2010).

- Game: concepto inglés que denomina al juego estructurado (Huizinga, 1938) y que se emplea en general para referirse al juego de los videojuegos. Históricamente se ha considerado a Wittgenstein ${ }^{3}$ como el primer académico que se refirió y definió el concepto game, considerando que fue el físico y diseñador de videojuegos Chris Crawford quien lo asimiló y concretó para juegos virtuales, siendo posiblemente el responsable de la asociación inmediata del concepto con los videojuegos.

En relación al espacio destaca el análisis de Price (2001) cuando se refiere a game como el juego conducido o conductivista con el jugador, que remite a un entretenimiento delimitado y asociado a juegos de amusement o leisure ${ }^{4}$. Esto tiene sentido en el caso

\footnotetext{
${ }^{1}$ El término juego en castellano contiene, por su origen latino, un margen de significados muy amplio, así por ejemplo, ligándolo con otros idiomas del mismo origen, en catalán se usa de forma común el joc (juego) para designar ciertas festividades o celebraciones ligadas al disfrute y a lo popular y en francés se emplea jouer (jugar) del mismo modo para tocar un instrumento (Huizinga, 1938).

${ }^{2}$ Cedric Price reflexiona sobre el concepto Play sobre todo a raíz de su proyecto del Fun Palace, cuando determina que son las actividades englobadas bajo ese verbo las que pueden darse dentro del mismo.

${ }^{3}$ Wittgenstein lo emplea en el contexto de su concepto Juego del lenguaje (game language) publicado de forma póstuma en 1953.

${ }^{4}$ Amusement, en castellano diversión o entretenimiento. Leisure en castellano ocio.
} 
concreto de los videojuegos teniendo en cuenta su origen estrechamente ligado a los amusement/leisure parks.

- Videojuego: juego electrónico que se visualiza en una pantalla (RAE, 2017) y con el que uno o más jugadores interactúan mediante elementos controladores (sean mandos, sean teclados, etc.).

- Tablero: soporte de cualquier juego. Ya sea tablero físico, como en juegos de mesa, discursivo, como en juegos como pillar o tablero virtual en videojuegos. Los tableros se despliegan (de manera completa o se van descubriendo o construyendo durante la partida) y son el soporte del juego. En lo que a esta investigación respecta se emplearán (acorde con el dualismo del propio concepto juego) dos términos complementarios para hablar del tablero:

- Gamespace: es el lugar del espacio virtual donde sucede el juego. También denominado escenario o entorno virtual. En el volumen 'Space. Time. Play' (2007) se analiza el concepto y se propone como definición del mundo virtual al que dan acceso los videojuegos (Wagner, 2007) (Boron, 2007).

- Playspace: es el lugar del espacio material donde sucede (o repercute si es el virtual) el juego. Además de Huizinga (al que se puede considerar el promotor del playspace) también Baudrillard (Schroeder, 1996) o Lefebvre han hablado sobre el playspace desde mediados de los años 50, asimilándolo al lugar donde se da el juego en el espacio material.

- Mundo/espacio material: entorno espacial que abarca una determinada zona del espacio-tiempo. Es entendido como el conjunto de objetivos perceptibles (o detectables por otros medios) que conforma un entorno sensible.

El concepto material actúa en este caso como contrapunto a inmaterial, como han venido definiéndose los mundos virtuales. Así por ejemplo la Biblioteca $\mathrm{Nacional}^{5}$ se refiere a los videojuegos como 'patrimonio cultural inmaterial'. Los videojuegos poseen sin embargo una repercusión material ligada al hecho de 'existir', es decir, requieren de un cartucho, un CD o, incluso cuando son plenamente virtuales, necesitan de un sistema de visualización a través de pantallas (ya sea de teléfonos móviles, de ordenadores, de gafas de realidad virtual, etc.). No se emplea el concepto mundo físico porque los mundos virtuales poseen 'físicas' propias, es decir, comportamientos físicos de los objetos, escenarios y personajes. Tampoco se emplea el concepto mundo real porque 'lo real' sería un término inexacto para dejar al margen a 'lo virtual' atendiendo al enlace real-realidad (Ferrater-Mora, 1941/2009) que remite a conceptos como realidad virtual o realidad aumentada.

- Mundo/espacio virtual: entorno interactivo digital que muestra escenarios reales o imaginarios. Para su visualización se requieren dispositivos tecnológicos.

Nótese que esta definición de virtual es la que atañe a esta investigación concreta, pero el término virtual no es exclusivamente un concepto ligado a lo digital o tecnológico. Así López-Galiacho lo define como 'Virtual (virtualis), derivado del latín virtus - energía, valor, esfuerzo,

\footnotetext{
${ }^{5}$ Consulta online http://www.bne.es/es/AreaPrensa/noticias2020/0204-BNE-reconstruye-pasado-videojuego-asegura-futuro. $h t m /$ consultado por última vez el 5 de junio de 2020.
} 
virtud, capacidad - aludía en la escolástica medieval a aquello que potencialmente posee virtudes o capacidades para ser algo, aunque en acto todavía no lo sea' (2014) y traza la conexión del concepto virtual original a través de Bergson y Deleuze al concepto de virtualidad digital y tecnológica (Lopez-Galiacho, 2014) al que se refiere esta tesis.

- Partida: situación temporal o tiempo que dura el juego, con un principio y fin determinado (Bloch, 1955) en la que el jugador se comporta acorde a unas normas conocidas como reglas del juego (Agamben, 2004).

\section{Sobre partes y características de los videojuegos}

- Sprites: imágenes de mapa de bits generados en la pantalla del ordenador destinadas principalmente a los protagonistas de los videojuegos.

- Mecánicas: se refiere a las estructuras de reglas de los videojuegos que sirven para que el jugador interactúe con el entorno y alcanzar los objetivos del juego.

- Tiles/sistema de tiles: el tile o tesela se refiere al componente gráfico de un videojuego que se usa para rellenar partes de un fondo a través de un set de teselas o tileset. En juegos 2D, los tiles se recogen en los llamados atlas de teselas que también se integran dentro de mapas de teselas y guardan toda la información de un videojuego.

- IA Inteligencia Artificial: tecnologías empleadas por consolas y ordenadores que intentan reproducir el comportamiento de los personajes no jugables (NPC) en el entorno virtual para que sea lo más ajustado a la realidad posible.

- HUD Heads Up Display: también se conoce como interfaz o UI (User Interface). Hace referencia a la información relativa a la partida del jugador (vida, armas, munición, objetos, tiempo restante, ubicación, puntos, etc.).

- Mundo abierto (no confundir con sandbox): los videojuegos de mundo abierto otorgan al jugador la posibilidad de moverse libremente por el mundo virtual y permiten interactuar con la mayoría de sus elementos.

- Modo Historia: aquellos videojuegos que poseen una historia que vertebra diversas misiones, fases o capítulos que el jugador debe ir superando para avanzar en el juego.

- Inventario: es una relación detallada y ordenada (normalmente clasificada por tipos) de los objetos del jugador (también pueden ser cualidades o materias aprendidas como hechizos).

- Combo: sucesión de acciones encadenadas y limitadas por el tiempo que producen un beneficio o efecto mayor. Este término surgió con los videojuegos de lucha que se basan en la combinación de ataques.

- Avatar: imagen gráfica que representa la figura principal de los jugadores y fueron adoptados en un principio en los juegos de rol y en los videojuegos MMORPG.

- Boss/bosses (monstruo final): son aquellos adversarios que controla la CPU del ordenador o la consola y el jugador los encuentra al final de los niveles o pantallas. Por lo general, el nivel de dificultad para derrotarlos es mayor que para otros enemigos. 
- Modding (mods): los mods son aquellas extensiones del software de un videojuego que puede realizar cualquier usuario. Pueden ser conversiones totales, parciales, extensiones que se agregan sin reemplazar el juego o parches para bugs. En la actualidad la mayoría de los juegos de PC permiten a los modders modificarlos a su gusto.

- Craftear (del inglés craft): en los videojuegos significa crear objetos a partir de otros ya existentes que se han recolectado previamente.

- Lore: hace referencia al trasfondo de un videojuego que conforma el universo de este y le da sentido. Se trata de las historias detrás de los personajes o de las escenas, que se cuentan fuera de la trama que el jugador está viendo y se esconde en la información del mundo que le rodea.

- Periférico/controller: todo dispositivo auxiliar o hardware independiente que, conectadas a la plataforma, gozan de una función (mandos, cámaras, armas, volantes, etc.).

- Realidad Virtual: tecnología que permite al jugador la inmersión dentro del videojuego gracias al uso de gráficos en 3D y de gafas o cascos que abarcan su campo de visión. Suele ir acompañado de periféricos como controllers o guantes que otorgan al jugador una mayor interacción con el entorno.

- Realidad Aumentada: tecnología que superpone elementos virtuales sobre el mundo real, combinando capas de elementos materiales y capas de elementos virtuales.

- Gráficos vectoriales: se trata de un tipo de imagen digital donde ésta se compone de elementos geométricos independientes y definidos por atributos matemáticos (de forma, posición, geometría, etc.) o vectores. La principal característica de estas imágenes es poder modificar su escala sin percibir cambios ni perder calidad.

- Gráficos ráster: se trata de un tipo de imagen digital donde está se compone de elementos geométricos cuadrados denominados píxeles situados en una matriz. También puede denominarse bitmap y posee unas dimensiones en altura y anchura definidas en cantidad de pixeles en ambos sentidos que determinan la escala de la imagen.

- Emulador: software que ejecuta videojuegos en plataformas distintas a aquella para la que fue diseñada. En la actualidad se usan emuladores para jugar a videojuegos antiguos.

- Guía de juego: compendio de todas las acciones, paso a paso, que debe llevar a cabo un jugador para completar un videojuego.

- Desarrolladora Third-Party: se refiere a aquellas empresas que desarrollan software para cualquier plataforma sin establecer exclusividad con ninguna. 
Sobre los géneros de los videojuegos

Se definen los conceptos/nombres que no se definen por sí solos en el Esquema 1.1 (ver página siguiente).

- RPG: siglas de rol player game. Juego de rol.9

- FPS: siglas de first person shooter. Juego de disparos en primera persona.

- Beat'em up (del inglés beat them up): es un género de videojuegos basado en el combate cuerpo a cuerpo entre el jugador (protagonista) e infinidad de enemigos. El jugador se desplaza en única dirección por diversos escenarios.

- Shoot'em up (del inglés shoot them up): subgénero de disparos en el que el jugador controla a un personaje o vehículo (por lo general se trata de una nave espacial) con un movimiento predeterminado debiendo disparar y eliminar a los enemigos que van apareciendo en pantalla.

- Survival horror: subgénero de aventura-acción que está inspirado en las películas de terror. Se caracterizan por una atmósfera de terror que hace sentir al jugador en inferioridad respecto a su enemigo (carecen de armas, visibilidad limitada, obstáculos, etc.). Estos juegos poseen una gran cantidad de puzles.

- Battle Royale: género de videojuegos en el que un gran número de jugadores debe luchar entre sí hasta que solo quede uno, que será el ganador de la partida. Durante la partida cada jugador deberá equiparse y mejorar para poder avanzar dentro de un "área segura".

- Metroidvania: subgénero de videojuegos de acción-aventura que se caracteriza por la exploración de escenarios de forma no lineal, por los que el jugador solo podrá avanzar a las zonas de juego tras adquirir objetos o habilidades. El nombre es una combinación de los máximos exponentes del género que son Castlevania (Konami) y Metroid (Nintendo).

- Arcade: máquina de juego en que el jugador introduce dinero para jugar una partida en que la consecución de la victoria (sea completar el juego, sea conseguir una mayor puntuación) depende de la destreza del mismo en la mecánica propia del sistema de juego en cada caso. Existieron arcades mecánicos que funcionaban sin elementos electrónicos y que fueron sustituidos por los arcade tal y como se conocen hoy en día (inicialmente sin microprocesadores).

- Tragaperras: máquina de juego de azar en que el jugador introduce dinero para jugar una partida en que la consecución o no de la victoria (normalmente ligada a un premio económico) no depende de la destreza del jugador sino de una serie de combinaciones que pueden darse o no de forma aleatoria, requiriendo del factor 'suerte'. 


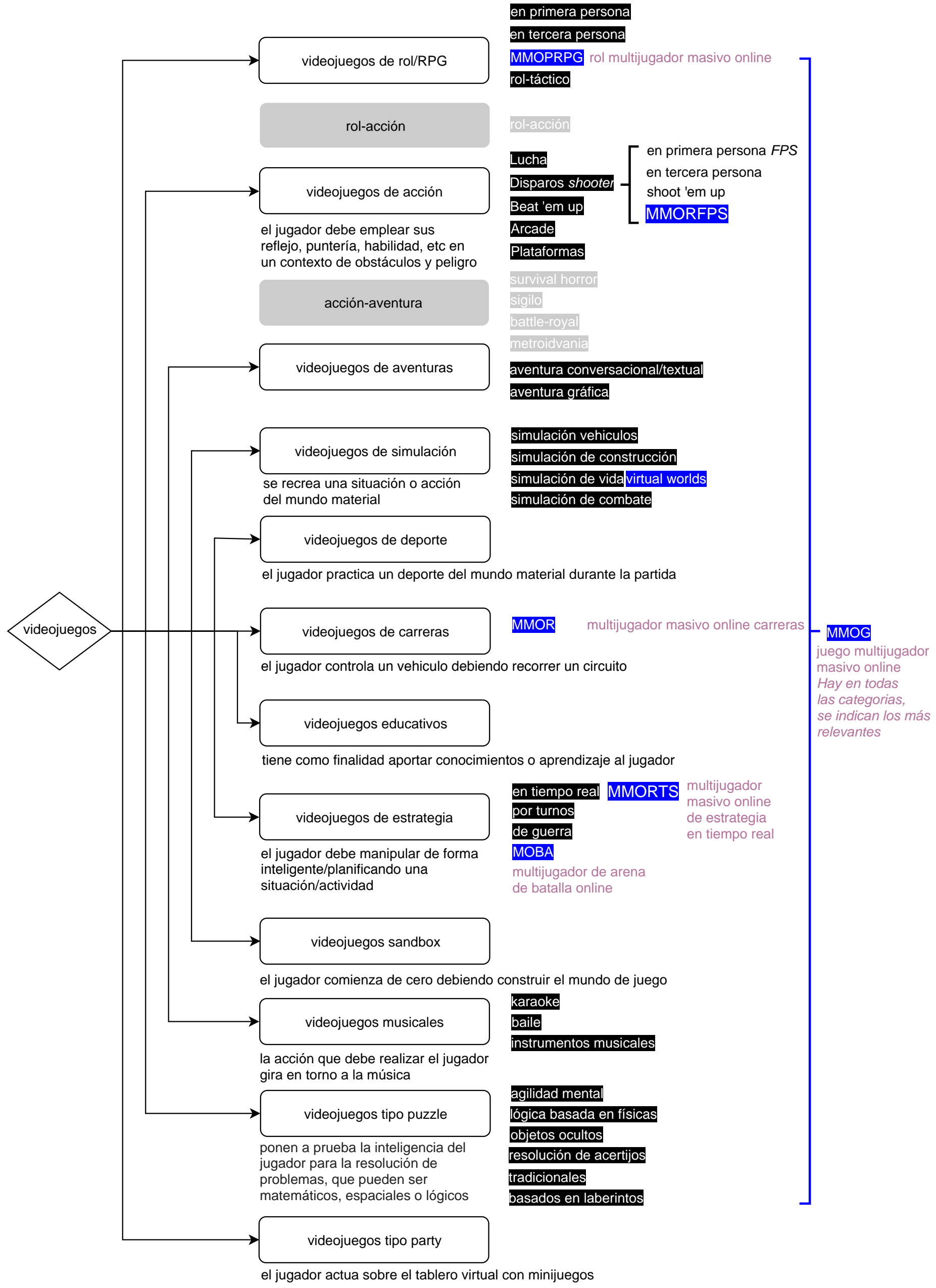




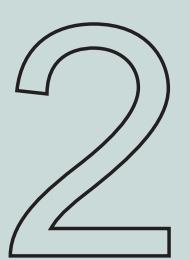

DEL ESPACIO ARQUITECTÓNICO AL ESPACIO DEL VIDEOJUEGO 
'Cuando la gente piensa en cómo se integran la arquitectura y el diseño de juegos, piensan normalmente en estilos arquitectónicos o referencias a edificios famosos. Mientras que estas cuestiones pueden ser interesantes para ayudar a crear espacios de juego, son solo la punta del iceberg en términos de diseño de espacios lúdico-virtuales y de su relación con la arquitectura"

(Totten, 2014, pg22) 
Tal y como analiza Totten (2014) al comienzo del capítulo, las conexiones que van de la arquitectura a los videojuegos se extienden mucho más allá de las meramente estéticas incluyendo también las referentes a los sistemas de representación del espacio (2.1), a los recursos espaciales para construir un espacio que permita orientarse en él (2.2) y a los límites del espacio en cuanto a la posibilidad de ser usado (2.3). Sin embargo, antes de todas ellas se encuentra una escasamente analizada y que va al origen mismo de las cosas: la relación etimológica entre ambos campos.

\subsection{Los orígenes. Las palabras y las cosas}

Son conocidos los primeros juegos de ajedrez para ordenador de Alan Turing ${ }^{1}$ y Claude Shannon ${ }^{2}$. No tanto el primer juego de damas para computadores de Christopher Strachey (Copeland, 2012), aunque fue posiblemente el primero que funcionó realmente como lo que hoy conocemos por juego de ordenador. Ese mismo año, 1952, Alexander Douglas propuso como parte de su tesis doctoral un juego de tres en raya para el ordenador EDSAC (Donovan, 2010). Seis años después, William Higinbotham planteó, usando un osciloscopio en su laboratorio Brookhaven, un juego para jugar al tenis entre dos personas (Kent, 2001).

Todos estos juegos de ordenador fueron pioneros y puede decirse que se trata de los primeros videojuegos, pese a que no eran todavía el concepto cultural y artístico que representan en la actualidad, y se trataba más bien de experimentos académicos. Estos juegos iniciales continuaron a través de distintos centros de investigación, universidades y programadores individuales que emplearon o bien ordenadores institucionales o bien primitivos ordenadores personales, en un tiempo en que no eran habituales ${ }^{3}$ para desarrollarlos.

Los primeros juegos de ordenador se adelantaron entre diez y veinte años (Donovan, 2010) a los juegos de otras plataformas y constituían un desarrollo, inicialmente, sin vocación de convertirse en objeto de consumo.

La transformación se produjo de una forma casi simultánea por dos vías: los arcades en el juego social y las consolas en el juego doméstico. ${ }^{4}$

\section{El concepto 'arcade'}

Los lugares de ocio social ya existentes amusement centers, penny arcades, salones recreativos y de pinball, etc. Se fueron adaptando a los nuevos avances tecnológicos y se transformaron en espacios de ocio digital y virtual.

\footnotetext{
1 Turing A.M. "Chess". In: Levy D. (eds) Computer Chess Compendium. (1950/1988)

${ }^{2}$ Shannon, Claude E. "A Chess-Playing Machine." Scientific American, 1950

${ }^{3}$ Según https://www.census.gov/programs-surveys/acs menos del 8.5\% de la población de Estados Unidos tenía un ordenador antes de 1984.

${ }^{4}$ Con esto no se está eliminando los ordenadores, pero se trata de una época en que éstos no eran tan abundantes como en la actualidad, por lo que, aunque son los responsables del origen de los videojuegos, el salto a convertirlos en un producto de consumo pasó necesariamente por dos realidades ya consolidadas, la TV doméstica y los salones de juegos recreativos.
} 


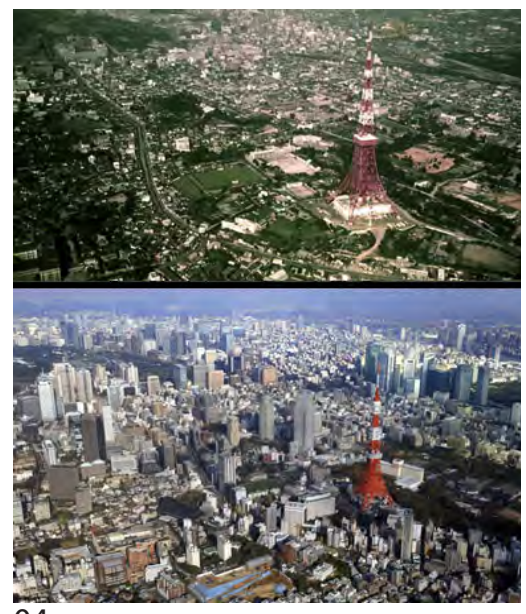

04

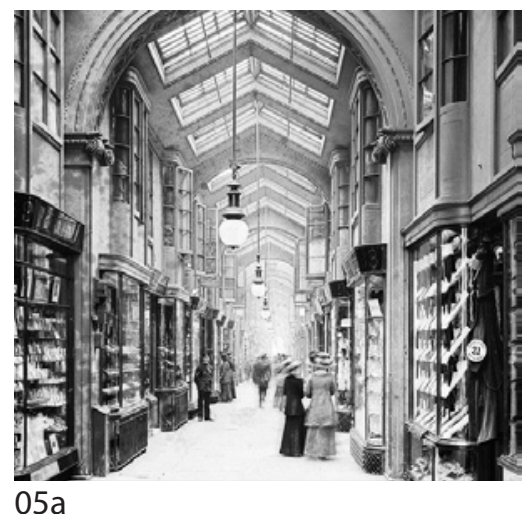

05a

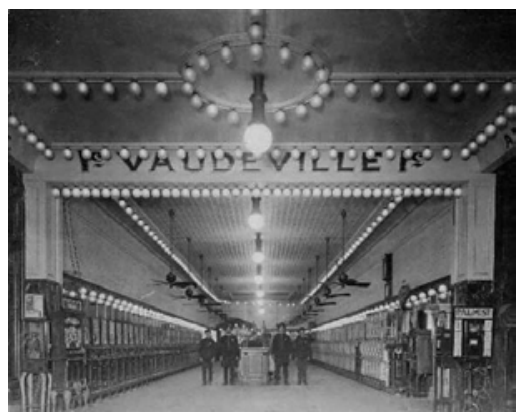

05b

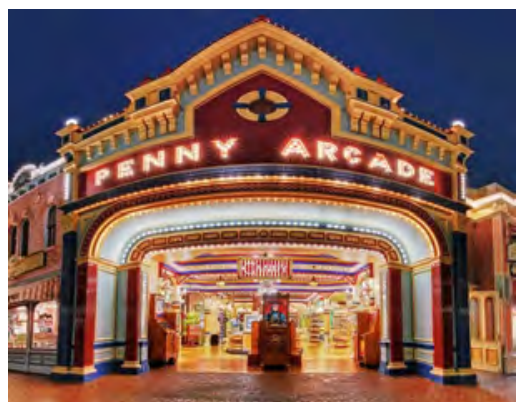

06
En el texto 'Performance, anxiety: The video games arcade and urban space' (Wilson, 2002), su autor reflexiona sobre el papel que cumplían los arcades para una generación de jóvenes que fue perdiendo espacio material de ocio en las ciudades, demandando ganar un lugar al que escaparse en el espacio virtual. El espacio virtual resultó en sus inicios una suerte de alternativa a un espacio material cambiante o inexistente.

Un enfoque similar muestra el creador de Pokémon al analizar el origen del juego. Cuando Satori Tajiri ${ }^{5}$ era un niño en los suburbios de Tokio disponía de espacios verdes, bosques e incluso lagos donde practicar su afición por recolectar insectos. El macro-desarrollo urbano japonés ${ }^{6}$ (04) hizo desaparecer estos sitios y cuando Tajiri pensó en Pokémon ideó un mundo alternativo donde la nueva generación podría ir a capturar los insectos como él había hecho en su día. Así, los arcades supusieron pues esa alternativa de ocio social durante varias décadas.

\section{La palabra 'arcade'}

Desde 1927 hasta su muerte en 1940, el filósofo alemán Walter Benjamin escribió y anotó sus observaciones de sus estancias en París; en los años 80 , y de forma póstuma, se publicaron estos textos recogidos bajo el nombre de Arcade Project ${ }^{7}$. En ellos, Benjamin hablaba especialmente del espacio del pasaje o arcada (concepto de origen latino) que antecedía a diferentes servicios como cafés o restaurantes, tiendas o pensiones. Este lugar intermedio que unía otros espacios actuó como origen de las galerías comerciales (05a). Tal y como analiza Benjamin, este ámbito constituía un espacio de 'excepción legal' (1983). Al no ser considerado un 'dentro' en los establecimientos, ni un 'fuera' en la calle, este espacio no tenía unas normas y leyes tan definidas como el resto.

Los arcades acogían las actividades sin un marco legal determinado, como los vendedores ambulantes durante el día o la prostitución por la noche. Cuando en 1930 aparecieron las máquinas de juegos, inicialmente mecánicas, se situaron en este lugar. El juego no estaba estrictamente prohibido, aunque pasó por diferentes periodos donde si lo estaba (Kent, 2001), pero tenía, sobre todo por su novedad y por las características propias de los juegos de azar, una connotación negativa implícita en torno a la ludopatía ${ }^{8}$. Así pues, las nuevas máquinas de juego se situaron en ese espacio en el 'entre', en las arcadas.

Sin embargo, debido al crecimiento económico que experimentaron, sobre todo en Reino Unido donde los avances tecnológicos permitieron mejores mecanismos, empezaron a aparecer tramos de estas galerías dedicadas exclusivamente al juego. Estos lugares recibieron el nombre en inglés de penny arcade. Con penny - penique - respondían a su funcionamiento con monedas y con arcade a las galerías de arcadas donde se situaban (05b).

Estos tramos de galería se terminaron convirtiendo en salas exentas dedicadas exclusivamente al juego. En los países anglosajones el apogeo de los parques recreativos - amusement park (06) - fundados desde finales del s. XIX y principios de s.XX (Anarling,1997), fomentó los amusement arcades como zonas exclusivas de máquinas de juegos, y éstas empezaron a ser llamadas arcade game. Cuando las máquinas de juego pasaron de ser electromecánicas a estar compuestas por circuitos electrónicos (microprocesadores después) y

\footnotetext{
5 TIME Asia VOL 155. N20 'The Ultimate Game Freak' Interview with Satoshi Tajiri (2009)

${ }^{6}$ Shelton, Barrie. Learning form the Japanese City: Looking East in Urban Design. Routledge (1999)

${ }^{7}$ Benjamin, Walter. Libro de los pasajes / Arcade project

${ }^{8}$ En 1866 Fiódor Dostoyevski había escrito ‘El jugador' donde se hablaba de la ludopatía.
} 
pantallas, heredaron consecuentemente el nombre de sus predecesoras.

Con el salto de las máquinas de juegos a mercados fuera del anglosajón el concepto se redujo a arcade, suprimiendo el game. Así, por ejemplo, el concepto arcade designa a las máquinas de juego en todos los idiomas latinos $^{9}$. Los juegos de arcade recibían - y reciben hoy en día - el nombre del espacio material que ocupaban originalmente.

\section{El concepto consola}

En cuanto al área del ocio doméstico, la casa, que había evolucionado rápidamente, desde la instauración de la radio primero, y de la televisión después, integró la otra línea de dispositivos de videojuego.

El ocio en el hogar (de Benito, 2014) no nació con la extensión de la radio en los años 20, sino que tenía un pasado intrínseco a las actividades y los juegos en el espacio doméstico previo (Green, 2005); la tecnología radiofónica y televisiva cambió sustancialmente el modelo de entretenimiento (Echevarria, 2004), aproximándolo a un modelo pasivo.

Hacia 1945 la televisión había comenzado a expandirse por Estados Unidos y su crecimiento fue exponencial. En 1946 había más de 6.000 aparatos, en 1951, 2 millones y para 1955 la mitad de los hogares estadounidenses tenía un televisor ${ }^{10}$, materializando así la idea de la canción de The Buggles: "Video killed the radio star".

En 2002 un coleccionista de videojuegos francés ${ }^{11}$ descubrió una documentación sobre patentes de juegos para televisor que demostraba la existencia de un primer modelo de dispositivo electrónico ideado en los años de la expansión inicial del televisor, concretamente en 1947, y que nunca llegó a desarrollarse (patente US 2455992), posiblemente por falta de un campo donde aplicarse.

Sin embargo, en 1972 cuando Baer retomó esta idea, el 90\% de los hogares de Estados Unidos tenía un televisor, por lo que idear un dispositivo para jugar en él equivalía a disponer de más de 150 millones de salones a los que poder llegar. Y así nació la primera consola.

\section{La palabra consola}

En los tiempos del rey Sol (Luis XIV) en Versalles había en casi cada estancia un mueble al que denominaban console (07a), que era una suerte de mesa alta y estrecha, pero sin función de mesa, siempre pegada a la pared y a mitad camino entre un armario y una cómoda, hecho para apoyar cosas sobre ella. La palabra console venía del latín

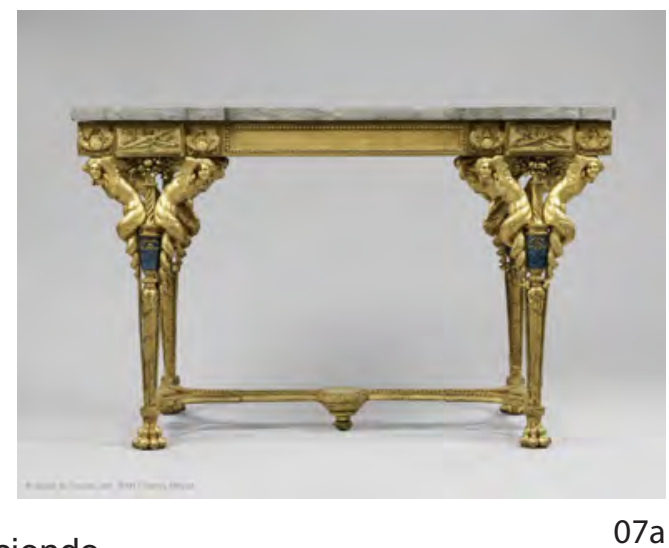
consolari y se refería, por una parte, a la pieza arquitectónica que naciendo de la pared soportaba algo que quedaba por encima, y por otra, entroncaba con el concepto consolidus de dar firmeza y rigidez a algo; lo que se entiende en la actualidad por consolidar (07b). Parece ser que en algún momento de la Edad Media $^{12}$ en Francia, el concepto evolucionó para nombrar no solo a la

${ }^{9}$ En España se les conocieron también con el nombre de salones recreativos (Fernández, Relinque-Pérez. 2017).

${ }^{10}$ Consulta online https://www.nielsen.com/us/en/insights/article/2010/u-s-homes-add-evenmore-tv-sets-in-2010/ consultado por última vez el 16 de junio de 2020

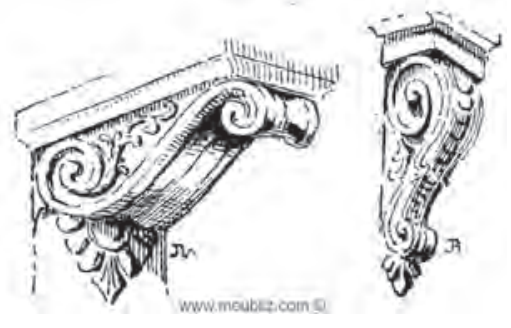

11 Consulta online https://www.lemonde.fr/pixels/article/2017/01/27/la-rocambolesque-redecouverte-du-plus-vieux-brevet-de-jeu-video_5070275_4408996.html consultado por última vez el 7 de junio de 2020.

${ }^{12}$ Consulta Online Etymology Dictionary https://www.etymonline.com/ 


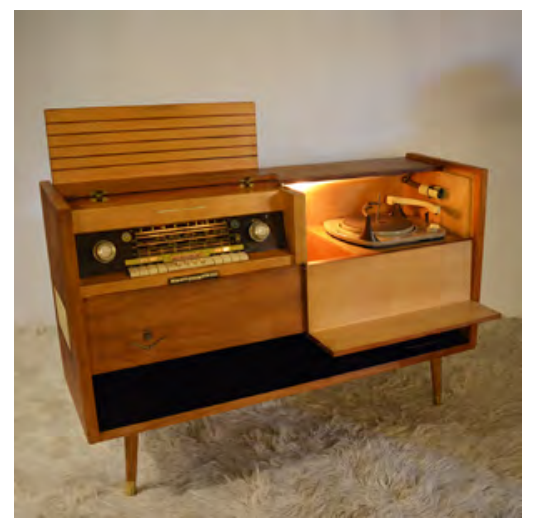

07c

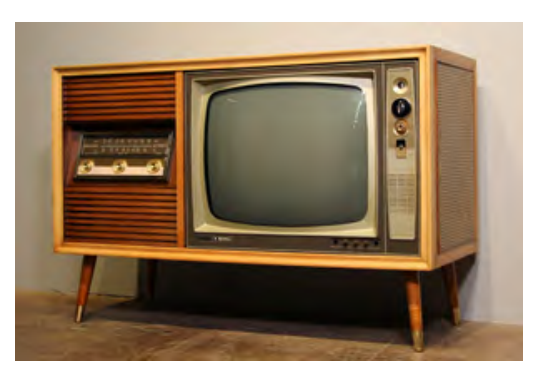

$07 d$

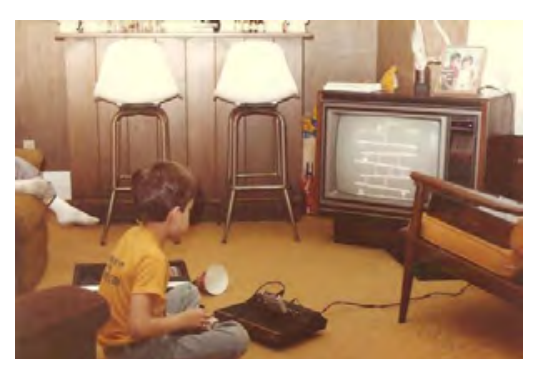

$07 e$ pieza arquitectónica sino también al mueble que se le asemejaba y que era la base de soporte de algún elemento. Esta idea de console se importó a otros idiomas dando lugar al término castellano consola y al término inglés console para denominar a piezas homónimas.

El concepto evolucionó primero hacia el cuerpo de un órgano musical ${ }^{13}$ (1881) y, a partir de $1925^{14}$, se comenzó a usar el concepto radio-console para denominar al mueble que soportaba y en el que se apoyaba el aparato de radio (07c). En 1944 se acuñó el uso equivalente para el aparato en que se apoyaba y sostenía la televisión, TV-console (07d). Para cuando en 1972 se publicó la Magnavox Odissey se incluyó en su libreto de instrucciones la denominación TV game console, que evidenciaba ser el elemento que sustentaba el juego de televisión (07e).

De nuevo, el origen de la consola se encuentra en un concepto puramente arquitectónico.

${ }^{13}$ Consulta Online Etymology Dictionary https://www.etymonline.com/

14 The Concise Oxford Dictionary of English Etymology. Editado T. F. Hoad. Oxford University Press (2003) 


\section{LA CONSTRUCCIÓN DEL ESCENARIO}

\subsection{La construcción del escenario}

La arquitectura que aparece en la película Blade Runner (1982) se inspiró en el movimiento Futurista y los bocetos de Saint d'Elia (Wilkinson, 2017). El mundo de Blade Runner 2049 (2017), en cambio, es de diseño español; en concreto de los estudios Barozzie-Veiga, RCR Arquitectes y del artista Eduardo Chillida como referencias espaciales (08).

De la misma forma que el cine ha recogido las propuestas de la arquitectura, en ocasiones convirtiéndose en el mostrador de proyectos utópicos que no tienen cabida en el mundo material (09), también lo han hecho los videojuegos.

Sin embargo, los videojuegos van un paso más allá al disponer de un espacio interactuable y no meramente observable. Por muy simple que sea un juego, el jugador siempre recorre, camina, bordea, visita o habita algo. Todo videojuego propone un espacio virtual asociado a él - sea físico y dibujado o discursivo y evocado mediante palabras - y, por tanto, implica un proceso de producción y diseño espacial (Totten, 2014).

La producción espacial de los videojuegos cobra especial relevancia por dos motivos: porque el espacio virtual no existe hasta ser creado - no es diseñado en cartón piedra como un escenario de Ben Hur sobre un plató (Ramírez, 1986) - pero, sobre todo, a diferencia del cine de animación o los efectos especiales (que también implican en muchas ocasiones espacios virtuales), en el videojuego el espacio puede ser recorrido y activado de diversas maneras por el jugador al presentar este cierta libertad de movimiento.

Este flujo de referencias que los juegos toman de la arquitectura a su vez puede abarcar dos grandes bloques, los que toman el diseño y estética del espacio (de un edificio, un período histórico, de un área de población, etc.) y los que toman la manera en que se representa el espacio.

\subsubsection{Referencias de diseño: de la realidad a la abstracción}

En 1982 la compañía británica Supersoft publicó un videojuego llamado Streets of London. El juego era una aventura textual sin imágenes diseñada originalmente para Commodore 64, pero que trataba de transmitir al jugador determinadas situaciones satíricas de las calles de Londres (el juego sigue la línea de los Monty Python, como muchos de sus coetáneos británicos). Es muy posible que este juego, junto a Raiders of the Lost Ark de Atari (1982) que contenía un escenario situado en El Cairo (que se resumía a formas de colores), sean los primeros intentos propiamente dichos de llevar al espacio virtual ciudades materiales.

Sin embargo, la realidad es que los videojuegos tomaron espacios materiales y los llevaron a la virtualidad desde su mismo nacimiento. Así,

por ejemplo, Pong, considerado el primer juego comercial, estaba inspi-

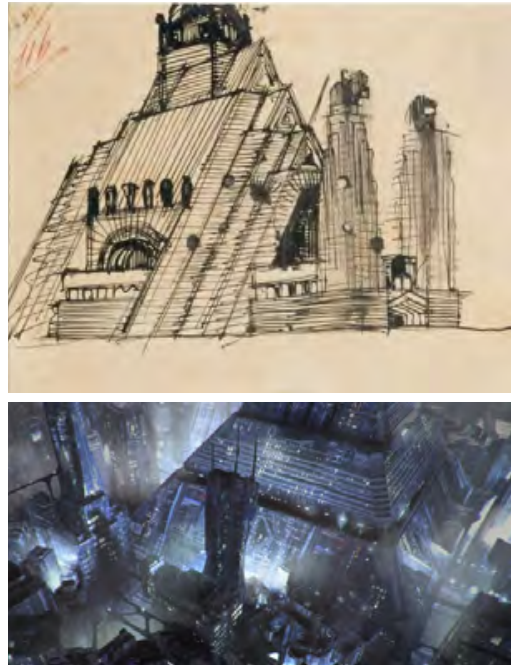

$08 a$

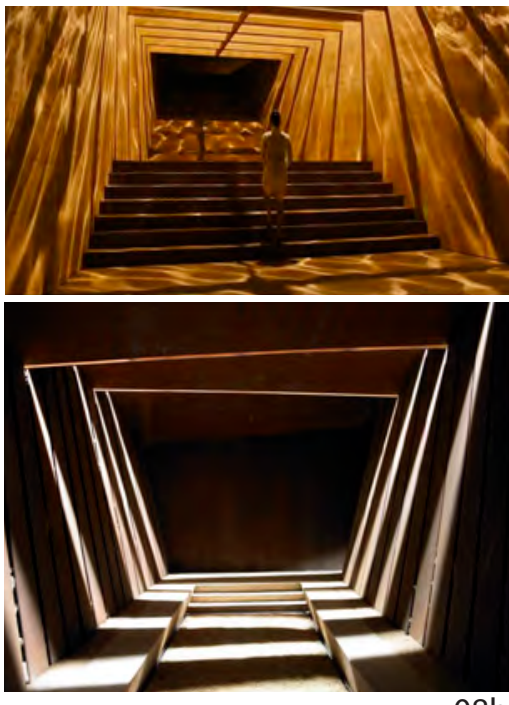

$08 \mathrm{~b}$
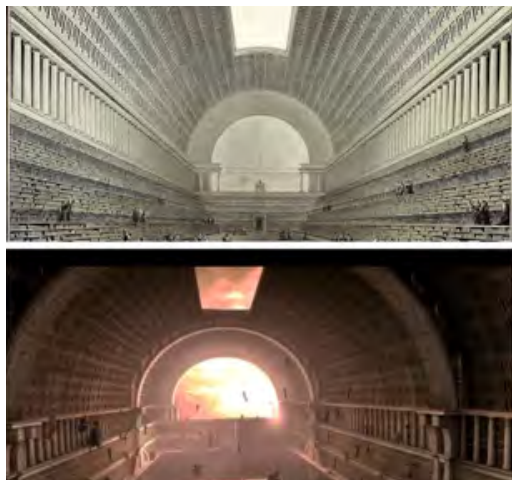


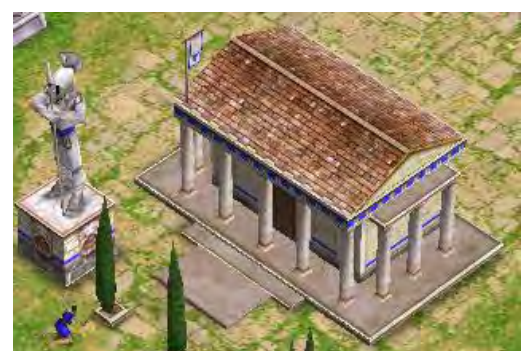

10 rado en Tennis Table de Magnavox juego en el que podía apreciarse el campo de tenis completo sobre el que jugar. Del mismo modo Super Mario trasladaba al jugador a un mundo de las plataformas, las cañerías por las que cabe una persona y los castillos, todos ellos elementos que existían previamente en el mundo material.

Otro ejemplo es Maze War, un juego de 1974 diseñado originalmente para Imlac PDS-1, y conocido por ser uno de los primeros intentos de hacer recorrer al jugador un espacio en tres dimensiones, se basaba en un laberinto con una estructura cuyo origen es puramente arquitectónico ${ }^{15}$. $\mathrm{O}$ el caso de Mistery House, el primer juego con escenario interactivo que, no por casualidad, es una vivienda en sección cuyas habitaciones puedes recorrer como jugador.

Esta representación del espacio material en el espacio virtual ha sido constante y para analizarla debe tenerse en cuenta que abarca un amplio rango de opciones de abstracción, un concepto ligado al dibujo arquitectónico (Sainz, 1986 p109-143).

Así, no es lo mismo hablar de la traslación del diseño de un templo griego hipotético (10) - caso de Age of Mitology (2002) - o del diseño del templo concreto del Partenón - caso de Civilization V (2010) - en el que además se incluye la reconstrucción basada en investigaciones históricas que permita visualizar cómo era el Partenón. Tampoco es igual que se decida representar el templo en un estilo hiperrealista o hacerlo en pixelart: la representación del mundo material en el mundo virtual, del mismo modo que la representación arquitectónica (Sainz, 1986), implica siempre un proceso de abstracción, característica contenida en el concepto mismo de representación. Del mismo modo, cabe tener en cuenta también:

'No está claro si la tecnología audiovisual del siglo XXI avanza hacia la representación hiperrealista del entorno físico o, en su caso, hacia una deformación especialmente sofisticada que, como paradoja, puede llegar a hacer más evidente la distinción entre imagen y realidad (entendiendo realidad en lo que a esta tesis respecta como materialidad)'

(Marfil-Carmona, 2017)

Los primeros juegos de ordenador que simulaban, pero no eran, espacios en 3d, como el ya citado Maze War o Spasim (1984), empleaban gráficos vectoriales, es decir, imágenes digitales compuestas de elementos geométricos independientes y definidos por atributos matemáticos. En ambos casos, los ordenadores en los que se reproducían - el imlac-PS1 y el PLATO System - poseían monitores vectoriales porque una de sus funciones, en el caso de PLATO la principal, era servir para el dibujo asistido por computadora o CAD (de inglés Computer-Aided Design). El dibujo o diseño asistido por ordenador nació hacia finales de los años 50 , y principios de los 60 y es el fundamento del dibujo arquitectónico en ordenadores, habiendo dado lugar a los principales programas de software con

\footnotetext{
${ }^{15}$ 'de origen egipcio - a través del griego - designaba un templo del sur de El Cairo al lado del mar y lleno de pasadizos que servían para confundir a los invasores. Documentado por Diccionario Etimológico del Castellano.
} 
los que se dibuja en arquitectura ${ }^{16}$ (Carlson, 2003). Esas capacidades de 'comprender' espacios vectoriales y trazarlos, de las que dispusieron los ordenadores de dibujo asistido, fueron clave para poder desarrollar juegos en los inicios del videojuego ${ }^{17}$. De hecho, varios avances tecnológicos se encuentran en el origen compartido de la visualización arquitectónica y la representación gráfica de los juegos, como el Light pen (MIT, 1955). Este dispositivo fue empleado por Iván Sutherland en su tesis doctoral conocida como Sketchpad (1963) (11), considerada la antecesora del CAD, y posteriormente fue empleado en múltiples juegos y dispositivos como la consola Vectrex, la SG-1000 de Sega o el estándar de ordenador para juegos
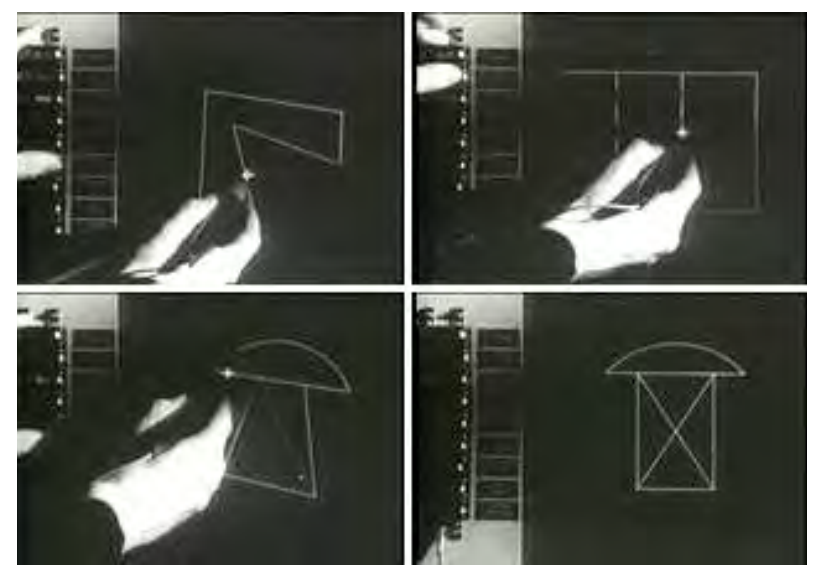

11 $M S X^{18}$.

Esta línea, que enlaza las capacidades gráficas de los ordenadores empleados para dibujo por ordenador con su uso para desarrollar juegos, no fue constante. Tras los juegos iniciales en ordenadores con pantallas vectoriales, la adaptación de estos a televisores en los años 70 implicó utilizar gráficos ráster; es decir, que se basaban en píxeles y que, debido a la calidad del momento, no eran capaces de definir formas muy nítidas, por lo que el juego requería un alto nivel de abstracción; y en juegos como los de Magnavox Odissey o el arcade Night Driver (1976) se recurrió a láminas de plástico coloreadas y con dibujos que se superponían en la pantalla para hacer entender el juego.

Sin embargo, los gráficos vectoriales de dibujo volvieron a ser fundamentales a partir de 1979. En ese año Atari lanzó al mercado el arcade Asteroids, un juego en que el jugador debía disparar a asteroides en el espacio exterior, utilizaba un generador de gráficos vectoriales para recreativas y, por tanto, daba lugar a formas muy definidas. Algunos meses antes, Atari desarrolló con este mismo sistema Lunar Lander, otro juego de gráficos vectoriales que, sin embargo, quedó eclipsado por el éxito de Asteroids. A su vez, también en 1979, y de forma prácticamente paralela, Cinematronics lanzó Tail Gunner, que ha pasado a la posterioridad por ser el primer videojuego con objetos animados en $3 d$; y que también contaba con un motor de gráficos vectoriales al ser en primera persona, lo que obligaba a requerir una nitidez mayor. Entre finales de los 70 y principios de los 80 aparecieron multitud de juegos arcade que usaban la tecnología vectorial del sistema CAD para mostrar el espacio. Sin embargo, a raíz de la crisis de 1983, junto al elevado precio de los sistemas vectoriales, estos motores fueron quedando en desuso según los televisores y los ordenadores fueron mejorando su calidad de imagen, dando lugar a conjuntos de píxeles más definidos.

Los gráficos vectoriales muestran que, en cierta medida, la representación del espacio material y el virtual se ha visto afectada por el desarrollo tecnológico, que ha hecho posible un mayor realismo en la representación. Es el caso de Flying Simulator con la geografía aérea (12). La primera versión de este simulador de vuelo, pionero en su campo

\footnotetext{
${ }^{16}$ En el libro/web 'A critical history of computer graphics and animation' de Wayne. E. Carlson, el profesor de The Ohio State University - The College of the Arts (2003), incluye un capítulo completo sobre gráficos para videojuegos analizando pormenorizadamente la relación intrínseca de ambos campos.

17J. Hurst, M. S. Mahoney, J. T. Gilmore, L. G. Roberts, and R. Forrest. 1989.

${ }^{18}$ Ver análisis de accesorios Capítulo 3.
} 


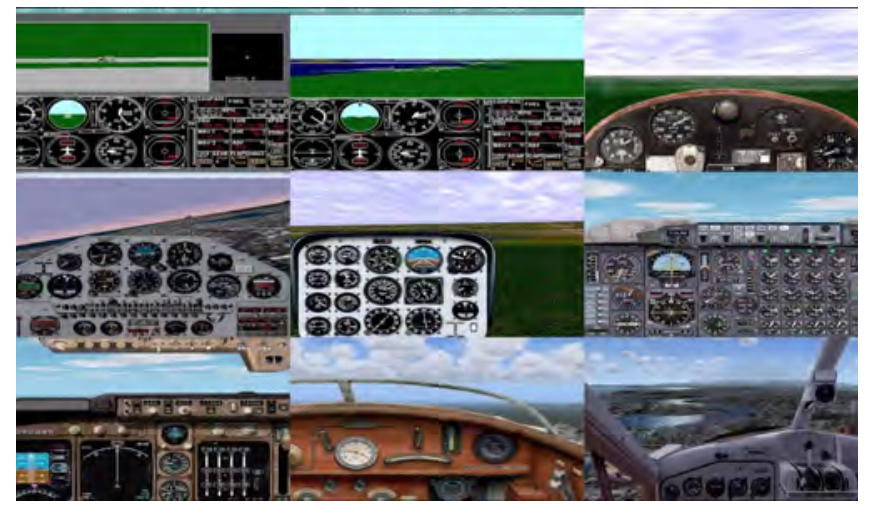

12

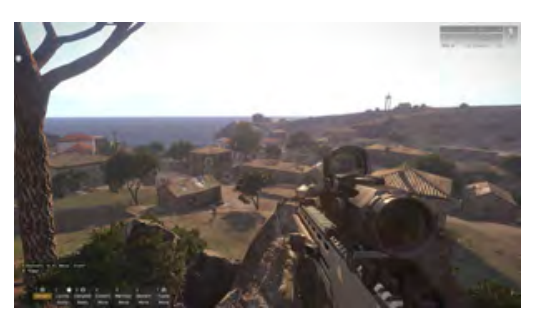

13

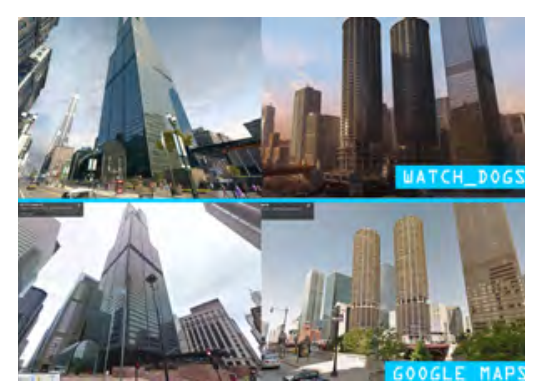

14 satélite. reproducida.
(1978), estaba formada por una cuadrícula de 6x6 líneas blancas sobre el fondo negro, en la que se construía el paisaje con gráficos vectoriales gracias a la potencia del Apple II. Pese a que había un modo de juego de 'Primera Guerra Mundial', en el que podía visualizarse cómo sería sobrevolar el cielo en ese momento, se trataba de un escenario abstracto en cuanto a su localización. Sucesivas versiones fueron implementando mapas cada vez más reales y de mayores dimensiones; así, Microsoft Flying Simulator 2.0, ya comprado por la compañía de Gates y publicado en 1984, permitía el acceso a casi todo Estados Unidos, Japón y algunas zonas de Europa. La versión 5.1 (1995), tomando como referencia el proceso seguido por los creadores de Flight Unlimited ${ }^{19}$, utilizaba imágenes reales de satélites para la construcción del mundo que sobrevolaba el jugador (Lee, 2005/2016). La versión más reciente, Microsoft Flying Simulator $2020^{20}$ inaugura una nueva generación donde se podrá recorrer el mundo entero de forma hiperrealista, tanto de día como de noche, usando información recogida por

Este recurso de combinar la información del espacio material para producir el espacio virtual ha permitido que los videojuegos bélicos utilizados como entrenamiento militar permitan también una función anticipatoria. Se trata de juegos que reproducen fielmente el espacio que va a recorrerse, empleando cartografías de satélite, levantamientos pormenorizados, emplazamientos reales, recorridos y comunicaciones detallados, además de información sobre posicionamiento y ataque; contienen también objetos, situaciones y personajes, tanto interactuables como no interactuables, creados con información completa sobre la situación real

Así, por ejemplo, en los escenarios sobre Afganistán los personajes visten prendas, se comportan, hablan e interactúan con una precisión bastante cercana a la realidad (Chirinos, 2010). La documentación sobre estos juegos requiere del envío de especialistas a cada lugar reflejado en el juego. Así en el caso de A.R.M.A III (versión comercial del videojuego de entrenamiento militar $V S B 3^{21}$ ) el equipo de diseño realizó un intenso trabajo de campo, fotografías y levantamiento del espacio para combinar con imágenes de satélite en Grecia (Lemmos) y Turquía (Shilling. Zyda. Wardynski, 2002) (13).

El empleo de mapas reales de satélite para construir escenarios de juegos no se ha limitado al espacio de dimensiones geográficas. Es el caso de Watch Dogs (2014), el escenario se ha elaborado con los datos reales de la ciudad de Chicago (McVittie, Davies. 2014), lo que permite pasear por calles y visitar espacios que existen en la ciudad material (14).

Los juegos que son los máximos exponentes de esta idea de usar el espacio material como escenario literal del virtual son, posiblemente, Ingress (2012), Pokémon Go (2016) y Harry Potter Wizard United (2019) (15). Los tres han sido desarrollados por la misma compañía de base,

\footnotetext{
${ }^{19}$ Grossman, Austin (June 7, 1995). Flight Unlimited Operator's Manual. Looking Glass Technologies.

${ }^{20}$ Artículo publicado el 18 de mayo de 2020 https://www.pcgamer.com/microsoft-flight-simulator-release-date-trailer/ consultado por ultima vez el 18 de junio de 2020

${ }^{21}$ Virtual Battlespace 3 (2016) simulación de entrenamiento militar.
} 
Niantic, que comenzó siendo una star-up dentro del sistema de mapas por satélite de Google Earth; el creador de ambas es el mismo, John Hanke, y actualmente es una desarrolladora de juegos de realidad aumentada ${ }^{22}$ que, en colaboración con otras compañías como The Pokémon Company en el caso de Pokemon y Warner en el caso de Harry Potter, construye mundos virtuales basados en el posicionamiento GPS del móvil de cada jugador sobre mapas exactos del espacio material. La traslación del mundo material al virtual del juego es tal que la acción de la partida genera movimientos de personas en el espacio material que cambian el uso de este ${ }^{23}$.

No obstante, la extrema fidelidad hacia los mundos/espacios que se representan en los juegos no siempre ha tenido que ver con las limitaciones tecnológicas. Es el caso de la saga

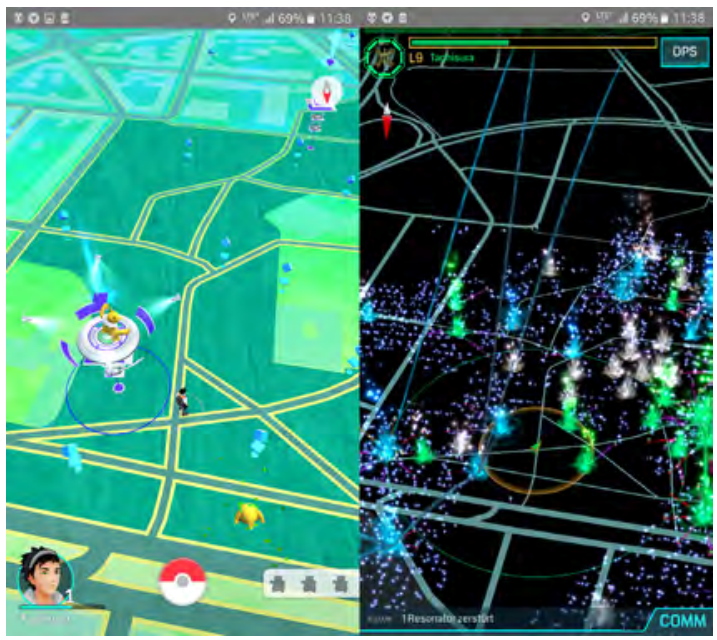

GTA en la que las principales ciudades Vice City (Miami), Liberty City (New York), Los Santos (Los Ángeles) o San Fierro (San Francisco) se basan en otras materiales ya existentes, pero implementan cierto grado de ficción espacial como herramienta con la que los diseñadores y guionistas del juego buscan un contexto en el que llevar a una reflexión sobre comportamientos sociales determinados, como el tráfico de drogas, la prostitución, el racismo o la violencia (DeVane, Squire, 2008) y la necesidad de dar al jugador la libertad de habitar en un mundo donde se encuentran a su alcance y no fuera de él en un espacio conductivista (Frascan, 2008). Así, el ficcionado de las ciudades en GTA remite a cuestiones implícitas en la narrativa:

'los bordes [de la ciudad, de las calles, de los barrios...] se emplean para definir límites geográficos, sociales y estéticos y dentro del marco lúdico general de este juego, los bordes estéticos y psicológicos de la ciudad también significan varias formas de entender el espacio de juego en relación con la ciudad'

(Garrelts, p151, 2006)

En el caso de GTA, además de la relación ficción espacial-espacio material, resulta especialmente relevante la dimensión del mapa. Al igual que sucede en Spiderman PS4 (2018) la dimensión del mundo abierto se encuentra alterada. Una dimensión demasiado fiel a la realidad podría llevar a que el mundo virtual heredara algunos de los 'problemas' del material para los habitantes/jugadores, como el aburrimiento yendo de un lugar a otro (Frascan, 2008), por lo que se modifican las dimensiones en muchas ocasiones, buscando un espacio de diversión continua en que el jugador no llegue a querer abandonar.

En otras ocasiones esta abstracción por la implementación de la ficción, al llevar una referencia del espacio material al virtual, se genera por la necesidad de re-construir ese lugar de referencia. El caso de multitud de juegos que no se centran en el contexto presente sino en uno pasado,

\footnotetext{
${ }^{22} \mathrm{RA}$ : realidad aumentada. Conjunto de tecnologías que permiten que un usuario visualice parte del mundo real a través de un dispositivo tecnológico con información gráfica añadida por este.

${ }^{23}$ `Ver análisis de accesorios Capítulo 4
} 


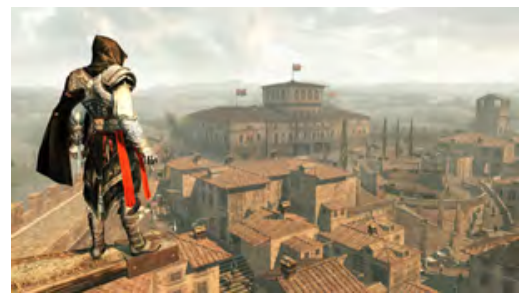

16

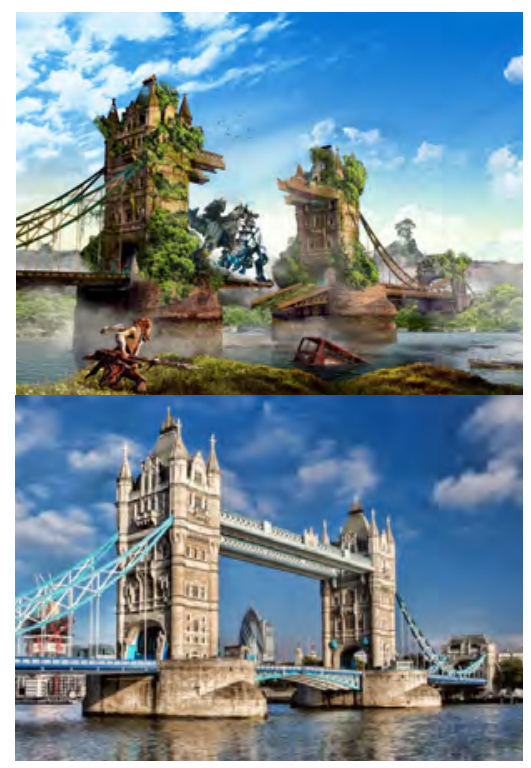

17

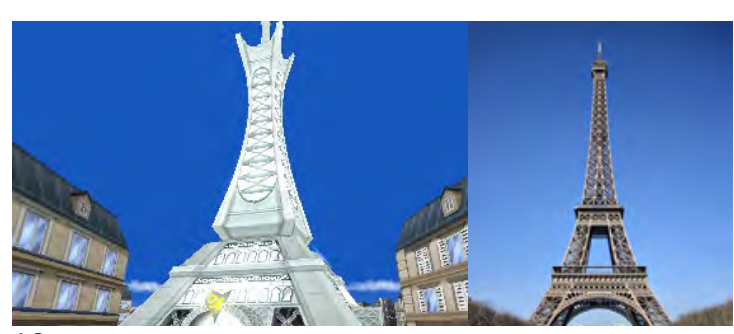

18
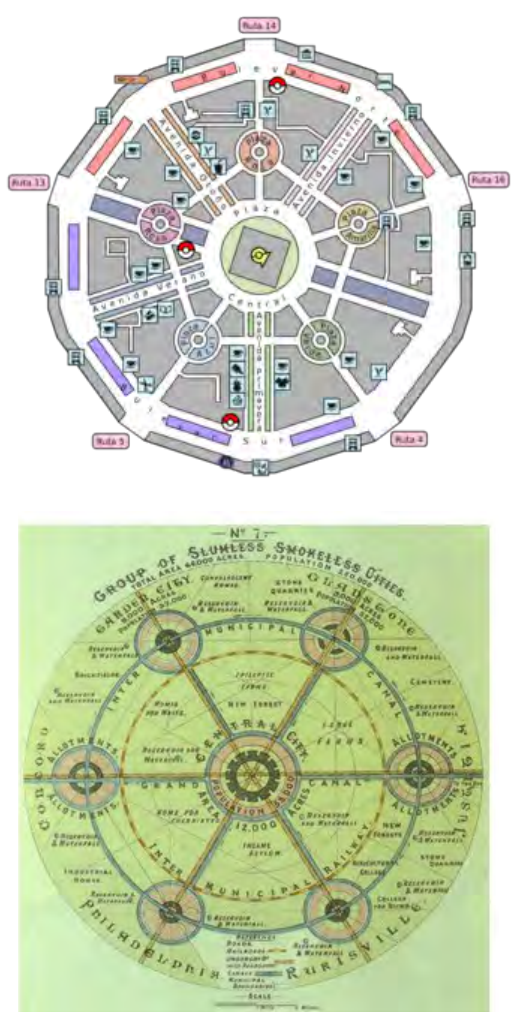

19 tales como Age of Empires (1997) - en diferentes épocas desde la edad de piedra - o Medal of Honor (1999) - durante la Segunda Guerra Mundial. Esta reconstrucción del pasado implica cierto grado de abstracción que requiere - de nuevo - de la traslación de conocimiento desde el campo de la arquitectura. Es el caso de Assassin's Creed II (16), donde Ubisoft contrató a la arquitecta y profesora de historia y teoría de la arquitectura María Elisa Navarro (Trinity College Dublin) como asesora para documentar el periodo entre 1476 y 1503 (Saga, 2015): el juego permite al jugador recorrer la Florencia, Venecia y San Gimigniano del Renacimiento. Fue indispensable aportar, no solo planos y dibujos, sino también conocimiento que permitiera entrelazar y dar veracidad al juego. Navarro explica que en el caso de Venecia hubo de indicar la importancia de no incluir las fachadas renacentistas que comenzarían a construirse después al frente de las iglesias ${ }^{24}$. Otro tema destacado por Navarro (2020) es que, habitualmente, no se emplean planos, si no que estos se ejecutan a posteriori como guías para el jugador. Al contrario que en la arquitectura contemporánea, pero del mismo modo que sucedía antes del renacimiento (Gombrich, 1950).

El trabajo inverso, también de carácter arquitectónico, sucede cuando el espacio virtual trata de construir un futuro que aún no ha tenido lugar. Así, por ejemplo, en el proceso de elaboración de la ciudad de Blade Runner25, que implicó a publicistas, a un equipo de urbanistas (Klein, 1991) y a diseñadores a fin de darle sentido, el juego Horizon Zero Down (2017) requirió de consultas a diversos estudios de arquitectura para dar por viables los modelos de destrucción e invasión de la vegetación en los edificios que salen en el juego (17); algo similar a lo que realizó el arquitecto John Soane en 1830 cuando dibujó su propio edificio del Banco de Inglaterra en ruinas, como un anticipo de un futuro incierto.

También puede suceder que esta abstracción no se encuentre ligada a una finalidad narrativa o de reconstrucción de un tiempo no-contemporáneo, sino que entre en el camino de la ciencia ficción, bien usando referencias materiales existentes o generando propuestas nunca ejecutadas materialmente. El primer caso sería el ejemplo de Colossal Cave Adventure (1975-1977), que toma de referencia el sistema de cavernas Mammoth Cave de Kentucky (Estados Unidos) para convertirlo en parte de un universo cercano a Tolkien (Kent, 2001), o The legend of Zelda (1986) que empleaba simultáneamente referencias medievales con escenarios inspirados en los alrededores de Kyoto $^{26}$. El segundo caso sería, por ejemplo, el de la Ciudad Luminalia de Pokémon X\&Y (2013) (18) que toma de referencia el modelo utópico de la Ciudad Jardín - tal y como hizo antes la película Things to Come (1936) propuesta por Sir Ebenezer Howard en 1898 (19).

En este camino de ciencia-ficción o fantasía - donde se encuentran los mundos que no atienden a leyes existentes e implican siempre un alto grado de ficción - se sitúa el ejemplo de The Witness (2016). El videojuego

\footnotetext{
${ }^{24}$ https://metaspaceblog.com/2015/04/29/architecturevideogamesmaria-elisa-navarroassassins-creed-2-arquitectos-que-hacen-videojuegos/ consultado por última vez el 14 de junio de 2020

${ }^{25}$ The Blade Runner Experience: The Legacy of a Science Fiction Classic. Will Brooker. 2005

${ }^{26}$ Vestal, Andrew; Cliff O'Neill; Brad Shoemaker (2000-11-14). "History of Zelda". GameSpot.
} 
del diseñador Jonathan Blow, quien ya había hecho el exitoso Braid (2008) y cuyas principales mecánicas jugaban con el tiempo, contó con un equipo de diseño formado por arquitectos (20). La directora de este equipo, la arquitecta Deanna van Buren, reconoce en una entrevista ${ }^{27}$ que el abanico de referencias arquitectónicas que emplearon fue enorme

'¡observamos todo en todo el mundo! [teníamos] un archivo masivo de referencias de diseño. La forma en que se veían los tornillos durante la época medieval y cómo se unían en la propia carpintería. Cada parte del proyecto tuvo que ser diseñado [los artistas no eran arquitectos, por lo que no sabían cómo se unían las cosas] Teníamos que resolver todo. [También empleamos] referencias muy contemporáneas. Cosas como películas de ficción que estábamos viendo [...] Todo, desde fábricas de hormigón abandonadas hasta cosas más científicas y de aspecto espacial, hasta las casas en los árboles, que son estos extraños [lugares] destartala-

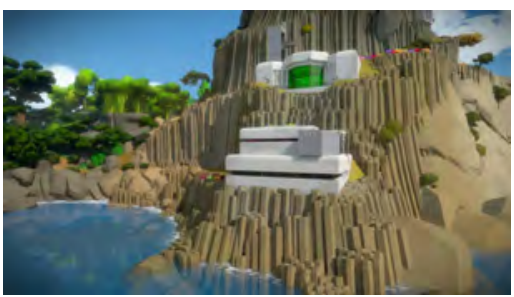
dos. Así que tenía un libro sobre casas en los árboles.'

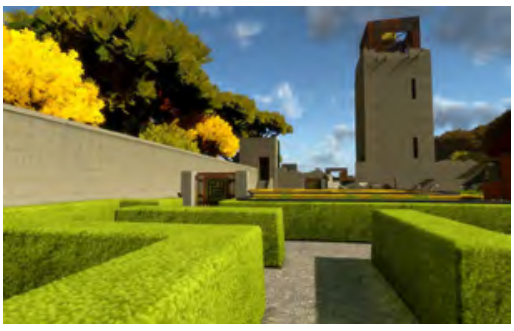

(van Buren, 2019)

En este proceso, destacó de nuevo las similitudes entre el diseño del espacio material y el diseño del espacio virtual como dos áreas de trabajo equivalentes:

'Siempre he sido arquitecta en las fases de diseño. Esto también era un trabajo de diseño, no era como si necesitáramos reunir documentos de construcción o cosas así [sin relación con el diseño]. Al final del día, [los arquitectos] sabemos cómo pensar conceptualmente sobre el espacio, [...] entonces se trata de procesos similares y ya conocidos. Hicimos muchos bocetos y una investigación previa. También hicimos muchos modelos tridimensionales. Es un trabajo de pensamiento conceptual, un proceso similar al que conoces'

(van Buren, 2019)

Los sucesivos ejemplos mostrados en todas las épocas, y con diferentes grados de abstracción, desde que comenzaron a diseñarse videojuegos hasta prácticamente la actualidad, tratan de mostrar que la utilización de la arquitectura y espacio material como referencia y como punto de partida del espacio virtual ha sido una constante.

Este proceso, que forma parte del propio diseño del videojuego, se ha visto lógicamente sometido a los vaivenes culturales y, un análisis pormenorizado de los juegos más destacados muestra que los espacios más representados han sido: el espacio exterior - sobre todo en la década de los años 60-70 coincidiendo con la carrera por la llegada a la Luna ${ }^{28}$ y por su directa relación con la pantalla negra inicial (Rogers, 2014/2018) - y Estados Unidos y Japón - lo que parece lógico por ser las dos grandes potencias en el desarrollo de juegos.

\footnotetext{
${ }^{27}$ Consultado online https://archinect.com/features/article/149964654/behind-the-scenesof-the-witness-a-video-game-designed-by-architects

${ }^{28}$ Consultado online https://www.theguardian.com/games/2019/jul/18/how-the-moon-landings-inspired-a-generation-of-game-designers
} 


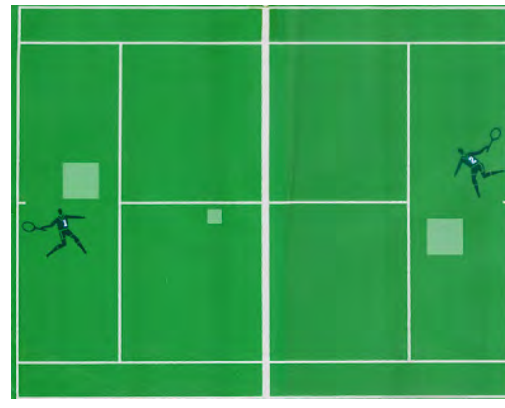

21

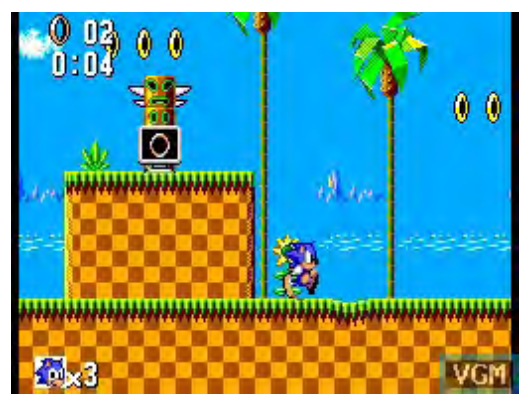

22

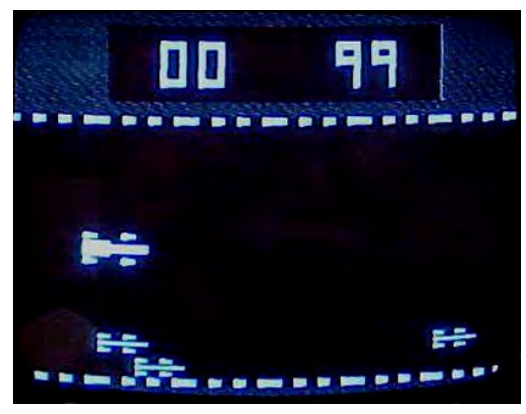

23

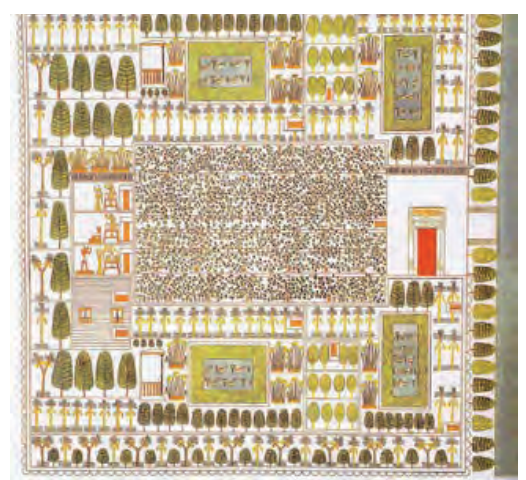

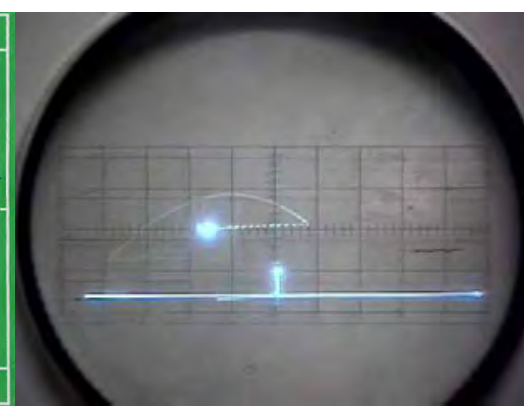

2.1.2 Referencias de representación.

En una conversación reciente con Martínez de Salazar (2019) - cuya tesis analiza los sistemas de representación de los juegos en 2 dimensiones (2016) - compartió una hipótesis inicial descartada que proponía que la representación de los juegos siguió una línea similar a la representación del espacio en arquitectura en su evolución. Esta hipótesis es errónea por el hecho de que la representación en los juegos estuvo ligada, sobre todo, a los avances técnicos, y fueron ellos los que permitieron el salto a las 3 dimensiones llegado el momento. Pero también porque los juegos tomaron como referencia los espacios ya representados en la arquitectura, y por tanto, encontraron un panorama muy rico en opciones para trasladar al espacio virtual.

Lo cierto es que el proceso de representación del espacio virtual es un proceso análogo al proceso de representación arquitectónico (Aarseth, 2000) principalmente porque comparten múltiples puntos de contacto y en el origen de ciertos cambios sobre los sistemas de representación de los juegos hay decisiones puramente arquitectónicas. Este es el motivo por el que en la actualidad son campos tan ligados que sus programas y profesionales pueden trasvasarse de uno a otro ${ }^{29}$.

\section{a. Las dos dimensiones}

Los primeros juegos de la historia fueron composiciones muy simples, que ya mostraban una intención al ser representados. Así, como ya se ha indicado, el juego Table Tennis de Magnavox (1972) y el juego Tennis for Two (1958) son juegos muy similares - en ambos se juega a tenis -, pero es sustancialmente diferente la representación; en el primero, el campo se muestra en planta, mientras que en el segundo aparece en vista lateral o alzado (21). Ambos puntos de vista se tratan posiblemente de las opciones más obvias para representar un espacio - en planta o en alzado -, sin embargo, priman los representados en alzado lateral.

Los juegos en vista lateral (22) suponen una línea tan importante que llega hasta la actualidad - incluyendo grandes títulos como Mario Bros (1983), Zelda II: the adventure of Link (1987) o Sonic (1991) - posiblemente porque, ya segun da Vinci, el alzado es el punto de vista que permite visualizar el espacio tal y como se recorrerá (Heydenreich, 1958), cuestión clave en los videojuegos.

Los juegos en planta, por su parte, han sido más limitados - así Racing (1976) de Coleco o Boxing (1980) de Atari (23) - por la temprana introducción (a partir de 1979) de los alzados dentro de la propia planta a fin de explicar mejor el espacio (Martínez de Salazar, 2016). Este tipo de representación, que muestra planta y alzado de forma simultánea en el mismo dibujo, ha recibido dentro del mundo de los videojuegos el nombre de vista tres cuartos, $y$, al igual que los juegos en perspectiva lateral, ha constituido una línea de representación de juegos con cientos de títulos que nace en los años 70 y llega hasta la actualidad.

La perspectiva tres cuartos se trata en realidad, de la mal llamada perspectiva egipcia o, más correctamente, perspectiva Hedjuk; un caso

${ }^{29}$ Ver Capítulo 4. 4.1 Herramientas de representación y creación del espacio 
particular de axonometría oblicua frontal isométrica en la que el plano secundario XY (la planta) se apoya sobre el plano principal de proyección (como en la perspectiva militar), pero con una dirección de proyección que forma $45^{\circ}$ con el plano de proyección principal y que está en el plano YZ (Izquierdo, 1999)

\section{La perspectiva egipcia ${ }^{30}$ o Hedjuk ${ }^{31}$}

Uno de los orígenes de este sistema de representación se ha registrado durante el periodo del antiguo Egipto correspondiente a los reinados de Tutmosis III (1479 a 1425 a. C) y Amenofis II (1427 a 1401 a. C) en el Imperio Nuevo; de ahí uno de sus nombres.

En este tiempo se encontraron en varias tumbas tebanas de la nobleza - concretamente de Rekhmire y Sennefer por una parte y de Nebamon por otra - los que, muy probablemente, sean los primeros dibujos que han perdurado hasta la actualidad en perspectiva egipcia (Gentil Baldrich, 2012) (24). Dibujos similares se han detectado en otras tumbas en El-Amarna, donde se han encontrado detallados mapas de jardines en este sistema de representación, como los de la tumba del sacerdote Meryra, en los que las fachadas de cada acceso se leen simultáneamente con las plantas (Perrot, Chipiez, 1903) (25).

Este 'primer origen' tiene su explicación en la concepción del mundo egipcio. Para los habitantes del antiguo Egipto, el mundo estaba organizado de una forma semejante a un cubo gigante (Ares, 1997). La cara superior era la diosa del cielo Nut, la inferior el dios de la tierra Geb, y las cuatro caras laterales estaban divididas en planos por cuatro cetros o puntos cardinales, los pilares de Shu, que hacían de columnas separadoras entre el cielo y la tierra (26). Tal y como menciona Ares (1997) dentro de este estricto sistema de esta caja imaginaria que era el mundo para los egipcios, las figuras eran colocadas en planos superpuestos diferentes y con estas estrictas reglas aseguraban la perfecta claridad de todos los elementos (Gombrich, 1950) (27). La distancia, entre los objetos incluidos en una representación, solamente podía ser medida con respecto a la paralela del plano de la superficie-soporte, anulando la visión oblicua y perpendicular de las imágenes (Ares, 1997). A partir de estas premisas es como se entendía el mundo egipcio, en planos que se superponían, de modo que incluyeran siempre la visión más característica de cada cosa dibujada. En el caso de los cuerpos humanos, dibujaban la cara de perfil, el cuello y los hombros de frente y la cintura y las piernas de perfil de nuevo, incluyendo todo ello en un mismo dibujo.

Como ya se ha dicho, a este sistema se le ha denominado contemporáneamente perspectiva egipcia, aunque se trataba en realidad más de un sistema de representación propio de una determinada concepción geométrica del mundo - los egipcios pensaban que éste era el único modo de entender el espacio - que de un sistema real de perspectiva (Gentil Baldrich, 2012). El concepto de perspectiva no apareció hasta el siglo XIII en Francia con las investigaciones en óptica y visión, y se define como un sistema de representación que intenta reproducir en una superficie plana la profundidad del espacio y la imagen tridimensional (RAE, 2017).

No obstante, en ocasiones en arquitectura ha persistido esta denominación porque, tras el fin de la cultura del antiguo Egipto (332 a.C), este modo de entender el mundo, y por extensión el uso de este sistema de representación tan específico desapareció prácticamente en

\footnotetext{
${ }^{30}$ Se considera un error esta denominación, por lo que se cita así para indicar que, pese a ser uno de los nombres por las que se le conoce, no puede considerarse correcto.

${ }^{31}$ Este apartado forma parte del primer avance de resultados de la tesis. 'Unexpected perspective' 2020 Revista de Expresión Gráfica Arquitectónica. EGA. Index Q1
}

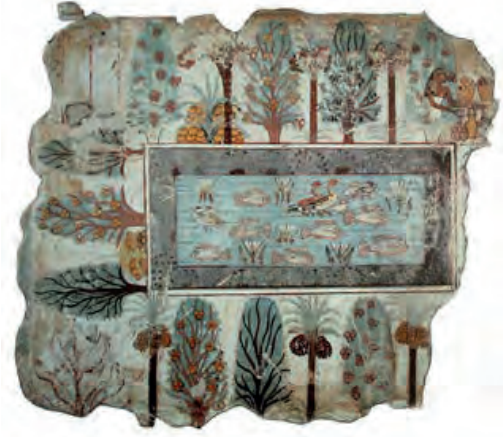

25

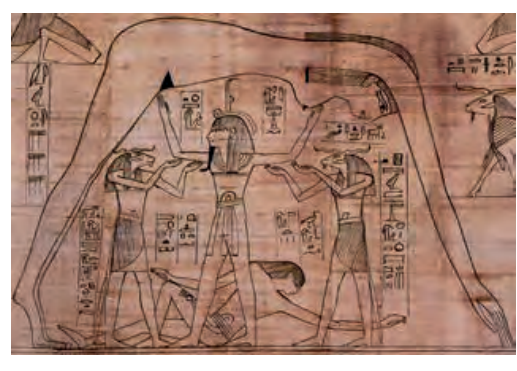

26

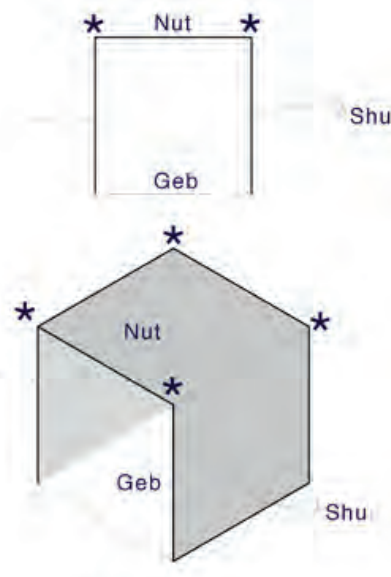

* pilares de Shu

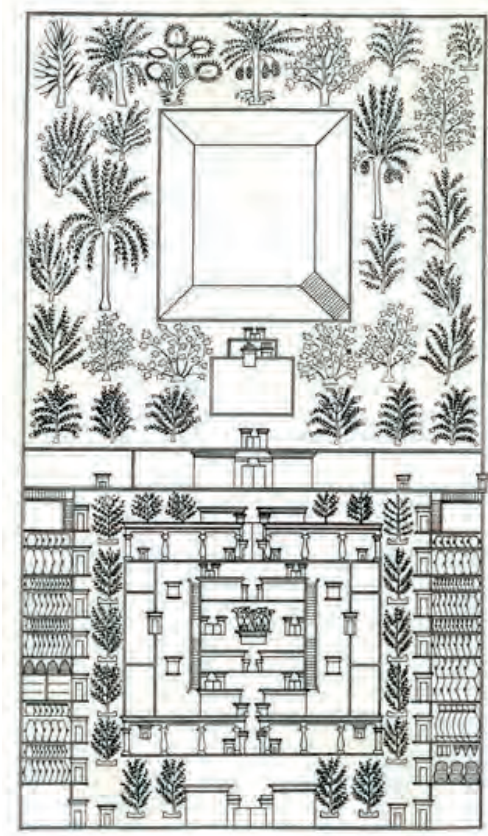




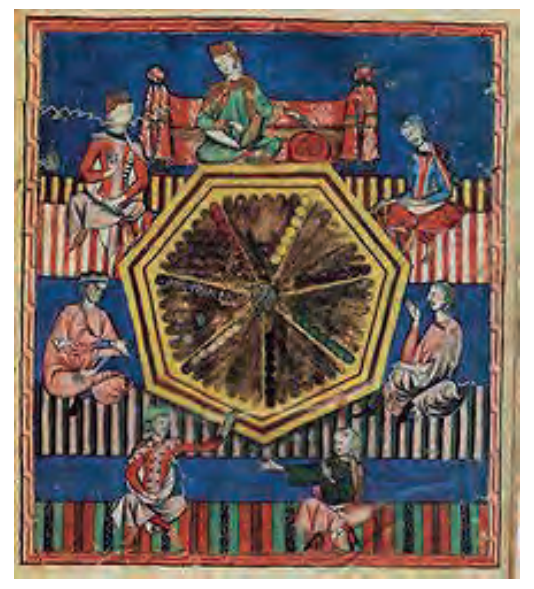

28 su totalidad (Deleuze, 2008) (22 $^{32}$ perdurando solo en determinadas áreas ligadas, justamente, al juego.

Así, durante el siglo XIII, Alfonso X encargó y supervisó la realización del Libro de juegos (Remie, 2007) (28) que contenía detallados dibujos y descripciones de juegos y sistemas lúdicos representados con los tableros en planta y los jugadores alrededor del mismo en alzado (Gentil Baldrich, 2012). En este caso, la combinación de vistas en planta y alzado en un mismo dibujo respondía más a la necesidad de leer los tableros en su verdadera magnitud que a una intención de construir una perspectiva.

Este libro resulta el precursor del uso lúdico de esta 'perspectiva' y evidencia la necesidad de contar el juego (como hecho) en planta - el lugar donde sucede - y de explicarlo temporalmente en alzado - el acto de jugar - simultáneamente, mostrando la superposición gráfica del espacio y de la acción como una característica de esta perspectiva y avanzando el uso que de ella harán los videojuegos.

A partir de los años 60 la perspectiva egipcia se puso de nuevo en el mapa, con un nuevo 'origen' que le dio el nombre de perspectiva Hejduk, en honor al arquitecto estadounidense John Hejduk, quien la empleó en sus dibujos durante gran parte de su práctica proyectual (Gentil Baldrich, 2012).

Su aproximación a este sistema de representación se debe, como él mismo reconoce (1989), a su estudio del Cubismo. En efecto, puede enunciarse una relación entre el modo de entender el espacio del arte egipcio y el origen del movimiento cubista. Pablo Picasso, considerado el precursor del Cubismo en pintura, mostró desde sus inicios un fuerte interés por el arte egipcio. Así, entre 1906 y 1908 reprodujo esculturas egipcias (Rubin, 1988) como referencias para el desarrollo que culminó en Las Señoritas de Aviñón (Luque, 2005). Esta obra es considerada la primera del período protocubista. Tiempo después, Picasso reconoció que su amigo, el pintor Henri Rousseau, compartió con él 'Nosotros somos los dos grandes pintores de la época; Usted, monsieur Picasso, en el género egipcio y yo en el género moderno' (Barolsky, 1993).

El cubismo imprimió un nuevo punto de partida, rompiendo con el realismo anterior y los cánones de profundidad espacial reduciendo toda la obra a un conjunto de planos angulares sin fondo ni perspectiva espacial. Por ello, el arte egipcio y el Cubismo pueden considerarse conectados en su idea básica de la descomposición en planos, pese a no poder ser esta una comparación directa por tratarse uno de un arte primitivo y el otro de un movimiento que alcanzó elevadas dosis de abstracción (Gombrich, 1950).

Hedjuk reflexionó sobre el Cubismo durante el proyecto Diamonds Catalogue (1963-1967). Debía este interés a su estancia en Europa como estudiante durante el curso 1953-1954, por la que reconoció posteriormente que dibujaba como un europeo y pensaba arquitectura como un americano (1989), así como al estudio del trabajo como pintor de Le Corbusier,

\footnotetext{
32 Solamente en algunas áreas del dibujo se realizaron aproximaciones parecidas que, sin poder considerarse perspectiva egipcia, guardaban con ella ciertas similitudes. Por un lado, a partir del 1200 empezaron a aparecer planos de ciudades que contenían la planta de las mismas y los alzados de las fachadas de las manzanas, en una pseudo-perspectiva que perseguía mostrar la distribución de la ciudad y el diseño de los alzados en un único dibujo, así la descripción del alcázar Real de Madrid en el plano de Teixeira en 1656. Del mismo modo, entre 1576-1579 el arquitecto francés Jacques Androuet du Cerceau incluyó algunos dibujos de su libro Les plus excellents bâtiments de France en este sistema, ententiéndolo como un caso especial de isometría (Gentil Baldrich, 2012).
} 
que había trabajado en una pseudo-perspectiva egipcia en su obra Nature Morte (1920) (29), y del Neoplasticismo de Mondrian y el grupo De Stijl cuyo origen se encuentra en el Futurismo y especialmente en el Cubismo (Gombrich, 1999). Es durante estas reflexiones que Hedjuk introduce su perspectiva egipcia:

"Cuando una forma cuadrada en planta se dibuja en perspectiva isométrica parece una proyección tridimensional. Cuando se proyecta más de un plano en planta en isométrica y se superponen de forma natural, sigue apareciendo como una representación tridimensional. Cuando el diamante - rombo - se dibuja en isométrico y tiene más de un plano, se produce un fenómeno muy especial [...] Las formas son bidimensionales; las plantas se superponen entre sí, y en esta superposición de las imágenes; el resultado visual es tridimensional [...]"

(Hejduk, 1989)

Hejduk llega a esta perspectiva a través de la superposición de planos cuadrados en su versión romboidal - giro de $45^{\circ}$ - representados en perspectiva isométrica (30).

"al igual que los cubistas en sus pinturas muestran los objetos
en diferentes planos, las proyecciones isométricas del diaman-
te logran algo similar para los dibujos arquitectónicos - al des-
componerlos en planos que se superponen en un único dibujo
- Las proyecciones isométricas del diamante y sus resultados
son proyecciones cubistas en arquitectura. completando así la
relación formal entre la proyección cubista en pintura y la pro-
yección cubista en arquitectura" (Hejduk, 1989)

En consecuencia, el arquitecto interpreta que en sus dibujos la superposición de planos que da lugar al efecto de perspectiva resulta equivalente a la superposición de vistas en un mismo dibujo del Cubismo. Entiende este modo de dibujar como una transposición de los principios cubistas a la representación espacial. Pone así de manifiesto que cualquier ruptura artística - como la que supuso el Cubismo frente al realismo previo precedente - tiene también su traslación a la arquitectura; el uso de este modo de dibujo en la representación del espacio no es más que la consecución lógica del efecto de ese cambio. Hedjuk no es ajeno a la existencia de la perspectiva egipcia, pero no llega a ésta de forma directa, sino a través del contacto con el Cubismo.

Ahora bien, ¿cómo llega la perspectiva egipcia o Hedjuk un modelo de representación puramente arquitectónico - a ser una de las más empleadas en videojuegos a partir de los años 70 hasta la actualidad?

Existen dos motivos, el primero es el que apunta Gombrich sobre este modelo de representación cuando dice de él que se trata de un sistema intuitivo, que en cierta medida se asemeja a la forma en que dibujan los niños, mostrando cada elemento en su visión más significativa (1950) y coincide con las reflexiones de Martínez de Salazar en su tesis (2016). Por ejemplo, en el juego Atari Football (1978) el campo se muestra en planta mientras que los jugadores se muestran desde el lateral a fin de que el jugador entienda mejor la representación.
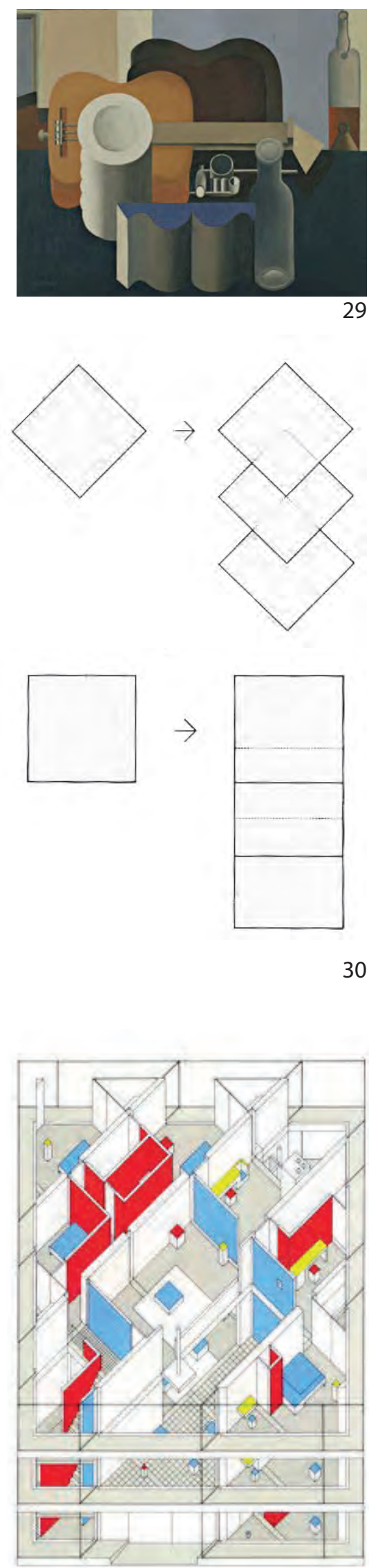
El segundo motivo es la aparición del videojuego Adventure (1979). Este juego - considerado el primer videojuego de aventuras con gráficos - fue desarrollado por el programador y diseñador Warren Robinett (Kent, 2016). Robinett se basó en Colossal Cave Adventure (1976-1977) considerado el primer juego de aventuras, pero construido como una aventura textual ya que no había una capa de diseño espacial en dicho juego, sino que se trataba de un texto que describía y situaba al jugador en la cueva mencionada y le permitía recorrerla viviendo aventuras e incorporando elementos de fantasía como elfos, enanos o trolls (Donovan, 2018). En este juego, el jugador tenía que teclear las respuestas - una o dos palabras como <coger varita>, <coger pájaro>, <ir norte>, <ir sur> - para poder avanzar en la partida, construyéndose el espacio del juego a través del texto. Fue el primer juego en proponer la 'creación de un mundo virtual y lo que significaba explorarlo' (Baton, 2008).

Según Robinett, conoció Colossal Cave Adventure jugando en el Stanford Artificial Intelligence Lab en Stanford University y pensó en llevar el juego de ordenador a la nueva consola VCS de Atari, empresa para la que trabajaba. Para ello tuvo que adaptar el juego a las limitaciones técnicas de una consola doméstica,

"La idea planteaba varios problemas, porque el juego original era todo texto. Todos los comandos usaban un verbo y un sustantivo para describir movimientos o acciones, y aquellas descripciones en texto ocupaban bastante memoria"

(Robinett, 2015)

A fin de reducir el peso del juego, Robinett decidió que los comandos de desplazamiento se asociaran con movimientos de joystick y las descripciones de los lugares se representaran gráficamente en la pantalla. Para ello subdividió el sistema de cuevas en rooms - estancias que podían leerse en la pantalla de una en una cada vez. Todas estaban conectadas entre sí, y si llevaba el cursor al borde de una pantalla, se aparecía en la siguiente estancia. Tal y como él comenta, Robinett tuvo en cuenta sus propios conocimientos como diseñador de espacios para solventar los problemas espaciales a los que se enfrentó durante la elaboración de Adventure:

"[...] en 1970-71, ocho años antes de crear Adventure, fui estudiante en Rice University en Houston, Texas, y tuve una asignatura llamada "Arquitectura para no arquitectos". Fue un curso impartido por estudiantes de arquitectura en Rice y trataba de comprimir los cuatro años de estudio de arquitectura en un curso de un semestre. En ese curso diseñé una casa, un aeropuerto y otra estructura que no recuerdo qué era. Fue en ese curso donde escuché por primera vez una discusión sobre "espacios".

"También cursé, además de las asignaturas de informática, varios cursos de arte, fotografía y dibujo. Esa parte de mis estudios resultó una muy buena preparación para mi carrera posterior como diseñador de videojuegos" 
Robinett reconoce, en una entrevista personal al ser preguntado por primera vez por este tema, que fue su conocimiento previo en representación espacial arquitectónica y arte el que le llevó a ese modo de dibujo (31). Durante estos cursos no sólo tuvo la oportunidad de experimentar con el diseño del espacio, también entró en contacto con diferentes sistemas de representación, entre los que se incluían los dibujos del arquitecto John Hejduk. Warren Robinett explica además que diseñó Adventure de la forma que consideró que resultaba más intuitiva para moverse en el espacio, mostrando cada elemento en su visión más característica, lo que corrobora el primer punto aquí mencionado.

Así mientras los planos se leían en planta, las fachadas y los monstruos aparecían en alzado de forma superpuesta en un único dibujo. Heredó pues el modo de representación de la situación lúdica de El libro de juegos de Alfonso X, retomando la idea de aunar en un dibujo lo estático (el plano) y el movimiento (alzado). El videojuego tuvo una secuela en forma de saga, SwordQuest (1982) (32), ya sin Robinett en Atari, que inicialmente iba a constar de cuatro títulos pero que fue cancelado tras el tercero, y mantuvo, efectivamente, el modo de perspectiva.

Adventure, que vendió más de medio millón de copias el año de su lanzamiento ${ }^{33}$, fue tomado como referencia por Nintendo (Robinett, 2015) para el diseño de los espacios exteriores de The Legend of Zelda (1986) y posteriormente Pokemon (1996) - Squaresoft para Final Fantasy (1987), Enix para Dragon Quest (1986) o Sega para Phantasy Star (1987) - y luego para Golden Axe Warrior (1991) - redefiniendo los juegos de rol $^{34}$ japoneses (33). También compañías americanas como Electronic Arts con Wasteland (1988) lanzaron sus propuestas e incluso en otros géneros como Konami para el juego de sigilo Metal Gear (1987). Todos ellos suman más de 50 millones de copias vendidas, lo que supone una cantidad considerable de jugadores que recorrieron, habitaron y entendieron mundos virtuales dibujados en esta perspectiva egipcia, Hejduk o tres cuartos.

\section{b. Las (casi) tres dimensiones}

Los videojuegos en dos dimensiones imperaron durante las décadas de los 70, 80 y persistieron durante los 90 (Donovan, 2010) hasta hoy, configurando un tipo que aún se desarrolla en el presente. Si bien los videojuegos de desplazamiento lateral representan un espacio puro en 2D - aunque en la actualidad existen juegos que muestran cierta profundidad espacial, con la acción ocurriendo solo en el plano continuo, tales como Super Mario 3d World (2013) - los videojuegos en perspectiva tres cuartos no se encuadran realmente en las dos dimensiones, y, como ya se ha señalado, se consideran una variación de la perspectiva axonométrica (Izquierdo, 1999). Esto muestra que la representación del mundo virtual requirió pronto - tratando de aproximarse al espacio material - la exploración de vías alternativas con las que mostrar más dimensiones

${ }^{33}$ Un año después se dio además a conocer la existencia de un Huevo de pascua en su interior, siendo el videojuego que inauguró también esta estrategia.
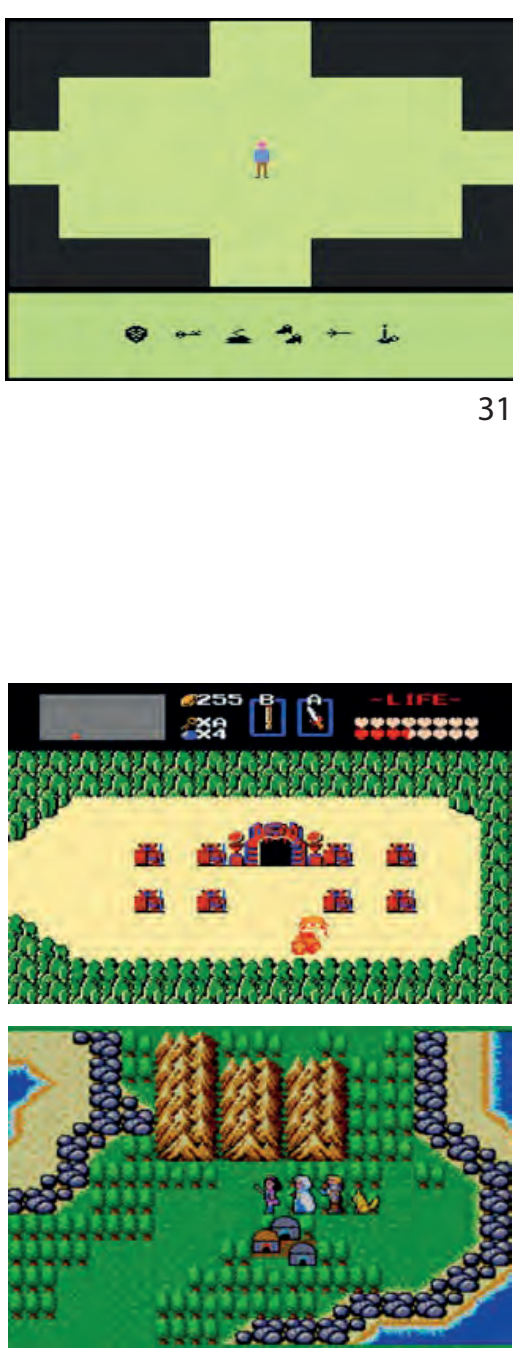

${ }^{34}$ Un juego en el que, tal como indica su nombre, uno o más jugadores desempeñan un determinado rol, papel o personalidad.

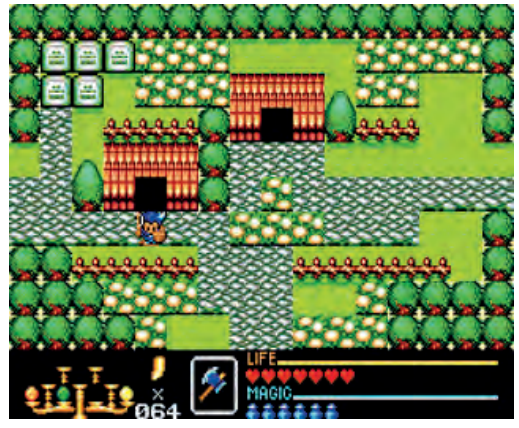




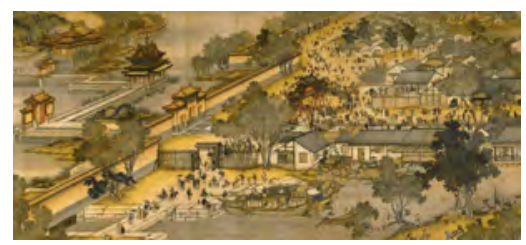

34

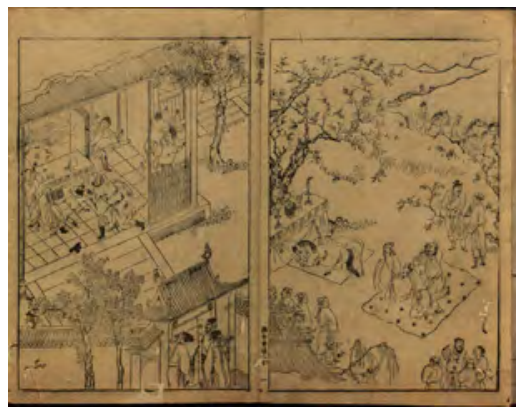

35

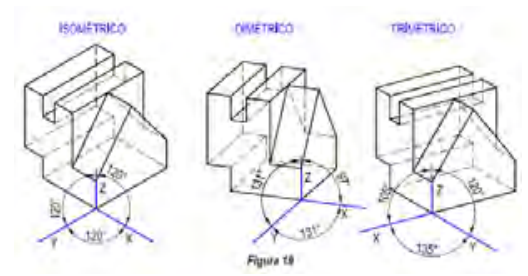

36

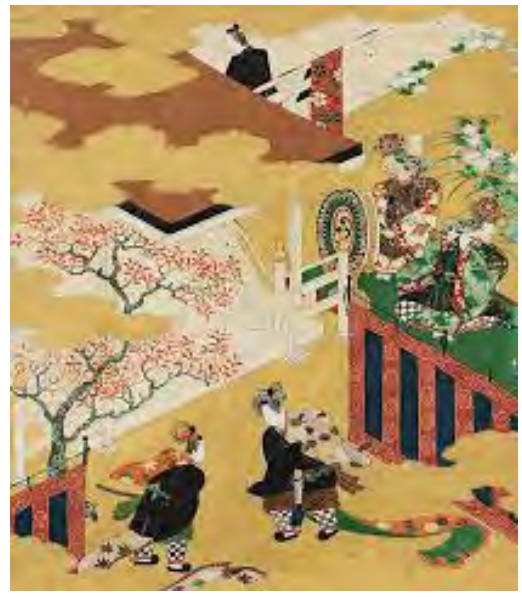

37

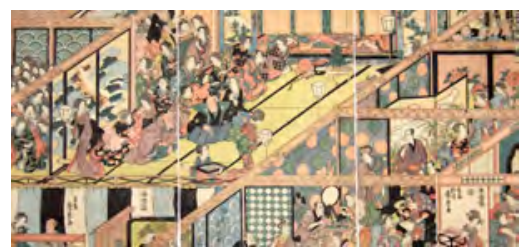

38

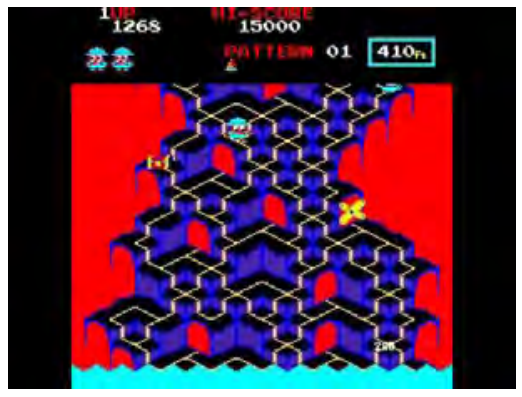

39 geométricas al margen del eje $\mathrm{XY}$, y por ello aparecieron una serie de juegos que simulaban entornos 3D, sin serlo.

En pintura y en dibujo, los primeros intentos de mostrar un espacio con profundidad de una tercera dimensión datan del período entre los años 40 y 30 a.C en Roma (Gombrich, 1950). Se trata de algunos frescos pintados en villas que muestran pseudo-cónicas, pese a que no pueden considerarse propiamente un dibujo en perspectiva todavía.

La perspectiva cónica se instaura en occidente de forma total en el Renacimiento - entre los siglos XV y XVI - cuando Brunelleschi (sobre todo entre los años 1416 y 1420) anota y elabora los principios matemáticos que la construyen (Kemp, 2000). Se empleará en la presentación espacial hasta hoy como modelo que permite percibir el espacio de una forma más similar a como lo hace un ojo humano.

De una forma casi análoga, los primeros intentos de mostrar el eje $z$ del espacio virtual fueron cónicas con un punto de fuga central, como el ya nombrado Maze War (1970), Battlezone (1980) o Tempest (1981).

Mención al margen merece Spasim (1974), un videojuego que era más bien un motor de simulación de vuelo y disparos en primera persona, y que usaba $C A D^{35}$ para mostrarse en diferentes perspectivas. Algunos juegos, como The Legend of Zelda (1986) emplearon la perspectiva cónica centrada para dar profundidad al espacio de las salas interiores, combinándose con la perspectiva egipcia en exteriores.

Los últimos juegos antes del salto al $3 \mathrm{~d}$, tales como Wolfenstein 3D (1992) o DOOM (1993) trataban de llevar al jugador a una experiencia cada vez más similar a la que sucede al recorrer el espacio material. Este último puede considerarse un juego en 2.5D al disponer en parte de una visualización que simula el $3 \mathrm{~d}$, pero cuyos personajes y objetos siguen siendo planos. En todos los casos se trataba de intentos, paulatinamente más cercanos, de mostrar el espacio virtual tal y como percibimos el material, que, de nuevo, constituía la referencia.

Sin embargo, en los países orientales la situación fue diferente. Desde finales del siglo XII es conocido el uso de la perspectiva axonométrica en China; así, por ejemplo, se observa en las pinturas Along the River During the Qingming Festival (34) (Zhang Zeduan (1085-1145) o en las ilustraciones de Romance of Three Kingdoms (35) (s. XV). Ello propició que se conociera a este modo de representar el espacio con el nombre de perspectiva china (Tyler, Chen, 2011), denominando a un grupo de dibujos que se representaron con un modelo similar (pero inicialmente sin una definición cerrada) muy similar a lo que hoy se entiende por perspectiva axonométrica, basada en la modulación característica de la arquitectura y el espacio matemático en Asia (Pipes, 2003).

Entendiendo por perspectiva axonométrica el sistema de representación de un cuerpo o espacio de tal forma que cada punto A se referencia a un sistema de ejes coordenados rectangulares $X Y Z$ - que pueden tener diferentes ángulos entre ellos - por medio de sus proyecciones Ax, Ay y Az para, luego, proyectarlo todo sobre el plano de dibujo (Izquierdo, 2003). Existen (Izquierdo, 2003) varios tipos de perspectiva axonométrica (36), destacando la isométrica - ángulos entre $X Y Z$ iguales $=120^{\circ}$ - la dimétrica - dos ángulos iguales y uno diferente - y la trimétrica - todos los ángulos diferentes. La ya mencionada perspectiva egipcia es un caso con-

${ }^{35}$ Tal y como se ha indicado Spasim fue diseñado para el ordenador PLATO system uno de los primeros sistemas generalizados de asistencia por computadora 
creto de dimétrica, como también lo son la perspectiva caballera (ángulo $X Z=90^{\circ}$ ) y la perspectiva militar (ángulo $X Y=90^{\circ}$ ), todas ellas modelos de representación usados habitualmente en arquitectura desde mediados del s. XVIII (Farish, 1822), pero no tanto en el resto de campos.

Así, el hecho de que en la tradición china el sistema de representación espacial imperante fuera el axonométrico (en sus diferentes variedades), dio lugar, por su influencia, a su importación a los países con más contacto cultural con ellos, como Japón y Corea. El caso de Japón se puede observar en las ilustraciones de "An Imperial Celebration of Autumn Foliage," (37) (s. XVII) o en los dibujos del artista japonés Hiroshige (17971858) (38) de importante relevancia cultural en el país nipón no solo en los campos ligados a la arquitectura. De este modo, cuando en 1981 la compañía japonesa Data East - con sede en Tokio - publicó el juego Treasure Island (39) en perspectiva isométrica, lo hizo gracias al background de representación espacial que tenía Japón.

Treasure Island, sin embargo, no fue publicado fuera de Japón, y hasta el año siguiente (enero de 1982) que Sega - empresa de capital americano, pero desarrollo, trabajadores y filosofía japonesa - publicó el videojuego Zaxxon (40) en axonométrica no se abrió el campo de diseño de multitud de juegos posteriores en modelos axonométricos.

Unos meses más tarde (en noviembre de 1982), Warren Davis y Jeff Lee, dos diseñadores de videojuegos que trabajaban en Gottlieb - una empresa de Chicago - idearon un juego de acción llamado $Q^{*}$ bert (41) en perspectiva isométrica, y como Lee reconoce (Kent, 2001), usó de referencia las imágenes de M.C. Escher (además de Zaxxon que ya existía).

El artista gráfico M.C.Escher - que había fallecido 10 años antes - estudió durante un tiempo en la universidad de arquitectura y artes decorativas de Haarlem (Holanda), y, aunque finalmente dejó arquitectura, entró en contacto con el dibujo arquitectónico (42) (Ernst,1978/1989), a través de su profesor S. Jessurun de Mesquita (43) cuya formación también había sido parcialmente arquitectónica y era un buen conocedor de las perspectivas axonométricas (Escher, 1956/1991). Escher desarrolló un estilo propio muy reconocido que combinaba modelos geométricos y matemáticos imposibles con el dibujo del espacio, siempre a mitad camino entre la realidad que parecían mostrar sus obras, con la ficción que siempre se encontraba en ellas.

Tras Treasure Island, Zaxxon y $Q^{*}$ bert se publicaron numerosos juegos en axonométrica, sobre todo para ordenador, como Ant Attack (1983), Kinght Lore (1984) o Spindizzy (1986). Cabe destacar Congo Bongo (1983) un juego de Sega mostrado en isométrica que se reprogramó en perspectiva caballera al adaptarlo al Commodore 64, convirtiéndose en el primer juego así visualizado (44).

Del mismo modo que la perspectiva egipcia llegó a los videojuegos a través de la arquitectura, la perspectiva axonométrica lo hizo a través del dibujo arquitectónico. Valga de ejemplo de uno de los juegos más reconocidos en isométrica, La abadía del Crimen (45) (1986). Este juego español - perteneciente a la denominada edad de Oro del videojuego en España fue programado por Paco Menéndez y diseñado por Juan Delcán, que era por aquel entonces un estudiante de arquitectura en la Escuela Técnica Superior de Arquitectura de Madrid y durante una entrevista reconoció porqué visualizó el espacio en isométrica 'era una de las 3 perspectivas que enseñaban en la universidad en primero de arquitectura' (Delcán, 2018)

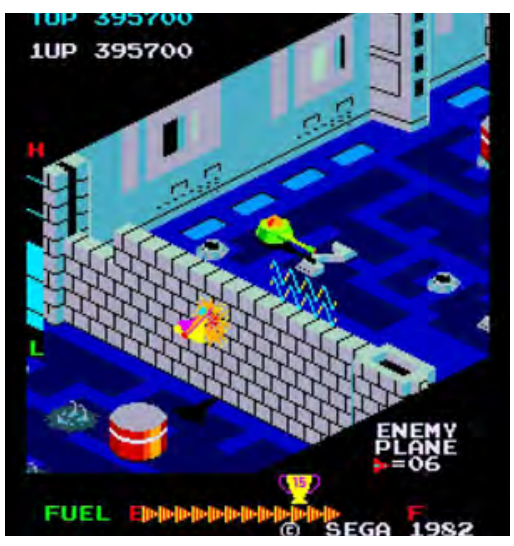

40

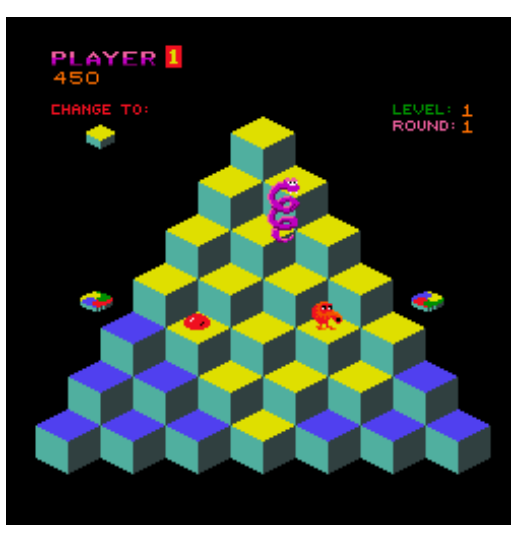

41

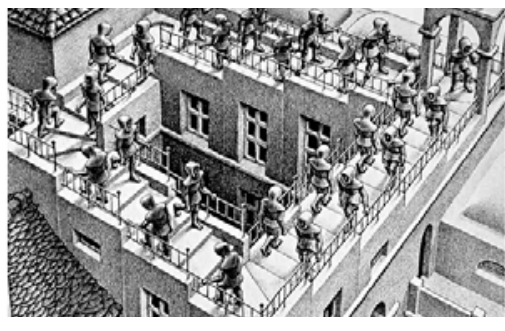

42

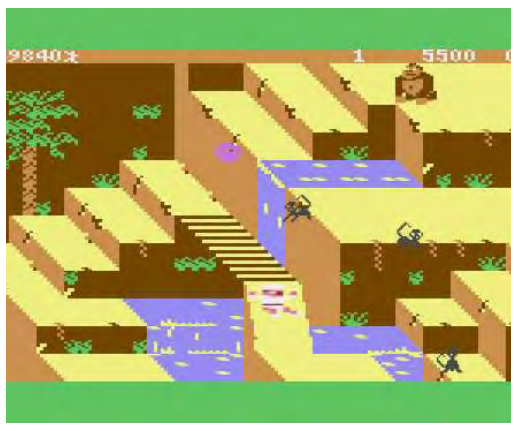

44

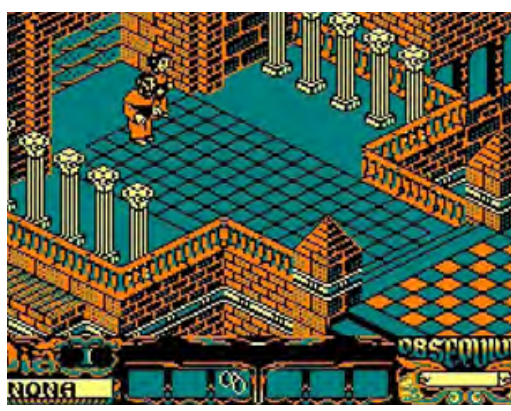

45 


\section{c. Las tres dimensiones}

El salto de los videojuegos a las tres dimensiones fue posible gracias a la evolución tecnológica (sobre todo en el campo de chips como el DSP-1 de la Super Nintendo y de los avances del grupo de investigación Sega AM-2).

Si bien es cierto que durante la década de los 80 desde el dibujo asistido por ordenador CAD se investigaron y propusieron ciertos avances sobre el dibujo informatizado en $3 d$, lo cierto es que el gran salto sucedió a raíz de la aparición del software de 3dmax (originalmente Cyber Studio CAD-3D) creado por John Hudson.

Esta historia muestra que, llegado el momento del paso a las tres dimensiones, fue la arquitectura la que tomó a los videojuegos como referencia y, por tanto, se incluye en el capítulo 4/4.1.1 - El desarrollo de las tres dimensiones de esta tesis. 


\subsection{Las estrategias de guía e interacción espacial.}

[...] la historia del juego debería contarse dentro de los niveles. Usar el espacio para explicar una historia no es un concepto novedoso; el diseño arquitectónico lleva usando esta técnica desde hace siglos.

(Rogers, p220, 2014/2018)

El diseñador de juegos Scott Rogers - que ha desarrollado juegos para Sony, Namco o la New York Film Academy - explica, tras su experiencia trabajando como 'imaginador del mundo de los parques Disney'36, que estos recintos de ocio 'le enseñaron todo lo que sabe sobre el diseño de niveles'37.

Walt Disney era aficionado a las maquetas de trenes, por lo que insistió a sus ingenieros que el primer parque Disney fuera un 'mundo en miniatura'. El proyecto se dividió en cinco áreas (Frontierland, Tomorrowland, Adventureland, Fantasyland y Main Street) cada una de ellas tematizada en torno a las ideas del propio mundo de ficción y llenas de atracciones acordes a las mismas (46). Así los visitantes podían recorrer los espacios materiales como las escenas de las películas Disney (Rogers, 2014/2018).

Para orientar a los visitantes Walt Disney (Rogers, 2014/2018) acuñó el concepto de weenies - en honor a las salchichas Franfurkt (informalmente weenies en inglés) que usan los adiestradores para captar la atención de los perros - para denominar a los elementos que era necesario introducir como referencias arquitectónicas (el castillo de la Bella Durmiente (47) o la Space Mountain $\left.{ }^{38}(48)\right)$ que resultan llamadas de atención espacial.

Multitud de videojuegos han copiado los weenies para 'guiar' al jugador por el espacio, así por ejemplo el castillo francés de Uncharted 3 (2011) (49), Rock of Ravatogh en Final Fantasy XV (2016) (50) o la torre Citadel de Half-Life 2 (2004) (51). Se trata de un recurso propio de los videojuegos tal y como indican Rogers (2014/2018) y Totten (2014) señalando la importancia de indicar al jugador puntos de referencia espacial que le muestren el camino.

Esta idea de emplear referencias visuales no fue un invento de Walt Disney ni de su equipo de ingenieros (Marling, 1997), sino que es una estrategia que la arquitectura y el diseño, tanto urbano como de paisaje, lleva décadas empleando. Lo nombra Kevin Lynch en su libro clave 'La imagen de la ciudad'y se refiere a ello como puntos de referencia (1960/2015) que ordenan la visión del entorno indicándolos - a veces - como alcanzables

\footnotetext{
${ }^{36}$ Así se autodenomina el propio Rogers en su Linkedin. Consultado por última vez el 21 de junio de 2020.

${ }^{37}$ En videojuegos se denomina nivel a cada uno de los mundos o escenarios del juego, así que decir nivel es - básicamente - decir mundo o entorno y su origen viene de Dungeons \& Dragons donde cada nueva etapa del juego es un 'nivel' de mazmorras (Rogers, 2014/2018).

${ }^{38}$ Space Mountain es una de las principales atracciones de todos los parques Disney, consistente en una montaña rusa cubierta que recorre un mundo espacial de ficción.
}

\section{LAS ESTRATEGIAS DE GUÍA E INTERACCIÓN ESPACIAL}

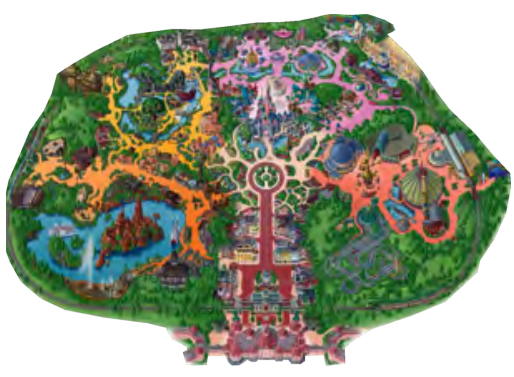

46

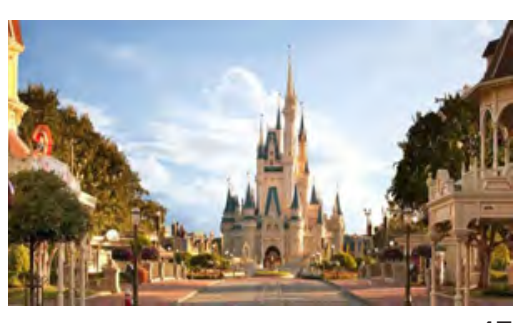

47

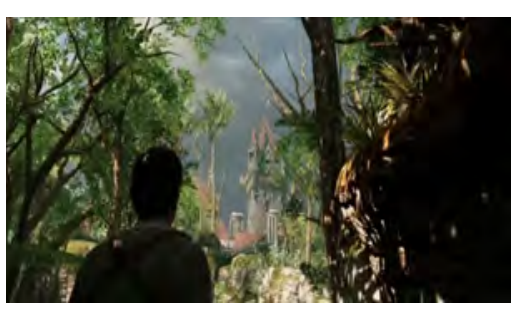

49

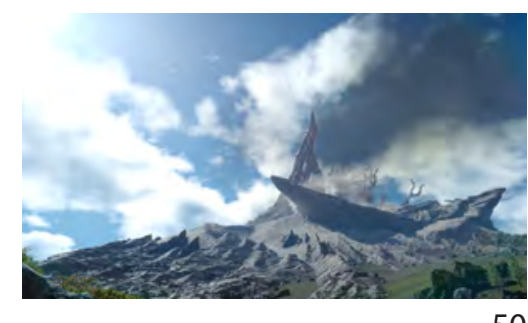

50

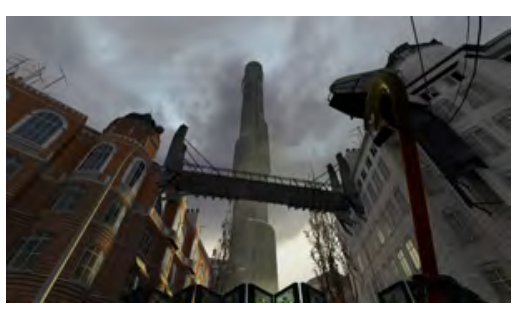

51 


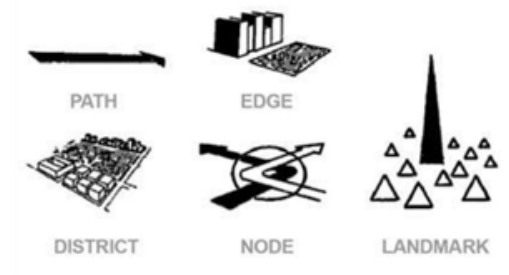

52

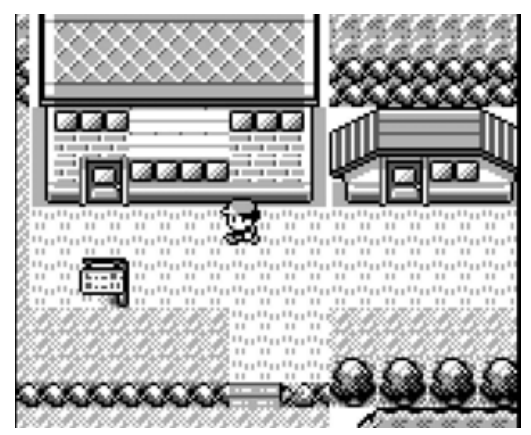

53

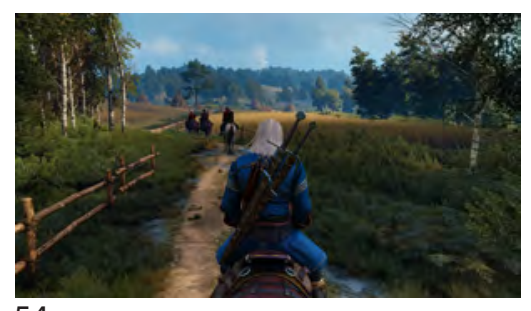

54

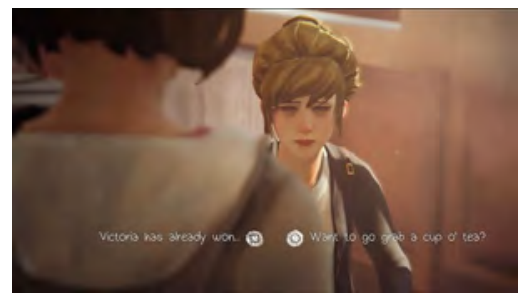

55

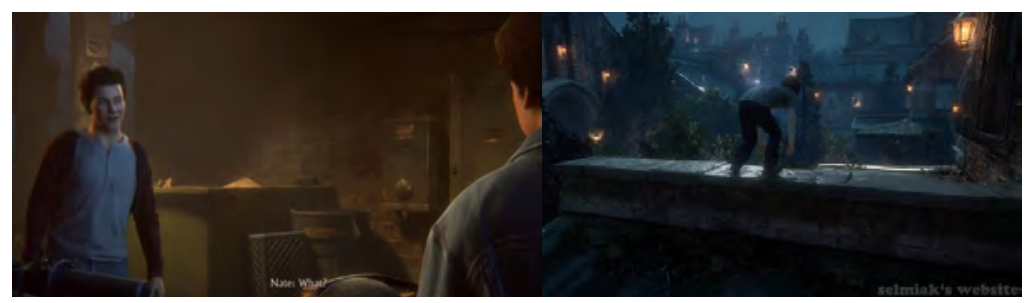

56

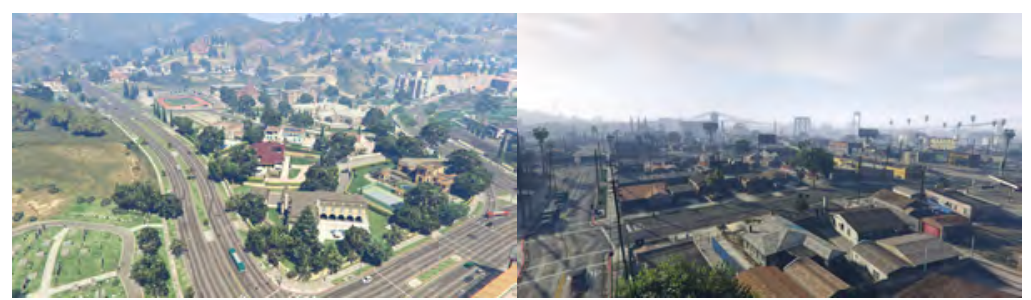

57 recorra. opciones textuales (55). y otras no ${ }^{39}$. En este sentido, por ejemplo, propuso el barón Hausmann (1852-1870) la edificación de monumentos que sirvieran como referencias continuas en el paisaje de París como el edificio de la Ópera (1861-1874).

En todos los casos, tanto Disney, como el diseño de juegos clásico y Hausmann, pretendían, con este simbolismo señalado en el espacio, conducir y orientar a los visitantes-jugadores-ciudadanos. Y, al hacerlo, buscaban dar una visión concreta de esos espacios, ligada obviamente a una narrativa específica. En los videojuegos esta narrativa que cuenta el espacio es imprescindible para que el jugador lo emplee o, al menos, lo

Lynch - a quien también remite Totten (2014) - clasifica los recursos que permiten ordenar las ciudades en puntos de referencia, caminos, nodos, bordes y distritos (1960/2015) (52). Los puntos de referencia serían los elementos que visualmente permiten orientarse en el espacio estando siempre presentes. Estas referencias no siempre son elementos que aparecen en todo el juego, sino que puede ser que se encuentren en determinados puntos y, por su diseño, den a entender al jugador/habitante su función. Así la facilidad de un ciudadano de distinguir una iglesia por su torre se puede transcribir a Pokémon (1996) en la facilidad de saber la función de los edificios por su fachada (por ejemplo, el gimnasio es un edificio de mayores dimensiones y ventanas pequeñas) (53).

En caminos se englobarían las carreteras, senderos y demás estructuras que dibujan en el suelo un recorrido posible - pero no obligatorio en videojuegos estos cambios de pavimento como guía se observan, por ejemplo, en Super Mario 64 (1996) o en The Witcher 3 (2015) (54).

Los nodos se refieren a los puntos de toma de decisiones, cruces, por ejemplo. En videojuegos los hay físicos como en Kingdom Hearts (2002) en los puntos donde puedes elegir qué mundos visitar primero o discursivos como en Life is Strange (2015) en los puntos de decisión entre varias

Los bordes por su parte se refieren a los límites o contornos de las diferentes áreas, pudiendo ser muros, árboles o, sencillamente, espacios entre dos zonas diferentes. En videojuegos en muchas ocasiones los bordes separan zonas que tienen distinto arte de escenario (otro recurso empleado para mostrar un cambio al jugador) en Uncharted 4 (2016) el borde al final del primer capítulo se indica con un cambio en la paleta de colores y la iluminación (de fríos a cálidos), que sucede al saltar el muro del internado (56).

Por último, los distritos son las áreas en que se segmenta el mapa. Del mismo modo que en las ciudades materiales existen estas zonas, en las virtuales como las de GTA IV (2008) también, pudiendo recorrer barrios pobres o ricos con funcionalidades diferentes

39 Con la 'La ley de Miyamoto' (Penner, 2006) el diseñador de videojuegos de Nintendo propone '[...] al principio de un juego se debe mostrar al jugador algo que no puede hacer' punto compartido con Lynch en la idea del icono referencia al que no se llega de forma directa (1960/2015) 
para el juego (57).

Todo ello muestra que, tanto el espacio virtual de los videojuegos como el espacio material de la arquitectura, se guían por estrategias y patrones similares, y ambos son, en mayor o menor medida, conductivistas, presentando recursos que guían y estructuran al jugador/habitante. Navarro y Londoño (2015) tratan en este sentido el ejemplo de Super Mario (1987):

Ias primeras pantallas de la franquicia Super Mario son siempre manuales de instrucciones sin palabras. El espacio se ordena para que el jugador aprenda los fundamentos del juego con el mando en la mano'

(Navarro, Londoño, 2015)

Si bien este conductivismo ha sido (y sigue siendo, aunque existen alternativas) una constante en los videojuegos, en cuanto al espacio material existen algunos ejemplos donde las estrategias para guiar a su habitante se hacen más obvias. Se trata de espacios fuertemente ligados a una narrativa concreta, y son los que mejor permiten trazar las múltiples conexiones entre las estrategias para guiar y conseguir que interactúe como se busca al jugador y al habitante.

El ejemplo de Versalles ${ }^{40}$.

Hacia 1623 (Barindon, 2003) Luis XIII de Francia decidió adquirir algunos terrenos en medio del bosque, y construir allí su refugio de caza. Los terrenos de Versalles se convirtieron en el lugar favorito del rey para practicar el deporte cinegético, siendo las construcciones paulatinamente ampliadas hasta que finalmente en 1632 el monarca adquirió por completo los terrenos.

Versalles se constituyó desde el inicio como un lugar de recreo, de diversión y de descanso lúdico. Tal es así que el propio Luis XIII en su lecho de muerte indicó que, si finalmente se recuperaba, solo deseaba retirarse a Versalles a 'entretenerse' (Barindon, 2003). Por aquel entonces, el pequeño palacio ya poseía jardines.

Su sucesor, Luis XIV, que había ascendido al poder con sólo cinco años, encontró en Versalles el lugar idóneo para conseguir todo aquello que se propusiera.

Y si bien el lugar, había sido hasta entonces criticado por " lugar ingrato, triste, sin vida, sin bosque, sin agua, sin tierra, parece que todo son arenas movedizas y pantanosas, sin aire, en consecuencia: no es bueno." (Beaussant, 1996) el joven rey decidió hacer en él grandes inversiones. Debe tenerse en cuenta, además, que, en aquel momento, Versalles era aún una 'residencia de placer' (Beaussant, 1996) y no una residencia permanente (papel que correspondía al Louvre).

Versalles, alejado de los problemas de París, era el lugar idóneo para desconectar, por lo que se convirtió en la sede de las mayores fiestas del reino. Luis XIV invirtió entre los años 1661 y 1662 un millón cien mil libras para ampliar el palacio, decorar las estancias y añadir instalaciones como

\footnotetext{
${ }^{40}$ Este ejemplo fue propuesto, en un contexto de debate sobre la tesis, por el profesor Guillermo Cabeza en 2014, a quien se quiere enviar, allí donde esté, el más fuerte de los abrazos.
} 


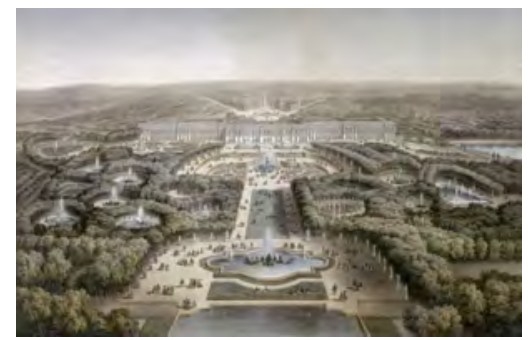

58

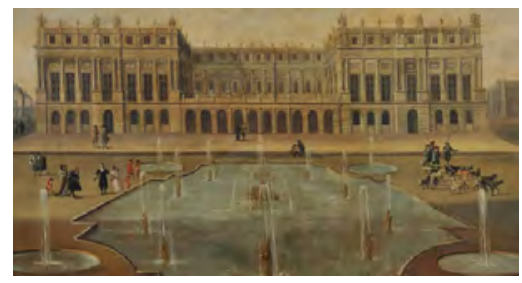

59 un invernadero y un zoológico (58). En 1664, la primera fiesta oficial tras las actualizaciones llevó por nombre 'Los placeres de la isla encantada'. Le siguieron otras muchas como la famosísima en la época 'Gran divertimento Real de Versalles' (1668) narrada por el arquitecto André Feliben en su 'Relación de fiestas de Versalles'.

Hacia 1670, el Rey se encontraba deseoso de ampliar el palacio y valoró para ello dos proyectos, ambos del arquitecto Le Vau: el primero destruía el palacio original y el segundo lo ampliaba. La enveloppe (Calatrava, 2004) de Versalles (59), ampliaba y revestía el palacio original como un decorado; caballerizas, esculturas mitológicas, grutas que parecieran reales, falsos bosquecillos y estanques (que requirieron bombear el agua del Sena en una gran inversión de ingeniería) dieron a Versalles el poder que necesitaba para que en 1682 se convirtiera en residencia permanente del rey. A partir de ese momento, y ya como la capital no oficial del reino de Francia, Versalles fue perdiendo su aura de excepcionalidad lúdica - aquella que empieza y acaba interrumpiendo la monotonía y constituye un acontecimiento siempre nuevo (Agamben, 2004) - anclándose en la cotidianeidad de una residencia de la corte.

Luis XIV, conocido como Rey Sol, hizo de su vida un espectáculo permanente y protocolario. Actividades como acostarse o levantarse eran casi una ceremonia donde Versalles constituía un escenario de excepción (Calatrava, 2004). Hacia 1700 el rey había invertido en el palacio más de 80 millones de libras, y la aldea que lo había rodeado era una ciudad de casi 70.000 habitantes. Es en esta época tardía de su reinado, cuando Versalles ya no era el pabellón de verano, cuando el rey decide escribir unas Maneras de recorrer los jardines (1689-1704/2004). Con ello pretendía controlar la imagen que se mostraba de su reinado y de él mismo, siendo, la idea clave de la narrativa del recorrido por el espacio, el engrandecimiento del rey, de su palacio y, a la postre, de la propia monarquía absoluta francesa. Similar objetivo tenían hasta entonces las sucesivas modificaciones del lugar, las obras de arquitectura e ingeniería y la planificación social del complejo. En este sentido, Calatrava reflexiona:

[...] estos jardines creados a lo largo de más de dos décadas, obra maestra paisajística de André Le Notre, no constituían un mero accesorio de la arquitectura, sino que eran parte esencial - a veces incluso en mayor medida que el propio palacio - del gran dispositivo [...] cuando Luis decide trazar su propio itinerario lo hace desde una intencionalidad diferente [...] un recorrido, el que mejor realce la gloria del monarca y del reino'

(Calatrava, 2004)

Así pues, dado el carácter especialmente narrativo de los jardines de Versalles - y también su carácter lúdico ${ }^{41}$ - hacen de él un excelente ejemplo para detectar recursos espaciales que actualmente se emplean en el diseño de espacios en videojuegos.

\footnotetext{
41 La componente lúdica de estos jardines es tan acusada que el propio Charles Perrault describe 'las estrategias para andar por una parcela del bosque joven muy espeso y frondoso, atravesado por multitud de paseos que se confunden unos con otros con tanto ingenio que nada resulta tan fácil, ni tan agradable, como perderse en ellos'. Esta estructura, la del laberinto, presente también en otros jardines de palacios contemporáneos a Versalles como San Lorenzo del Escorial o en Jardines del Moro - ambos en Madrid - pretendía crear una completa escenografía de diversión. 'palacios de verdor, setos que imitan arquitectura, esplendorosas construcciones efímeras...' (Calatrava, 2004)
} 
De entrada, cabe señalar el paralelismo entre el diseño de Versalles - un palacio barroco que 'envuelve' un antiguo pabellón de caza - con, por una parte, el optimizado que se lleva a cabo al diseñar niveles disponiendo en multitud de edificios y piezas únicamente la fachada que envuelve algo (ya que, si su interior no va a ser usado, no tiene sentido ni es eficiente programarlo) $y$, por otra el dualismo entre interior y exterior. En videojuegos en muchas ocasiones se recurre a la narrativa ilusoria (Rogers, 2014/2018) para sugerir un espacio/acto al jugador, pero no desarrollarlo tal cual. Por ejemplo, en el videojuego Golden Axe Warrior (1991) las construcciones se 'indican' con fachadas de dimensiones ilógicas en comparación con su interior (que se descubre al traspasar el umbral) (60). El jugador no dispone nunca de un mapa dentro-fuera simultáneo, pero si lo viera, observaría que los interiores no 'caben' en las fachadas indicadas, y que éstas son sólo un recubrimiento ilusorio. La misma estrategia aparece en multitud de otros juegos como The legend of Zelda: Link's Awakening (1993).

Al margen del diseño puramente estético, en Versalles
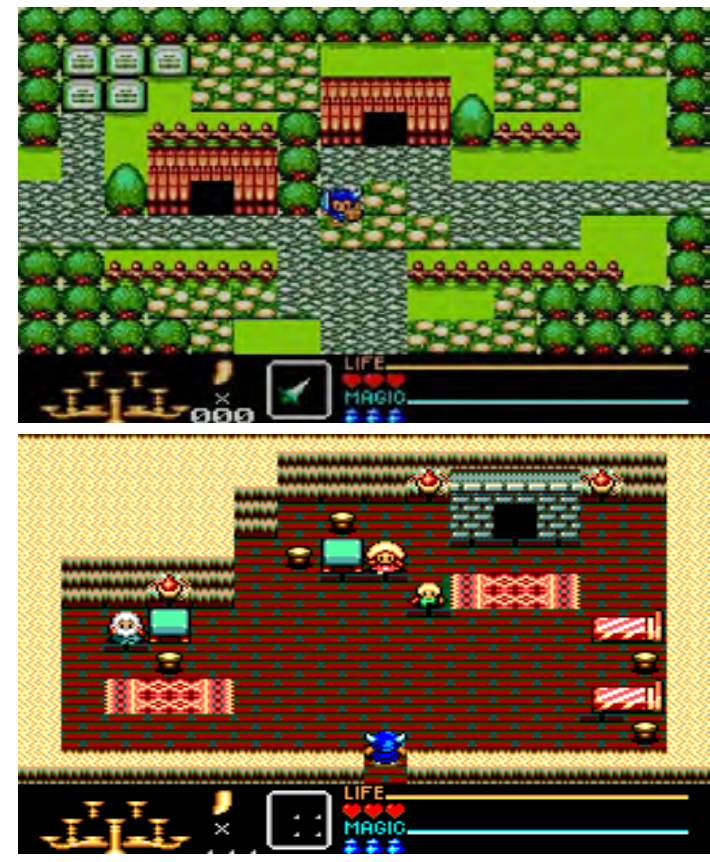
se muestran al menos cuatro grandes estrategias de guía e interacción comunes a los videojuegos: la forma de los elementos de guía/interacción, la posición de los elementos de guía/interacción, la iluminación y la posición del jugador como desencadenante de acciones.

Es habitual en urbanismo y planificación urbana incluir árboles de distinto tipo para marcar finales de calles, giros o plazas. En el caso de Versalles esto sucede no solo con las especies vegetales sino además con la forma que éstas tienen. Así, destaca en Versalles el denominado arte topiario (Thompson, 2006) que consiste en dar formas geométricas a los elementos vegetales. El arte topiario en Versalles solía tener una función señalética (Kluckert, 2007) indicando espacios para que el movimiento del visitante cambie, se detenga, llegue a algún lugar o se siente (61). Esta idea de que ciertos elementos cambien de forma para indicar al jugador un cambio en el juego es una constante, así por ejemplo en el caso concreto de la primera generación de Pokémon los árboles del juego se muestran de un modo muy concreto en general, pero cuando ese árbol puede ser cortado por el jugador (y se quiere indicar que es distinto) este árbol toma una forma diferente (62). En el diseño de juegos esta estrategia tiene que ver con el feedback que se le otorga al jugador para que éste sepa cómo interactuar con el entorno. La forma se refiere, en ocasiones, también al tamaño, así en el laberinto de Versalles los árboles de mayor tamaño se sitúan en los extremos de los caminos para facilitar la orientación (Thompson, 2006) y en la segunda generación de Pokémon los árboles de mayores dimensiones del Encinar son los que no puedes golpear para encontrar Pokémon en ellos.

Por otra parte, estos elementos no solo pueden cambiar de forma, sino también de posición, ubicándose habitualmente en lugares no contemplados que tratan de sorprender al visitante. En Versalles aparecen multitud de esculturas habitualmente con motivos clásicos y mitológicos (Thompson, 2006) que sirven como referencia, pero también - de nuevo - como significación de que en ese lugar hay un cambio de actividad, como por ejemplo se pasa de caminar a contemplar el espacio (63). En videojuegos los elementos 'extraños' fuera de contexto que reclaman una

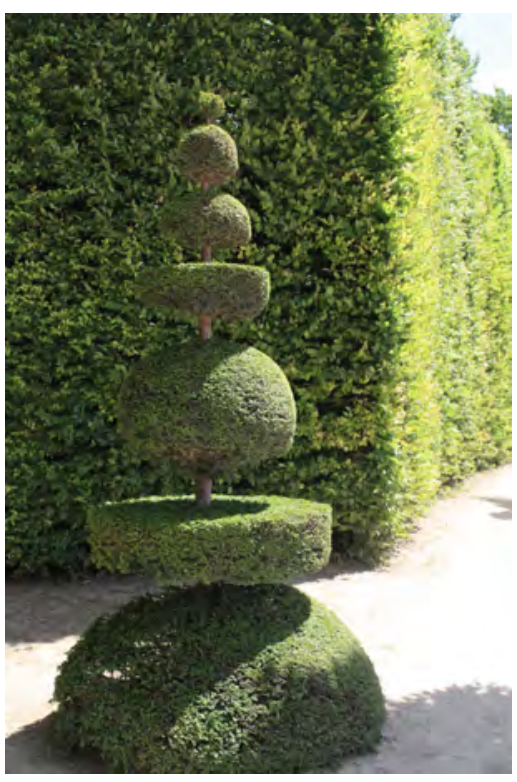
acción por parte del jugador son continuos. Así en Super Mario Bros (1983) aparecen monedas fuera de escala - otra vez el tamaño - flotando con la intención de indicarle al jugador que las 'recoja' (pasando por encima),

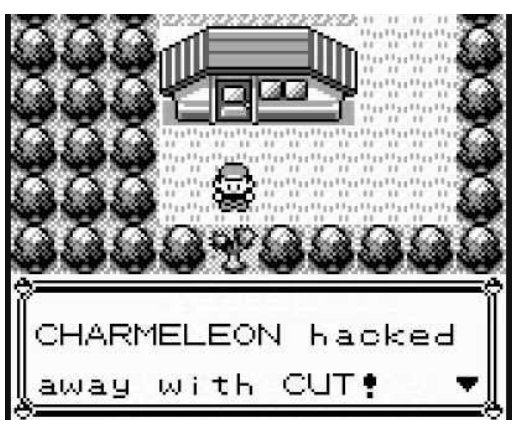




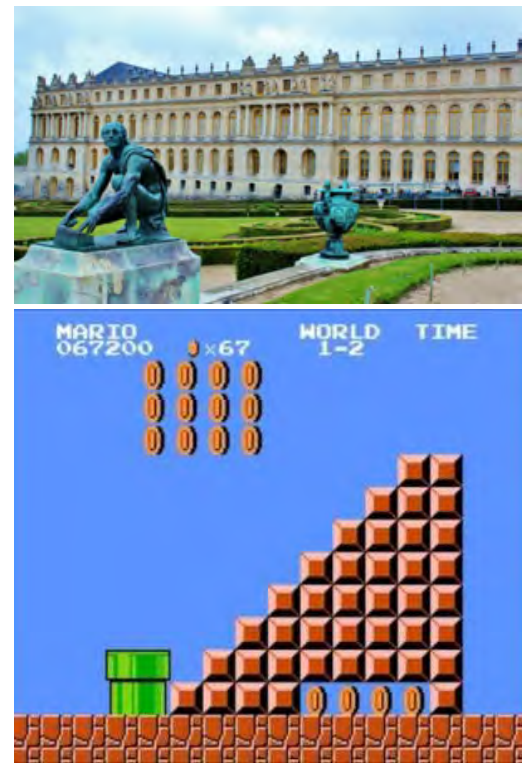

63

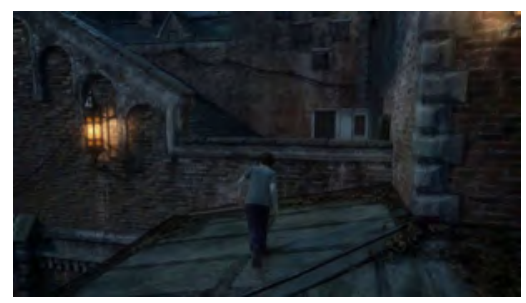

64 cumpliendo la misma función que los anillos de Sonic (1991).

La iluminación es, en la actualidad posiblemente el recurso más empleado por los videojuegos para dar feedback al jugador e indicar qué elementos son interactuables. Así en Uncharted 4: A thief's end (2016) se iluminan levemente las piedras a las que el jugador puede sujetarse, pero también aparecen luces como weenies (64) en The last of Us (2014) donde la iluminación tenue corresponde a los elementos del juego activables. Versalles fue, desde su conversión en palacio de verano, lugar de multitud de fiestas y celebraciones nocturnas - muchas de ellas pormenorizadamente detalladas por personalidades como el arquitecto Andrew Felibéin o la misma Madelaine de Scudery (Calatrava, 2004) - lo que hizo que dispusiera de una iluminación centrada en engrandecer el palacio y - no por casualidad - los elementos referenciales de los jardines (habitualmente esculturas). En L.A. Noire (2011) esta idea de iluminación se traslada al concepto de brillo, así, los pomos de los edificios en los que puedes entrar brillan dorados (Totten, 2014). Cabe señalar también que el uso de la iluminación para captar la atención de quienes recorren el espacio es común en el mundo occidental desde hace más de 120 años con una perspectiva comercial, de ahí la función de los neones, señales luminosas y escaparates iluminados (Benjamin, 1983)

Por último, señalar la relevancia de la posición del jugador/ habitante en el espacio para guiarle y centrar en él la experiencia de juego. En este sentido, Versalles, una vez más, anticipa el uso de los videojuegos. El palacio francés fue construido con un gran esfuerzo técnico e ingenieril, la idea del rey de esconder un pabellón de cazar y mostrar un palacio barroco hacía notar un intento por mostrar un mundo ficticio que funcionaba sistemáticamente.

'Los estanques, fuentes, surtidores y juegos de agua constituían, en efecto, uno de los aspectos esenciales de la mise en scène real - siempre limitado por las dificultades de abastecimiento hídrico - El rey sabe hacer de la necesidad virtud y transformar la exigencia práctica del ahorro de agua en metáfora [...] solo las fuentes que entran en cada momento en el campo de visión de los participantes en el recorrido debían estar en funcionamiento, y el flujo se interrumpía después de cesar la presencia'

(Calatrava, 2004)

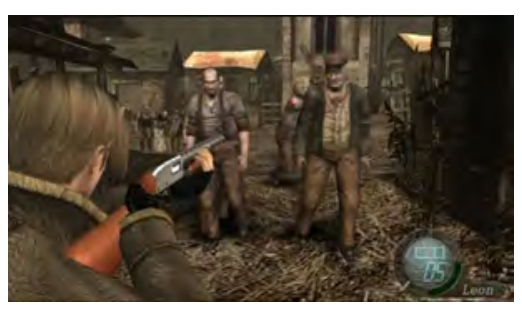

65
Estos sistemas concedían al palacio algunos recursos muy propios de, por ejemplo, Resident Evil 4 (2004) en el que se inician las interacciones sólo cuando el personaje haya alcanzado ciertos puntos (65). En la franquicia de Capcom los zombies solo aparecen y atacan al jugador cuando este aparece en el nivel - por una cuestión de cantidad de memoria empleada, es decir, también tras ello como tras Versalles hay una necesidad técnica - del mismo modo que sucede en Versalles con las fuentes encendiéndose a la llegada de quienes lo recorren. En ambos casos se da además a entender al jugador/habitante que es el centro de la interacción espacial.

El caso de Versalles no es único; es especialmente claro por ser un lugar que contiene una narrativa muy marcada (la de contar las bondades del monarca y la monarquía absoluta) y por tener un extraordinario carácter lúdico (Calatrava, 2004). Otro ejemplo podría ser Villa Adriana (Cánovas, 2018) como lugar de escenificación del poder y a su vez como lugar de retiro. Como se ha podido observar, los recursos espaciales empleados en videojuegos para organizar el espacio y guiar al jugador son en realidad recursos propios del diseño de espacios materiales. 


\subsection{El papel del jugador en el espacio}

\section{EL PAPEL DEL JUGADOR EN EL ESPACIO}

¿Tienes la habilidad constructora de desarrollar una metrópolis con elevados rascacielos o la sensibilidad estética para crear una atractiva ciudad? ¿Disfrutas reparando el mundo, ensanchando la orilla de un río por aquí o aumentando impuestos por allá, para poder ver los efectos en los habitantes de tus dominios?'

(Frases de inicio de Simcity 4, 2003)

En 'Situations of Play: Patterns of Spatial Use in Videogames' Leigh Mcgregor (2007) desarrolló una clasificación de juegos atendiendo al uso/ relación que estos mantuvieran con el espacio. Así propuso 5 categorías que pueden combinarse entre ellas, dándose más de una de forma simultánea:

1. Espacio-desafío: donde es el espacio el que supone un reto para el jugador. En este grupo estarían los juegos de aventuras como Tomb Raider (1996)

2. Espacio-disputado: donde el lugar de juego es el recurso clave entre dos o más entidades (una el jugador) enfrentadas. Este sería el caso de Civilization (1991)

3. Espacio codificado, en que los elementos representan cosas de una forma simbólica, no real. Por ejemplo, los edificios del Age of Empires (1997) no son usables, pero construirlos implica conseguir una serie de cosas, así si construyes la armería puedes crear soldados armados.

4. Espacio de creación: donde el jugador puede construir todo/parte del espacio como mecánica de juego. Así por ejemplo Minecraft (2009).

5. Telón de fondo: cuando el jugador no interactúa de forma directa con el espacio, como los videojuegos de conducción.

6. Espacio nodal: donde aparecen patrones sociales de uso del espacio para darle veracidad. Este sería el caso de The Sims (2000).

En el contexto de esta investigación, por el contrario, la división en cuanto al espacio se ejecuta en relación al papel que sobre él ejerce el jugador, es decir, el uso que puede darle y las modificaciones que puede implementarle. Y si puede hacerlo dentro de unos límites o incluso fuera de estos, resultando una combinación de los patrones de Mcgregor (2007) en la que prima el subtipo 4.

\subsubsection{Del jugador espectador al jugador constructor.}

La gran mayoría de juegos buscan un jugador que recorra el espacio e interactúe con él sin modificarlo, disparando a los enemigos, moviendo piezas, acumulando cosas, coleccionando Pokemons o superando niveles, es por ello que, como se ha analizado, se emplean estrategias propias del diseño del espacio material para guiar al jugador por el virtual. Sin embargo, existen una serie de juegos en los que el jugador dispone de la opción, dentro de las propias reglas, de modificar ese espacio. 
Atendiendo a la clasificación de juegos por géneros en doce categorías $^{42}$, sólo tres de ellas contienen algún tipo de juego en el que el jugador tiene algún poder de decisión sobre el espacio. Son, los videojuegos de simulación con el subtipo de construcción, los videojuegos de estrategia en el subtipo construcción de imperios - o juegos $4 X^{43}$ y algunos videojuegos de tipo sandbox. El origen de estos juegos 'espaciales' parte de dos puntos comunes; los juegos de mundo abierto que permiten al jugador escoger y elegir qué historia vivir (y por tanto qué espacio recorrer) y los juegos de simulación primitivos (Donovan, 2010)

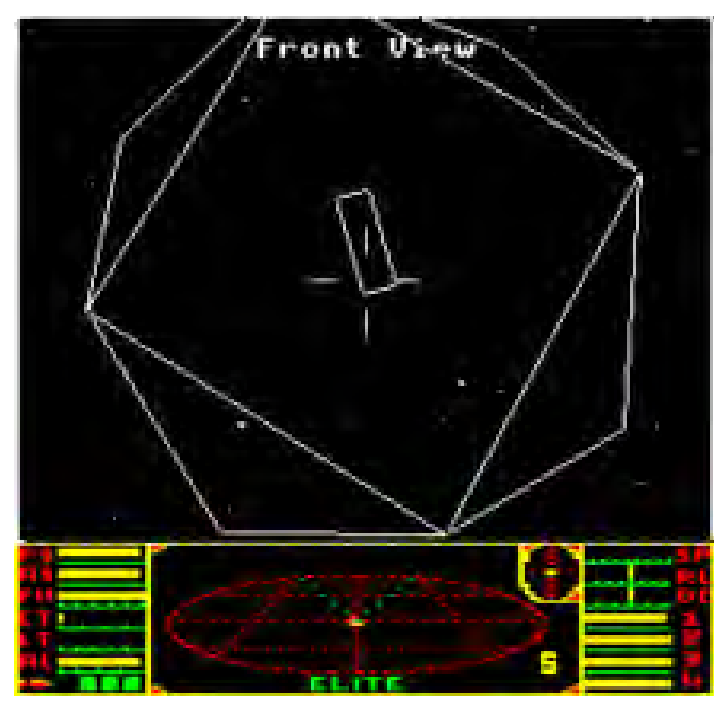

66

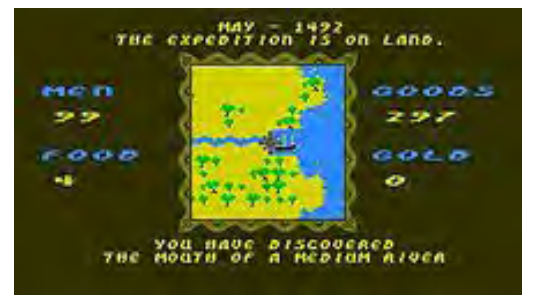

67

\section{a. El mundo abierto}

Respecto a los juegos de mundo abierto, son importantes por permitir al jugador guiarse entre opciones y maneras de jugar y de moverse en el espacio. En multitud de ocasiones responden a narrativas no-lineales ${ }^{44}$. La aparición de esta incipiente libertad para el jugador dejaba en parte de lado el conductivismo espacial (dentro de que lo que no está programado no puede hacerse, así que, lógicamente existen límites) y abogaba por sistemas lúdicos más complejos. Históricamente se ha considerado que Elite (1984) fue el primer videojuego de mundo abierto ${ }^{45}$ (66). En 1982 dos estudiantes de la Universidad de Cambridge - lan Bell ${ }^{46}$ y David Braben - comenzaron a desarrollar un juego tratando de llevar los gráficos $3 d$ vectoriales de las recreativas a pantallas ráster (Gazzard, 2013). Dos años después publicaron Elite (1984) - un juego en que el jugador comenzaba con una nave espacial y podía explorar un universo inmenso - para BBC Micro, que era mucho más que una adaptación de recreativas.

'El mundo entero dentro de una caja que representaba Elite abrió un nuevo camino que los diseñadores de videojuegos podían explorar: el concepto de un mundo abierto, en el que los jugadores deciden qué hacer y a dónde quieren ir, en vez de requerir objetivos preestablecidos en un mundo que limitara sus opciones'

(Donovan, pag. 149, 2010)

Casi de forma simultánea a Elite se publicó en Estados Unidos The Seven Cities of Gold (1984), considerado también uno de los primeros juegos de mundo abierto, $y$, además, uno de los primeros juegos de estrategia (Computer gaming World n75, 1990). El juego comenzaba dando al jugador una serie de recursos - 4 barcos, 100 hombres y artículos

\footnotetext{
${ }^{42}$ Esquema de clasificación de juegos en la 'Terminología para esta tesis'

${ }^{43} \mathrm{Abreviatura} \mathrm{-} \mathrm{en} \mathrm{inglés} \mathrm{-} \mathrm{que} \mathrm{denomina} \mathrm{a} \mathrm{los} \mathrm{juegos} \mathrm{que} \mathrm{implican} \mathrm{eXploración,} \mathrm{eXpan-}$ sión en el mapa, eXplotación de recursos y eXterminación del enemigo.

${ }^{44}$ Los juegos no-lineales permiten al jugador resolver la partida sin seguir un orden concreto, pudiendo realizarse las acciones de forma que el jugador escoja.

${ }^{45}$ Los juegos de mundo abierto disponen de un escenario amplio y dan la posibilidad al jugador que lo recorra según sus propias decisiones.

${ }^{46}$ En el capítulo 4 - 4.1 se vuelve sobre Bell dado que, tras publicar Elite, empleó sus conocimientos de representación espacial trabajando para Autodesk ( https://through-the-interface.typepad.com/through_the_interface/2013/10/an-interview-with-ian-bell. html consultado por última vez el 24 de junio de 2020 )
} 
comerciales - y le situaba en una ciudad de dominación española en la América colonial (67), pudiendo este gestionar y desarrollar la partida de diferentes formas. The Seven Cities of Gold empleó tecnologías expresamente desarrollados para él. Así, un sistema de transmisión para permitir que el mapa se cargara sin interrumpir el juego: la partida sucede en un único "mundo" muy similar al real, que incluye detalles tan pequeños como los Cayos de Florida y los ríos más conocidos. El juego también incluye un motor de creación de mundo que permite al usuario construir el Nuevo Mundo propiamente nuevo, pudiendo almacenarse en un disco duro del usuario (Koon, 2012). Su diseñadora, Danielle Bunten aplicó, para el desarrollo de este juego, sus conocimientos adquiridos trabajando para National Science Foundation como diseñadora de modelos urbanos ${ }^{47}$

De forma prácticamente coetánea a Elite y The Seven Cities of Gold, hubo otros juegos con ciertos grados de libertad para el jugador, aunque pertenecen a otros géneros y presentaban ciertas limitaciones en algunos aspectos, como The portopia serial murder case (1983), Ant Attack (1984), AR:The City (1985) - Ultima IV: Quest of Avatar (1985). En este último caso el jugador podía, además de escoger recorridos $\mathrm{u}$ opciones dentro del juego, plantearse actuar en términos como la bondad o la maldad, premiando el

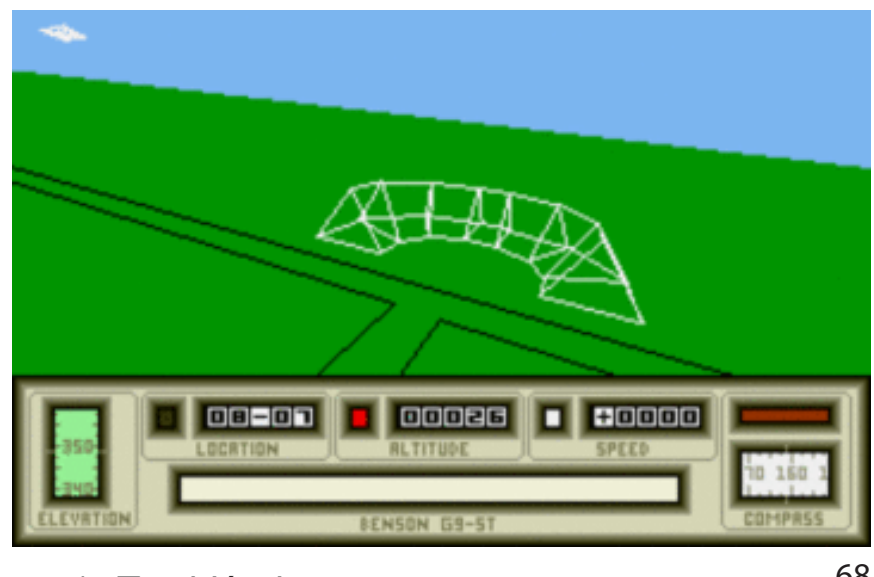
juego a los que escogían valores positivos (Donovan, 2010). También la primera generación de FS1 Flying simulator (1979) disponía de ciertas nociones de mundo abierto durante el vuelo del jugador. En 1986 vio la luz el que posiblemente sea el primer juego de mundo abierto en $3 d$ (Tringham, 2015), Mercenary (68), desarrollado con gráficos vectoriales y que construía un mundo enorme tridimensional que el jugador debía explorar en tiempo real. Dada la elevada libertad del jugador existieron packs de expansión y tres títulos principales - Mercenary (1985), Damocles (1990) y The Dion Crisis (1992) - que se hacian referencias entre ellos.

Entre los juegos de mundo abierto en $3 d$ posteriores destacan Hunter (1991) y, sobre todo y ya posteriormente, Shenmue (1999) que además de un mundo abierto comenzaba a poseer otras interacciones con el mundo material como sistema de noche y día, horarios y tiempo atmosférico, además de un entorno detallado sin precedentes (Donovan, 2010).

El punto de inflexión de los juegos de mundo abierto llegó con GTA, Grand Theft Auto (1997). El director creativo de GTA, Gary Penn, había trabajado en Elite II (1993) con David Braben y era un buen conocedor del concepto de mundo abierto. El juego, originalmente basado en la conducción de coches, cambió y situó al personaje en la piel de un delincuente que debe conseguir ciertos logros en tres ciudades de ficción (basadas en tres ciudades norteamericanas) y, para ello, dispone de un mundo enorme frente al que decidir cómo conseguir su objetivo (Garrets, 2006).

El acierto de RockStar llegó de la mano de Grand Theft Auto III (2001) y el paso a los gráficos en 3D (69). Este tercer título de la saga continuó la esencia de sus predecesores, pero gracias al 3D el jugador podía ver de manera más real el mundo del juego. GTA III dejó atrás los mundos de juego estáticos que apenas ofrecían interacción al jugador:
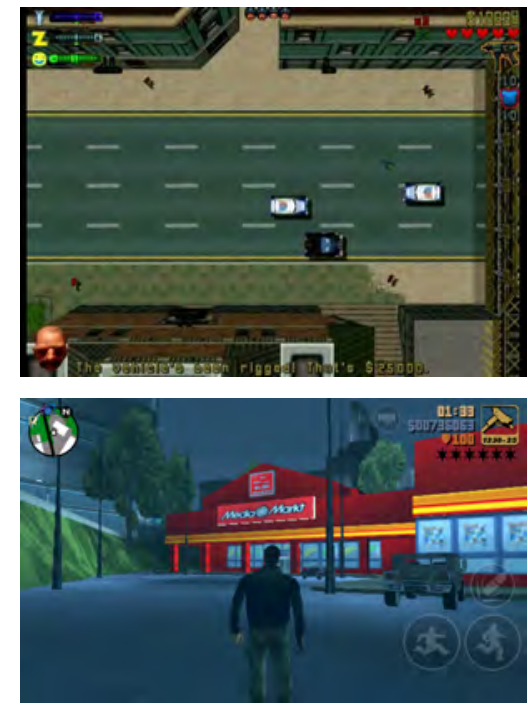

${ }^{47}$ Consultado en Encyclopedia of Arkansas: https://encyclopediaofarkansas.net/entries/ danielle-bunten-berry-4524/ 
"Antes de este juego, salvo algunas excepciones, el mundo del juego era estático y por lo general había muy poca interacción entre el mundo del juego y el jugador. [...] Grand TheftAuto III cambió esto dejando que el entorno jugase un papel en la experiencia de juego de los jugadores"

(Cullen, 2015)

Por primera vez en un mundo abierto, el jugador participaba de un entorno que era una parte activa de su experiencia de juego y las cosas que pasaban en ese entorno y ese mundo de juego afectaban directamente al progreso del jugador. Para lograr esto el juego tenía que ser verosímil, es decir, tener un entorno creíble. Según Tony Cullen "con el fin de diseñar un entorno creíble, este debe estar poblado de edificios, objetos y personajes" (2015). Estos tres elementos han estado presentes en GTA desde el lanzamiento de la primera entrega, pero fue el paso al 3D lo que permitió crear un entorno palpable para el jugador y, sobre todo, inmersivo. Gracias a los detalles que sus secuelas perfeccionaron como los ciclos de noche y día o las condiciones climáticas.

"Como resultado de la limitada narrativa de los videojuegos de mundo abierto, el entorno virtual [...] juega un papel vital para la inmersión de los jugadores en el mundo del juego"

(Cullen, 2015)

Todo este 'contexto' que puebla los juegos de mundo abierto supone más recursos, algo que ha sido posible con el avance tecnológico y la mayor capacidad de almacenamiento que permite que los mundos de los juegos posean mayor dimensión. GTA sentó las bases no solo de sus propias secuelas, también de otros títulos como Fallout 3 (2008), Red Dead Redemption (2010) y la saga Assasin's Creed (2007) todos ellos de mundo abierto.

Los juegos de mundo abierto no son por sí mismos juegos en los que el jugador tenga la opción de modificar el espacio, pero, al abrir el abanico de acciones y decisiones que podía tomar este y, sobre todo, al no delimitar el espacio de forma concreta, dieron lugar a otros en los que estas opciones sí existían.

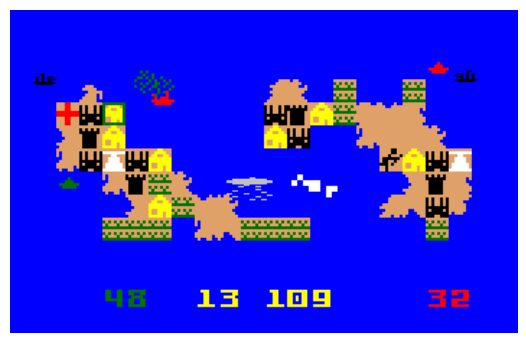

70

\section{b. Los juegos de simulación.}

El concepto de simulación está en el origen propio del juego (Huizinga, 1938/2012), así los niños emplean el juego simbólico imitando lo que ven y aprenden con este juego su propia visión del mundo. Los videojuegos de simulación imitan un aspecto de la realidad y permiten al jugador participar de esa perspectiva. Un claro ejemplo serían los juegos de simulación de determinadas situaciones/aventuras como Sid Meier Pirates! (1987) en el que el jugador toma el control de un pirata y de su vida. El poder de la simulación ya se ha anticipado en capítulos previos: 
riesgos económicos y humanos de la experiencia real'

(Navarro, Londoño, 2015)

Dentro de estos, los juegos de construcción simulan cómo se modifica el espacio según se desarrollan diferentes proyectos llevando al jugador a una posición de diseñador espacial (Marlow, 2009).

Los juegos de construcción nacieron de los juegos de gestión de ciudades eimperios. El primer juego de construcción de ciudades seconsidera Utopia (1982), diseñado por Don Daglow y que se trata de un juego de tipo Dios; es decir, el jugador tiene como objetivo desarrollar una civilización y, como mecánica disponible del juego, se encuentra la construcción de edificios (70). Los juegos de construcción en general - y sobre todo los de imperios - partieron en gran medida de los juegos de estrategia de tablero (Kent, 2001), que ya incluían mecánicas similares y, al igual que otros ya analizados, pueden centrarse en un pasado histórico - caso de Civilización (1991) o Age of Mitology (1995) - en un futuro hipotético de ciencia ficción - caso de Master of Orion (1993) o Alpha Centaury (1999) o en un espacio de fantasía - como Heroes of Might and Magic (1986). Todos ellos se consideran juegos de simulación pese a que, por su fuerte componente de gestión de recursos y por su origen ya señalado, muchos puedan englobarse también en los juegos de estrategia.

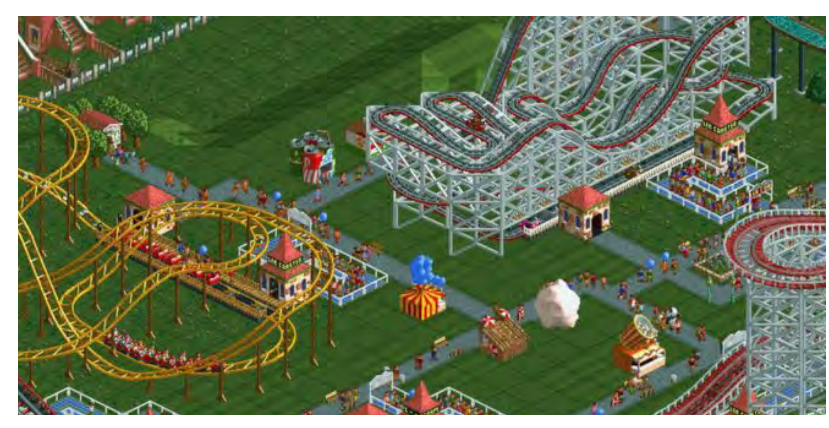

Han ido apareciendo también juegos de simulación de construcción no sólo de ciudades, también de parques temáticos - Rollercoaster Tycoon (71) (1999) - y hasta de fortalezas - Dwarf Fortress (72) (2006).

Un ejemplo no tratado en los puntos anteriores es el de Freescape (1987). Este programa podría enmarcarse en lo que ahora se conoce como un motor de videojuego con constructor 3D, pero en su día respondió a las inquietudes del desarrollador Chris Andrew por generar un sistema que permitiera diseñar espacios incluso desde el papel del jugador (Fahs, 2019). Freescape fue el motor detrás de algunos juegos de edición de espacios como Construction Kit (1991) (73) y Construction Kit II (1992).

Esta idea de mostrar un espacio y modificarlo sin necesidad de repercutir en el espacio material ha permitido que la función anticipadora también pueda aplicarse en la arquitectura. Así multitud de artículos se han referido a ello 48 :

[...] el uso del análisis "qué pasaría si" en los juegos de
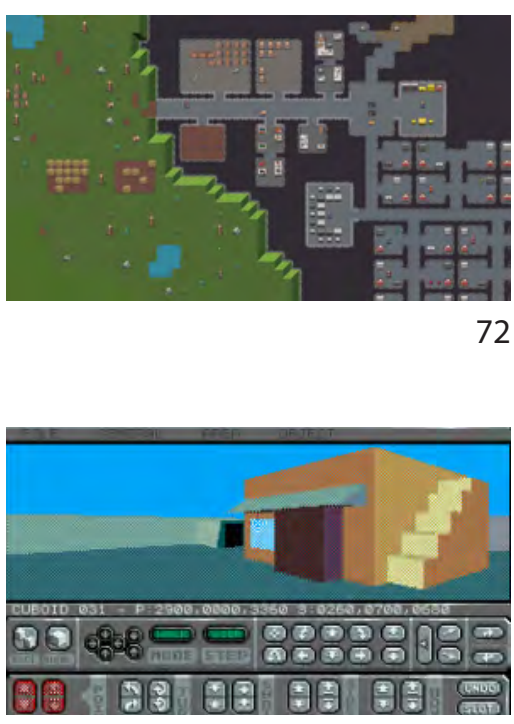
simulación como herramienta para la toma de decisiones espaciales mediante la introducción del concepto de mundos múltiples. La navegación a través de estos escenarios múltiples brinda a los usuarios la posibilidad de formular una respuesta sólida para los problemas espaciales específicos.'

(Fumarola, Verbraeck, 2008)

${ }^{48}$ Se profundiza en ello en el capítulo 4. 


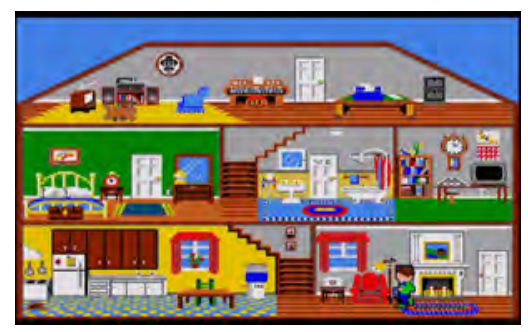

74

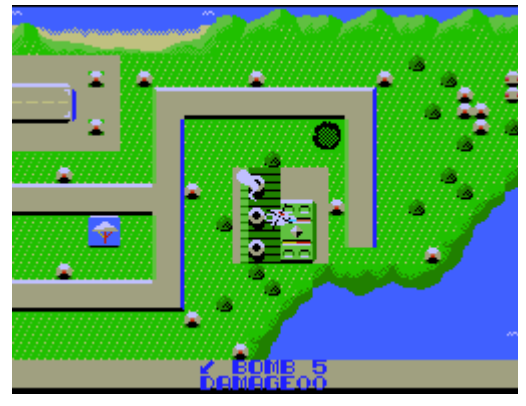

75

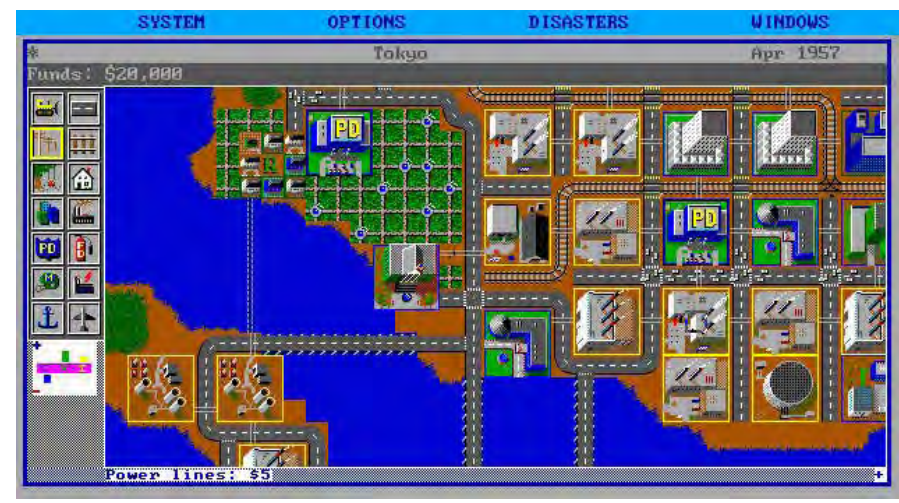

76 la idea. 2016).
El concepto de simulación no sólo se relaciona con la arquitectura a través de los juegos de simulación espacial/constructiva, sino también de los de simulación de vida.

El juego pionero en este tipo de simulación fue Little Computer People (74) (1985). Activision, la empresa que lo publicó, explicó (Donovan, 2010) que el juego se basaba en un prototipo previo que exploraba la idea de las piedras-mascota ${ }^{49}$ y colocaba en el interior de la pantalla un pequeño humano-mascota. Cuando el juego llegó a Activision, el diseñador David Crane le implementó ciertos elementos de interacción; por lo que el jugador podía comprarle comida, animarle a escribirle cartas o jugar a poker (Pollen, Nelson, 1986). Little Computer People no fue ningún éxito, pero si un juego de culto (Donovan, p373, 2010), y sirvió de base para que algunos años después un diseñador llamado Will Wright se interesaba por

Will Wright comenzó estudiando arquitectura, en Louisiana Tech University, para posteriormente cambiarse a ingeniería mecánica (Hansen, 2016). Se interesó por el urbanista y arquitecto Christopher Alexander; en sus propias palabras:

'Alexander era un amante de la física que estudió arquitectura y se sentía frustrado porque no era ciencia suficiente para él [...] quería que todos los principios de la arquitectura fueran claramente reducibles a unos principios fundamentales, que era de lo que trataba su libro 'El lenguaje de los patrones'

(Wright, 1994)

Pero, sin duda la mayor inspiración del juego vino a través de Jay Forrester, uno de los principales desarrolladores de la dinámica de sistemas, interesado en analizar cómo los sistemas complejos varían con el tiempo. En 1969 - y pese a no ser un experto en planificación urbana publicó la aplicación de estas ideas a la simulación urbana computerizada en su libro Dinámicas Urbanas, reconocido referente de Wright (Lobo,

Combinando algunas de las ideas recogidas a través de Alexander y Forrester sobre el urbanismo, el videojuego de construcción Utopia y la inspiración del juego Wright publicó Simcity (1989) un videojuego sobre la gestión de una ciudad. Wright usó para el mismo una aplicación de creación de mapas que había implementado en su juego anterior, Raid on Bungeling Bay (75) (1984), ya que descubrió que esa era la parte más entretenida del juego (Wright, 2008). Simcity colocaba al jugador en el papel de un gestor de una ciudad que debía conseguir su desarrollo considerando aspectos como la contaminación, la densidad de población, la delincuencia, la calidad del espacio, etc ${ }^{50}$. El juego no era estrictamente de mundo abierto, pero al contrario que los juegos precedentes, no disponían de un final claro ni un objetivo determinado: el jugador podía escoger cómo usar el juego

\footnotetext{
${ }^{49}$ El concepto de piedra-mascota (pet-rock) fue creado por el publicista Gary Dahl en 1975 y consistía en piedra con ojos que la gente adquiría como mascotas. El concepto fue posteriormente referenciado en los Tamagotchi (1996).

50 Consultado online http://simcity.ea.com/about/inside_scoop/sc_retrospective.php
} 
(Lobo, 2016). El propio Wright reconoció en 1992 que se sorprendió de que le hubiera interesado a alguien además de arquitectos y urbanistas ${ }^{51}$ (76). Simcity sentó el precedente de un juego con una relación directa arquitectura-videojuegos y se convirtió en el referente de otros juegos revolucionarios, desde el punto de vista espacial, que vinieron después.

Unos años después Wright continuaba con la intención de aproximarse a la idea de un juego que evaluara la arquitectura que el jugador pudiera diseñar (Donovan, p372, 2010). Para ello empleó los conocimientos adquiridos diseñando Sim Ant (77) (1991) un juego de simulación de vida sobre hormigas, y cambió a éstas por personas, situando al jugador al control de estas. The Sims (78) (2000), como finalmente se llamó el juego, combinaba las características de un juego de simulación de vida con cierto grado de voyeurismo y, además, disponía de un amplio sistema de diseño espacial, dando al jugador la opción de construir la casa de sus Sims, el barrio, la casa de sus vecinos, el jardín y hasta de elegir el papel pintado (Wright, 2008). El nuevo título de Wright tampoco tenía un final concreto ni un objetivo determinado. El mundo sim estaba a disposición del jugador para poder ser usado y construido como quisiera. El equipo de desarrollo de Maxis implementó un botón que permitía subir capturas de pantalla de la partida de cada jugador y añadirles texto para contar historias.

'[...] las personas van jugando y llega un momento en el que se meten en los personajes y empiezan a dirigir la historia. Para algunas personas va de una forma de entretenimiento a una forma de expresión persona. La mayoría de las historias [que la gente contaba usando el juego The sims] trasmiten un mensaje. Había una mujer que contó sobre cómo su hermana estaba en una relación abusiva y al final logró salir de ella. Te das cuenta de que quería escribir la historia porque quería que otra gente supiera que se puede salir de ese tipo de relación [...] quizás jamás escribiría un libro, pero con The sims ha podido comunicar a un grupo más amplio un mensaje que la marcó'

(Wright, 2008)
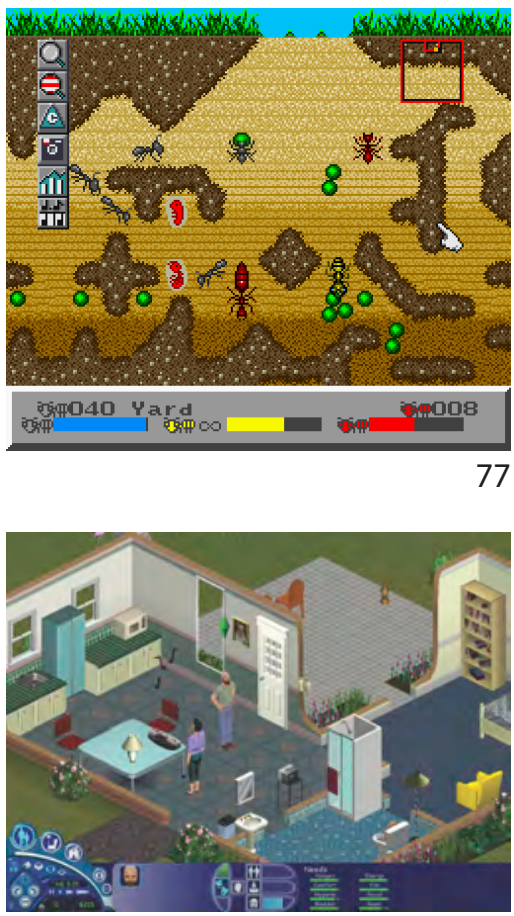

78

Así, The Sims, mostró que los juegos que daban mayor libertad al jugador y no le dirigían a través del espacio se convertían en herramientas que este podía usar para diseñar sus propios lugares y las historias que sucedieran en ellos. En esta línea apareció también The Movies (79) (2005) un juego que llevaba al máximo esta funcionalidad y permitía al jugador hacer pequeñas películas dentro de la partida (Hill, 2004).

Tanto Simcity (1989) y sus secuelas - así como otros juegos de construcción de ciudades aparecidos posteriormente como Monopoly Tycoon (2001), Trópico (2001), Imperivm Civitas (2006) o Cities in Motion (2011) (80)- como The Sims (2000) y las suyas marcaron un antes y un después en cuanto a las opciones del jugador para modificar el espacio. Pero esta modificación no dejaba de ser una mecánica propia del juego e ideada por su diseñador, por lo que presentaba ciertas limitaciones.

${ }^{51}$ Consultado online https://www.theguardian.com/sustainable-business/2016/jul/13/simcity-legacy-smarter-cities-when-urban-planners-play-for-keeps

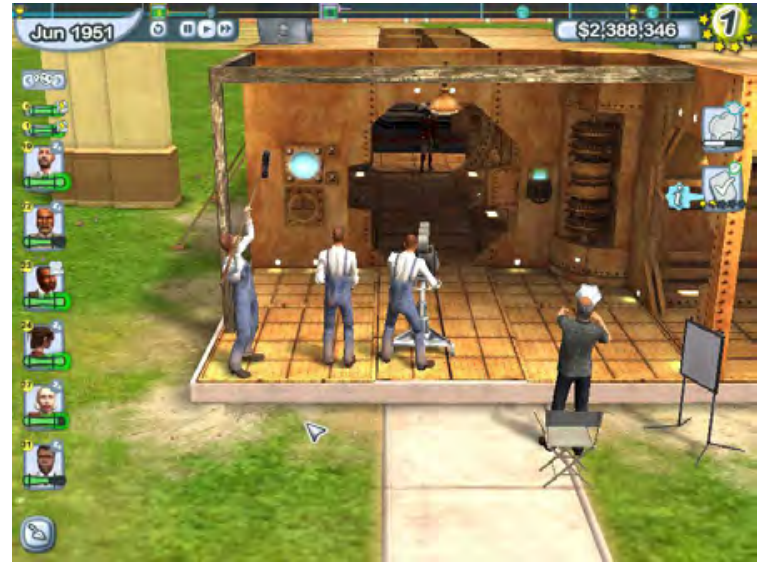

79

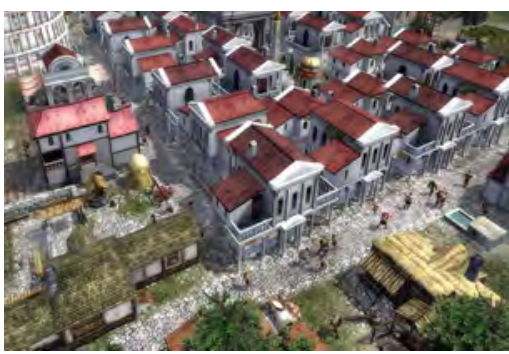




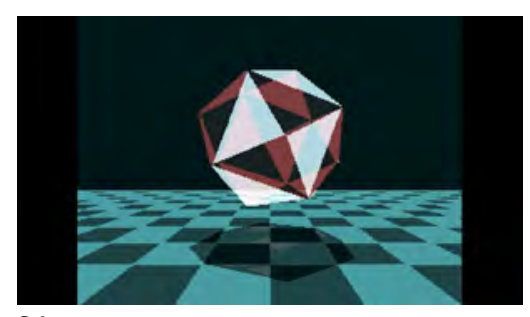

81

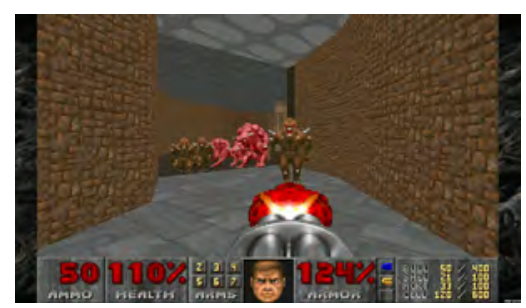

82

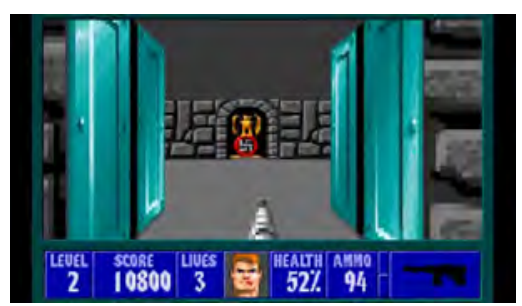

83

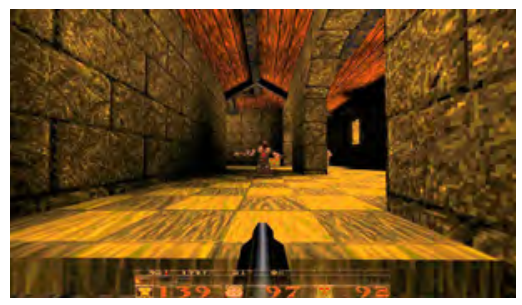

84

\subsubsection{Los límites del espacio de juego para el jugador}

Si bien es cierto que existen juegos en los que el papel del jugador en el espacio no se limita a ser un espectador/conseguidor de objetivos preparados por el diseñador, por ejemplo sucede en los juegos reseñados anteriormente, la realidad es que, incluso en estos, el jugador presenta poca capacidad de decisión. Así mismo en los juegos de mundo abierto el jugador está obligado a seguir unas 'reglas del juego', fuera de las cuales éste no se da (Agamben, 2008). Esto es, si un jugador quiere tirarse por la ventana en GTAIV no podrá hacerlo a menos que el diseñador haya situado una ventana donde esto sea viable, la programación lo haya implementado en el código y los artistas le hayan dado forma a esa ventana.

Esta limitación implícita al hecho de que el juego exista se ha puesto en cuestión en diversas ocasiones, contribuyendo al desarrollo de nuevos límites espaciales y nuevos 'papeles' para el jugador.

En 1985 se originó en Holanda un grupo de programadores llamado 1001 Crew (Donovan, 2010) que se dedicaban a copiar versiones piratas de juegos oficiales saltándose las propias medidas de protección antifraude. El reto de conseguir 'crackear' un juego y obtenerlo saltándose a la propia empresa hizo que el grupo aumentara rápidamente y empezara a tener réplicas en otros países. A ese submundo de programadores que trataban de desentrañar el juego y hacerlo accesible en sus propias versiones se le vino a llamar la demoscene. El nombre venía del concepto demo, la prueba del juego que ejecutaban (Carlsson, 2019). El crecimiento del movimiento trajo consigo que los programadores incluyeran 'portadas' que identificaran quienes habían conseguido la copia del juego. Estas portadas debían ocupar muy poco espacio y eran una antesala no ideada por el diseñador del juego. Así quienes frecuentaban la demoscene se convirtieron en re-programadores de los límites del juego - en muchas ocasiones aportaron conocimientos que fueron absorbidos por la propia industria (Honig, 2010) - y por tanto en re-diseñadores de este (81).

Paulatinamente la demoscene se fragmentó en dos caminos, ciertas personas tomaron el papel de convertirse en desarrolladores profesionales de juegos (Donovan, 2010, siendo de los pocos autores generalistas que la analiza), mientras que otras siguieron alimentando la piratería, lo que les valió fuertes enfrentamientos con la industria del videojuego (Kent, 2001).

Ocho años más tarde del nacimiento de la demoscene, uno de los videojuegos más revolucionaros de su tiempo, Doom (1993) estaba a punto de salir al mercado. Doom (82) fue pionero en el uso de la tecnología gráfica para la perspectiva 3D espacial (los enemigos y los objetos aún eran sprites 2D presentados desde varios ángulos de visión establecidos, una técnica a veces denominada gráficos 2.5D) lo que le posicionó en el punto más elevado de la industria del momento (Kent, 2001). Sin embargo, además de los avances técnicos y de visualización el equipo de Doom decidió inspirase en las copias piratas de su anterior juego - Wolfenstein $3 d$ (83) - e incluyó en Doom las herramientas necesarias para permitir a los jugadores rediseñar el juego a su gusto (Donovan, 2010).

No se trataba sólo de diseñar niveles propios - un tema en que ya habían profundizado títulos como Pinball Construcción Set (1982) o 3D Construction Kit (1991) y más recientemente Super Mario Maker (2015) - sino el ofrecer el juego de forma que los propios jugadores pudieran intervenir en él y modificarlo; no en vano a esa corriente se la denominó modding (Scacchi, 2010). Cuando Id Software (empresa desarrolladora de Doom) publicó su último título de forma conjunta - posteriormente el equipo se separaría - lo llamó Quake (84) (1996) y llevó al máximo 
la idea de permitir modificarlo. El juego disponía de su propio lenguaje de programación QuakeC, que abría las opciones de generar no sólo escenarios, sino también juegos totalmente nuevos (Donovan, 2010). Quake también disponía de una opción de graba partidas, lo que junto al propio motor del juego modificable dio lugar a un abanico inmenso de posibilidades que el jugador podía desarrollar.

El propio Wright reconoció la influencia de Quake a la hora de darle

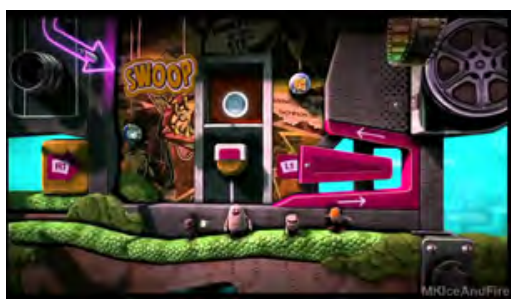

a The Sims un motor de edición del espacio y sus características lo más rico posible (Wright, 2008), así como el diseñador Peter Molyneux empleó la funcionalidad del grabado de partidas para dar lugar a The Movies (Musgrove, 2005).

La apertura y popularización de los mods gracias a Quake abrió un camino que siguieron muchísimos juegos posteriores dando al jugador el papel de constructor en su sentido más amplio, ya fuera de los límites del propio 'mundo del juego'. De entre todos los juegos a los que impulsaron destacan dos: LittleBigPlanet (85) (2009) y Minecraft (86) (2011).

Por una parte, LittleBigPlanet fue ideado como un juego que permitiera crear juegos (Donovan, 2010), idea apoyada por Sony quien impulsó a la empresa Media Molecule para su desarrollo. LittleBigPlanet requirió un desarrollo de 3 años

'Diseñar el aspecto de la creación de contenido

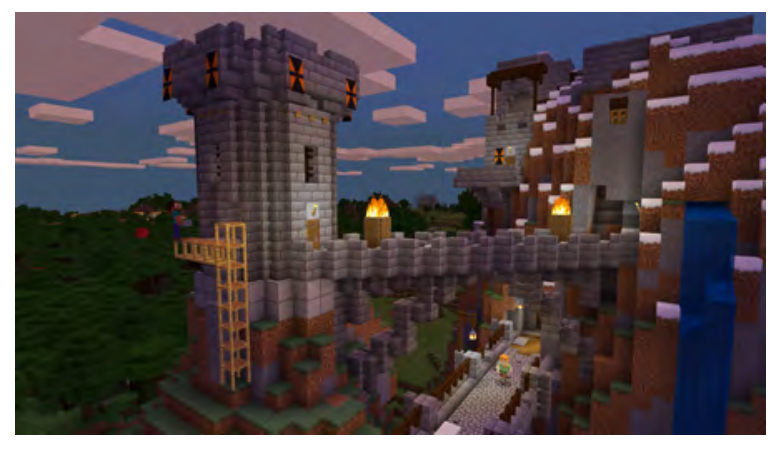

fue un proceso de iteración [...] El aspecto físico era demasiado trabajo, así que fuimos en la otra dirección, pero nos pasamos y acabamos haciendo un sistema la mar de complicado. [...] entonces dimos con un sistema de estampado, para estampar cosas y fijarlas en el sitio, y aquello fue lo único divertido de crear en aquel momento. A partir de ahí, la idea de estampar se extendió al resto del modo de creación. Todo lo que creas es, básicamente, un proceso de estampar cosas, borrar formas o recortar'

(Evans, 2009/2010)

Ocho meses después de su debut los jugadores habían subido a la plataforma de LittleBigPlanet más de un millón de juegos ${ }^{52}$. Este impulso permitió a Media Molecule lanzar su propio sistema de creación de juegos, Dreams, publicado en 2020.

Por otra parte, un programador de videojuegos, que trabajaba para King en 2009, corroboró - al ver publicado LittleBigPlanet - su intención de desarrollar un proyecto inspirado en Rollercoaster tycoon, Dwarf Fortress

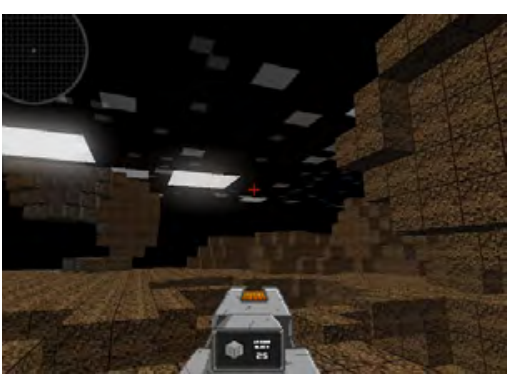
y GTA (Cox, 2018/2019). Este programador, Markus 'Nocht' Persson pasó dos años desarrollando un proyecto personal que tomó también referencias de Infiminer (87) (2009) - según reconoció el mismo ${ }^{53}$ - y la construcción cúbica del espacio, comenzó a lanzar versiones aún sin terminar durante 2010 hasta dar con una versión completa beta ya bajo el nombre de Minecraft a finales de ese año y fundando a su vez la empresa Mojang para su desarrollo completo.

\footnotetext{
${ }^{52}$ Consultado online https://blog.playstation.com/archive/2009/07/22/littlebigplanet-community-reaches-one-million-creations/

${ }^{53}$ Goldberg, Larsson, Minecraft, Second Edition: The Unlikely Tale of Markus "Notch"

Persson and the game that change everything. (2011)
} 
En 2011 el desarrollo creativo del juego pasó a manos de Jens "Jeb" Bergensten un diseñador que había trabajado con mods en Quake y finalmente se publicó una versión completa del juego (Goldberg, Larsson, 2011).

Minecraft pone al jugador en el papel de un constructor en un mundo abierto de dimensiones descomunales. De hecho, se trata del juego con mayor extensión jugable de la historia:

"El volumen cúbico de un mundo de Minecraft es doscientos sesenta y dos billones, ciento cuarenta y cuatro billones de "bloques". Si cada bloque tuviera lados de un metro de largo, entonces un mundo de Minecraft tendría una superficie mayor que Neptuno"

(Darrell M. West and Joshua Bleiberg, 2013).

Minecraft otorga al jugador un servidor único en el que lanzar su propio mundo (generado aleatoriamente por un algoritmo) y ese espacio se encuentra construido en unidades cúbicas. El jugador puede romper o construir unidades cúbicas que adquieren diferentes formas (madera, piedra, diamantes, etc.) que se convierten en recursos que puede gestionar. Además, el jugador puede interactuar y modificar el espacio que le rodea en base a algunas reglas básicas.

Este juego de mundo abierto posee tres modos de "un jugador": supervivencia, hardcore y creativo. En el modo supervivencia el jugador debe gestionar los recursos, ganar experiencia y aprender una serie de encantamientos para llegar a un mundo final y derrotar a un dragón. El juego obliga al jugador a explorar el mundo que le rodea para aprender su funcionamiento. En segundo lugar, el modo hardcore es igual que el modo supervivencia, pero de mayor dificultad y con una única vida. Por último, el modo creativo en el que el jugador tiene a su disposición todos los bloques de los materiales existentes, por tanto, no tiene que explorar todo el mundo que el servidor le ofrece para encontrar dichos materiales.

Minecraft dispone también de modo multijugador que permite "visitar mapas predeterminados cargados en el juego base o descargar los creados por los usuarios que traen consigo algunas actividades que el jugador podrá realizar" (Andrés Alvarado Barraza, 2019).

Si bien es cierto que Mojang también cuenta con un modo historia de Minecraft, la versión del modo supervivencia y del modo creativo han abierto las posibilidades a los jugadores, debido a las dimensiones del mundo; además también han aumentado las posibilidades de usar el juego como una herramienta de construcción. En ese equilibrio entre la supervivencia y la construcción reside la clave del éxito de Minecraft:

"El equilibrio del modo de supervivencia evita que el juego se desplace hacia el territorio del aburrimiento, mientras que la construcción creativa del juego ayuda a evitar que la ansiedad sea la experiencia primordial del juego. Los componentes individuales de la supervivencia y la construcción se necesitan mutuamente para conducir a los jugadores más profundamente en el juego y lograr un estado de juego alegre y de "flujo"

(Sean C. Duncan, 2011) 
Por todo esto, Minecraft ha revolucionado los videojuegos de mundo abierto, ya que, por una parte, ofrece las herramientas propias de los videojuegos de construcción y de simulación y, por otra parte, brinda al jugador la posibilidad de perseguir una serie de objetivos (que se asemejarían a las misiones que pueden encontrarse en Grand Theft Auto) que le permiten sobrevivir en ese basto mundo creado únicamente para él o para ella.

El modding no desapareció con el paso del tiempo, como muestra que en 1996 algunos jugadores que exploraban los límites de Pokémon consiguieran activar casillas de la programación no previstas y encontraran un Pokémon no contemplado a priori, Mew (Morimoto, 2010) o en 2004 cuando se descubrió una escena sexual oculta en GTA: San Andreas (Kutner, Olson, 2008) que la compañía había querido ocultar, lo que le valió bastantes problemas legales, según explica Donovan (2010/2018).

Sin embargo, la aparición de juegos donde el jugador tenía tanta libertad de recorrer y usar el espacio como Dreams (2020) o Minecraft - considerados motores de creación de lugares - ha abierto un campo inmenso relacionado directamente con el diseño espacial ${ }^{54}$. En la actualidad gran cantidad de juegos han incluido un modo creativo a sandbox - a imagen de Minecraft - en el que el jugador tiene la opción de recorrer el mundo y modificarlo, así por ejemplo existe en Fornite.

Desde el origen puramente arquitectónico de las perspectivas y modelos de visualización de los primeros videojuegos, pasando por el uso de los recursos propios de la arquitectura para poder guiar al jugador en el espacio virtual, hasta el cuestionamiento de la relación espacio de juego - jugador y la posibilidad/libertad de este último de tomar el papel de un arquitecto del espacio virtual se ha trazado una línea que muestra que el diseño del espacio virtual de los juegos tiene su origen en el espacio material que diseña la arquitectura.

Si bien este camino prosigue construyéndose en la actualidad como se observa con el creciente número de profesionales de la arquitectura que entran a diseñar videojuegos ${ }^{55}$, de un tiempo a esta parte es el videojuego el que repercute sobre la arquitectura.

\footnotetext{
52 La influencia de ambos juegos en la arquitectura se analiza en el capítulo 4.

${ }^{53}$ Consultado online https://elpais.com/cultura/2020/01/03/babelia/1578074550_156680. $\mathrm{html}$
} 
*conclusiones de la terminología

- el concepto gamespace se refiere al espacio de juego en el interior de la pantalla, es decir en el mundo virtual.

- el concepto playspace se refiere al espacio de juego frente a la pantalla, es decir en el mundo material.

\section{CONCLUSIONES} PARCIALES CAPÍTULO

\section{4}

En cuanto a la arquitectura como referencia y punto de partida de los videojuegos, se encuentra y analiza que, incluso en el origen etimológico de las palabras clave de los dispositivos materiales que soportan el juego consola y arcade - se encuentran conceptos arquitectónicos y espaciales.

La construcción de los escenarios lúdico-virtuales presenta además referencias continuadas al espacio material arquitectónico, tanto literales (como modelos y diseños tomados de la arquitectura) como en cuanto a los procesos (como los programas de dibujo 2D inicialmente concebidos para diseñar espacio material) o los sistemas de representación del mismo. Es decir, por una parte, los videojuegos toman de referencia la arquitectura en cuanto al diseño y visualización del espacio.

En este sentido dos ejemplos significativos que ilustran cómo los videojuegos han tomado de referencia la arquitectura son el uso de la perspectiva egipcia en ellos - tomada por el diseñador Warren Robinett tras sus clases de arquitectura de la universidad - y el de la perspectiva isométrica por la influencia de ésta en la representación tradicional de la arquitectura asiática. También la incorporación de información del mundo material para elaborar el espacio virtual como medio para alcanzar mayor calidad gráfica o la abstracción implícita en los videojuegos que permite representar espacios del pasado o de futuros utópicos/distópicos que la arquitectura material.

Por otra parte, los sistemas de guía e interacción para/por el habitante de la arquitectura también han sido trasladados a los videojuegos y sus jugadores. Así por ejemplo el análisis del espacio que ofrece Kevin Lynch en La imagen de la ciudad es empleado de referencia de forma ininterrumpida en videojuegos. Ejemplos especialmente ilustrativos, por lo fácilmente asimilables a videojuegos, serían los jardines de Versalles o Villa Adriana, por presentar una narrativa implícita muy clara (la alegoría al poder que los diseña) y contener un fuerte componente como espacios de retiro vacacional o lúdico.

Por último, también en cuanto al papel del jugador en el espacio ,los videojuegos presentan claras referencias arquitectónicas. Pero es que, además, aunque en la mayoría de los casos se trata de un jugador que recorre y habita el espacio previamente diseñado, en algunos géneros concretos el jugador toma el papel de un editor espacial o arquitecto, llevando un paso más allá la relación intrínseca entre ambas áreas de la producción espacial. 
(5) 


\section{INTRODUCCIÓN \\ AL ANÁLISIS}

3.1

Cuando en 2006 Nintendo mostró la consola tras el nombre en clave $R e$ volution (Gorges 2016/2018) - cuyo nombre oficial pasó a ser Wii - Will Wright ${ }^{1}$ dijo que era la única consola realmente de otra generación que conocía, pues hacía que los espacios lúdico-virtuales llegaran a demografías históricamente sin interés por los videojuegos (Wright, 2006).

El logro de Wii - que a la postre vendió 101,82 millones de copias, tercera consola más vendida de la historia, y la consola más rápidamente vendida hasta el momento ${ }^{2}$ - se centró en ofrecer un nuevo modelo de entretenimiento que consiguió ampliar el mercado llegando a jugadores que no responden a un modelo clásico (Donovan, 2010). Este nuevo modelo de entretenimiento no tenía tanto que ver con los gráficos de la consola (Johnson, 2007/2008) - es decir, no se soportaba en el entorno dentro del juego - si no que se relacionaba de forma directa con el entorno fuera de la consola, ya que una Wii convertía el espacio enfrente de la pantalla en un espacio dinámico y de actividad.

Wii mostró que la relación entre el espacio material, el playspace, y el espacio virtual, el gamespace, era un campo de investigación lúdica escasamente aprovechado, cuando no sencillamente omitido. Nintendo puso con Wii en el mapa el espacio material que envuelve al juego virtual.

Si bien los videojuegos han tomado infinidad de recursos de la arquitectura - tal y como se ha analizado en el capítulo 2 - y la arquitectura se está dejando influir por los videojuegos - como se verá en el capítulo 4 es necesario analizar los espacios en los que se mueven estas relaciones, punto en que se centra este análisis, y que permite construir las dos caras de dicha conexión.

Se considera este un análisis mayoritariamente gráfico, organizado de forma cronológica, y dividido atendiendo a las diferentes generaciones de consolas - haciéndose extensivas al resto de dispositivos por la relevancia de éstas ${ }^{3}$ - identificándose cada generación con un color (ver página siguiente). Se entiende por generación de consolas a los periodos de tiempo que agrupan determinados dispotivios con características comunes. Estas generaciones suelen ser denominadas por los mismos desarrolladores o la prensa especializada, y sin embargo se han empleado en diferentes trabajos de investigación como el de Donovan (2010/2018) 0 artículos como 'Prolonging the Magic: The political economy of the 7th generation console game' (Nieborg, 2014).

Siguiendo la línea de investigación del trabajo se compara en cada generación un espacio material arquitectónico producido y los dispostivios lúdicovirtuales contemporáneos al mismo. Considerando 4 tipos de espacios o playspace:

- El espacio doméstico (espacio más significativo) sobre el que actúan los juegos de consolas domésticas y ordenadores. Para este análisis se ha escogido un espacio doméstico por cada generación. Estos espacios domésticos o viviendas se han seleccionado atendiendo a los siguientes criterios (1) viviendas colectivas (2) viviendas representativas de su época (3) viviendas con connotaciones culturales de su época. Para dicha selección se han empleado los

\footnotetext{
${ }^{1}$.Entrevista a Will Wright el 26 de octubre de 2007. https://www.theguardian.com/technology/2007/oct/26/willwright

${ }^{2}$.En la actualidad la Playstation 4 y la Nintendo Swicht se han vendido más rápido. https:// elpais.com/tecnologia/2009/03/26/actualidad/1238059678_850215.html

${ }^{3}$.Existen generaciones de ordenadores que no coinciden con las de las consolas y que no se consideran en esta tesis.
} 
dos volúmenes de Atlas de vivienda colectiva en España, 19291992 y 1992-2015 (Canovas, Espegel, Delapuerta, Martínez Arroyo y Pemjean, 2016). Se incluyen sobre los dibujos de las viviendas las áreas o playspaces en unidades métricas. Se incluye a su vez una comparativa directa playspace/gamespace, mostrando el espacio donde se juega en el mundo material con el espacio en que se juega en el mundo virtual.

- El espacio exterior de la ciudad sobre el que actúan los juegos de las consolas portables y dispositivos móviles. Estos lugares se corresponden con el espacio exterior de los conjuntos de viviendas previamente seleccionadas. Se incluyen datos sobre los dibujos datos indicativos de la libertad del suario para moverse en este espaco urbano, tanto de forma métrica como en pasos.

- El espacio social del juego; recreativos, arcades y salas de juego. Estos espacios se analizan a través de la información recopilada gracias a las normativas que rigen el juego en España. Las máquinas arcade pertenecen al tipo A, sólo diversión - aunque excluido de la Directiva 123/2006 / CE, que dejan fuera a los juegos de azar que no son objeto de esta tesis: Tipo B (diversión con premio, "AWP"); y tipo C (de casino). Las principales leyes que han actuado sobre ellas a nivel estatal son: Real Decreto del 25/02/1977 en BOE del 07/03/1977, RD 11/03/1977 en BOE 24/03/1977, RD 14/10/1978 en BOE 17/11/1978, Orden Ministerial del 03/04/1979 en BOE 21/04/1979, RD 24/07/1981 en BOE 18/08/1981 y OM 20/04/1982 en BOE 24/04/1982. A partir de ese momento la regulación de las máquinas tipo A pasa a depender de las Comunidades autónomas y se bifurcan en diferentes normativas ${ }^{4}$

- La ausencia de espacio material; en ciertos casos, no existen dispositivos ni espacios materiales sobre los que repercutan de forma directa. Por una parte estarían, los juegos que pueden darse en difrentes plataformas de forma online, en los que si existe un playspace pero es indiferente pues lo que rpima es el espacio virtual conjunto donde sucede. Por otra parte se encuentran juegos cuyo espacio donde se ubican es una plataforma virtual, como es el caso de juegos flash en webs o de los juegos de Facebook.

En cada generación se reseñan también los diferentes dispositivos y los principales juegos de éstos, incluyendo imágenes de todos los gamespaces, y los accesorios que tienen la finalidad de modificar el uso del espacio.

\footnotetext{
${ }^{4}$ Se adjunta lista completa de normativas empleadas en la Bibliografía final.
} 


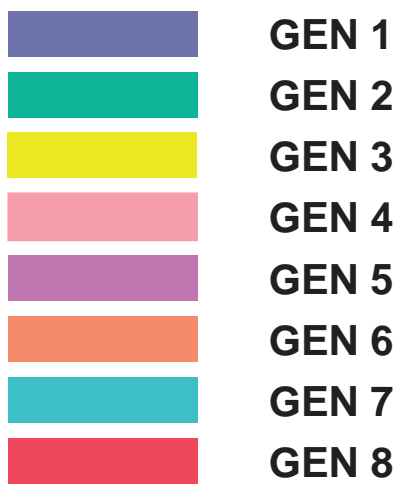

ordenador
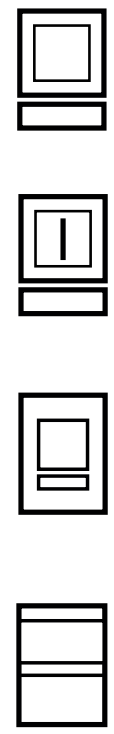

$0:$
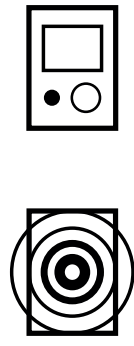

juego online

videoconsola portable

ordenador

micro

máquina arcade

videoconsola doméstica

X

other

videoconsola híbrida

ordenador

único

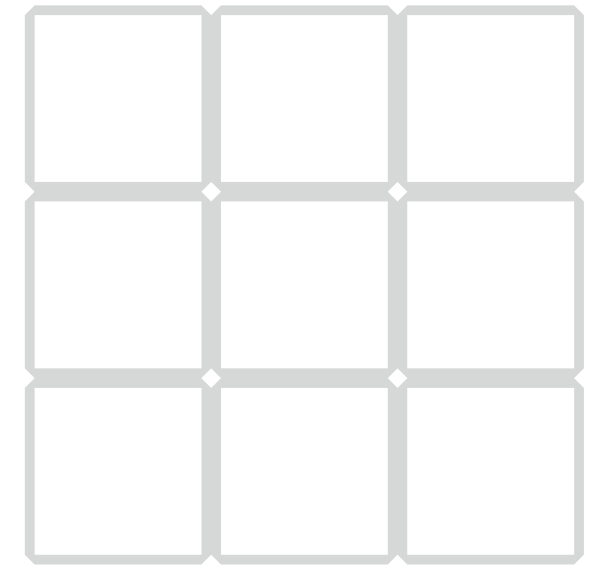

Un cubo de Rubik Estandar (5,7cm de lado) se emplea como referencia gráfica. 


\section{GENERACIÓN 1}

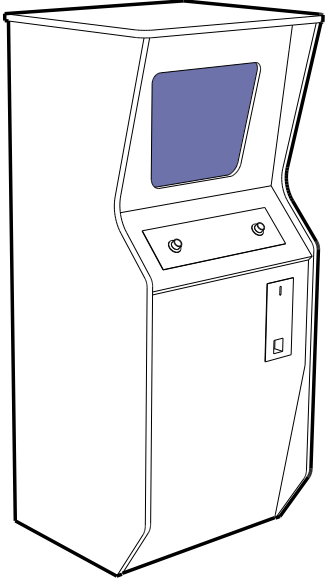

1972

El comienzo del juego virtual como entretenimiento podría decirse que fue la primera consola doméstica de la historia, Magnavox Odissey. Aún faltaban 3 años para que saliera a la luz el primer ordenador personal, el Altair 8800 y los juegos de computador funcionaban en ordenadores de instituciones y universidades como el PDP-10 del MIT. S.

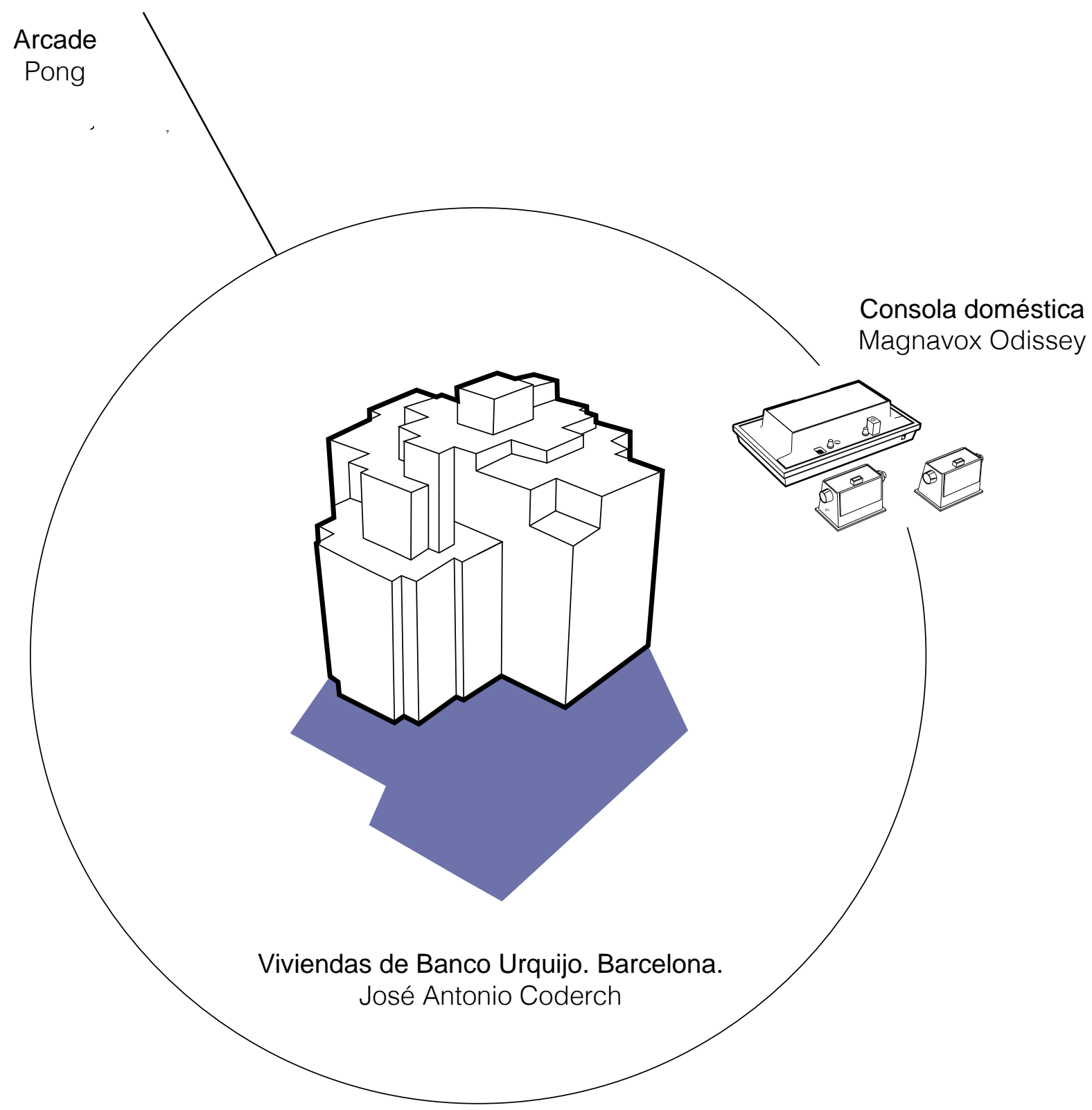


DPE

El salón viviendas del Banco Urquijo

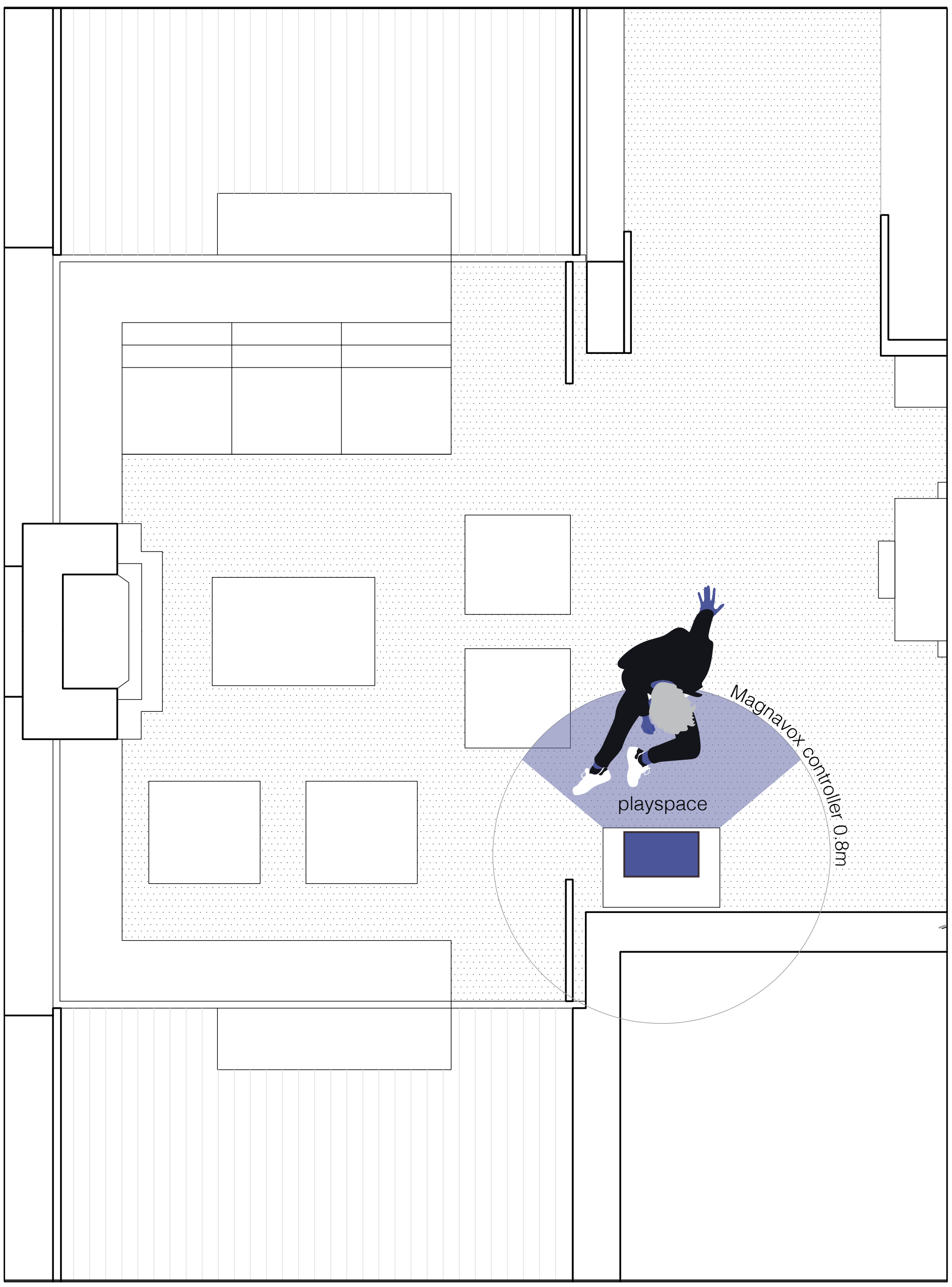




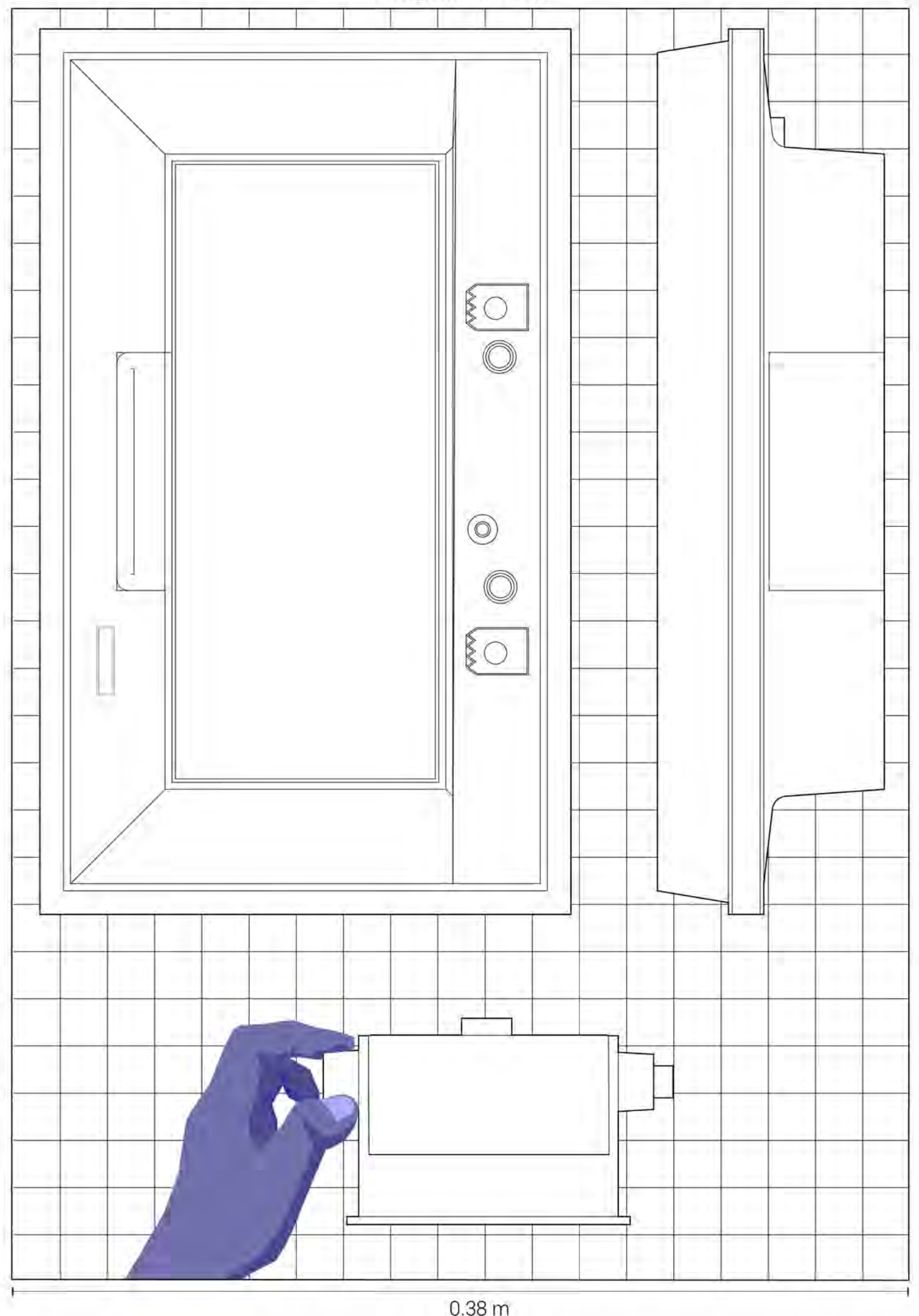


El juego más destacado de Magnavox Odissey (no se vendieron prácticamente de forma individual, si no con la propia consola) fue Table Tennis, que simulaba una partida de tenis.

Así, el campo de juego al que podía accederse tenía una dimensión aproximada 252 m, más del doble de la dimensión de una vivienda de Banco Urquijo donde podía localizarse la consola.

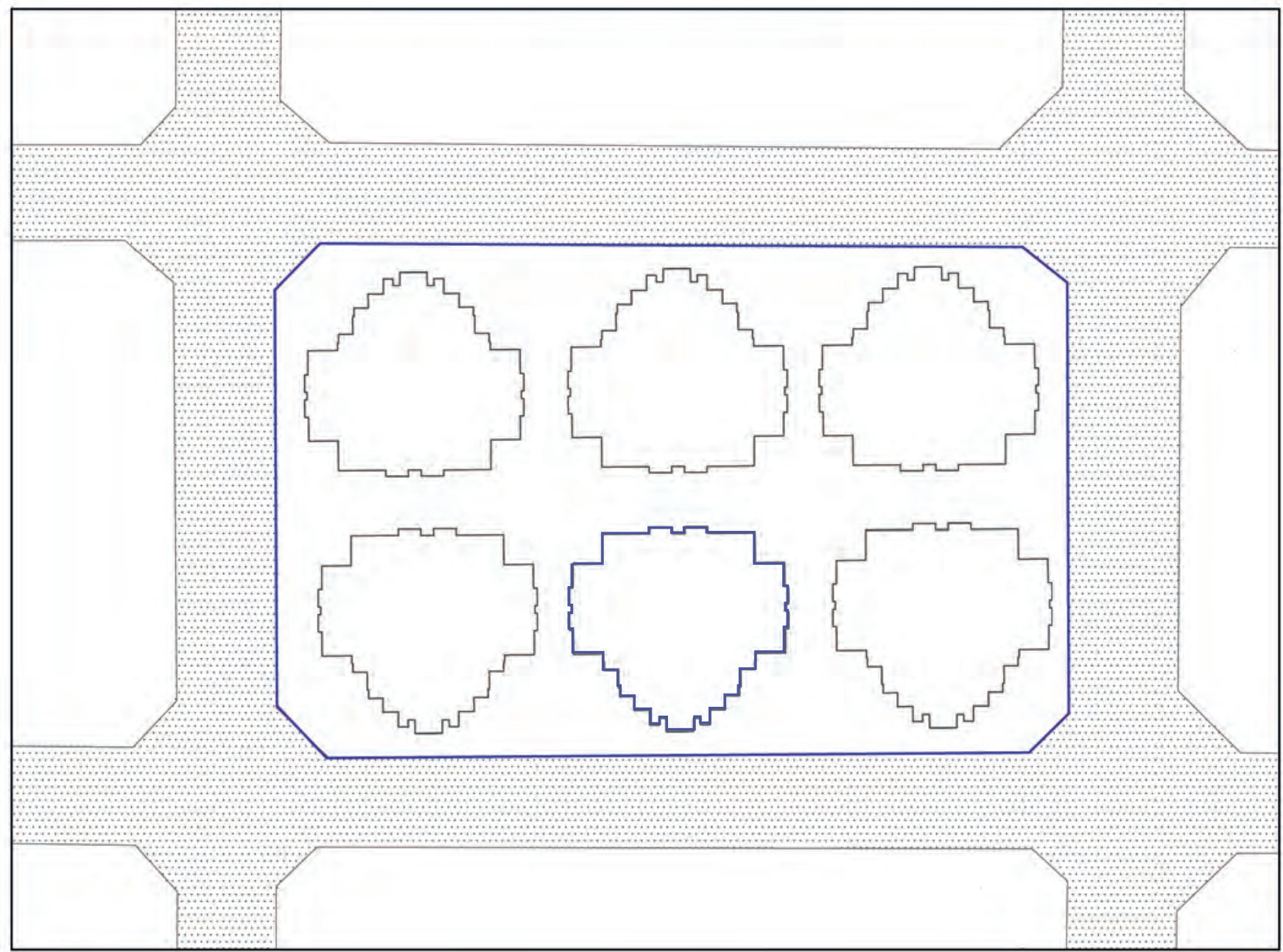

$165 \mathrm{~m}$ 


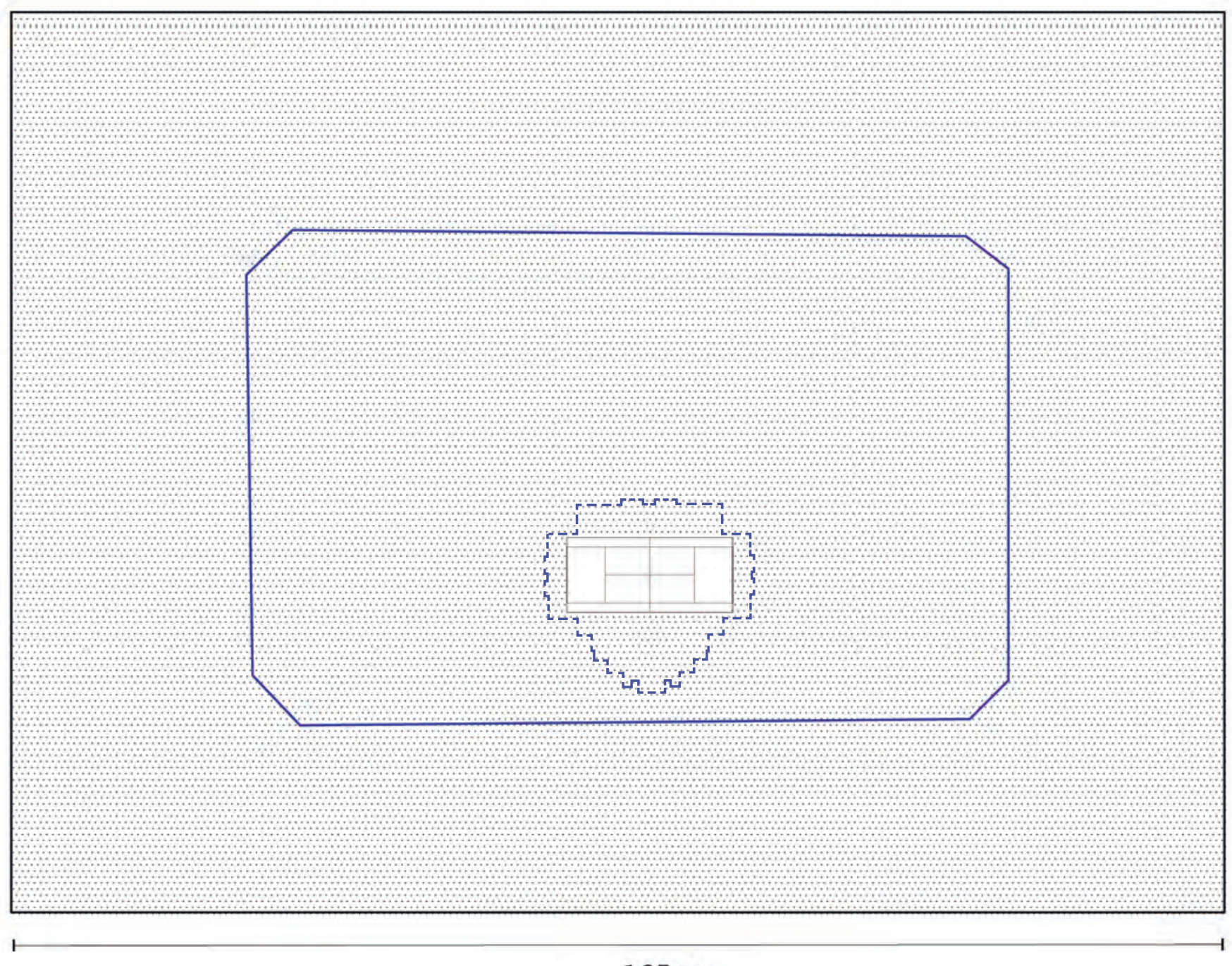

$165 \mathrm{~m}$

Tennis field

campo de juego 


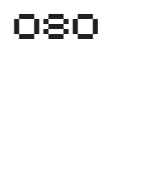

$\square:$

00 
ㅁ:어

Pong.
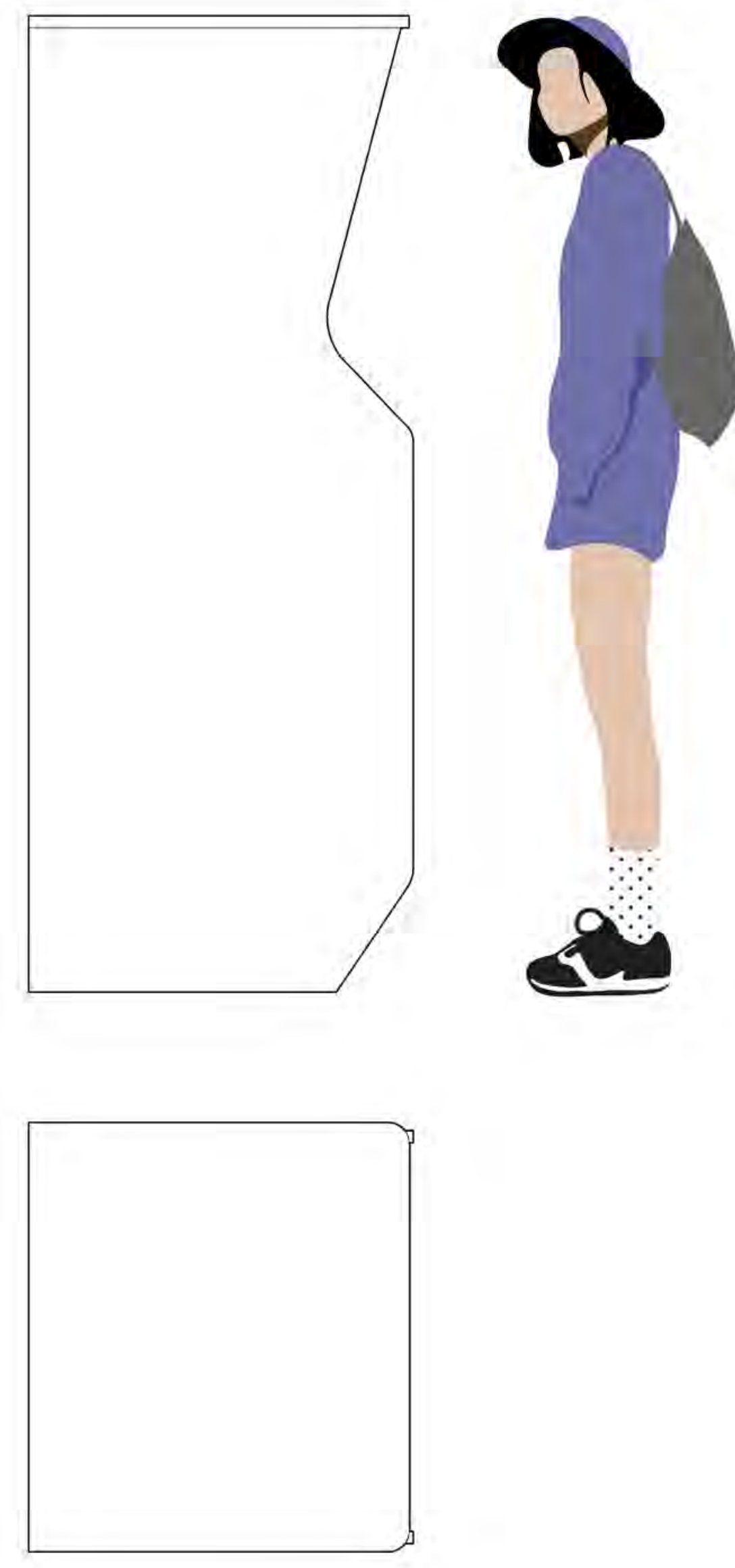

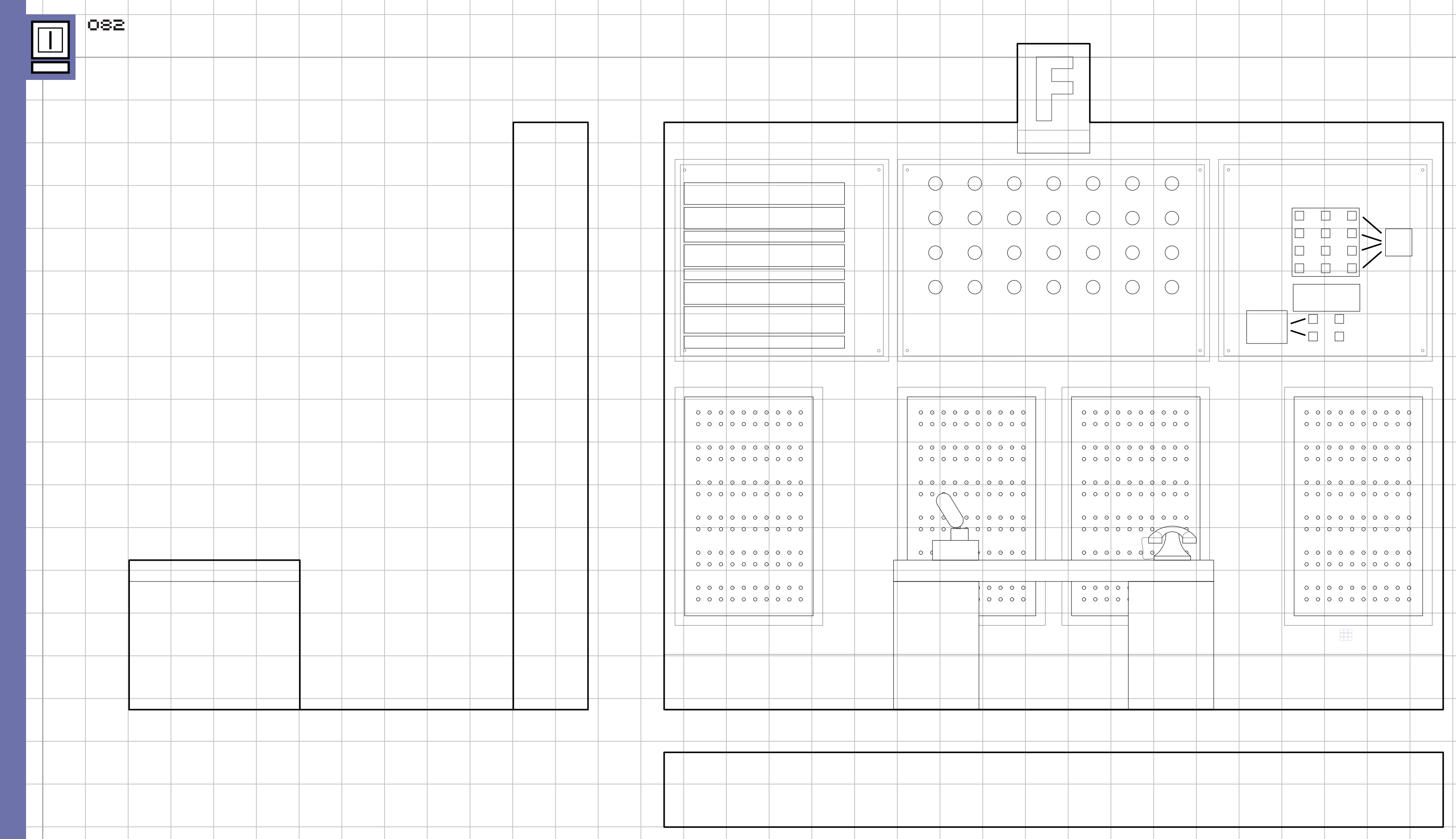


\section{Nimrod.}

\section{1}

\section{Ferranti International plc.} Ordenador único.

Ordenador primitivo diseñado por la compañía Ferranti y presentada en el Festival of Britain (1951) (Ceruzzi, 2012). Esta máquina fue construida expresamente para jugar al juego Nim y, además, fue el primer sistema en mostrar cierto grado de inteligencia artificial al enfrentarse en cada partida a un jugador.

Nimrod ocupaba una pared completa de casi cuatro metros de largo y disponía de una mesa en la que se sentaba cada jugador. Sin embargo, la mayor parte de este espacio solo se utilizaba con fines de visualización en una pantalla de luces que se iluminaban en función de la respuesta y de las operaciones del ordenador.

Entre sus contrincantes se encontró Alan Turing, que había sugerido por primera vez la importancia del juego en la investigación de computación (Copeland, 2012/2013). Durante la presentación:

"Ferranti comprendió el poder de los juegos para hacer que los ordenadores fueran relevantes o, al menos, emocionantes para el público [...] con un público que en su mayoría solo quería jugar en lugar de involucrarse con las matemáticas y la ciencia detrás del cerebro electrónico de Nimrod"

(Stuckey, Swalwell, and Ndalianis, 2013). 
可
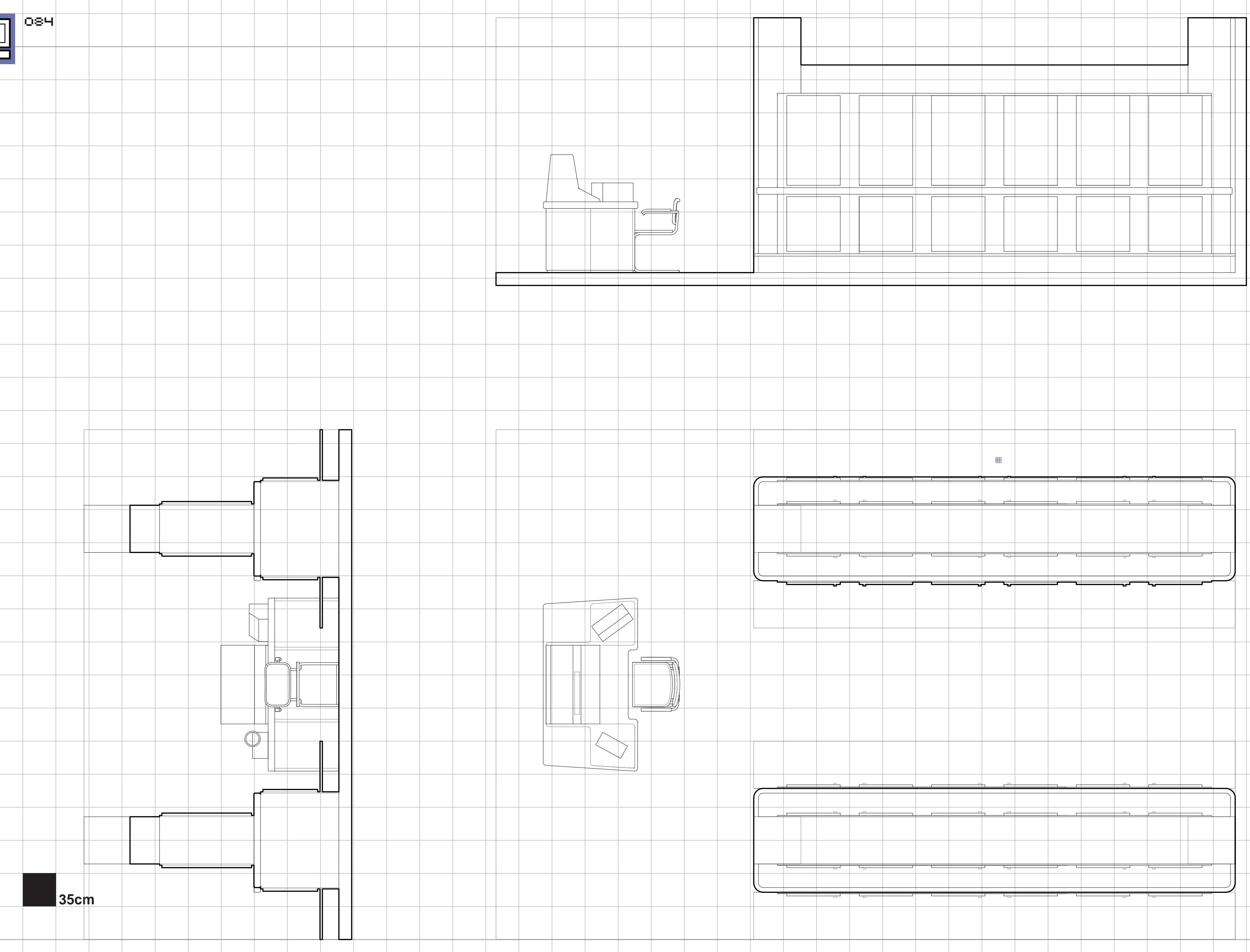


\section{Ferranti mark I.}

\section{1}

\section{Ferranti International plc.} Ordenador único.

Primer ordenador electrónico comercialmente disponible que perteneció a la Universidad de Manchester, instalado allí en 1951 y desmantelado y devuelto a Ferranti en 1959 ( $\sin$ la mayoría de sus partes) (Ceruzzi, 2012).

Este modelo, elaborado por el personal de la universidad, tomó como referencia el Manchester Mark I, añadiendo memorias primarias y secundarias. Es especialmente relevante por haber sido la primera máquina en acoger la programación de un juego, ya que en 1951 el doctor Dietrich Prinz la programó para jugar al ajedrez, sin embargo, "el Mark 1 no era lo suficientemente potente como para jugar la partida entera" (Peddie, pg 321, 2013). Posteriormente, Alan Turing usó esta máquina para tratar de implementar su propia programación de ajedrez (Copeland, 2012/2013).

Este ordenador ocupaba una sala completa y disponía de una mesa con dos pantallas circulares para visualizarlo y otras cuatro de menor dimensión.

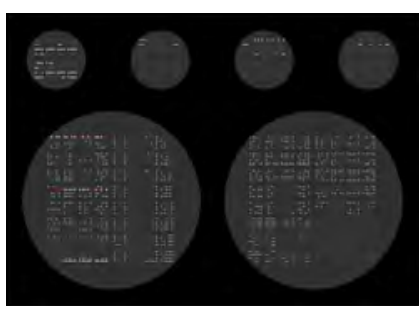

Programminng a Computer for Playing Chess.

Shannon \& Turing.

1948

Primer intento de videojuego propiamente dicho. Se basaba en el ajedrez y fue desarrollado por el

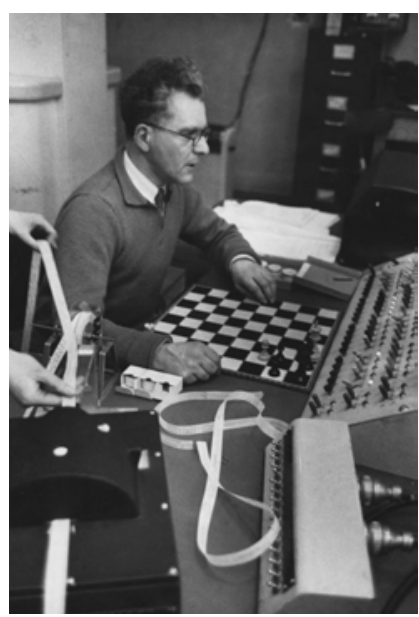
matemático británico Alan Turing y el americano Claude Shannon. El primero intentó implementar la programación pero solo lo logró en parte. Finalmente hizo que un amigo simulara los movimientos del ordenador y ganó la partida.

\section{Fuente análisis gráfico:}

Elaboración propia a partir de la información recibida de The School of Computer Science, The University of Manchester (Manchester, UK) y completada con la obtenida en 'Early Computing in Britain: Ferranti Ltd. and Government Funding, 1948-1958' (Lavington, 2019). 

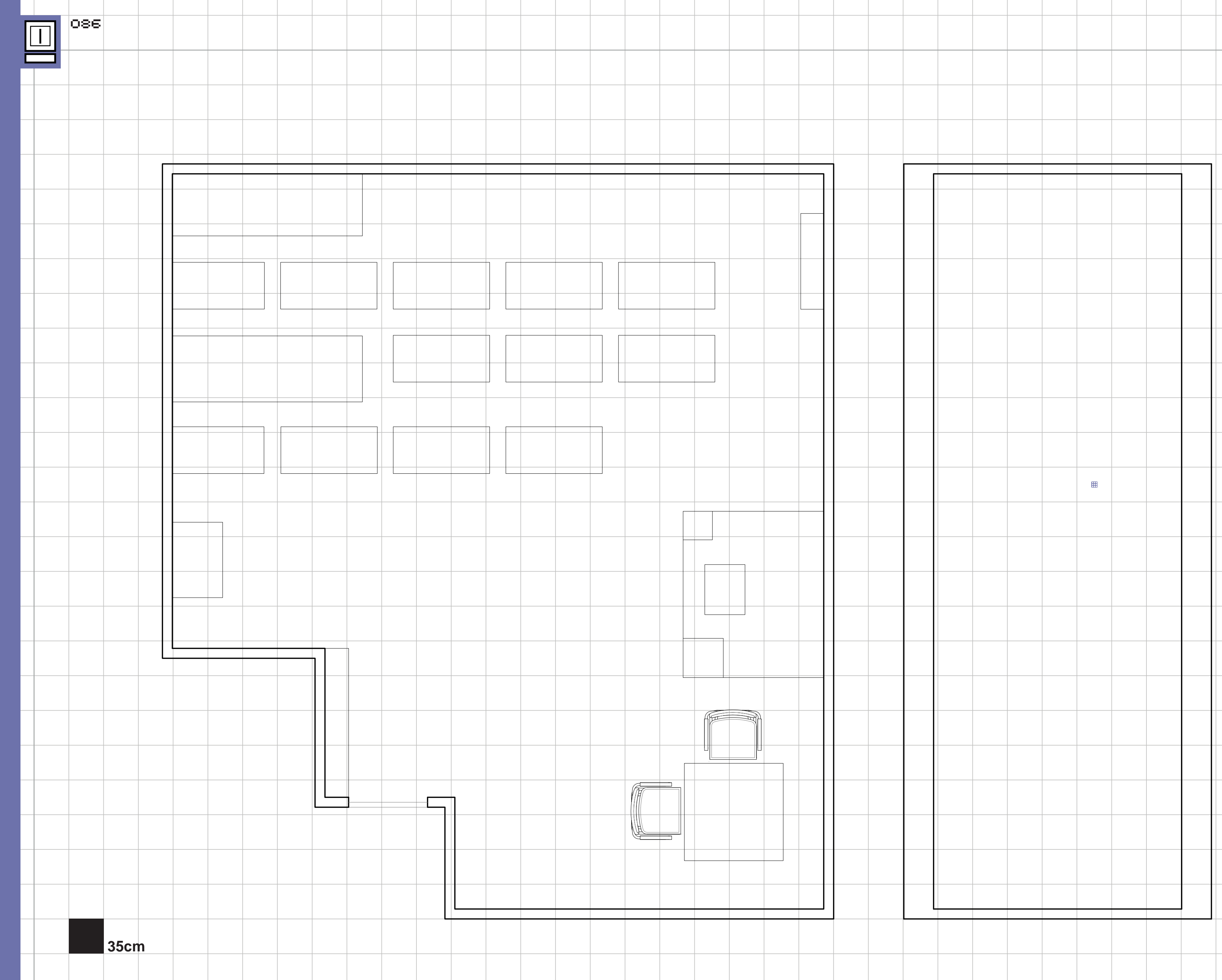

$35 \mathrm{~cm}$

\begin{tabular}{|l|}
\hline 1 \\
\hline 5
\end{tabular}

t

\begin{tabular}{|l|l|l|l|l|l|}
\hline+2 & & & \\
\hline
\end{tabular} 


\section{EDSAC.}

1952

University of Cambridge Mathematical Laboratory. Ordenador único.

Ordenador primitivo construido en 1949 por Maurice Wilkes y su equipo de la Universidad de Cambridge (Ceruzzi, 2012). Las siglas responden a Electronic Delay Storage Automatic Calculator.

"Utilizó líneas de retardo de mercurio para la memoria, tubos de vacío para la lógica, y la entrada se realizó mediante una cinta perforada de 5 agujeros, la salida se realizó mediante una teleimpresora"

(Peddie, pg 84-85, 2013)

En 1952, Sandy Douglas la utilizó para programar OXO (una versión de tres en raya) que se visualizaba en una pantalla circular de 6 pulgadas (Wolf, 2012).

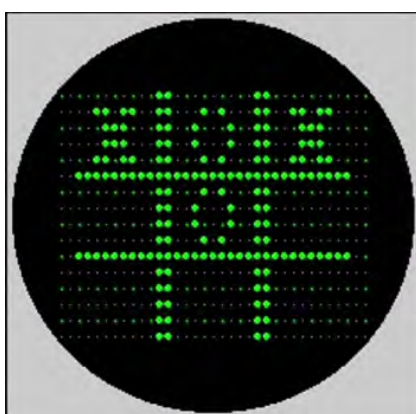

OXO.

1952

Videojuego tipo puzzle basado en el juego del tres en raya. Desarrollado como parte de una tesis doctoral. Considerado el primer videojuego. 

Osciloscopio.

1958

Brookhaven National Laboratory.

Ordenador único.

Instrumento de visualización electrónico en que se muestra una representación gráfica de señales eléctricas que varían en el tiempo. En 1958 existía un osciloscopio en el Laboratorio Nacional de Brookhaven donde trabajaba William Higinbotham (quien había colaborado en el Proyecto Manhattan) y que utilizó este instrumento proponiendo un pequeño sistema para jugar al tenis en la pantalla del osciloscopio (Kent, 2001).

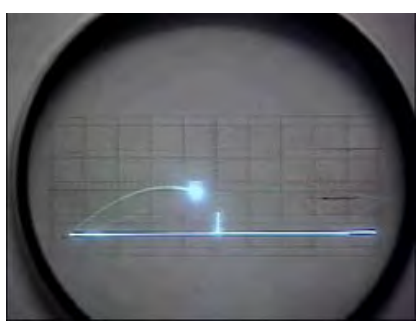

Tennis for two.

1958

Videojuego deportivo basado en el tenis para dos jugadores. Desarrollado empleando un osciloscopio. El juego constaba de dos líneas únicamente, el suelo y la red,

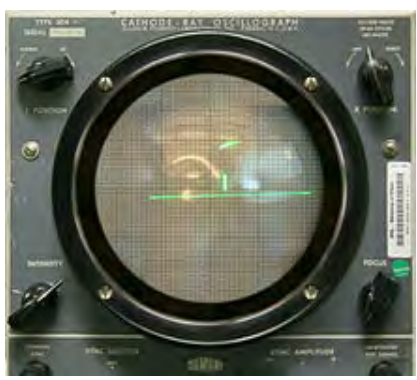
los jugadores escogían de qué lado sacar.

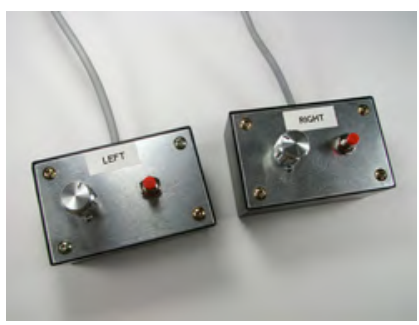


可变
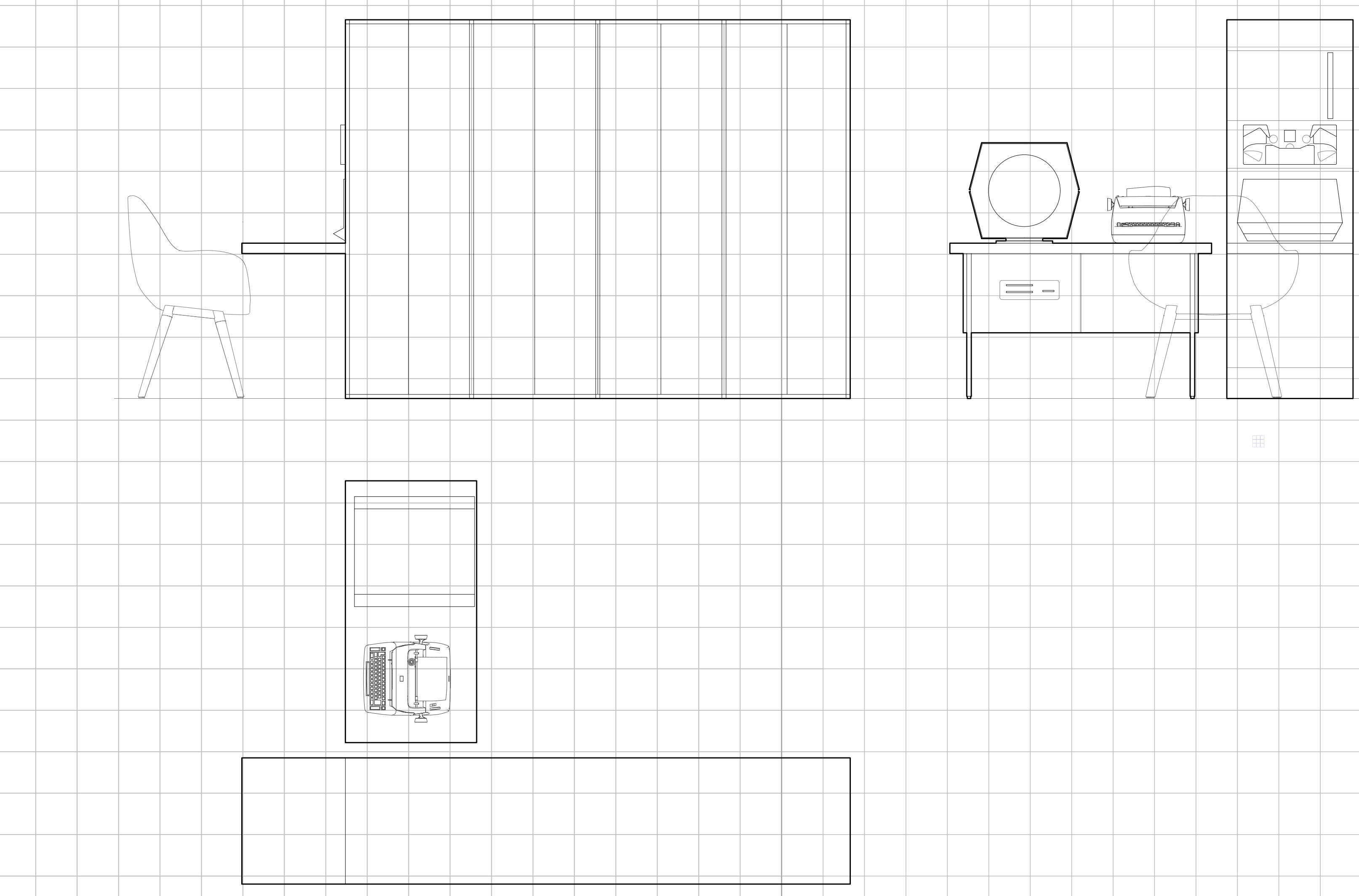

$20 \mathrm{~cm}$

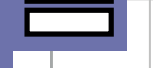




\section{PDP-1.}

1962

\section{Digital Equipment Corporation. Ordenador de acceso limitado.}

Primer ordenador desarrollado en 1960 por la compañía Digital Equipment Corporation y que inauguraba la serie PDP (considerados de tipo miniordenador), DEC construyó 50 unidades. Una de esas unidades perteneció al Instituto Tecnológico de Massachusetts (MIT) (Ceruzzi, 2003).

El ordenador medía unos tres metros de largo y metro y medio de alto, disponía de una pantalla circular de 19 pulgadas, que era monocromática, así como de una máquina de escribir que hacía las funciones de un teclado. Este ordenador pesaba 730 kilogramos.

En 1962, Steve Russell, durante su tiempo como miembro del club de modelado de trenes del MIT, tuvo acceso al ordenador (Donovan, 2010). Al frente de un pequeño equipo, programó el primer videojuego creado para un ordenador Space War!

"La computadora dibujaba y actualizaba imágenes, dibujando trazos en la pantalla CRT (pantalla de tubo de rayos catódicos). [...] El objetivo del juego era maniobrar una nave espacial y disparar a tu oponente antes de que te disparara"

(Peddie, pg 88-89, 2013)

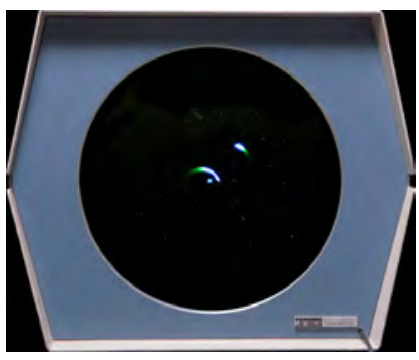

Spacewar!

1962

Programa de ordenador capaz de procesar lenguaje natural y que trataba de mantener una conversación coherente con el usuario.
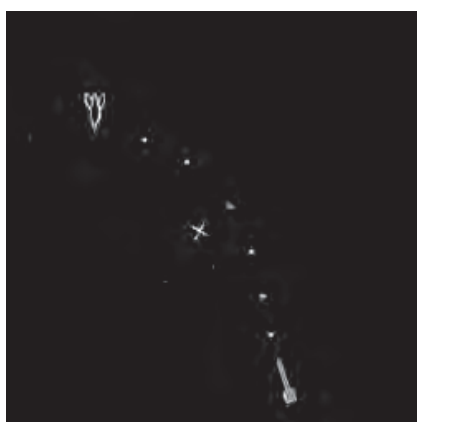

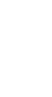



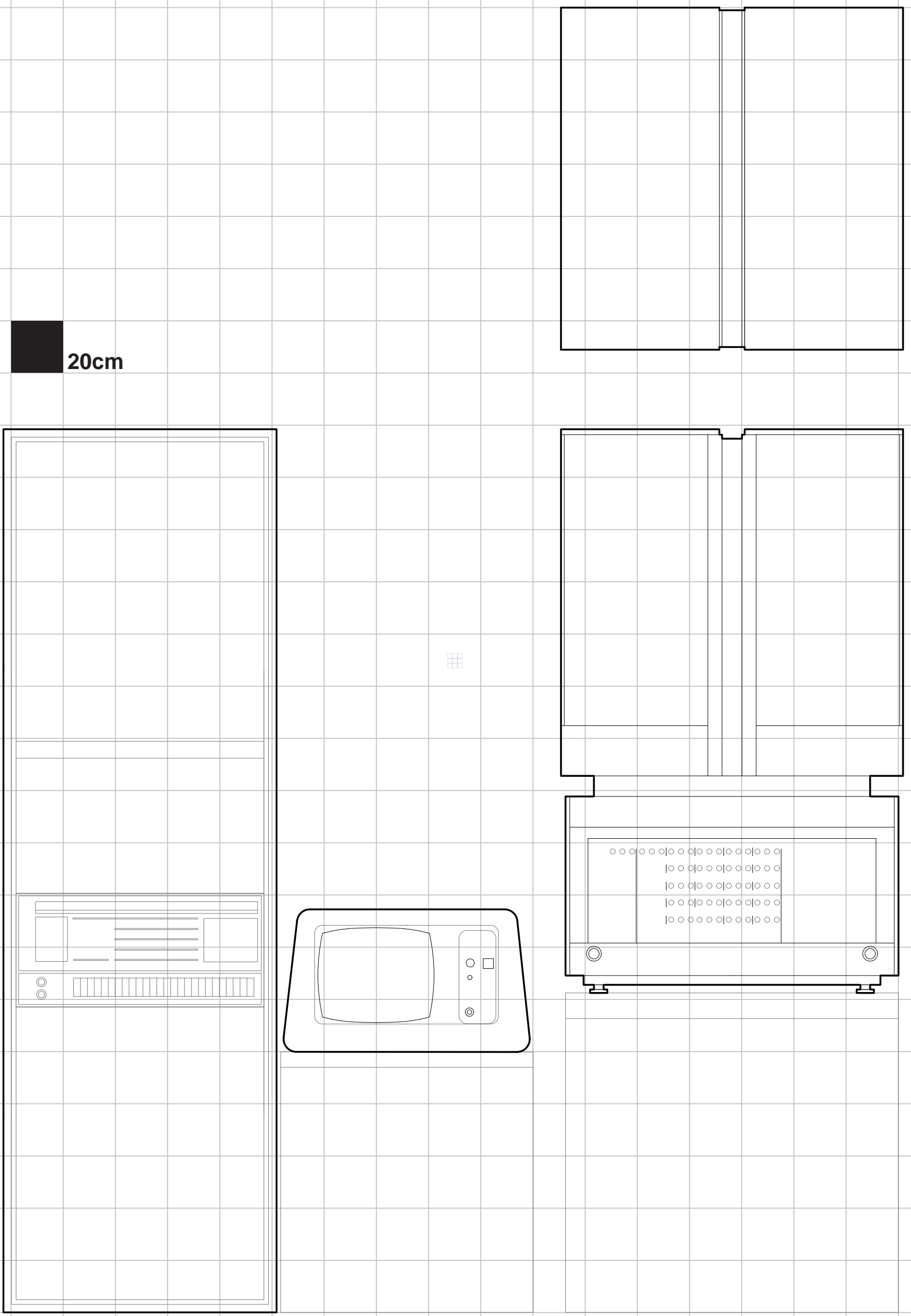


\section{PDP-8.}

1965

Digital Equipment Corporation. Ordenador único.

Octavo miniordenador de Digital Equipment Corporation de su serie PDP, que salió al mercado en 1965 a un precio de 18.000 dólares, el miniordenador PDP más barato y, además, el primero comercialmente exitoso al vender 50.000 unidades (Ceruzzi, 2012).

Se trataba de un ordenador de 12 bits, considerado un ejemplo histórico del diseño de ordenador ya que supuso un salto importante gracias a su simplicidad, capacidad de expansión e ingeniería cuidadosamente diseñada (Ceruzzi, 2003).

El PDP-8 contó con una gran variedad de modelos: PDP-8/S, PDP-8/I, PDP-8/L, PDP-12, PDP-8/E, PDP-8/F, PDP-8/M, PDP-8/A, entre otros. Estos modelos variaban en tamaño y en peso, debido a los cambios en las memorias y en las puertas lógicas. Estas "versiones posteriores aprovecharon circuitos integrados a pequeña escala" (Peddie, pg 154, 2013)

En 1968, Doud Dyment diseñó para este ordenador el videojuego Hammurabi, conocido durante su desarrollo bajo el nombre de King of Summeria y The Summer Game. Se trataba de un videojuego de estrategia basado en texto. Dyment fue contratado como parte de una demostración de lo que el nuevo de sistema de programación FOCAL era capaz de hacer. Posteriormente, este juego fue reprogramado en BASIC (Ahl, 1973/1978)

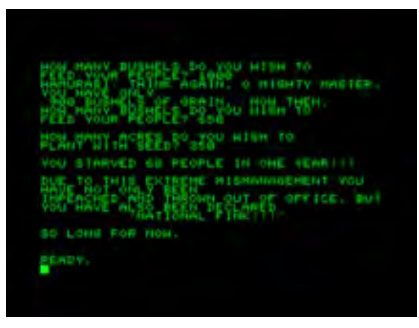

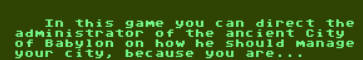

H A M M U R A I

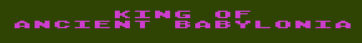

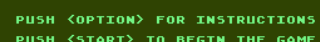
PUSH (STRRT) TO BEGSN THE GAME

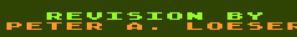

Hammurabi.

1968

Videojuego textual desarrollado por primera vez bajo el nombre de The Sumer' Game por Doug Dyment en 1968 en Digital Equipment Corporation como un juego de computadora para el recién inventado lenguaje de programación FOCAL de Richard Merrill. Existieron varias versiones del juego para los idiomas FOCAL y FOCAL-69, pero en 1973 David H. Ahl creó BASIC Computer Games, un libro que explicaba la programación de videojuegos en el lenguaje BASIC, incluyendo en él una versión de The Sumer Game. Esta versión ampliada del juego fue titulada Hammurabi, y se convirtió rápidamente en la versión más conocida debido a la popularidad tanto del libro como del lenguaje de programación. Hammurabi influyó en muchos juegos de estrategia y simulación posteriores y también es un antecedente del género de construcción de ciudades.

${ }^{1}$. Sumer, de Sumerian, del pueblo Sumerio. 
可
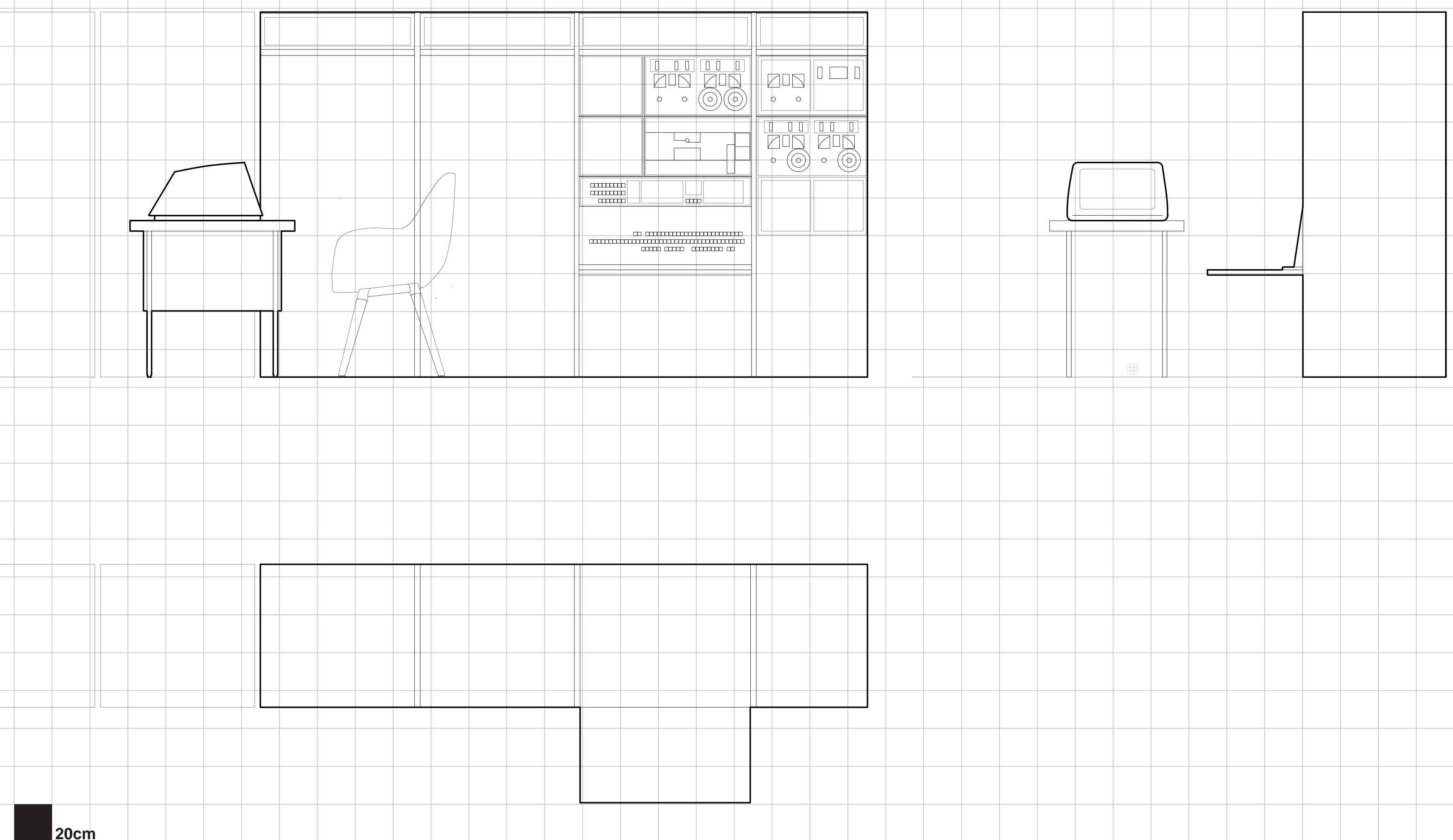


\section{PDP-10.}

1969

\section{Digital Equipment Corporation. Ordenador único.}

El décimo miniordenador de Digital Equipment Corporation de la serie PDP, lanzado en 1967. Este ordenador tuvo gran éxito en la década de los setenta y fue adquirido por multitud de universidades y centros de investigación de Estados Unidos (Ceruzzi, 2003)

Este ordenador compartía la arquitectura con su predecesor PDP-6 y tenía la misma longitud de palabra de 36 bits. Su primer sistema operativo Monitor, fue posteriormente conocido como TOPS10.

Este ordenador fue la base de ARPANET (red de computadoras que se usaban como medio de comunicación para el Departamento de Defensa de Estados Unidos, una especie de Internet primitivo).

El sistema TOPS-10 acepta aplicaciones de tiempo compartido interactivas, procesamiento por lotes y procesamiento de aplicaciones en tiempo real, todo ello de manera simultánea. Su cancelación fue anunciada en 1983, ante el eclipse de las nuevas máquinas supermini de VAX.

Durante los setenta, William Crowther, que había estudiado Física en MIT, tuvo acceso a uno de estos ordenadores y programó un juego de exploración de cuevas, Adventure (como resultado de su afición por la escalada) para que sus hijas pudieran entretenerse cuando pasaran tiempo con él (Donovan, 2010/2018).

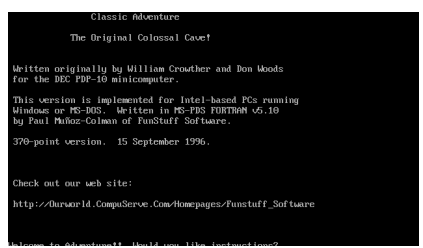

Colossal Cave Adventure. 1976

Videojuego textual desarrollado por Willie Crowther y Don Woods en lenguaje de programación Fortran en 1976. La trama del juego lleva al protagonista a recorrer y explorar una cueva (basada en Mammoth Cave, Kentucky, USA) en la que aparecen algunos elementos de fantasía tales como elfos $y$ troles. El juego funciona a través de un sistema de preguntas y respuestas que permiten avanzar. Se trata de la primera occasión en que "the creation of a virtual world and what it meant to explore it”. (Barton, 2008).

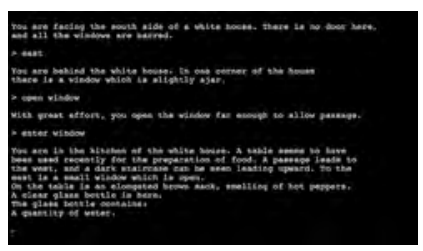

Zork.

1977-1979

Videojuego textual que suponía una versión nueva de Colosal Cave Adventure usando comandos de texto y mecanismo de exploración similares. Sin embargo Zork era mucho más avanzado técnicamente, permitiendo comandos más largos y más específicos. También usaba un mapa completamente nuevo que fue diseñado en múltiples áreas con sus propias historias y rompecabezas independientes, mientras que Cave es puramente exploratorio. 
$a^{-1}$
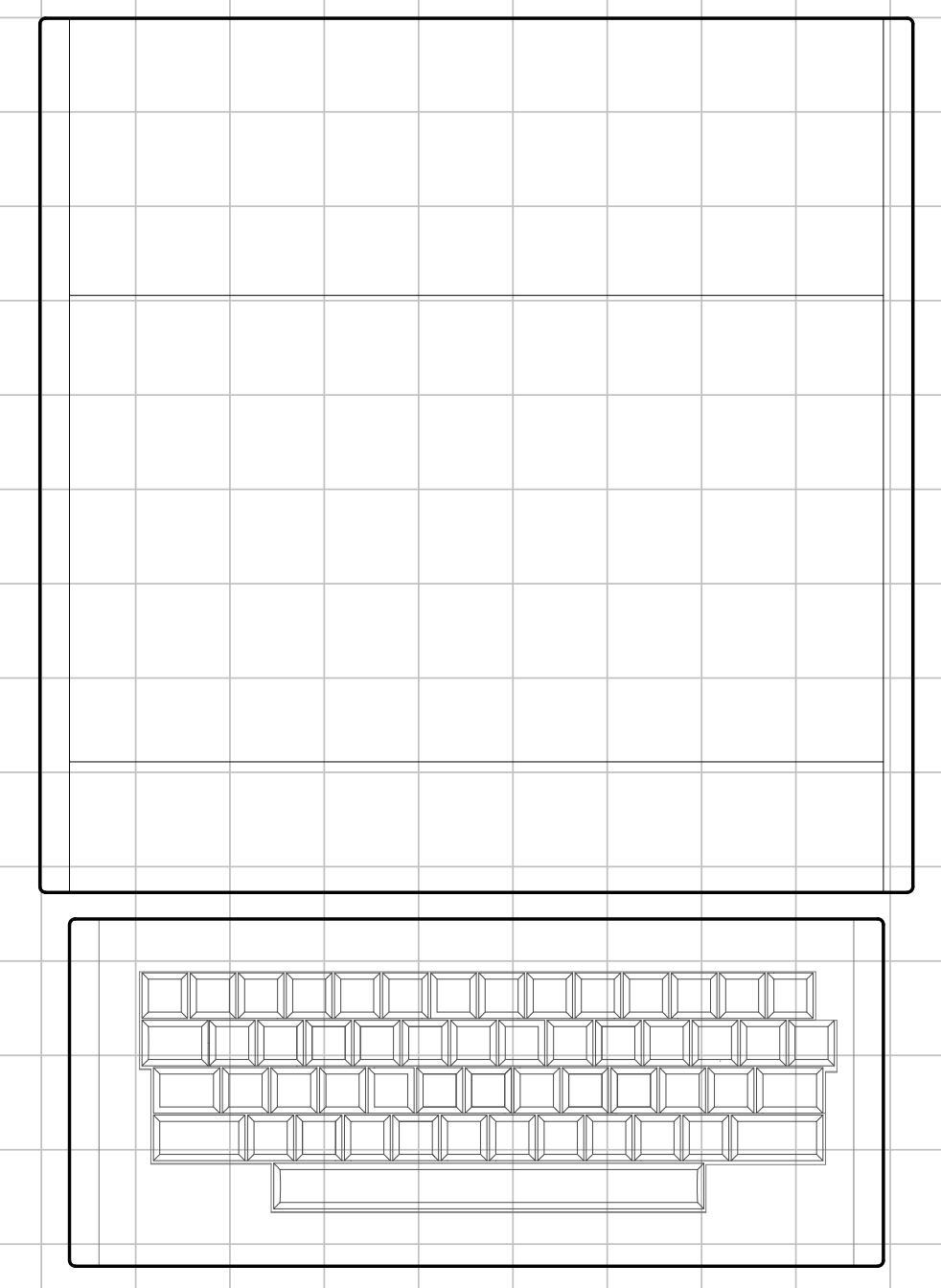

五
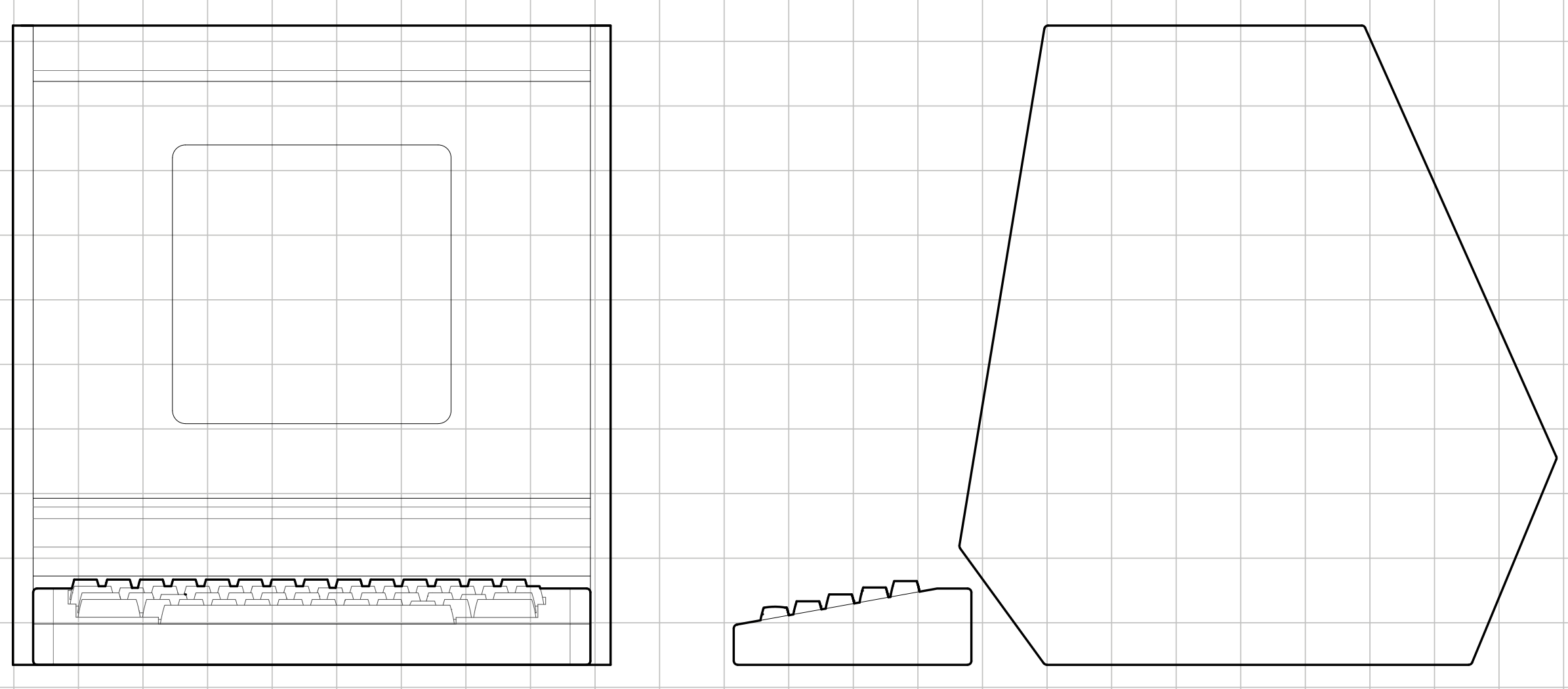

$5 \mathrm{~cm}$

\begin{tabular}{|l|l|l|l|l|l|l|l|l|l|l|l|l|}
\hline & & & & & \\
\hline
\end{tabular} 


\section{PLATO system.}

\section{0s}

University of Illinois.

Sistema asistido para ordenador.

Se trataba de "una red informática diseñada para servir a los terminales de los colegios" (Donovan, 2010/2018) y fue uno de los primeros sistemas asistidos por ordenador que fue desarrollado en 1959 como parte de una investigación del Departamento de Física de la Universidad de Illinois. Las siglas de PLATO responden a Programmed Logic For Automated Teaching Operations (Lógica Programada para Operaciones Docentes Automatizadas).

“En 1967, Paul Tenczar (1945-) desarrolló un lenguaje poderoso para el sistema PLATO que cualquiera podía usar y que las personas que no eran informáticas podían aprender; llamó al idioma TUTOR. TUTOR proporcionó el lenguaje de programación necesario para crear programas altamente interactivos $y$ orientados gráficamente"

(Peddie, pg 93, 2013)
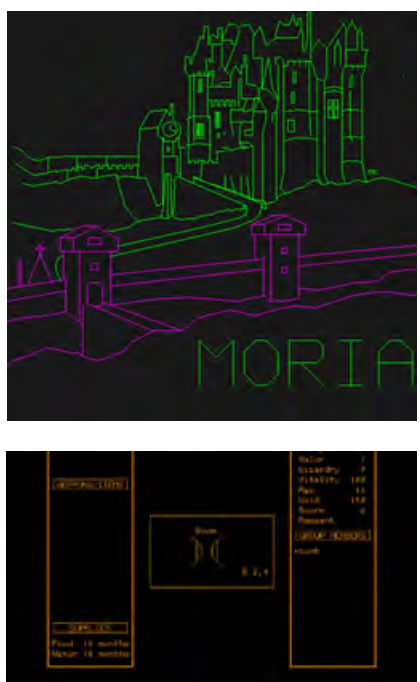

Moria.

1975

Videojuego en primera persona en perspectiva cónica centrada con gráficos de estructura alámbrica. Permitía la unión de hasta 10 jugadores que podían enviarse mensajes entre ellos. El videojuego se basaba en un mundo similar al de El Señor de los Anillos, a través de mazmorras dinámicas.

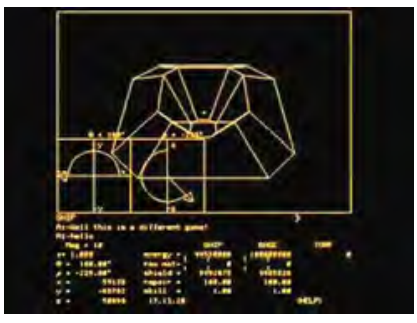

Spasim.

1974

Videojuego considerado como el primero en 3D de disparos en primera persona multijugador en red.

Este lenguaje permitió que durante los años setenta diferentes personas que tuvieron acceso a este sistema desarrollaran juegos para el mismo, aprovechando sus capacidades gráficas. Todos ellos fueron desarrollados en 2D.

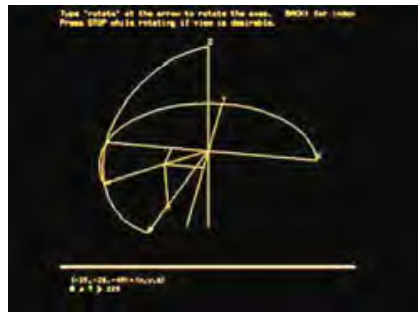




\section{Imlac PDS-1}

1970

IMLAC Corporation.
Ordenador único.

Se trata de un miniordenador diseñado por la IMLAC Corporation, una pequeña empresa de Massachusetts. Debutó en 1970 a un precio de 8.300 dólares, lo que le convirtió en la primera comercialización de un ordenador de bajo coste (Ceruzzi, 2003).

Disponía de una pantalla vectorial monocromática de catorce pulgadas (un monitor CRT de rayos catódicos) que se actualizaba desde la memoria local. Además, incluía un teclado, un lápiz óptico (light pen) y un panel de control en un escritorio. Este ordenador tuvo varios modelos, entre ellos: PDS-1D, PDS-1G y, su sucesor, el PDS-4.

"La capacidad de actualización del CRT permite una visualización que siempre permanece en la pantalla, pero que se modifica dinámicamente cuando se agregan o eliminan atributos del mapa de discurso (en inglés discourse map)".

(Kemerer, 1974)

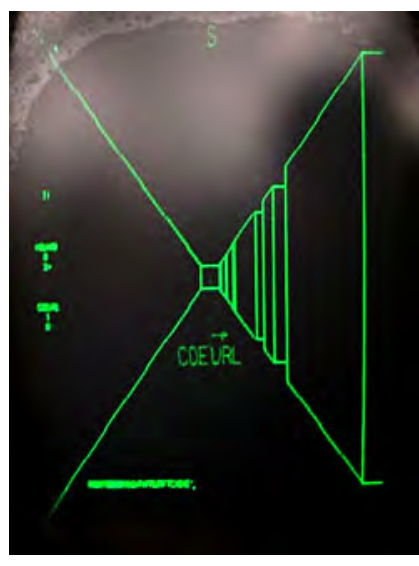

Maze War.

1974

Videojuego de disparos en primera persona a través de un laberinto. Reconocido como el primero en su género. Innovador en el uso de perspectiva cónica en 2D para mostrar la idea de profundidad 3D.

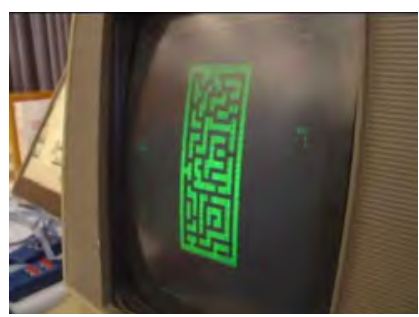

Para este equipo se desarrollaron diferentes sistemas de visualización gráfica populares en la década de los años setenta, que fueron aprovechados para impulsar el desarrollo de diferentes juegos. 

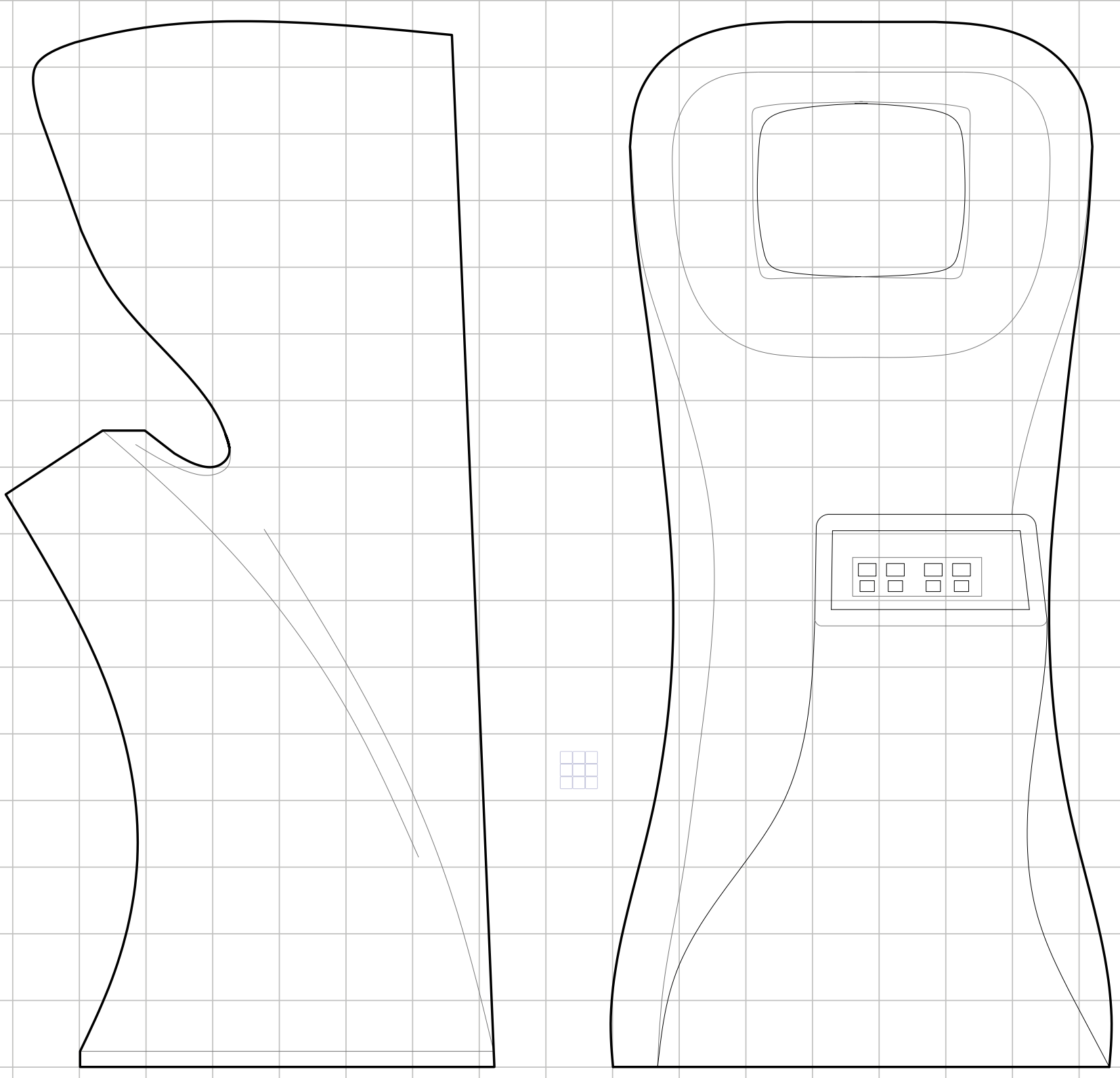


\section{Computer Space.}

\section{1}

\section{Nutting Associates. Máquina arcade}

Primera máquina de arcade de la historia, diseñada en 1971 por Nutting Associates. Esta máquina de arcade disponía de una carcasa futurista de fibra de video que le otorgaba un aspecto innovador, a pesar de su rudimentario sistema. Este arcade contaba con una pantalla monocromática horizontal de 9 pulgadas y estaba basada en tres placas conectadas que permitían encender el juego (Donovan, 2010).

Computer Space contó con dos cabinas, ligeramente diferenrtes, para el juego de un solo jugador y para el juego de dos jugadores. Esta máquina es considerada, además, el germen de Atari.

“Después de crear un prototipo funcional del juego, Bushnell se puso a buscar un socio que pudiera fabricarlo. Encontró a Bill Nutting, fundador de Nutting Associates [...] Contrató a Bushnell y adquirió la licencia de su juego [...] Después del fracaso de Computer Space, Bushnell decidió crear su propia empresa, Atari"

(Kent, pg 32-33, 2001)

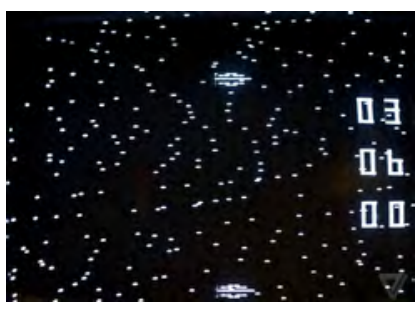

Computer Space.

1971

Videojuego de temática espacial considerado el primer videojuego vendido comercial que funcionara a monedas. Su diseño exterior - en fibra de vidrio - era muy distinto a lo existente y estaba pensado para llamar la atención de los jugadores. 
1믈

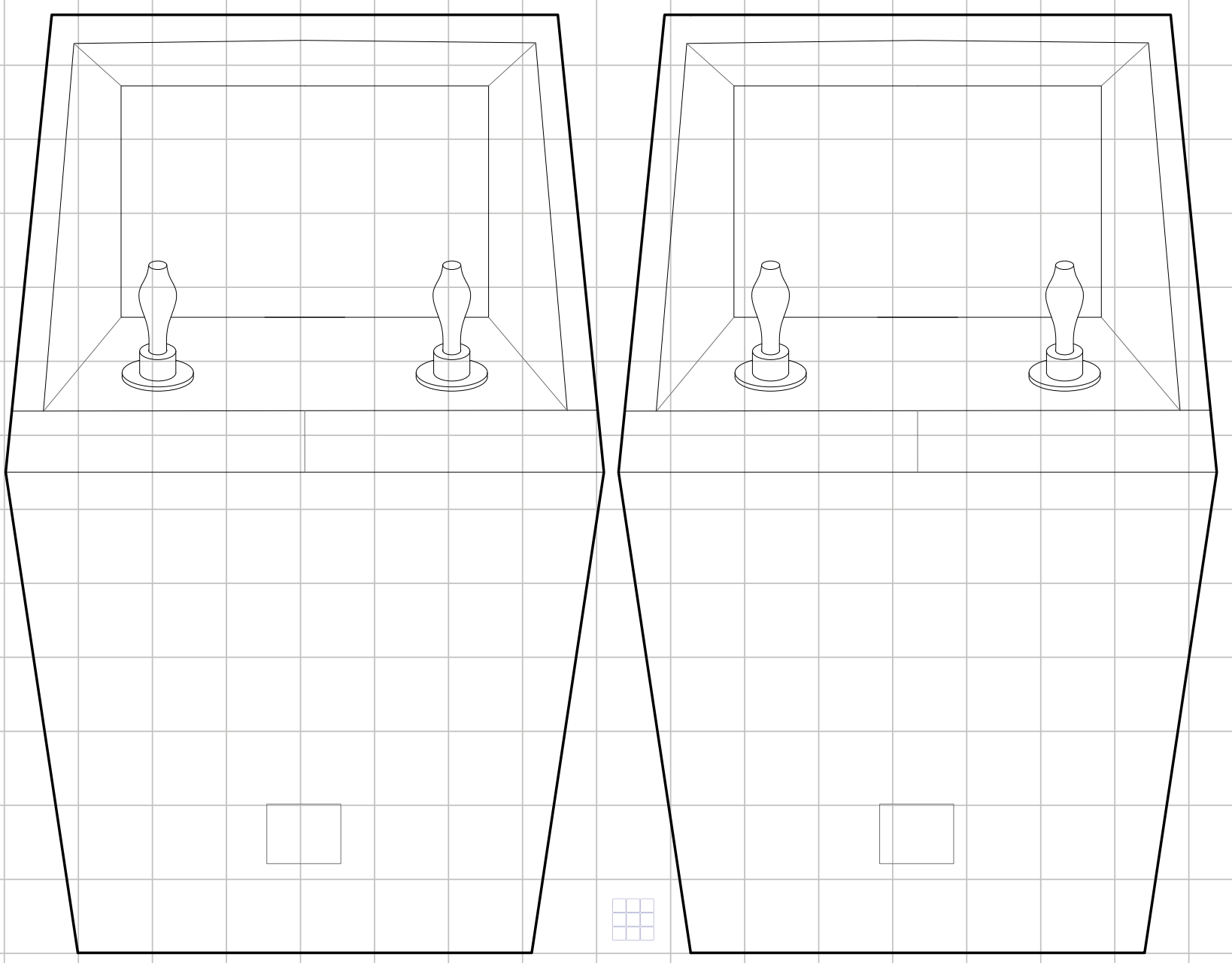


Galaxy game.

1971

Videojuego de temática espacial basado en Spacewar! y considerado la primera maquina a monedas. La única unidad del juego instalada en la Universidad 1971 de Stanford generaba colas

Bill Pitts \& Hugh Tuck. Máquina arcade

Máquina de arcade considerada como la primera máquina de videojuegos que funcionaba con monedas (diez centavos una oportunidad o veinticinco centavos tres oportunidades). El primer y único prototipo fue construido por Bill Pitts y Hugh Tuck en la Unión de Estudiantes de la Universidad de Standford ${ }^{2}$.

Esta máquina que era versión del juego de ordenador Space War!, disponía en su interior de un PDP-11/20 lo que dificultó su réplica a gran escala debido al gran tamaño.

"La generosa propuesta sobre el precio hizo que Galaxy Game no ganara, en absoluto, lo suficiente para defender su coste, pero la popularidad del juego animó a Pitts y Tuck a continuar [...] con la segunda versión"

(Donovan, 38, 2010).

Esta máquina fue retirada en 1979 a causa de las pantallas dañadas.

${ }^{2}$ Actualmente la única copia se encuentra en Computer History Museum (CHM) quienes han facilitado la información completa. Ver en Bibliografía: Fuentes de datos. 


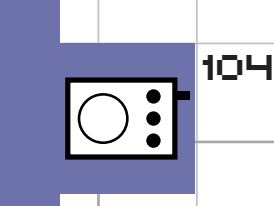

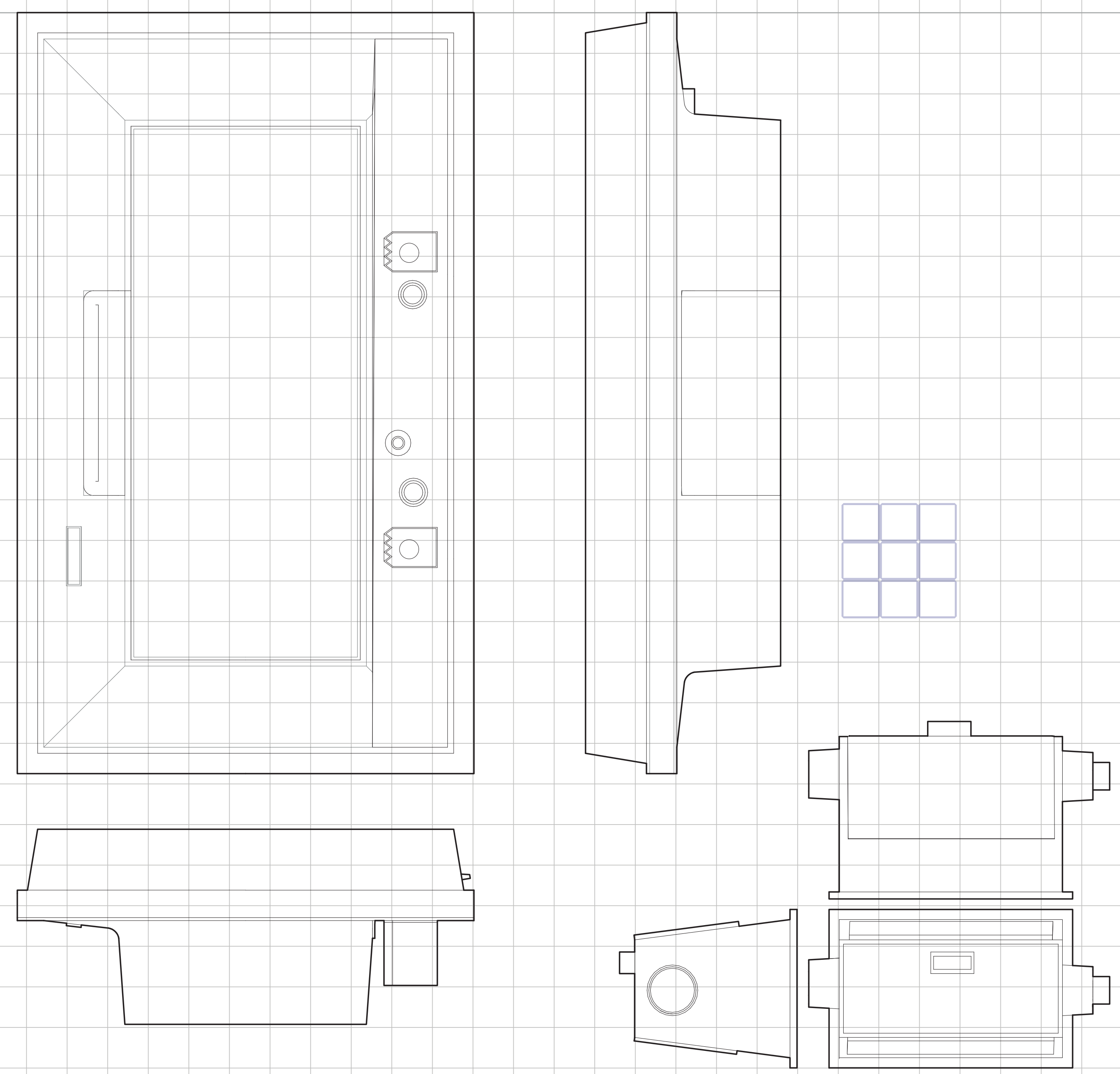




\section{Magnavox Odissey.}

1972

Magnavox

Videoconsola doméstica.

Estaba sentado en una estación de autobuses del East Side durante un viaje de negocios a Nueva York y pensaba en qué cosas se podrían hacer con una tele además de sintonizar canales que no te interesaban. Y fue entonces cuando se me ocurrió la idea de crear juegos [...] Fue en agosto, en 1966

(Baer, 2005)

La Magnavox Odissey - cuyo prototipo inicial recibió el nombre de Brown Box - salió en EEUU en 1972 y vendió aproximadamente 350.000 copias hasta su descontinuación en 1975 (Donovan, 2010/2018).

Seis años antes el ingeniero Ralph Baer que era entonces jefe del equipo de diseño de una proveedora militar, Sander Associates, había tenido la idea de usar el televisor para 'jugar a juegos'3 y había construido un equipo de desarrolio dentro de la empresa apoyado por el director de + D. Hacla 1969 el proyecto fue ofrecido a los fabricantes de televisores mayoritarios que lo rechazaron, hasta que en 1971 Magnavox accedio a firmar un contrato para distribuir el producto. La consola no resultó e exito que podria preverse por la desastrosa campaña de marketing (solo podia comprarse en los concesionarios Magnavox), pero es considerada la primera videoconsola doméstica de la historia y Baer el padre de los videojuegos ${ }^{4}$ (Kent, 2001)

La consola original construida por Baer era marrón y su carcasa fue com-

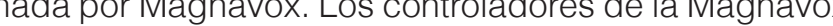
Odissey (con un boton de RESET y dos botones de tipo sintonizador, uno para la dirección vertical y otro para la horizontal) contaban con un alcance muy limitado que obligaba a los jugadores a permanecer muy cerca de la pantalla. La consola se vendia con algunos accesorios como el rifle que serva de base a la Shooting Gallery - juego que daba la oportunidad de interactuar de forma directa entre el espacio domestico y el interior de la pantalla por primera vez - asi como transparencias de plastico que permitían colorear los juegos, y otros accesorios como cartas y fichas que trataron de mostrar la Odissey más como un juguete que como un dispositivo (Kent, 2001)

Magnavox Odissey era una máquina construida sobre 40 diodos y 40 transmisores capaz de generar señales sobre un televisor, pero incapaz de, por ejemplo, recontar las puntuaciones (lo que obligaba a los jugadores a apuntarlas a mano)

${ }^{3}$ Ralf Baer publicó sus memorias en el libro 'Videogames: the beginning' (2005) Fuente análisis gráfico: of American History

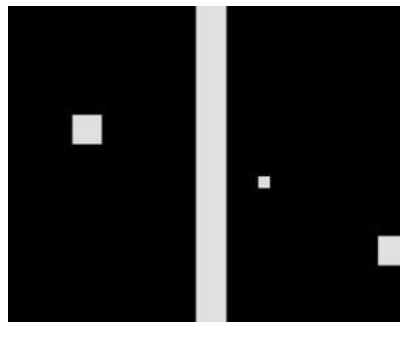

Videojuego de temática

deportiva basado en el tenis de mesa. Su estructura se componía de dos elementos muy simples: las palas (o pala si era individual) y la

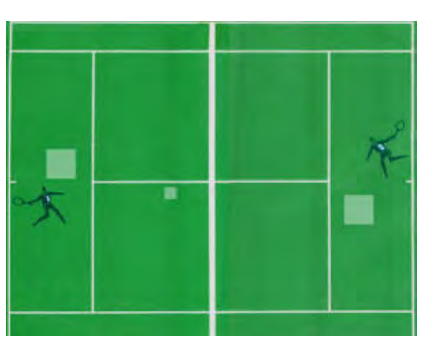
pelota. Se considera el primer videojuego doméstico.

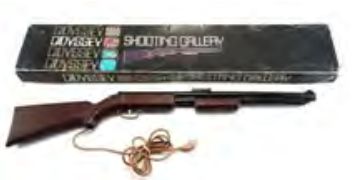

ACCESORIO

Laser Gun

Rifle de juguete fabricado en plástico que empleaba la tecnología de luz para permitir al jugador disparar sobre la pantalla, fue el prime tipo de acciones en un espacio doméstico. Se incluyó en el pack de lanzamiento de la consola.

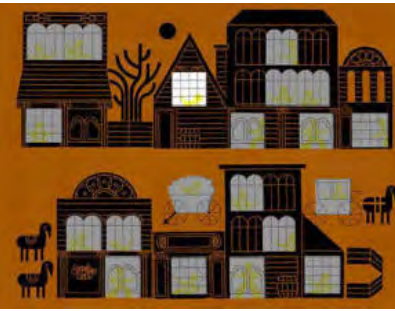

Shooting Gallery.

Videojuego de disparos que empleaba por primera vez un dispositivo exterior: un rifle de luz de juguete que disparaba sobre la pantalla.

\section{ACCESORIO}

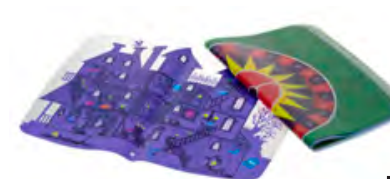
Láminas de plástico coloreadas con diferentes motivos que ponían en contexto y definian el escenario del juego ante la limitada capacidad de la consola. Se trataba de una estrategia empleada habitualmente en máquinas arcade. Se incluyó en el pack

$\square$ de lanzamiento de la consola.

\section{Cat and Mouse.}

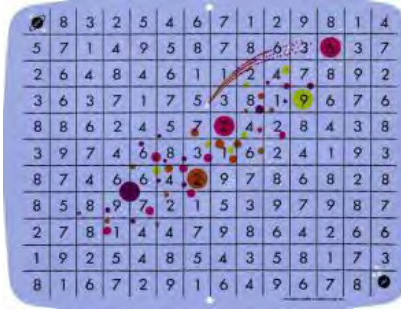
de Table tennis conseguidas con la superposición de transparencias sobre la pantalla.
ACCESORIO

Board game accesories.

Cartas, fichas y dados de dierentes juegos que se vendieron junto al pack original de Magnavox con el fin de dar una imagen similar a los juegos de mesa. 

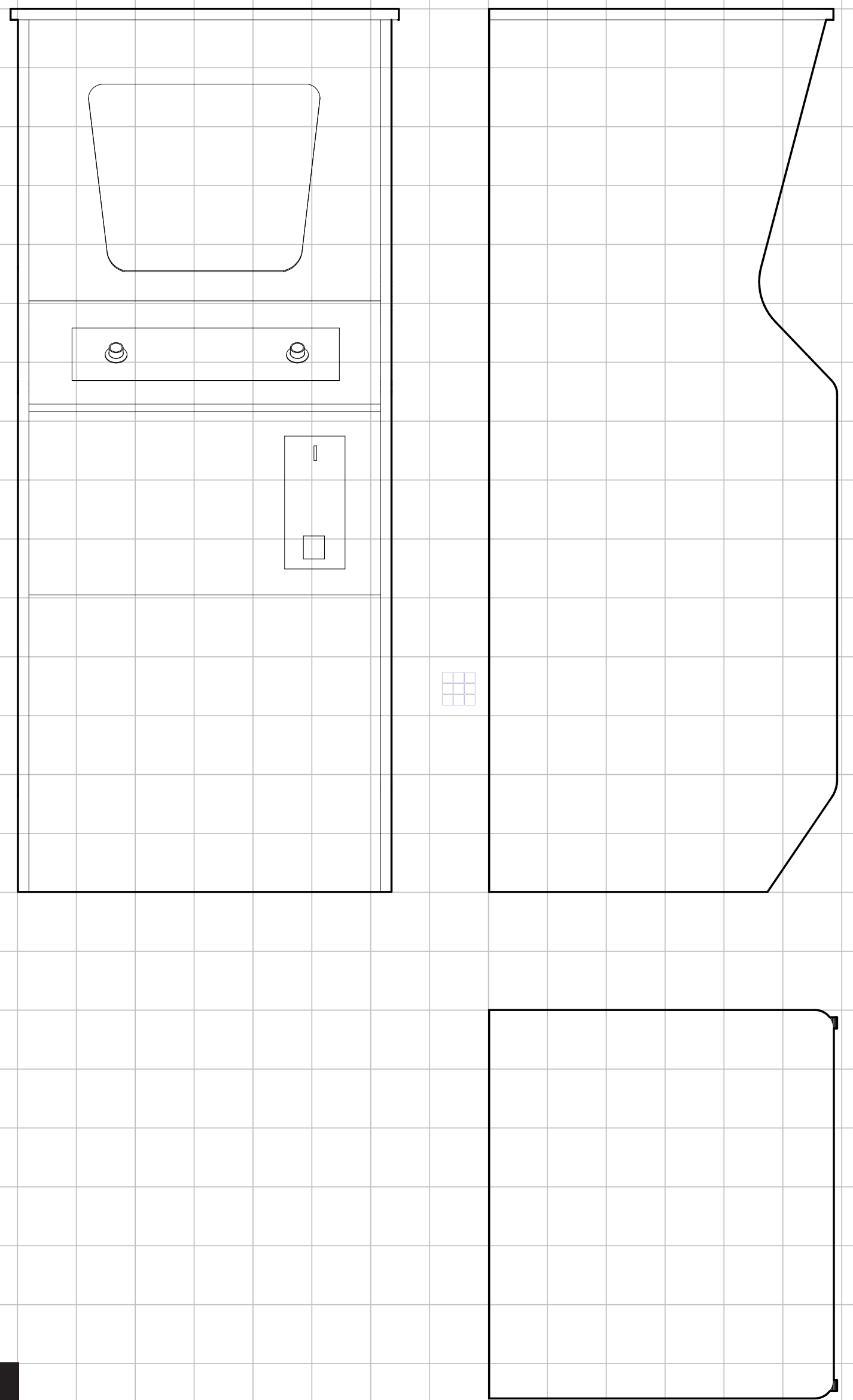
Atari Arcade.

Máquina arcade.

"Me dijo: Al, me ha pasado una cosa muy rara. Al abrir el bar esta mañana había dos o tres personas haciendo cola. Han entrado y se han puesto a jugar con la máquina esa sin consumir nada. Nunca había visto algo así.

(Alcorn, en Kent, pg 44, 2001)

Máquina de arcade diseñada y construida por Bushnell y Alcorn (Atari) lanzada en 1972. La cabina medía algo más de metro y medio y estaba construida en madera con el frontal en color amarillo (únicamente alrededor del monitor de juego). La pantalla CRT de visualización era monocromática en blanco y negro y permitía jugar a dos jugadores gracias a los dos botones de tipo sintonizador. Esta máquina fue todo un éxito, tanto en Estados Unidos como en el resto del mundo (Japón, Italia o Francia):

"Pong había arrasado a nivel nacional, dando a conocer el concepto de videojuego. Otros fabricantes de máquinas de entretenimiento rápidamente se pusieron a producir sus propias versiones del juego con la esperanza de sacar tajada de la nueva moda".

(Donovan, pg 44, 2010) 

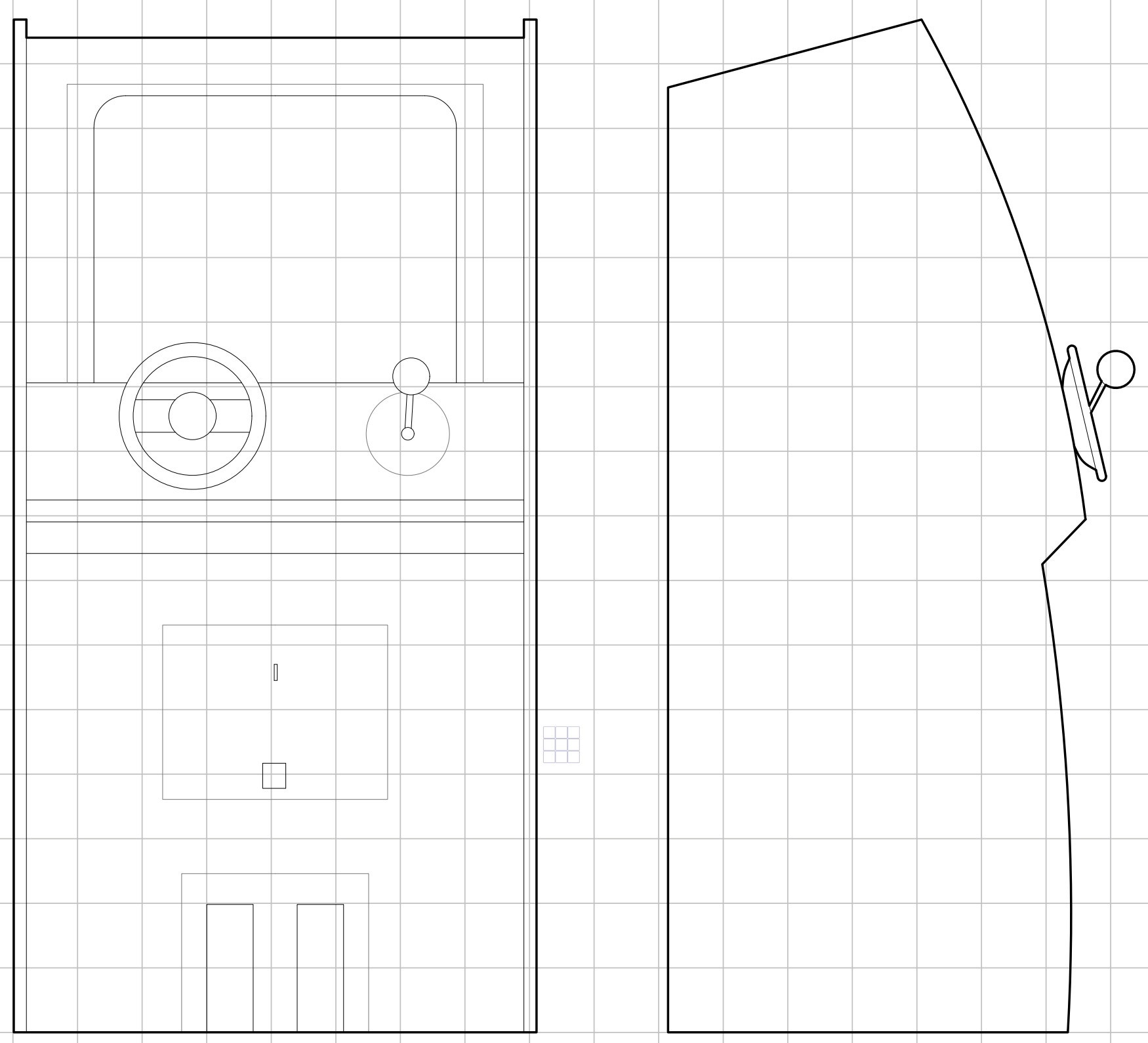


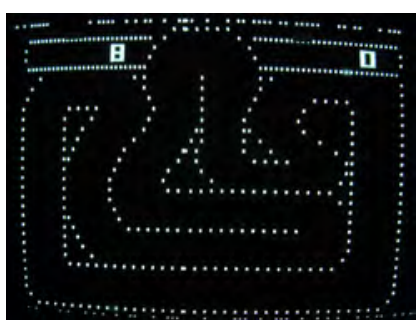

1974

Atari arcade.

Máquina arcade.

"En una reunión de distribuidores, Nolan, otras personas y yo, estábamos sentadas alrededor de una mesa. Después de comer, y romper un poco el hielo, Nolan soltó una pregunta-afirmación inolvidable:

-Me gustaría saber qué más podemos hacer con los videojuegos, aparte de jugar al tenis o al hockey.

Él mismo respondió a la pregunta lanzando juegos de conducción como Gran Track 10, es un visionario."

(Adlum, en Kent, pg 62, 2001)
Gran Track 10.

1974

Videojuego arcade de carreras pionero en su género. El jugador corre contrarreloj en una pista vista en perspectiva aérea y acumulando puntos. Fue el primer juego en el que se emplearon formas definidas como personajes y no simples rectángulos.

Máquina de arcade desarrollada por Atari en 1974 que fue el primer videojuego de carreras. La cabina disponía de un monitor monocromático en blanco y negro y poseía un volante, una palanca de cambios, un pedal de freno y un acelerador, para que los jugadores pudieran controlar el coche de la pantalla.

Este videojuego fue el primero de muchos de los experimentos de Atari y se convirtió en un éxito de ventas de la compañía en el año de lanzamiento.

Este arcade contó con una versión de cabina para dos jugadores, Gran Trak 20, lanzada el mismo año y con las mismas características que Gran Trak 10. Disponía de dos volantes, dos palancas de cambio y cuatro pedales (dos aceleradores y dos frenos). 

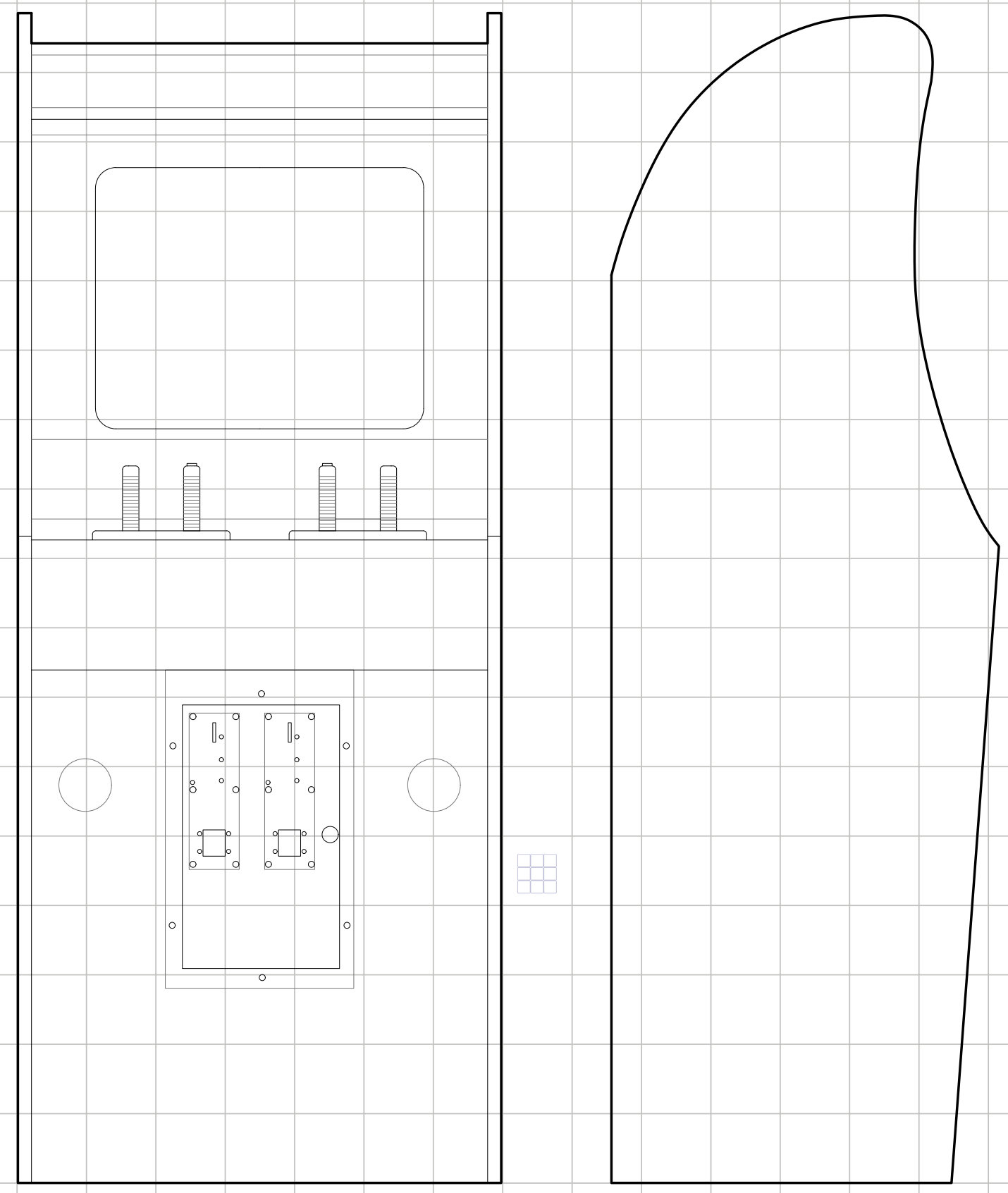


\section{Tank.}

1974

Kee Games.

Máquina arcade.

Máquina de arcade desarrollada en 1974 por Steve Bristow, de Kee Games. Contaba con un monitor en blanco y negro de tipo ráster de resolución estándar, según Atari 456×336 píxeles, es decir, ofrecía unos gráficos muy primitivos. Gracias a los avances tecnológicos, Tank almacenaba ya gráficos en chip de memoria RAM.

Esta máquina fue un juego de carreras (primer juego de duelo uno contra uno) y la cabina contaba en su frontal con cuatro joysticks, dos para cada uno de los jugadores que se enfrentaban en la batalla de tanques, sorteando un laberinto infestado por minas. Tras su lanzamiento, Tank se convirtió en el juego más famoso desde Pong, con más de quince mil ventas.

"La idea surgió porque Bristow quería actualizar el primer videojuego de Bushnell y Dabney, Computer Space. [...] De joven, mi tío me había mandado limpiar su huerto con un tractor-oruga que se conducía de forma parecida a un tanque. Pensé que aquello podía llegar a ser un Computer Space bien hecho."

(Bristow, en Donovan, pg 52, 2010)

Su éxito fue tal que este arcade dejó un legado de varios modelos, entre ellos: Tank II, Tank III, Tank 8 y Ultra Tank.

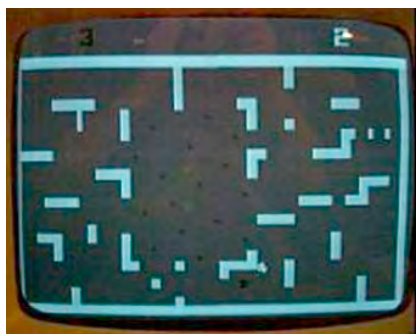

Tank.

1974.

Videojuego arcade de guerra pionero en su genero. En él, el jugador debe controlar un tanque a través de un laberinto disparando al enemigo. 

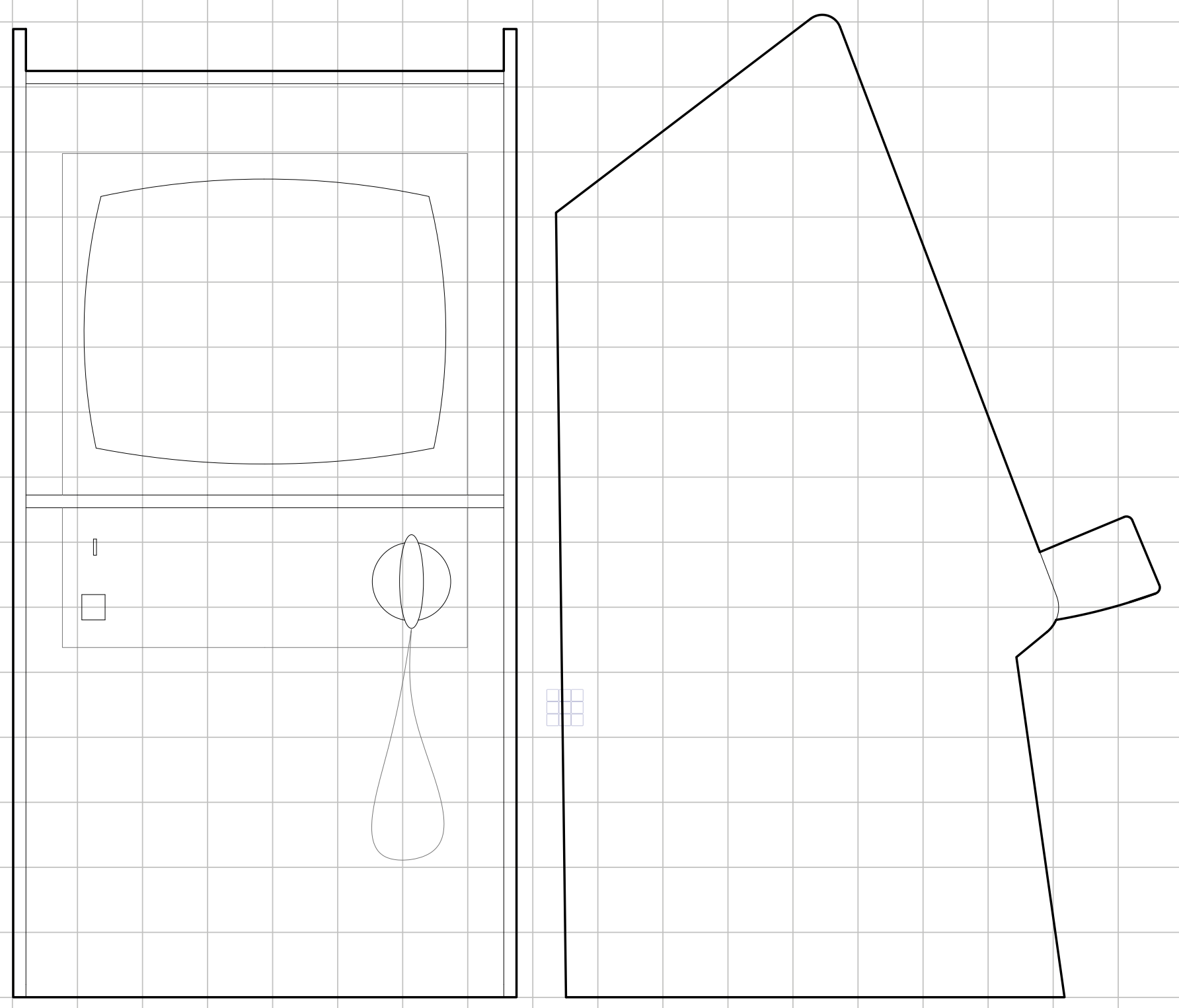


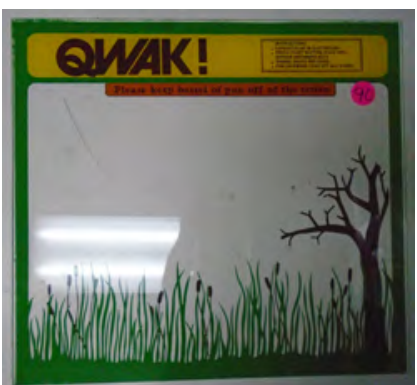

Qwak!.

1974

Videojuego arcade de disparos en el que se permite a

1974

los jugadores disparar patos que salen volando usando

Atari arcade.

Máquina arcade.

rifles laser desde fuera de la pantalla.

Máquina de arcade fabricada por Atari en 1974 con un videojuego de disparos en el que el jugador era un cazador que disparaba a un pato. Para ello la cabina de tipo vertical contaba con una pistola de luz en forma de rifle que permitía disparar los patos virtuales de la pantalla.

La máquina contaba un monitor en blanco y negro de tipo ráster de resolución estándar (al igual que Tank). ¡Sin embargo, Qwak! no funcionó bien comercialmente y tan solo vendió unas 250 unidades. 


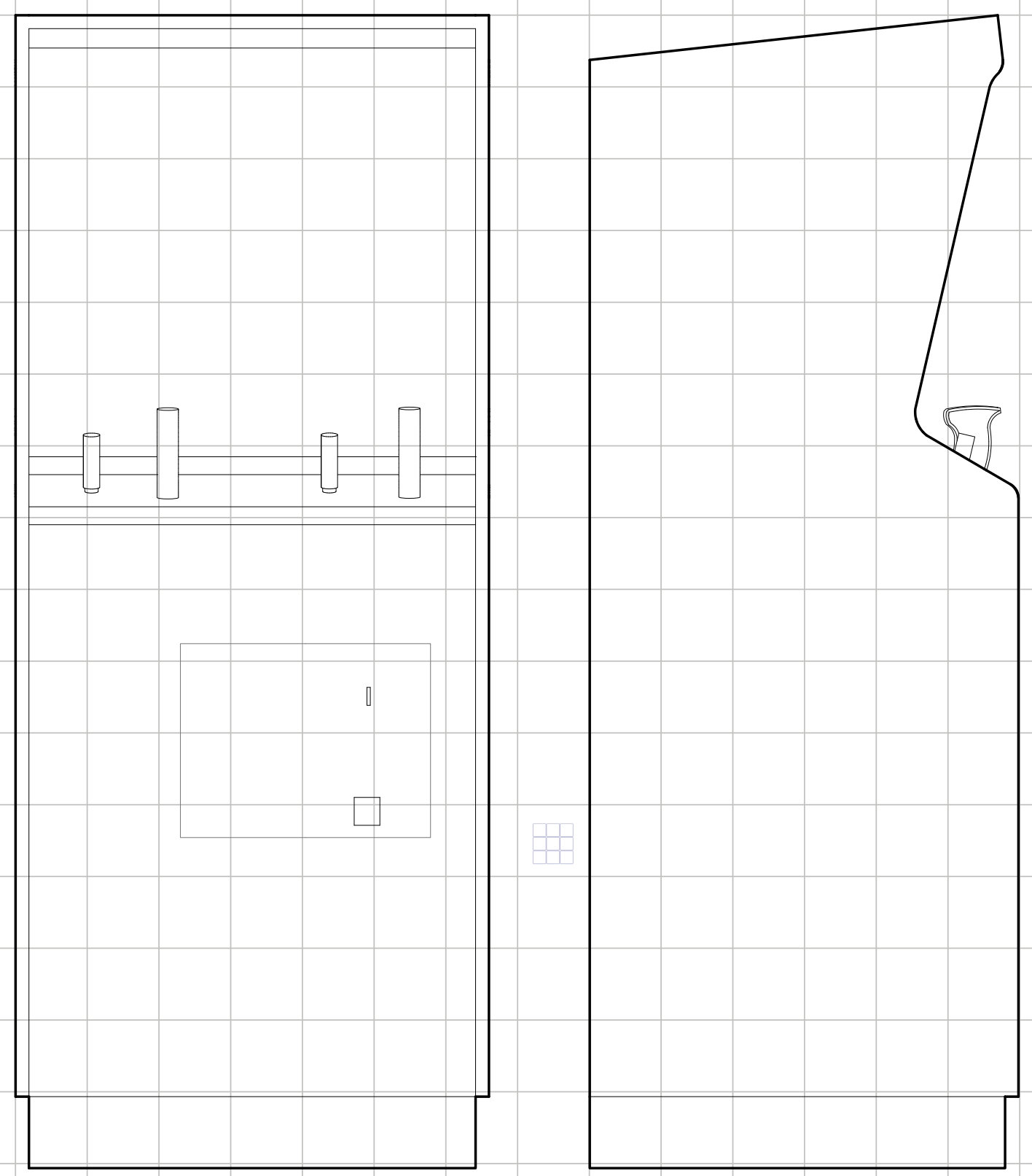




\section{Gun \\ Fight.}

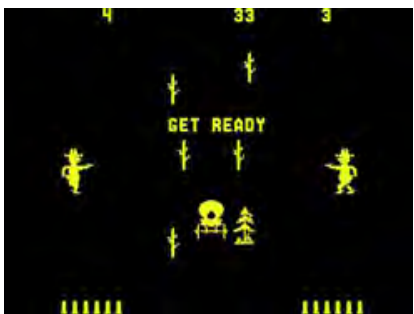

Gun Fight.

1975

Videojuego de disparos versión del previo western gun. Considerado el primer videojuego arcade desarrollado en base a microprocesadores.

\section{5}

Taito JP\& EU, Midway USA.

Máquina arcade.

"La jugabilidad en Gun Fight no era muy buena, y mi versión de Western Gun tuvo mejor acogida en Japón. Pero me impresionó mucho el uso de la tecnología de microprocesadores y estaba deseando aprender a trabajar con ella. Me puse a analizar el juego cuanto antes."

(Nutting, en Donovan, pg 60, 2010).

Máquina de arcade de 1975 de Midway Manufacturing $\mathrm{CO}$ (que había rechazado anteriormente hacer Pong). Este juego no fue una idea original, "lo había desarrollado una empresa japonesa y luego Midway lo había licenciado al mercado estadounidense" (Kent, 63).

Se trataba de un juego de disparos de vaqueros para dos jugadores, cuya cabina vertical contaba con dos controles distintos para cada jugador (dos joysticks), uno para cambiar la dirección del vaquero disparador y otro para cambiar la dirección del disparo.

En su adaptación al mercado de Estados Unidos, Midway (de la mano de David Nutting) incorporó un microprocesador, lo que convirtió a Gun Fight en la primera máquina de arcade que utilizó microprocesadores. Esto permitió mejorar los gráficos y la animación del juego.

La cabina disponía de un monitor ráster CRT monocromático en blanco y negro. Sin embargo, la pantalla contaba con una capa amarilla para dar sensación de (falso) color al juego. 


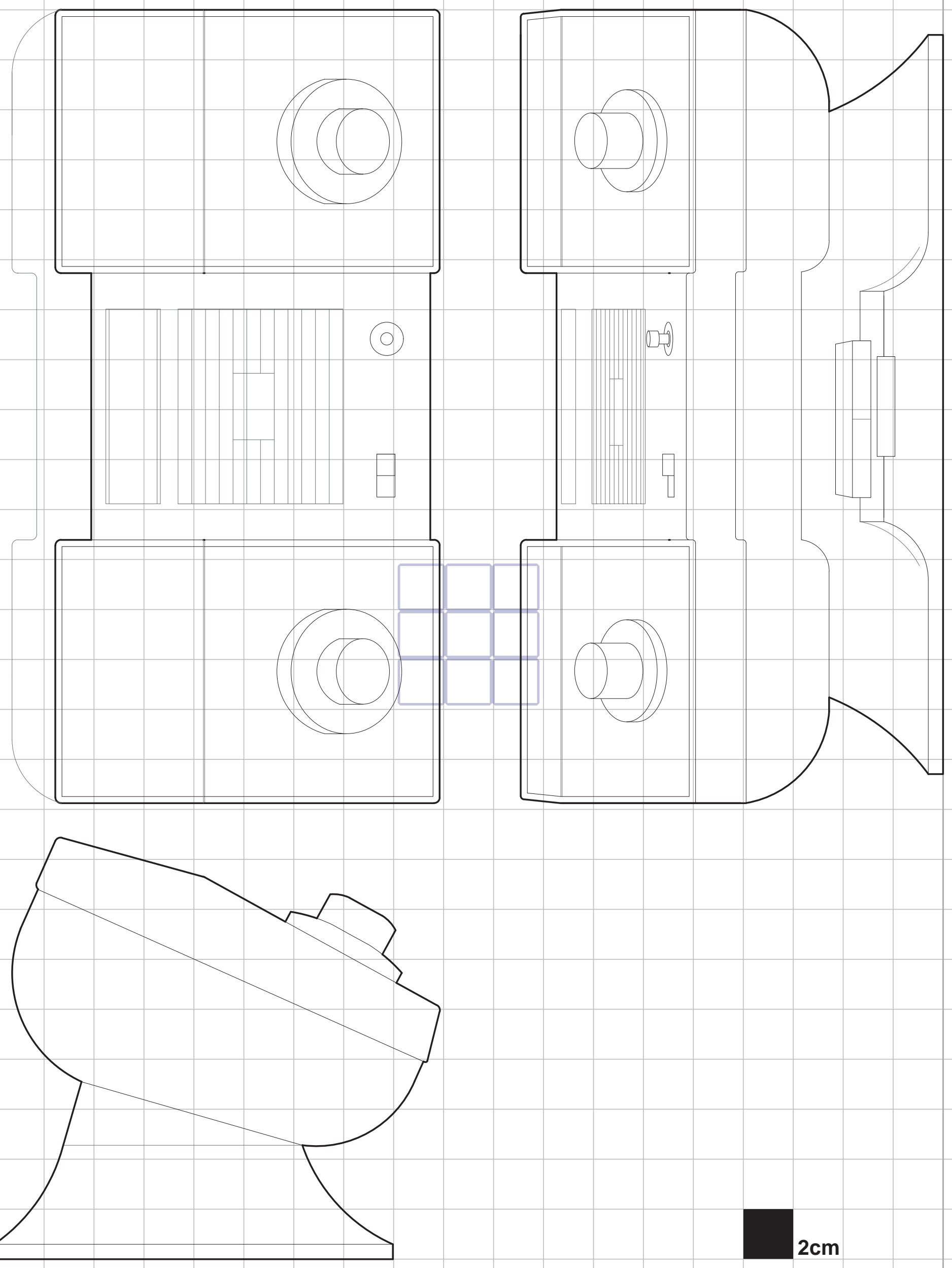




\section{Pong- Telegames.}

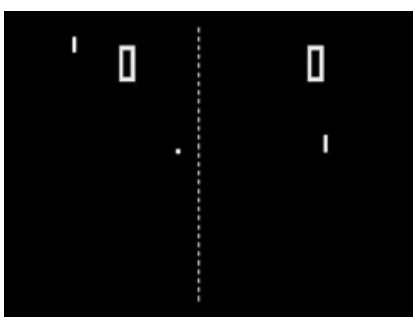

Pong.

1975

Videojuegos deportivos basados en Pong con ligeras variaciones.

\section{5}

\section{Atari/Sears.}

Videoconsola doméstica.

'[...] A aquel tipo [Tom Quinn] le había ido muy bien el año anterior vendiendo mesas de ping-pong. En invierno Sporting Goods se dedicaba a vender equipos de hockey y algunos balones de baloncesto y ya está. Para mejorar el negocio en Navidad, el encargado de compras de Sears se estaba centrando en las mesas de ping-pong y de billar, y pensó que la versión doméstica de Pong podría ser un buen entretenimiento familiar'

(Bushnell, en Kent, 2001)

Consola creada por Atari en 1975 que se trataba de una máquina muy simple construida sobre un chip 6502 (similar al 6507 de Atari), pero que estaba dotada de más memoria y de un segundo procesador que mostraba más colores y gozaba de gráficos más detallados y mejores que cualquier otro sistema anterior ${ }^{5}$

La primera versión de Pong Telegames no tenía controladores separados de la consola, si no que ésta disponía de dos botones tipo sintonizador sobre la misma uno a cada lado que hacían la función de controladores. A partir de Pong Telegames IV se añadieron controladores por cable independientes, hasta un total de cuatro.

\footnotetext{
${ }^{5}$ Kent, Steven. 2001 / Donovan, T. 2008
}

Fuente análisis gráfico:

Elaboración propia a partir de los datos contenidos en los documentos originales archivados en digitalgamemuseum.org. 


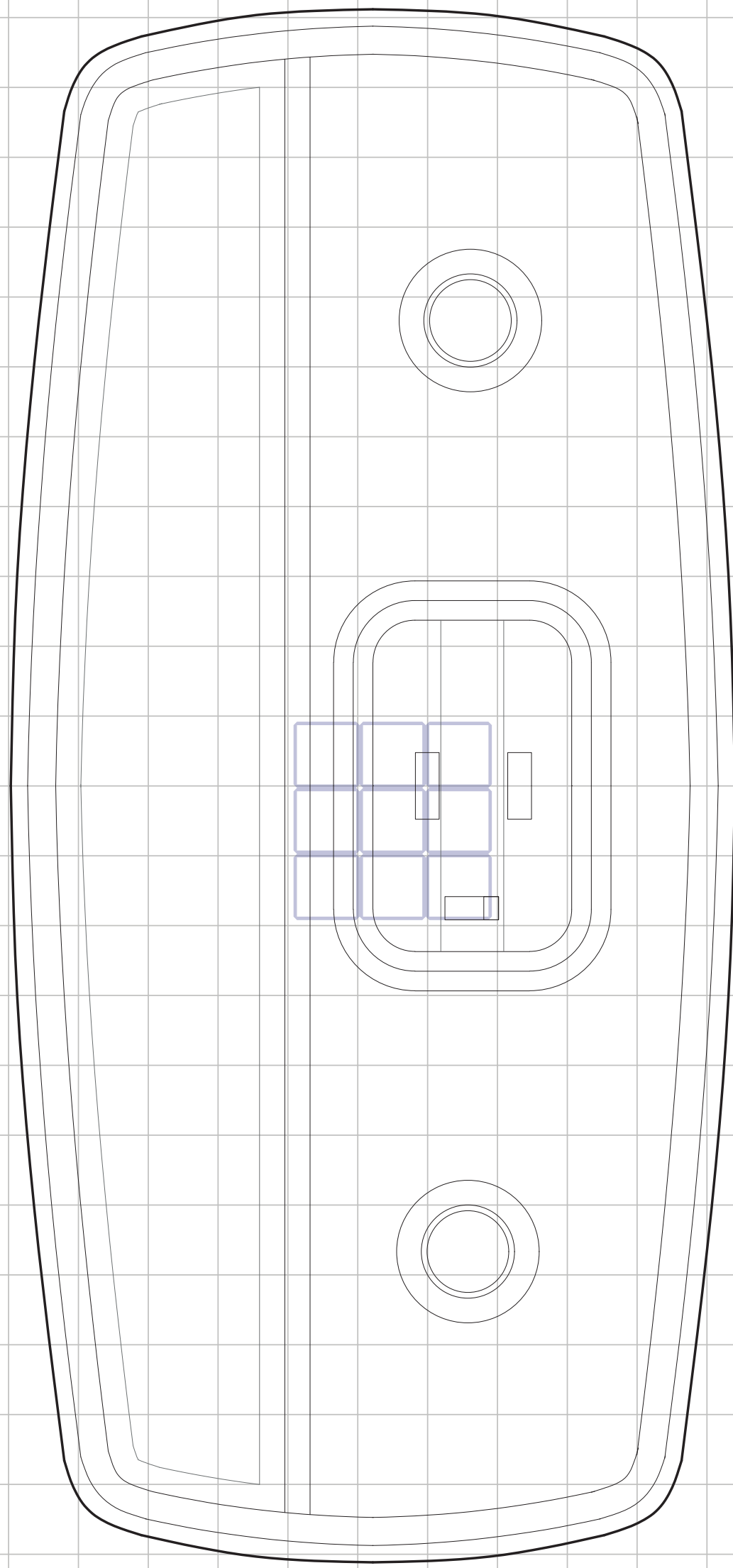




\section{Coleco Telestar.}

\section{6}

\section{Coleco.}

Videoconsola doméstica.

Se trata de una serie de consolas de videojuegos domésticos, incluidos en la primera generación de consolas, que fueron producidos y comercializados por la empresa Coleco de 1976 a 1978. El primer modelo fue un clon de Pong y, esta serie, utilizaba un chip AY-3-8500 para su visualización en una televisión y sus "juegos se almacenaban en cartuchos triangulares que se conectaban por la parte de atrás" (Kent, pg 195, 2001).

Coleco lanzó catorce modelos diferentes que incluían juegos de disparos, de hockey, de tenis, de combate, pinball e, incluso de carreras. Entre los modelos más representativos destacan Coleco Telstar Combat! (1977) y Coleco Telstar Arcade (1977). El primero estaba basado en el arcade Tank y contaba con cuatro joysticks. Por su parte, Coleco Arcade tenía una extraña forma triangular y "contaba con un volante para los juegos de carreras, una pistola para los de disparos y diales para los juegos tipo Pong, dispuestos en los paneles de cada cara de la consola" (Kent, pg 195, 2001)

\section{Variaciones:}

Coleco Telestar

Coleco Telestar Classic

Coleco Telestar Deluxe

Coleco Telestar Marksman

Coleco Telestar Geminis

Coleco Telestar Ranger

Coleco Telestar Alpha

Coleco Telestar Colormatic

Coleco Telestar Regent

Coleco Telestar Sportsman

Coleco Telestar Combat!

Coleco Telestar Colortron

Coleco Telestar Galaxy

Coleco Telestar Arcade

\section{Fuente análisis gráfico:}

Elaboración propia a partir de los datos contenidos en las guías de compra de 1978 y 1979 Kaplan, Deeny, ed. (Winter 1978). "The Video Games". (Buyer's Guide). Vol. 1 no. 1. Reese Communications. pp. 17-30 y Kaplan, Deeny, ed. (Winter 1979). "Video Games". (Buyer's Guide). Vol. 2 no. 1. Reese Communications. pp. 33-42.

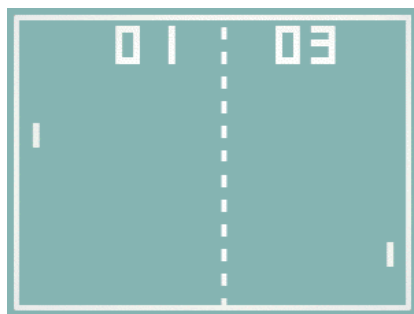

Coleco Telestar.

1976

Videojuegos deportivos basados en el Table Tennis de Magnavox y el Pong de Atari. Existían variaciones a color.

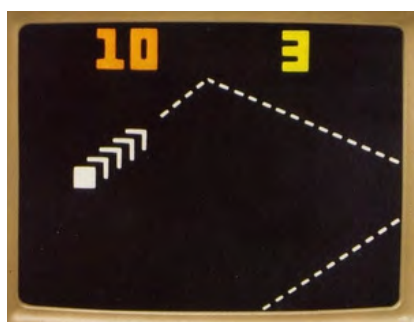

Coleco Telestar Marksman. 1975

Videojuegos de disparos basados en el Shooting Gallery de Magnavox.

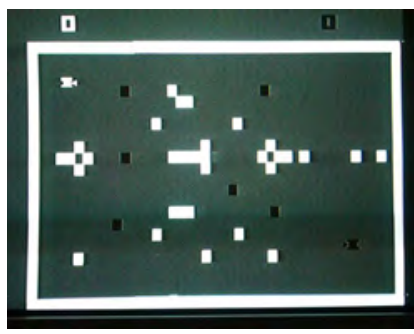

Coleco Telestar Combat! 1975

Videojuego de guerra basado en una variación de Spacewar!

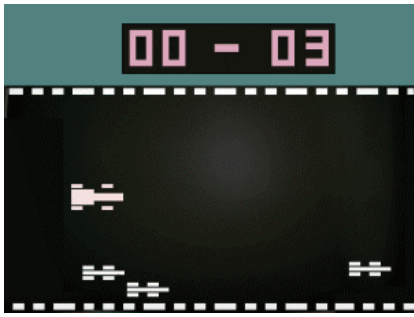

Coleco Telestar Arcade.

\section{5}

Videojuego de conducción basado en el videojuego para recreativas Gran Track 10.

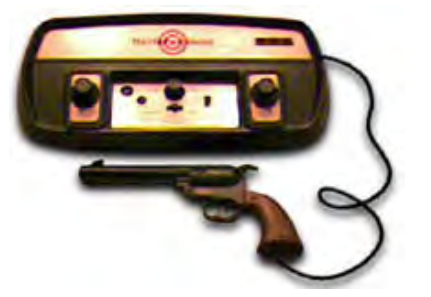

\section{ACCESORIO}

Laser Gun

Pistola de luz que, siguiendo la idea desarrollada por Magnavox, permitía al jugador disparar sobre la pantalla. Existían diferentes modelos, todos ellos

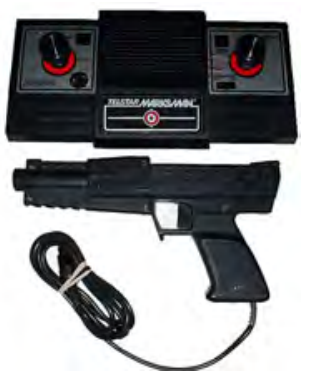
conectados por cable a las consolas. 

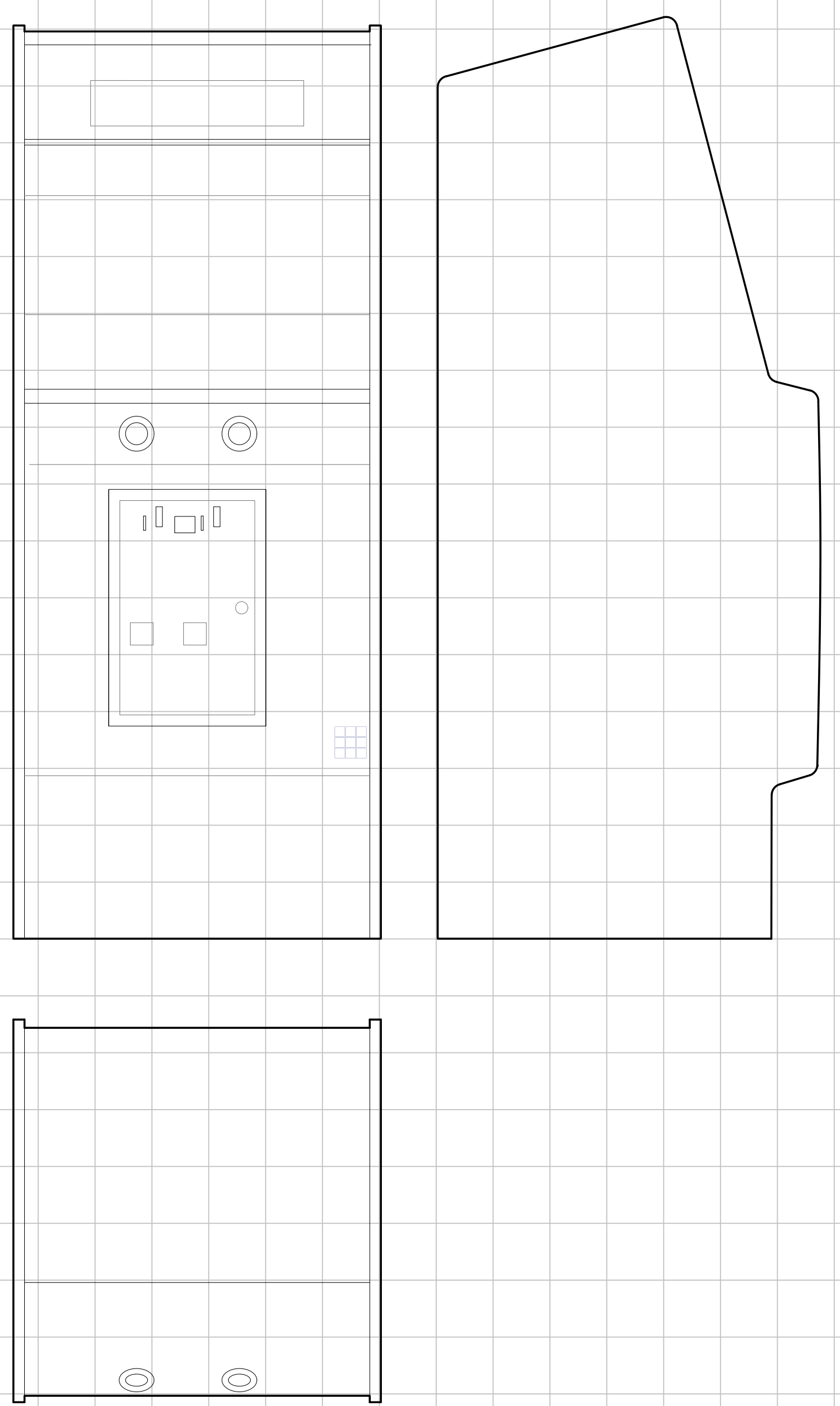


\section{Breakout.}

1976

\section{Atari arcade. \\ Máquina arcade.}

Se trata de una máquina de arcade con una pantalla de resolución estándar y monocromática en blanco y negro. Esta máquina fue fabricada por Atari en 1976 y permitía el juego de un solo jugador. Atari lanzó un modelo inicial en madera de tipo bartop que no se comercializó hasta que llegó al modelo de cabina vertical clásica (que no dejaba la madera a la vista), al que luego se sumaría el modelo cocktail.

La historia de Breakout se encuentra ligada a la de las figuras de Steve Jobs y Steve Wozniak. Cuando Jobs trabajaba para Atari se le propuso el reto de reformular un juego todavía en proceso, premiándole la eliminación de cada chip extra con 100 \$ (ya que los chips encarecían su fabricación y cada juego podía llegar a tener unos 75 chips), además de un pago por su trabajo. Jobs habló con Wozniak del proyecto y lo dejó en sus manos, sin comentarle del dinero de la bonificación por chip eliminado. Wozniak consiguió eliminar 50 chips, pero no supo, hasta años después, que nunca recibió los 5000 \$ que le hubiesen correspondido.

Wozniak consiguió reducirlo a unos 20 o 30 circuitos integrados, pero su diseño era tan complicado que era el único que podía entenderlo.

"El diseño era demasiado complejo de fabricar y la empresa decidió hacer unos cambios al juego después de su trabajo. Tras el lanzamiento, Breakout se convirtió en el juego de recreativa más importante de 1976"

(Donovan, pg 63, 2010).

Finalmente, el juego contó con unos 100 chips. Breakout fue el último juego con tecnología TTL de Atari (tecnología de circuitos electrónicos digitales de "lógica de transistor a transistor"), debido al auge de los microprocesadores en la industria.

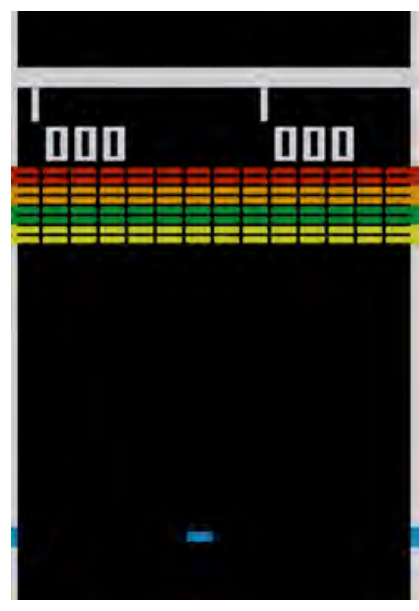

Breakout. 1976

Videojuego arcade basado en una versión mejorada de Pong en que el jugador rompía con la pelota una serie de bloques que se situaban en la parte superior de la pantalla. Su importancia radica en la implicación en su desarrollo de Steve Jobs y Steve Wozniak.

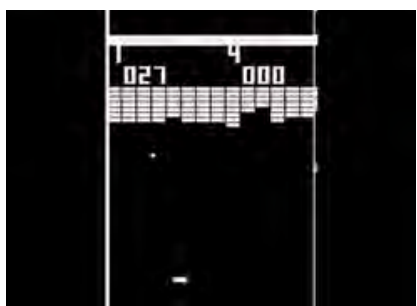



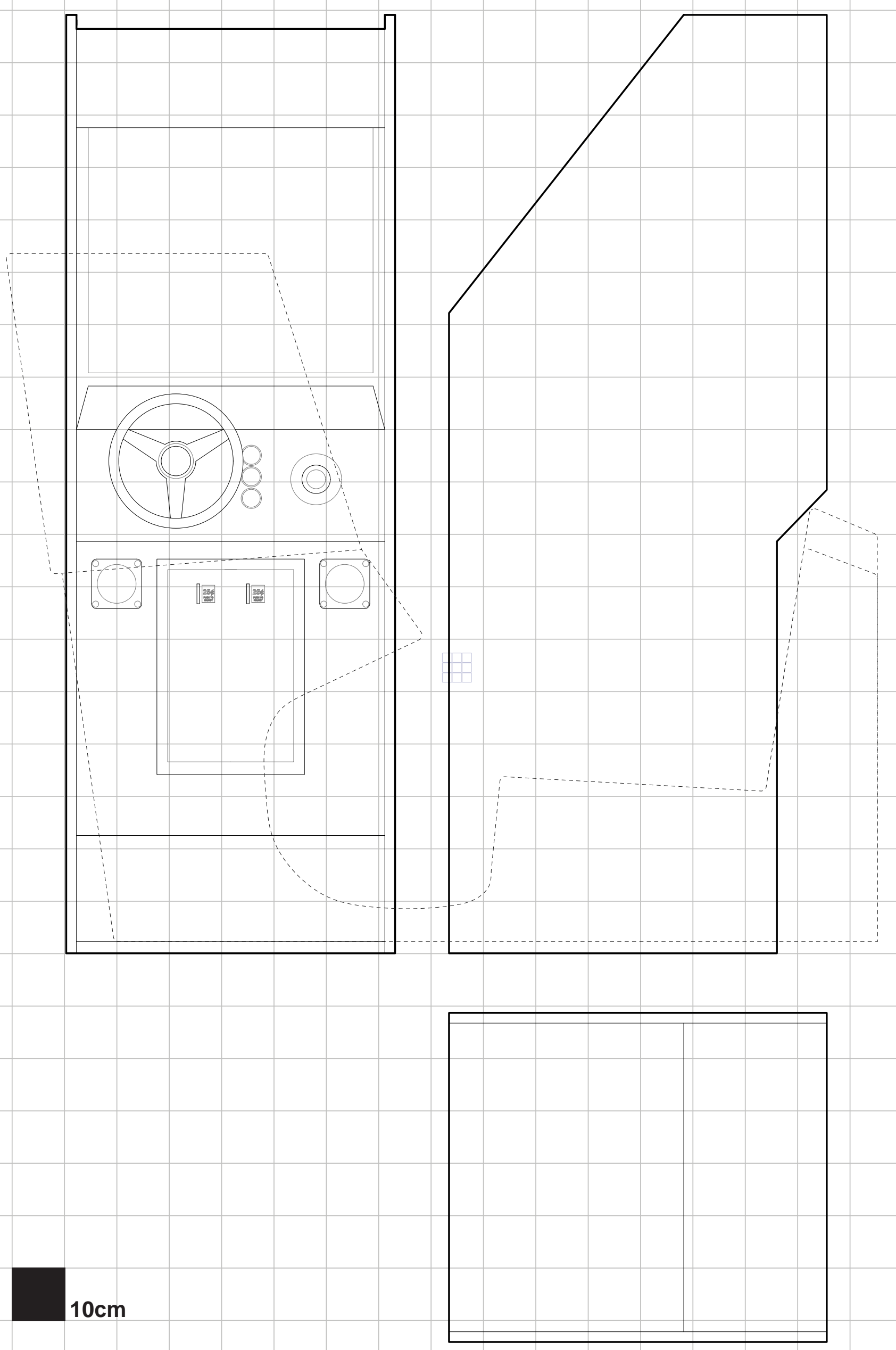
Videojuego de conducción considerado pionero - se considera previo el juego alemán Nürburgring - en la visualización en primera 1976 persona y tiempo real.

Atari arcade.

Máquina arcade.

Máquina de arcade de simulación de conducción lanzada por Atari en 1977 que contó con un modelo de cabina clásica vertical y un modelo tipo cockpit ambiental que simulaba un coche de carreras. Disponía de un monitor de 23 pulgadas en blanco y negro, de resolución estándar, y una lámina de color superpuesta en la pantalla con una pegatina de un coche en el centro del monitor.

Esta máquina disponía de un volante, una palanca de cambio con cuatro posiciones y dos pedales (uno de freno y otro de acelerador).

"A diferencia de los primeros juegos de conducción [...] que se veían desde arriba, Night Driver se veía desde el asiento del piloto [...] La ilusión del movimiento rápido que evocaba el juego también demostró lo mucho que los microprocesadores habían hecho por liberar a los videojuegos de los grilletes del diseño basado en hardware"

(Donovan, pg 65-66, 2010) 
1루니 


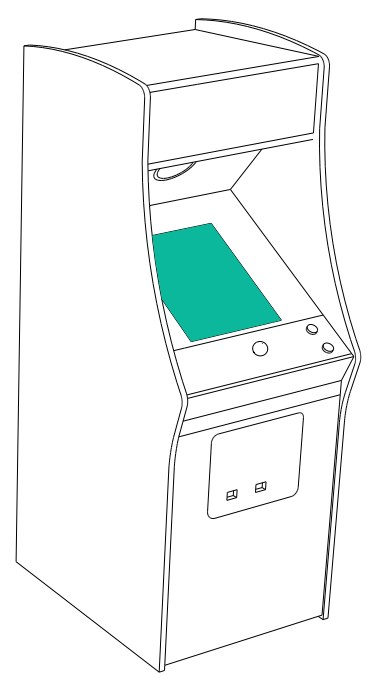

\section{GENERACIÓN 2}

1977

Tras un inicio inestable, el mundo de los videojuegos comerciales se consolidó con el lanzamiento de la primera consola de Atari de juegos intercambiables, la Atari 2600 (inicialmente conocida como VCS). Apple lanzó su revolucionado Apple II, un ordenador doméstico que permitía jugar y Nintendo - que aún no había desembarcado propiamente fuera de Japón - vió la oportunidad de incluir en el negocio del juego a los adultos lanzando las portable Game \& Wacht.

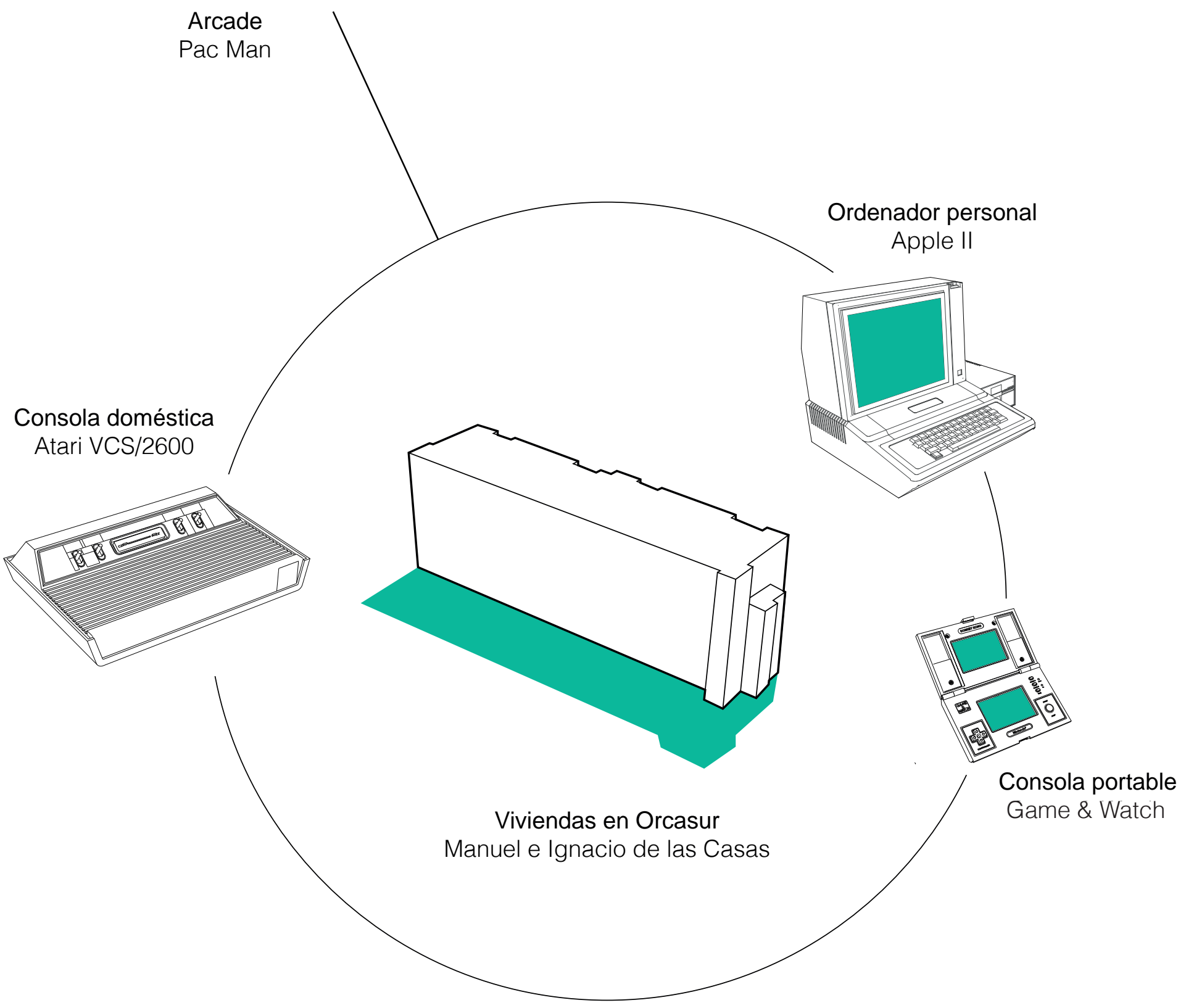




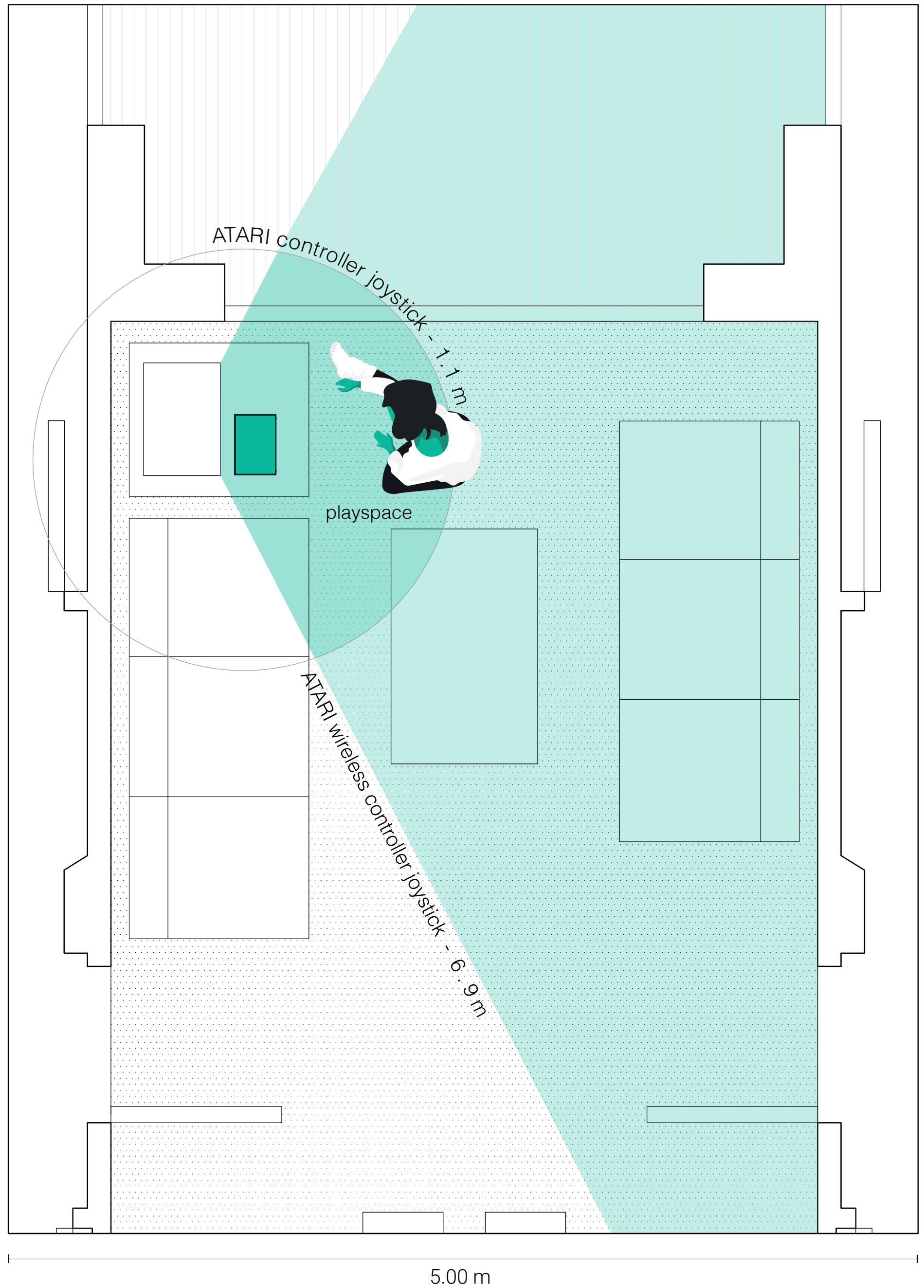




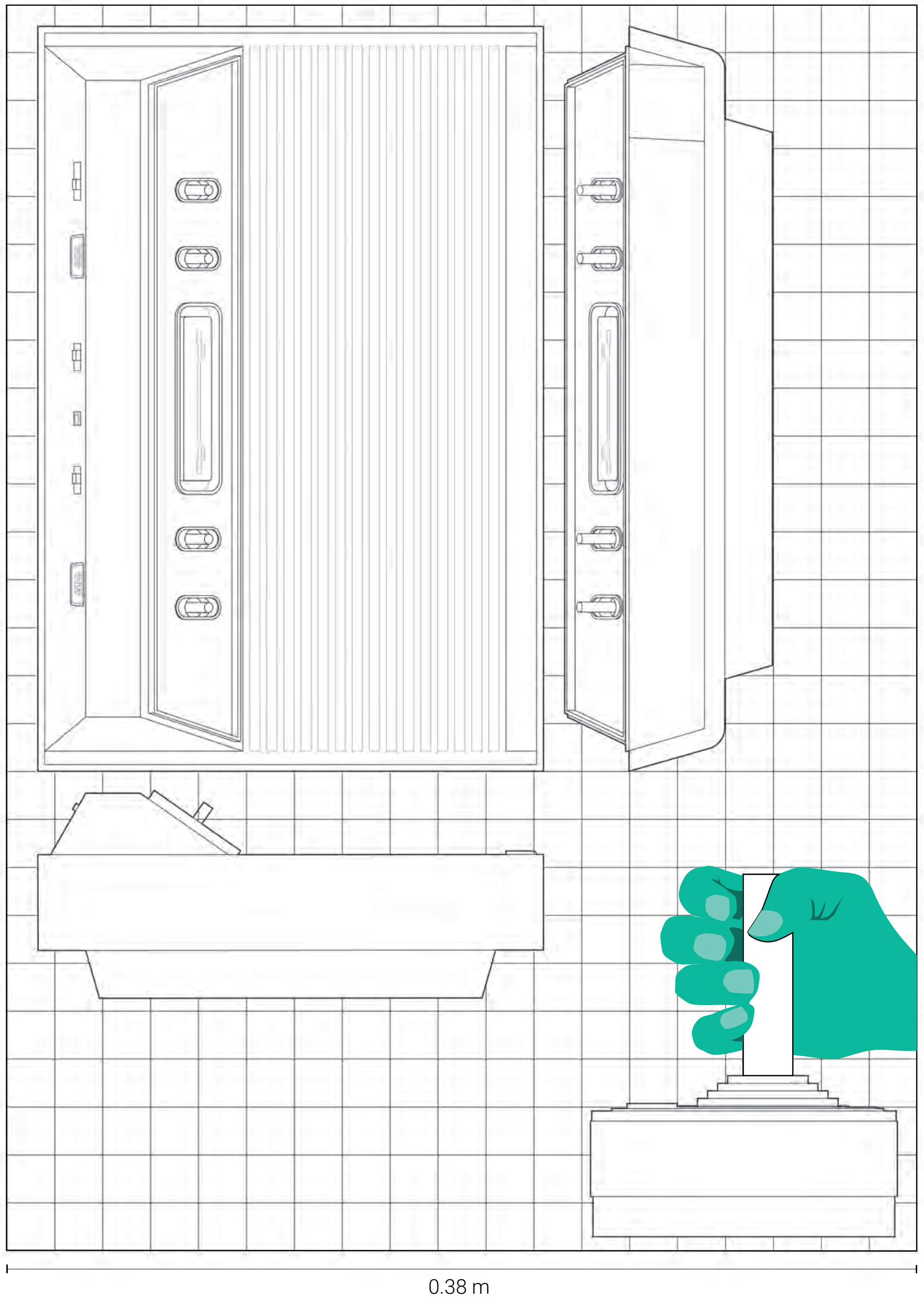


El primer juego considerado una aventura interactiva - en cuanto a la acción del jugador en el espacio - fue Adventure, para Atari 2600 que vendió medio millón de copias.

El mundo de Adventure era tan grande que los jugadores elaboraban sus propios mapas para poder recorrerlo.

Estaba formado por 31 habitaciones que equivalían a más del cuádruple del área del edifico completo de viviendas de Orcasur.

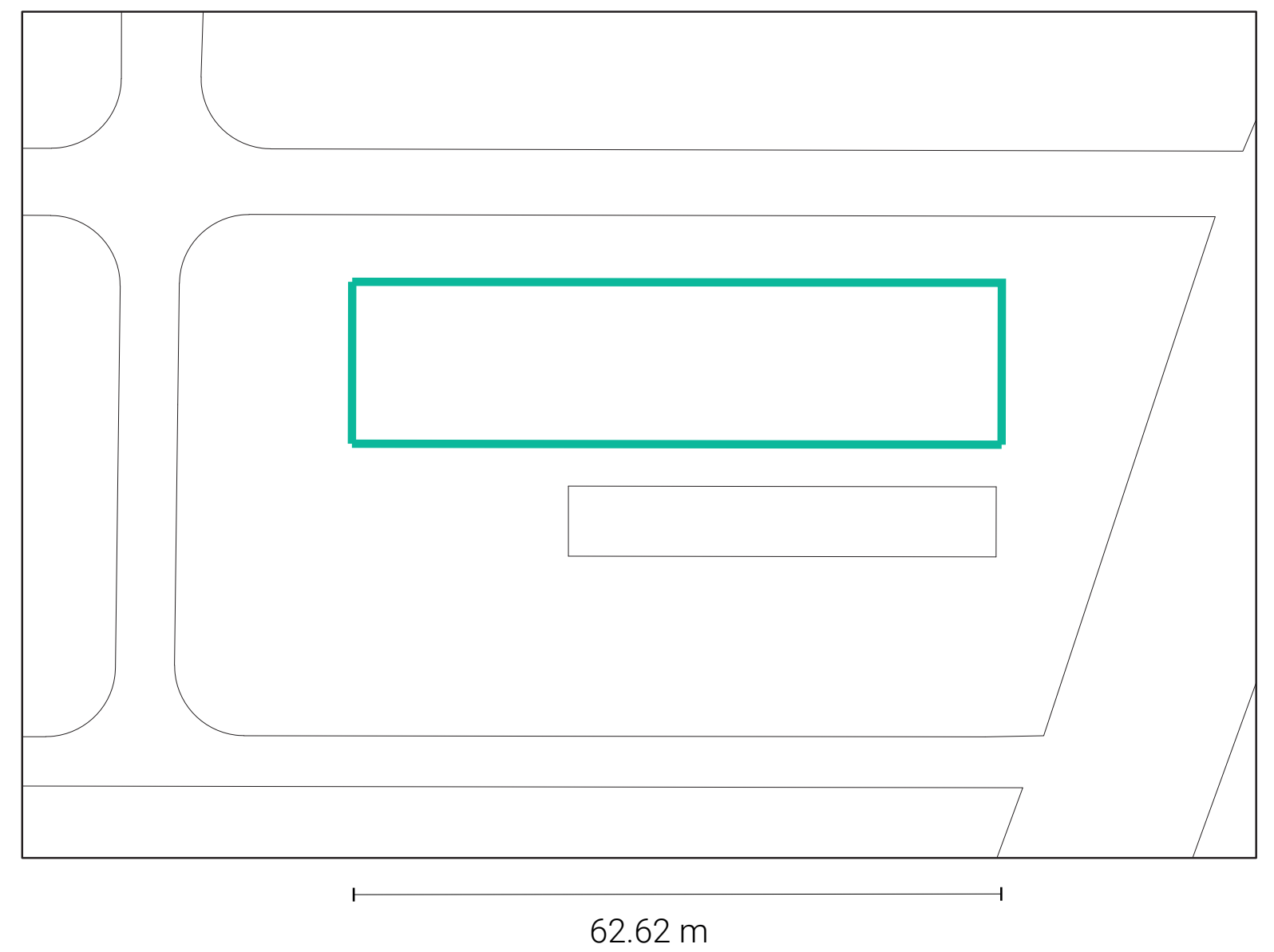




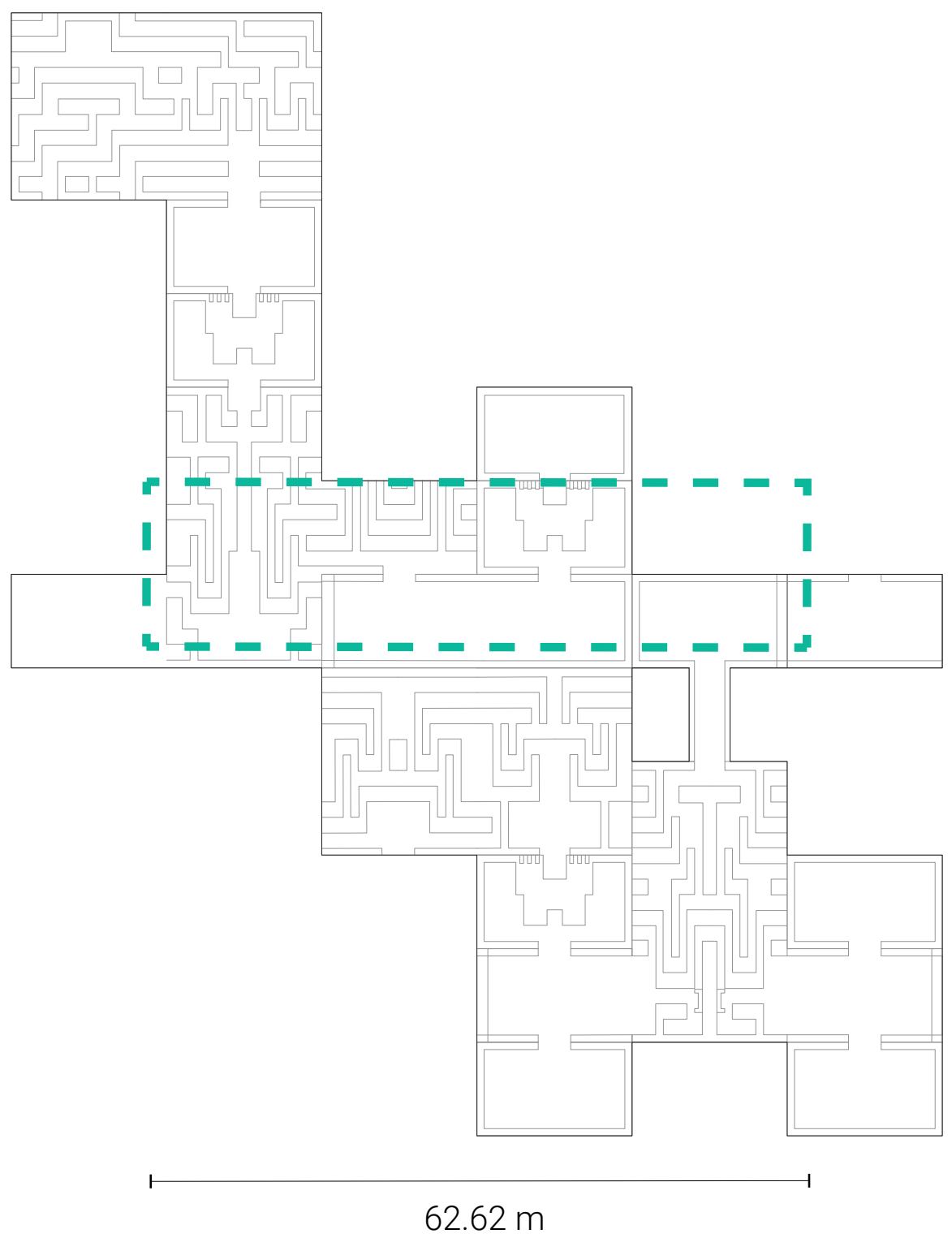

Adventure map

plano de salas 
Nintendo Game\&Watch paseando por Orcasur.

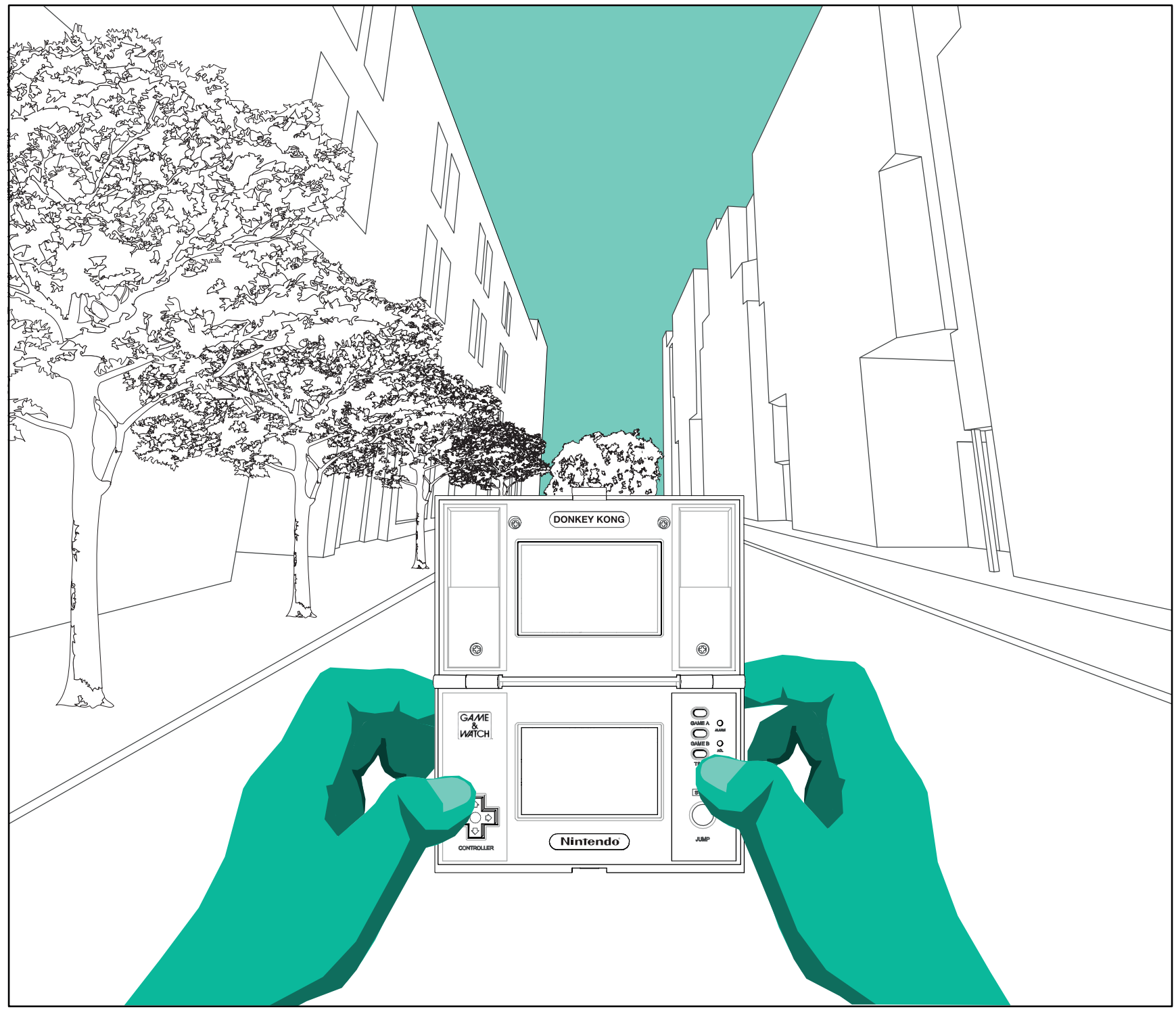



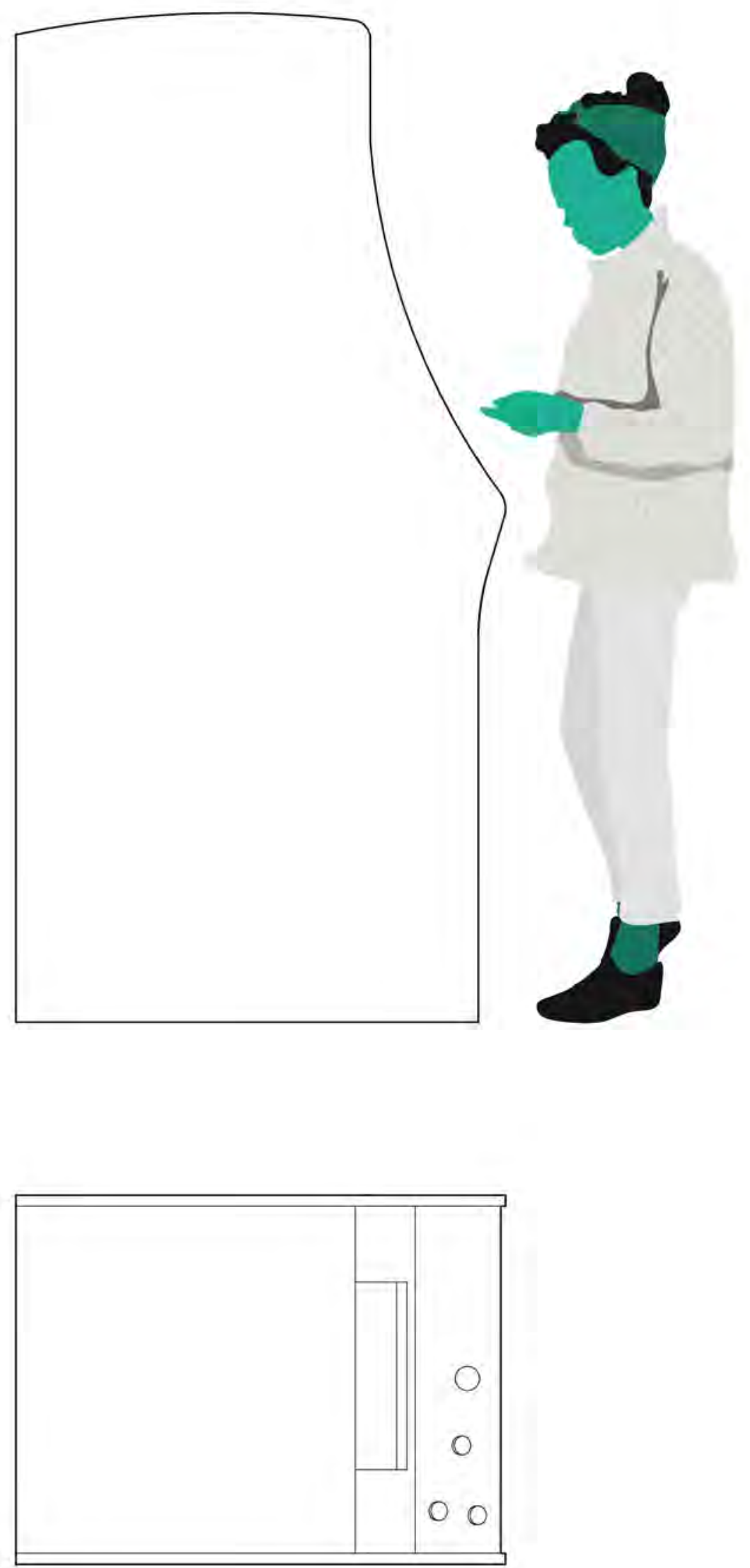


\section{$O::^{138}$}
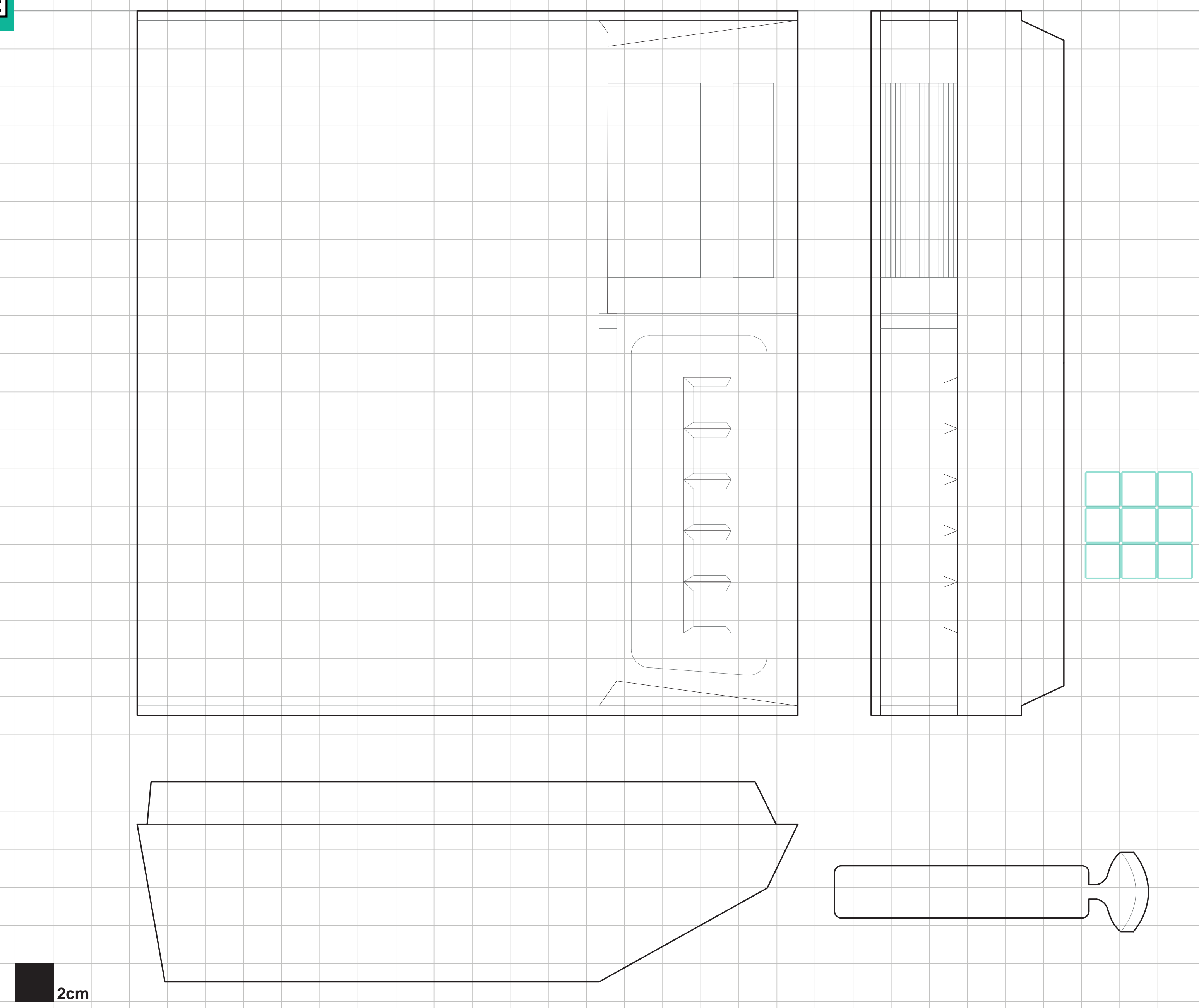


\section{Fairchild Channel F.}

\section{6}

\section{Fairchild Camera and instrument. Videoconsola doméstica.}

Videoconsola doméstica que fue pionera por utilizar un microprocesador, fabricada por Fairchild Camera and Instrument en 1976. Fue una consola muy llamativa por sus controladores únicos que eran un mango con una palanca triangular. La consola de Fairchild cambió el mercado de los videojuegos al ser la primera consola de videojuegos basada en cartuchos.

"La Channel $\mathrm{F}$ tenía juegos de tenis y hockey programados en los circuitos, como el resto de sistemas, pero Fairchild puso a la venta juegos adicionales que venían dentro de unas carcasas parecidas a las de los cartuchos de 8 pistas. Aquellas unidades de juegos se llamaron videocartuchos. Cada uno de ellos contenía un juego programado en un microchip"

(Kent, pg 98, 2001).

En 1979 salió un rediseño de la consola conocida como Channel F System II que presentó algunos cambios sobre todo en la posición de los mandos (extraíbles), la salida de audio (ya no necesitaba altavoces al usar los de la televisión) y la simplificación electrónica. Además de una carcasa mucho más minimalista y actualizada.

Fuente análisis gráfico:

Elaboración propia a partir de los datos obtenidos en la oficina de patentes de Estados Unidos. Patente 4,095,791. 20 de Junio de 1978

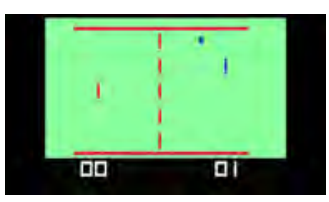

Se trataba de juegos sencillos, generalmente basados en títulos ya existentes, se publicaron 27 en cartuchos de forma inicial, además de los dos incluidos en la consola.

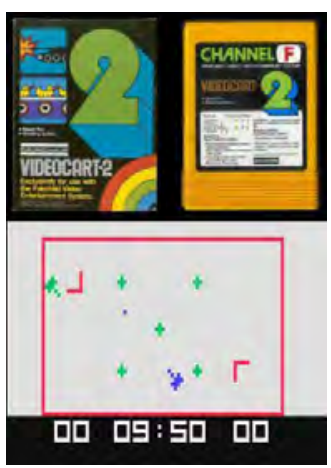

Hockey y tennis.

Videojuegos incluidos en la consola y basados en modificaciones de Pong y Football de Atari.

\section{Videocart-2.}

Desert Fox, Shooting Gallery. Videojuegos de disparos inspirados en Shooting Gallery de Magnavox pero que empleaban el propio controlador de la Fairchild para disparar.
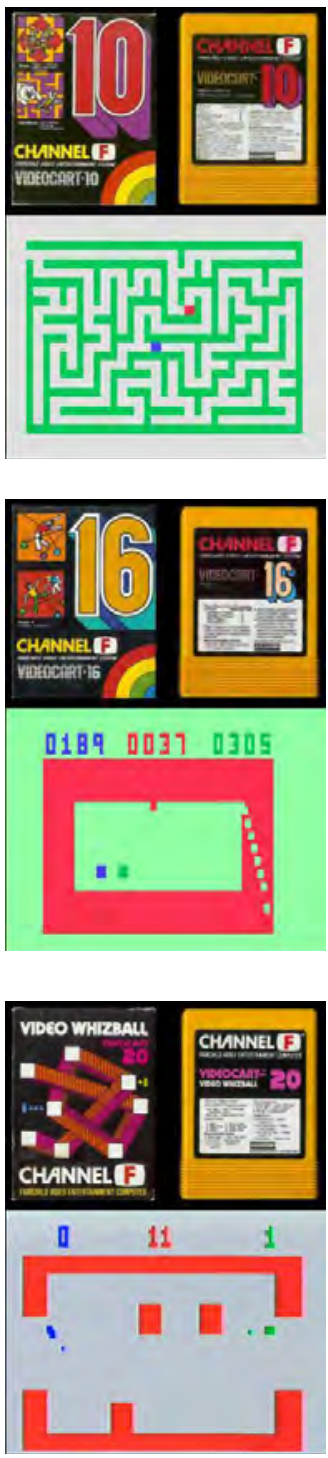

Videocart-20.

Video Whizball

Videojuego de disparos y tipo arcade en que dos jugadores debían dispararse esquivando bloques que aparecían y desaparecían entre ellos. 


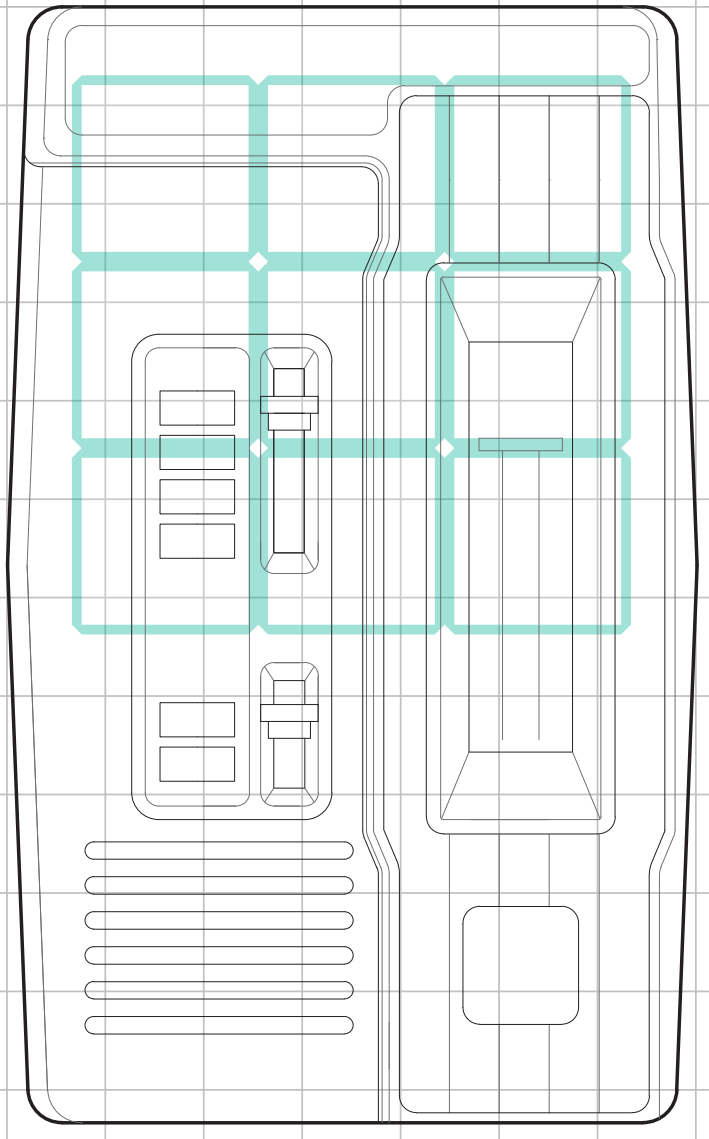




\section{Autorace Mattel.}

\section{6}

\section{Mattel.}

Videoconsola portable.

Esta consola está considerada como la primera consola portátil de la historia. Fue desarrollada por Mattel y lanzada al mercado en 1976, posicionándose como la empresa pionera en juegos portátiles. Esta consola tenía una dimensión de once centímetros de longitud y se basada en la tecnología de luces LED. Contaba con varias tiras de plásticos de diferentes colores y tiras de LED que simulaban los coches en movimiento (aunque el equipo de Mattel no se esforzó en que pareciesen coches de carreras).

"Varias filas de LED que podían moverse y controlarse como las imágenes en pantalla de un videojuego. Los jugadores podían controlar las luces que se movían por la tira hacia delante, atrás, arriba y abajo con cuatro botones direccionales"

(Kent, pg 200, 2001).
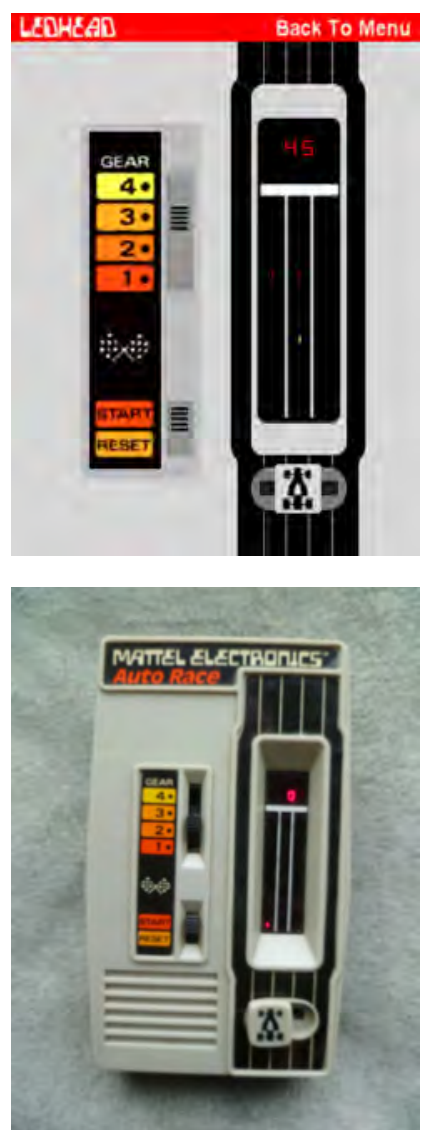

Autorace.

1976

Videojuego portátil considerado el primero de su clase. Basaba su estructura en una tira de plástico en las que se insertaban tiras de leds que podían encenderse y apagarse hacia arriba y hacia abajo con botones direccionales. El objetivo del juego era guiar la luz desde la parte inferior de la tira hasta la superior cuatro veces sin chocar con otras luces. Considerando cada vez que se completaba una vuelta al circuito.

Después de este modelo, Mattel lanzó al mercado Football, Basketball, Hockey y Baseball, con un precio de 20 o 35 dólares que consiguieron recaudar más de 400 millones de dólares. 


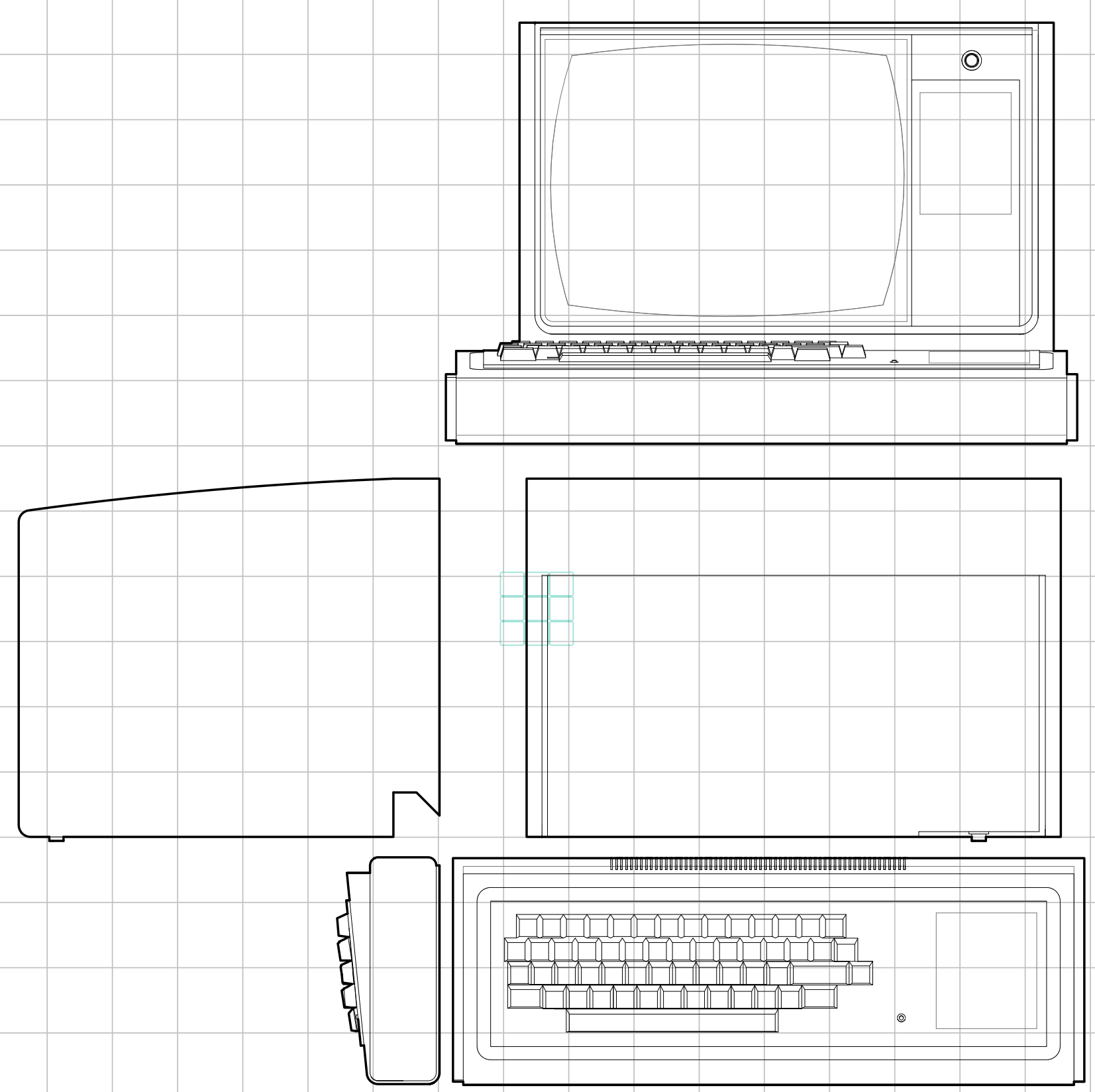




\section{TRS-80.}

1977

Tandy Corporation.

Ordenador.

Microodenador diseñado por Tandy Corporation y lanzado el mercado en 1977, que fue considerado como uno de los primeros en llegar a los espacios domésticos. Contaba con un monitor de doce pulgadas en blanco y negro de $64 \times 15$ caracteres en la pantalla y, además, un grabador/reproductor de cassettes. EI TRS-80 poseía un procesador Zilog Z 80 y estaba programado en lenguaje BASIC. Tandy lanzó al mercado cuatro modelos de este ordenador y se vendieron más de 250.000 unidades hasta que se descatalogó en 1981.
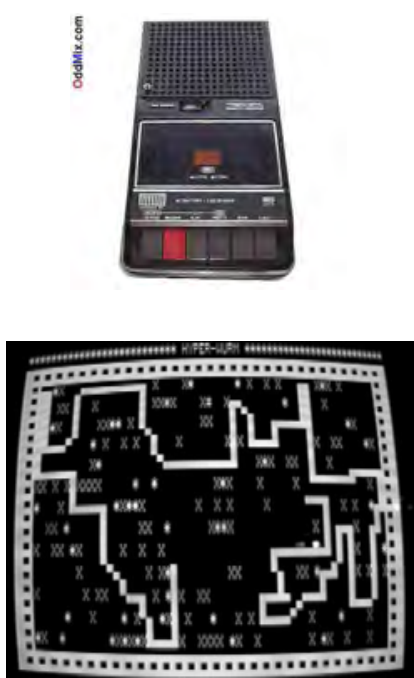

nake/Blockade.

Gremlin. 1976

Videojuego arcade cuyo concepto se basaba en una serpiente que recogía puntos y crecía cada vez que conseguía uno. El principal obstáculo consistía en no chocar con la longitud creciente de la cola y persistir el mayor tiempo posible.

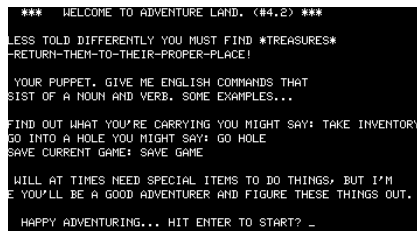

Adventureland. Scott Adams. 1978

Videojuego de tipo aventura textural pionero en este género para microordenadores. El juego convierte al jugador en un explorador en busca de trece artefactos perdidos en un entorno fantástico. La partida se controla mediante palabras escritas, pudiendo reconocer hasta 120 términos. El juego está basado en Colossal Cave Adventure.

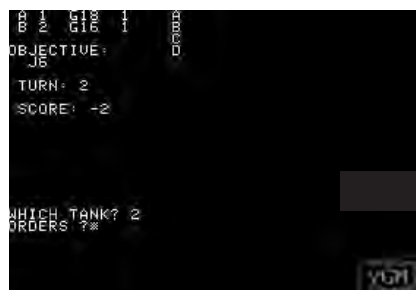

Tanktics.Chris Crawford.1977 Videojuego de guerra que introdujo por primera vez el término 'niebla de guerra'. Este concepto se refiere a información geográfica oculta para el jugador hasta que este va explorando todas las zonas del mapa.

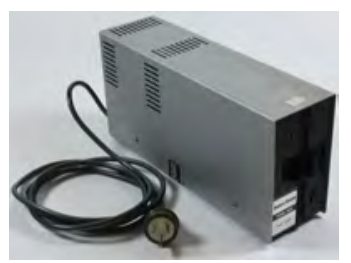

\section{ACCESORIO}

Floppy disk drives.

Lector de disquetes que permitían leer juegos en este formato. Salió al mercado en 1978.

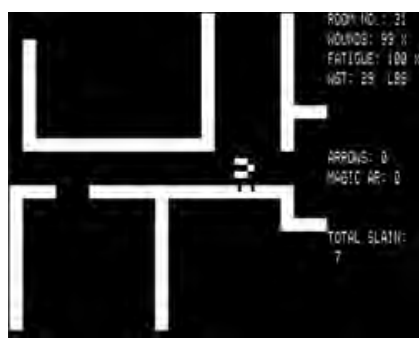

Temple of Apshai. Automated Simulations. 1979

Videojuego de rol de mazmorras considerado uno de los primeros juegos de rol gráficos para computadoras domésticas (anterior incluso al lanzamiento comercial de Akalabeth: World of Doom). La documentación del juego incluía instrucciones para importar personajes de juegos de rol de papel y lápiz.
Elaboración propia a partir de los datos obtenidos de la web de coleccionistas y entusiastas del TRS-80 trs-80.com 


\section{$0: 3^{138}$}
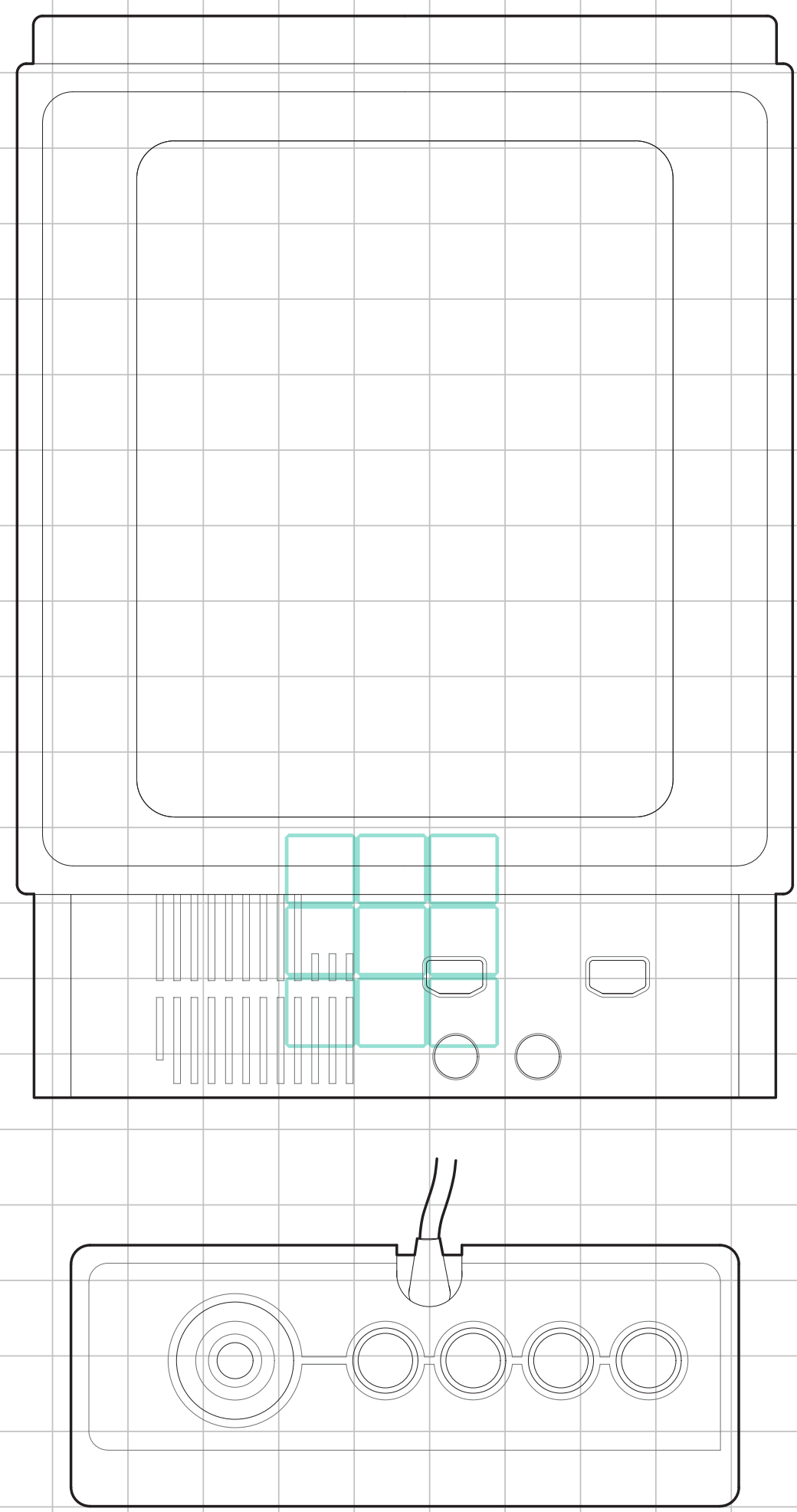


\section{Vectrex.}

\section{5}

\section{General Consumer Electronics GCE. Videoconsola doméstica.}

Primera videoconsola doméstica que aunaba en un mismo producto un monitor en blanco y negro (integrado de nueve pulgadas), que ofrecía gráficos vectoriales y contaba con una ranura para cartuchos, así como un controlador unido al dispositivo mediante un cable y que tenía cuatro botones y un joystick. Esta consola que integraba la pantalla, fue desarrollada por General Consumer Electronics (Kent, 2001) y lanzada al mercado en 1982 por $199 \$$. Pese a que fue todo un éxito y se vendieron todas las unidades fabricadas, se descontinuó en 1984 por la competencia de las consolas ráster y por su limitado catálogo de juegos.
Fuente análisis gráfico:

Elaboración propia a partir de los datos contenidos en los documentos originales archivados en Vectrex Academy 2019 (HS PF, Pforzheim University of Applied Sciences).

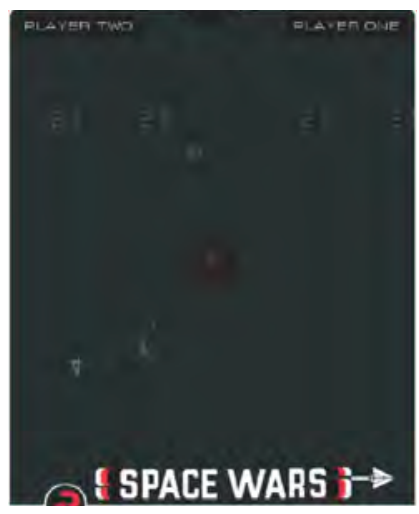

Space Wars.

1977

Videojuego de temática espacial basado en Spacewar! del que resulta una versión mejorada. A diferencia de su antecesor tenía varias alternativas para escoger, como la presencia o ausencia de una estrella en el medio del campo de juego -con una atracción gravitacional positiva o negativa - si los bor-

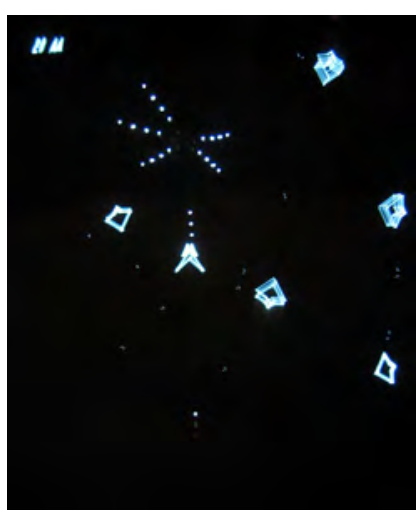
des del campo de juego "se envolvían" a sus lados opuestos o no, y si las naves rebotaban. Las naves podían sufrir daños y no destruirse por completo y en su versión recreativa resultó novedoso por depender su duración del dinero que se introdujera y no tanto de la habilidad del jugador.

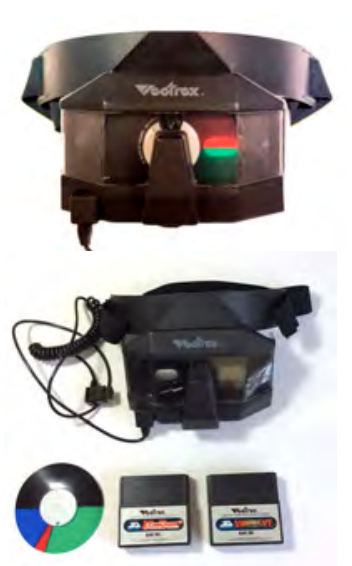

\section{ACCESORIO}

Vectrex 3D Imager.

Sistema de visualización de juego en 3D en forma de gafas que el jugador podía ponerse. Lanzado en 1984, su vida fue extraordinariamente corta por la crisis del videojuego de 1983 pese a ello fue el primero de su tipo y se adelantó al equivalente publicado por Sega a los 4 años. Destacó en juegos como 3d Narrow Escape que simulaban un escenario en 3D.

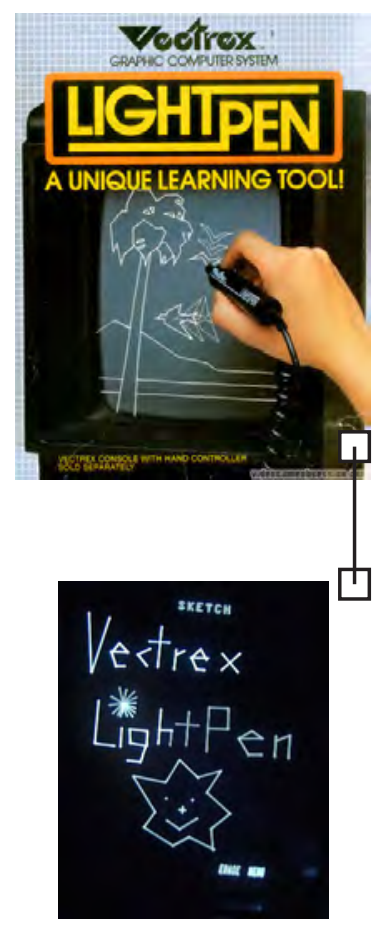

\section{ACCESORIO}

Vectrex-LightPen.

Bolígrafo que permitía dibujar sobre la pantalla de la consola. Usaba una tecnología que enviaba una señal cadavez que detectaba cierta intensidad de luz que detectaba en pantalla y permitía saber el punto donde se dibujaba. Se trató de un accesorio revolucionario para su época, pese a que la crisis de los videojuegos de 1983 hizo que fuera un fracaso comercial.

\section{Art Master.}

1983

Videojuego de tipo artístico que - usando una cruz de luz en pantalla - permitía dibujar sobre esa usando el accesorio LightPen. 

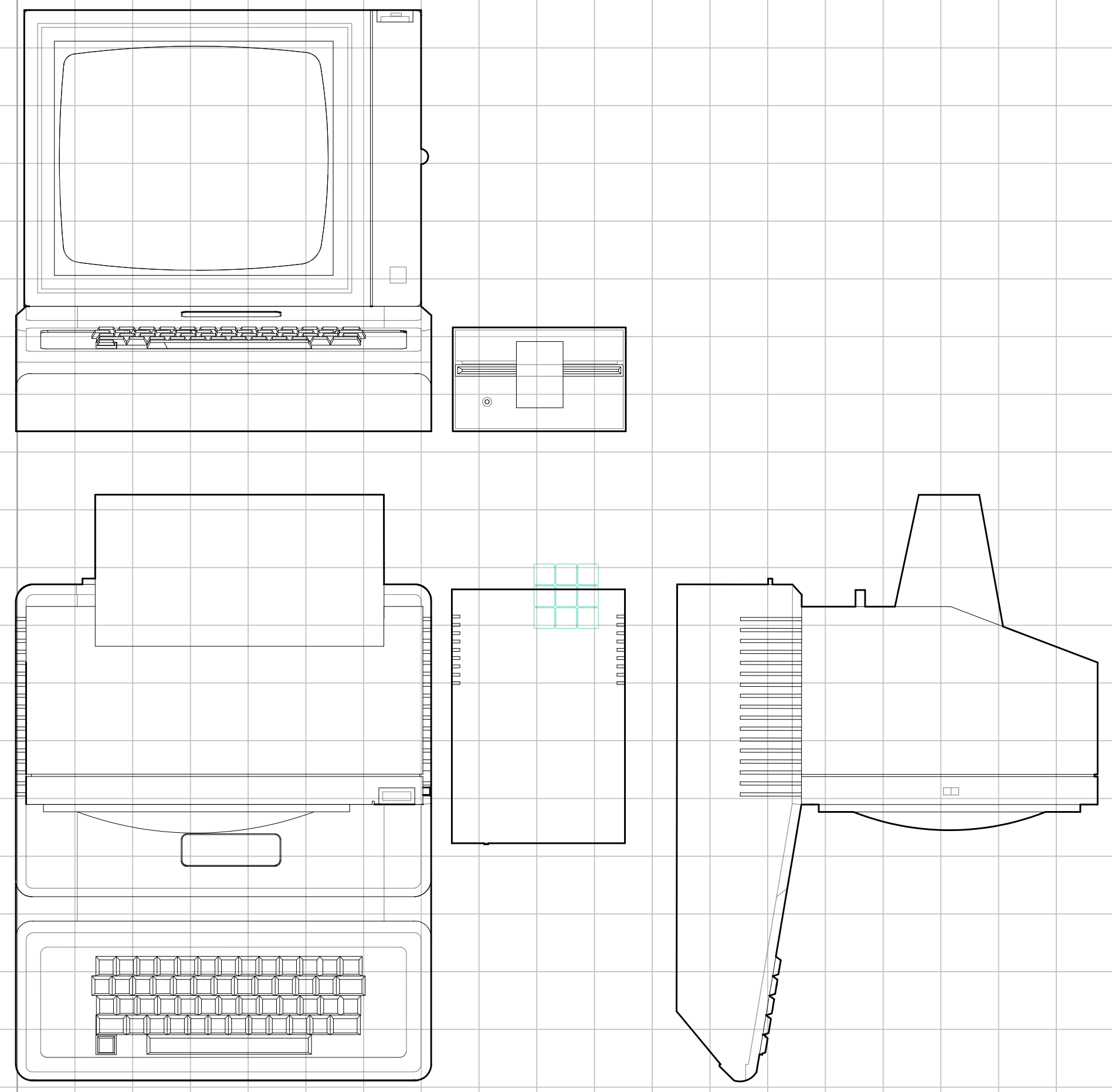


\section{Apple II.}

Apple Computers Inc.
Ordenadorer.

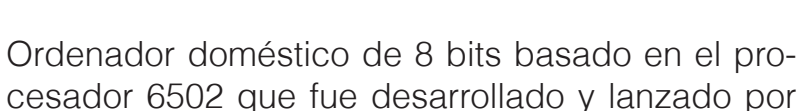
Apple Computer en 1977 . Estat consididerado coma
el primer rodenadore en ser producido de forma

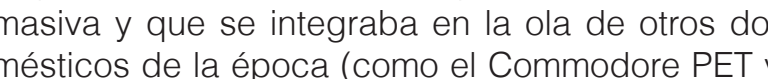
sumpo
Apple

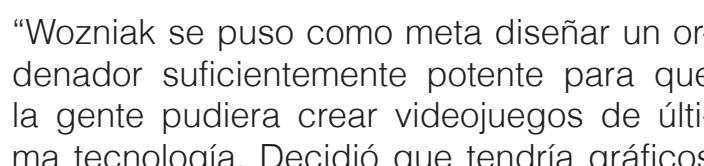

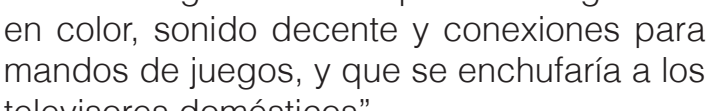

(Donovan, pg 75, 2010/2018)

Steve Wozniak lo diseñó con la ambición de conseen el lenguaje de programación BASIC. Este orde-
nador domésticic contó con varios modeless: Apple

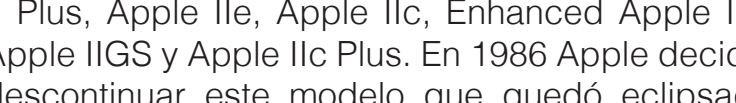
descontinuar ese
por Macintosh.

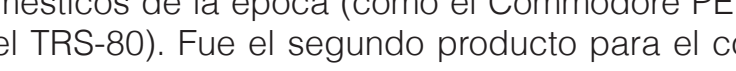
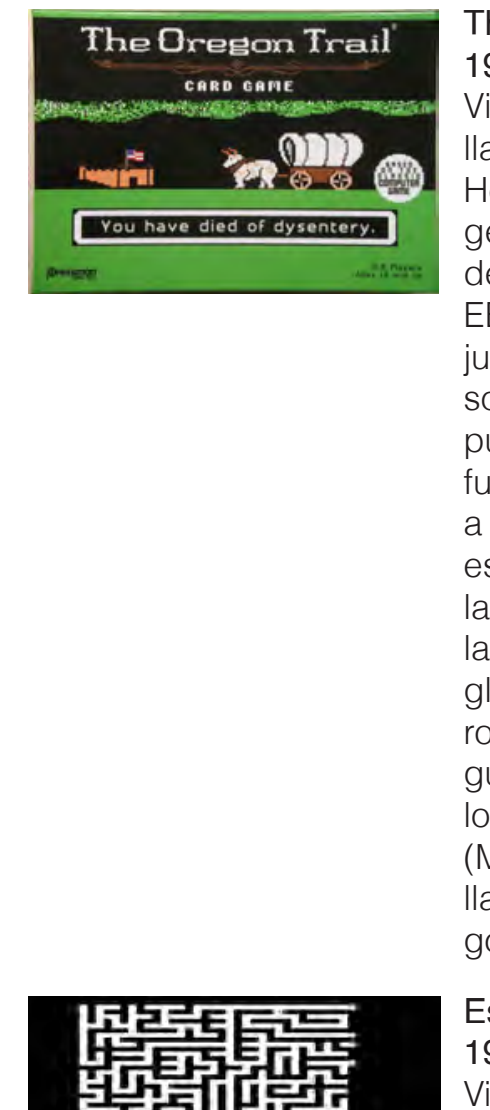

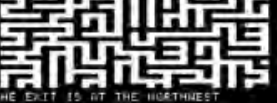

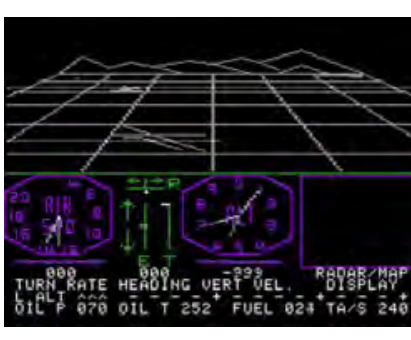

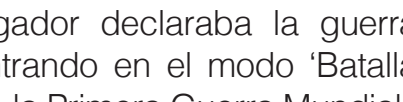

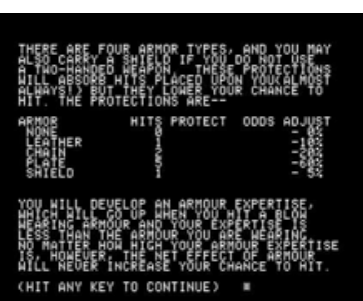

\section{Eamon.
1978}

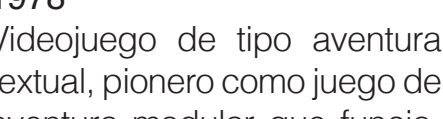

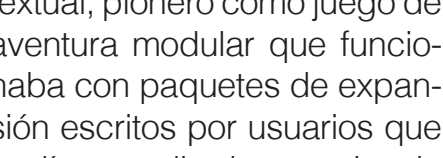

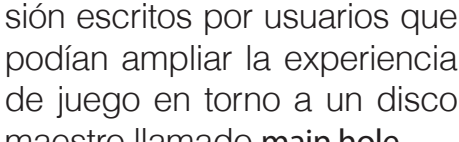

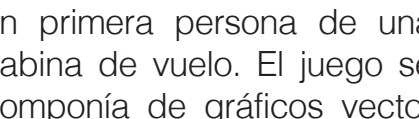

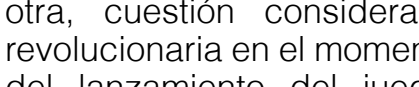

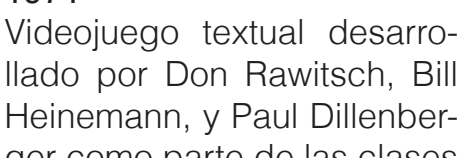

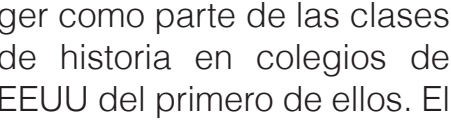

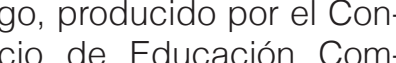
Titacional de Minnesotata alos nifios de las esculalas
estadoundidenses acercas de

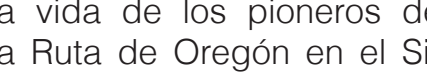

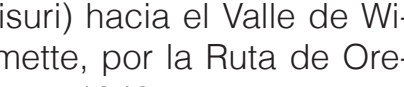

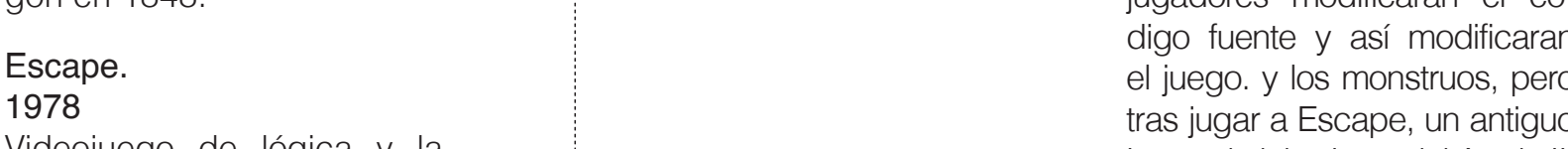

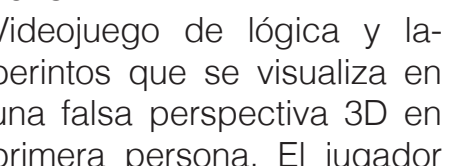

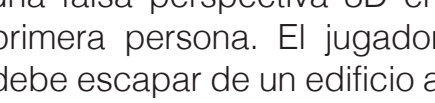
laves de difierentes laberintes
generacados aleatoriamente.
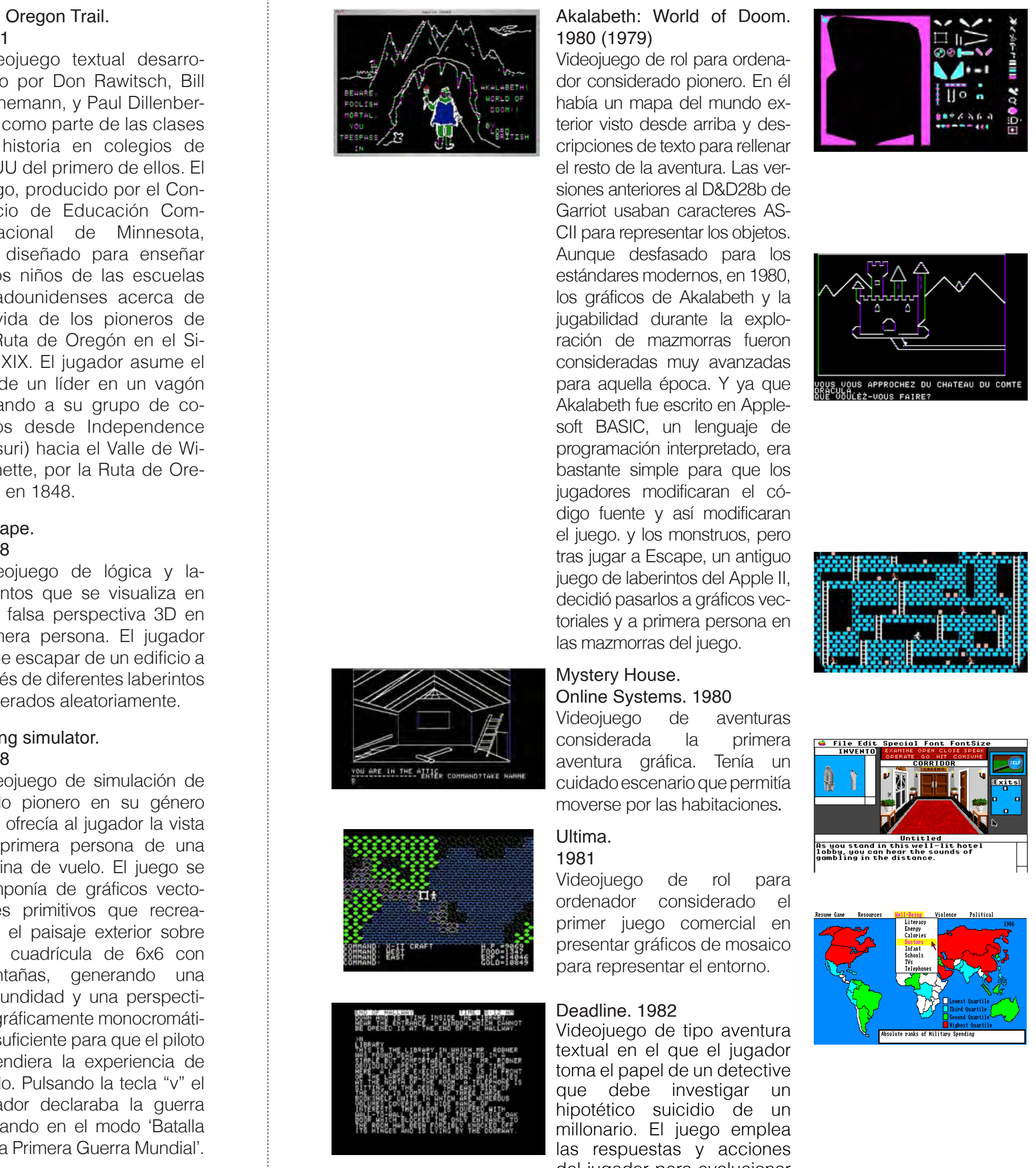

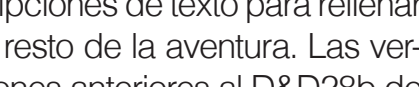

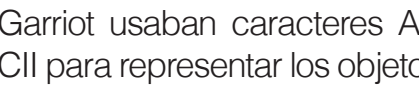

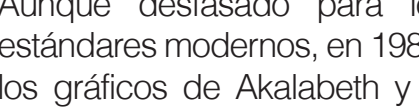

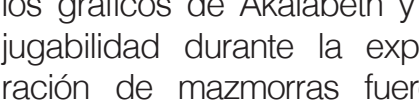

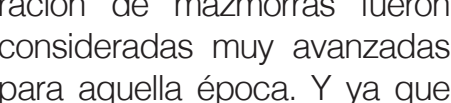
solt BASIC, un lenguaie de

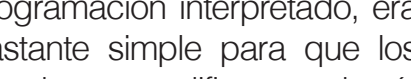

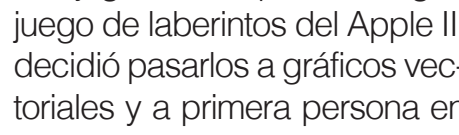

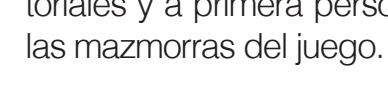

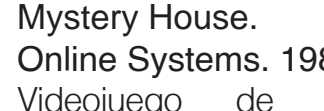

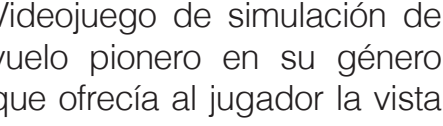

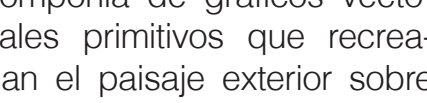

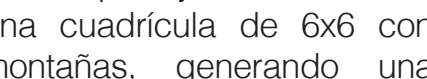

potundidad y una perspocti-

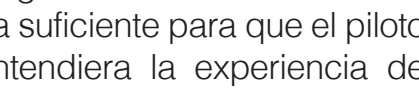

Pusando I I a eccla w" vel

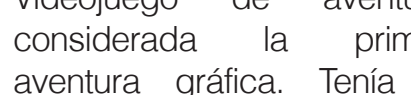

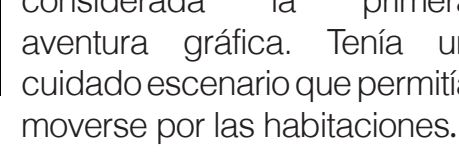

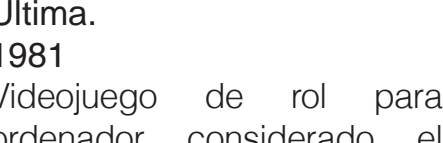

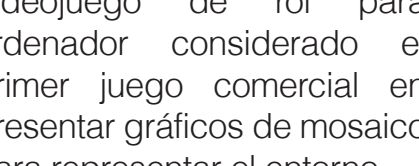

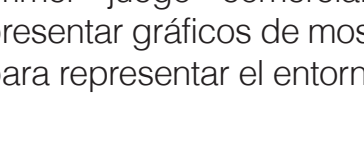

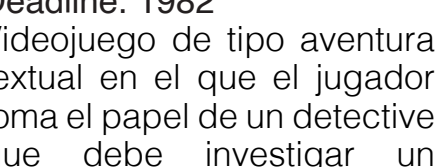
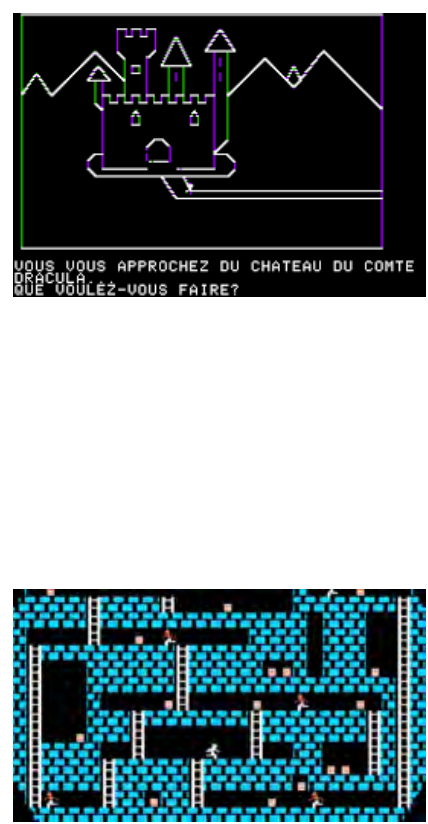

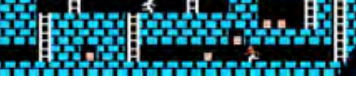
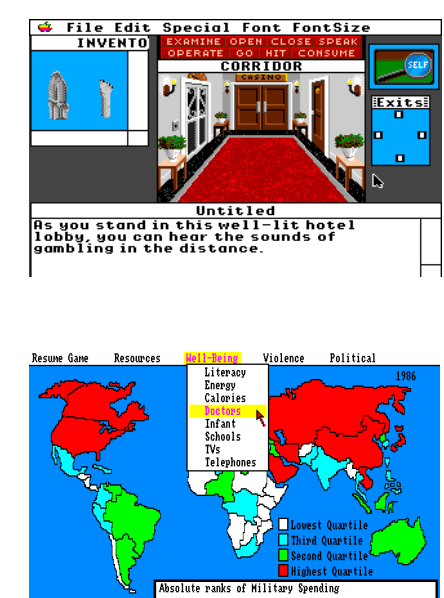

mas

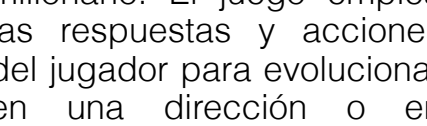

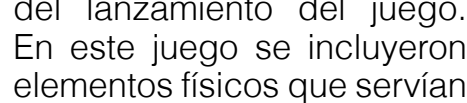

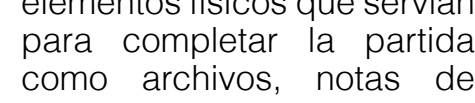

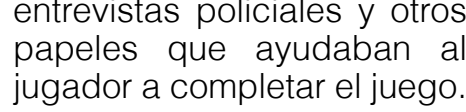

${ }_{1983}^{L}$ V Vampire Fou

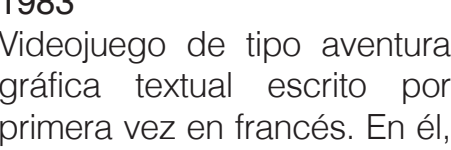

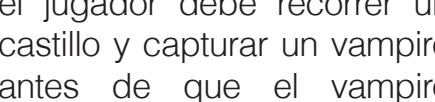

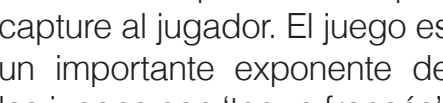
ina personalidad propia de

${ }_{1983}^{\text {Lode }}$ Bunner.

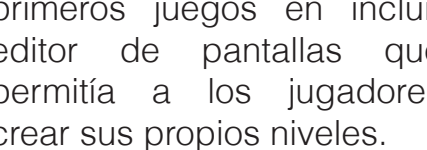

Videjiuego de aventuras aue
destaca por ser en primero
de la serie Macventure, que Introducian un menu
and lick en la interfaz

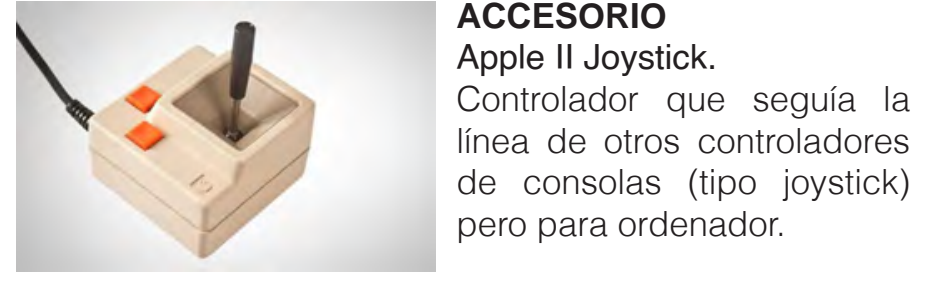

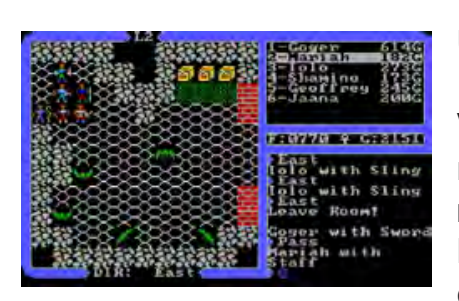

1985 : Quest of the Avatar. a que dostaca por su base
moral y por l a bussueda, en

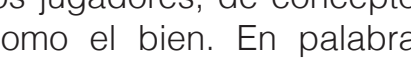

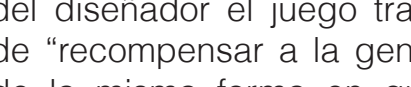
unciona el mundo reall.'de
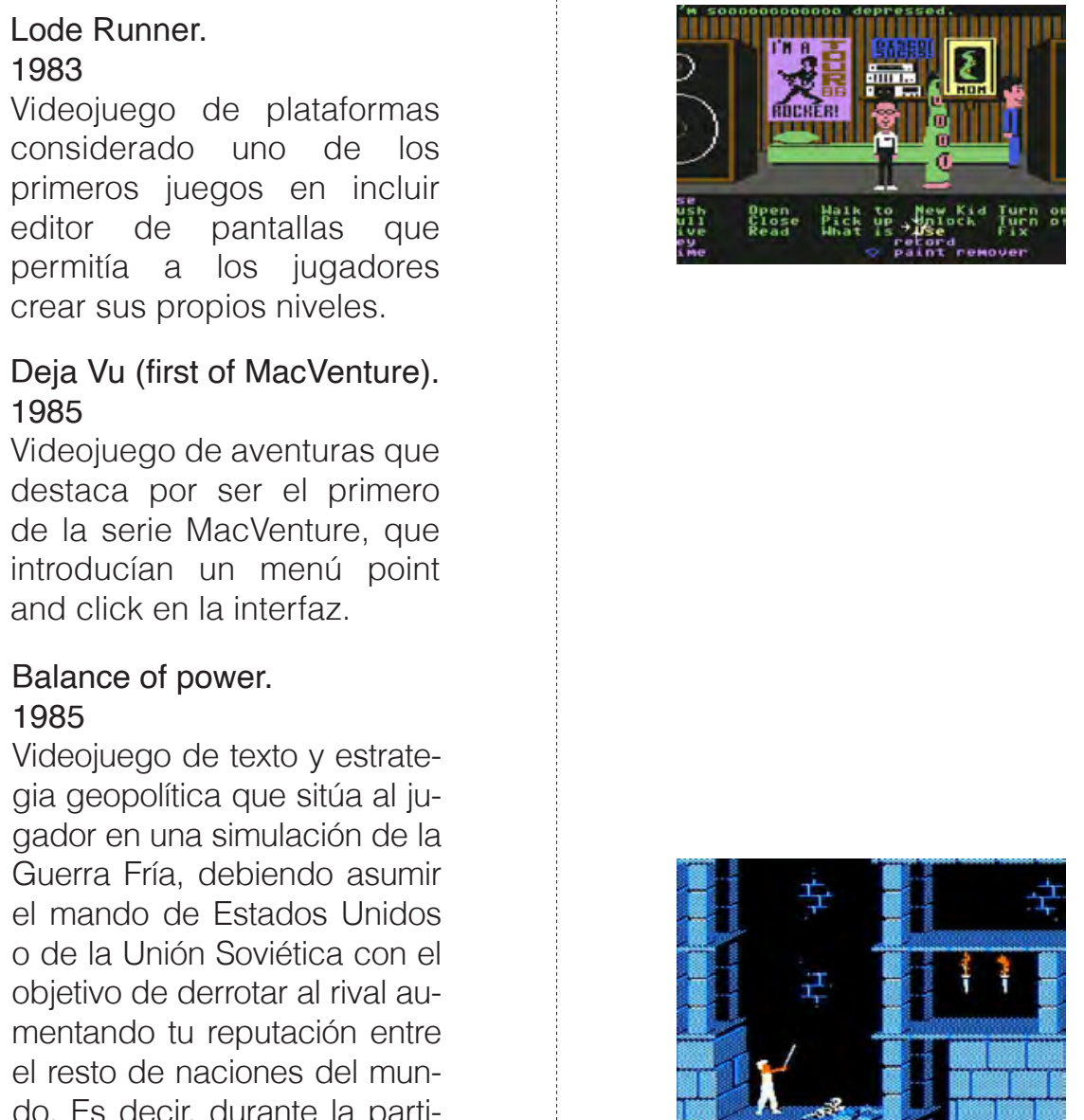

然

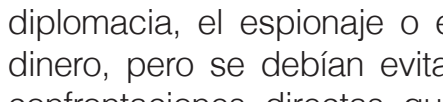
desenencadenaran una gueta

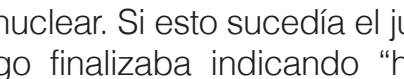

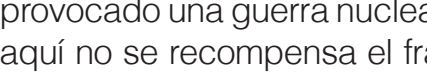

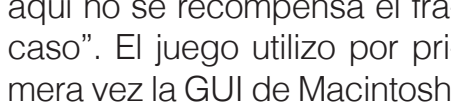

Je opciones y tramas alter-

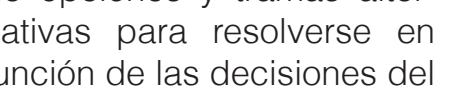

\section{(1)}

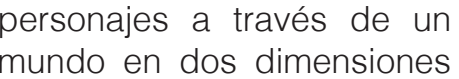

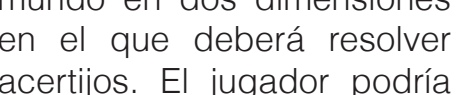

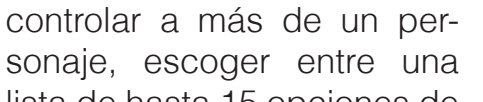
Video
que
adel
anim
gos,
oos

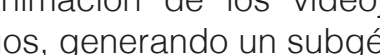

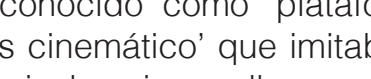

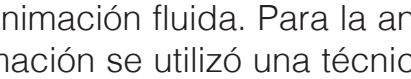
lamada 'rotoscopia' utirizan-
do una grabacion en feal. El principal objetivo del
jugadore rer completera el ive-
go en menos de una hora en go en menos de una hora en 


\section{$\mathrm{O}::^{142}$}

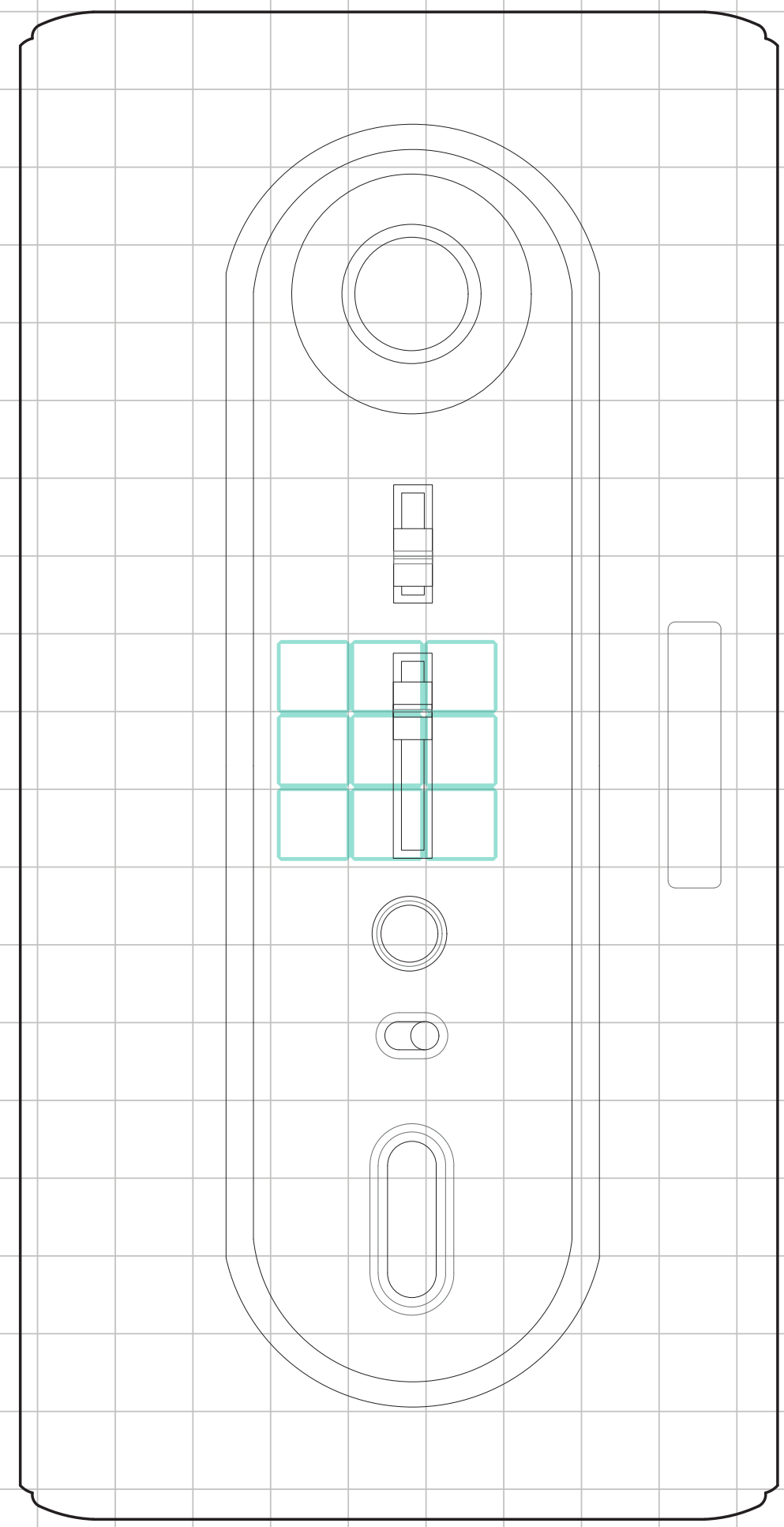




\section{Nintendo TV Games.}

1977

\section{Nintendo. \\ Videoconsola doméstica.}

Serie de cinco consolas domésticas vendidas por Nintendo en Japón y consideradas las primeras de la compañía (Gorges, 2016). Las 5 variaciones contenían distintos juegos y diseños de hardware.

Color TV-Game 6 disponía de 6 juegos en color y disponía de dos controladores integrados en la consola en forma de botones tipo sintonizador. Color TV-Game 15 disponía de 15 juegos en color y disponía de dos controladores también integrados pero que podían extraerse y quedar conectados por cable. Color TV-Game Racing 112 se centraba en juegos de conducción y por ello disponía de un volante integrado y una palanca que simulaban un coche, además de 5 botones integrados y dos controladores conectados por cable.

Color TV- Game Block Breaker se basaba en juegos similares a Breakout de Atari y disponía sólo de un solo botón de juego tipo potenciómetro y 5 pequeños botones extra. Computer TV Game se trataba en realidad de una consola que contenía exclusivamente la adaptación de un juego arcade y permitía jugar a dos jugadores simultáneamente gracias a dos controladores integrados de 4 botones. Nintendo vendió un total de 3 millones de copias.

\section{Variaciones:}

Nintendo Color TV-Game 6

Nintendo Color TV-Game 15

Nintendo Color TV-Game Racing 112

Nintendo Color TV-Game Block Breaker

Computer TV Game

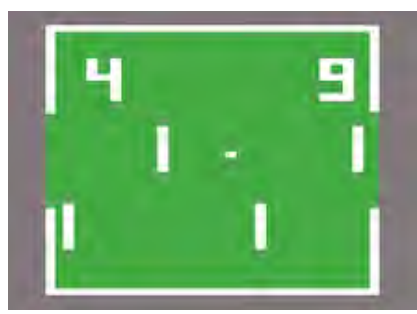

Tennis.

Videojuegos en color basados en Pong o Table tennis.

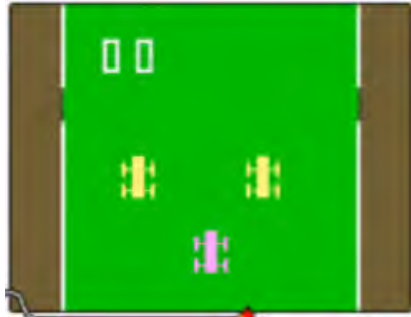

Racing 112.

Videojuegos de conducción similares a Gran Track 10.

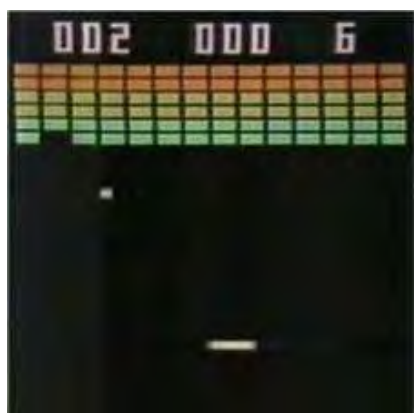

Block Breaker.

Videojuegos tipo arcade en color basados en Breakout de Atari.

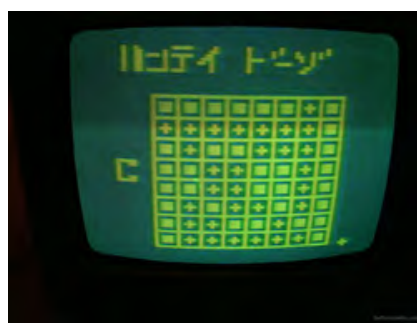

Computer Othello.

Videojuego de estrategia basado en un juego de mesa para dos jugadores (uno con fichas inicialmente blancas, otro con fichas inicialmente negras) sobre un tablero de 8x8. El objetivo del juego es convertir todas las fichas del oponente al mismo color, teniendo para ello que saltar sobre ellas dos casillas. 


\section{$O::^{144}$}

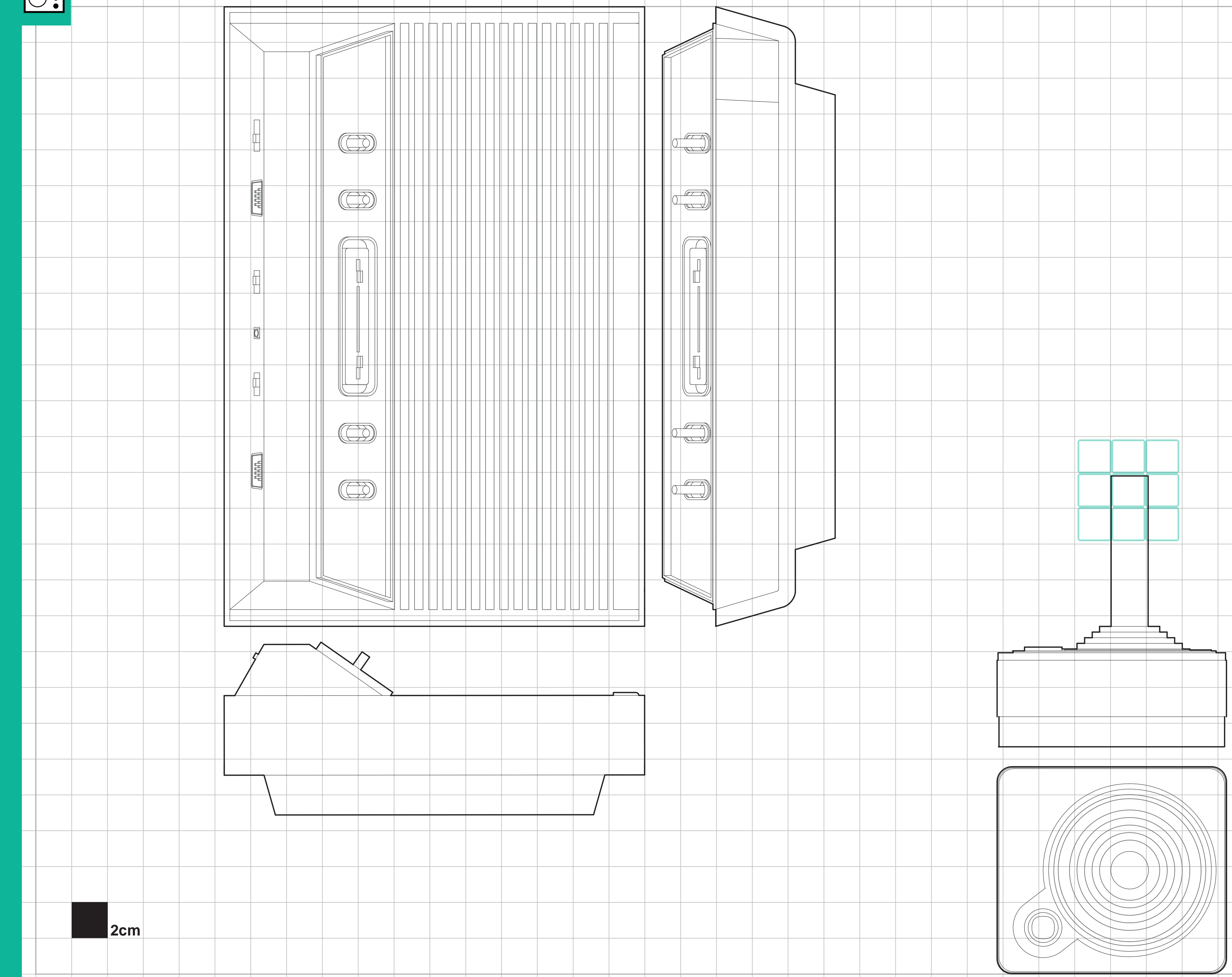




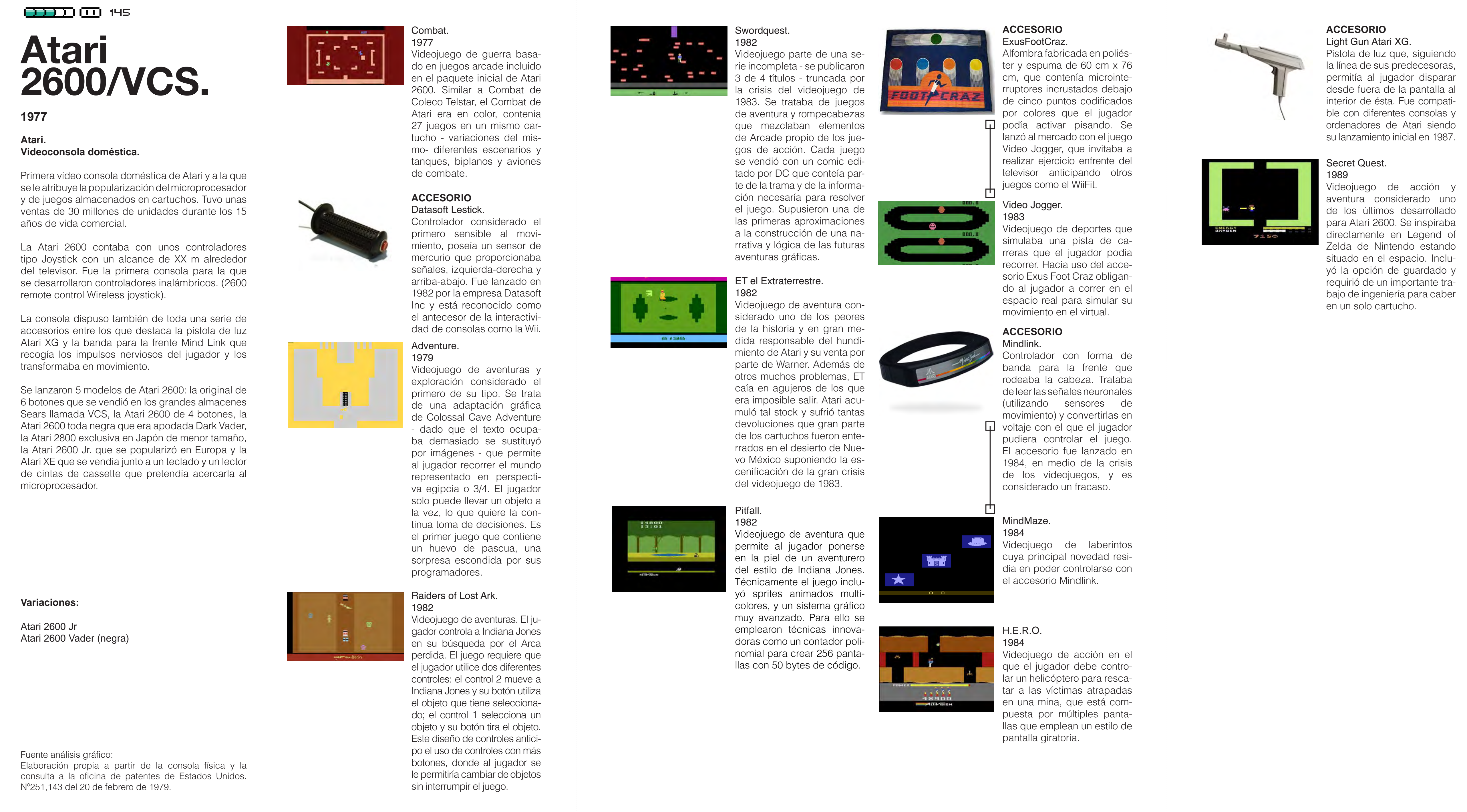


(니트

(๑)
(2) (2. 
피 푸

\section{MUD.}

1978

Juego online.

Mundo virtual online multijugador en tiempo real originariamente basado en texto. Los jugadores podían desarrollar ficciones interactivas, juegos de rol, enfrentar a otros jugadores o chatear en línea, a través de la escritura de comandos. 

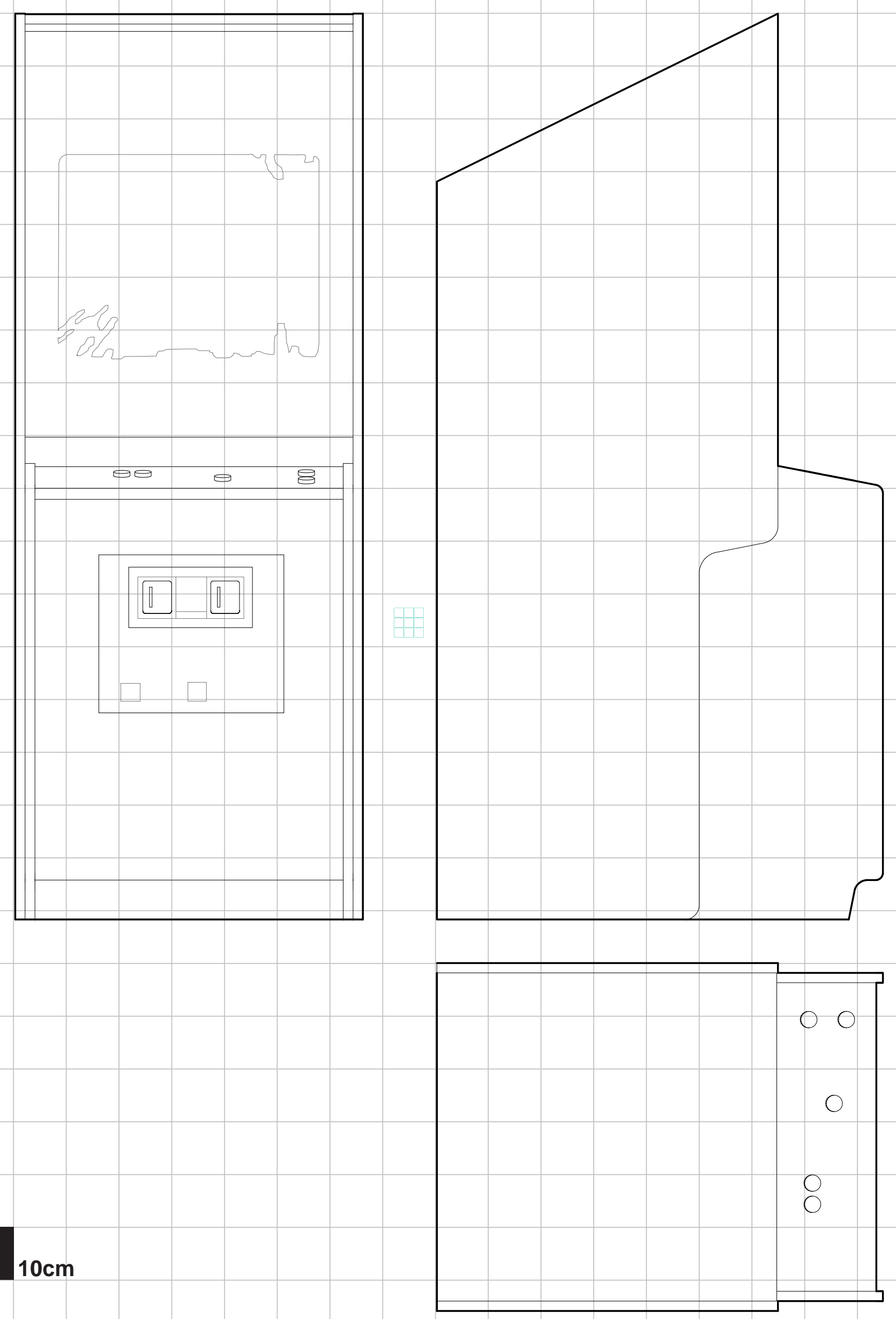


\section{Space \\ Invaders.}

\section{8}

Taito arcade.

Máquina arcade.

Máquina de arcade fue distribuida en Japón por Taito en 1978 (creadores del juego) y en Estados Unidos por Midway, tras negociaciones para su distribución. Disponía de una pantalla CRT de tipo ráster en blanco y negro. Contaba con una cabina clásica vertical con tiras plásticas naranjas y verdes sobre la pantalla para simular el color, sin embargo, en Japón se trataba de un formato de mesa de tipo cocktail con gráficos en blanco y negro.

Space Invaders tomó la idea de utilizar un microprocesador creado expresamente para ella de Gulf Fight. Fue la primera máquina Arcade que contaba con tablero de puntuación y la primera en alcanzar una fama de tal dimensión, provocando incluso una escasez de monedas de 100 yenes en Japón.

"Tuvo un éxito tan rotundo en aquel país que muchas tiendas de verduras y otros pequeños comercios dejaron de lado sus productos y dedicaron todo el espacio de los locales a Space Invaders"

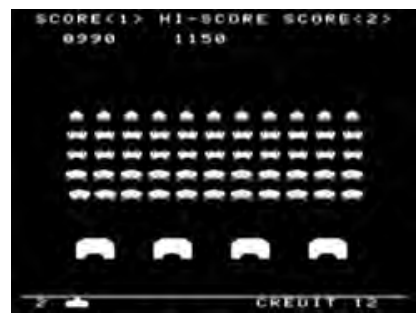

Space Invaders.

1978

Videojuego arcade de tipo 'matamarcianos' concebido originalmente como una prueba para evaluar a programadores e informáticos. El jugador debía eliminar oleadas de alienígenas empleando un cañón láser y cuatro puntos de protección situados en la parte inferior de la pantalla. El único movimiento del jugador era horizontal, de izquierda a derecha.

(Kent, pg 116, 2001) 

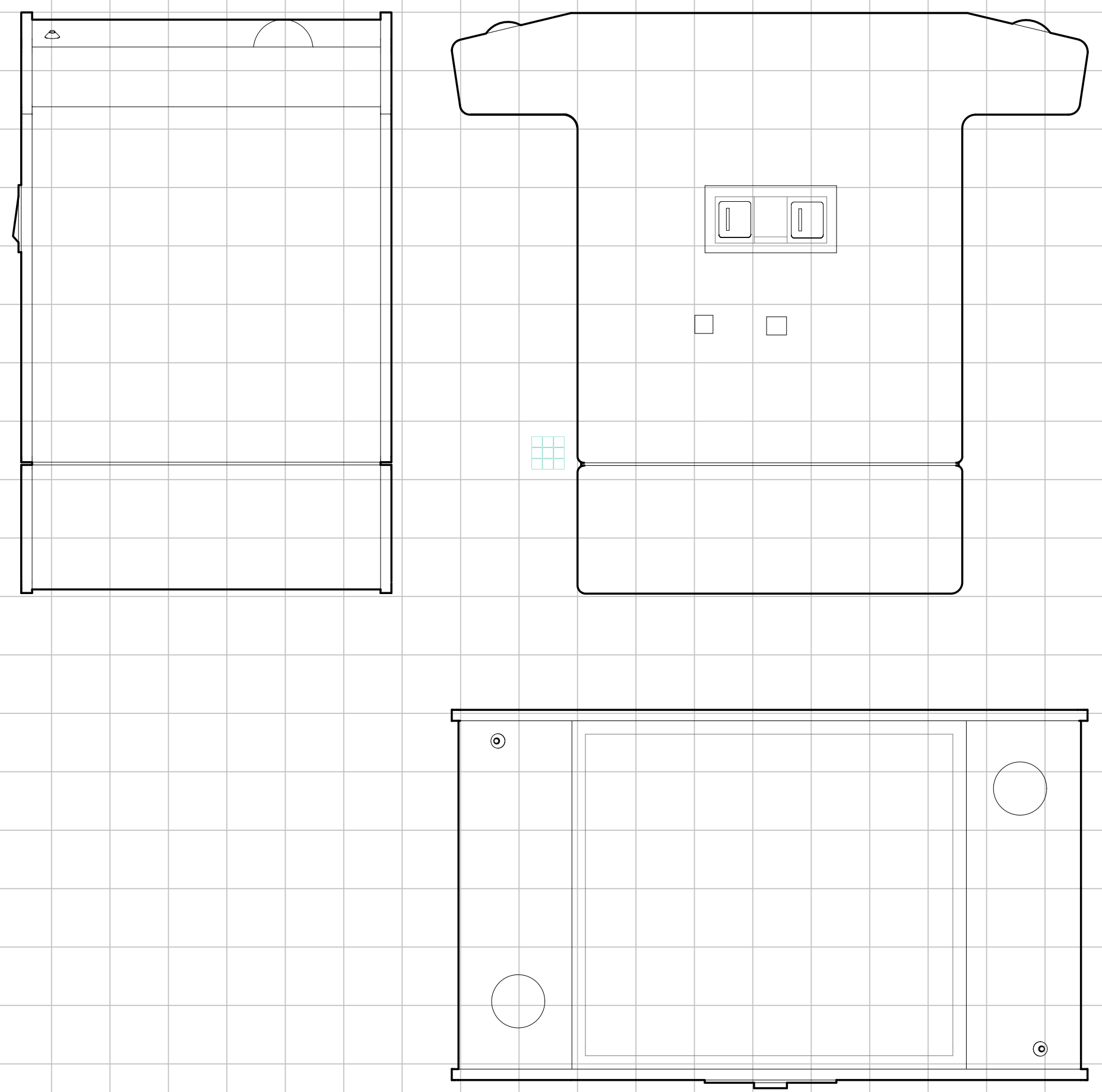


\section{Atari Football.}

\section{8}

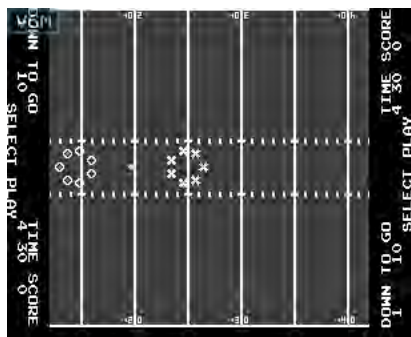

Atari Football.

1978

Videojuego arcade de tipo deportivo pensado para dos jugadores que se enfrentaban sobre una pantalla en horizontal. Los jugadores eran representados por ' $\mathrm{X}$ ' y 'O'.

Atari arcade.

Máquina arcade.

Esta máquina arcade no fue el primer juego de TrackBall, pero sí al que se le atribuye su popularización. Es considerado físicamente agotador por implicar girar la bola dentro del panel de control lo más rápidamente posible. Las partidas medias de 90 segundos podían causar dolor, y si el juego duraba más tiempo ampollas en las manos. Durante la temporada de fútbol de 1978 su popularidad era equiparable a Space Invaders, decayendo posteriormente. 

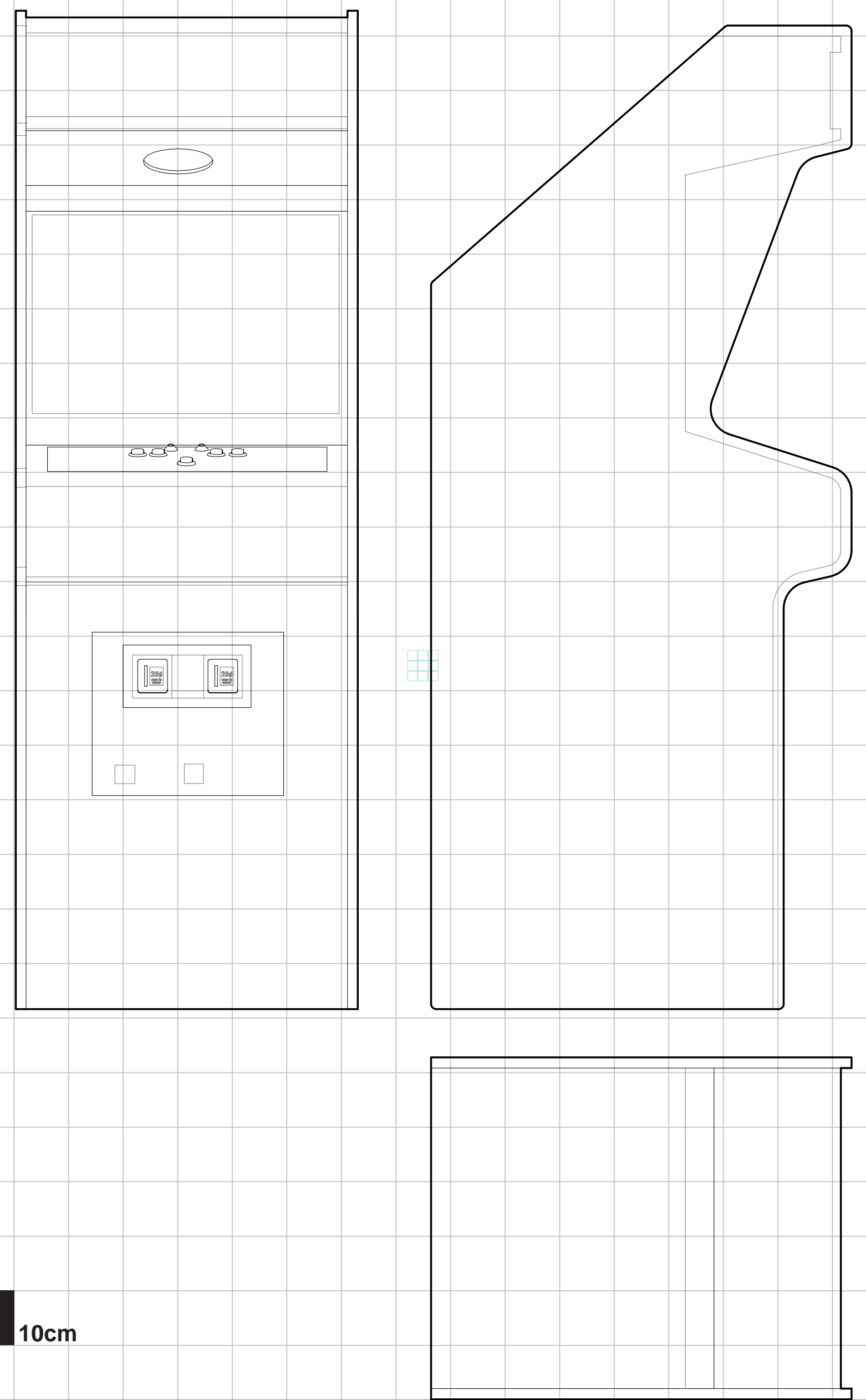


\section{Asteroids.}

1979

Atari arcade.

Máquina arcade.

Máquina de Arcade desarrollada y lanzada al mercado por Atari en 1979, que fue la primera máquina que contaba con tablero de puntuación que permitía añadir las iniciales de los jugadores.

Esta máquina poseía un monitor de gráficos vectoriales en blanco y negro y de 19 pulgadas, Electrohome G05-802/805. Contó con un modelo clásico vertical, un modelo mini y un modelo cocktail.

Al principio, muy pocos jugadores podían conseguir partidas de más de un minuto, ya que era un juego que requería un período de aprendizaje previo. Atari vendió más de 70.000 unidades de Asteroids en Estados Unidos.

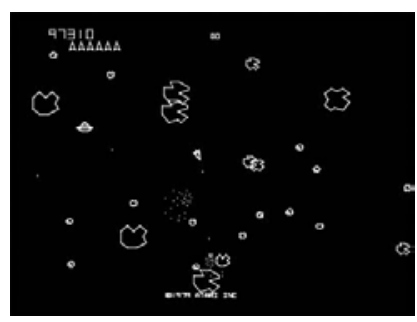

Asteroids.

1978

Videojuego arcade de disparos en el que el jugador debía disparar y destruir asteroides, evitando chocar contra estos y sus fragmentos. Se trata de una

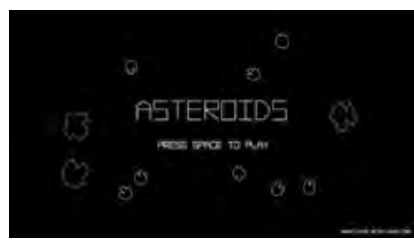
versión de 'Space Wars'. El juego requería mucha resolución por lo que usó gráficos vectoriales. 

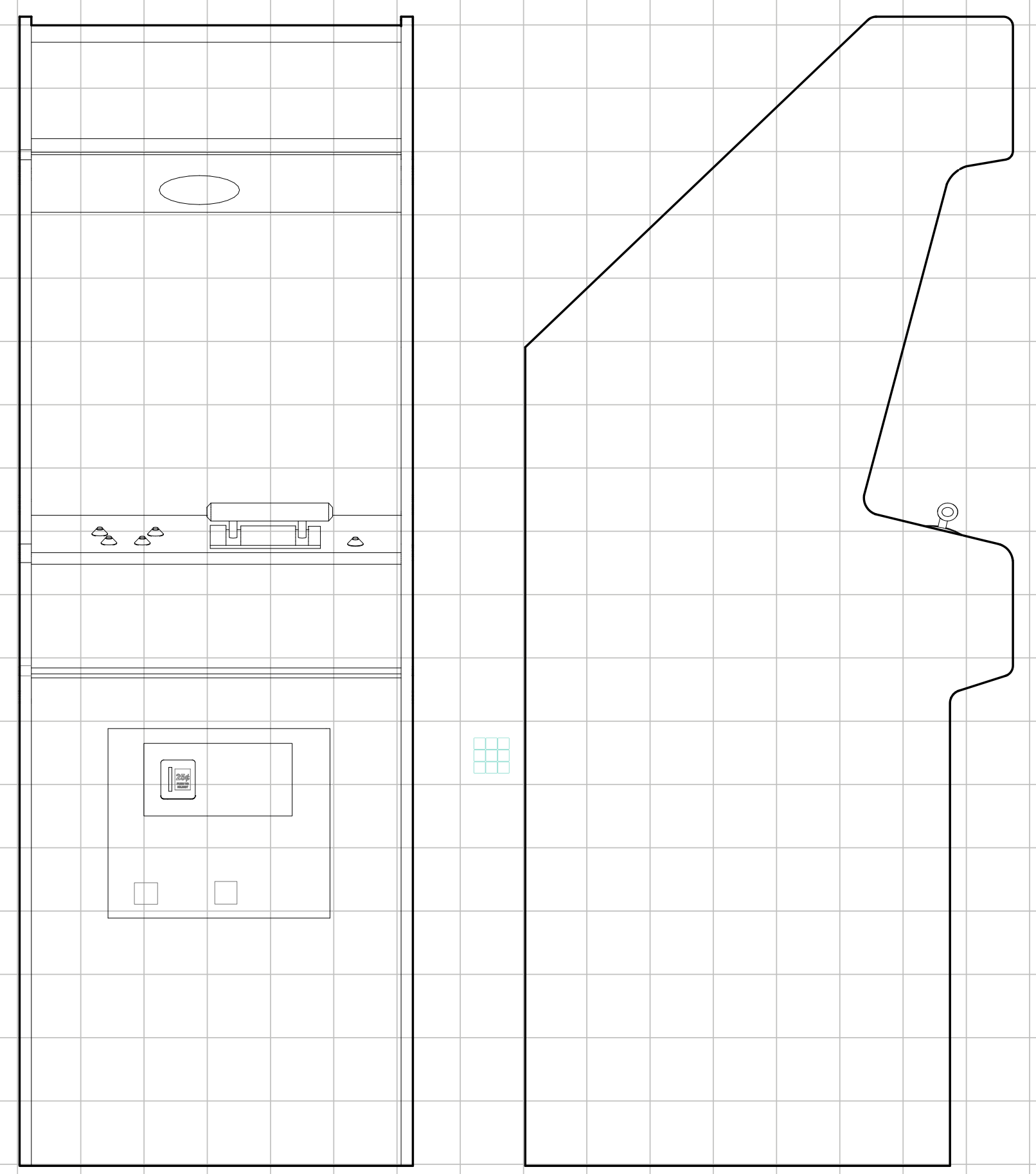


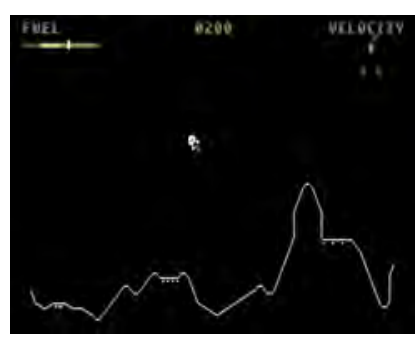

1979

Atari arcade.

Máquina arcade.

Máquina de Arcade desarrollada y lanzada al mercado por Atari en 1979 con gráficos vectoriales y que contaba con un potente hardware desarrollado por el ingeniero de Atari Howie Delman. Contaba con monitor CRT en blanco y negro de 19 pulgadas Electrohome G05-801. Lunar Lander contó con un único modelo de cabina clásica vertical.

El equipo de Atari dotó a esta máquina de una gran palanca de dos manos con la que el jugador podía controlar los motores de propulsión del módulo lunar. Sin embargo, esta palanca contaba con muelles que la devolvían a su posición original al soltar dicha palanca. 

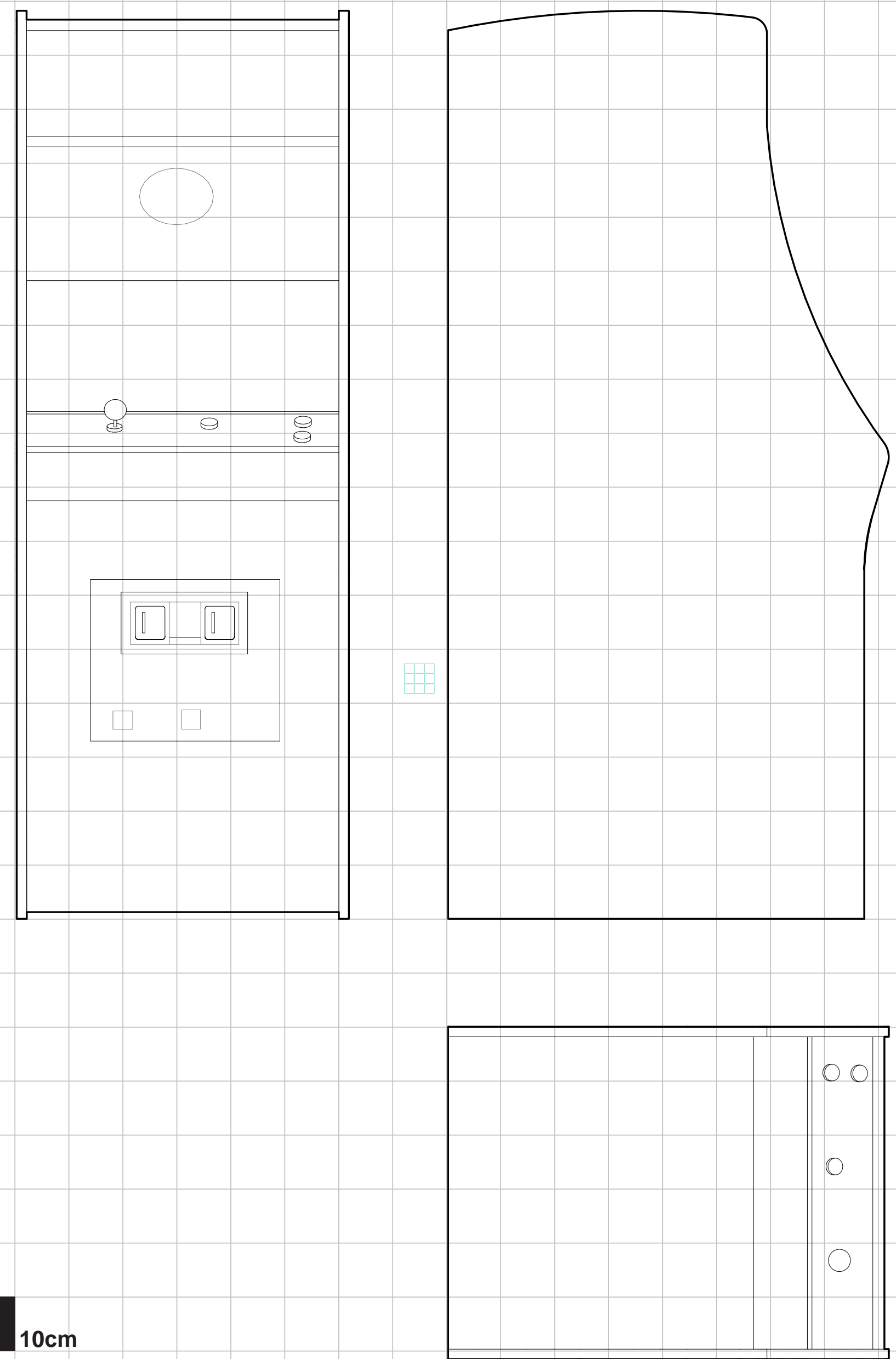


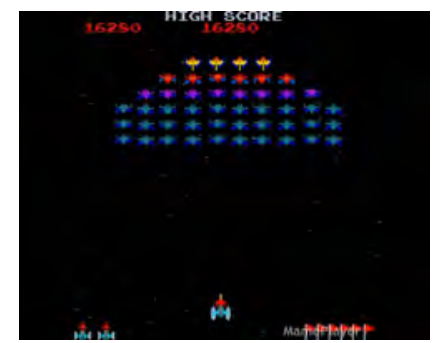

Namco arcade.

Máquina arcade.

Máquina de arcade desarrollada por Namco y distribuida por Midway y que llegó al mercado japonés en 1980. A diferencia de Space Invaders, contaba con un monitor a color y gráficos ráster y, además, permitía movimientos en todas direcciones y no solo verticales y horizontales.

El juego tenía un monitor de orientación vertical, un joystick para mover las naves y un botón de disparos. Contó con tres modelos de cabinas: clásica vertical, cocktail y mini. En Japón esta máquina de arcade resultó ser más exitoso que Pac-Man, tanto que Midway desafió el liderazgo que tenía Atari dentro el mercado de las máquinas recreativas.
Galaxian.

1979

Videojuego arcade de tipo 'matamarcianos' basado en 'Space Invaders' pero con ciertas modificaciones que hacían que aumentase su dificultad al ser los ataques de los extraterrestres de estilo kamikaze. Además, fue el primer juego en presentar sus gráficos completos en color RGB verdadero. 

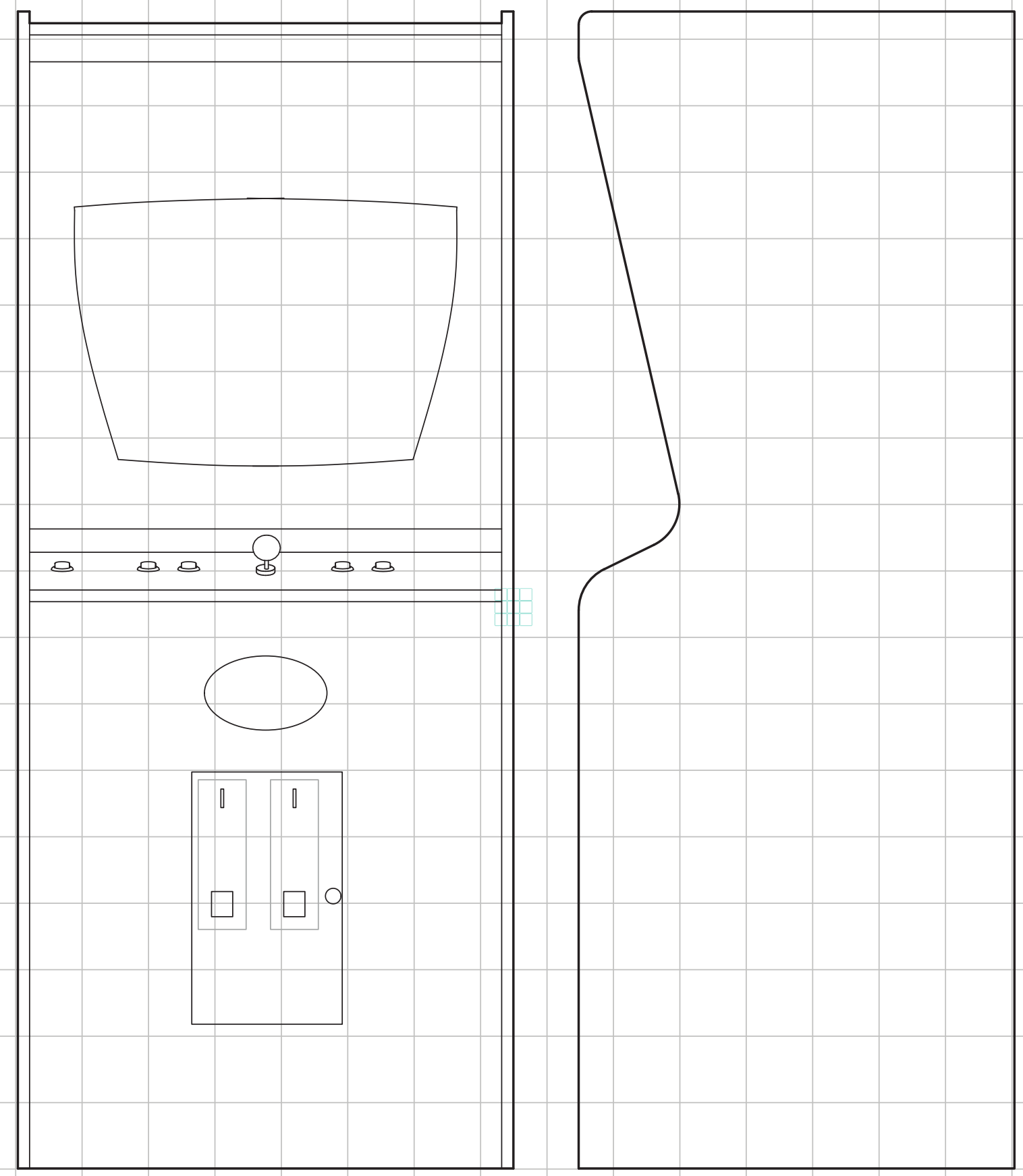


\section{Tail \\ Gunner.}

1979

Vectorbeam.

Máquina arcade.

Máquina de arcade desarrollada y lanzada al mercado por Cinematronics en 1979 que fue pionero por incorporar objetos animados en tres dimensiones.

"Los jugadores tenían que utilizar un pequeño joystick cromado para apuntar con el cañón trasero de una gran nave espacial. El juego utilizaba una perspectiva en primera persona"

(Kent, pg 130, 2001)

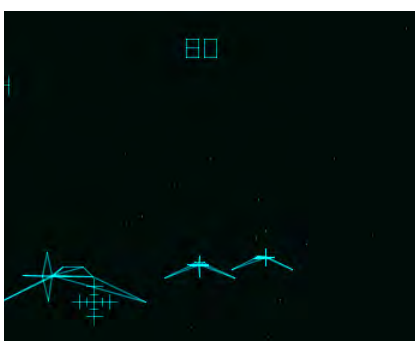

Tail Gunner.

1979

Videojuego de disparos y simulación espacial tipo arcade en el que el jugador controla un artillero de una gran nave espacial. Como consecuencia del punto de vista del juego, se pierde la sensación de adentrarse en el campo estelar y parece que sean los astros los que se desplacen hacia el centro de la pantalla. Fue el primer videojuego con objetos animados en $3 d$.

Esta máquina contaba con un monitor horizontal CRT con gráficos vectoriales en blanco y negro. El panel de control disponía de un joystick analógico y dos botones a cada lado de este (además de uno extra) que servían para disparar y para activar el escudo (protegerse). Contó con un único modelo clásico vertical de cabina. 


\section{$0 ; 5^{1100}$}

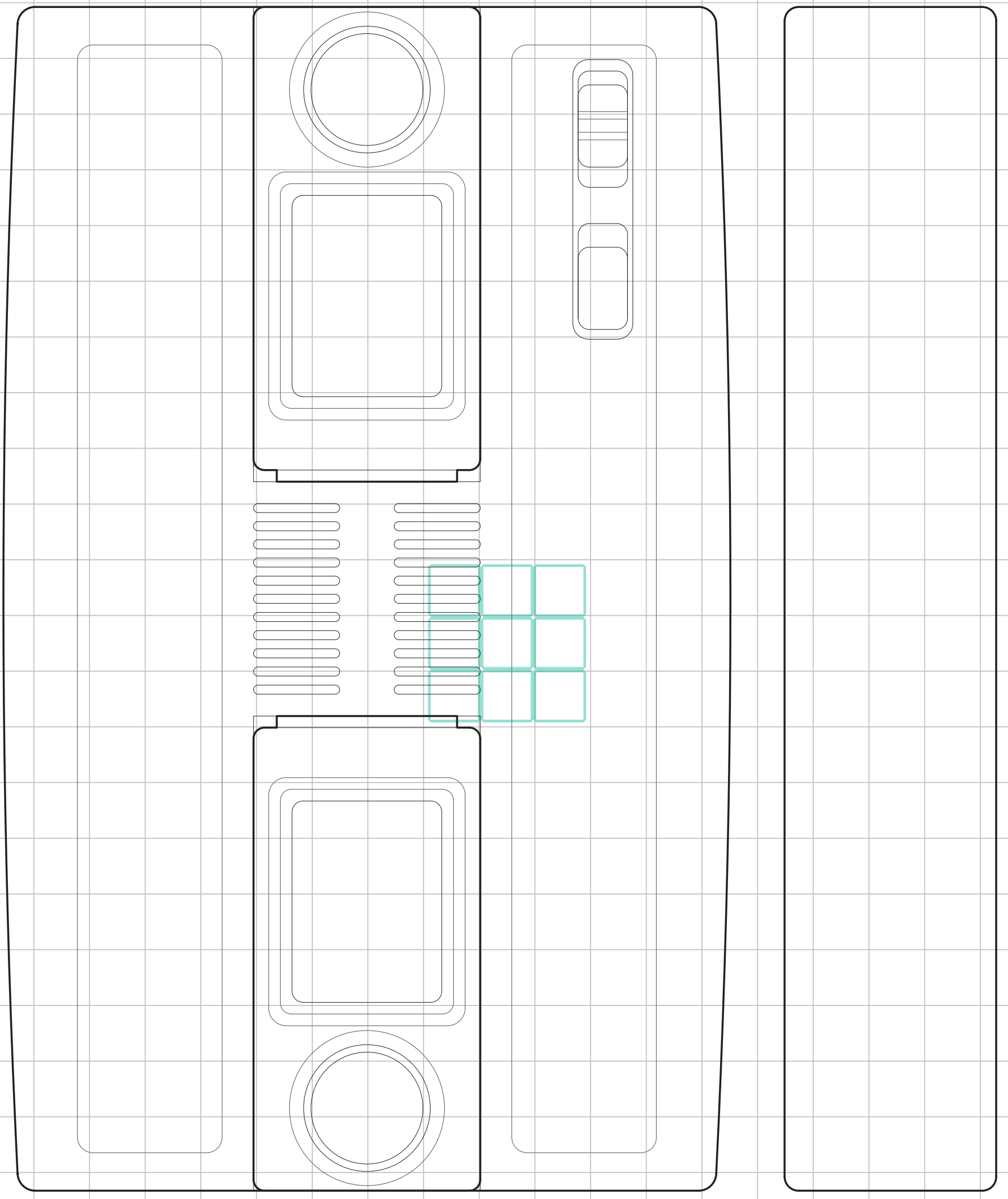




\section{Mattel} Intellivision.

1979

Mattel.

Videoconsola doméstica.

Consola doméstica que vendió más de 3 millones de copias durante su vida útil entre 1979 y 1983.

Se trata de una consola basada en un conjunto de chips y no en microprocesadores. Mejoraba los gráficos y el sonido de la Atari 2600, y poseía dos controladores con 9 teclas numéricas y con un dial circular cada una. Estos controladores tenían una escasa longitud de cableado.

Se distribuyó un teclado que convertía la Intellivision en una especie de computadora doméstica modular, pudiendo tambien anadirse una lectora de cintas de casete. Posteriormente, se diseñó una impresora termica de 40 columnas y un modem telefonico junto a un sistema de reconocimiento de voz, accesorios Etos tres ullimos que no llegaron a popularizarse. En 1983 Mattel introdujo la nueva versión, Intellivisión II. La nueva consola era fundamentalmente un rediseño estetico y mas compacto que su predecesora, incluyendo una entrada de video en el poder leer cartuchos de la Atari 2600.

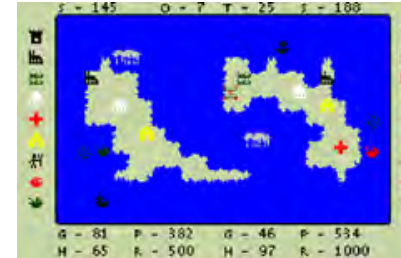

Videojuego de estrategia citado habitualmente construcción de ciudades control tipo 'dios' (donde el jugador controla el mundo). En Utopia no existe una IA a la que enfrentarse si no que deben participar siempre dos jugadores que controlan dos islas. Los algoritmos de juego generan y determinan el curso de las nubes de lluvia, tormentas tropicales, huracanes, bancos de peces $y$ barcos piratas. Formo parte de la selección de la exposición "The Art of Video Games" de Smithsonia Institution

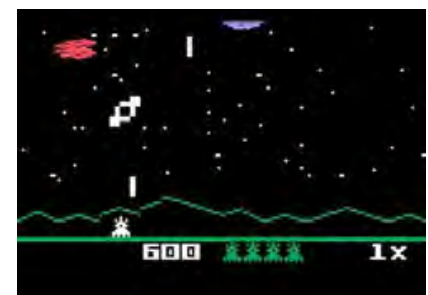

Astrosmash

198

Videojuego de disparos y temática espacial. El jugador controla un canon laser que puede desplazarse hacia la izquierda o hacia la derecha a lo largo de un plano para apuntar a objetos que caen (meteoritos grandes $\mathrm{O}$ pe queños, bombas giratorias grandes o pequeñas, misiles guiados...). El jugador no se enfrenta al fuego enemigo directo, no puede esconderse en ningún tipo de protección y el juego no termina cuando los objelvos golpean el suelo. El juego tiene seis niveles, cada uno de los cuales presenta mayor velocidad puntuación. Cada nivel está de diferentes colores.

\section{ACCESORIO}

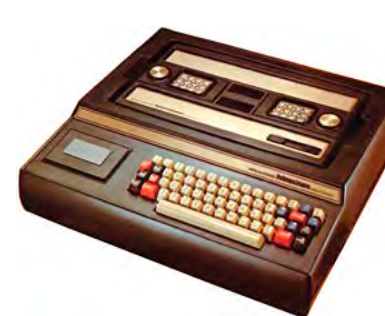

Keyboard Component.

Teclado diseñado para con-

vertir la consola en un orde

nador modular. Posela lector de cintas de casete lo que juegos en este

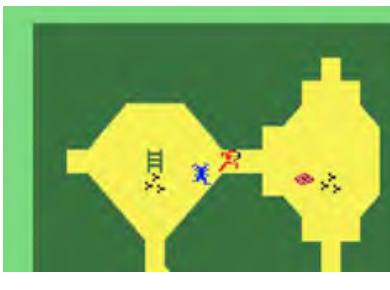

Advanced Dungeons \& Dragons. 1982

Videojuego de acción y avenuna que permite explorar ados aleatoriamento busca tesoros y armas con las que derrotar a los monstruos recuperar las dos piezas de la Corona de Reyes. El jugador debe guiar a la figura a través de un laberinto, que inicialmente está envuelto en a oscuridad. A medida que la figura explora, el espacio aparece, revelando más de aberinto. Esta idea de que el espacio aparece según el jugador explora continúa utilizándose en muchos juegos producidos desde entonces.

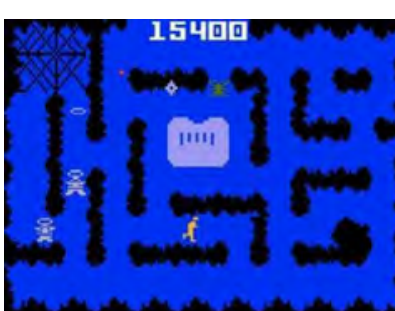

1982

Videojuego de disparos laberintos en vista aérea. El jugador controla un persona- atrapado en un laberinto donde los puntos de recarg de balas (5) tienen una posición aleatoria.

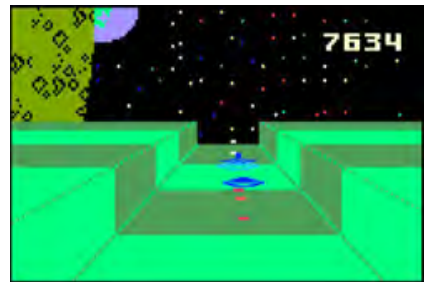

ar Strike.

Videojuego de disparos en el espacio en el que el jugador salvar la tierra de un arma que le apunta para escena de Star Wars Episode IV en que Luke destruye la Estrella de la Muerte.

\section{ACCESORIO}

Intellivoice.

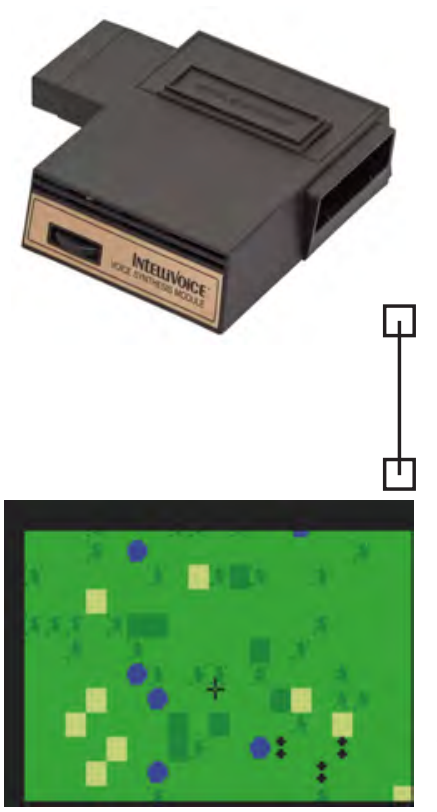

dor de voz que permitía al jugador aportar inormación al juego de forma oral Se empleó por primer vez en el juego B-17 Bomber.

B-17 Bomber.

1982

Videojuego acción que

empleó el módulo de voz

Intellivoice para alertar el

jugador de la posición en el

espacio de los enemigos. 


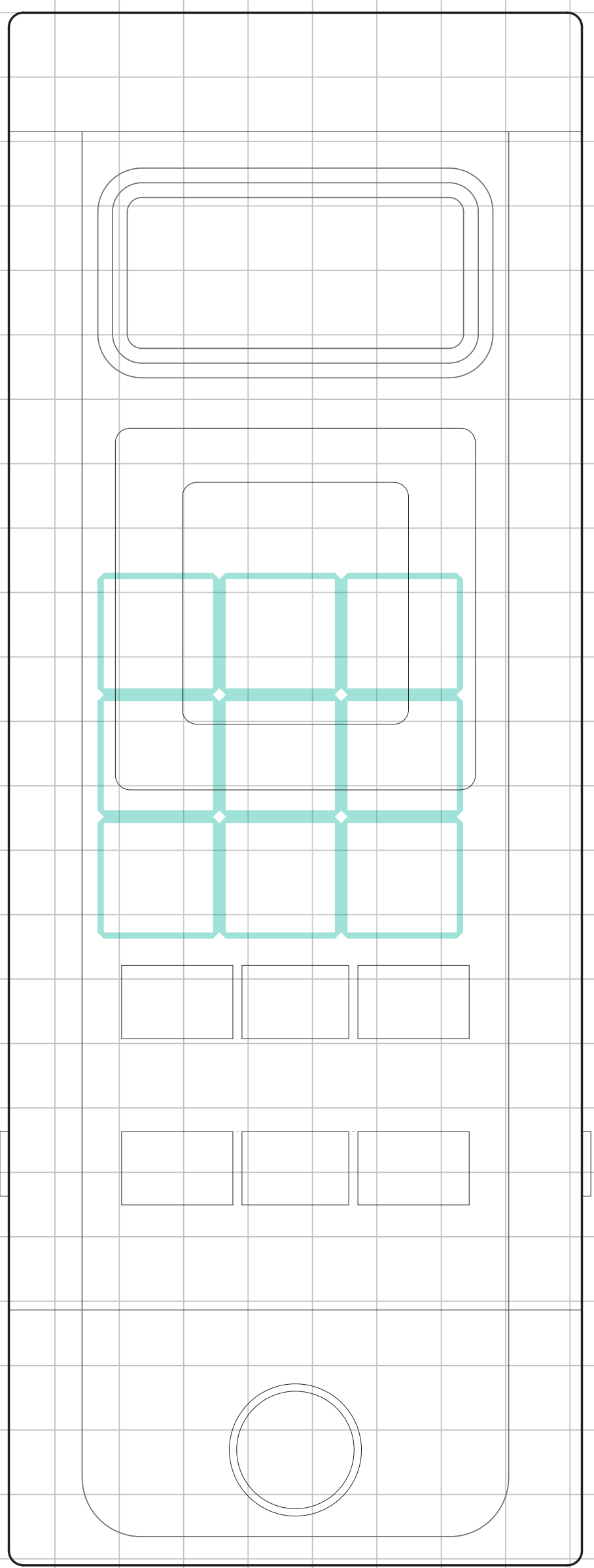




\section{MB \\ microvision.}

\section{9}

\section{Milton Bradley Company.}

Videoconsola portable.

Primera consola portátil de la historia que contaba con cartuchos intercambiables. Fue lanzada al mercado por Milton Bradley Company en 1979 y dejó de fabricarse en 1982. Esta consola contaba con una pantalla LCD de 16×16 píxeles y no disponía de un procesador integrado, sino que estos se encontraban en los cartuchos de juego.

Los primeros cartuchos de la Microvision usaron procesadores Intel 8021 , pero pronto MB cambió a TMS1100 puesto que permitía una mayor capacidad de memoria.

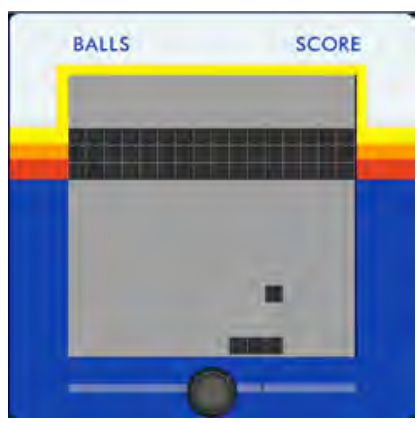

BlockBuster.

1979

Videojuegos intercambiables muy básicos inspirados en juegos de arcade y pinball en una pantalla de $16 \times 16$ bits 

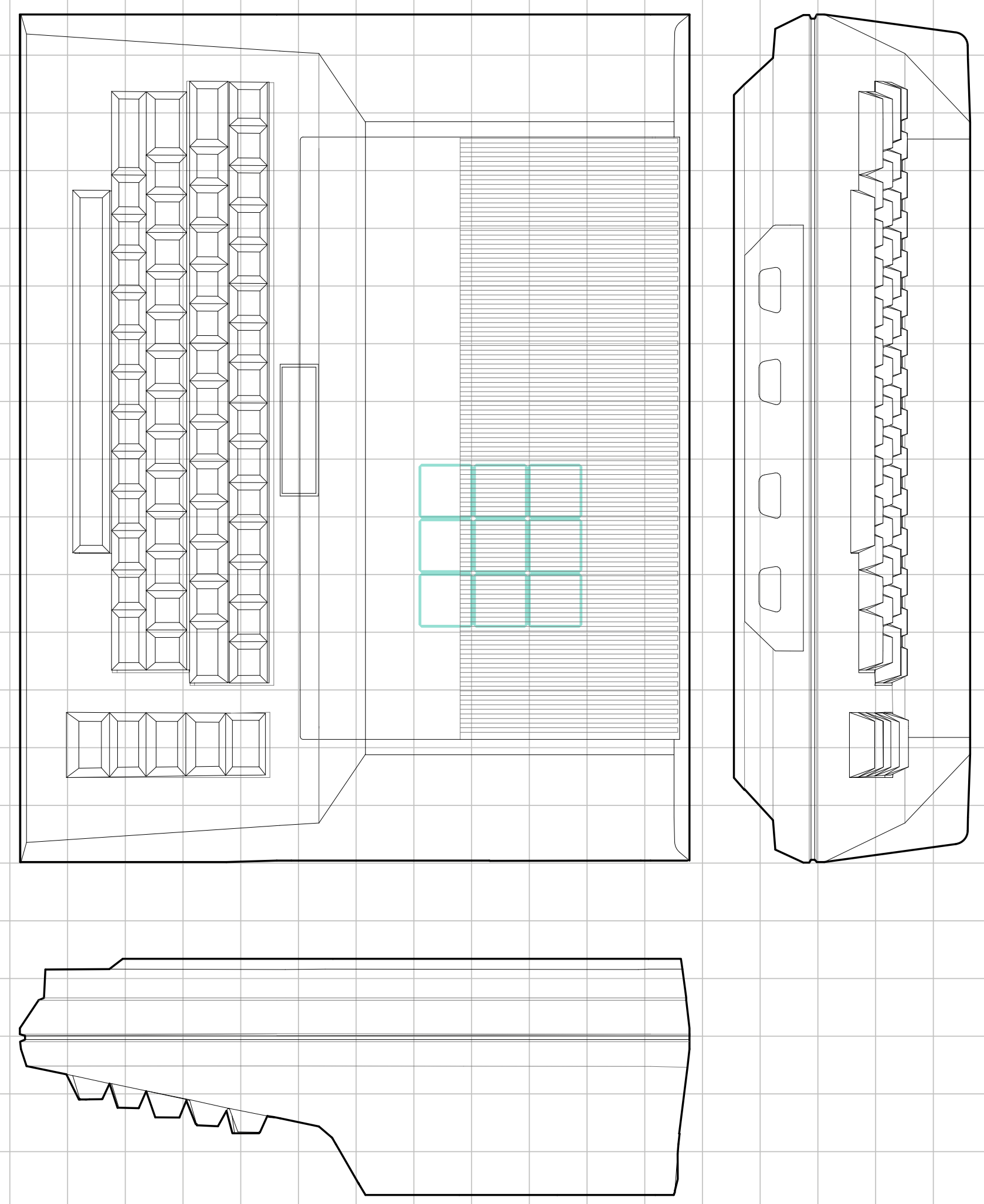


\section{Atari 8-bits.} 1979 Atari.
Ordenador personal.

Familia de microordenadores de la marca Atari que

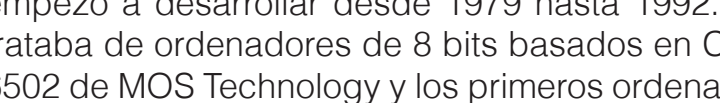
(1) Entre los ordenadores de esta serie se incluyen
Atari 400, Atarir 800 y las series XL $y$ XEE Esta titi-
mat también se lanzo en formato de videoconsola Ilamada Atari XE Eame System. Respecto a la me-
moria, "al principio, el 400 tenía 4 Kb de RAM; y el moria, "al principio, el 400 tenía $4 \mathrm{~Kb}$ de RAM; $y$
$800,8 \mathrm{~K}$. Después se aumentó a $48 \mathrm{~Kb}$ " (Donovan, El desarrollo de esta línea de Atari comenzó justo
después del lanzamiento de la 2600 , previendo la contra los ordenadores domésticos de la déceadi: contra los ordenadores domésticos de la décad
el TRS 80, el Apple Il y el Commodore PET.

Variaciones:

Atari XE Game System (videoconsola doméstica)

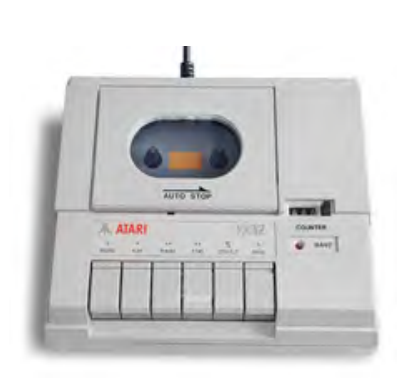

ACCESORIO
800xI Tape Drive.

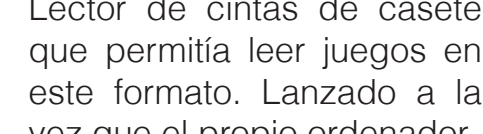

ACCESORIO
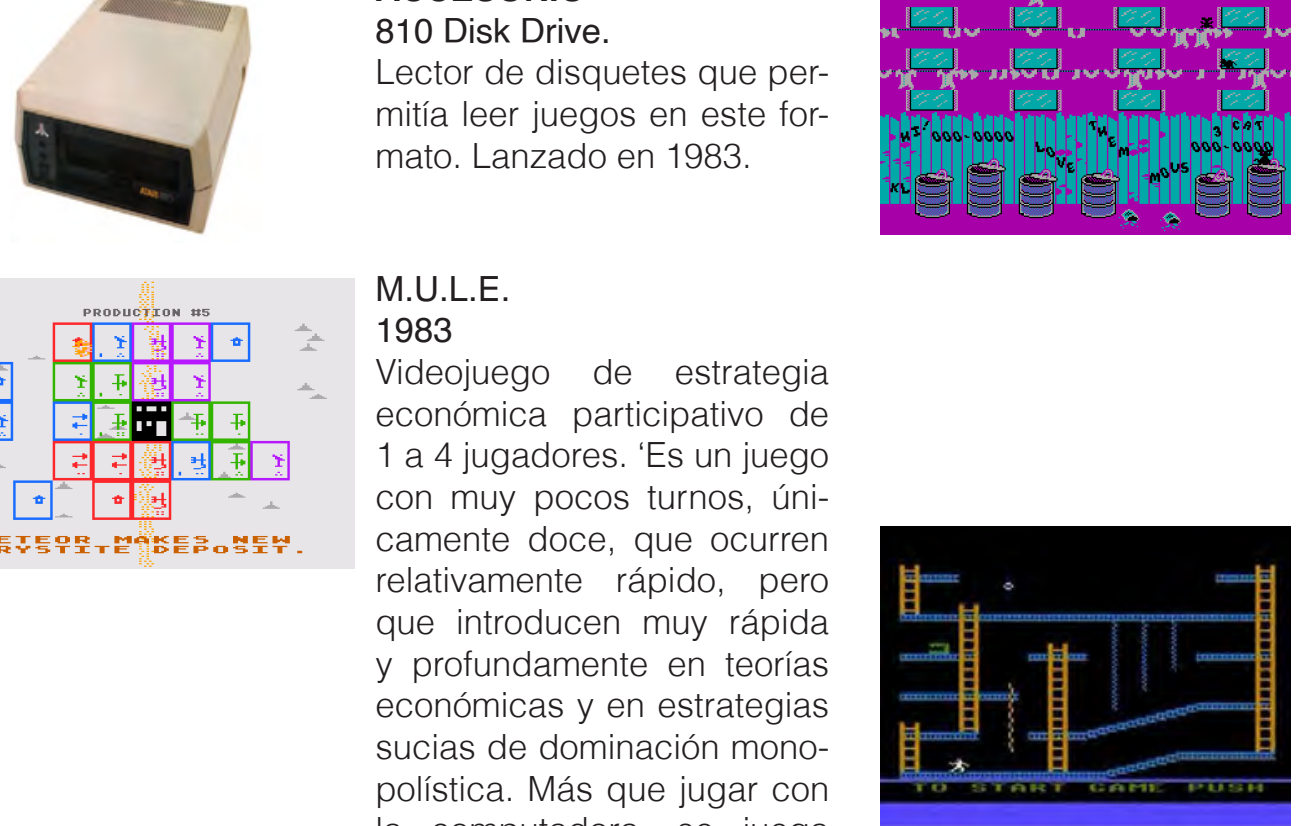

Videojuego de tipo arcade
con minijuegos y partes de
aventura. El juego permite

jugador controlar a un gato
que debe entrar en todas

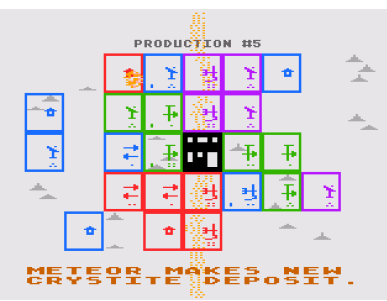

un callejon en las que
completarse difieren

Star Raiders.
1979

Videojuego de simulación de
combate espaciale en primera

combate espacial en 30 id en-
cre la nave del jugador y una

Iota invasora de naves alie-
nigenas "Zylon"." Star Raiders

oss, que, además de mostrar
afierentes vistasas de explo-

acance, proporcionaban vis

las en primera persona hach
adelante y hacia atrás, con

un campo de estrellas en $3 D$
$3 D$

laba a la nave espacial ene

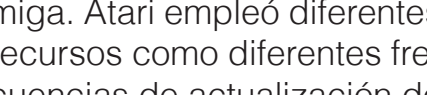
los sprites, para conseguir su

- srectunker

Miner 2049er

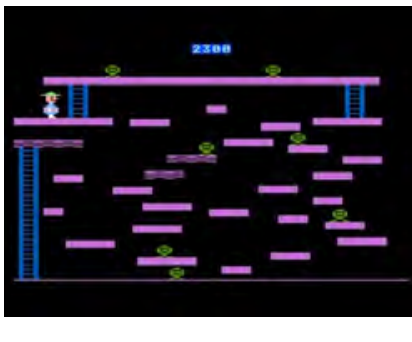

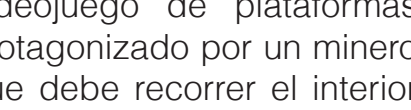

de la tierra. En el momento
de su lanzamiento y con 10

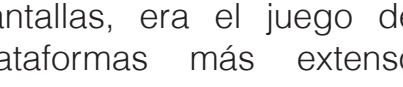

4 pantallas). La mayoyria de
de

los niveles continenen alacun
elemento personalizado, que

varía de un nivel a otro. En
Jas fue 'El juego electrónico

ACCESORIO

B50 Expansion System.
Módulo que añadia dos puer

tos de conexión extra que
permititian conectar joysticks

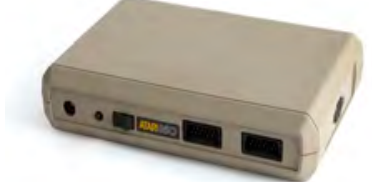

mplantarlo y sembró el pun-

completarse diferentes
ones que al finalizar nos

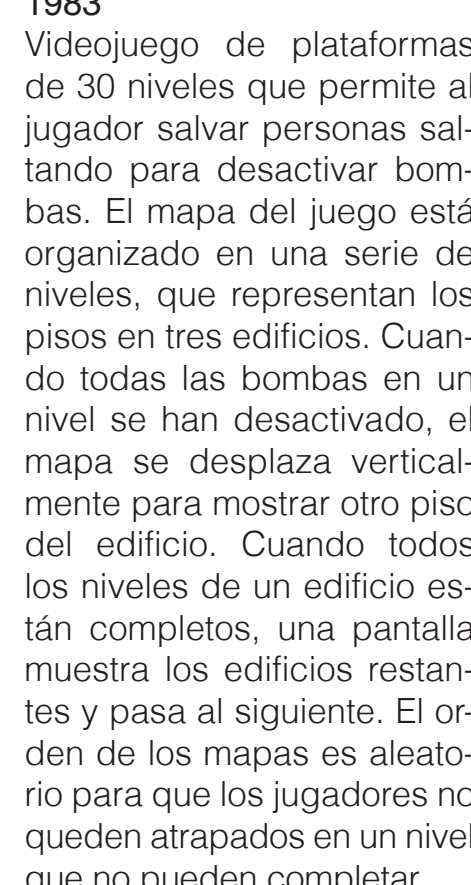

la computadora, se jueg
con el resto de personas te vigilar los guiños de as ciones de los demás para
cimient

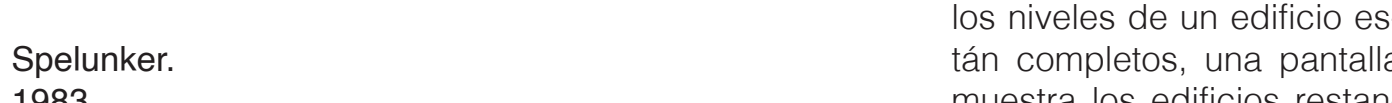

Spelunker.
Videojkego de acción y pla-
Vider

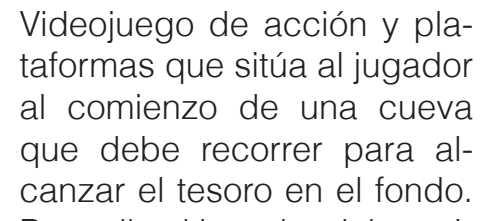

Para ello el jugador debe evi-
tar obstáculos saltando yn
quedarse sin arre (que puede

reponer en algún punto). La
cueva tiene 6 niveles conec-

tados entre sí que forman un

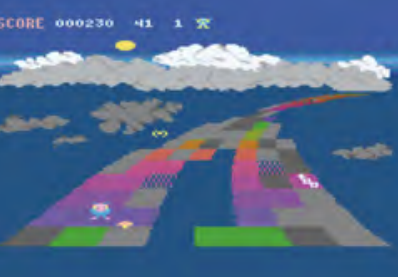

Rainbow Walker.

d

ACCESORIO

Altarl que podia utilizarse
como controlador

deojuego de acción que
basa su estructura en un
aco que se curva (simulan-

do un falso $3 D$ ) y que debe
colorearse (al comenzar e
todo gris). Fue parte de estrategia comercial que
mociono juegos en disautest que contenía un segundoj ju-
go al otro lado del disquete.

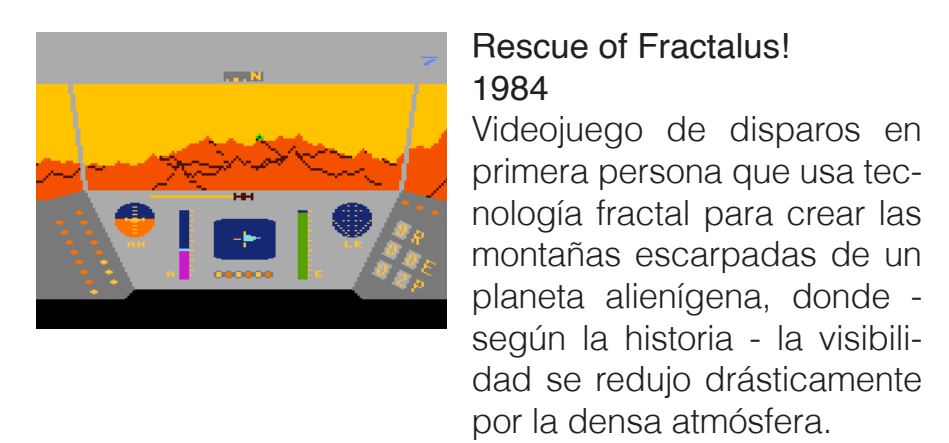

Archon: The Light and the Dark
Videojuego de estrategia que por se reaujo diasticanta

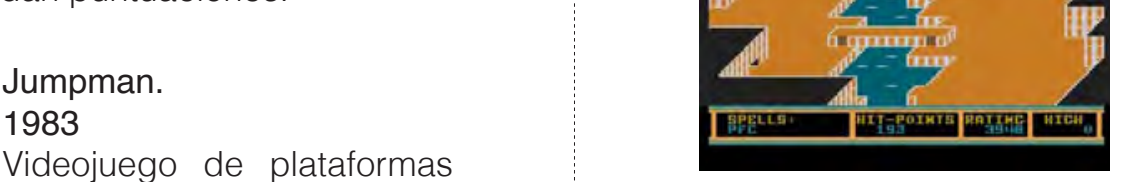

ACCESORO

Impresora que perter.
genestia imá.

CX40 Standard Joystick.
Joystick de diseñotipico de
Atari que podia utilizarse

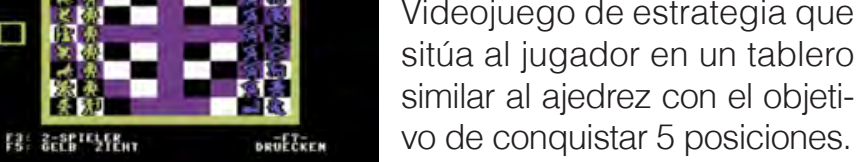

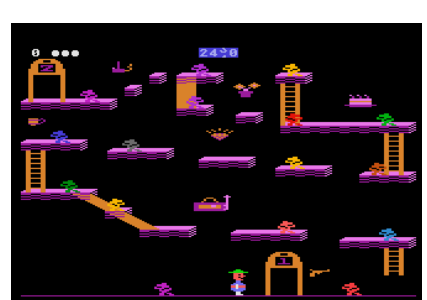

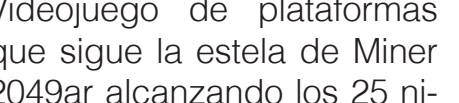

veles $y$ generando un aspec-
to de pseudo-3D.

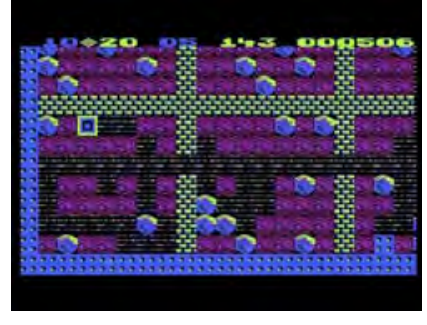

Boulder Dash.

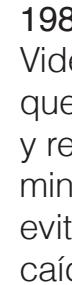

elego de lógica en el

minado de piedras preciosas,
evitando a los enemigos y
caídas de rocas. Destaca por

importancia del movimier

tos y la direccion del jugador
para poder resolver el puzz

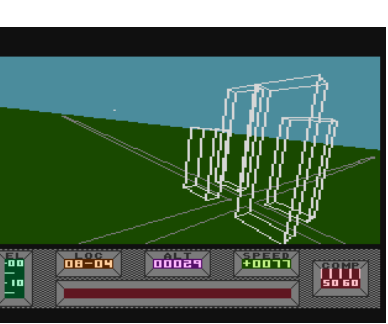

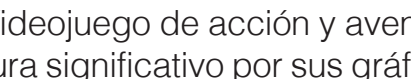

cus extensoss entorionos y $y$ afierentes maneras de con-
pletar cada partida. El ento-j-
no del juego so p. pletar cada partida. El entor
no del juego se presento uth
lizando graticos de alambre 

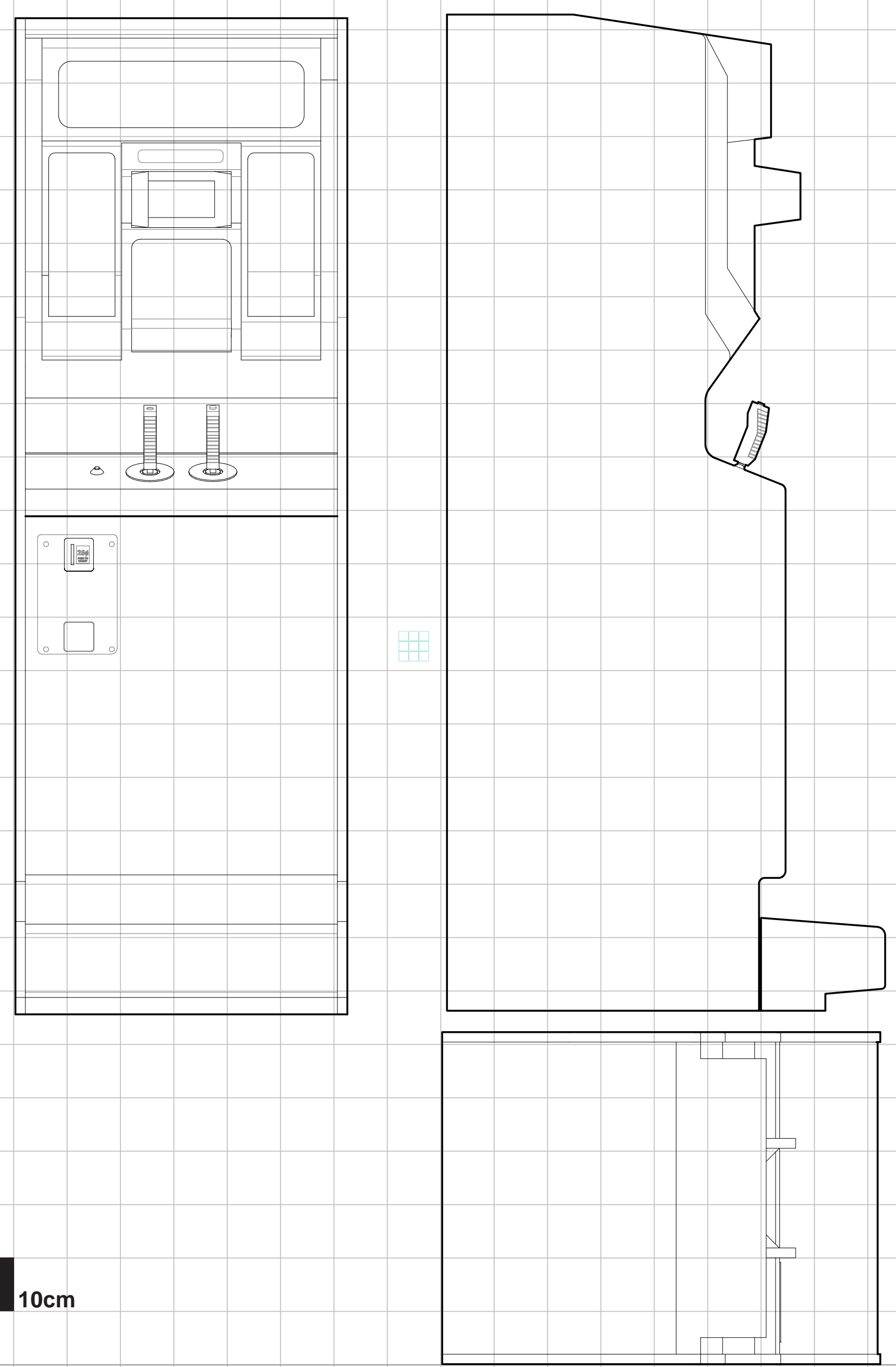


\section{Battlezone.}

\section{0}

Atari arcade.

Máquina arcade.

Máquina de arcade desarrollada y lanzada al mercado por Atari en 1980, contaba con gráficos vectoriales y un monitor de 19 pulgadas en blanco negro con láminas superpuestas para dar sensación de color al juego. Contó con varios modelos de cabina: dos modelos clásicos en vertical (uno con profundidad y otro abierto), un modelo cocktail y un modelo mini.

Battlezone contaba con un visor rígido de plástico que simulaba el periscopio de un tanque, para potenciar la sensación inmersiva en el juego, y que obligaba al jugador a mirar a través de este. Sin embargo, no servía para apuntar ya que el tanque solo disparaba en una dirección (hacia delante). El jugador tenía dos controladores de joysticks para dirigir al tanque y ocho botones en el panel de la cabina.

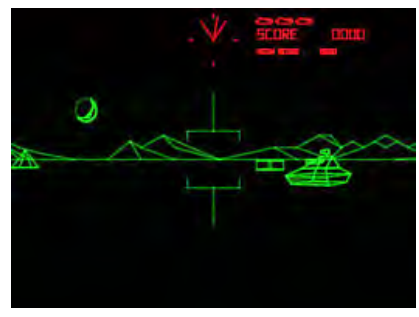

Battlezone.

1979

Videojuego de guerra que actualizaba la temática de combates de tanques. Battlezone usaba gráficos vectoriales y se trataba de un juego en primera persona. El escenario era una llanura en 3 dimensiones que servía como campo de batalla. Había bloques y pirámides que daban profundidad $y$ permitían esconderse al jugador de los disparos enemigos y un volcán que escupía fuego en el horizonte. El juego tenía un visor en forma de periscopio a través del cual se veía la pantalla que simulaba la sensación de encontrarte dentro de un tanque. Los controles eran dos joysticks grandes y existía además un radar en la parte superior de la pantalla que mostraba la posición de los enemigos. Posteriormente al lanzamiento, el ejército de Estados Unidos solicitó una versión profesional para entrenamiento. 

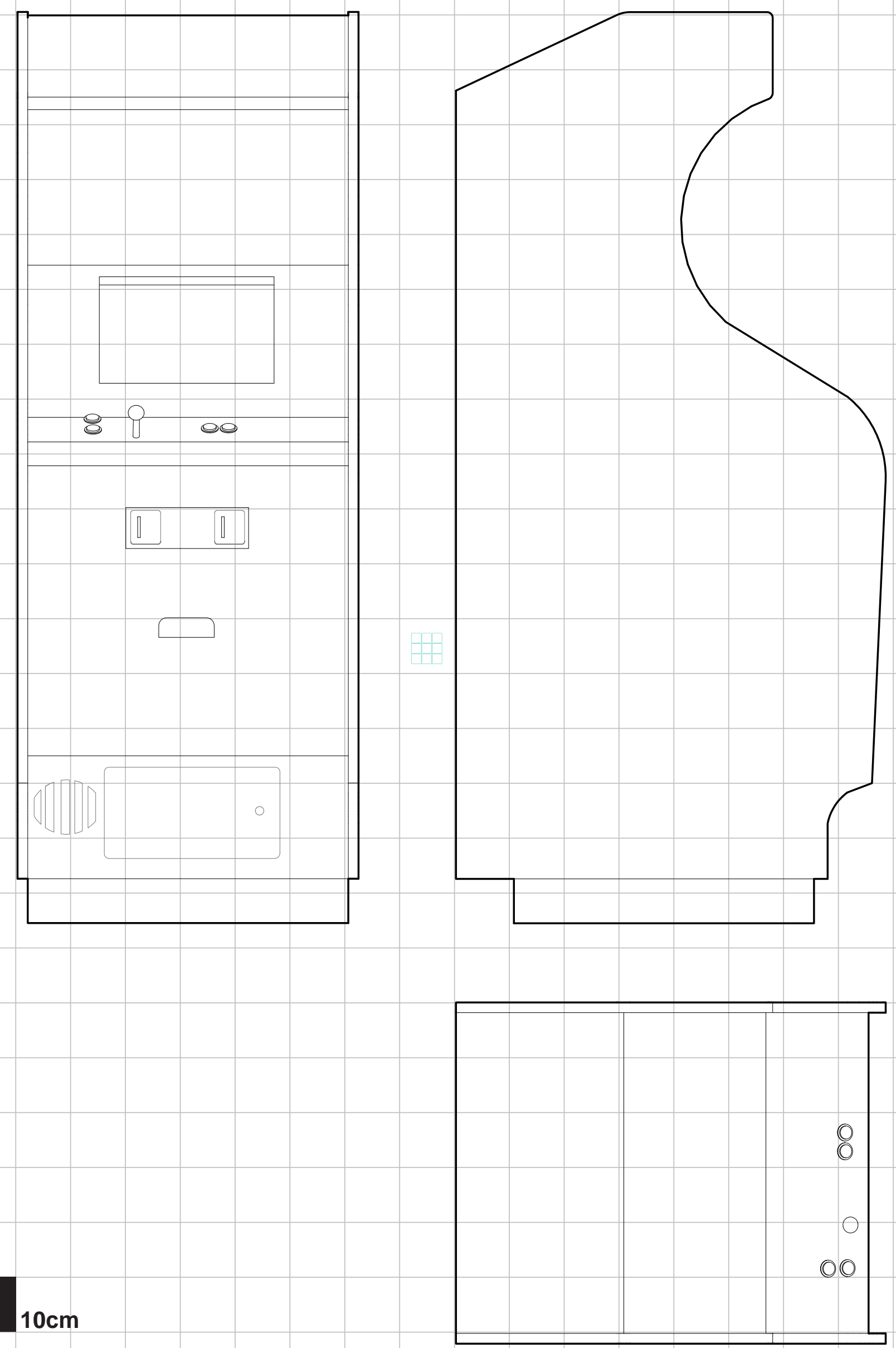


\section{Space}

\section{0}

\section{Universal Entertainment Corporation. Máquina arcade.}

Máquina arcade desarrollada y lanzada al mercado por Universal Entertainment Corporation en 1980 y que es conocido coloquialmente como "el abuelo de los juegos de plataformas". El juego se visualizaba en un monitor vertical CRT con gráficos ráster en color (y una resolución 336 × 240 píxeles).

Contó con varios modelos de cabina: el clásico vertical, el modelo mini y el modelo cocktail. El jugador disponía de un panel de control basado en un joystick que permitía mover al personaje en cuatro direcciones (arriba, abajo, izquierda y derecha) y con dos botones.

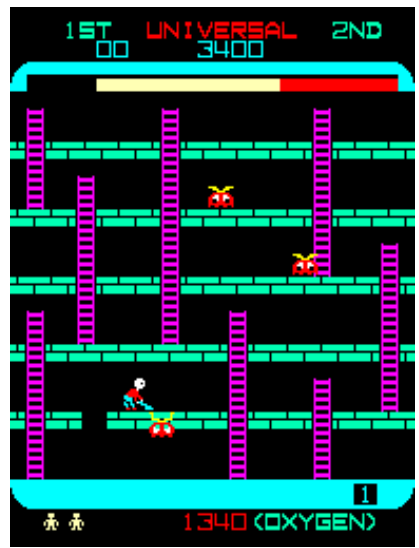

Space Panic. 1980

Videojuego arcade de tipo plataformas considerado pionero de este género que, sin embargo, carece de la mecánica de salto propia del mismo. El personaje principal debía cavar agujeros en plataformas a los que debía atraer a extraterrestres enemigos. Existían limitaciones de oxígeno que actuaban como temporizadores. 

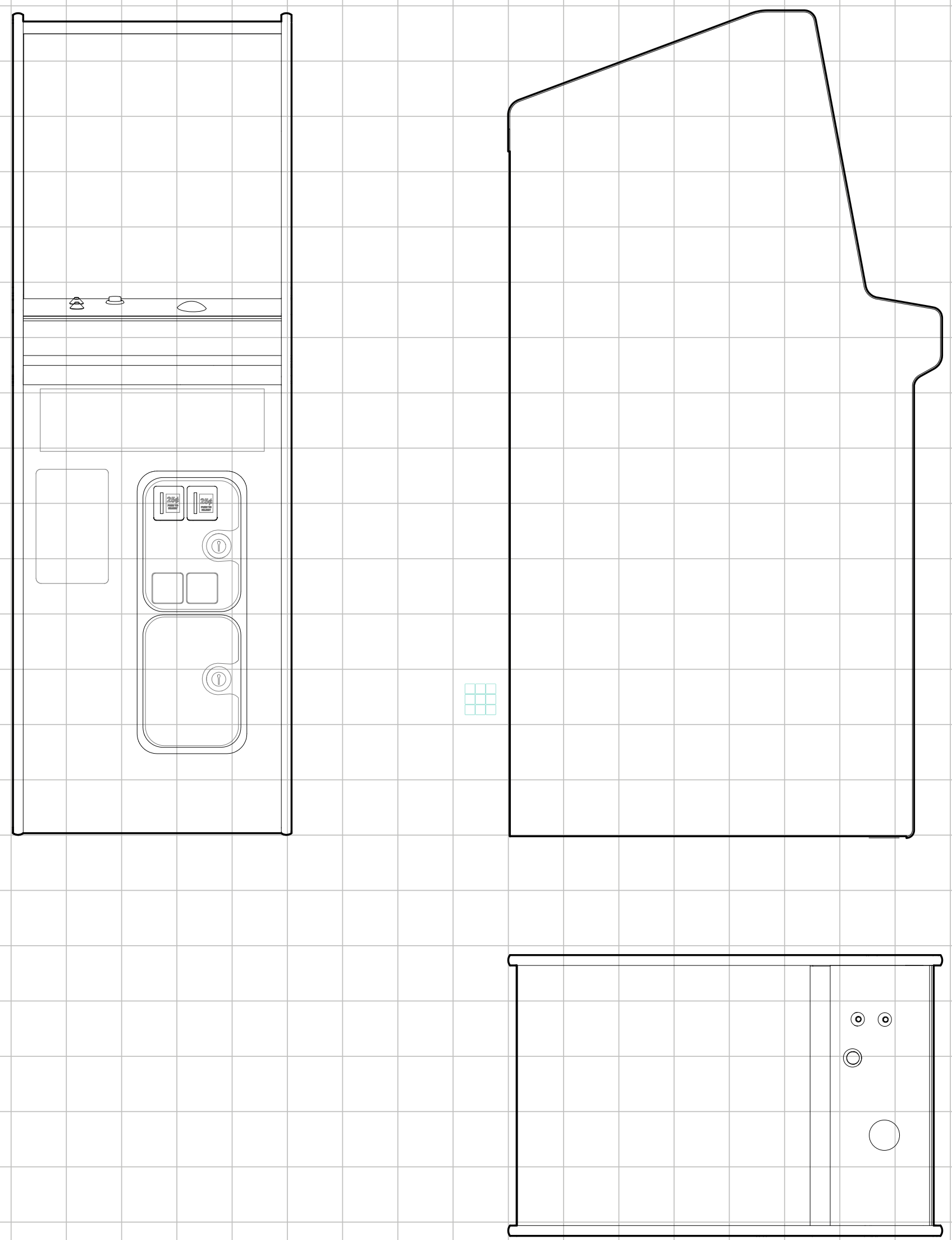


\section{Centipede.}

\section{0}

Atari arcade.

Máquina arcade.

Máquina Arcade desarrollada y publicada por Atari en 1981 que disponía de un monitor CRT con gráficos ráster a color. Esta máquina contó con varios modelos de cabina, entre ellos el clásico vertical, el modelo mini y el modelo cocktail. El panel de control del jugador se basaba en un trackball con el que podía moverse por la parte baja de la pantalla en modo de cursor con forma de cabeza de serpiente, además de un botón de disparo.

Este fue el primer videojuego diseñado por una mujer, Dona Bailey, que, por primera vez, usó una trama de colores pasteles para el juego, cuando lo normal era que los diseñadores optasen por colores brillantes y estridentes. De la programación de Centipede se encargó Ed Logg. Este juego fue especialmente popular entre las mujeres jugadoras.

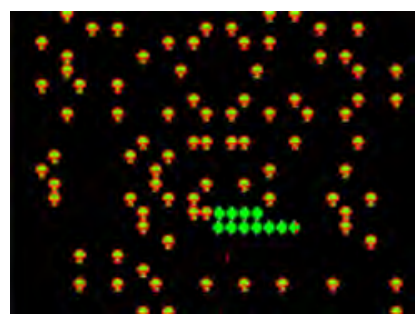

Centipede.

1980

Videojuego arcade de tipo acción matamarcianos en el que el jugador lucha disparando contra diferentes insectos como ciempiés, arañas o pulgas. El juego

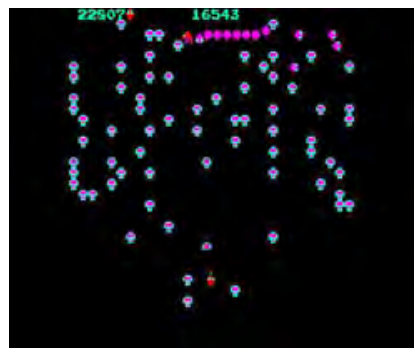
fue programado por una de las pocas mujeres programadoras de la época Dona Bailey, quien influyó en la gama cromática empleada de tonos pastel lo cual llevó a que Centipede fue uno de los primeros juegos arcade en atraer a jugadoras. 

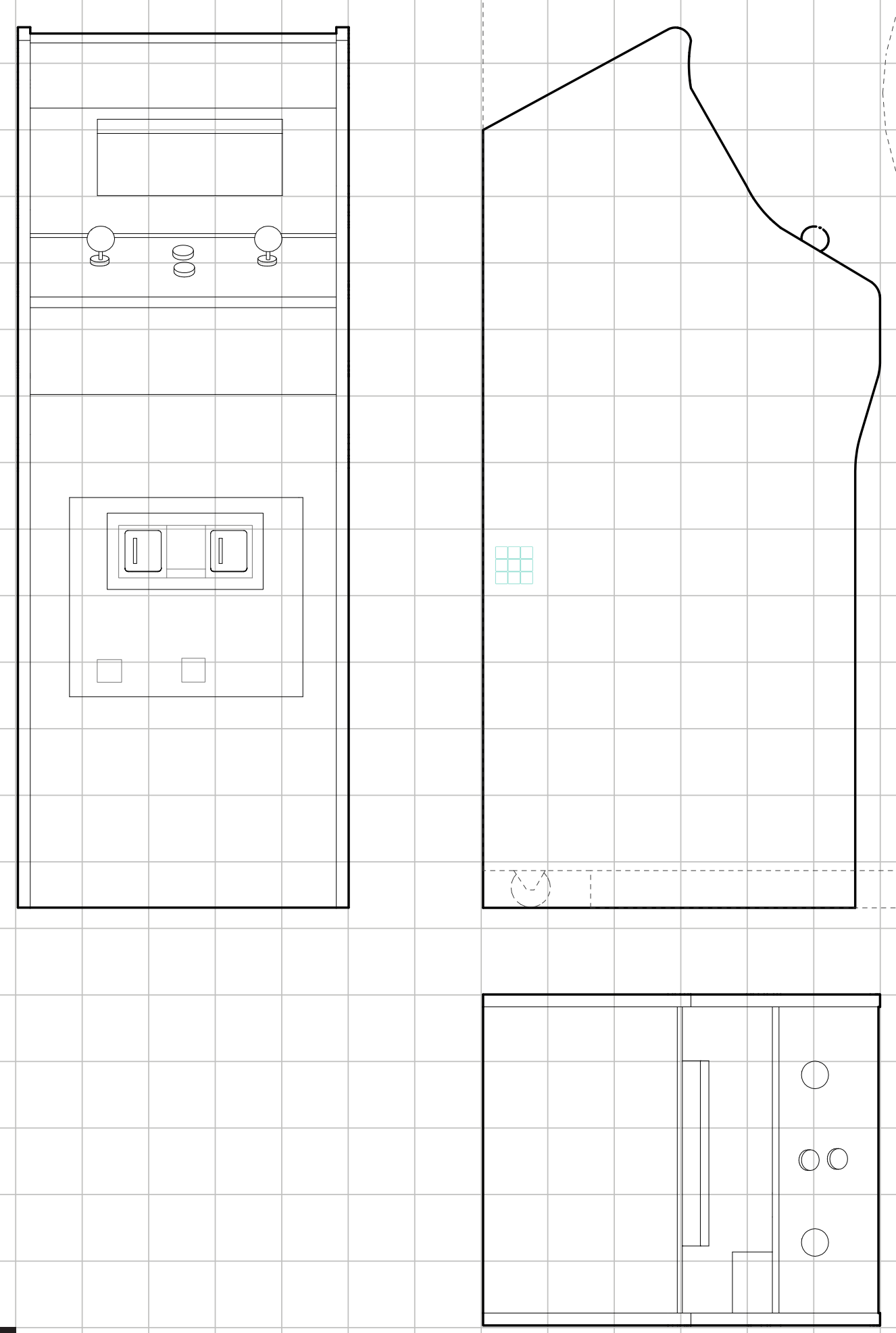


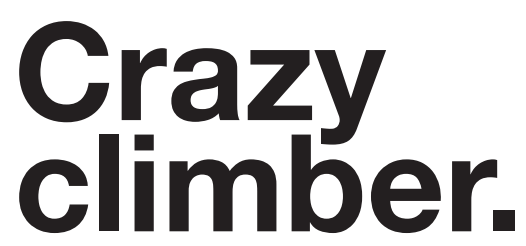

1980

Nichibutsu/Taito arcade.

Máquina arcade.

Máquina de Arcade desarrollada y lanzada al mercado por la compañía Nichibutsu en 1980, que contaba con un monitor en horizontal CRT y con gráficos ráster en color (y una resolución de 256×224). Dos años después se lanzó en Estados Unidos, comercializado por Taito América.

Se trataba de un videojuego de plataformas que fue pionero en los videojuegos de tipo escalada. La cabina poseía un panel de control con dos joysticks de ocho movimientos cada uno, uno de los mandos era para la mano derecha y el otro para la mano izquierda. Como otras Arcade de la época, contó con un modelo de cabina tradicional en vertical, un modelo cocktail y un modelo mini. Permitía jugar hasta dos jugadores, por turnos.

Máquina Arcade con un monitor en horizontal con gráficos ráster en color. Poseía un panel de control con dos joysticks de ocho movimientos, uno para la mano derecha y otro para la izquierda.

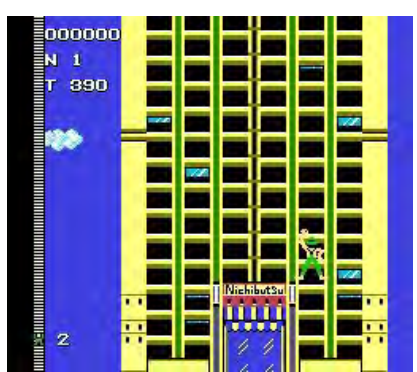

Crazy climber. 1980

Videojuego arcade considerado un precusor del género de plataformas. Fue el primer videojuego cuyo tema giraba en torno a la escalada de edificios. El jugador debía esquivar diversos obstáculos hasta

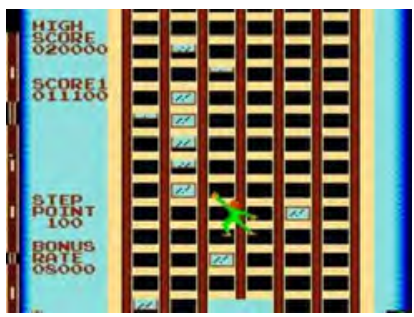
alcanzar la cima de cuatro niveles (rascacielos). 

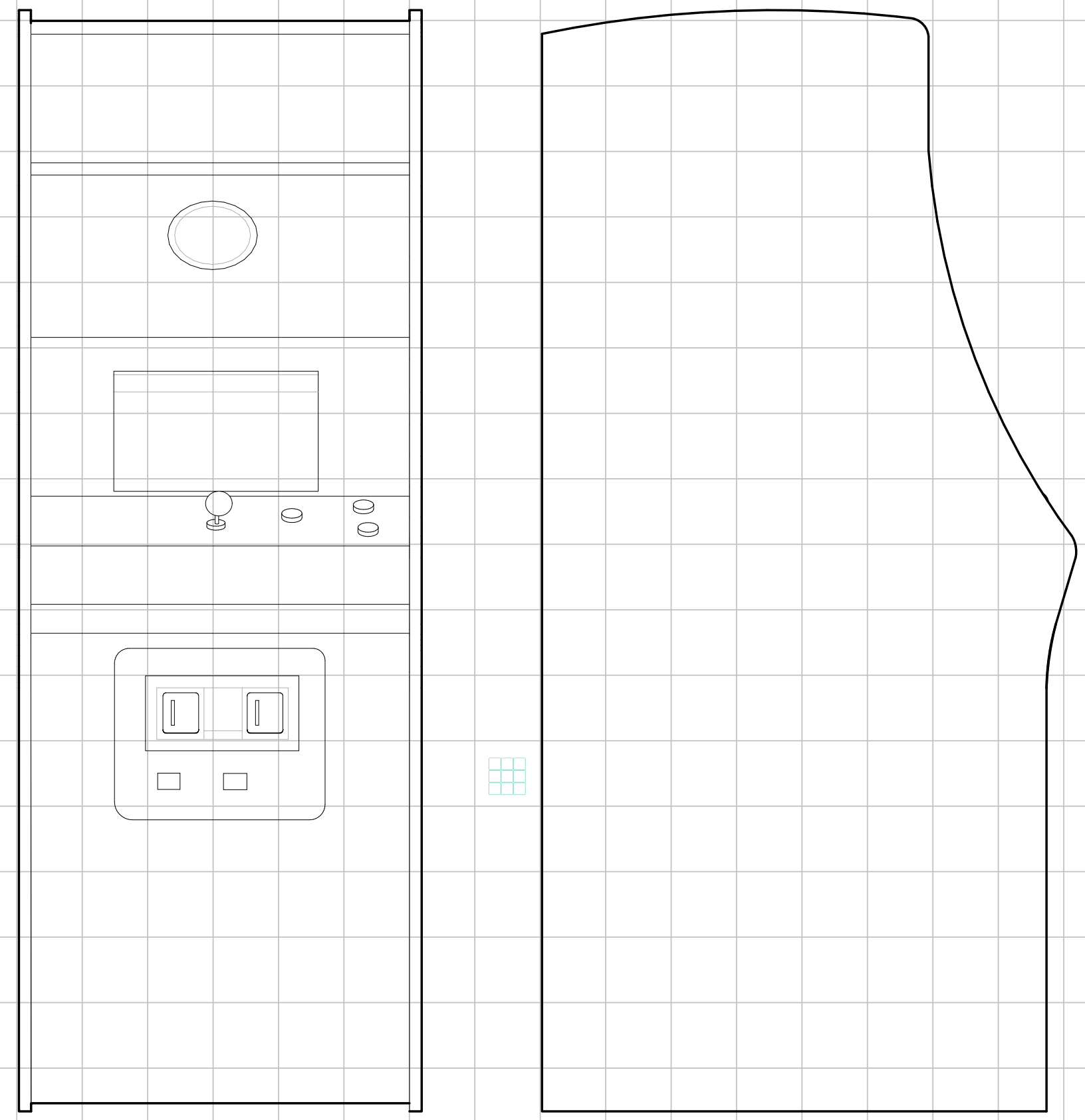

0
0
0




\section{PACMAN.}

1980

\section{Namco arcade. Máquina arcade.}

Máquina arcade desarrollado y lanzado al mercado por Namco en 1980. Este videojuego fue desarrollado por un joven diseñador, Toru Iwatani, un joven aficionado al pinball. Este Arcade contaba con un monitor CRT en orientación vertical y gráficos ráster en color, con una resolución de 224 $\times 288$ píxeles.

El jugador disponía de un panel de control con un joystick y dos botones. Un control sencillo para un juego de una sencillez excepcional. Contó con varios modelos de cabina: la clásica vertical, el modelo mini y el modelo cocktail.

"La forma de Pac-Man me vino a la cabeza un día que comía pizza. Cogí una porción y allí estaba, aquel era Pac-Man".

(Kent, pg 141, 2001)
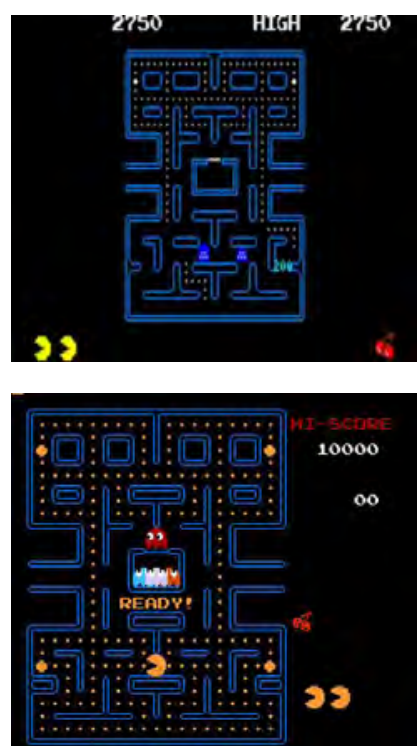

PACMAN.

1980

Videojuego arcade situado en un laberinto y diseñado originariamente para cambiar la estética de los juegos y hacerlos atractivos para el público poco habitual como las mujeres. El jugador debía controlar un personaje diseñado en estilo artístico kawaii dentro de un laberinto, tratando de esquivar a una serie de fantasmas.

Este videojuego dio lugar a una saga que ha contado con decenas de títulos para diferentes consolas a lo largo de las siguientes décadas después de su lanzamiento e incluso teléfonos móviles. 


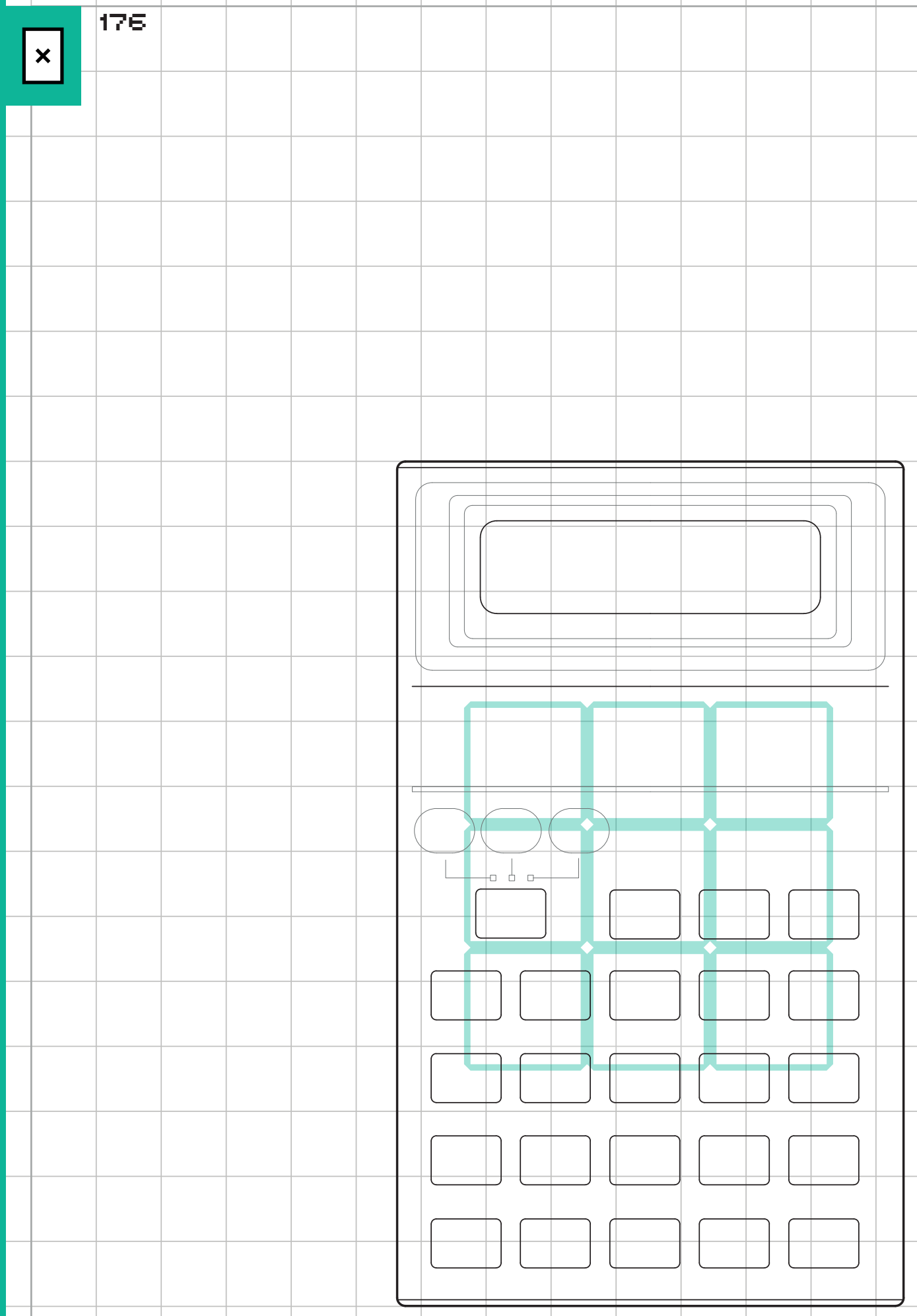




\section{Casio Game Calculator.}

\section{0}

\section{Casio.}

Videoconsola portable.

Dispositivo portable de juego en forma de calculadora con pantalla LCD. Aparecieron a partir de 1980 a raíz de la investigación de la empresa japonesa en videojuegos, anticipándose a Nintendo con Game\&Watch ${ }^{6}$.

"Casio, prestó atención a la tendencia del juego en auge, contempló la fusión del juego y el dispositivo que la gente siempre usa o lleva a cualquier parte"

Yuichi Masuda, director ejecutivo y miembro de la junta de Casio $^{7}$

Existieron múltiples modelos, destacando los publicados en la primera mitad de los años 80.

MG-880 (1980): Primera calculadora que permitía jugar con ella. Disponía de una pantalla numérica.

MG-777 (1981): Tenía una pantalla considerablemente más grande que su predecesora que incluía una cuadrícula de cuadrados de $3 \times 3$ pintada sobre la misma.

BB-10 (1981): Dispositivo que conservaba las funciones de calculadora, pero se aproximaba más a la imagen de una consola portable. Disponía de pantaIla con figuras sobreimpresas, 4 botones de control, 3 de cambio de juego y 18 pequeñas teclas numéricas. BG-15T (1982): Calculadora de diseño tradicional que sin embargo disponía sobre la pantalla rectangular de la opción de visualizar juegos con formas más complejas. Tres teclas del teclado habitual de calculadora disponían de la opción de convertirse en controladores del juego incluido.

PG-200 Pachinko (1983): Retomaba las dimensiones de pantalla del modelo MG-777 incluyendo dibujos sobre la pantalla más complejos que servían como base del juego.

MG-200 Turbo Drive (1983): Dispositivo que retomaba la forma y el número de botones de la línea de la BB10 (más cercana a las consolas portables) con una pantalla de mayor dimensión y juegos más ambiciosos (por ejemplo, representados en perspectiva cónica).

${ }^{6}$ La historia de Game\&Watch se pormenoriza en el capítulo 4. Punto 4.2/4.2.3

7 Consulta online; https://www.polygon.com/a/smartwatch-history-guide-evolution/watch-history

\section{Fuente análisis gráfico:}

Elaboración propia a partir de los datos consultados en el ithistory.org, retrogames.co.uk y el Center for Computer History Museum de Cambridge.

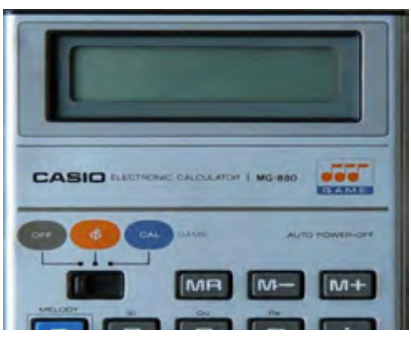

Invaders.

1980

Videojuego similar a Space Invaders pero con números en lugar de alienígenas. Disponía de un modo musical.

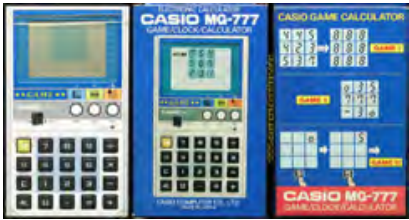

Game I, II y III.

1981

Videojuego con tres modalidades todas basadas en una cuadrícula de $3 \times 3$ sobre la que se situaban números, la tercera de ellas era algo similar a un buscaminas.

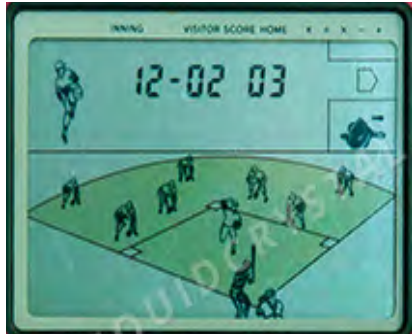

\section{Baseball Game.}

\section{1}

Videojuego deportivo basado en el juego del béisbol y que muestra partes del propio campo de juego.

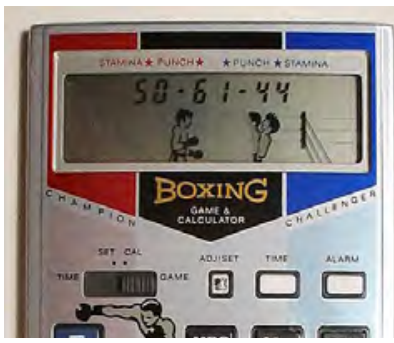

\section{Boxing Game. \\ 1982}

Videojuego de lucha situado en un ring de boxeo.

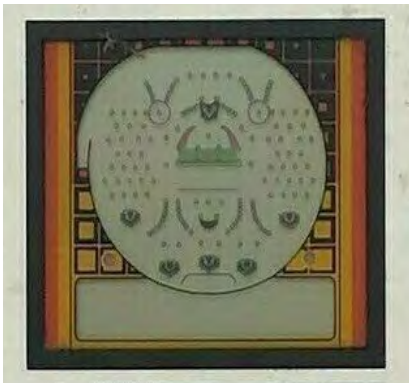

Pachinko.

1983

Videojuego inspirado en un juego popular japonés similar a una combinación entre el pinball y el sistema de las tragaperras.

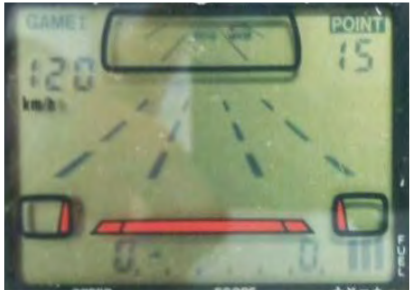

\section{Turbo Drive.}

\section{3}

Videojuego de conducción en primera persona con dos modos de juego y que simulaba profundidad en pantalla con una perspectiva cónica centrada. Permitía visualizar

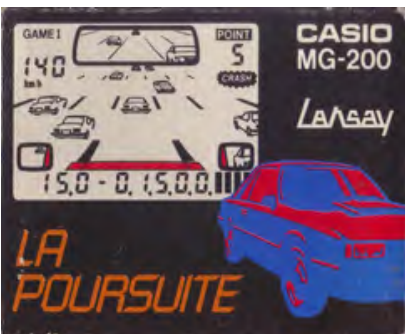
los kilómetros por hora alcanzados. 


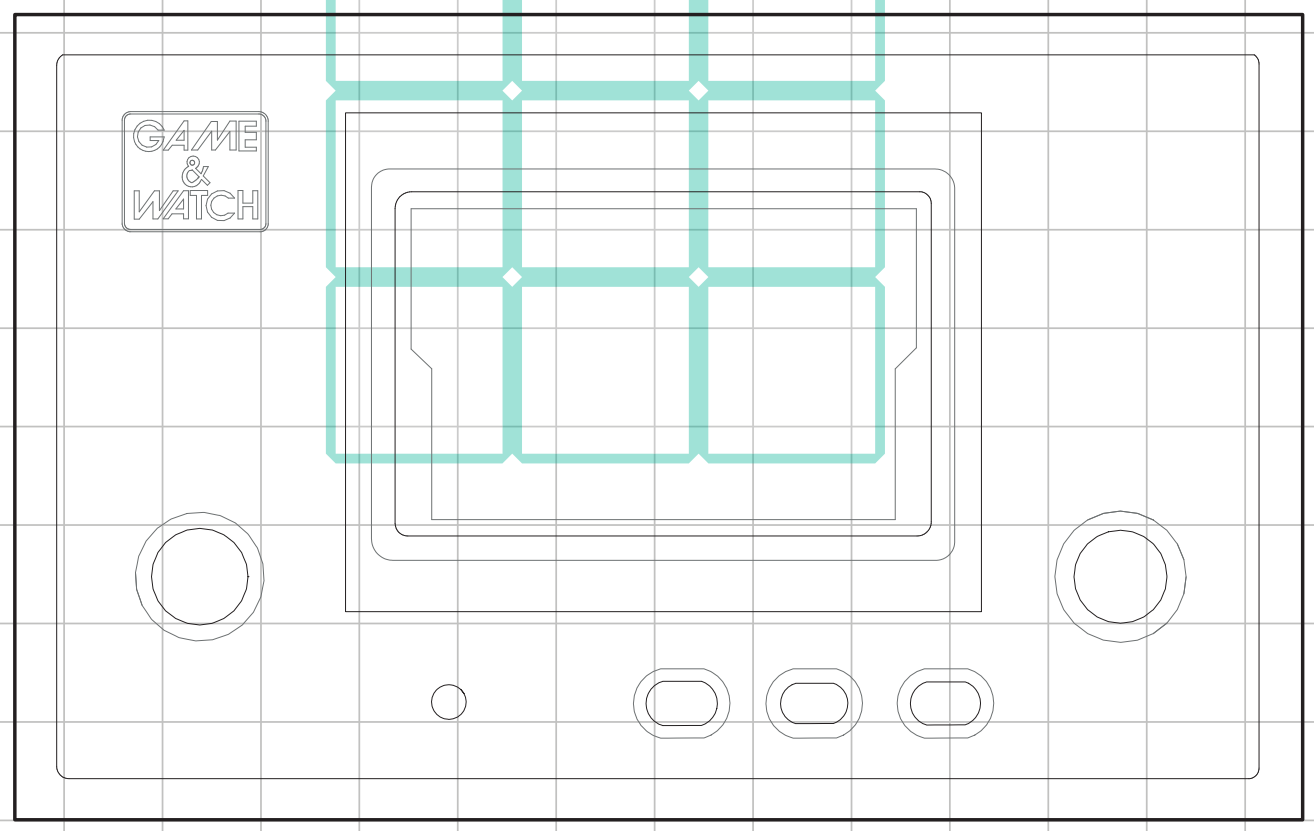




\section{Nintendo Game\& Watch.}

1980

\section{Nintendo. Videoconsola portable.}

Se trata de una línea de consolas portátiles desarrolladas por Nintendo desde 1980 hasta su descontinuación en 1991 (Gorges, 2016). Cada consola llevaba incorporado un único videojuego y contaban con pantallas LCD, además de reloj y alarma.

Nintendo lanzó diez variaciones de diseño de estas consolas portátiles y hubo un total de 59 videojuegos. Algunos modelos contaban con una sola pantalla (serie Silver, serie Gold, serie Wide Screen, serie New Wide Screen, serie SuperColor y serie Crystal Screen), mientras que hubo ediciones con doble pantalla (serie Multi Screen), ediciones que parecían máquinas recreativas en pequeño (serie Tabletop y serie Panorama) y una edición que poseía dos joypads que se guardaban en su interior para jugar contra la computadora o dos jugadores uno contra el otro.

El controlador de la consola, conocido como cruceta (D-Pad), fue patentado en 1982 por Yokoi y se usó por primera vez en el modelo que incluía el juego de Donkey Kong. Este controlador obtuvo un premio Emmy de Tecnología e Ingeniería. La batería tenía una duración entorno a los seis meses de vida útil, generalmente se trataba de pilas de botón.

\section{Variaciones:}

Serie Silver (1980)

Serie Gold (1981)

Serie Wide Screen (1981-1982)

Serie Multi Screen (1982-1989)

Serie Tabletop (1983)

Serie Panorama (1983-1984)

Serie New Wide Screen (1982-1991)

Serie SuperColor (1984)

Serie Micro VS. (1984)

Serie Crystal Screen (1986)

Edición especial Super Mario (1987)

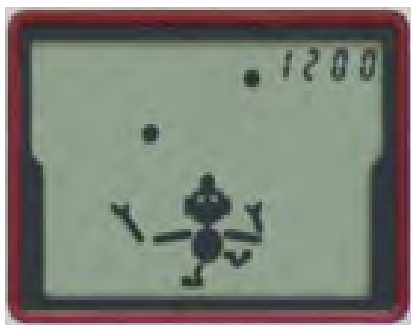

Nintendo Game\&Watch.

1980

Videojuegos construidos con tecnología de pantallas de LCD (al igual que las calculadoras). El jugador ejecuta acciones sobre la imagen. Sus controles hacen que el personaje o la herramienta que se

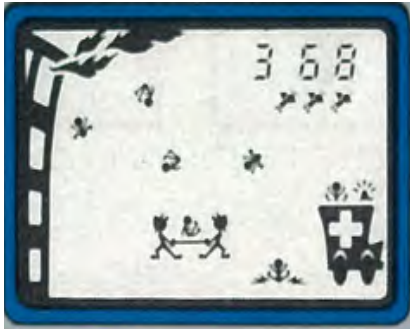
ve en la pantalla LCD, cambie y hagan la ilusión de que se mueva. Una imagen es conectada junto a la otra, dando origen a un control, como si fuera un botón nuevo, que enumera la puntuación del número o de las vidas que se van perdiendo. Se trata de juegos sencillos consistentes en atrapar bolas, platos, disparar, etc (siempre la misma acción repetida pues se trata de una cantidad limitada de imágenes que se repiten) tratando de mejorar las puntuaciones. 
$凶$

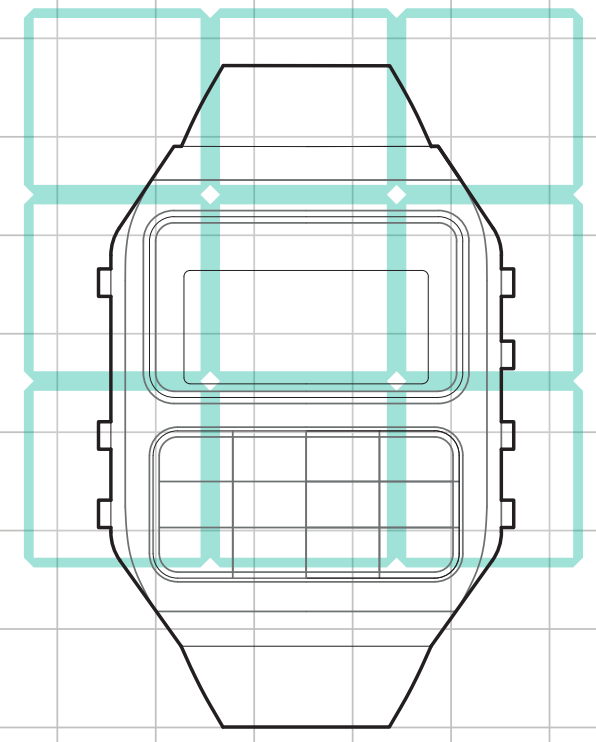




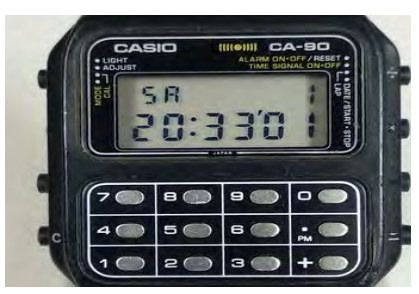

Invaders.

Videojuego que era en realidad una adaptación del desarrollado por Casio para calculadoras y se basaba en Space Invaders.

\section{1-1996}

Casio.

Videoconsola portable.

Dispositivo portable en forma de reloj de muñeca con pantalla LCD. En 1981 Casio publicó el primero siendo pionero en el desarrollo de la idea, disponía de un mini-teclado como el de una calculadora y un juego interno. Hasta 1996 salieron variedad de modelos basados en un diseño muy similar entre ellos de dos botones e identificados con el nombre Casio GX-Y donde $X$ era una letra del alfabeto e $Y$ un número. En 1995 se lanzó al mercado el JG-100 que además de incluir un juego disponía de sistema de infrarrojos para conectarse con otro reloj, con la televisión o ciertos dispositivos del coche. Un año después el JG.-200 añadió la capacidad de vibrar durante las partidas entre dos personas con el reloj en la muñeca.

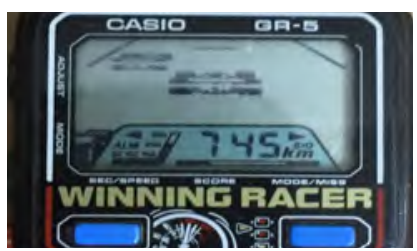

Winning racer y otros.

Videojuegos varios que suponían adaptaciones de otros, principalmente de arcade, pero sin ser licenciatarios oficiales.

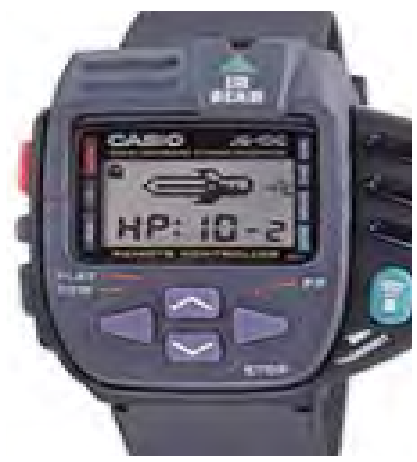

Dungeons and Demons.

Videojuego de aventuras textual/numérico que permitía al jugador partidas con otros jugadores usando el puerto de conexión (hasta 10 simultáneamente), disponiendo también de un sistema de envío de mensajes entre los propios jugadores.

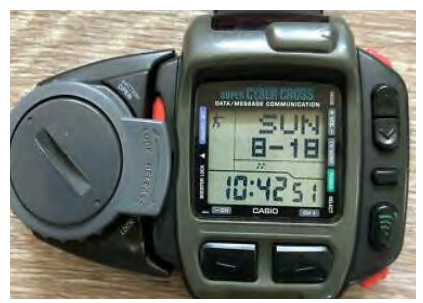

\section{Super Cyber Cross.}

Videojuego de acción y lucha que permitía al jugador partidas con otros poseedores del reloj. Durante las batallas el jugador podía recibir golpes y efectos a través del sistema de vibración del dispositivo.

\section{Variaciones:}

Casio GA-90 (1981)

Casio GR-5 (1987)

Casio JG-100 (1995)

Casio JG-200 (1996) 

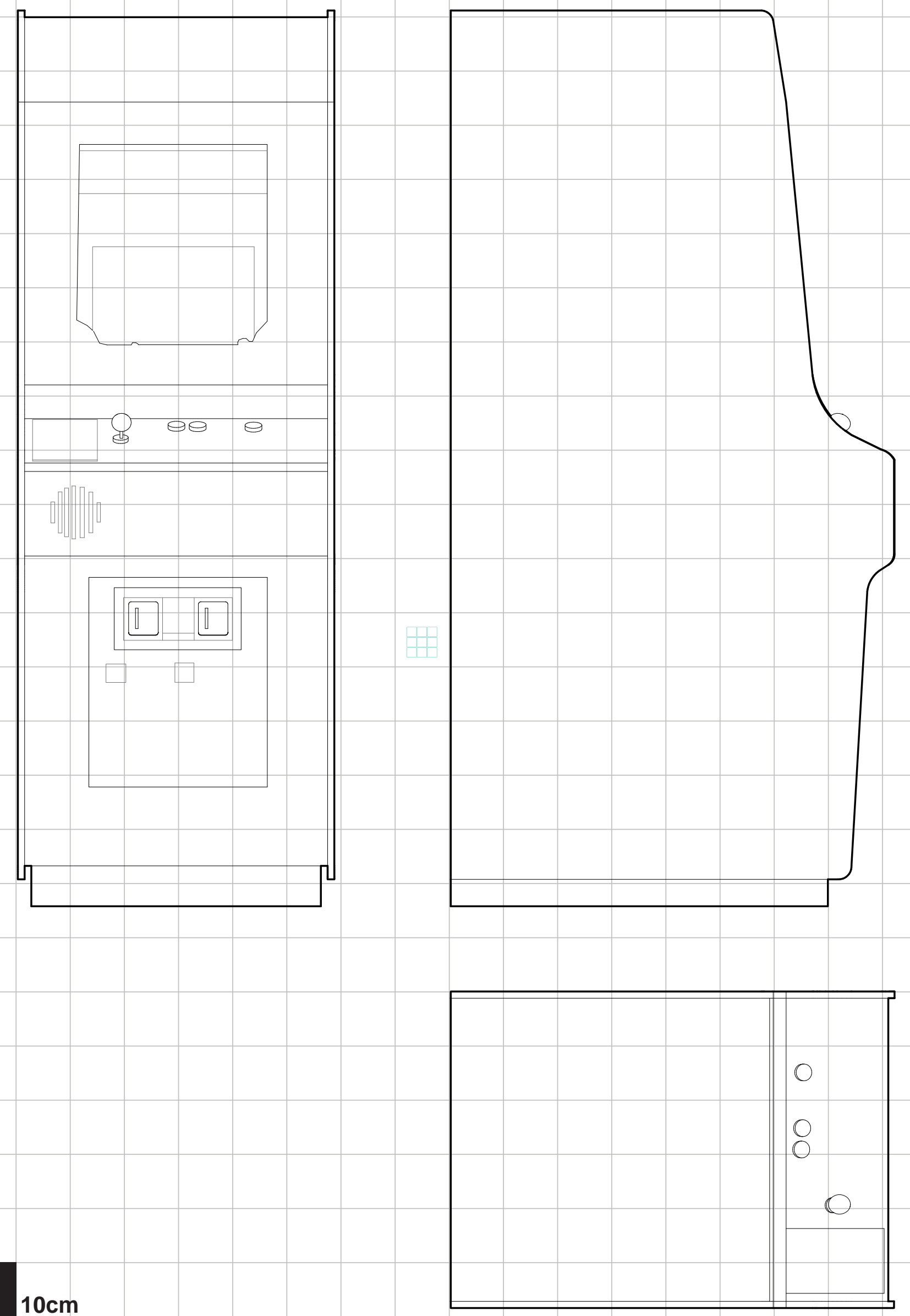


\section{Donkey Kong.}

1981

\section{Nintendo arcade.}

Máquina arcade.

Máquina Arcade desarrollada y lanzada al mercado por Nintendo en 1981, que incluía el videojuego de Donkey Kong (un primitivo juego de plataformas) diseñado por Miyamoto.

Contaba con un monitor vertical CRT con gráficos ráster en color y el jugador disponía de un panel de control con un joystick que permitía cuatro direcciones (arriba, abajo, derecha e izquierda) y un botón que permitía al personaje saltar. Este Arcade contó con varios modelos de cabina: el clásico vertical, el tipo cocktail y el tipo mini.

Este juego supuso un gran éxito para Nintendo, tanto en Japón como en Estados Unidos. Al igual que Pac-Man, dio lugar a una saga de videojuegos alrededor de la figura de Donkey Kong, en varias consolas de Nintendo, así como en otras consolas como Coleco.

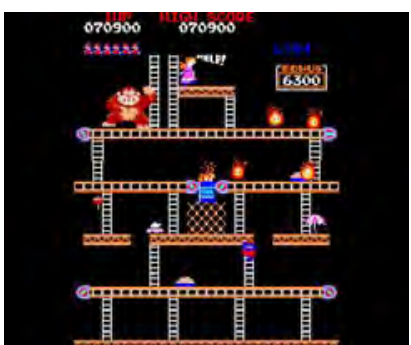

Donkey Kong.

1981

Videojuego arcade considerado el primer título de plataformas. El jugador controlaba a un fontanero llamado Mario (en honor al dueño italiano del local que Nintendo tenía en América, Mario Segale) que debía salvar a su novia de un gorila que la había secuestrado. Las limitaciones técnicas del momento definieron el diseño gráfico, siendo el primer juego que introduce una historia completa contada empleando escenas intermedias para hacer avanzar el guión. El juego se divide en cuatro zonas, cada una de ellas equivalente a veinticinco metros de un edificio, hasta llegar a la cima. 

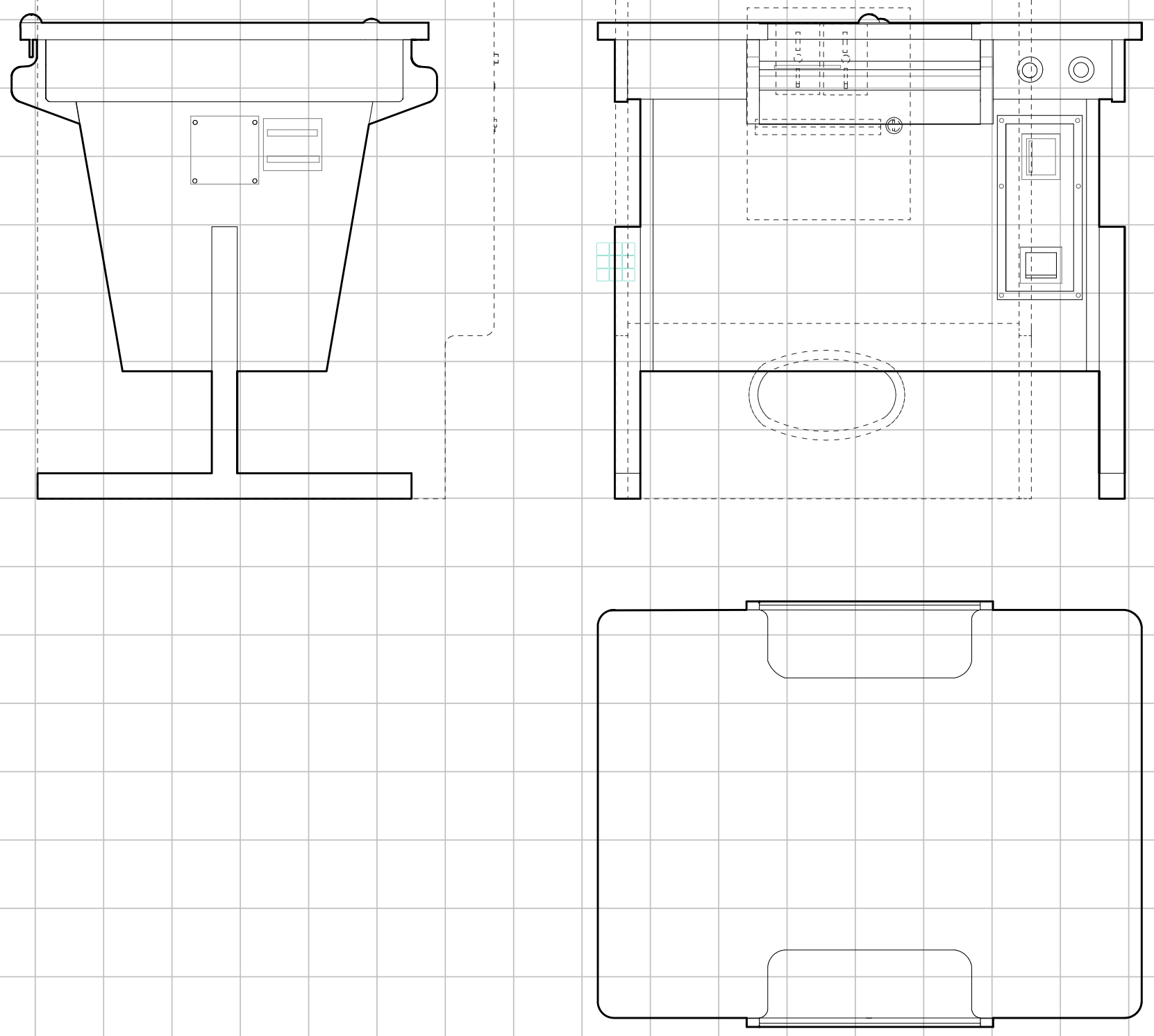


\section{Frogger.}

\section{1}

Konami arcade.

Máquina arcade.

Máquina Arcade desarrollada por Konami en 1981 y distribuida mundialmente por Sega que adquirió su licencia. Esta máquina contaba con un monitor vertical CRT con gráficos ráster a color y un CPU Zilog Z80 (como muchos de su época). El jugador disponía de un panel de control formado por un único joystick de cuatro posiciones (arriba, abajo, derecha e izquierda). Contó con varios modelos de cabina: el clásico vertical y el modelo cocktail.

Frogger dio lugar también a una saga con casi 30 secuelas en diversas consolas y arcades durante las décadas posteriores a su lanzamiento, así como para móviles y ordenador.

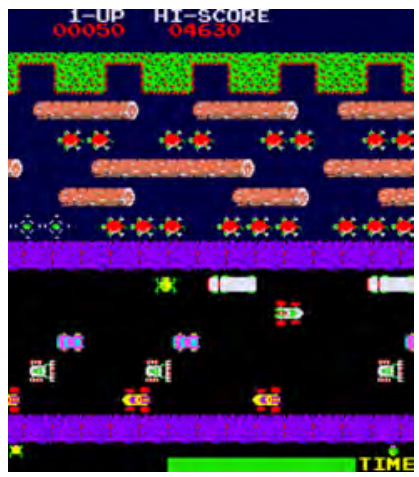

Frogger.

1981

Videojuego arcade en que el jugador debe conducir 3,5 o 7 ranas a través de una carretera evitando que las atropellen hasta lugar seguro, al otro lado de ésta. Se considera un videojuego clásico, siendo de los 20 arcades más vendidos de la historia y que tuvo una fuerte repercusión también en el mundo de la animación. 

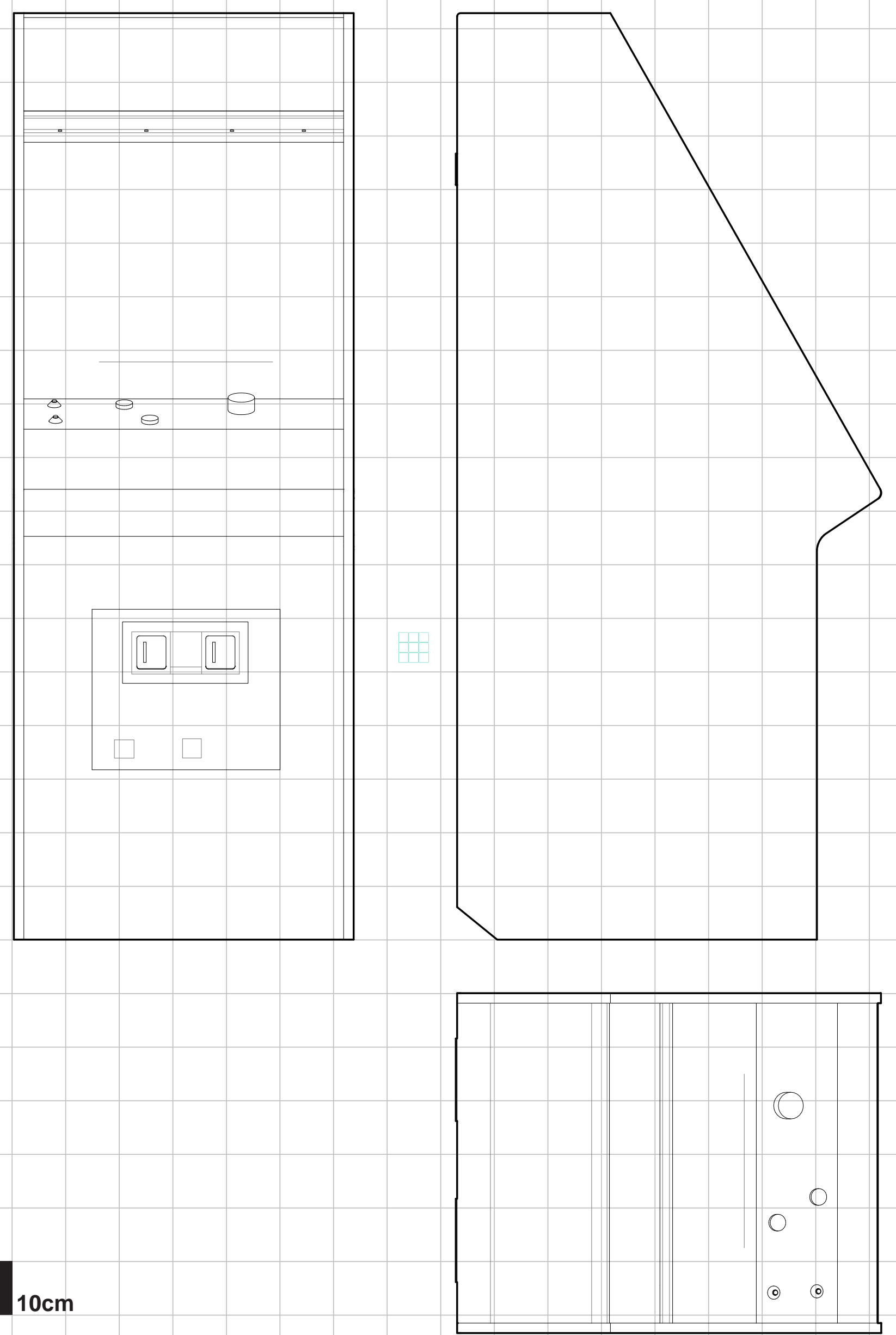


\section{Tempest.}

1981

Atari arcade.

\section{Máquina arcade.}

Máquina Arcade desarrollado y publicado por Atari en 1981. Fue pionero por ser el primer juego que permitía seleccionar el nivel de dificultad y la primera máquina de Arcade que permitía al jugador insertar una moneda para continuar desde donde le habían matado (Kent, 2001). Este juego fue diseñado y programado por David Theurer.

La máquina contaba con un monitor CRT de 19 pulgadas, con gráficos vectoriales a color. Se trataba de un monitor de tipo X-Y en el que se visualizaban gráficos de alta definición que, sin embargo, conllevaban un sobrecalentamiento del generador a color. Contó con varios modelos de cabina: el clásico vertical, un modelo de cocktail y modelo mini.
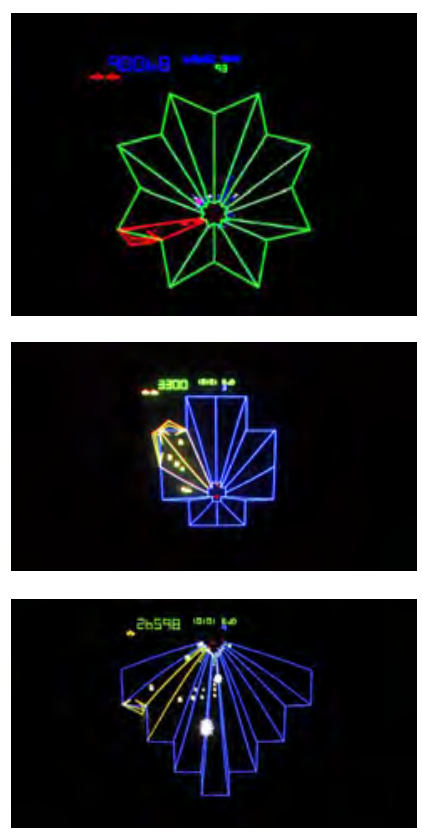

Tempest.

1981

Videojuego arcade de disparos que sucede sobre una superficie tridimensional que, dependiendo del nivel, se envuelve en un tubo y que se ve desde un extremo y dividido en 15 o 16 carriles. El objetivo del jugador es sobrevivir durante la mayor cantidad de tiempo posible. Tempest fue pionero en el uso de gráficos vectoriales en color gracias al ColorQuadraScan de Atari así como en presentar una opción de selección de dificultad para el jugador ('skillstep'), teniendo un diseño progresivo de niveles.

Poseía un diseño de cada uno de los laterales en forma de triángulo rectángulo apuntando hacia el techo, lo que le daba un aspecto muy llamativo. El jugador disponía de un panel de control formado por tres botones, dos de pulsación y otro de rotación. 

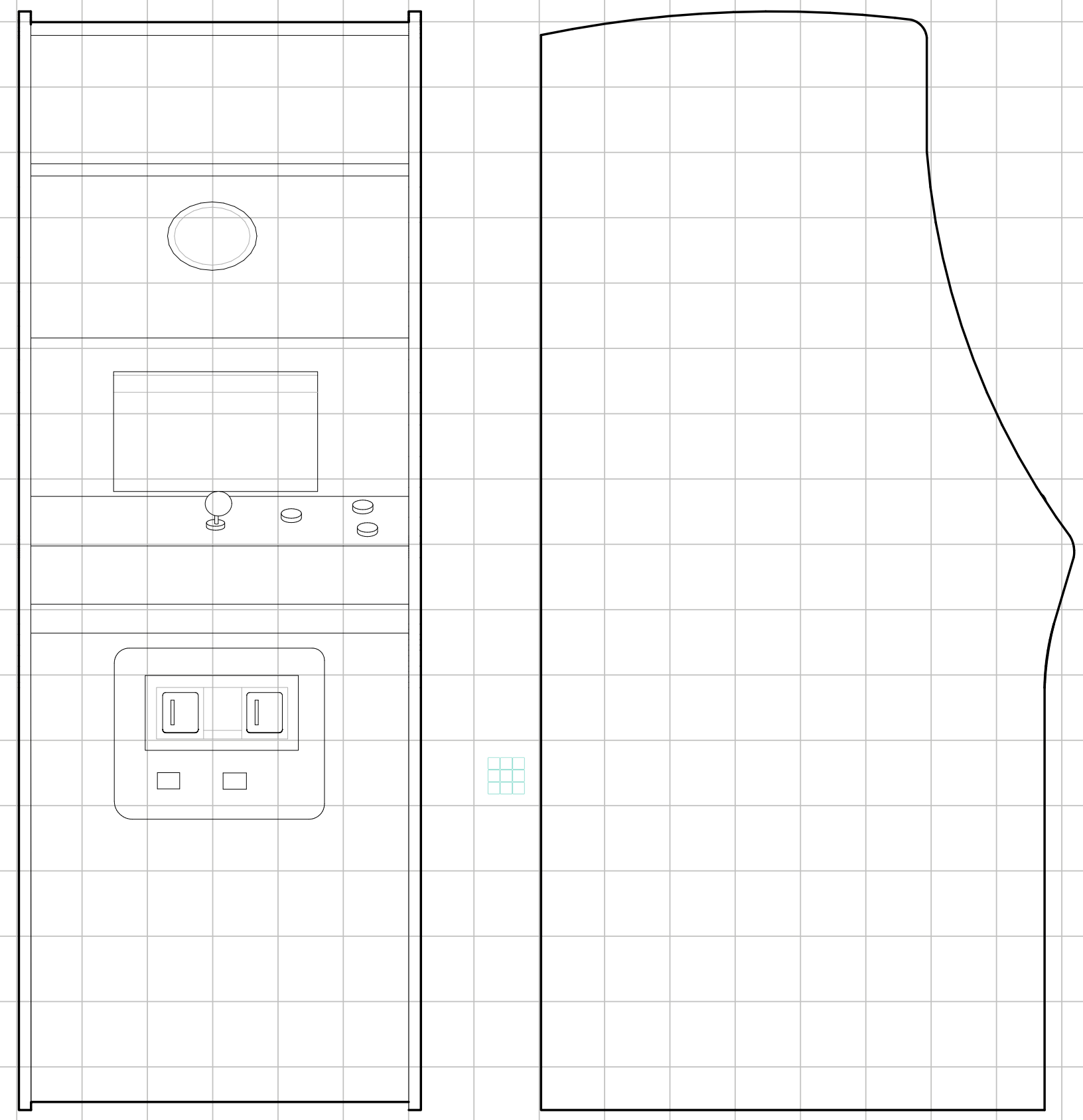

\begin{tabular}{ll}
0 \\
0 \\
0 & 0 \\
\hline
\end{tabular}




\section{Ms Pac Man.}

\section{1}

\section{Midway/Namco arcade.} Máquina arcade.

Máquina Arcade producida por Midway, que empezó como una secuela no autorizada hasta que Namco pasó a ser el licenciador oficial. Esta máquina salió al mercado en 1981 y fue diseñada por dos universitarios del MIT (Doug Macrae y Kevin Curran).

"Midway nunca fabricó una placa de Ms. PacMan, lo que hicieron fue fabricar más placas de Pac-Man y añadirles el kit de mejora de General Computer"

(Kent, 172)

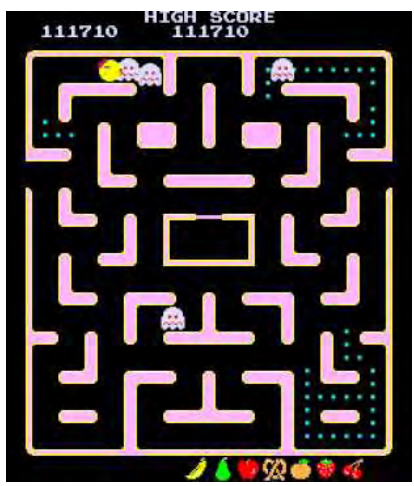

Ms Pac Man.

1981

Videojuego arcade de tipo laberinto que introduce ciertos cambios sobre el Pac Man original. El juego cuenta con cuatro laberintos en diferentes colores, algunos de ellos con túneles. También cambia la puntuación. El juego fue creado por General Computers Corporation como parte de un kit de desarrollo para modificaciones de arcade.

Esta máquina disponía de una pantalla en disposición vertical y tipo CRT con gráficos ráster a color. El jugador disponía de un panel de control con un joystick que permitía mover al personaje en cuatro direcciones (arriba, abajo, derecha e izquierda). La cabina tuvo tres modelos: la clásica vertical, el modelo cocktail y el modelo mini. 

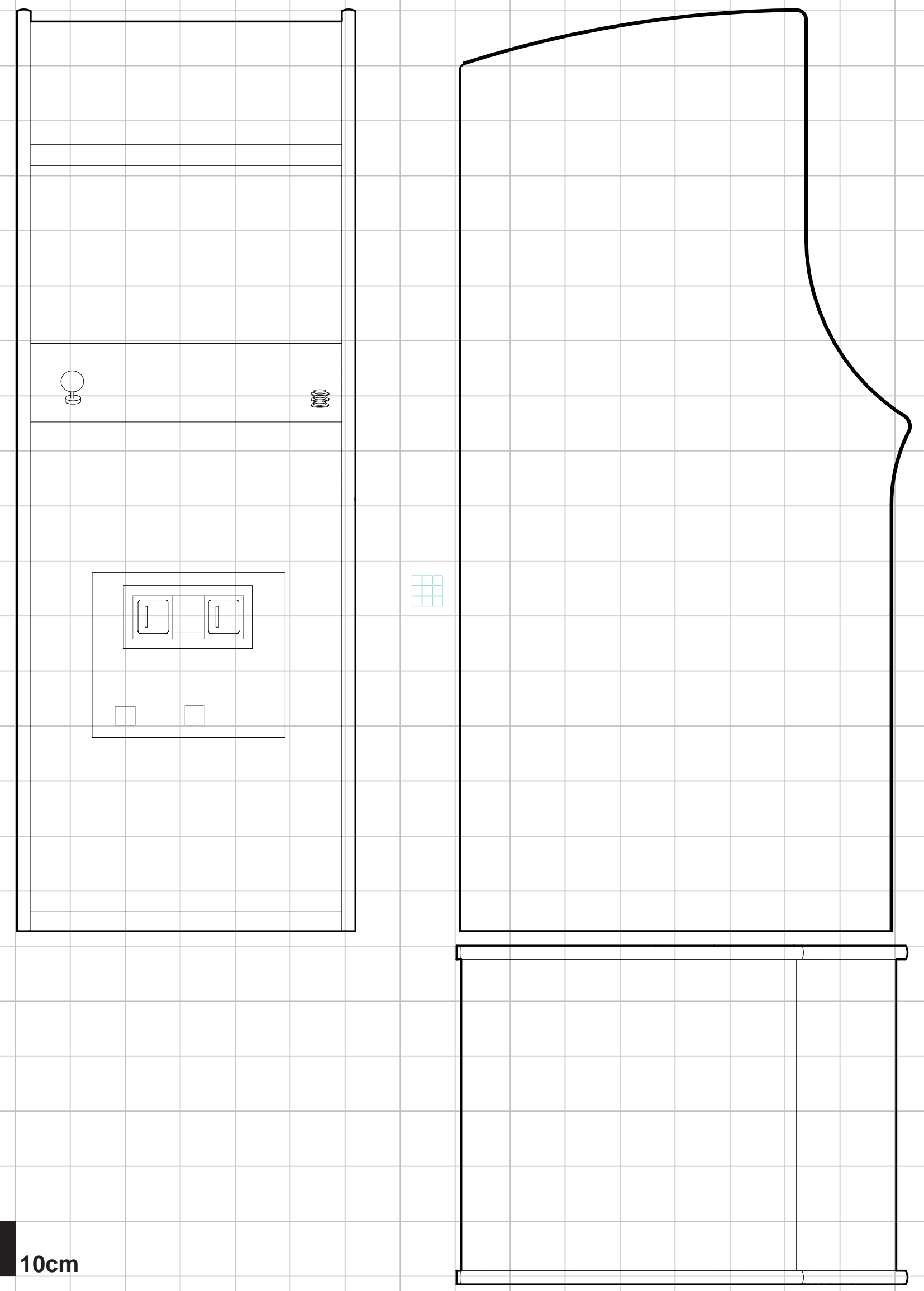


\section{Galaga.}

1981

Namco arcade.

Máquina arcade.

Máquina de Arcade desarrollada y publicada por Namco en 1981 que disponía de un monitor CRT de 19 pulgadas en el que se visualizaban gráficos ráster a color.

El jugador disponía de un panel de control formado por un joystick que permitía dos movimientos (derecha e izquierda) y un botón que permitía disparar. Este Arcade contó con dos diseños de cabina clásica vertical (uno más grande y otro más pequeño y compacto), un modelo cocktail y un modelo mini.

Este juego fue diseñado como una secuela del juego Galaxian (1979) y dio lugar a una saga con juegos que han sido publicados para diversas consolas (entre ellas la Game Boy Color, así como para ordenador).

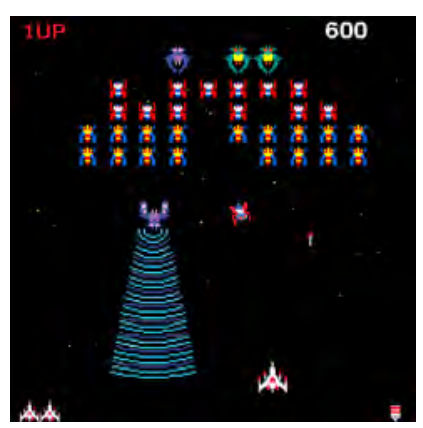

Galaga.

1981

Videojuego de disparos en primera persona. El jugador tiene un caza estelar solitario en la parte inferior de la pantalla y debe evitar que las fuerzas de Galaga - que cambian en cada etapa - destruyan a toda la humanidad disparando contra hordas de marcianos. Cada vez que el jugador pasaba tres niveles podría enfrentarse a un nivel extra que permitía conseguir 10000 puntos extra. 

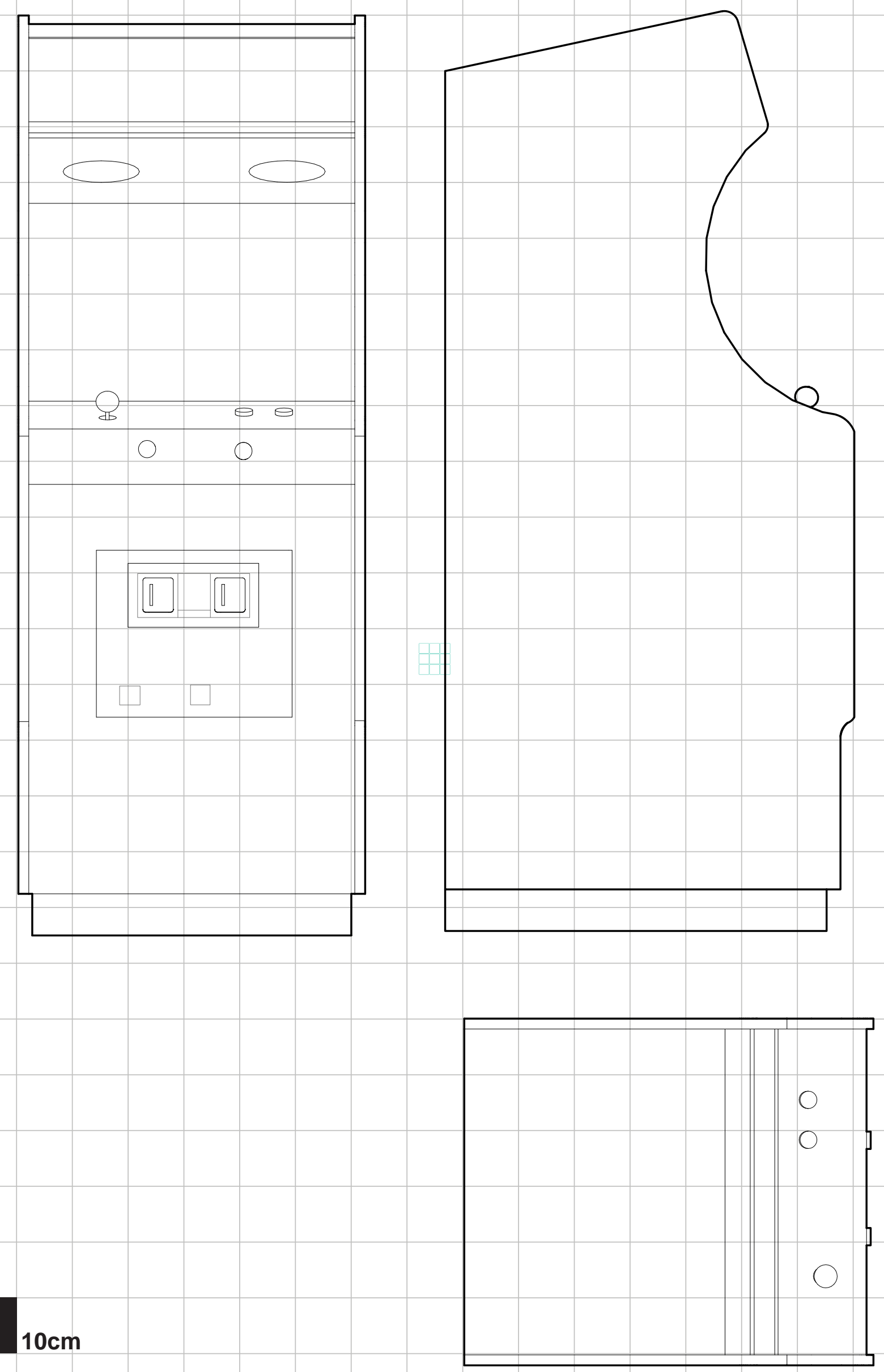
Videojuego arcade de acción muy innovador para su época en que el jugador debe 'capturar' espacio en la pantalla. Cada nivel empieza con un

Randy Pfeiffer, Sandy Pfeiffer. Máquina arcade.

Máquina Arcade diseñada y publicada en 1981 por Taito América, se trató de su primer gran éxito desarrollado de manera íntegra en Estados Unidos. Este juego dio lugar a una serie de cinco entregas más y esta primera tuvo versiones en varias consolas y ordenadores domésticos (entre ellos la NES, la Game Boy o la Atari 5200).

Esta máquina contaba con un monitor vertical CRT con gráficos ráster en color. El jugador disponía de un panel de control con un joystick que permitía al jugador moverse en cuatro direcciones (arriba, abajo, izquierda y derecha), así como dos botones que permitían dibujar deprisa o dibujar despacio. Esta máquina tuvo dos diseños de cabina: el clásico vertical y un modelo de tipo cocktail. rectángulo dentro del cual se encuentra el Qix, un 'elemento' que se mueve de formas inesperadas. El jugador puede dibujar empleando los botones generando formas cerradas (que son diferentes en función de la velocidad a la que tengan lugar), cada nivel se supera al conseguir más del 75\% del área. 

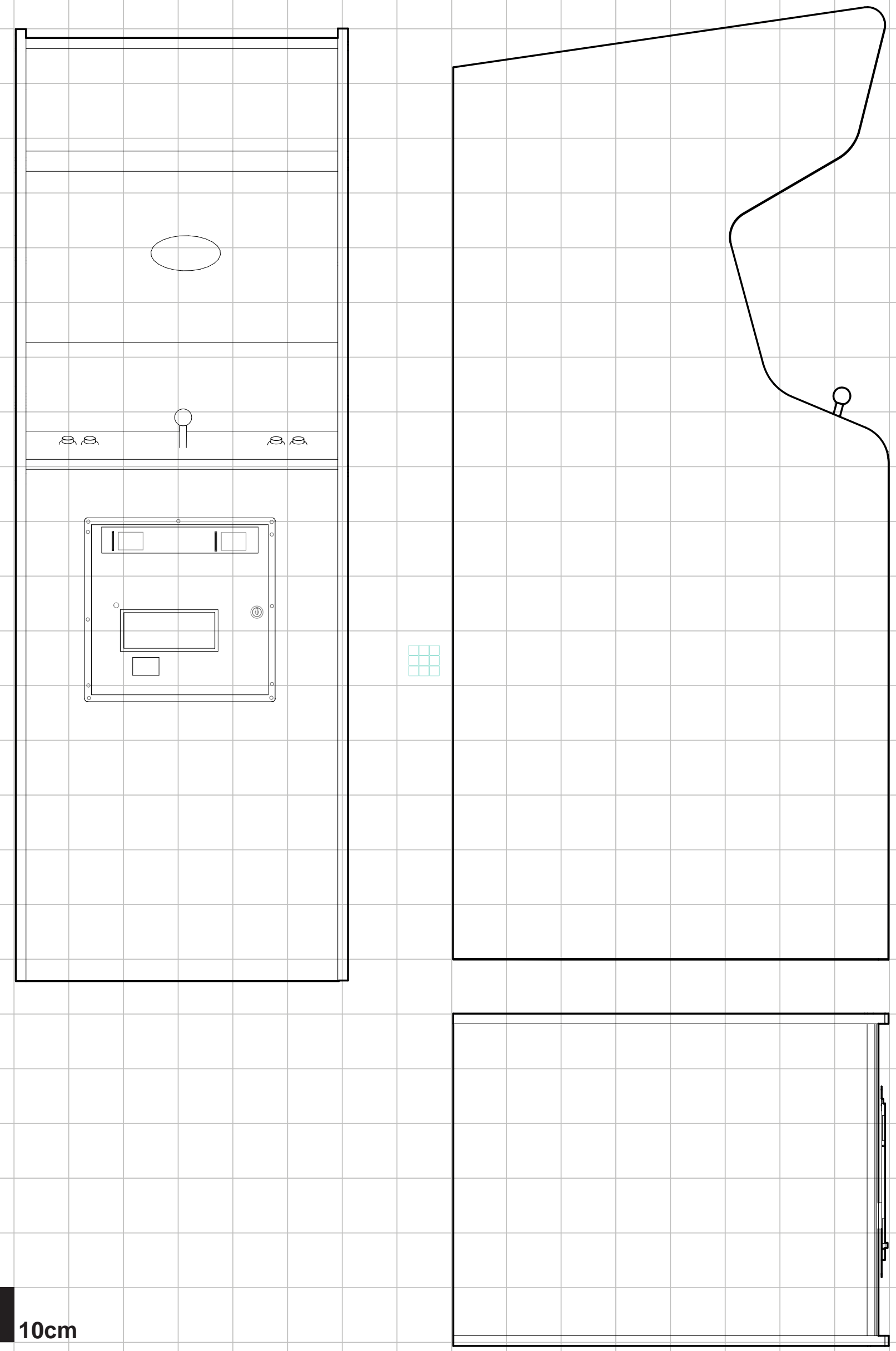


\section{Scramble.}

\section{1}

\section{Konami arcade.} Máquina arcade.

Máquina Arcade desarrollada por Konami en 1981, en América del Norte fue distribuida por Stern y en Japón por Leijac. El hardware de la placa del sistema Konami Scramble (una placa utilizada por Namco para los arcades) utilizaba dos microprocesadores para el CPU y, además, dos chips AY3-8910 de sonido y hardware de vídeo para los gráficos.

Contaba con un monitor vertical CRT de gráficos ráster en color y tuvo dos únicos diseños de cabina: el clásico vertical y el modelo tipo cocktail. El jugador disponía de un panel de control con un joystick que permitía ocho movimientos y cuatro botones (aunque solo dos servían para jugar y valían para bombardear).

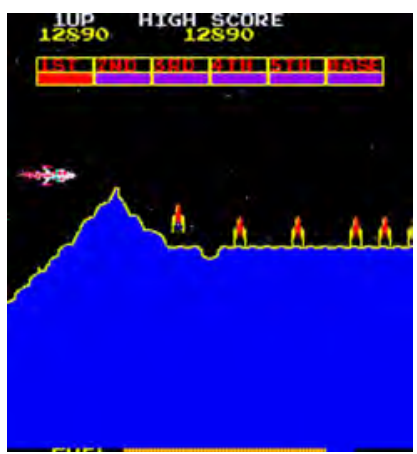

Scramble.

1981

Videojuego arcade de disparos considerado pionero en su desplazamiento lateral forzado y en su composición en base a múltiples niveles. El jugador controla un avión que debe guiar evitando los obstáculos.

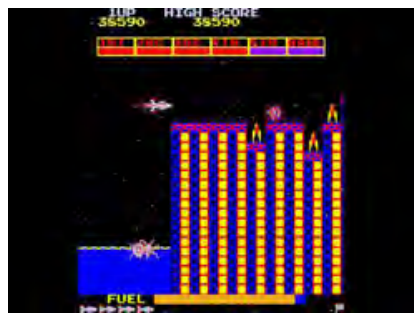



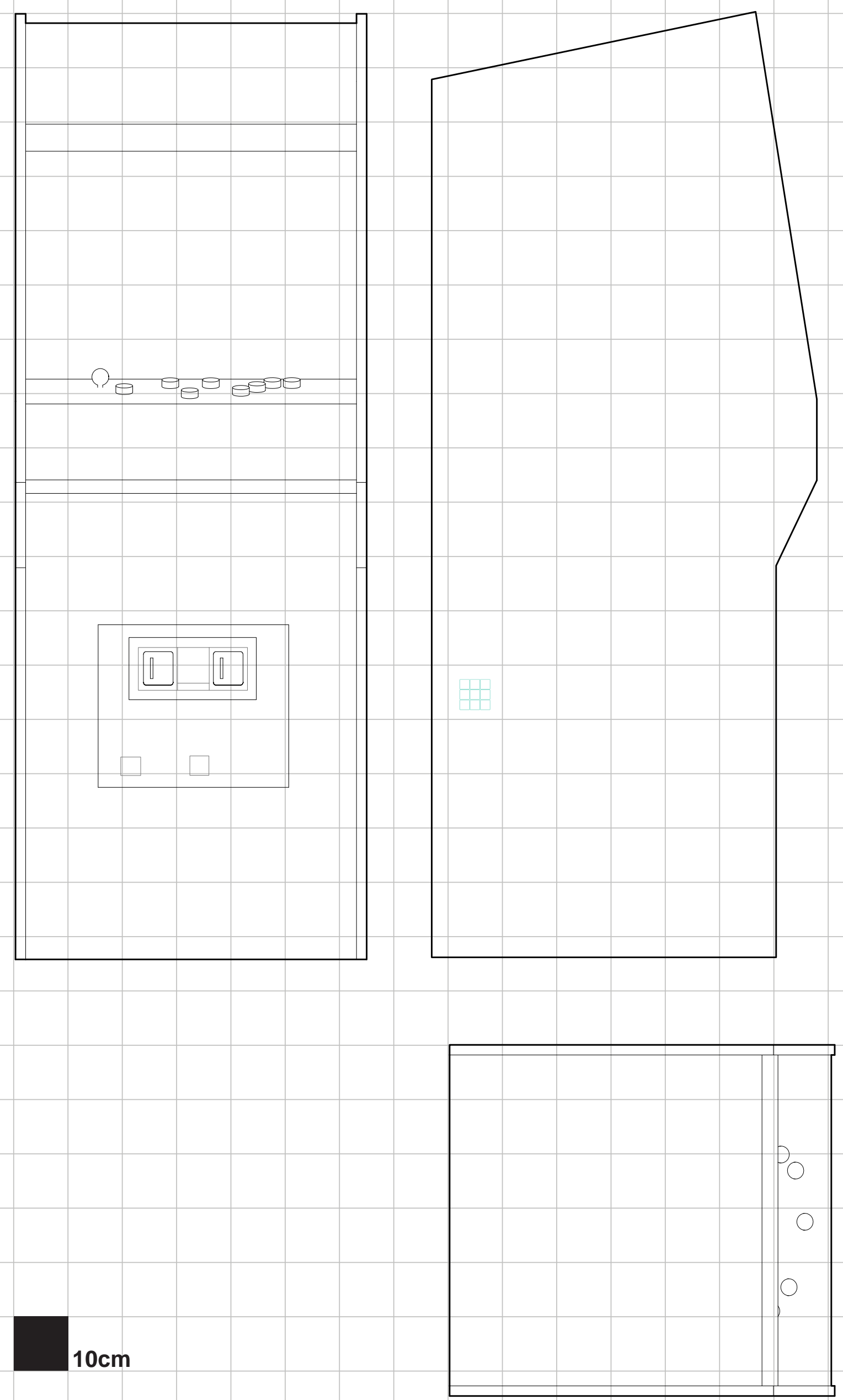


\section{Stargate.}

\section{1}

\section{Vid Kidz.}

Máquina arcade.

Máquina Arcade desarrollada y lanzada al mercado en 1981 por Williams Electronics. Este juego diseñado por Eugene Jarvis y Larry DeMar fue considerado como una secuela de Defender (1980).

Esta máquina disponía de un monitor orientado horizontalmente y de tipo CRT que permitía visualizar gráficos ráster en color. El jugador disponía de un panel de control que contaba con un joystick que le permitía moverse en dos direcciones (arriba y abajo), así como seis botones que servían para: dar marcha atrás, acelerar, abrir fuego, saltar al hiperespacio, lanzar una bomba inteligente y para camuflarse.

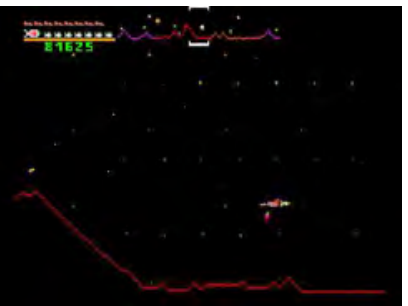

Stargate.

1981

Videojuego arcade de disparos considerado el sucesor de Defender. A diferencia de su antecesor, la nave que controla el jugador - quien dispara protegiendo una colonia de humanoides - posee un dispositivo de ocultamiento con carga limitadada que permite desaparecer de los enemigos y destruirlos. 

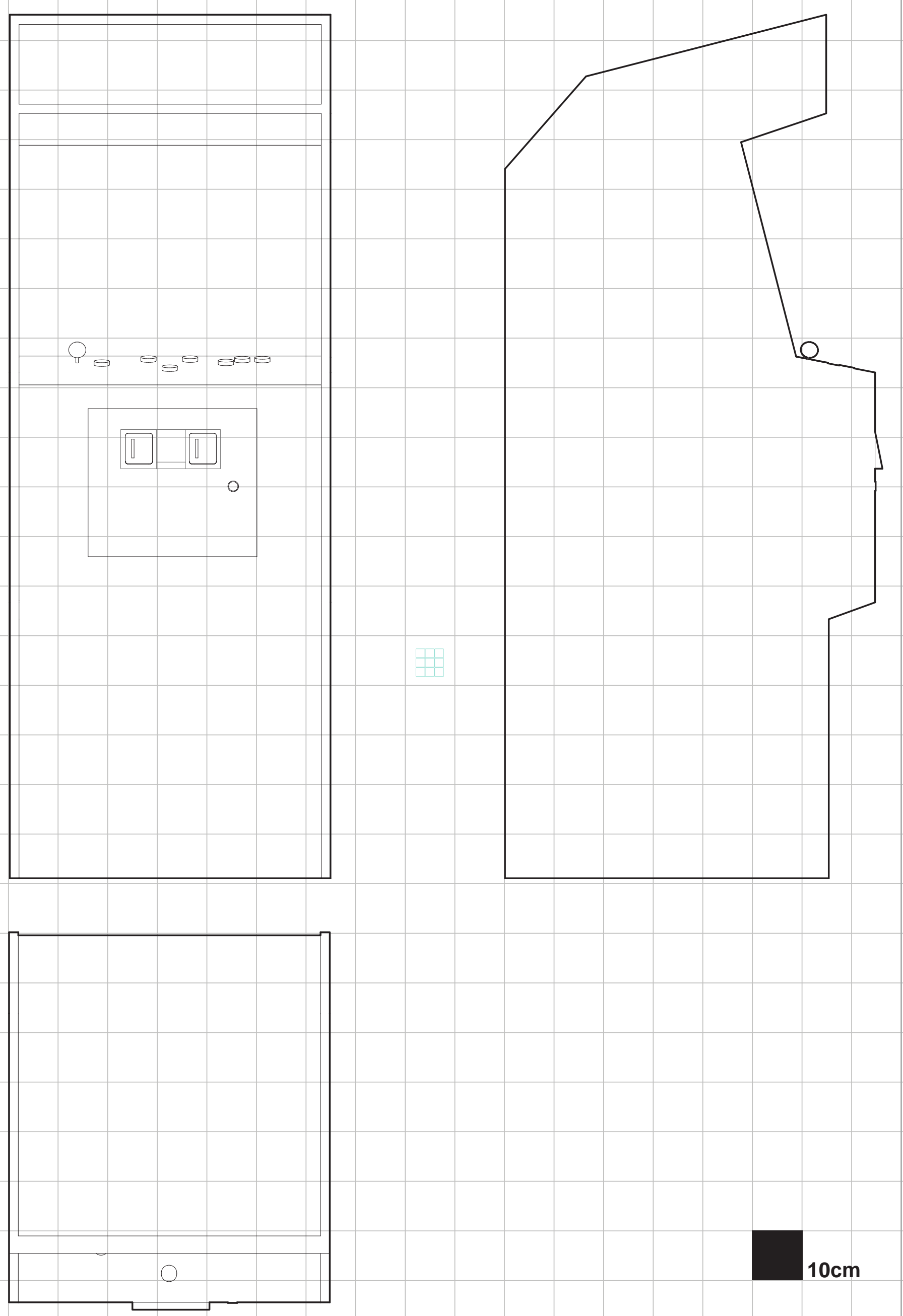
Williams.

Videojuego arcade de disparos en desplazamiento lateral. Fue pionero al permitir que cada píxel de la pantalla mostrara hasta 16 colores y, sobre todo, al generar un es-

Máquina arcade. pacio de juego mayor que la pantalla en sí misma, lo que

Máquina Arcade desarrollada y publicada por Williams Electronics en 1980. Este juego, diseñado por Eugene Jarvis y Larry DeMar, se convirtió en un éxito comercialmente hablando, siendo el arcade mejor vendido de la compañía con 55.000 unidades.

Esta máquina contaba con un monitor horizontal CRT que permitía visualizar gráficos ráster en color. Disponía de un panel de control muy elaborado con un joystick que servía para controlar la altitud (el jugador podía moverse arriba y abajo) y cinco botones para disparar cañones, lanzar bombas inteligentes, acelerar, cambiar de dirección y saltar al hiperespacio. 

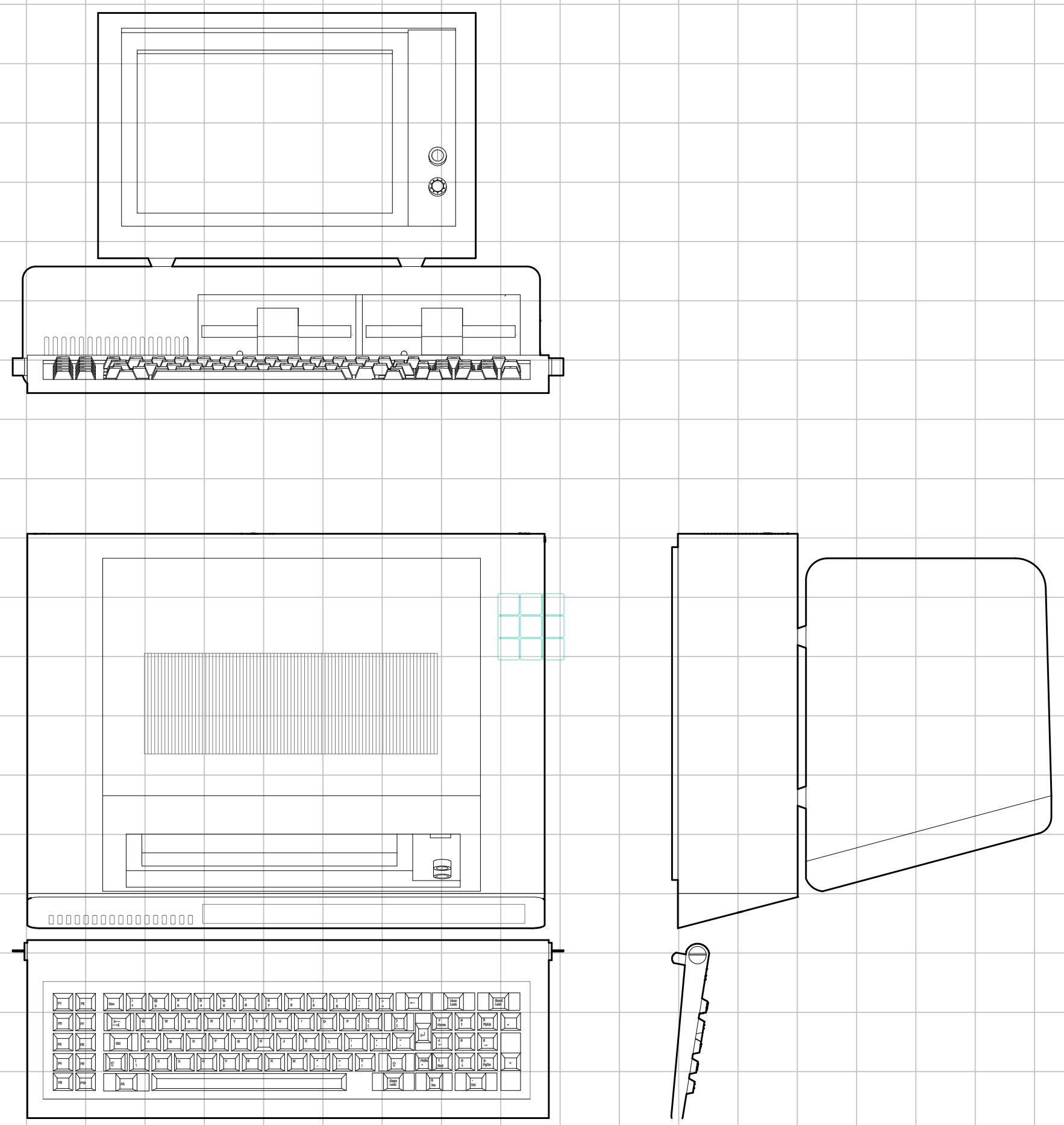


\section{IBM PC.}

1981

Ordenador.

Ordenador domestico lanzado al mercado en 1981 por la tion). Desarrollado por un equipo de ingenieros con Don Estridge y William C. Lowe al frente. Este ordenador se Estidge y Wilim C. Lowe a frente Este ordmador se BM (International Business Machines Corporation) llevaba desarrollando desde 1911 hardware y software para diferentes servicios como el Gobierno de USA o diferentes Universidades tecnológicas (Ceruzzi, 2012).

El IBM PC (Personal Computer) supuso su primer sistema completo para entornos domésticos. Contaba con dos unidades de lector de disquete, un teclado con un microprocesador, un monitor inicialmente monocromático de doce pulgadas, dos tarjetas gráficas de vídeo. Pero lo más destacable de este ordenador fue su arquitectura abierta que permitio que otros fabricantes produjesen y vendiesen componentes y software para el sistema.

"A finales de los años ochenta, los sistemas compatibles con IBM PC fabricados por las firmas rivales superaban en ventas a los propios PC de IBM. Los sistemas operativos MSDOS y Windows, de Microsoft, pasaron a ser el estándar común de software de los PC $y$, despues de tener éxito en el mercado empresarial, el PC se extendió a los con la tecnología multimedia y, más tarde, internet"

(Donovan, pg 487, 2010/2018)

Este ordenador, de 16 bits, utilizaba el lenguaje de programación BASIC y, desde sus inicios, se convirtió en el computadora contó con varios mo videojuegos. Esta destacó especialmente el IBM PC Jr.

Este ordenador fue el primer ordenador de IBM que fue ealmente competitivo en el mercado. A raíz del éxito del IBM Personal Computer, con los años sus siglas de PC se estandarizaron para denominar a los ordenadores personales.

"La PC de IBM definió y estandarizó la pequeña computadora personal, tal como la conocemos los conceptos de diseño desatrodujeron en la década de 1970, se diferenciaba principalmente por la elección de sistema operativo y el poderoso marketing"

(Peddie, pg 193, 2013)

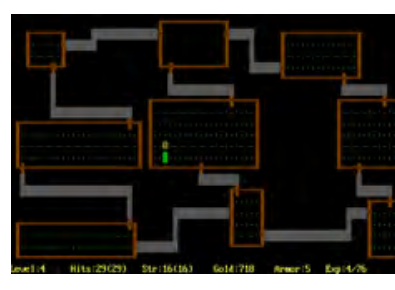

1980

Videojuego roguelike que basa su construcción del espacio en caracteres ASCII y se inspira en el mundo de eñor de los Anillos.

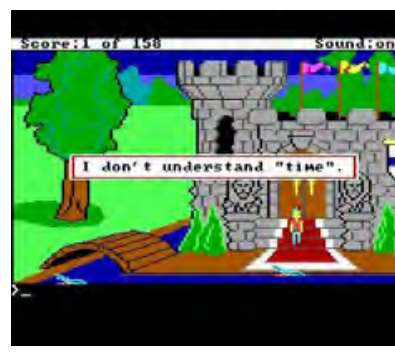

Videojuego de aventuras en que el jugador toma el pape de Sir Graham, un valiente caballero que debe encontra 3 tesoros para salvar al reino. El juego fue pionero en el uso de gráficos interactivos, siendo considerado el primer juego de aventuras que integra animación gráfica en la visión del mundo del juego por parte del jugador Aparecen se cuencias de animación para la mayoría de las interacciones jugador-mundo a las que se puede acceder a través de curso normal de exploración.

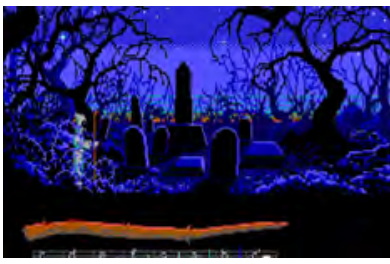

Videojuego de tipo aventura gráfica fantástica cuarta desarrollada con SCUMM y pionera en SCUMM interfaz verbo-objeto - que se había implementado en Manic Mansion - utilizando mecánicas y acertijos en torno a melodías musicales y las notas que las componen.

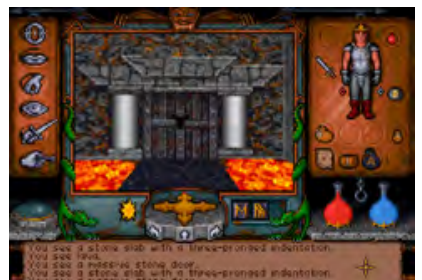

tima Underworld: The

Stygian Abyss.

deojuego RPG en primera persona. Se desarrolla en un mundo de fantasía, basado en una sistema de cuevas que contiene los restos de una civilización utópica fallida. El jugador debe intenta encontrar y rescatar a la hija secuestrada de un barón. Es considerado el primer juego de rol que presenta la acción en primera persona en un entorno en 3D, introduciendo de forma pionera, la forma de que el jugador mire hacia arriba y hacia abajo. Se trata de un juego no lineal que permite un juego emergente.

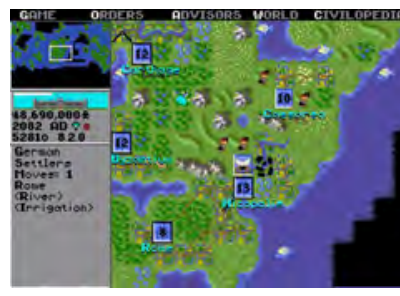

Videojuego de estrategia por turnos que dio origen a la saga del mismo nombre. E objetivo del jugador es dirigir una civilizacion desde sus inicios hasta la conquista de planeta. El juego permite la exploración, la guerra, la diplomacia, la construcción de nuevas ciudades, los avances en conocimiento y las transformaciones de la tierra para sacar el máximo beneficio. El tiempo de avance de juego es considerado tiempo histórico que permite el desarrollo de nuevas tecnologías. Se puede ganar el juego conquistando las demás civilizaciones o ganando una carre ra espacial que permita llegar a un sistema estelar nuevo.

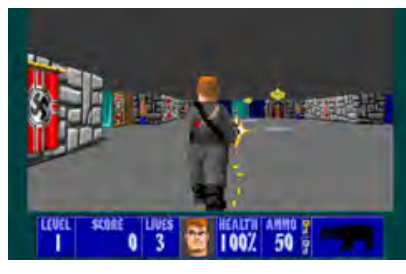

1992

Videojuego de disparos en primera persona en que e jugador asume el papel de un espía aliado durante la Segunda Guerra Mundial mientras trabaja en misión contra los nazis. El juego emplea el motor mejorado de John Camark, que funcionaba en perspectiva 3D de forma rápida, pero mantenía en sprites 2D los enemigos y los objetos. La versión origina del juego permite al jugado guardar su progreso en cual-

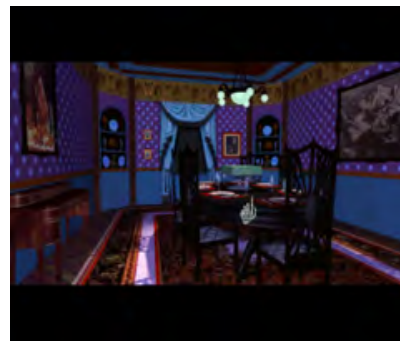

1993

Videojuego de puzzles y aventuras pionero por ser uno de los primeros juegos publicado en CD-ROM. El jugador toma el papel de un amnésico a través de una historia de terror en la que debe recorrer una mansión resolviendo acertijos que se intercalan con vídeos que profundizan en la trama. Estos vídeos de acción en vivo y parte centra del juego poselan una calldad sin precedentes de gráficos 3D pre-renderizados.

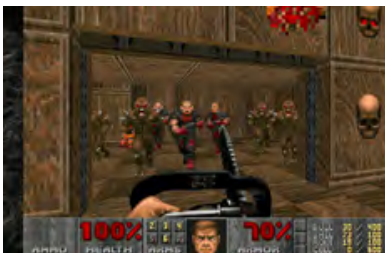

 primera persona considerado revolucionario. Pionero en el uso de la tecnología gráfica para la perspectiva 3D - los enemigos y los objetos son sprites 2D presentados desde varios angulos de visión establecidos, una técnica a veces denominada gráficos $2.5 \mathrm{D}$ - los juegos en red multijugador y la presentación como un juego facimente modificable por los propios jugadores a través de archvos empaquetados (WAD). Los niveles son a menudo laberinticos, pero hay disponible un mapa de pantalla completa que muestra las areas exploradas hasta el momento. El jugador controla un soldado espacial a través de una serie de niveles establecidos en bases militares y bunkeres en las lunas de Marte y en el Infierno. Se trata de un juego contr debido a su violencia gráfica. 

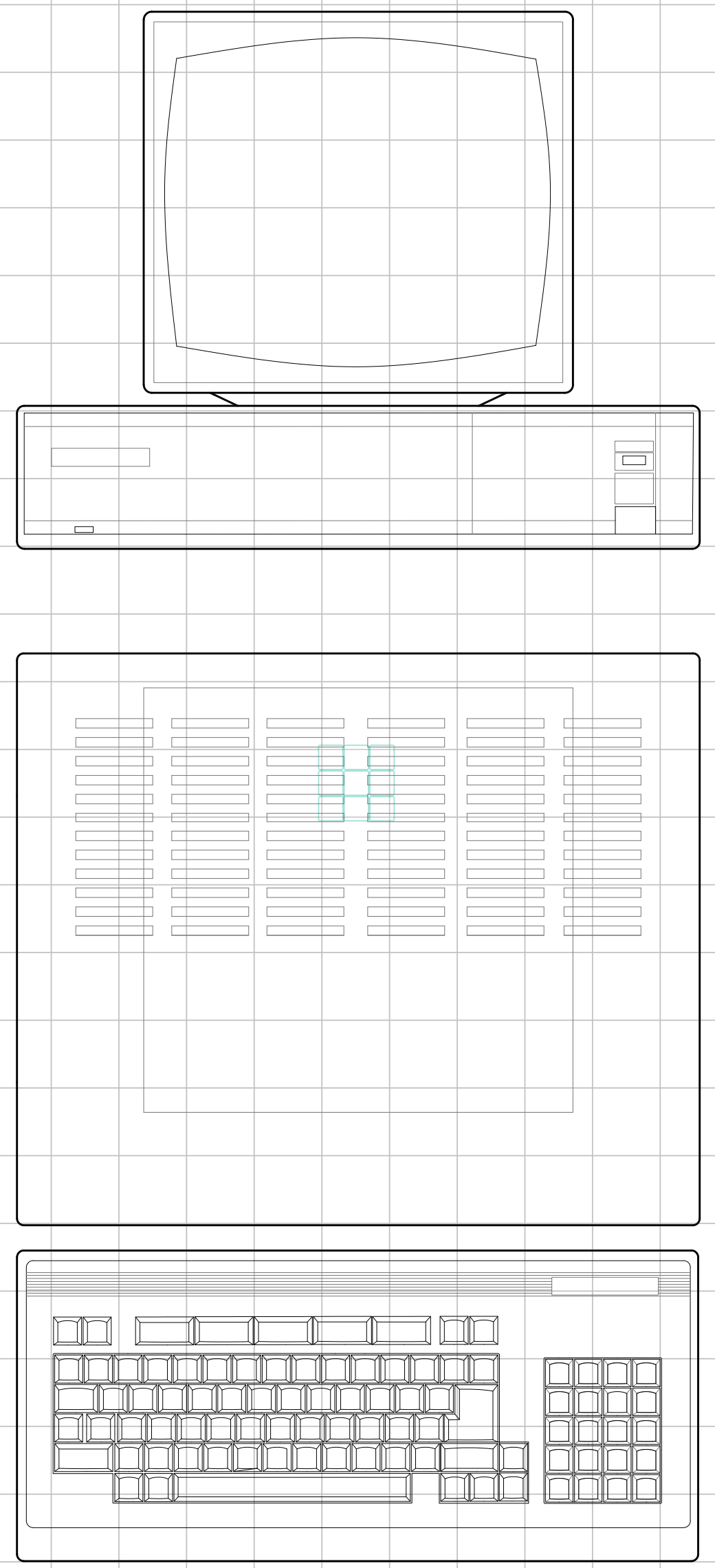


\section{PC-8800.}

\section{1}

\section{NEC Corporation. Microordenador.}

Este ordenador pertenecía a la serie NEC PC-8801, de la que salieron al mercado ocho modelos. Comúnmente conocido como PC-88 salió al mercado en 1981, desarrollado por la NEC Corporation, y se descontinuó en 1989 con el último modelo de la serie.

Fue uno de los primeros ordenadores basados en el microprocesador Zilog Z80, que ya habían sido utilizados por muchas máquinas arcade. Contaba con un procesador NEC D780C. En su momento, podía mostrar en pantalla una resolución alta de $640 \times 200$ píxeles. Sin embargo, solo podía mostrar simultáneamente 8 de sus 512 colores. A partir de 1985 se distribuyó con puertos de conexión para joystick de Atari.

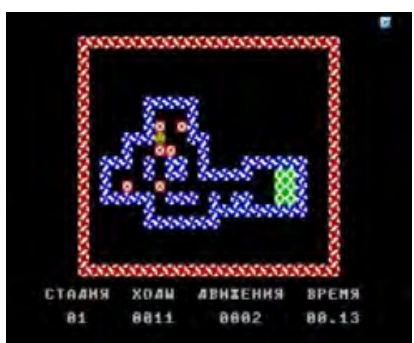

Sokoban.

1981

Videojuego de lógica y laberintos considerado un clásico.

El jugador controla al encargado un almacén - Sokoban en japonés - que debe mover una serie de cajas a lugares elegidos dentro de un espacio reducido, teniendo en cuenta el número mínimo de movimientos y no puede tirarse de las cajas, solo empujarlas.

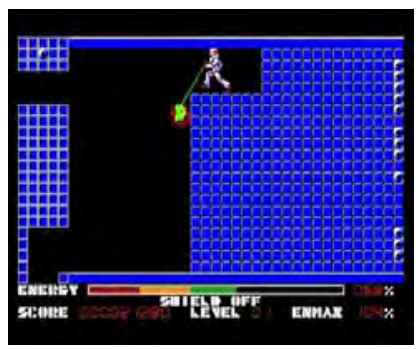

Thexder.

1985

Videojuego de carreras y disparos que no se limitaba a un desplazamiento lateral si no que el jugador podía moverse en todas las direcciones. Éste controlaba un avión que podía transformarse en un robot y que le servía de sistema de ataque y defensa.

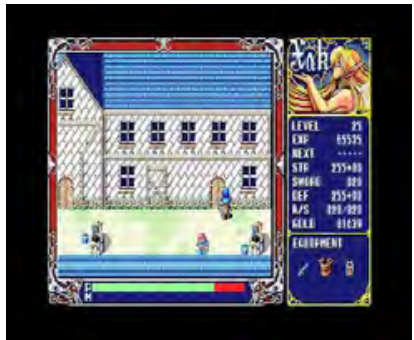

Xak: the art of Visual Stage. 1989

Videojuego de rol y acción en el que el jugador asume el papel del hijo de un famoso guerrero que se ve embarcado en una aventura en la búsqueda de un rey y de su propio padre. El juego destacaba por sus elaborados y coloridos gráficos y, sobre todo, por su uso de música y sonido. 


\section{回 ${ }^{200}$}
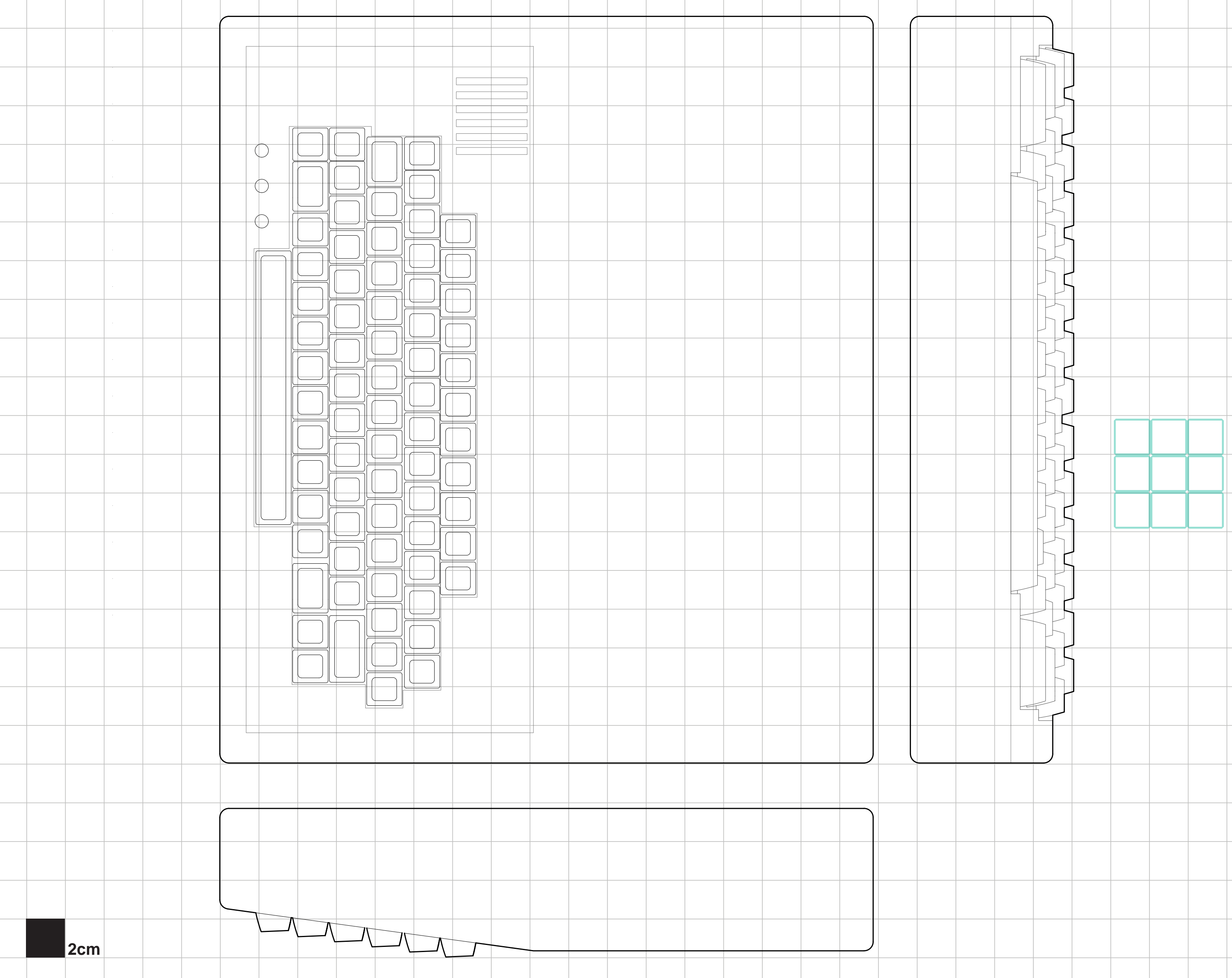


\section{BBC Micro.}

1981

BBC.

Microordenador.

Microordenador diseñado por Acorn Computers para la BBC (Britsh Broadcasting Corporation) en 1981 que fue uno de los primeros ordenadores domesticos. Este ordenador personal nació a raíz del Proyecto de Alfabetización Informática de la BBC cuyo pilar principal fue el programa de televisión The Computer Programme (BBC, 1982) en el que enseñaban a usar la computadora (Donovan, 2010/2018)

Este ordenador tuvo un gran éxito a nivel nacional, tanto en los hogares como en las escuelas británicas. Acorn desarrolló en esta máquina la arquitectura ARM (una familia de arquitecturas de computación de conjuntos de instrucciones reducidas, conocidas como RISC) que seria usada años más tarde para teléfonos móviles y tabletas.

Se distribuyeron dos modelos: Model A y Model B, y se vendieron un millón y medio de unidades. Debido a su papel de computadora doméstica y educativa, se convirtió en una plataforma que acogió el desarrollo de un buen número de juegos en la naciente industria de videojuegos del Reino Unido. Se trataba de un ordenador de $32 \mathrm{~Kb}$ el Model A y $48 \mathrm{~Kb}$ el Model B, lo que ofrecía una velocidad de ejecución mayor que la de otros ordenadores de la enca. Pernita visualizar una resolución de $640 \times$ 256 y hasta ocho colores.

Existía la posibilidad de conectarle múltiples periericos, entre los que destacaron: joystick, lectores cluso, cluso, el llamado BBC Turtle que se trataba de un ron dibujar formas geométricas, rellenos sólides ron y sprites, y un lápiz óptico (light pen) dispohible únicas fotosensor de alta velocidad para leer y controlar la visualización de la pantalla.

\section{ACCESORIO}

BBC Turtle (robot)

Robot de juguete que permilla interactuar a través del conono como parte de los juegos la

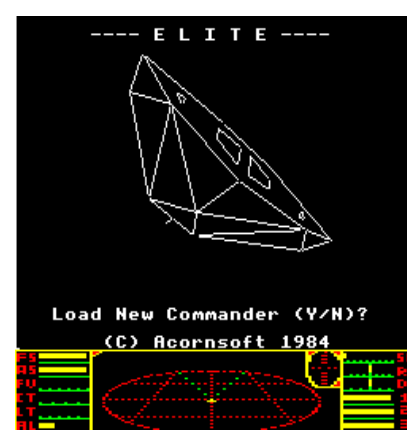

Elite.

en cada cambio de posición. ficos en 3D wireframe grá eliminación de línea oculta en ordenadores. 'El mundo dentro de una caja que presentaba Élite abrió un nuevo camino que los diseñadores de videojuegos podían explorar: el concepto de mundo, en que los jugadores deciden qué hacer y adónde ir en vez de requerir objetivos preestablecidos en un mundo que limita sus opciones' (Donovan, 2010/2018). Destacó también por mostrar los códigos legales y morales a los que los jugadores debían aspirar incluyó el desarrollo de una novela que contextualizaba juego.

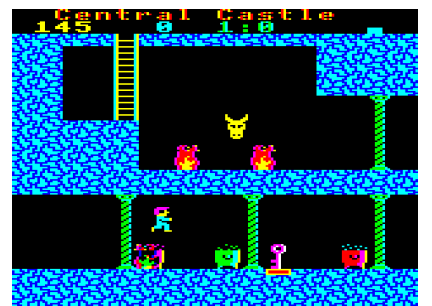

Videojuego de plataformas y puzzles en el que le jugador debe recorrer un enorme castillo - y sus áreas exteriores en búsqueda de 5 cristales jugador se tes cristales, el un conjunto separado de ubicaciones para completar la partida. Cuando los 5 cristales son encontrados el jugador queda libre para explorar el castillo y encontrar los objetos extra que le permiten alcanzar la máxima puntuación. El juego fue pionero en permitir la elección del sexo del personaje y presenta un característico efecto cuando este se cruza con los objetos, haciendo que el sprite se les superponga y cambie de color. etc) en primera persona $\mathrm{Si}$ el Centinela nos detecta comenzará a quitarnos ener-

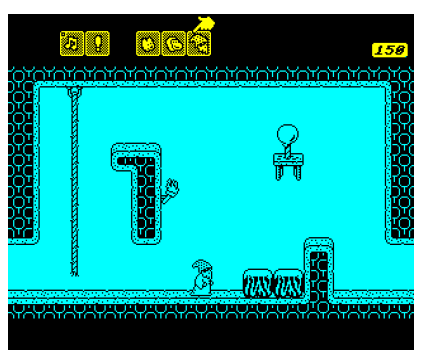

Videojuego de plataformas y puzzles en el que el jugador - que tras enloquecer se encuentra encerrado en un caabozo dentro de una montaEl mago puede convertise on tres animales diferentese en poderes distintos diferentes: pájaro mono y gato. El juepajaro, 16 niveles que juecada uno deben encontrarse los fragmentos de un hechizo que están siempre en lugares inicialmente inaccibles, que potencia el pensamiento diagonal en el jugador. recen en orden a que apa-
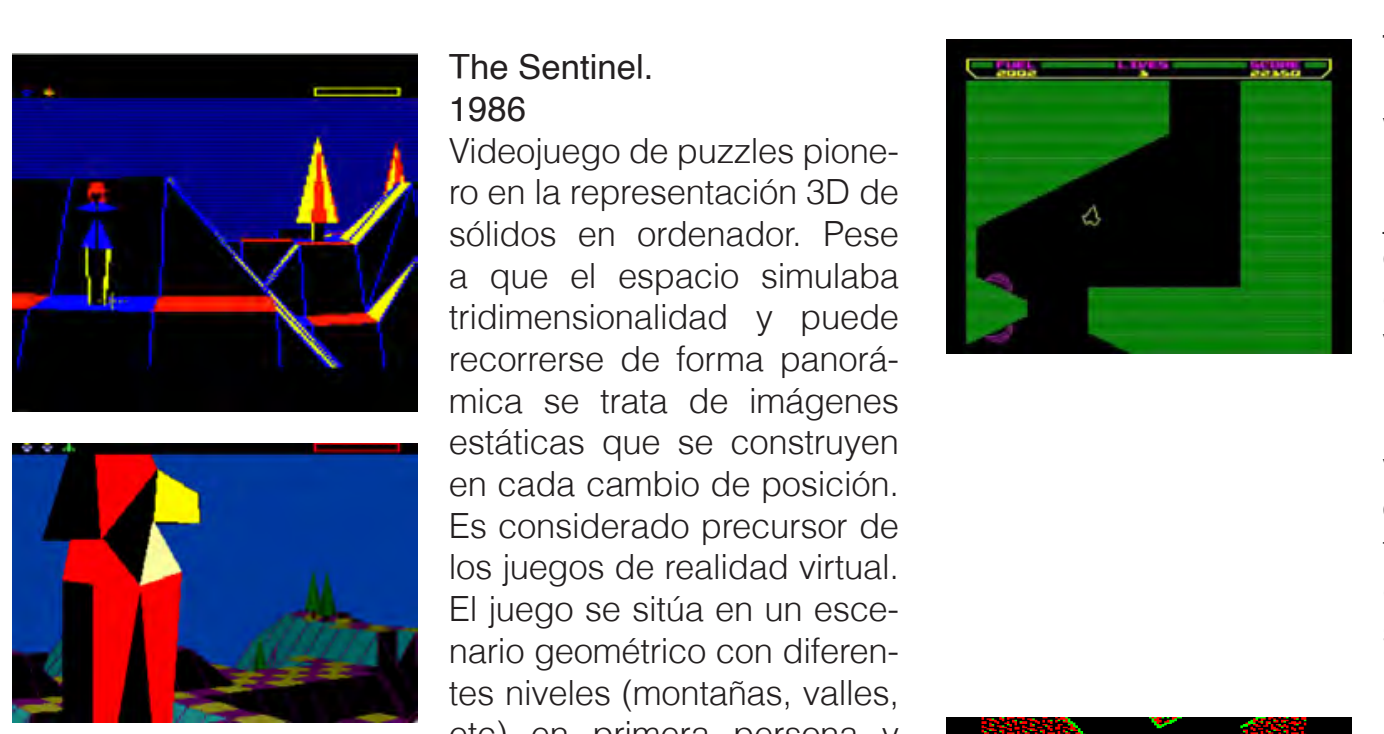

mideojuego de tipo shooter ultidireccional en el que el gador controla una nave espacial que debe conseguir que una cápsula levante el vuelo. A partir del nivel 6, los niveles comienzan de nuevo; primero con la gravedad invertida, luego con todos los objetos invisibles, y finalmente con paredes invisibles y gravedad invertida de forma simultánea. El juego se sitúa en un escenario geométrico con diferentes niveles (montañas, valles, de el Centinela Para ello de bemos mover nuestra 'energía' de un cuerpo a otro disponible pudiendo reabsorber los que dejamos atrás (asi como otros elementos como árboles) en un nivel inferior gía - hasta perder el juego - mientras que no nos traslademos a otro cuerpo lejos de su mirada.

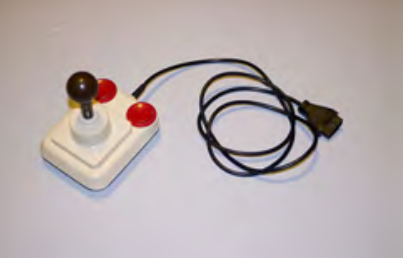

\section{ACCESORIO}

BBC Pro Joystick.

Controlador tipo joystick di-

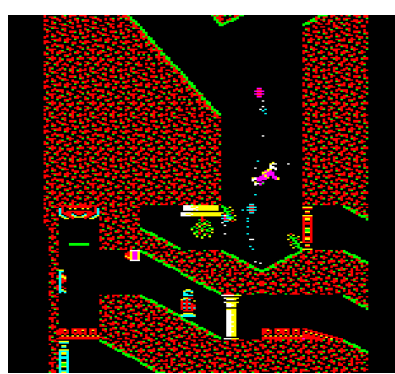

Exile.

Videojuego de acción y aventura que permite partidas no lineales protagonizadas por Mike Finn, un explorador espacial en un mundo giganiesco. Al igual que en Exile novela para construir la histo-

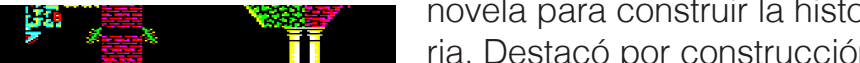
de las físicas en el juego: gravedad realista inercia y masas de objetos, etc al poseer un motor capaz de seguir las tres leyes del movimiento de Newton. Basado en el sigilo, aparece una mecánica de teletransportación entendida como predecesora de Portal. 

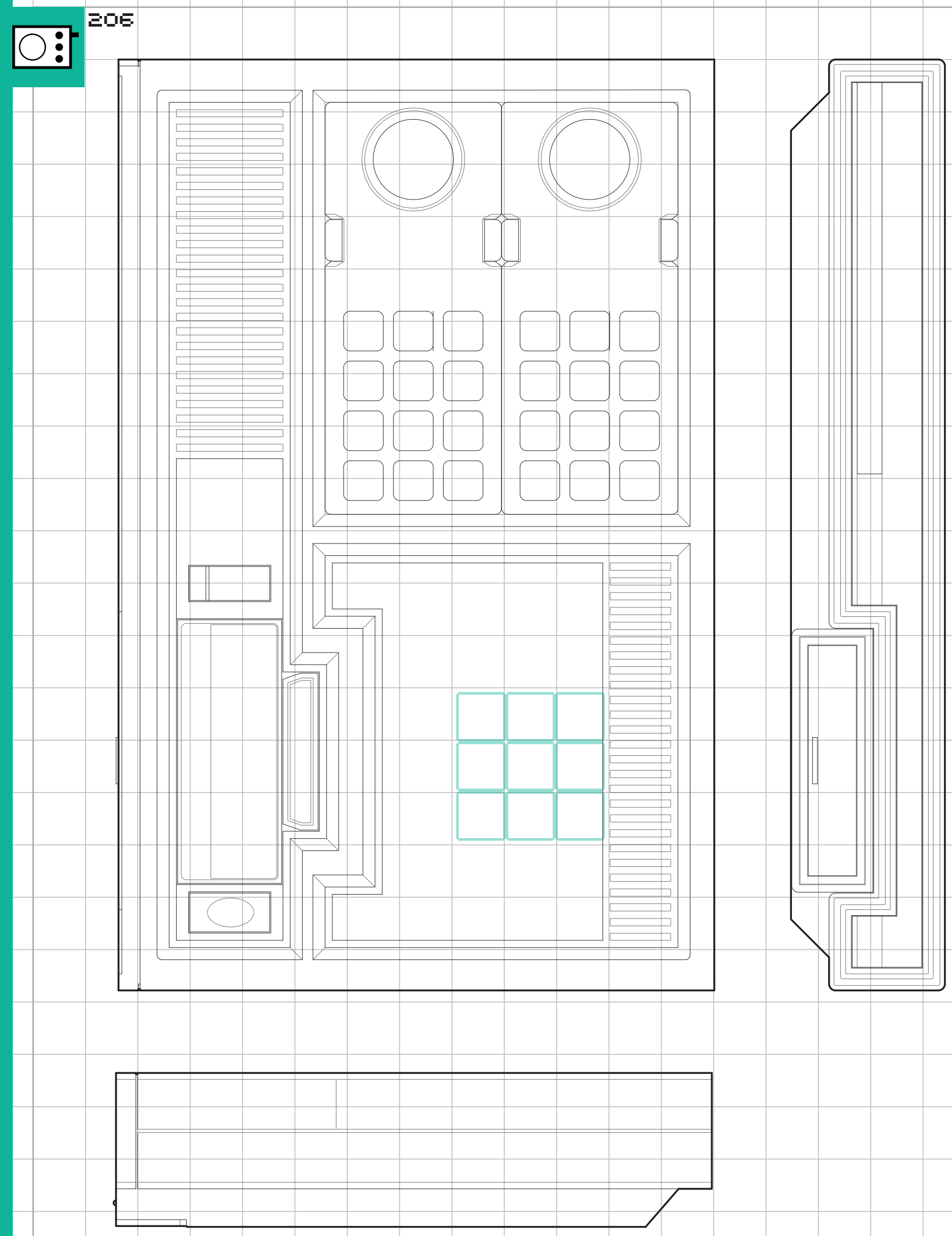


\section{Coleco Vision.}

\section{2}

\section{Coleco.}

Videoconsola doméstica.

Consola doméstica perteneciente a la segunda generación que la empresa estadounidense Colepara su tiempo unos gráficos y una jugabilidad superiores a las unos graficos y una jugabilidad superiores a las de consolas de su momento, como propia de las máquinas Arcade.

"Tenía un procesador de 8 bits, 8Kb de RAM (memoria de acceso aleatorio) y $16 \mathrm{Kbs}$ adicionales de memoria RAM de vídeo [... Coleco se pudo permitir un chip con el mapeo de memoria y los framebuffers [...] Estos añadidos consiguieron que la ColecoVisión tuviera animaciones más fluidas [...] Coleco aumentó la potencia de la ColecoVision con un circuito integrado auxiliar de Zilog"

(Kent, pg 206, 2001)

Esa potencia tecnológica fue acompañada de una buena estrategia de marketing por la que Coleco consiguió licencias de juegos como Venture, Mr. Do, Lady Bug o Avenger. Pero su gran acierto fue el acuerdo logrado con Nintendo para obtener la licencia exclusiva de Donkey Kong durante seis meses. Esto le permitió alcanzar su punto álgido durante seis meses y vender seis millones de copias. Sin embargo, este éxito terminó de manera abrupta por la crisis de los videojuegos de 1983.

Cada consola tenía encajados dos mandos con un control rotatorio y doce teclas. números del 0 al 9 asterisco (") y almohadilla (\#). Colecovision contó con tres módulos de expansión. El primero se trataba de un adaptador que permitía a los jugadores poder usar los cartuchos de la Atari 2600. El segundo consistla en un sistema de conducción con volante y pedal. Y el tercero convertía la consola en un ordenador con teclado y lector de casete.

Fuente análisis gráfico:

Elaboración propia a partir de los datos del manual orisulta de modelos $3 d$ prediseñados por coleccionistas en 3dwarehouse.sketchup.com

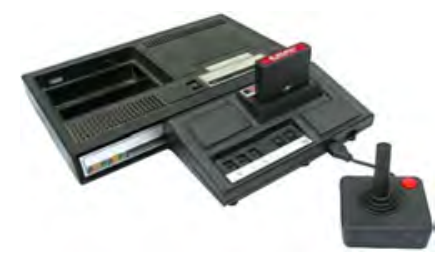

ACCESORIO

Expansion Module \#1.

Expritía a la

consola leer los juegos de Atari 2600

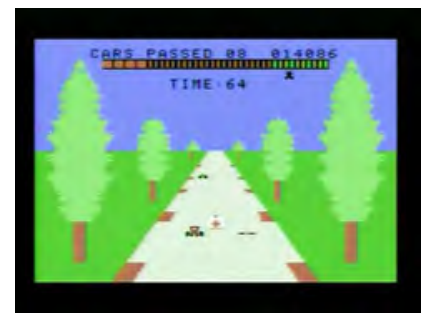

Turbo.

Videojuego de conducción

visualizado en perspectiva

cónica centrada. Se trata de

una adaptación del juego

arcade de nombre homónimo de Sega y permitía el uso de

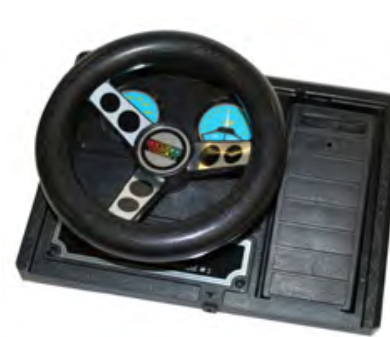

\section{ACCESORIO}

on Module \#2.

Driving Controller.

Expansion con volante y pe

dal que permitla interaccionar

con los juegos de conducción como Turbo (juego originaadaptado a la versión doma ytica por Coleco en 1983).

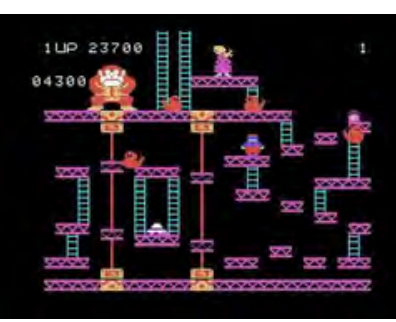

Donkey Kong.

1982

Videojuego de plataformas desarrollado originalmente como arcade. Es especialmente significativo para Coleco pues su presencia en la consola le permitió obtener un exclusividad en el mercado que le favoreció. En el juego el jugador controlaba a un fontanero llamado Mario que debia salvar a su novia de un gorila que la habia secuestrado. Las limitaciones técnicas del momento definieron el diseño gráfico, siendo el primer juego que introduce una historia completa contada empleando escenas intermedias para hacer avanzar el guión. El juego se divide en cuatro zonas, cada una de ellas equivalente a veinticinco megar a la cima.

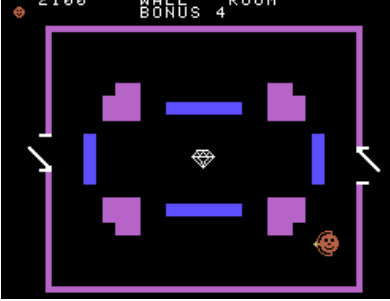

Videojuego de fantasía origi-

nalmente desarrollado como

arcade. El jugador - Winky -

equipado con flechas y arco

debe rescatar los tesoros

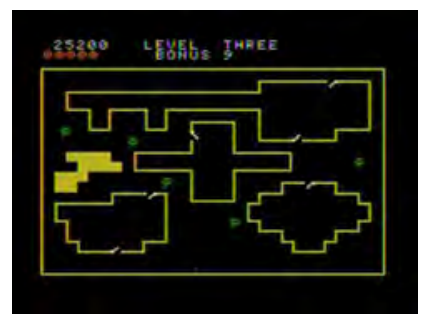

en las habitacionos. Los enemigos son tanto monstruos como trampas. Los monstruos se mueven en patrones especificos y pueden esquivar los disparos de versos grados de inteligencia (IA). En el juego hay tres niveles con diferentes salas que una vez pasados se repiten a mayor velocidad y con un conjunto diferente de tesoros.

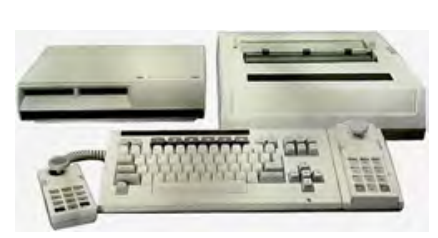

ACCESORIO

Expansion Module \#3.

Adam computer expansion.

vertir la consola en un ordenador ADAM. Lanzado smultáneamente al ordenador

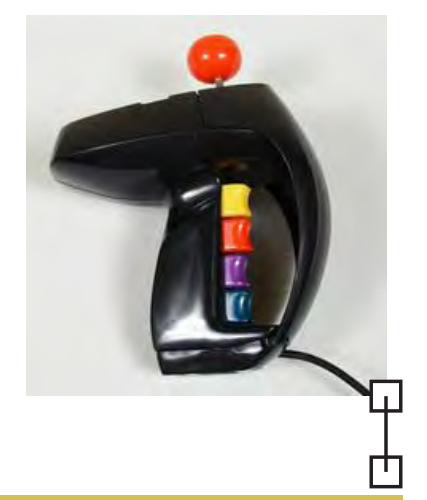

ACCESORIO

Super Action Controller.

Controlador especial que

además del teclado de 12

botones numéricos incluía 4

botones de acción por colores para el juego Super Action Baseball y publicado a la vez

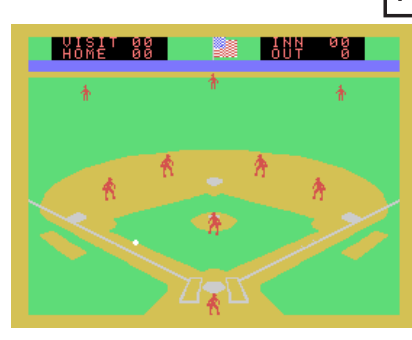

Sup

Super Action Baseball.

1983

Videojuego de deportes béisbolo en la práctica de en una vista en ángulo en la que se ve el campo en parte inferior izquierda de la pantalla y el lanzador en el centro-derecha. La parte superior de la pantalla está reservada para vigilar las bases en 3 ventanas. Permitía el uso del Super Action Controller.

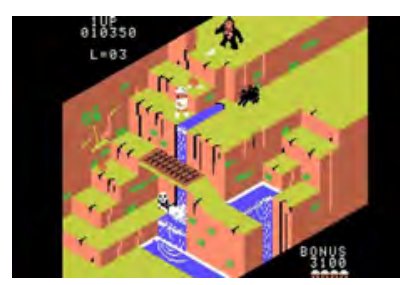

Congo Bongo.

1984

Videojuego de plataformas lanzado originalmente como arcade. El jugador controla a un cazador que debe cazar un mono. El juego original se encuentra en perspectiva isoadaptación, esta se modifica a perspectiva caballera o militar

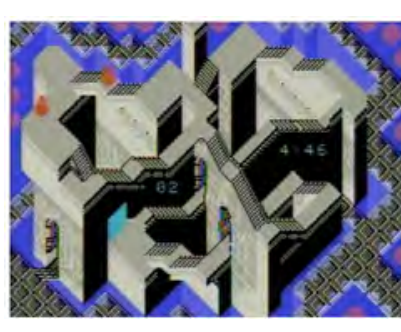

Videojuego de puzzles y e surrealista. E! jugado ractúa con piezas geométricas alrededor de la pantalla rarlas. Pueden aparecer la
gartos que se transforman en gartos que se transtornanen jugador. Presenta un estilo gráfico considerado muy innovador.

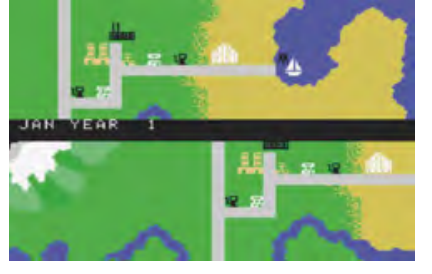

ortune Builder.

1984

Videojuego de simulación empresarial pionero, considerado educativo que permite enseñar los fundamentos de la interacción entre emrrollar empresarialmente un tramo de terreno permitiendo interactuar con elementos como casas, casinos, hoteles, fábricas y otros negocios.

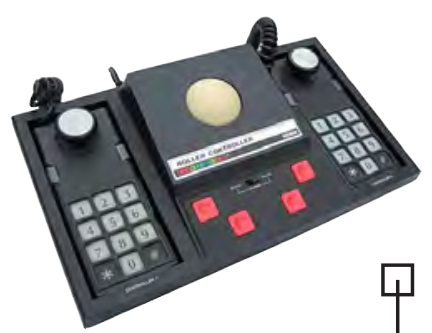

ACCESORIO

Controlador que incluía una bola que servía como botón de de $360^{\circ}$ No era compatible

con el Expansion Module \#3 y empleado en juegos como WarGames.

๑

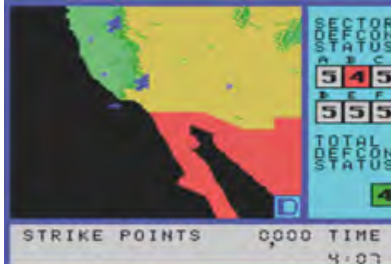

War Games

1984

Videojuego de estrategia guerra. El objetivo del juego es defender a Estados Unidos de ataque nuclear. La pantalla principal del juego destaca por presentar un sobre los que pueden actuar diferentes niveles de amenaza nuclear. 


$$
x
$$

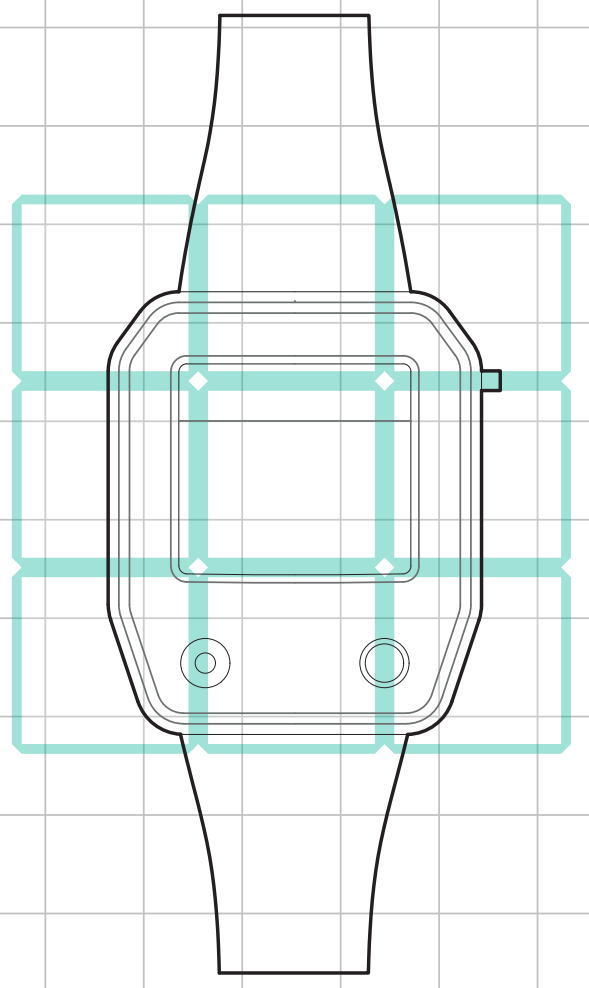




\section{GCE Game Watches.}

1982

GCE.

Videoconsola portable.

Dispositivo portable en forma de reloj de muñeca. Su tecnología se basaba - al margen del modelo inicial que no era digital, Maze Lab - en la tecnología LCD. Los fundadores de GCE, pretendían fabricar una consola con monitor integrado desde el día en que fundaron la empresa y para poder sacar adelante su proyecto estrella - que acabó siendo la Vectrex - decidieron probar primero con una serie de tres relojes que se vendieron a precios muy asequibles (Kent, 2001)

"[...] desarrollamos tres relojes con juegos, GameTime, ArcadeTime y SportsTime. Los dos últimos hasta tenían unos pequeños joysticks incorporados al reloj, además de un botón. Y todos ellos tenían la opción de desactivar el sonido. Con aquello nos ganamos a los padres, $y$, además, los chavales podían jugar con ellos en la escuela sin que el profesor se enterara."

Hope Neiman, ex director de márketing GCE (Kent, p179, 2001)

Tom Sloper, ingeniero en Western Industries - que colaboró con GCE en el desarrollo de la tecnología - manifestó la idea de que los relojes de juego eran tan populares en aquel entonces porque eran portátiles, algo que no se podía decir de la mayoría de los dispositivos electrónicos de la época8.

Los tres modelos disponían de una pantalla vertical y un botón y un mini joystick (en Game time eran dos botones).

\section{Variaciones:}

Sports time (1982)

Arcade time (1982)

Game time (1982)

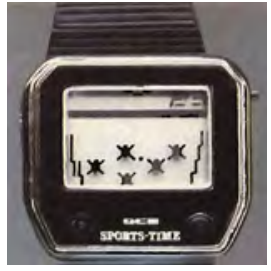

Football, Basketball y Soccer. 1982

Videojuegos de temática deportiva inspirados en otros arcade y constituidos como una versión simplificada de los mismos.

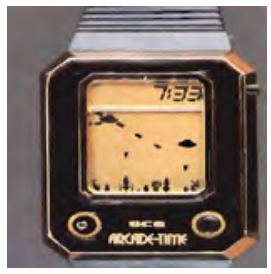

Hyperblast, Planet Riders, Galaxy Gunner y Cosmic Clash.

\section{2}

Videojuegos de temática espacial basados en juegos arcade simplificados para poder ser jugados en un escenario reducido.

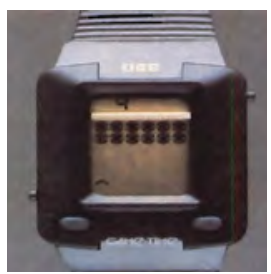

Firing Squad, Missile Strike, Allen Assault y Blast Away. 1982

Videojuegos de temática de disparos basados en juegos arcade simplificados.

\footnotetext{
${ }^{8}$ En 1982 hacía solo dos años que habían aparecido las Nintendo Game \& Watch, y al margen de las calculadoras y relojes Casio, solo existían ciertos juegos portables para niños muy simples.
} 


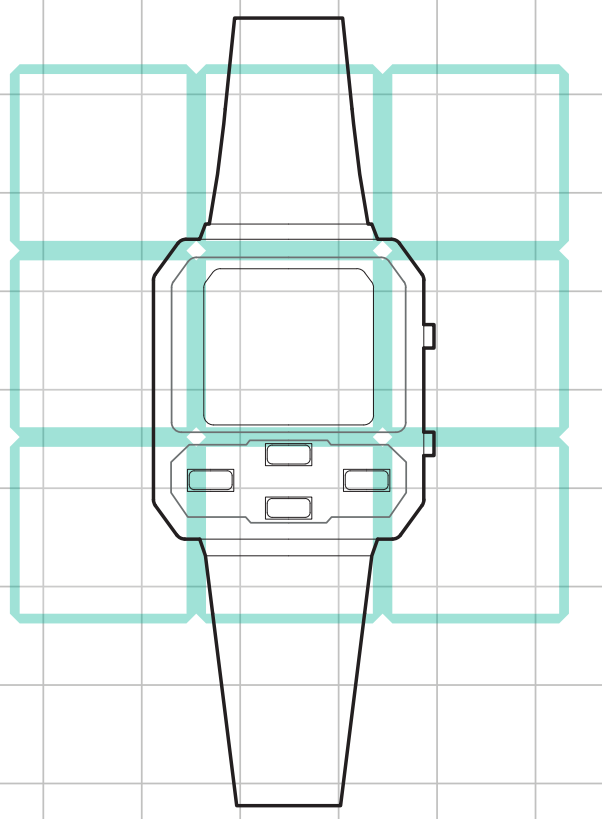




\section{Nelsonic Game Watches.}

\section{2-1997}

\section{Nelsonic. \\ Videoconsola portable.}

Dispositivo portable en forma de reloj de muñeca. Seguía la línea de GCE y Casio con sus juegos para relojes que empleaban una pantalla $L C D$ similar a la de las calculadoras y Game\&Watch de Nintendo. Se publicaron más de 30 modelos que sin embargo estaban basados en 15 diseños. La mayor diferencia fue la estrategia comercial de Nelsonic - una empresa norteamericana nacida de MZ Berger \& Co. Fabricante de joyas y relojes - adquirió los derechos de multitud de franquicias de cine, TV y juegos de otras compañías, creando versiones portables simplificadas. Esto los llevo a vender millones de relojes en todo el mundo.

"Jugar este juego en tu muñeca era simplemente increíble. Una versión en realidad suministraba cuatro mini joysticks de colores para insertar en el puerto en la esfera del reloj y jugar el juego como si estuviera en la sala de juegos".

Bernard Frieder, extrabajador de Nelsonic en los años 80

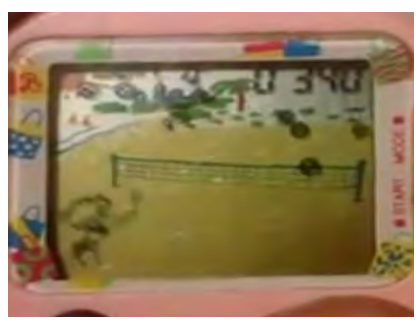

Catálogo de juegos existentes: Videojuegos considerados versiones de otros existentes (como PAC-MAN, Super Mario, Donkey Kong, Zelda, Tetris, etc) de los que son licenciatarios. Los títulos disponen de pocas opciones de jugabilidad al situarse sobre una pantalla LCD.
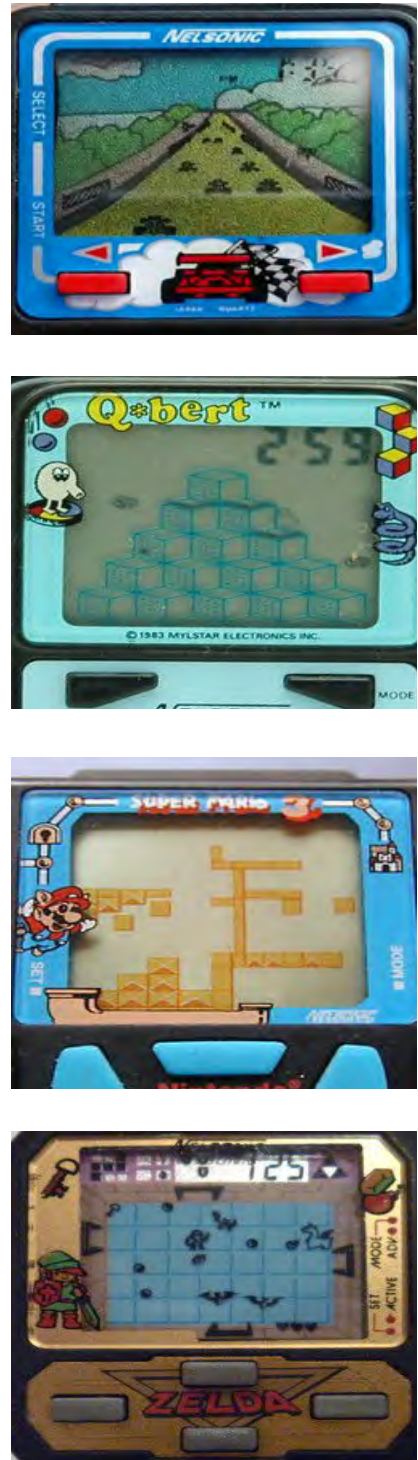
$\Xi 1$
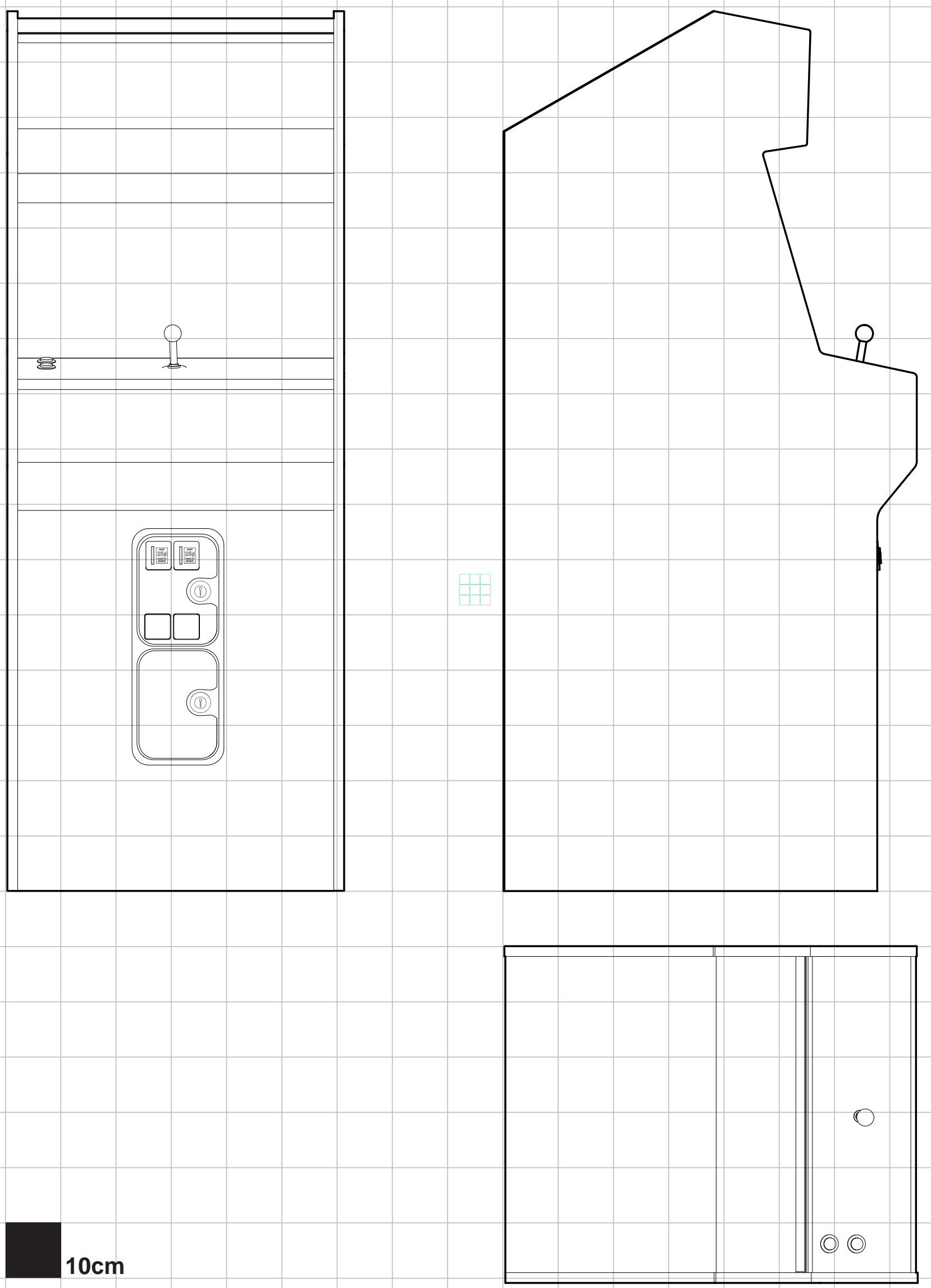


\section{Q*bert.}

\section{2}

Atari arcade.

Máquina arcade.

Máquina Arcade desarrollada por la empresa Gottlieb \& Company en 1982 y diseñado por Warren Davis y Jeff Lee. Esta máquina disponía de un monitor vertical CRT que ofrecía gráficos ráster en color y una resolución de 256 × 240 píxeles.

"Warren vio el trabajo de Jeff Lee, aquellos cubos sombreados que cubrían la pantalla, y le pidió que le dejara una copia. Empezó a jugar y dijo: «El problema es que cubre demasiado la pantalla». Así que lo que hizo fue formar una pirámide"

(Kent, pg 223, 2001).
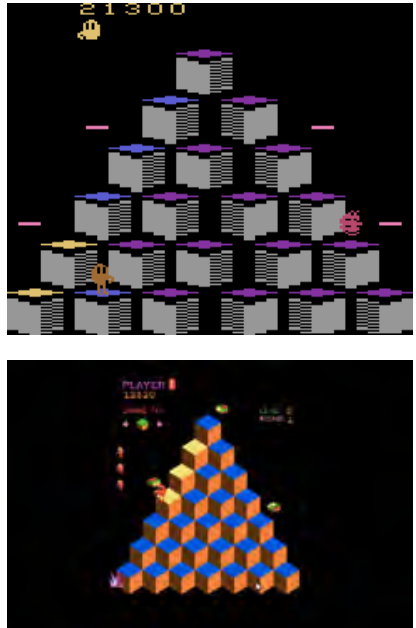

Q*bert.

1982

Videojuego arcade de puzzles y plataformas en $2 \mathrm{D}$ en el que el jugador se desplaza por una pila de cubos dibujada en perspectiva isométrica con el objetivo de cambiarlos de color (cosa que sucede cuando los pisa). El diseño se basó en los dibujos de MC. Escher y su protagonista Q*bert fue un personaje pionero en convertirse en objeto de merchandising.

El jugador disponía de un panel de control formado únicamente por un joystick que permitía moverse en cuatro direcciones (arriba-izquierda, abajo-izquierda, arriba-derecha, abajo-derecha). Este Arcade contó con varios modelos de cabina: la clásica vertical, el modelo cocktail y el modelo mini. 

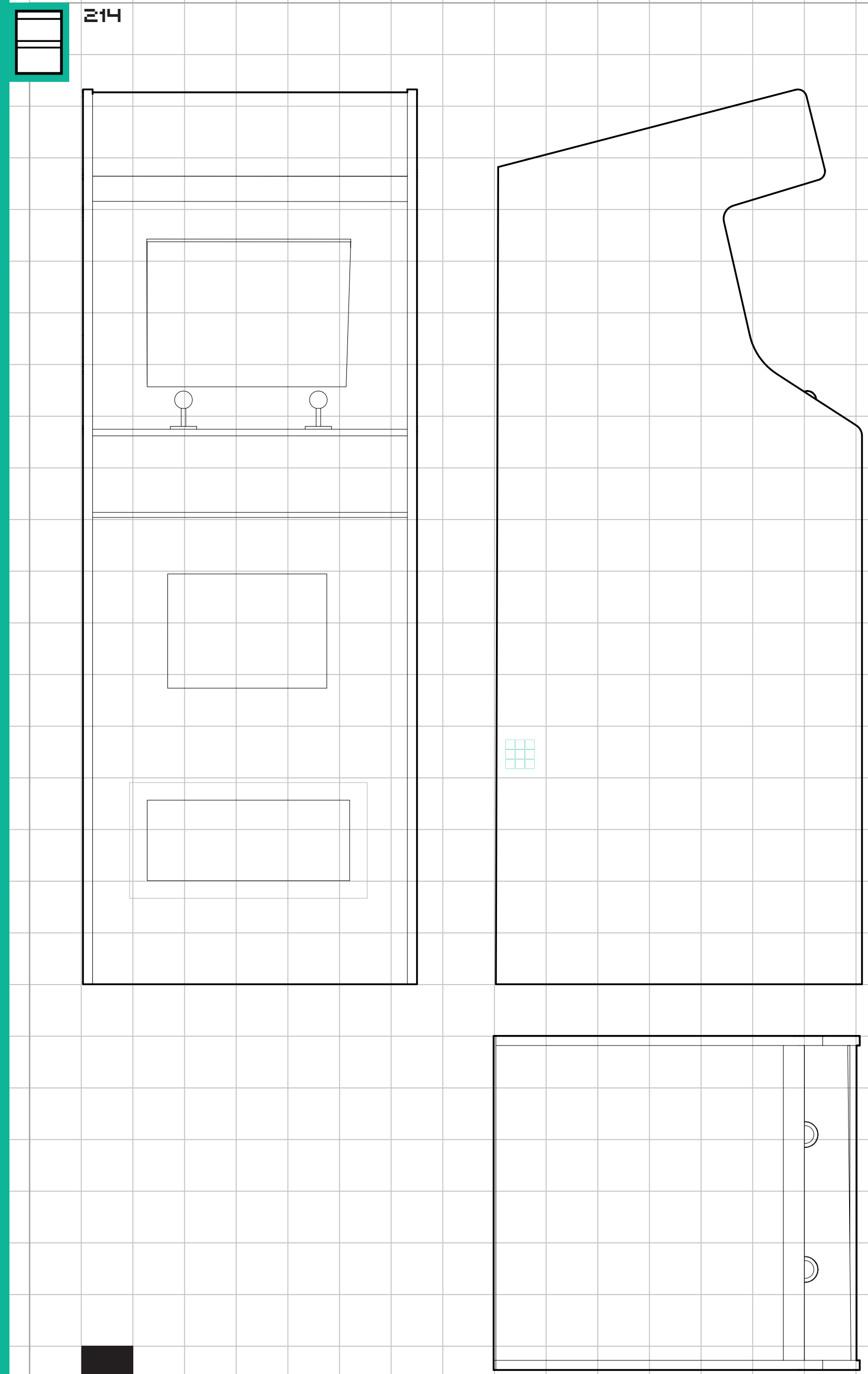


\section{Robotron 2084.}

1982

Williams.

Máquina arcade.

Máquina Arcade desarrollada por Vid Kidz y que fue comercializado por Williams Electronics en el año 1982.

Esta máquina contaba con un monitor horizontal CRT con gráficos ráster en color. Contó con varios modelos de cabina: el clásico vertical, uno de tipo mini y otro de tipo cocktail.

"Era el primer juego en el que se usaban dos joysticks, lo que te permitía moverte en una dirección mientras disparabas hacia otra. Los controles eran difíciles de dominar y mucha gente no podía [...] Exigía mucha coordinación manual y la capacidad de escapar en una dirección mientras disparas hacia otra"

(Kent, pg 222, 2001).

El jugador poseía, por primera vez, dos joysticks de control que permitían ocho movimientos cada uno. Uno de los joysticks servía para mover y el otro para disparar. Esto otorgaba una increíble libertad de movimiento al controlar, no solo, la dirección del movimiento del personaje sino también la del disparo.

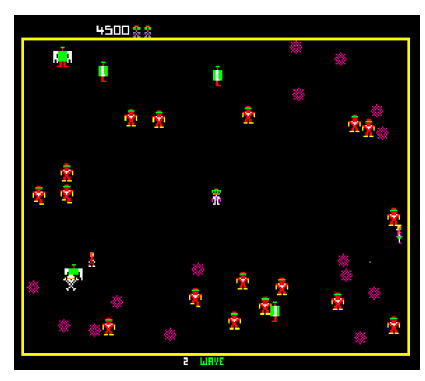

Robotron 2084.

1982

Videojuego arcade de disparos en 2D que sitúa al jugador en el año 2084 - a imagen y semejanza del "1984" de Orwelll - en un futuro distópico en el que los ordenadores se han vuelto hostiles con los humanos. La misión del jugador era derrotar a los robots y rescatar a los humanos supervivientes. 

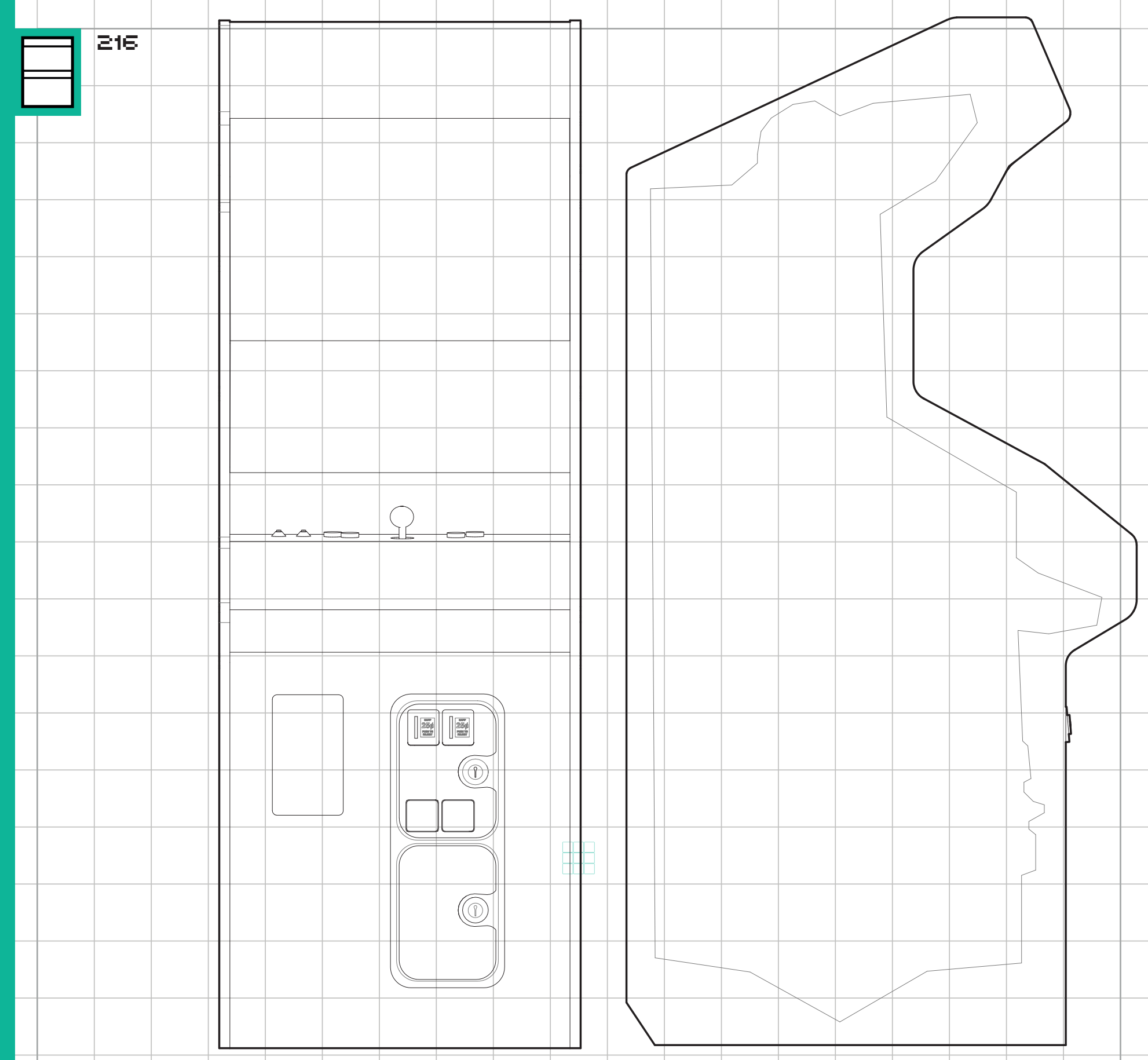


\section{Xevious.}

1982

\section{Namco arcade.}

Máquina arcade.

Máquina de Arcade diseñada por la compañía Namco y fabricado por Atari en el año 1982 Esta máquina poseía un monitor de orientación vertical CRT de 19 pulgadas que permitía visualizar gráficos ráster en color.

El jugador contaba con un panel de control formado por un joystick que permitía moverse en ocho direcciones y dos botones para interactuar (blaster y zapper). Contó con dos únicos modelos de cabina: el clásico vertical y el modelo tipo cocktail.

Este juego fue después publicado en ordenadores y consolas contemporáneas y posteriores a su lanzamiento como el Apple II, la NES, la Master System, la Game Boy Advance e, incluso teléfonos móviles.
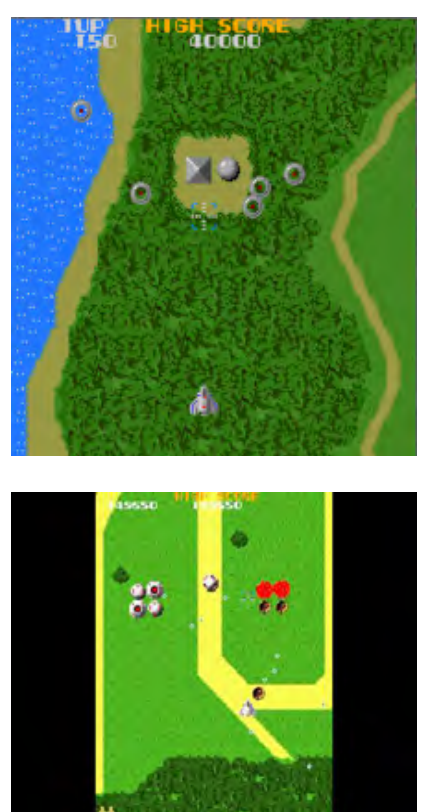

Xevious.

1982

Videojuego de disparos que se vendió acompañado por una novela para darle forma a la historia de combates aéreos entre planetas alienígenas. La partida se desarrollaba sobre campos verdes divididos por autopistas y enormes extensiones de terreno donde unos geoglifos enormes estaban grabados en el suelo. Las bases, las naves y demás elementos alienígenas poseían un grafismo espectacular. La nave del jugador tenía definido un viaje con un movimiento hacia delante que no podía detenerse, por lo que el jugador no tenía que tomar direcciones sobre la dirección a seguir y su papel se centraba en zigzaguear por la pantalla. Este tipo de movimiento marcó la pauta de juegos posteriores. 

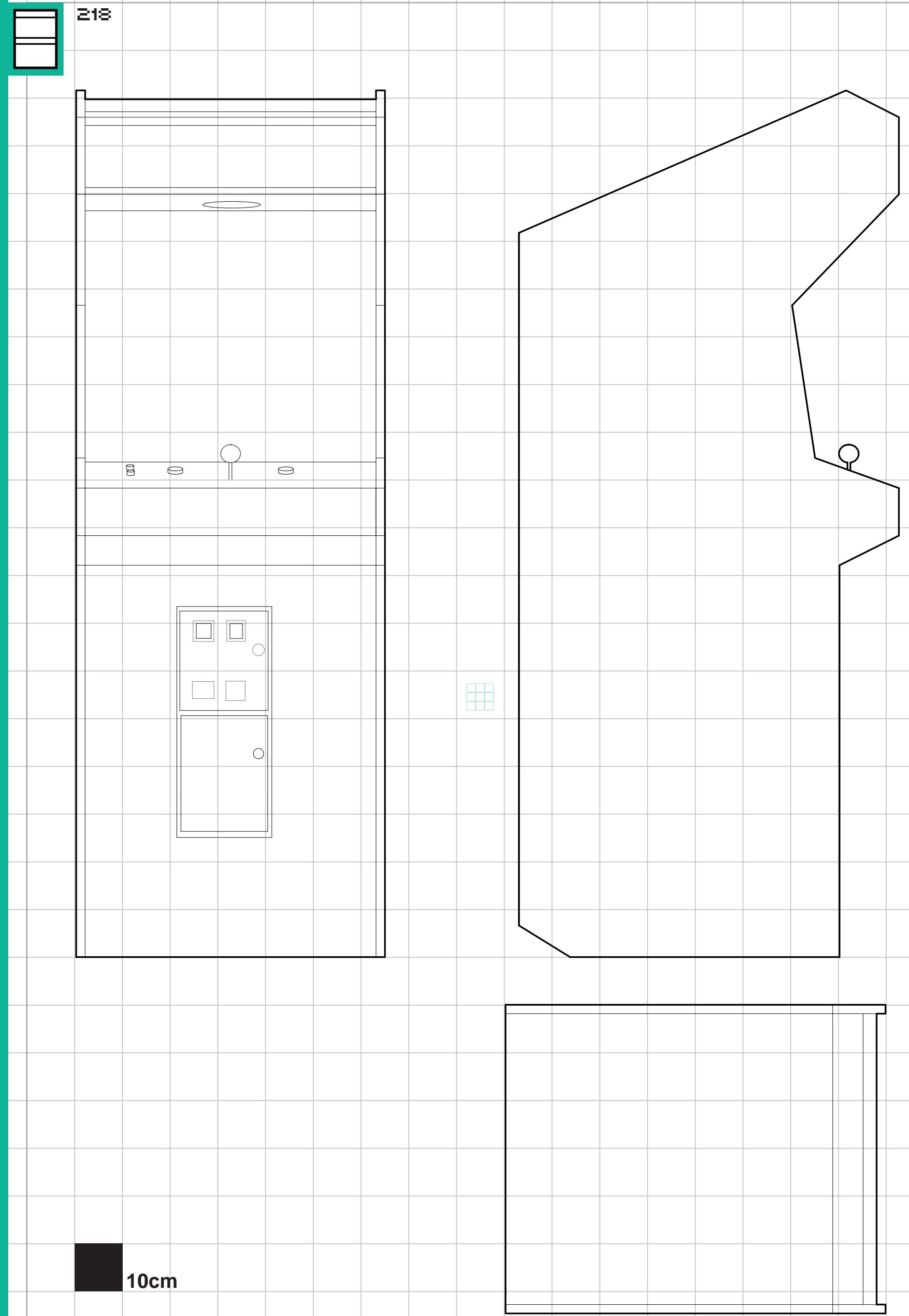


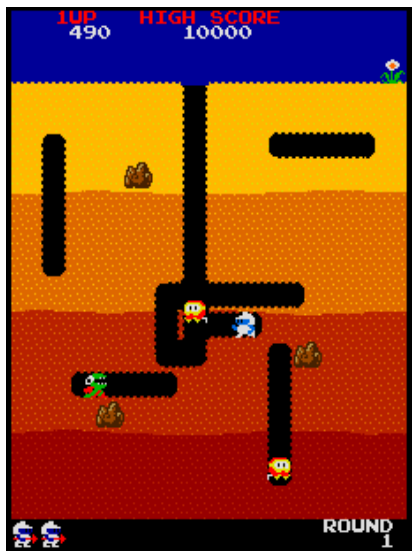

DigDug.

1982

1982

\section{Namco arcade.}

Máquina arcade.

Máquina Arcade desarrollada por Namco y distribuida por Atari en 1982. Esta máquina contaba con un monitor vertical CRT con gráficos ráster en color.

Videojuego arcade de acción definido como "un juego de excavación estratégica" en la que el jugador debía excavar túneles bajo tierra con los que hacer explotar a los enemigos.

El jugador disponía de un panel de control formado por un joystick que permitía moverse en cuatro direcciones (arriba, abajo, derecha e izquierda) y un botón para activar acciones. Este Arcade contó con varios modelos de cabina: el clásico vertical, un modelo mini y un modelo cocktail. 

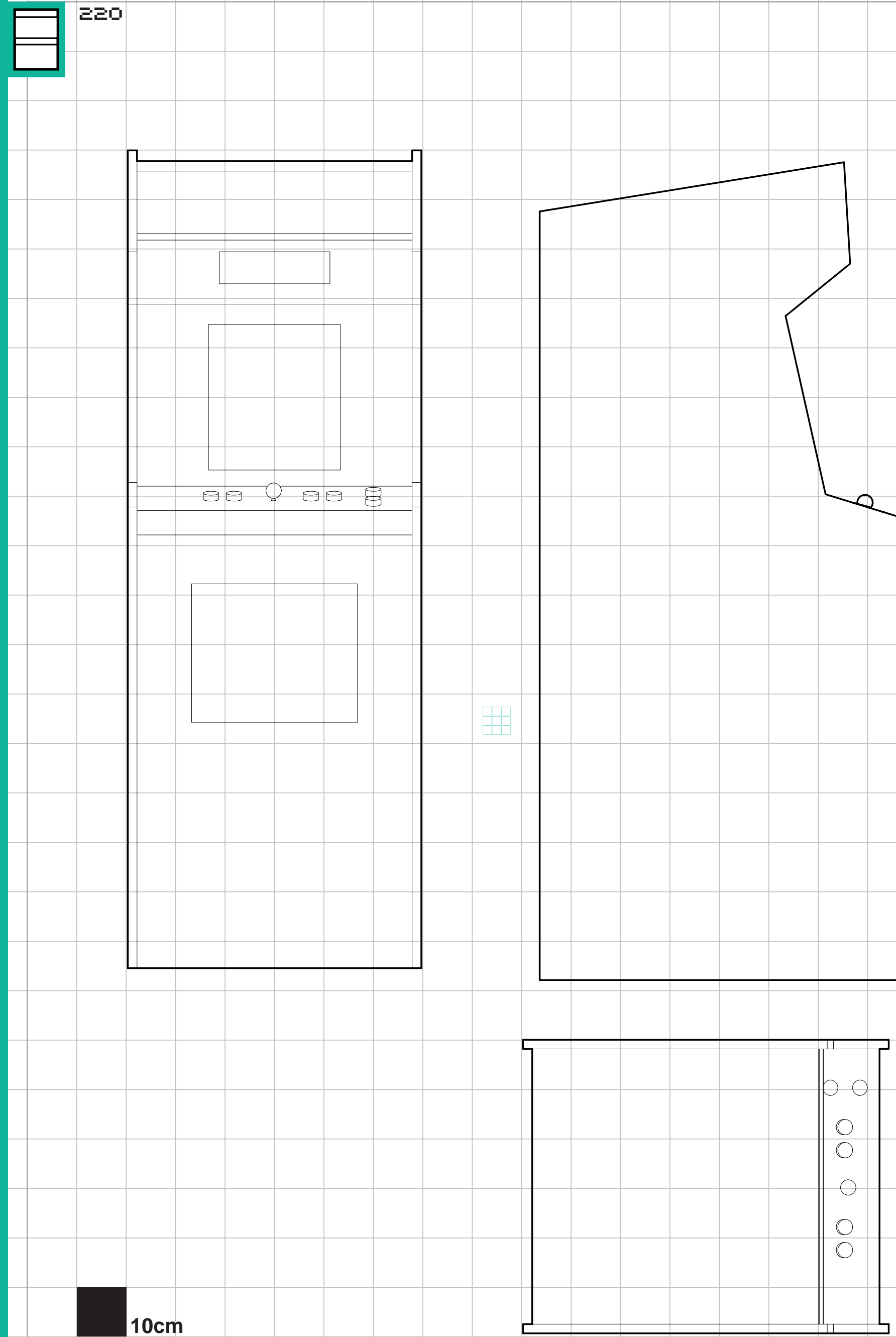


\section{Mr Do!}

1982

\section{Universal.}

Máquina arcade.

Máquina de Arcade desarrollada por Universal Sales en 1982, cuyo juego estuvo diseñado por Kazutoshi Ueda.

"Universal Sales hizo historia en la industria de las recreativas [...] En lugar de vender máquinas exclusivas de Mr. Do!, Universal vendía el juego como un kit. Aquel kit contaba con un panel de control personalizable, una placa de ordenador con los chips de memoria solo de lectura (ROM) de Mr. Do!, pegatinas para colocar en los laterales de los muebles y una marquesina de plástico. Era el primer juego que se vendía exclusivamente como un convertible"

(Kent, pg 352, 2001).

Es decir, esta máquina se trataba de un kit conversión que permitía adaptar las cabinas ya existentes en los salones recreativos. Contaba con un monitor vertical CRT de gráficos ráster en color y un panel de control con un joystick de cuatro direcciones (arriba, abajo, derecha e izquierda) y un botón de interacción. 
$\square$

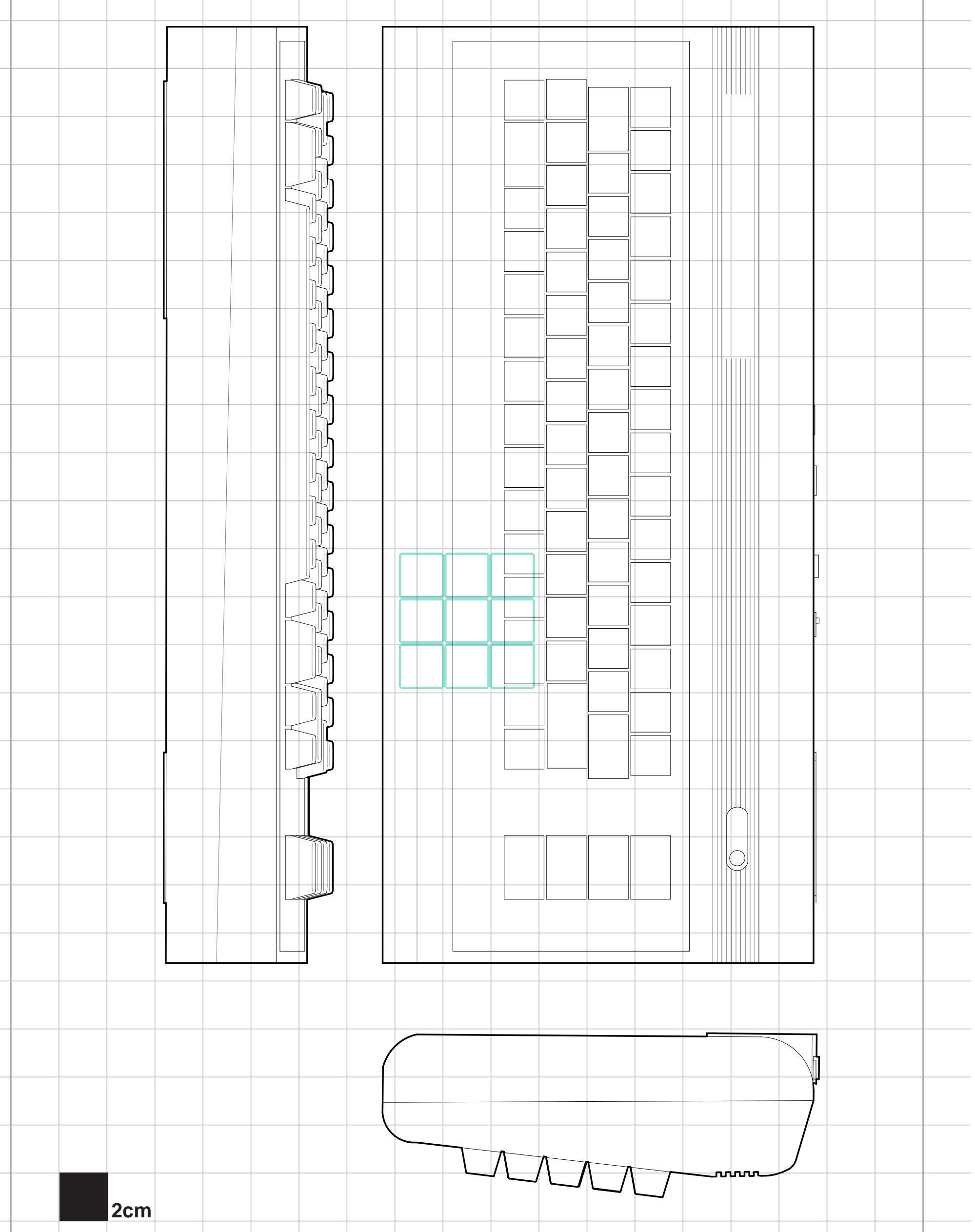

\section{D回 シேシ}

\section{Commodore 64.}

1982

Commodore.

Microordenado

Se trata de un ordenador doméstico (microordenador) de 8 bits que fue desarrollado por Commodore International y lanzada al mercado en 1982 (Bagnall, 2006).

Contaba con 64Kb de memoria RAM y 20Kb de memoria ROM. Disponía de una paleta de 16 colores y leía lenguaje de programación BASIC Su éxito residió, además de un precio asequible, en los gráficos y sonidos superiores a los de sus competidores. Esto se debe a que, además de su microprocesador, usaba un chip para el vídeo y otro para el sonido.

La base de este microordenador era un robusto teclado al que se podía conectar una unidad de casete, una ranura para cartuchos y una disquetera. Disponía de otras muchas tomas en las que podían integrarse controladores como joystick. En 1990 se lanzó al mercado un sistema de juegos conocido como C64 Games System, basado en Commodore 64.

"Como los disquetes eran más baratos de fabricar y tenían mayor capacidad de almacenamiento, los desarrolladores de software profesional y de entretenimiento preferirín publicar sus productos en ese soporte, aunque la base de usuarios con disquetera era mucho menor"

(Kent, pg 260, 2001). 


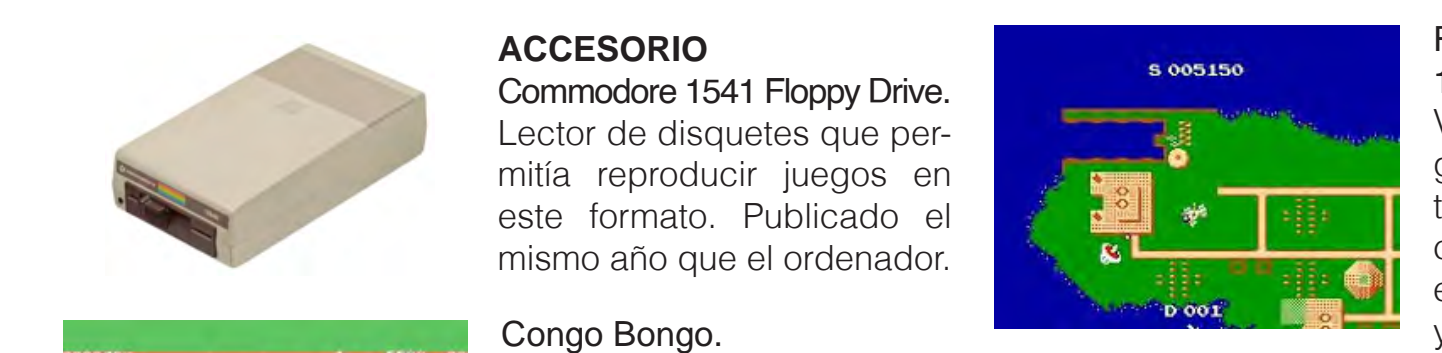

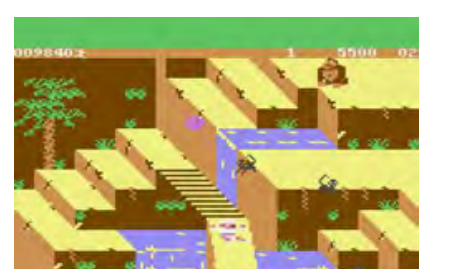
Congo Bongo.
1983

y dicionaban con el tiempo

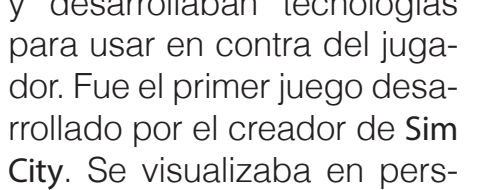
City. Se visualizaba en pers-
pectiva aérea en $2 \mathrm{D}$. un cazador que debe cazar
un mono. Il juego original
encuentra en perspectiva iso-

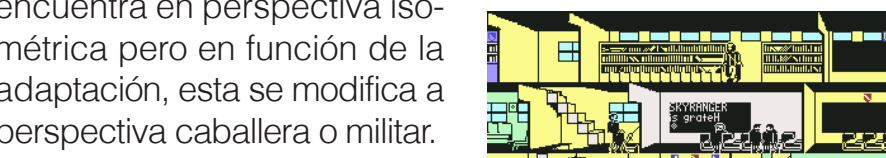
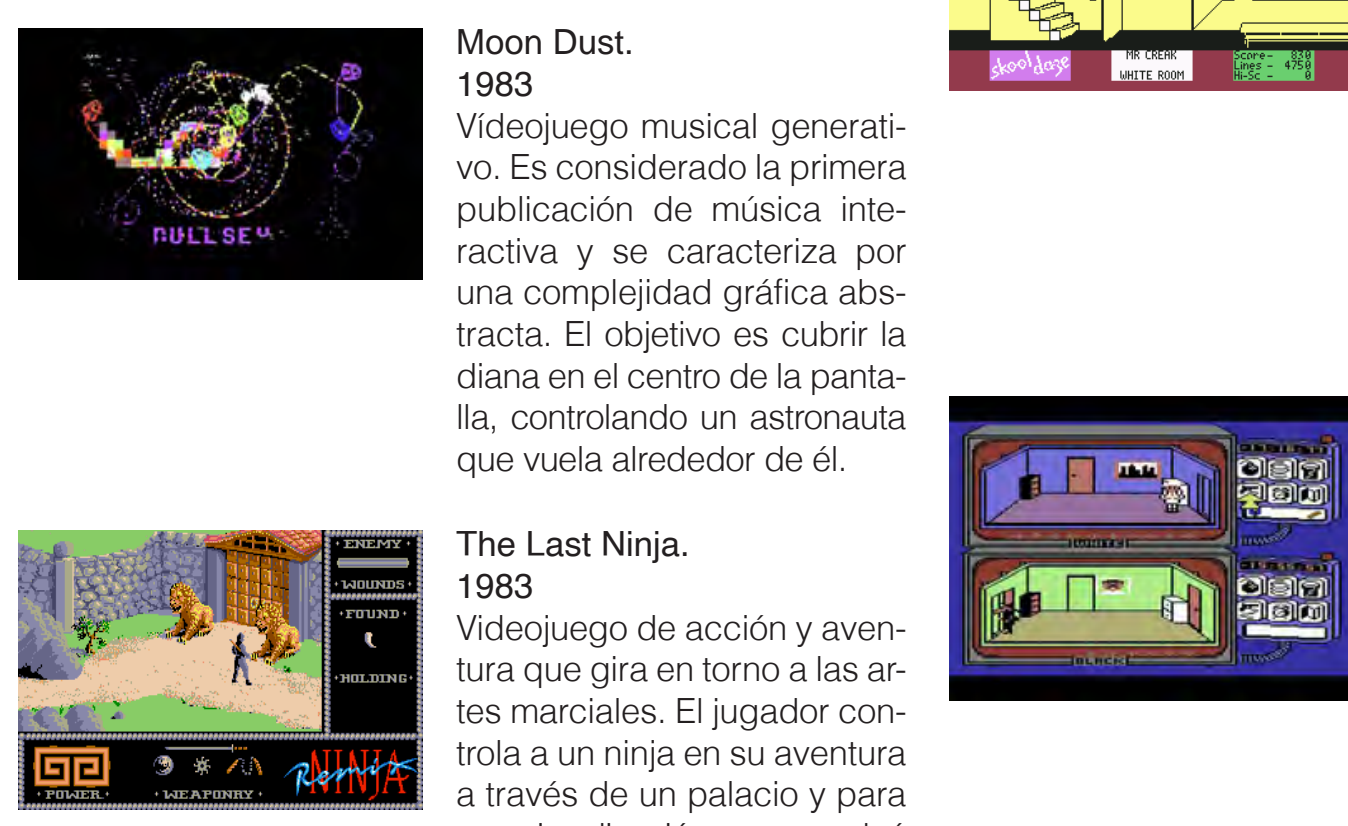

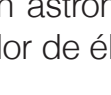
Ila, controlando un astronauta
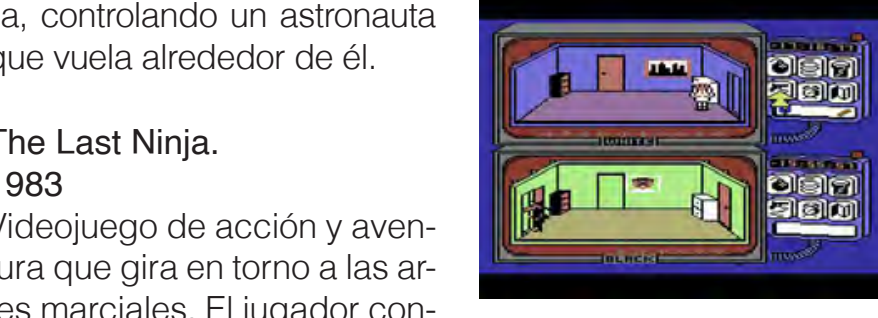

Videojuego considerado uno

nero sandobox en el que el ju-
gador ontrola a un sutudian-
te que debe robar sus notas

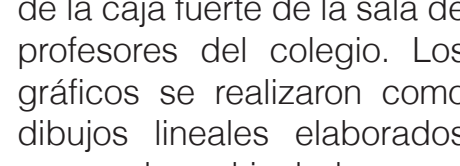

Spy vs Spy.

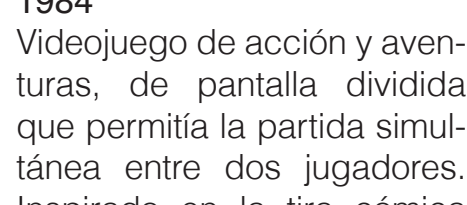

tánea entre dos jugadores
Inspirado en la tira cómica Spy rus Spy de la revisista MAD.
Los jugadores deben usar
trampas y desactivarlas para viraves de un palacio y pa
visualización se emples
perspectiva $3 \mathrm{D}$ isomét a, lo que permite desplazar
protagonista en 8 direcciones

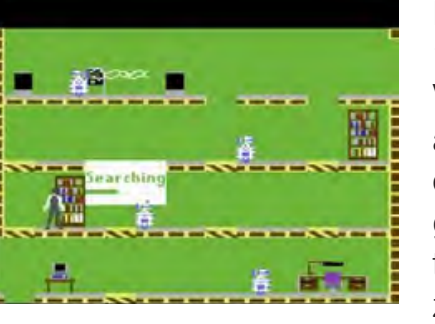
I mpossible Mission. Videojuego de plataformas
aventuras aue tue pionero por
el usu de vo digitalizada. El ju gador se convierte en un ager-
e secreto infititrado en la fortale
za enemiga y dispone de ses

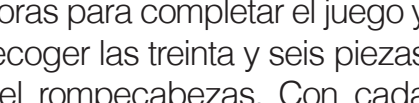
nuerte se desccuentan disan
untos del tiempo total.
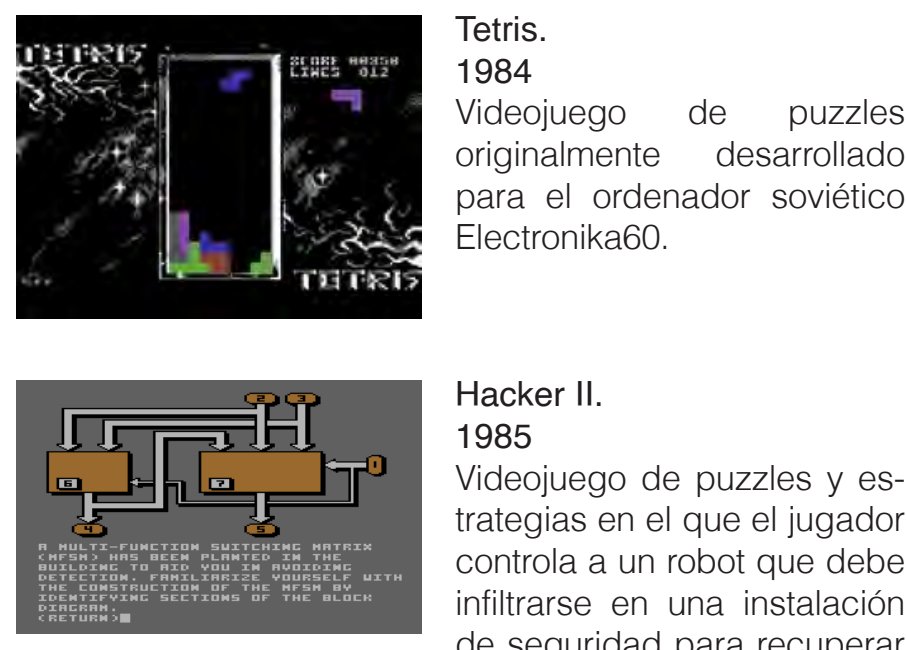

onginalmente desarrollado
para el ordenador soviético
Electronika60.

PlayNET.
1984

y comunicación persona-per-

sona desarrollado para el en-
orno doméstico y basada en
rráficos.

1985
Videjuego de puzzles y yes-
trategias en el que el jugador

infiltrarse en una instatalación
de seguridad para recupera

cuatro cámaras de seguridad
de la instalación que pueden

utilizarse junto al mapa en la
exploración del espacio.
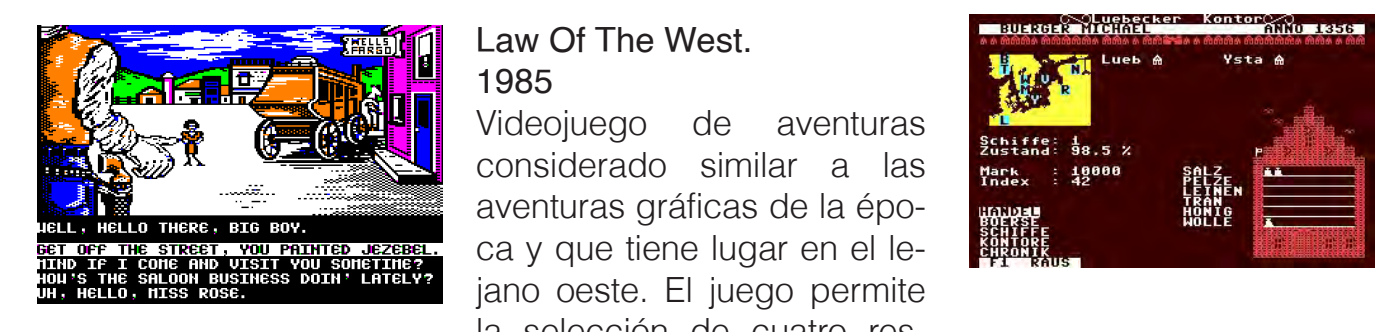

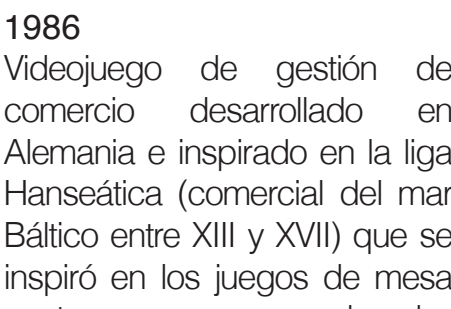
la violencia o la apología a la puestas diferentes y y avanzar
en fatron

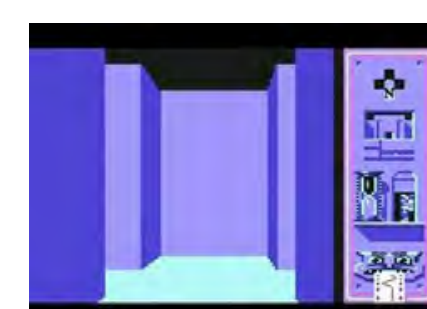

Scarabaeus

$6 \frac{18}{4}$

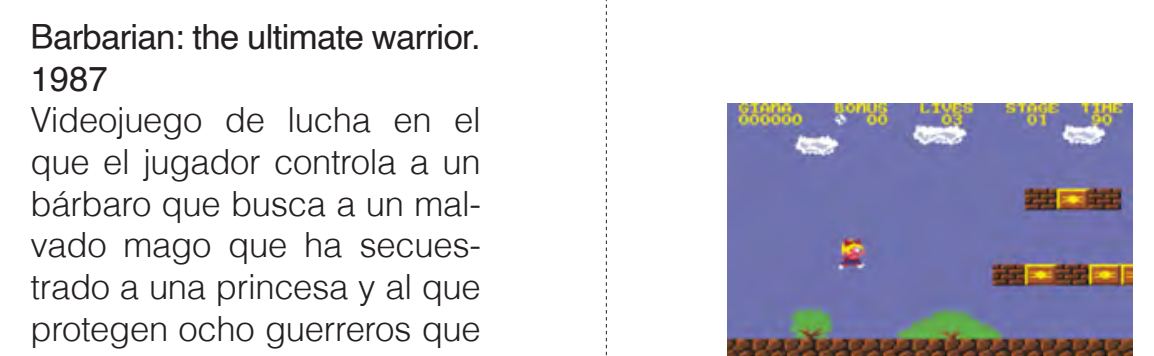

1987
Vid
en
con
mant
en 32 -

The Great Giana Sister.
1987

protegen ocho guerreros que

seño de la cajas se utilizaron
mágenes reales que suscita basón laveserie Conan el Bárdieciséis movimientos film el juego. Cada uno de estos cuadros de acción se tras-
paso a láminas de plastico transparenties que, coloca-
das sobre la pantalla, perm del juego pixel a pixel sobs
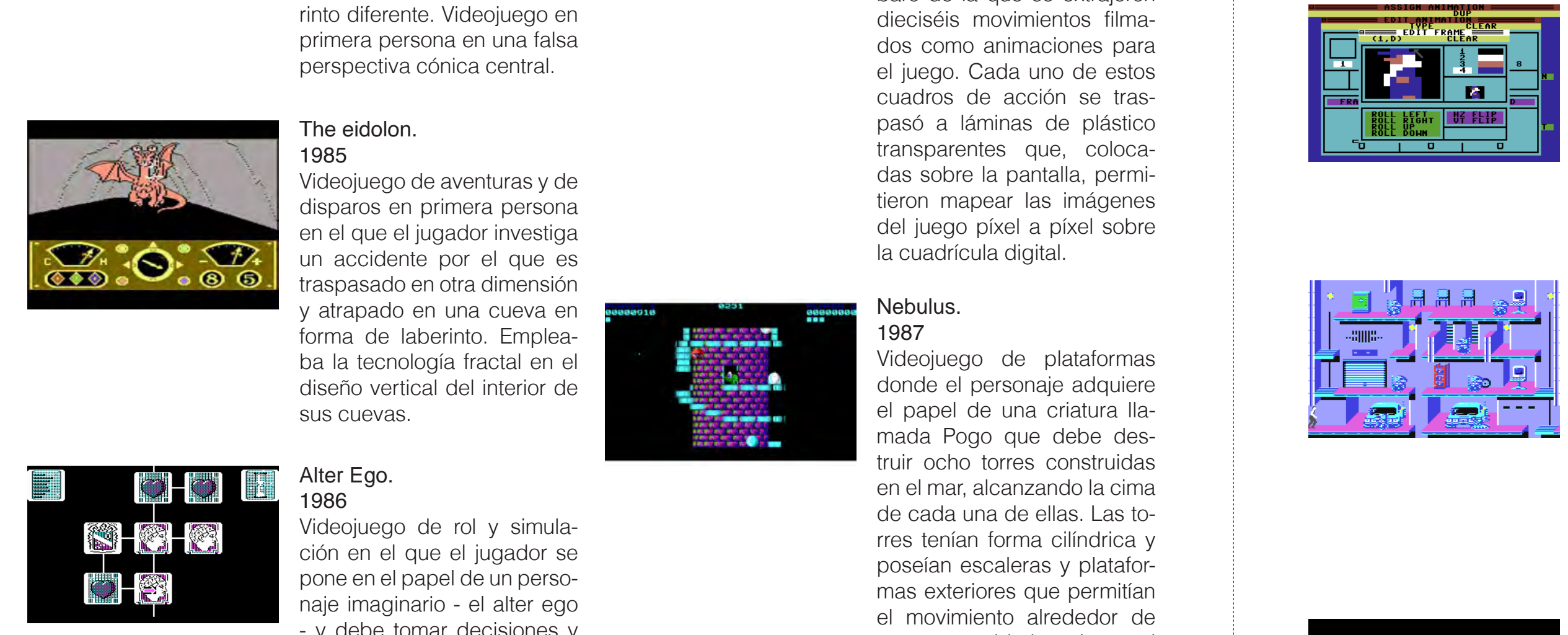

unos documentos. La panta-
Ila muestra simultáneamente

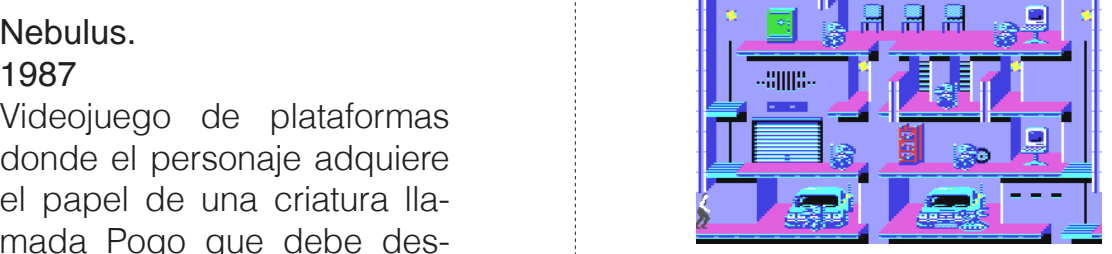

possible Mission

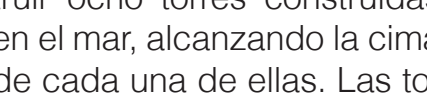

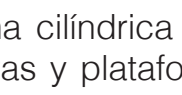

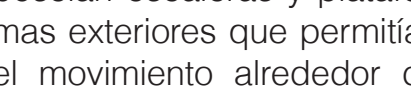

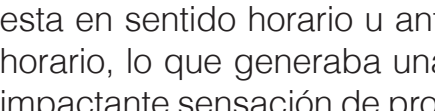
debe tomar deciciones y

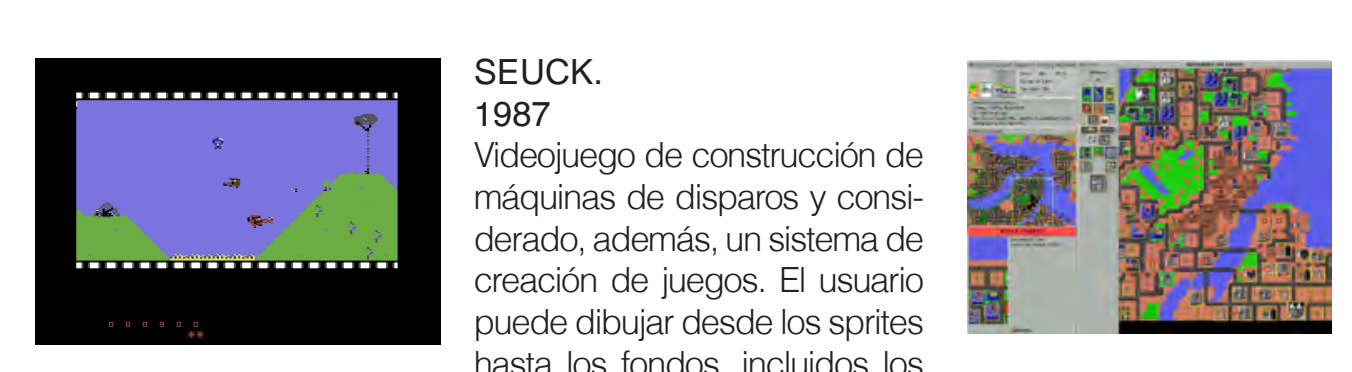
20 una herramienta previa a

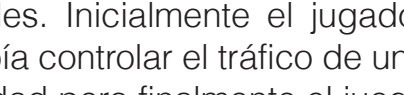
se empleó para simular la cons

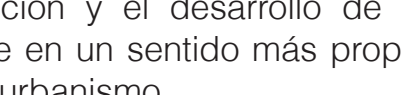

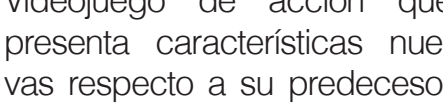

\%

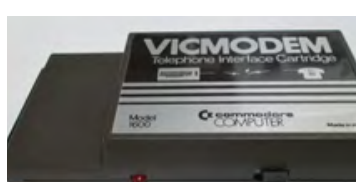

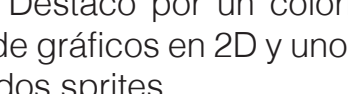
Accesopio

Commodore VVI-Modem.

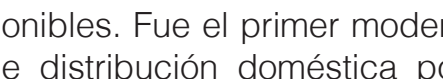

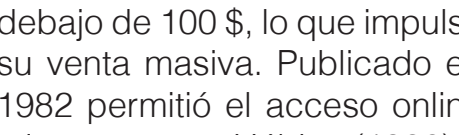
Videojuego de rol en linea multiju-
gador masivo (MMORPG) Pirone-
roder IIring $9=0$

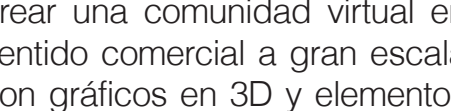

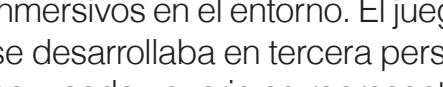

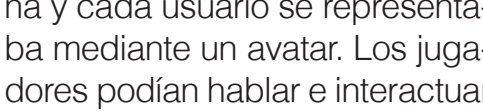
entre ellos. Los usuaros eran
los responsabies de las leyes

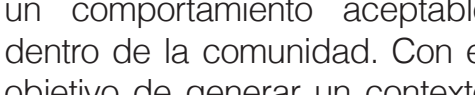

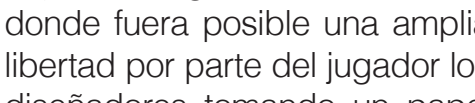

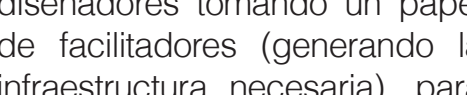

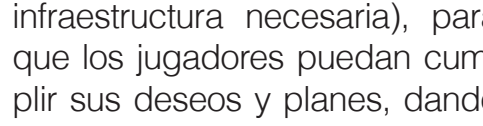

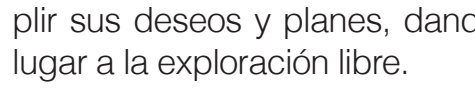

ACCESORIO
Commodore 1530 Datasette.
Lector de cintas de casete que
permitia reproduci juegos en
ese formato. Habitat. LucasaAts. 1998 


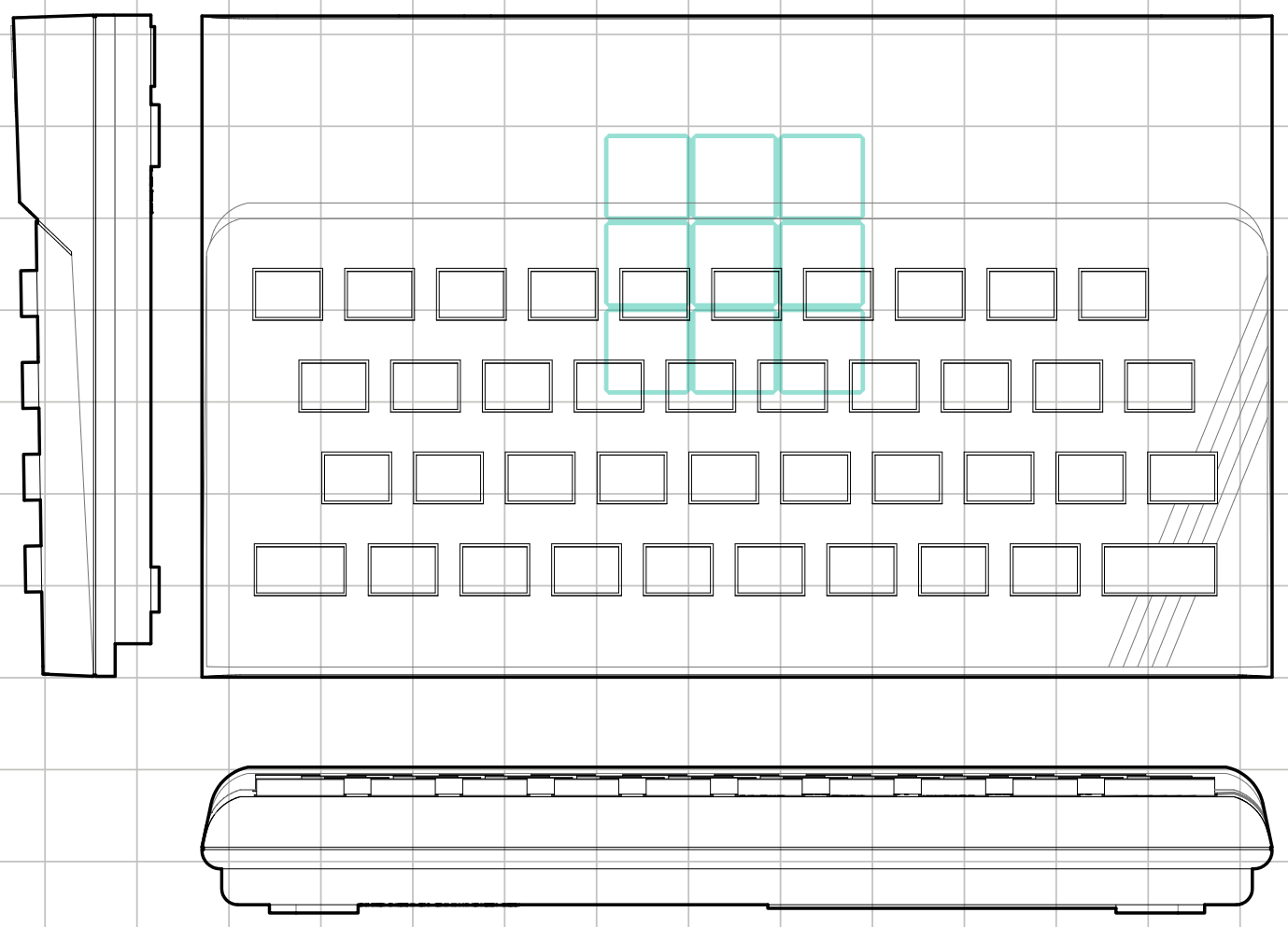




\section{$\left.O^{8}\right]^{\sum \Sigma \varepsilon}$}
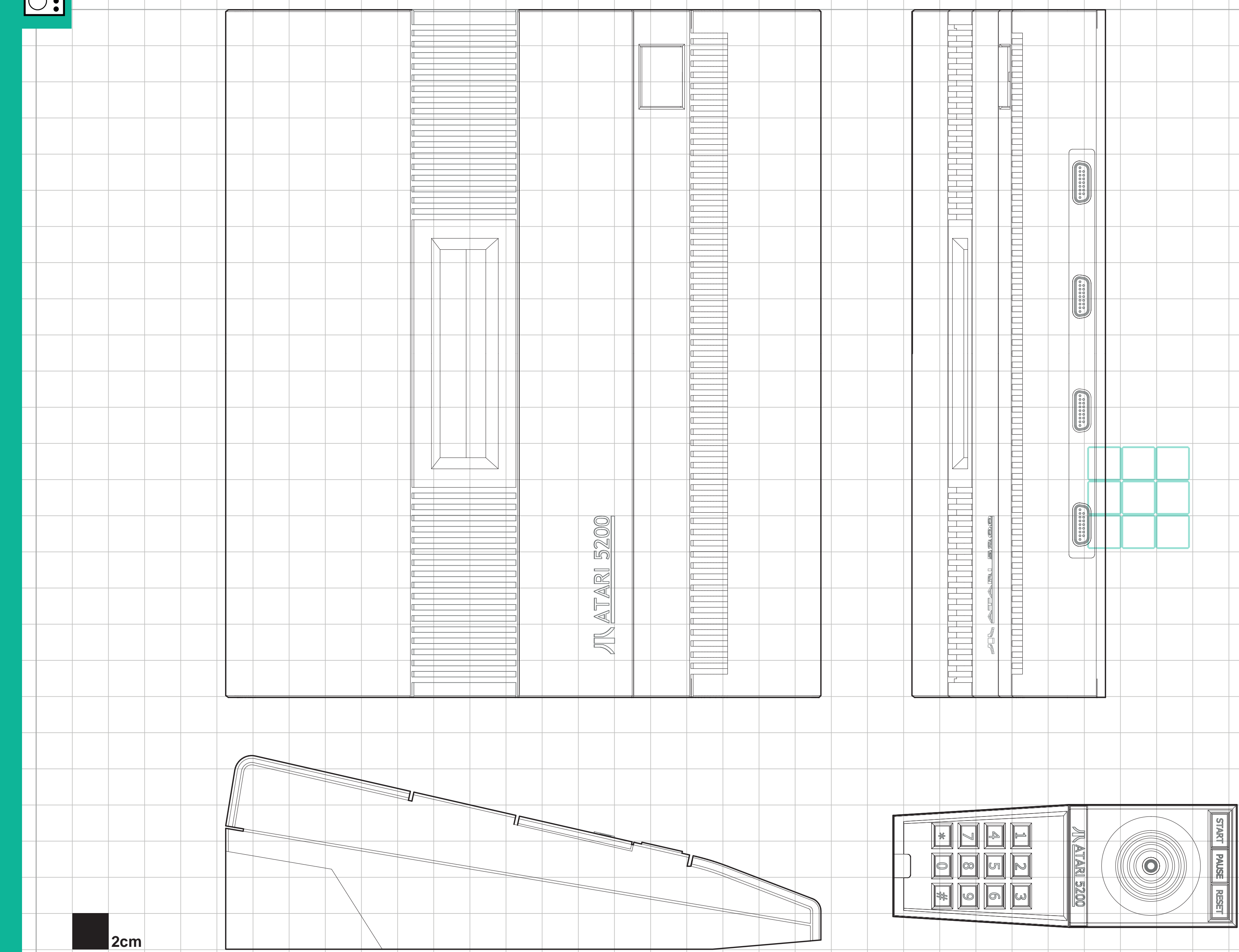


\section{Atari 5200.}

1982

Atari.

Videoconsola doméstica.

Videoconsola doméstica desarrollada y lanzada al mercado en 1982 por Atari, hasta que se descontinuó en 1984 tras haber vendido solamente un millón de copias. Esta consola estaba construida con una base prácticamente idéntica a los ordenadores de 8 bits de Atari. Poseía un procesador MOS 6502C y contaba con 16Kb de memoria RAM. Permitía una resolución de 320×192 píxeles y mostraba 16 colores simultáneamente de sus 256.

Presentaba unos controladores con un pequeño joystick integrado que disponía de un teclado que contaba con doce botones: del 1 al 9, asterisco $\left(^{*}\right)$ y almohadilla (\#). Estos controladores tenían un problema al centrar sus movimientos en la pantalla ya que "otros joysticks tenían muelles para dejarlos centrados, pero los de la 5200 quedaban sueltos" (Kent, pg 230, 2001), lo que hacía muy difícil jugar de forma precisa con ellos. Hecho que explica su fracaso en el mercado.

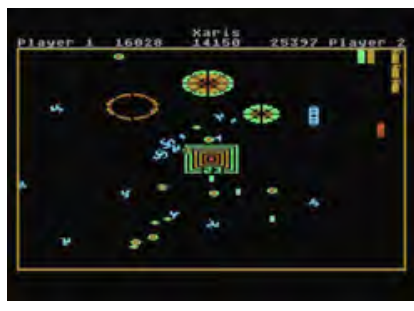

Xari Arena.

Not released

Videojuego de temática espacial no publicado desarrollado para poder jugarse con el track-ball de Atari.

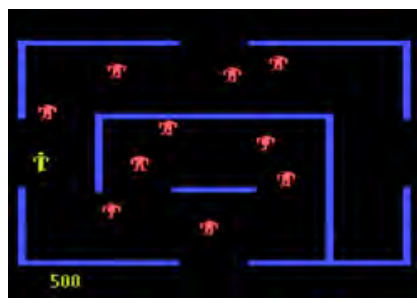

Berzeck.

1980

Videojuego de disparos multidireccional originalmente desarrollado como arcade. El jugador se sitúa en un laberinto de una serie de salas que recorre de arriba hacia abajo y los que se encuentran robots armados y un personaje extra inmortal - Evil Otto - cuya función es acelerar el ritmo del juego. Fue inicialmente ideado en blanco y negro pero finalmente decidió lanzarse en color. El juego se ubica en una cuadrícula de 256×256 habitaciones en las cuales se generan laberintos de forma aleatoria.

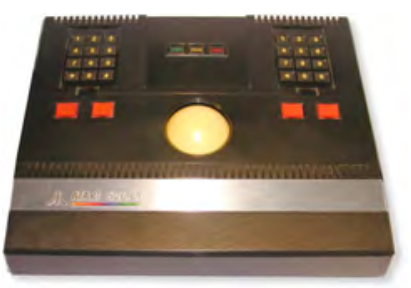

\section{ACCESORIO}

Pro-Line Track Ball.

Controlador basado en una bola rotatoria que permitía giros de $360^{\circ}$ y seguía la línea del Roller Controler de la Coleco Vision y - sobre todo - de la máquina recreativa Atari Football. Fue publicado en 1983
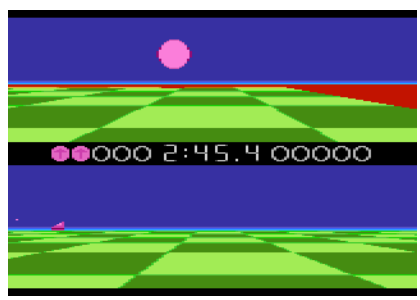

Ballblazer.

1984

Videojuego de deporte y acción en primera persona. El jugador (representado como una nave espacial) debe marcar goles en la portería contraria. El campo de juego es una cuadrícula.

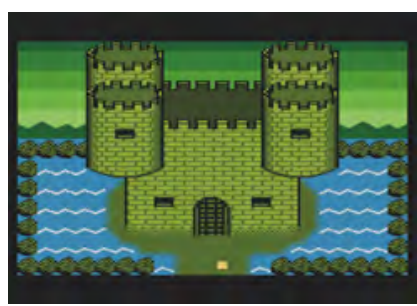

Adventure II.

2007

Videojuego de aventura desarrollado en 2007 (con la 5200 descontinuada) como una secuela de Adventure. 
$\Xi \Xi \Xi$ 


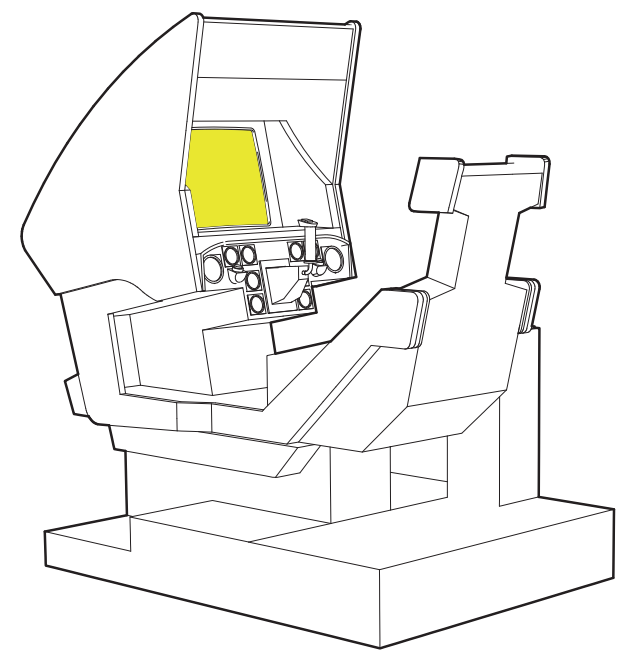

\section{GENERACIÓN 3}

\section{6}

Tras la gran crisis del videojuego de 1983 poca gente esperaba un resurgir de la industria en Estados Unidos. Es por ello que la tercera generación comenzó en Japón y gracias a empresas japonesas, Nintendo lanzó su Nintendo Entertaiment System, NES, en 1986 y Sega comenzó a desarrollar una línea propia de innovación en arcades conocida como Sega AM-2 entre los que presentó Space Harrier (1985). Debido a la crisis no aparecieron consolas portables reseñables pero sí ordenadores (pues no se ceñían a los juegos) entre los que destacó el Macintosh de Apple.

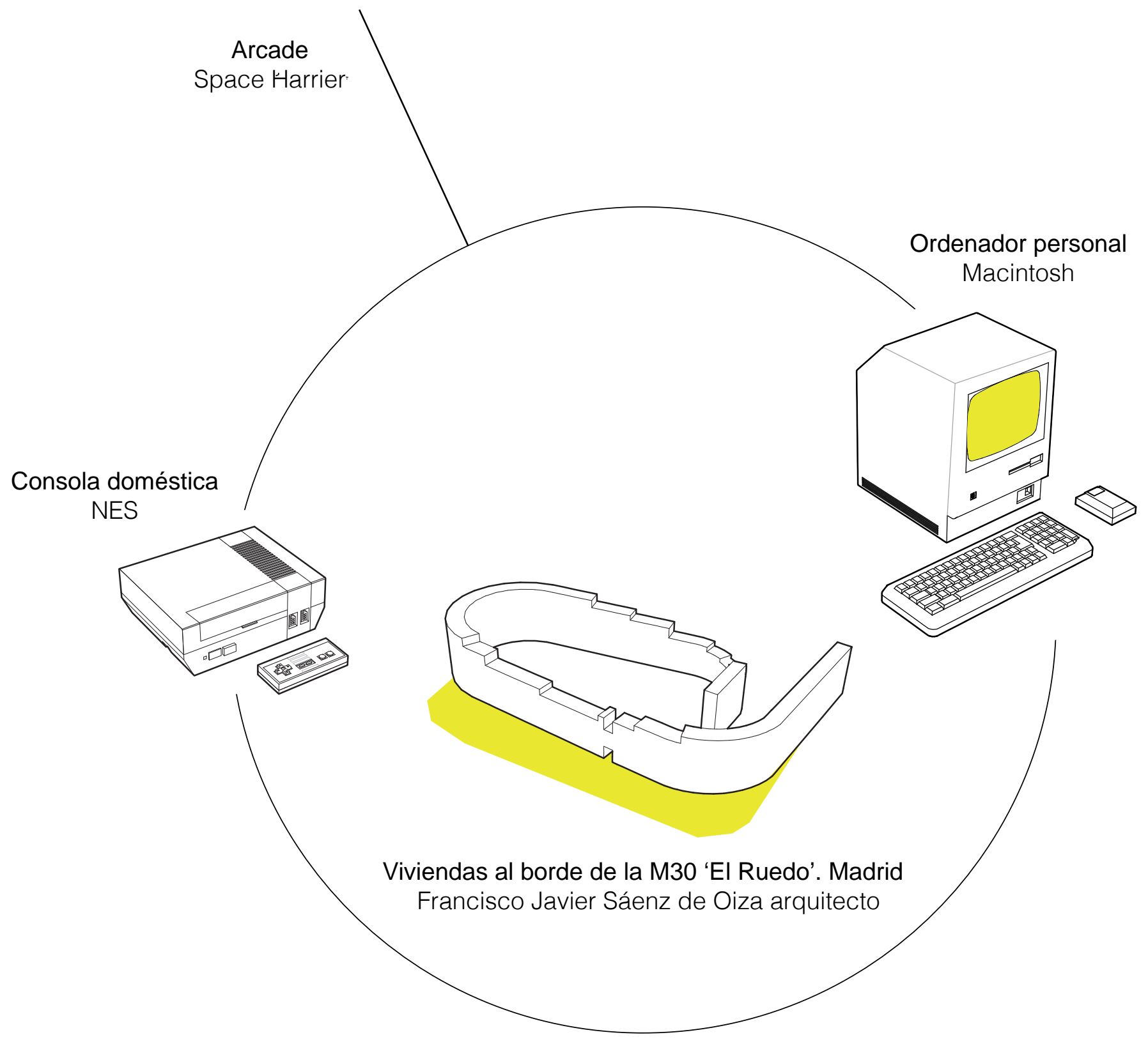




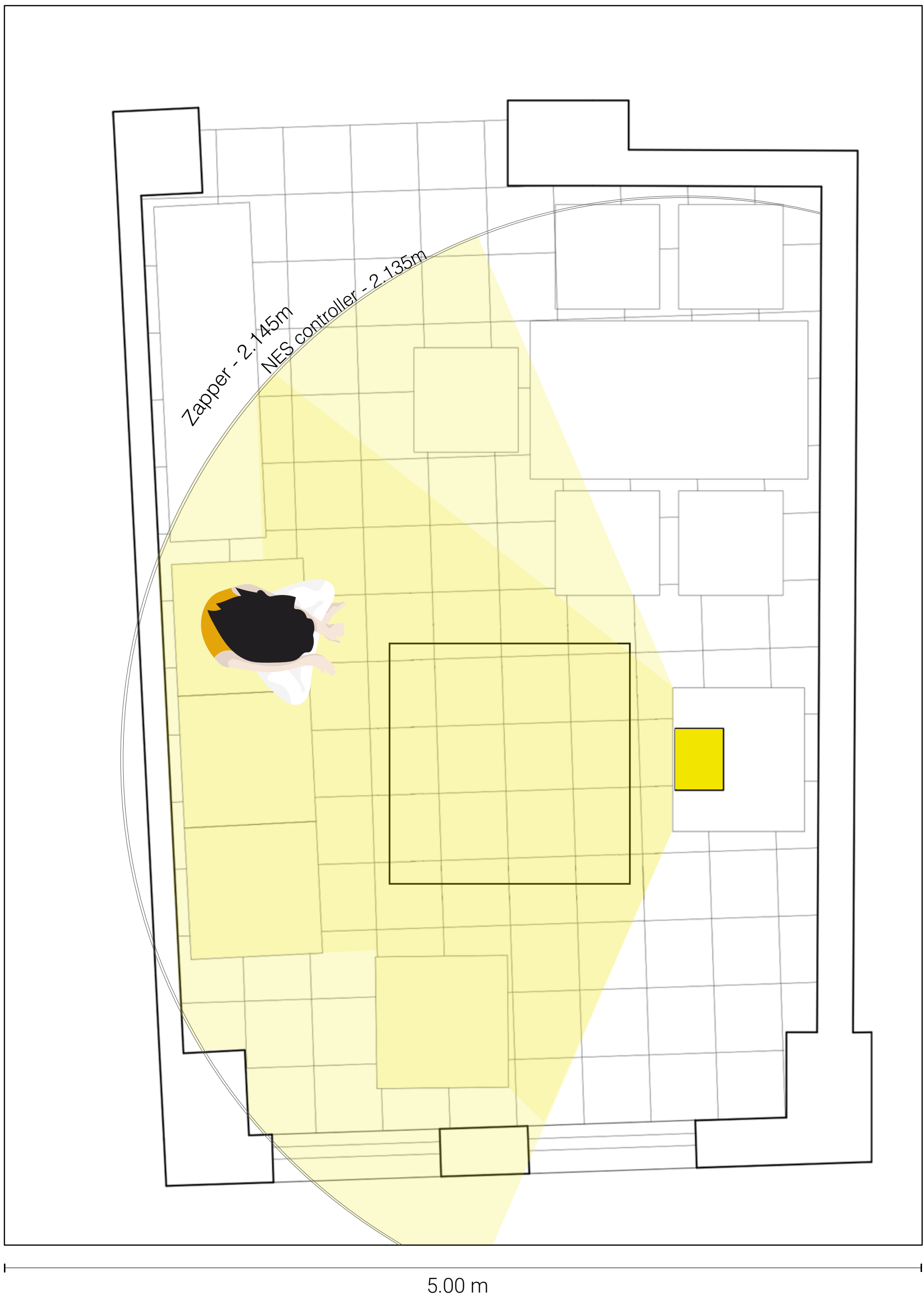




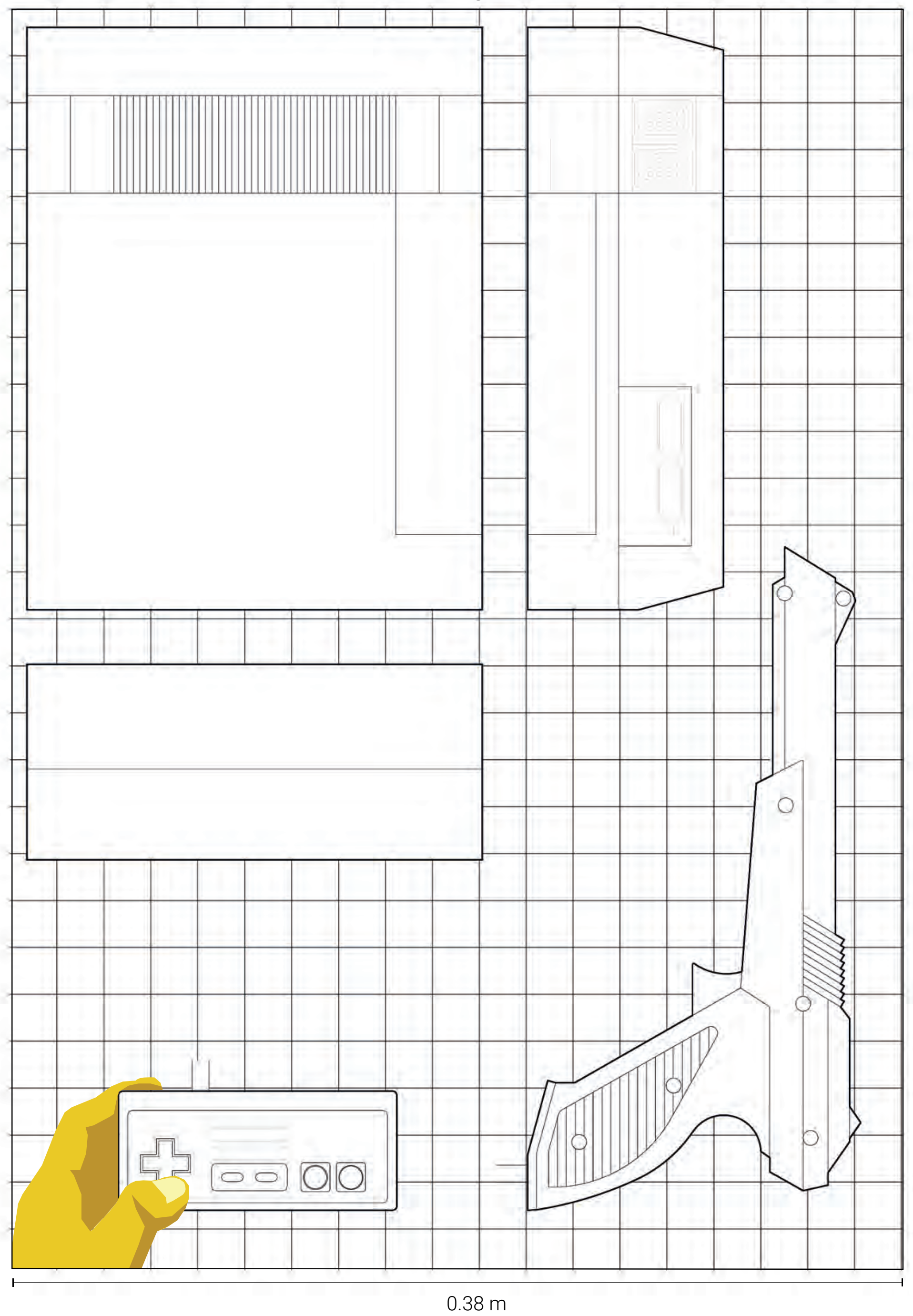


El juego más vendido de NES fue Super Mario Bros. Permitía acceder, desde las viviendas de la M-30 a un mundo compuesto por 32 niveles. El más largo de ellos, el 8-1, mide 357 metros, frente a los 180 metros de fachada longitudinal del edificio completo de 'El Ruedo'

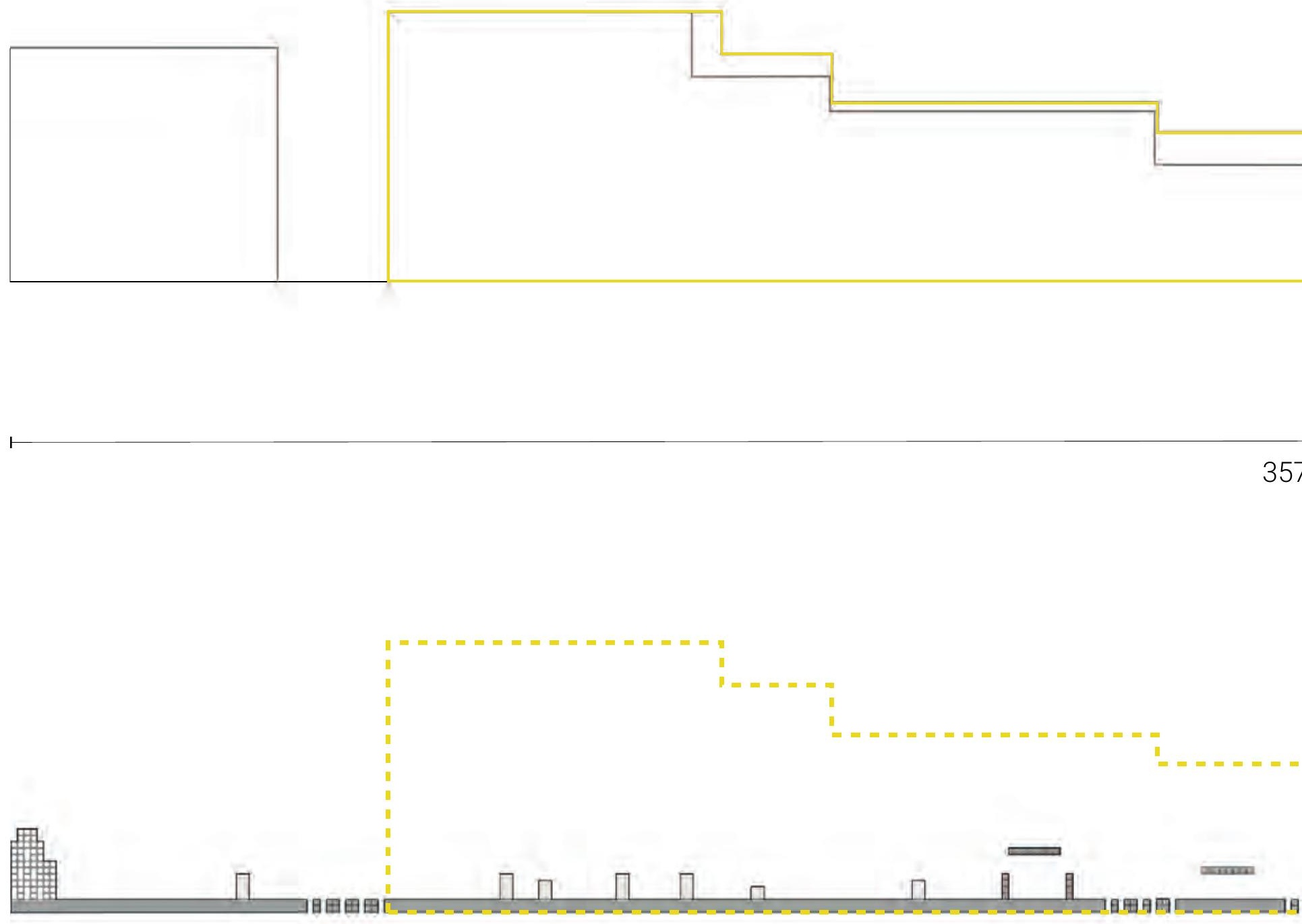


ㄹ:34니 


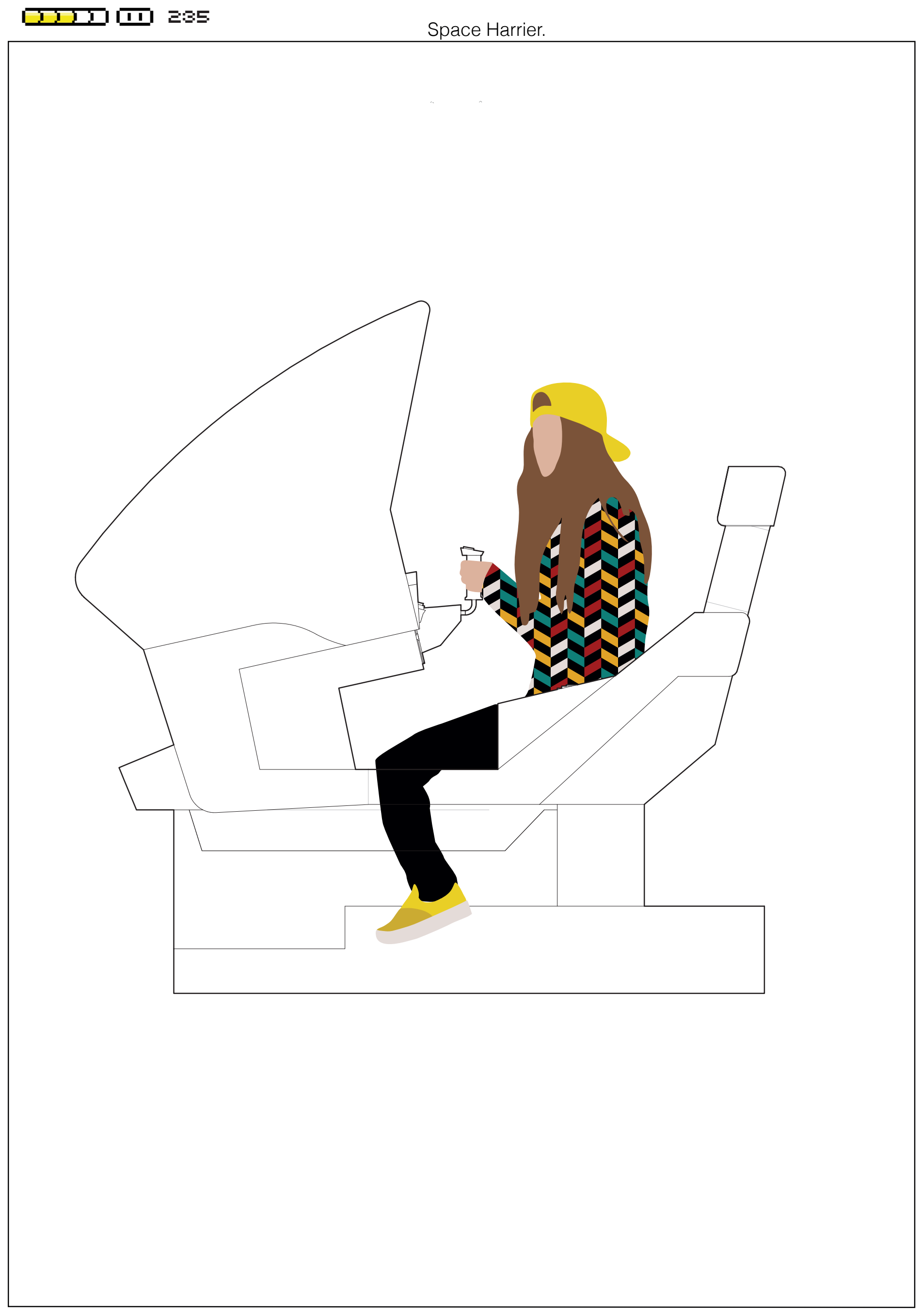



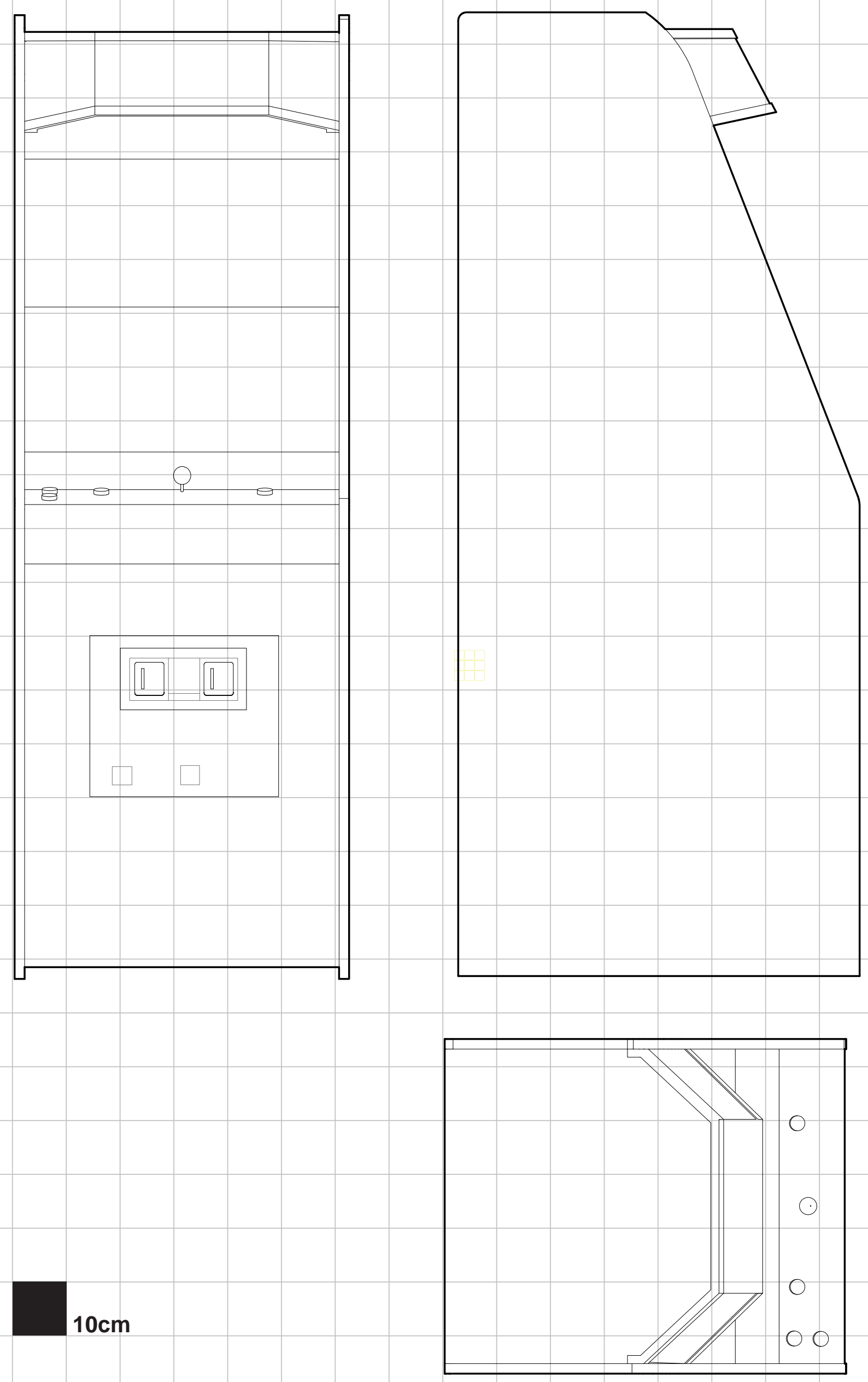


\section{Dragon's Lair.}

1983

Cinematronics.

Máquina arcade.

Máquina de Arcade desarrollado y publicado por la empresa Cinematronics en 1983. Esta máquina fue pionera por el uso de la tecnología laser-disc (en concreto de Pioneer), puesto que se trataba de una película interactiva que tenía gráficos de dibujos animados (Donovan, 2010/2018).

Disponía de una pantalla horizontal CRT con gráficos ráster en color que permitía animaciones. El panel de control contaba con un joystick que permitía moverse en ocho direcciones y un botón con el que el jugador podía manejar la espada. El modelo de cabina fue únicamente el clásico vertical. La máquina contaba con un procesador Z-80.

Pese a la innovación que supuso, y al éxito comercial ya que vendieron más de 16.000 máquinas ese año, las limitaciones de hardware hicieron que las animaciones se vieran limitadas y, por consecuente, también la jugabilidad.

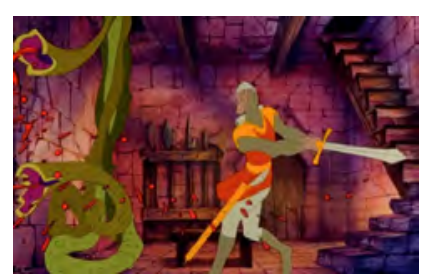

Dragon's Lair.

1983

Videojuego considero una película interactiva pionero en el uso de la tecnología laserdisc. Los jugadores debían elegir sus acciones lo que propiciaba mostrar una u otra imagen de la partida y por tanto de la historia. 

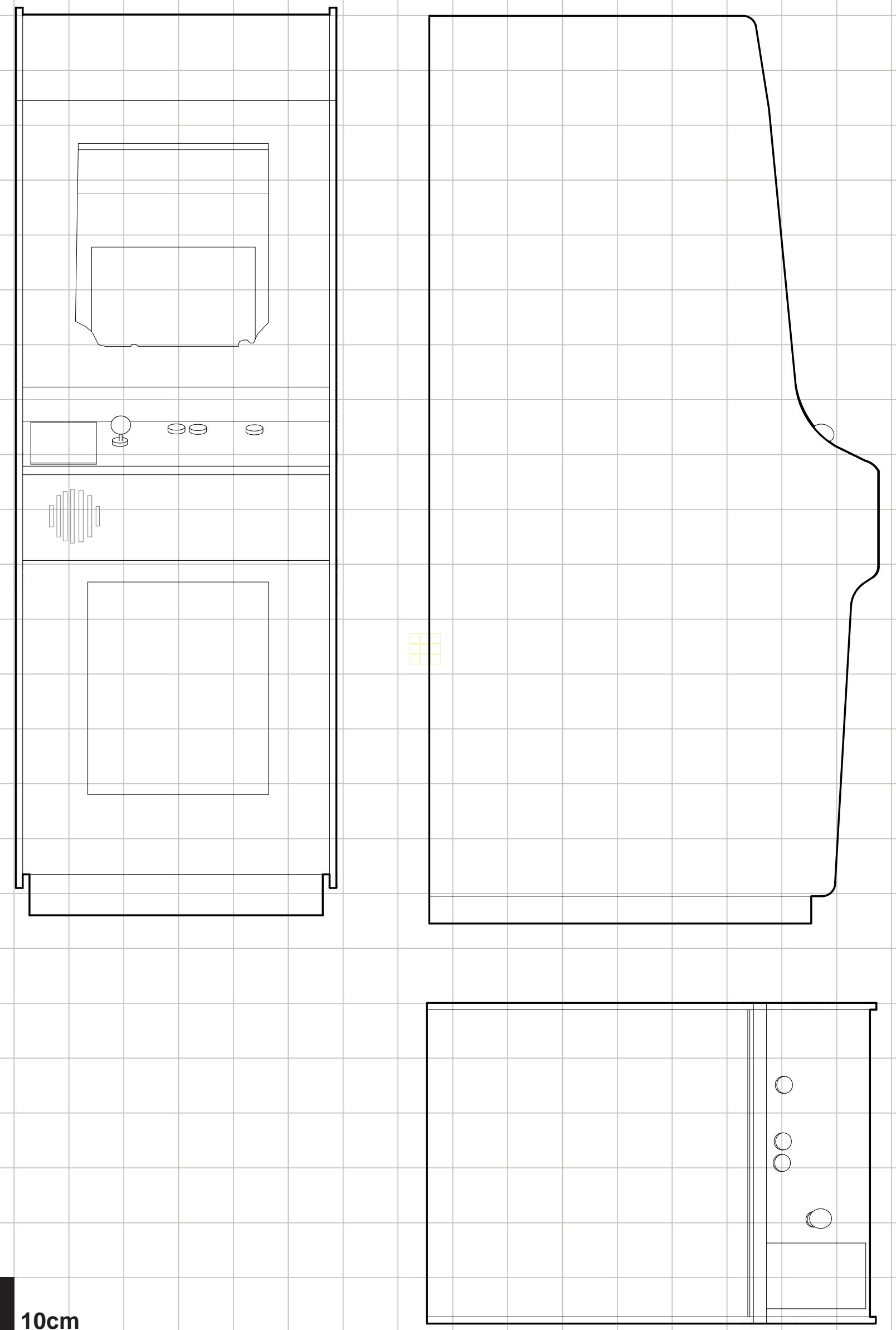


\section{3}

\section{Nintendo arcade.} Máquina arcade.

Máquina de Arcade desarrollada y publicada por Nintendo en 1983, el juego Mario Bros fue creado por Shigeru Miyamoto. El diseño era similar a Donkey Kong, pero se trataba de un juego pensado para dos jugadores.

Contaba con un monitor horizontal CRT con gráficos ráster en color y una resolución de $256 \times 224$ píxeles. Respecto al hardware, contaba con un microprocesador Zilog Z80 de 8 bits.

El jugador disponía de un panel de control dividido en dos partes (para ambos jugadores) y en cada una de ellas disponía de un joystick que permitía mover a los personajes en dos direcciones (izquierda y derecha) y un botón para saltar.

El regreso de Jumpman (así se conocía al personaje de Mario en el primer Donkey Kong) dio lugar a la saga de Mario de Nintendo que contó con versiones en otras consolas de la empresa nipona y numerosas secuelas hasta la fecha actual.

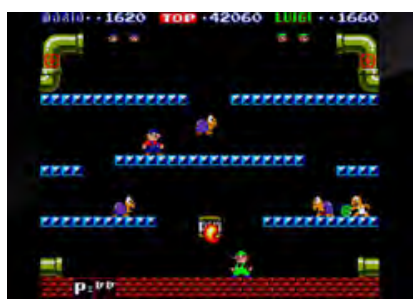

Mario Bros.

1983

Videojuego de plataformas. Posiblemente su mayor aportación sea la de tratarse del primer juego donde aparecieron Mario y Luigi quienes luego protagonizarían Super Mario Bros para NES. Se trataba de un juego de dos jugadores. 

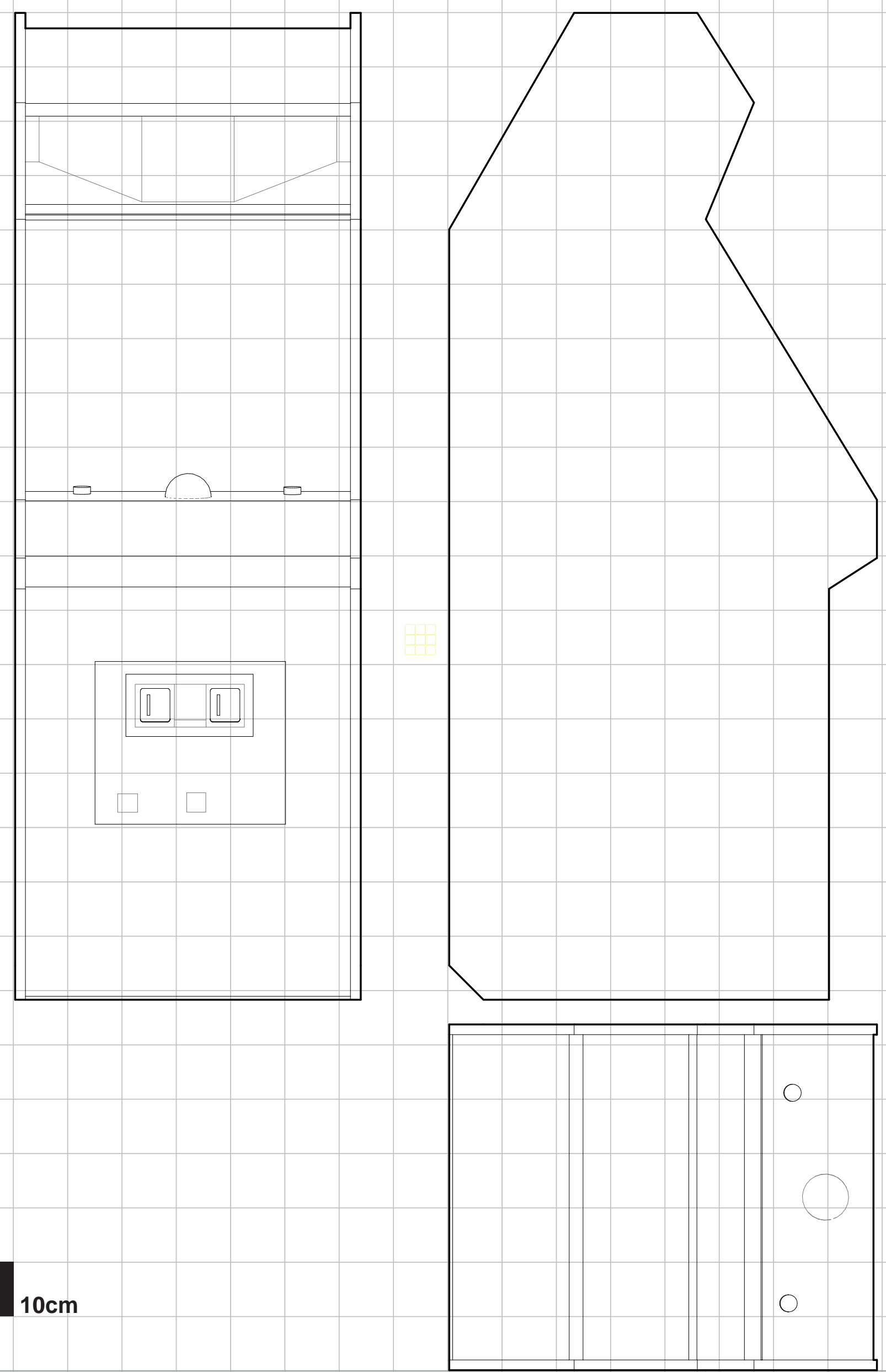


\section{Crystal Castles.}

1983

\section{Atari arcade.}

Máquina arcade.

Máquina de Arcade lanzado por Atari en 1983 que contaba con un monitor horizontal CRT que permitía visualizar gráficos ráster en color con una resolución de 256 × 232 píxeles y una paleta de 32 colores.

El jugador contaba con un panel de control que estaba formado por un trackball rotatorio y un botón que permitía saltar. Tuvo varios modelos de cabina: el clásico vertical, el modelo mini y el modelo cocktail.

Crystal Castles fue portado a diversos ordenadores domésticos entre ellos el Apple II, Commodore 64, ZX Spectrum o BBC Micro.

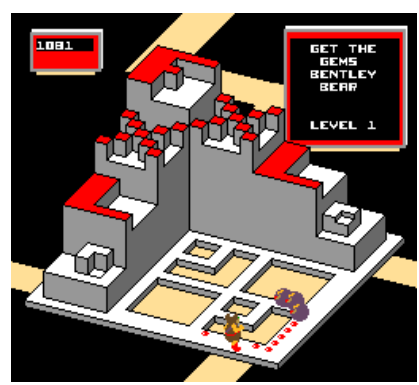

Crystal Castles.

1983

Videojuego de laberintos controlado por un track a través del chip Leta. El juego consistía en 9 niveles cada uno de ellos con cuatro castillos más uno final representado en axonométrica (trimétrica) que el jugador debe recorrer recogiendo gemas. 


\section{O:}
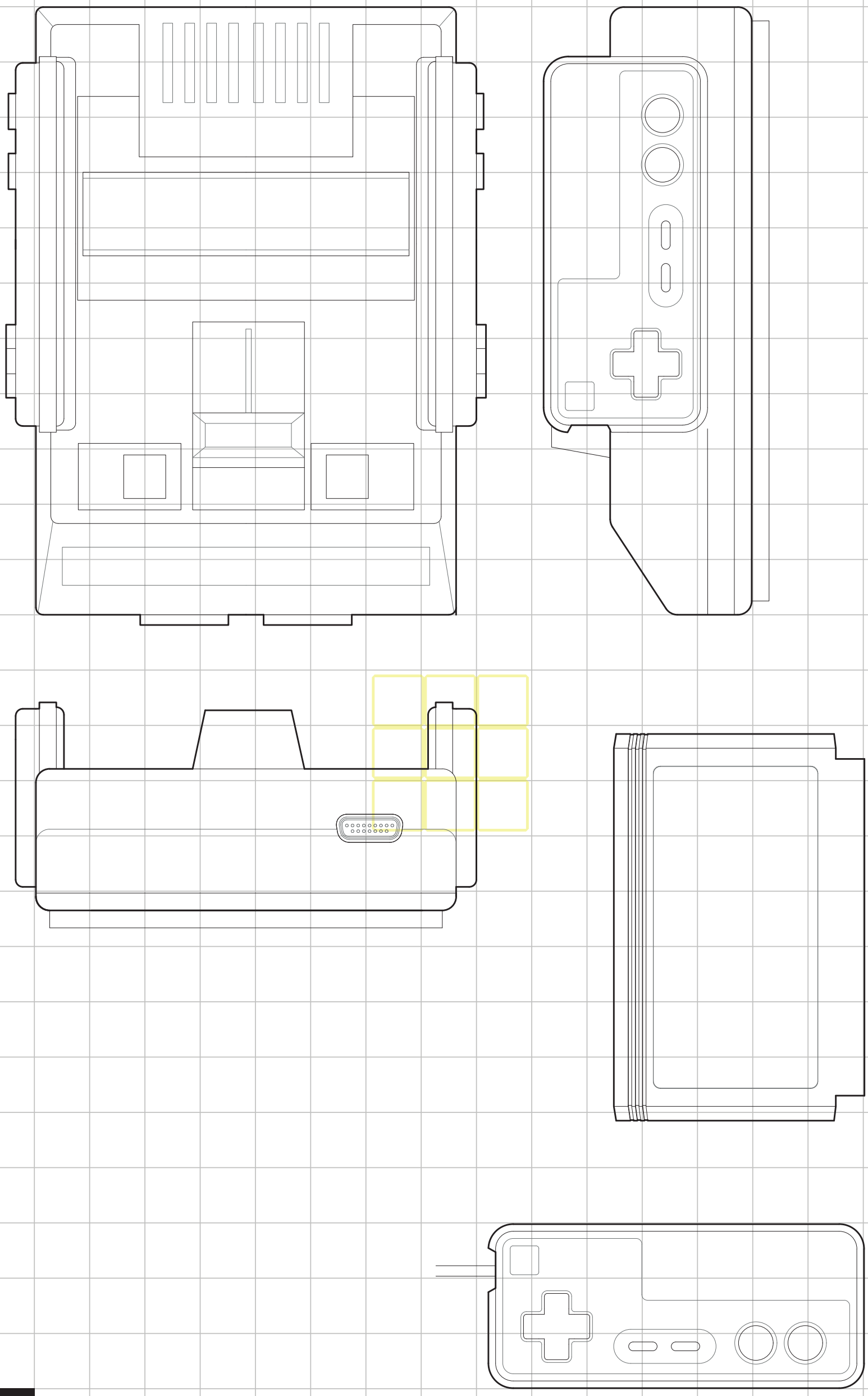

$2 \mathrm{~cm}$

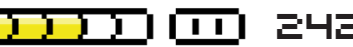

\section{Nintendo Family Computer.}

1983

\section{Nintendo.}

Videoconsola doméstica.

[...] volví a Nueva York por Navidad (en 1985) y, como necesitaba cinta para grabar, fui a una tienda de cámaras. Allí me encontré con un grupo de chavales que se apiñaban alrededor de un mostrador para jugar a un nuevo juguete. Cuando me acerqué, vi que se trataba de un nuevo sistema de videojuegos creado por Nintendo. Daba la sensación de dio la impresión de que iba a ser algo grande'

(Zito, en Kent, 2001)

La Family Computer - abreviada Famicom - salió en Japón en 1983 y vendió medio millón de copias en dos meses (Gorges, 2018) mientras Estados Unidos vivía una crisis que destrozó la industria del videojuego, hizo quebrar salones arcade y llevó a la reestructuración de las principales empresas (como Atari) e incluso a la desaparición de algunas que habían sido clave hasta el momento (como Coleco).

La crisis del videojuego de 1983 dejó a empresarios y jugadores recelosos y cuando Nintendo trató de entrar en el mercado estadounidense con su consola lo tuvo realmente dificili3. Sin embargo, tras una serie de estrategias comerciales - como su asociación con Worlds of Wonder (Kent, 2001) - consiguió su objetivo y terminó vendiendo más de 614 millones de videoconsolas en todo el mundo (duplicando a la Atari 2600, la más popular de la generación anterior). Esos 61 millones de consolas pueden traducirse en 61 millones de televisores a los que estaba conectada y por tanto de hogares que contaban con una Nintendo Entertaiment System (NES, el nombre que le dio Nintendo con el salto a USA)

Hay que señalar que, al igual que en las anteriores domésticas, en un buen número de casos la consola se stuaba en el salón, por haber un unico televisor en el hogar, adquiriendo un papel central en el ambito doméstico. Los controladores de la NES contaban con un alcance casi 4 veces mayor que la Atari 2600, Io que permitia una zona de juego más amplia. Además, posela diversos accesorios que permitlan interactuar con el espacio material alrededor de la consola (como el Nintendo Zapper) que se volvieron increíblemente populares6.

La NES estaba construida sobre un chip 6502 - similar al 6507 de Atari - pero estaba dotada de más memoria y de un segundo procesador que mostraba más colores y graficos mas detallados y mejores que cualquier otro sistema anterior7. Pero, sobre todo, la NES tenia un controlador - pad - que dejaba atrás el joystick de la generación previay tomaba la cruceta direccional diseñada por Gunpei Yokol para Game\&Watch, Io que hacla que la consola fuera más sencilla de usar, más intuitiva y cómoda. La plataforma que supuso NES dio lugar a algunos de los juegos más innovadores de momento como The Legend of Zelda o Super Mario Bros.
Variaciones:

NES (1985) NES 2 JP (1993) NES 2 US (1993) Fuente análisis gráfico: 

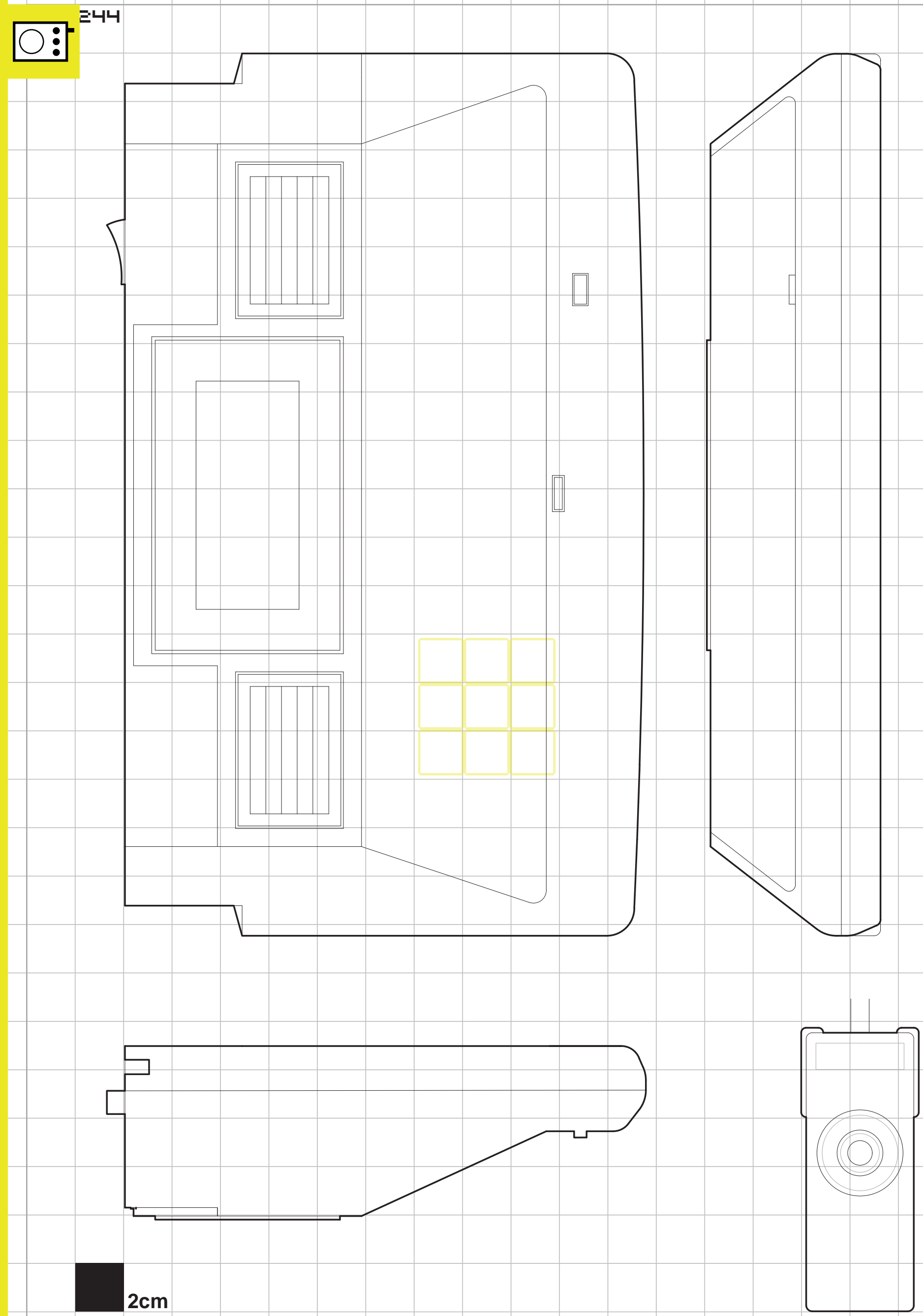


\section{뀨미 트농}

\section{SEGA SG-1000.}

1983

SEGA.

Videoconsola doméstica.

Primera videoconsola doméstica desarrollada por SEGA y lanzada al mercado en 1983 que perteneció a la tercera generación de consolas. Esta consola Sega Game 1000 trataba de aprovechar la experiencia de la compañía en hardware de arcades para saltar a mercado doméstico (Harris, 2014).

Esta consola funcionaba en base a un procesador Zilog Z80 y permitía una resolución de 256 × 192 pixeles con 16 colores. Su RAM tenía una capacide vídeo de 128 Kbits.

La SG-1000 disponía de un sistema de juegos en cartuchos y contaba con un puerto de entrada de casetes, además de conectores para dos controladores y cada uno de ellos con un pequeño joystick integrado (existieron también otros como Sega SJ150, que anticipaban el D-pad de Nintendo).

Existieron algunas actualizaciones de esta consola como la SG-1000 II, que era muy similar a la SEGA Mark III, asi como su conversión a microordenador denominado SC300.

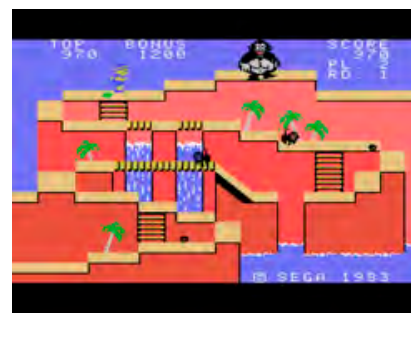

Videojuego de plataformas . arcade. El jugador controla a un cazador que debe cazar un mono. El juego original a en perspectiva isométrica pero en función de la adaptación, esta se caballera o se cambia a 2D.

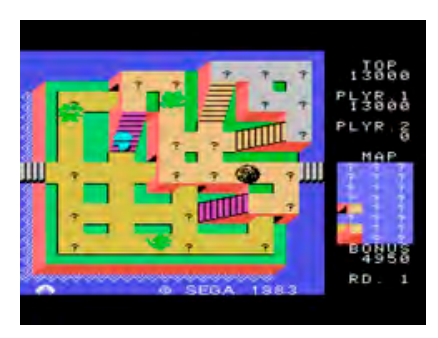

Sindbad Mystery.

1983

Videojuego de acción lanzado originalmente como arcade. El jugador debe guiar a Sindbad por una serie de laberintos representados en perspectiva militar que puzzles inteligentes

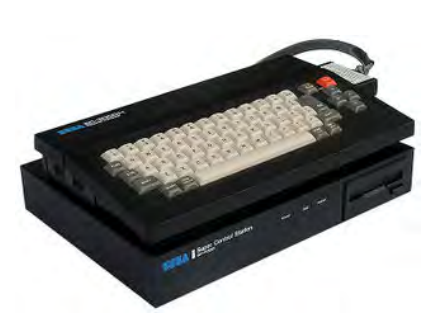

\section{ACCESORIO}

SF-7000 Keyboard.

Expansión en forma de

teclado que convertía la consola en un ordenador doméstico SC-3000. Incluía puertos para impresora y lector de casete y fue puesto a la venta en 1984. En Japon existio un lanzamiento especial bajo de nombre de defecto, el teclado.

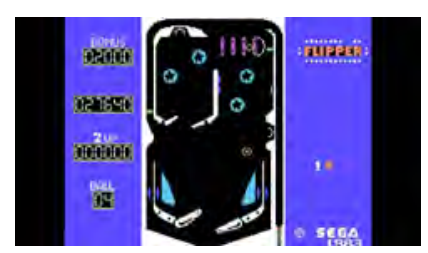

Sega Flipper.

Videojuego de pinball pionero por ser uno de los primeros pinballs para videoconsola. Con el que podian jugar uno o dos jugadores.

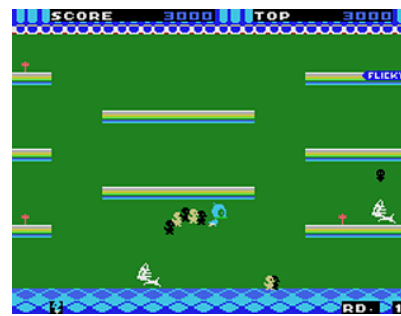

Flicky.

Videojuego de plataforma originalmente desarrollado como arcade. El jugador se pone en la piel de un pajaro azul que debe conseguir agrupar a olros pequeños pájaros y salvarlos. Estos pequeños pajaros se desarmaron en modulos de $8 \times 8$ pixeles to que permitió darles detalles personalidad.

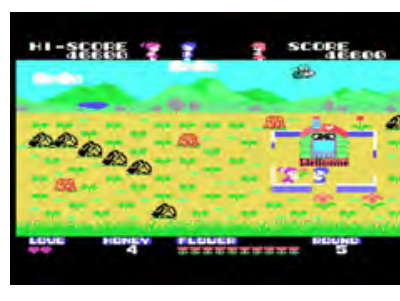

Videojuego de acción simulación de citas en el que el jugador controla una niña, que debe ganarse el amor un uno. Es considerado técnicamo simple pero era mo os primers jue y uno de notables.

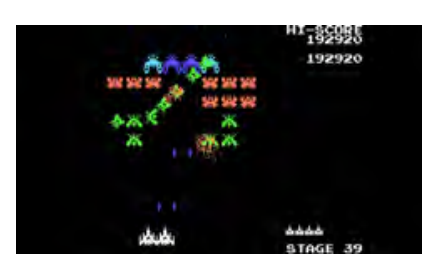

Sega Galaga.

1984

Videojuego de disparos en primera persona lanzado originalmente como arcade. El jugador tiene un caza estelar solitario en la parte inferior de la pantalla y debe evitar que las fuerzas de Galaga - que cambian en cada etapa - destruyan toda la humanidad.

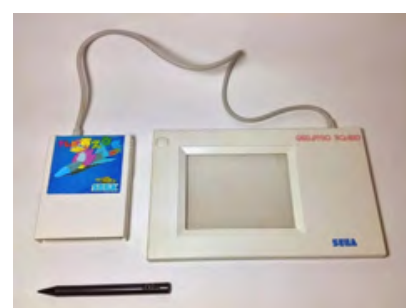

\section{ACCESORIO}

Sega Graphic Board

Accesorio diseñado como

una tableta gráfica básica y publicado en 1985 exclusivamente en Japón. Disponía de un área de dibujo muy limitada $(8 \times 10 \mathrm{~cm})$ con el juego Terebi Oekaki (de hecho, estaba conectada él). Su funcionamiento estaba limitado a 16 colores (por la capacidad gráfica de 也 tapiz oplico.

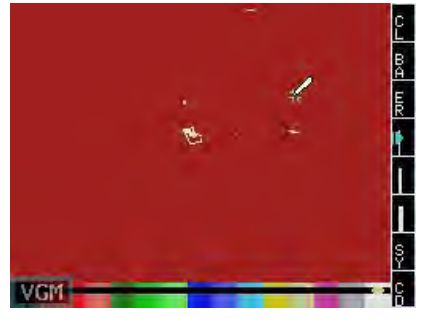
1985

Videojuego de arte que empleaba la tableta gráfica de la SG 1000 para dar la posibilidad al jugador de dibujar en el interior de la pantalla. Presentaba una limitación en cuanto a colores por la capacidad de la consola

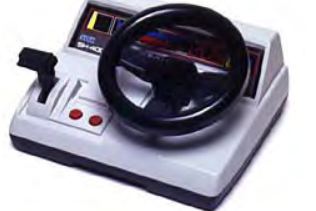

ACCESORIO

SH-400 Wheel.

Controlador en forma de

con consolas posteriores.

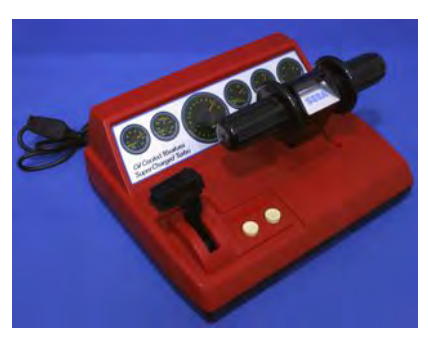

ACCESORIO

entrolador en forma de ar de bicicleta disenado uniendo la línea de juegos como Paperboy. Dispuso de compatiblilidad con consolas posteriores hasta la Sega Mega Drive y fue diseñado para juegos como Hang-On. 198

\section{ACCESORIO}

SR-1000 Casette.

Lector de cintas de casete que permitía reproducir juegos en este formato.

\section{ACCESORIO}

SP-400 4-color printer.

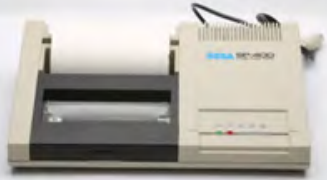



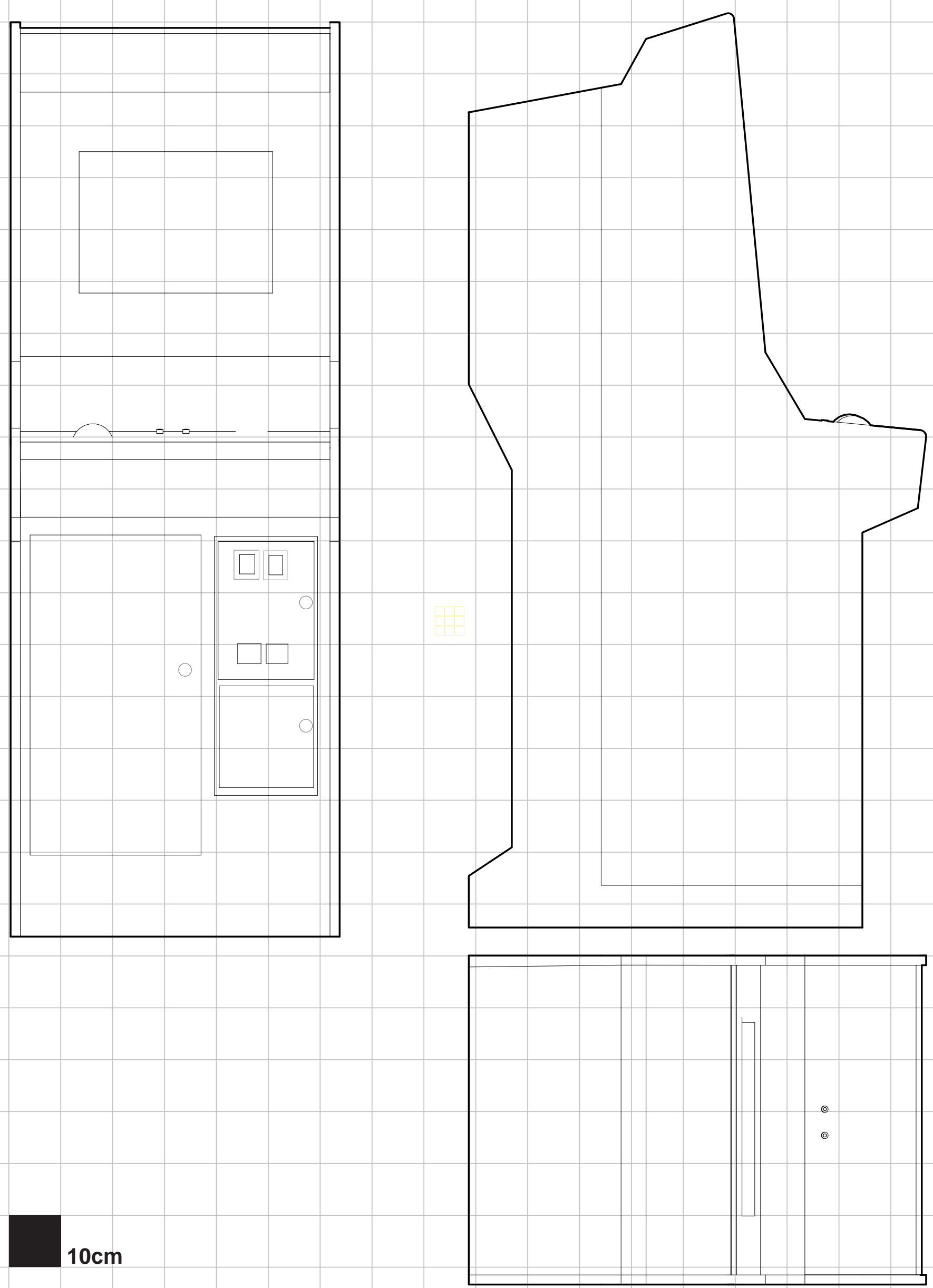


\section{Marble Madness.}

1984

\section{Atari arcade. Máquina arcade.}

Máquina Arcade desarrollado y lanzado al mercado en 1984 por Atari que fue pionero por utilizar sonido estereofónico real (ya que hasta el momento se trataba de sonido en un solo canal o estéreo simulado). También fue el primero en usar el sistema Atari System 1 y pionero en ser programado en lenguaje C.

Esta máquina contaba con un monitor horizontal CRT con gráficos ráster a color. El monitor de 19 pulgadas emitía a una resolución estándar de 336 x 240 píxeles. El juego permitía la partida simultánea a dos jugadores y no por turnos como venía siendo lo habitual.

Los jugadores disponían de un panel de control formado por dos trackballs, cuyos movimientos simulaban el de la canica que aparecía en la pantaIla. Este arcade únicamente tuvo el diseño clásico vertical para su cabina.

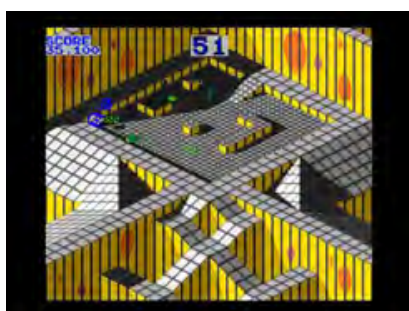

Marble Madness.

1984

Videojuego arcade de tipo carreras en que el jugador controla una canica sobre un escenario isométrico a través de 6 recorridos (solo o compitiendo contra otro jugador). Su diseño se inspiró en el trabajo de M.C. Escher y se considera un juego minimalista (en parte conseguidas debido a las limitaciones técnicas). Se programó un modelo de física tridimensional para generar los movimientos de la canica y un guión interpretado para el comportamiento del enemigo. 


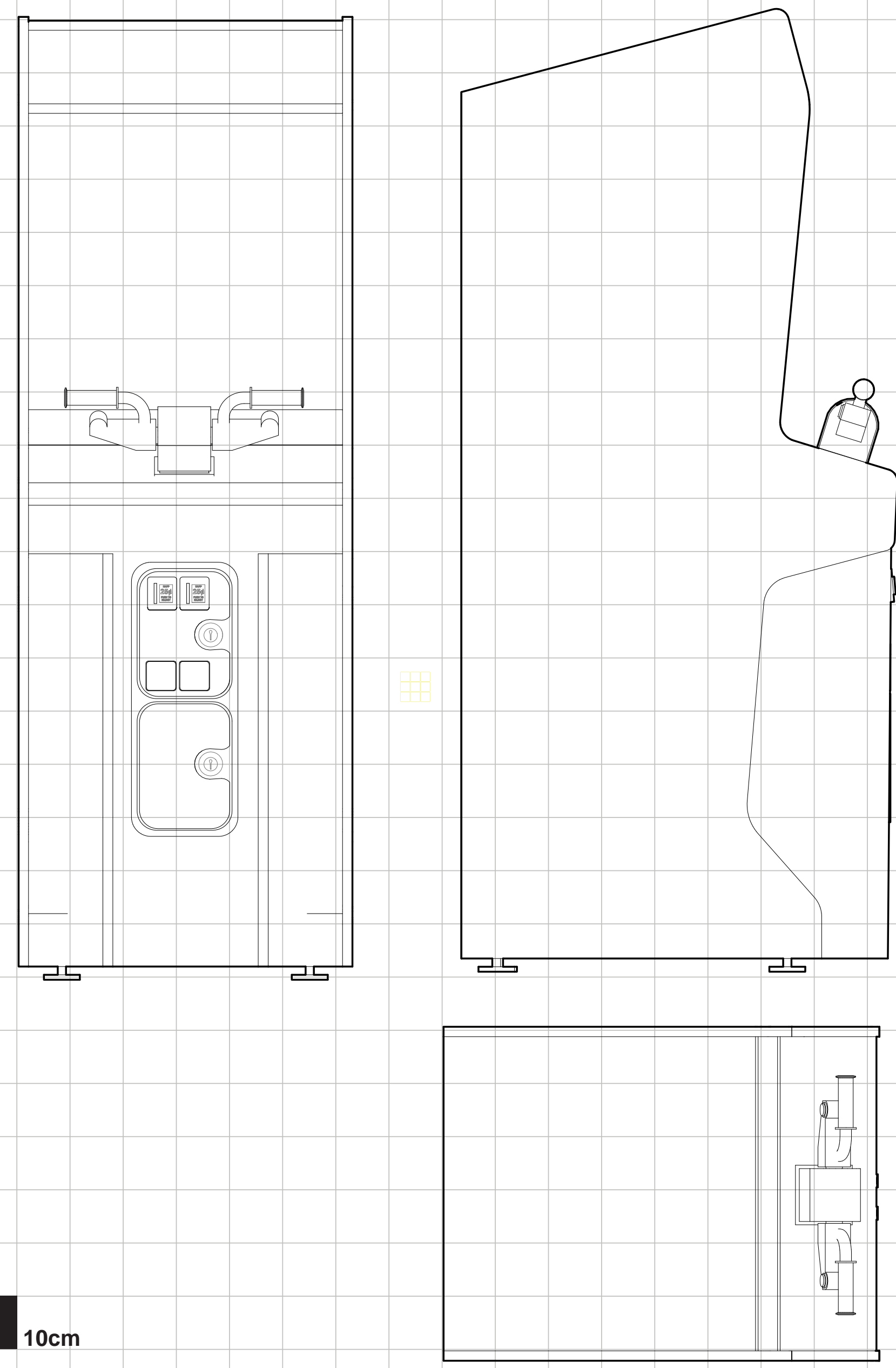




\section{Paperboy.}

1984

Atari arcade.

Máquina arcade.

Máquina Arcade desarrollada y publicada por Atari en 1984 Contaba con un monitor horizontal CRT que permitía visualizar gráficos ráster a color. El panel de control era muy elaborado y, además de un botón, contaba con un manillar de bicicleta anclado a la máquina cuyo giro permitía el giro del personaje en pantalla y que incluía además sistema de aceleración y frenada en el mismo manillar.

Paperboy estaba construido sobre una plataforma Atari System II, un microprocesador y varios chips para el sonido. Este juego contó con tres secuelas Paperboy 2 (1992), Paperboy 64 (1999) y Paperboy para iPhone (2009).

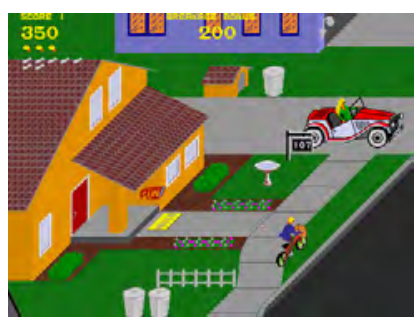

Paperboy.

1984

Videojuego arcade de acción y conducción en el que el jugador se pone en la piel de un joven en bicicleta que reparte periódicos por un barrio de los suburbios. El juego se desarrolla en perspectiva oblicua. 


\section{$\mathbb{Q}^{2300}$}
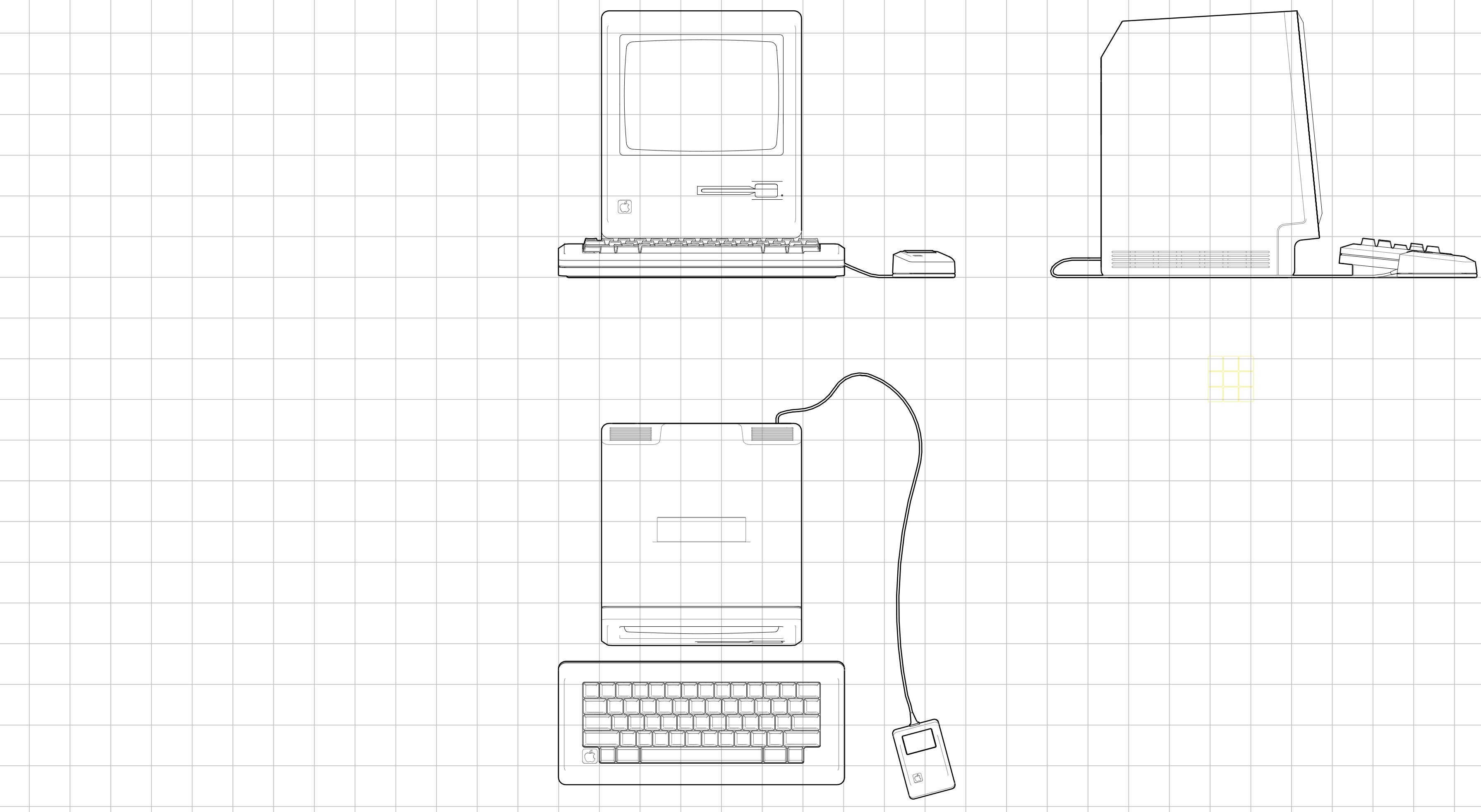


\section{Macintosh.}

Apple.

Ordenador.

Primer ordenador personal de la línea de computadoras diseñadas y comercializadas por Apple y que se ha extendido hasta la actualidad. Macintosh fue lanzado al mercado en 1984 y fue pionero por interfaz gráfica de usuario (GUI) y que, además interfaz grálica de usuario (GUI) y que, además, incorpar el uso de se tern pán convirtiendo con la sistema estándar en la industria.

Este ordenador tenía el sistema operativo System 1, una memoria RAM de $128 \mathrm{~Kb}$ (por lo que coloMacintosh 128K) y un procesador Motorola 68000 a pantalla del ordenador (monocromática) tení nueve pulgadas y permitía una resolución de 512 $\times 342$ píxeles.

Macintosh poseía un lector de disquetes, dos puertos RS232 (que permitía conectar la mayoría de los joysticks y controladores de videoconsolas de mercado) y el teclado original M0115 numérico, asi como el ratón. El ordenador fue diseñado para un óptimo rendimiento gráfico. Con un precio de 2495 dólares, vendió 70.000 unidades.

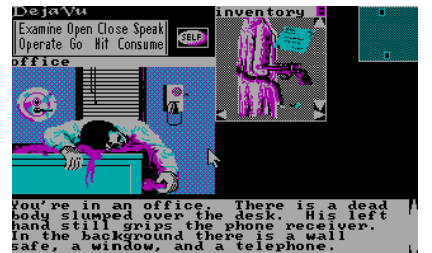

Videojuego de aventura grafica de point and click en el que el jugador controla a un boxeador retirado que trabaja como detective debe resolver un asesinato ser detenido como sospechoso. juego, así como su secuela, requerían un pensamiento lateral significativo.

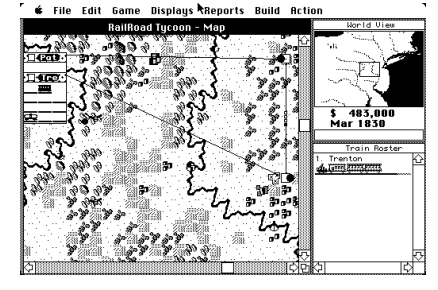

ad Tycoon.

Videojuego de simulación de negocios en el que e objetivo del jugador es construir y manejar una compañia ferroviaria construyendo tambien las estaciones y elaborando los horarios de los trenes. Existen variaciones de juego en cuatro escenarios geográficos

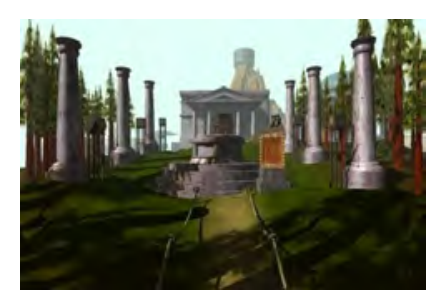

1991

Videojuego de tipo aventura gráfica en primera persona. Se trata de un juego revolucionado para su momento de publicación que tiene lugar en un escenario interactivo de point\&click. Se da muy poca información de incio al jugador, que debe explorar la isla de Myst y los diferentes 'libros' que contiene. No hay enemigos obvios, no hay violencia fisica, no hay limite de tiempo para completar e juego, y no hay amenaza de morir en ningún momento. El juego se desarrolla a su propio ritmo y se resuelve mediante una combinación de paciencia, observación pensamiento ló

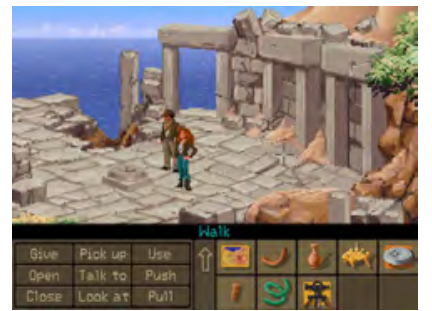

Alana Jones and the Fate o Atlantis.

1992

Videojuego de aventura de pointaclick basado en universo de Indiana Jones y la búsqueda de la ciudad sumergida de Atlantis. En él, el jugador explora un mundo estático e interactúa
con objetos y personajes mediante el uso de comandos construidos con verbos predeterminados. Existen tres opciones o caminos que recorrer en el juego y que influyen en el desarrollo de la historia, el juego y los rompecabezas. El juego fue diseñado mayoritariamente con el software Deluxe Paint; los fondos se dibujaron primero a lápiz convirtiéndose y retocándose luego a 256 colores, mientras que las animaciones de los personajes eran rotoscópicas elaboradas con imágenes de video.

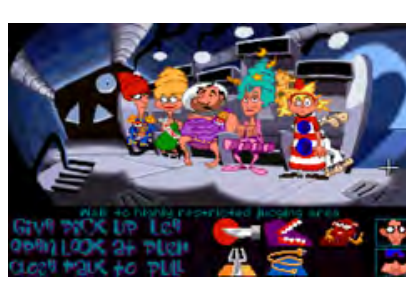

Maniac Mansion 2: Day of the tentacle.

1993

Videojuego de tipo aventura gráfica point\&click en 2D y último juego en el moto SCUMM. El jugador toma e control de tres amigos que tratan de salvar el mundo del malvado Tentáculo Púrpura interactuando con el mundo. El juego emplea como recurso el viaje en el tiempo, pudiendo enviar e interactuar con personajes $y$ objetos en periodos de tiempo separados, haciendo que lo cambios en el pasado afecten al presente y futuro. MODDING

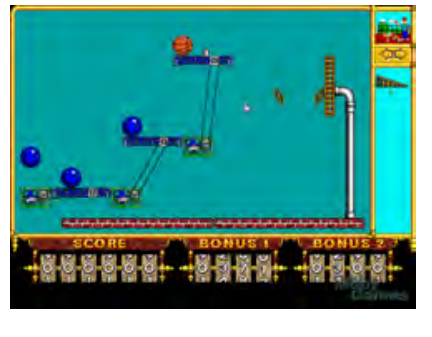
1993

educativo en el que el jugado tiene la misión de crear una serie de dispositivos a partir de una colección dada de objetos de una manera innecesariamente compleja para realizar una tarea simple. Los sistemas simulan las interacciones físicas de los objetos, pero también las ambientales (como la presión del aire o la gravedad). Existe un modo de juego libre en que se puede experimentar con los objetos sin objetivo definido.
Sim City 2000.

Videojuego de simulación de construcción de ciudades visualizado, a diferencia de su predecesor, en pugactiva isometrica. É crear tiene como misión sus diferentes áreas (residenciales, industriales, de infraestructura... aumentando el nivel de vida de la población y manteniendo un equilibrio entre los diferentes sectores (ambientales, económicos...). Tras su publicación, SimCity 2000 se convitió en modelo de simulación urbana de referencia durante la década posterior. El juego incluyó escenarios posibles donde se daban desastres basados en situaciones de la vida real huracanes, inundaciones, recesiones económicas, etc. 
回 ${ }^{202}$
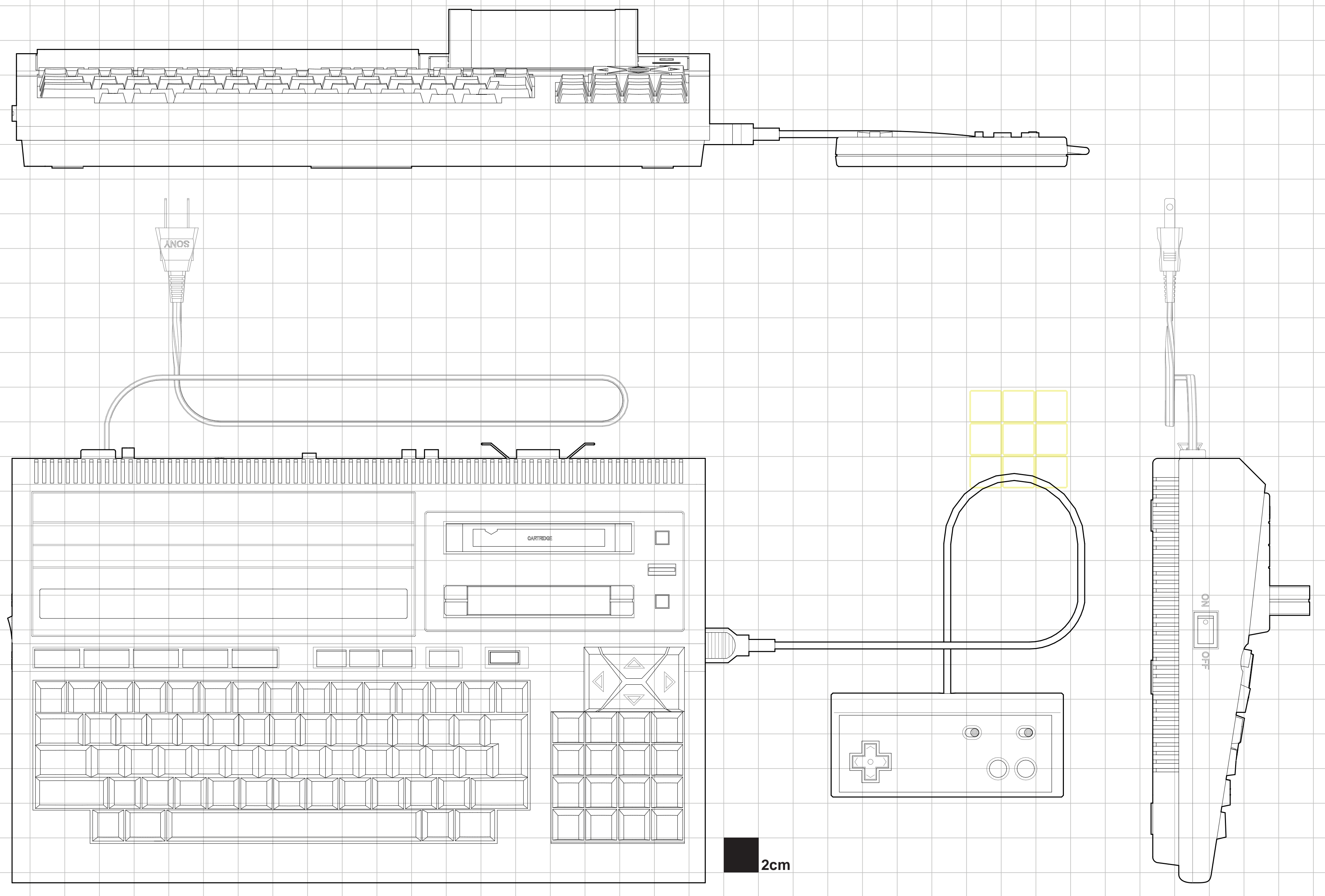


\section{MSX.}

1984

Microsoft y ASCII.

Microordenador.

Ordenador doméstico que se trataba de un estándar de micrordenador doméstico de 8 bits que no respondían a un modelo único, sino a un estándar, dentro del que se agruparon diversas Philips. Estos ordenadores se lanzaron en 1983.

Estaban basados en un microprocesador Z80 de 8 bits y programado en MSX Basic 1.0 (de Microsoft). y permitía ver 16 colores. La RAM del ordenador era de $8 \mathrm{~Kb}$ y la RAM de vídeo de $16 \mathrm{~Kb}$.

Este primer modelo contaba con un teclado y una grabadora/reproductora de casetes. Además, cartuchos para juegos, programas o, incluso, periféricos. Dentro de la norma MSX, hubo varias versiones: MSX-1, MSX-2, MSX-2+ y MSX-TurboR. La segunda versión MSX 2 fue lanzada cinco años más tarde y presentaba, sobre todo, mejoras gráficas y de unidades de disco. Este segundo modelo también incluía un nuevo periférico, un lápiz óptico (light pen). Estas diferencias se traducen en una mayor memoria RAM (64Kb), una mayor memoria RAM de vídeo (128Kb) y resoluciones de $512 \times 212$ píxeles (con 16 colores) y 256×212 píxeles (con 256 colores). Aunque tuvieron cierto auge en Japón, fuera
del mercado nipón no consiguieron triunfar: en Estados Unidos el líder era el Commodore 64 y en Europa el liderato de los ordenadores domésticos lo ostentaba el ZX Spectrum.

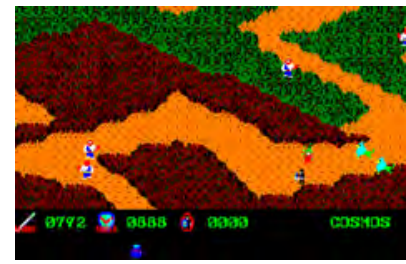

Teous Perseus.

Videojuego de rol y que el jugador asume el papel del héroe legendario Perseo dirigiendose a una isla plagada de bestia mitológicas. Se trata de un juego de mundo abierto exploración visualizado en perspectiva aérea.

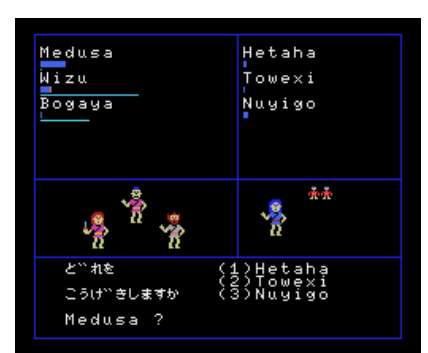

The Black Onyx

1984

Videojuego de rol pionero en el genero en Japón responsable de la eclosión del rol en el país nipón. El jugador debe explotar un sistema de mazmorras laberínticas bajo la ciudad que posee diversas entradas y cuenta con seis pisos correspondientes a los seis colores que podia mostrar el ordenador. Cada uno de los niveles debía resolverse en un orden concreto para

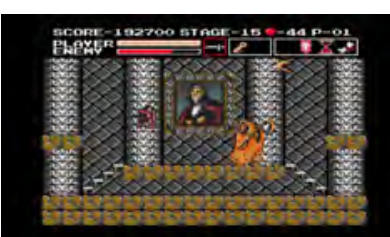

Videojuego de acción y plataformas cuya trama se integra en la saga Castlevania. El jugador toma el papel de un asesino de vampiros que recorre un castillo. El juego no posee pantalla a pantal

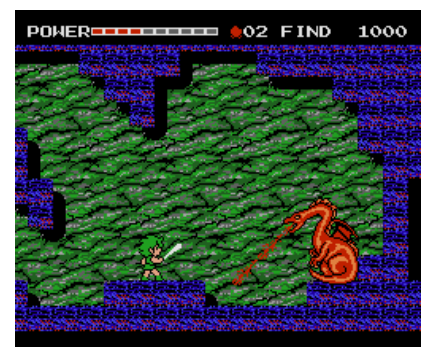

Golvellius.

1987

Videojuego de rol y acción en el que el jugador es un guerrero con la misión de encontrar a Golvellius y rescatar a la princesa El escenario se dividía en mundo exterior y mazmorras en las que se encuentran escondidos siete demonios a los que el jugador debe enfrentarse. Contaba con la función de guardar a traves de una contraseña que permitia volver al juego sin comenzar de cero. Se trataba de un juego en 2D lateral y aérea.

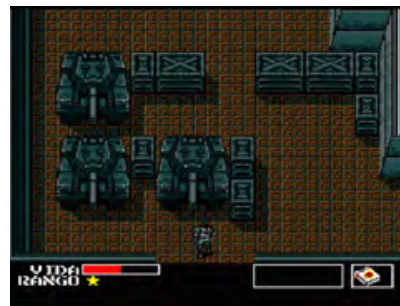

Videojuego de acción y sigilo

en el que el jugador encarna

a un agente secreto que debe

infiltrarse en una fortaleza con

el fin de destruir un arma de destrucción masiva llamada Metal Gear. El jugador debe evitar el contacto visual y la confrontación con soldados enemigos siendo clave el concepto de sigilo. E espacio se representó en perpectiva egipcia.

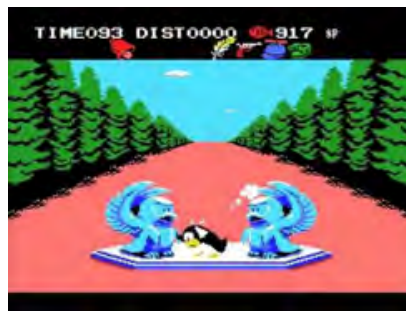

in Adventure.

Videojuego de plataformas y carreras con elaborados gráficos basados en mosaicos pseudo 3D. El protagonista encarna a un pingüino que debe conseguir una manzana dorada con capacidades curativas. Se trata de una secuela de un juego llamado Antartic Adventure. Contaba con un diseño de niveles variado que presentaba, además, múltiples finales.

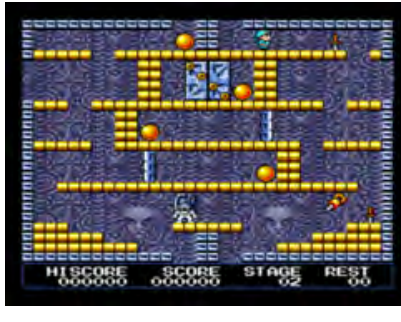

1988

Videojuego de plataformas y puzzles en el que se llevó a cabo un peculiar concurso en el que cada participante debía crear un nivel de juego.

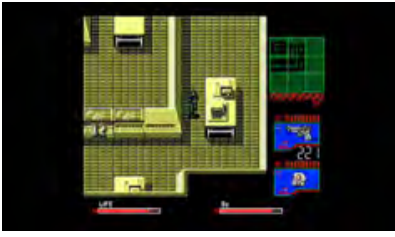

1950 juego de acción que. al igual que su predecesor basa su sistema de juego en el sigilo. El jugador debe infiltrarse una vez más en una fortaleza enemiga evitando ser detectado por soldados, camaras, sensores infrarrojos y otros dispositivos de vigilancia. A diferencia de la primera versión, los enemigos pueden patrullar en diferentes pantallas en un solo mapa y tienen un campo de visión expandido de 45 grados, además de la capacidad de girar la cabeza. En la esquina superio derecha de la pantalla aparece una cuadrícula de $3 \times 3$ que hace las funciones de un radar. El progreso del juego podia guardarse en un floppy disk a través del uso de contraseñas.

\section{ACCESORIO}

Light Pen

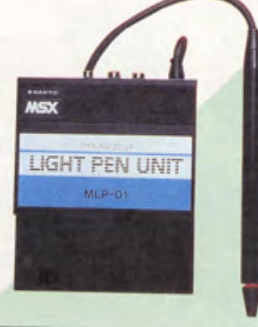

que permitía dibujar sobre la pantalla a la que estuviera conectado el ordenador. Se basaba en una patente de una tecnología de 1955 diseñado en el MIT, que enviaba una seña cada vez que detectaba cierta intensidad de luz en pantalla y permitía saber e punto donde se dibujaba. Fue un accesorio que apareció tambien para otros ordenadores o consolas. 

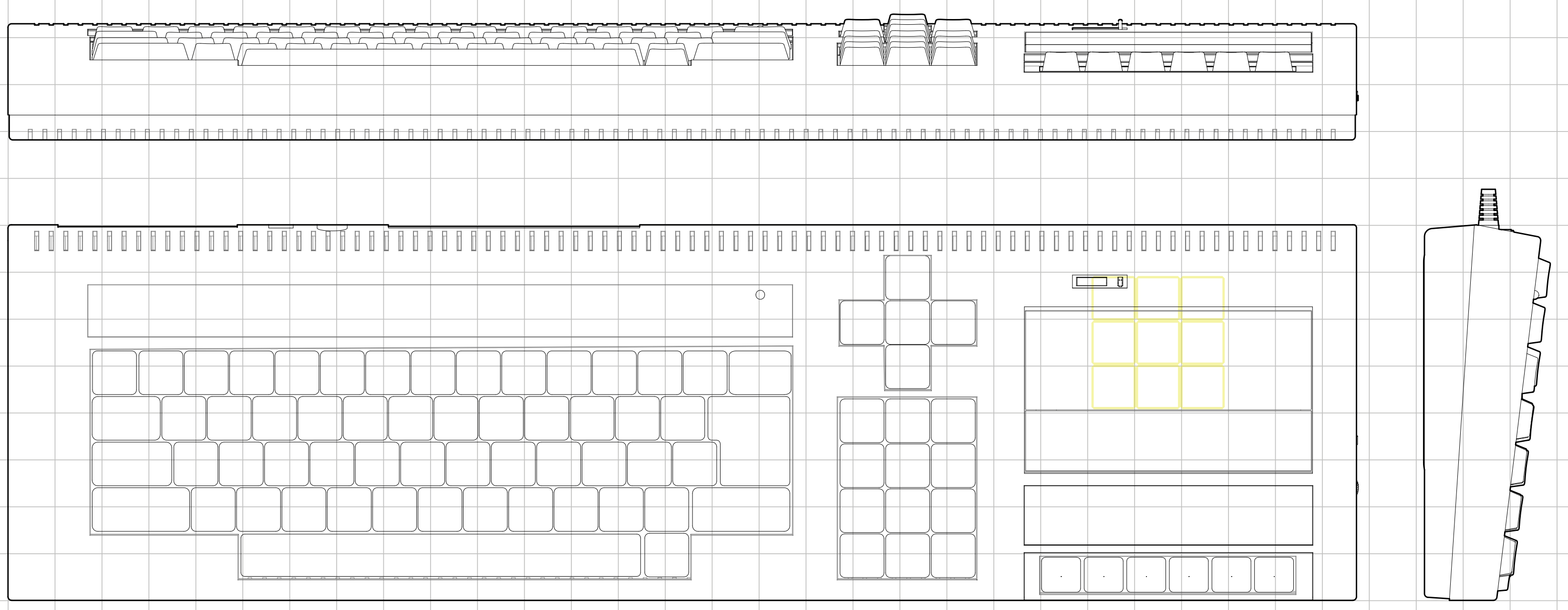


\section{Amstrad CPC.}

1984

Amstrad.

Microordenador.

Ordenador doméstico de la gama de microordenadores de 8 bits producidos por Amstrad en la década de los ochenta y principios de los noventa. El primer modelo de la serie salio Sus siglas CPC responden a Colour Personal Computer.

Este ordenador contaba con un procesador Zilog Z80A y una memoria RAM de 64Kb, que se amplió con las siguientes versiones y con expansiones de memoria de terceros. Compitió con el Commodore 64 y con el ZX Spectrum. Tenía disponbibles tres resoluciones: $160 \times 200$ píxeles con 16 colores, $320 \times 200$ pixeles con 4 colores y y $640 \times 200$ píxeles con 2 colores. Incorporaba el sistema operativo denominado AMSDOS (Amstrad Disc Operating System). El Amstrad CPC poseía un intérprete del lenguaje de programación BASIC.

Disponía de un teclado con entrada de cartuchos y un lector de cintas de casetes, además permitia e conexion de un monitor y de unidades de disco extra. Esta serie tuvo seis modelos diferentes y videoconsola doméstica de escaso éxito comercial.

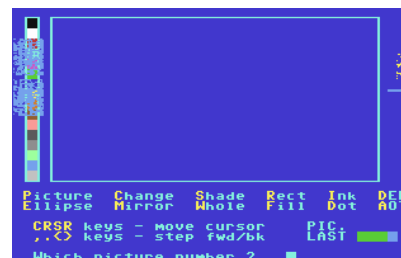

creación de

aventuras gráficas que permitía el diseño de juegos este género tanto a nive de programación como de edición de gráficos. Se incluía una aventura a modo de demostración en el $\mathrm{kit}$ inicial.

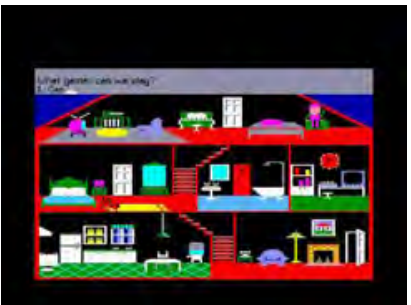

Little Computer People.

Videojuego de simulación de vida, citado como predecesor de los Sims Este juego no tiene un fina definido, y presenta una una lasa de tres plantas, una casa de tres plantas, en la que los jugadores personaje animado que hace personaje animado que hace del juego tiene un personaje

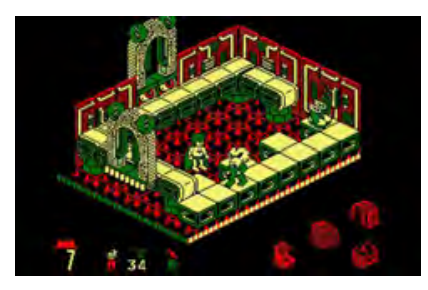

\section{Batman.}

1986

Videojuego de acción y aventuras en perspectiva isométrica 3D en el que el objetivo del jugador recomponiendo las siete partes del bat-craft que se encuentran dispersas en la batcueva. Destaca su sistema de guardado de juego que permite a los jugadores reiniciar en un punto intermedio.

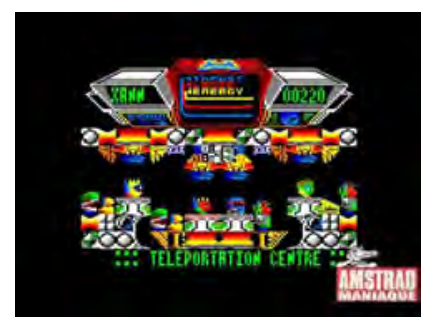

1986

Videojuego de tipo laberíntico. El jugado controla a 4 personajes que se mueven volando, uno de los cuales posee la habilidad de gravedad inversa. Siendo la primera vez que se dio esta caracteristica en el

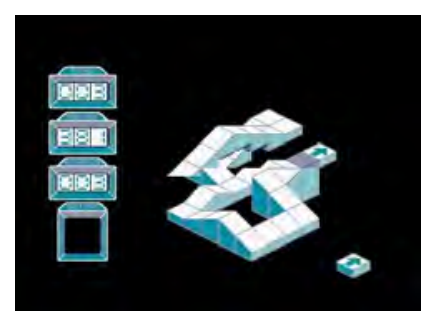

Spindizzy.

Videojuego de acción y puzzles en perspectiva puzzétrica on porspectiva de exploración. Se puede visualizar el campo de juego desde cuatro ángulos y rotar entre ellos. Este lugar es un paisaje ficticio con diferentes interconectados suspendidos en el espacio dimensional. Existe un límite de tiempo para la exploración $y$ el juego termina cuando expira el tiempo o cuando el jugador explora el mundo por completo. Se aprecia una importante influencia Marble Madness.

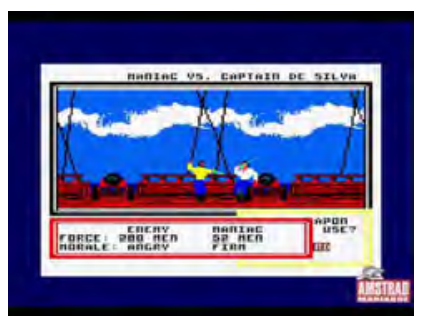

Videojuego de aventuras y estrategia que pone al jugador en la piel de un pirata en el mar del Caribe con el objetivo de conseguir el exito y recuperar su familia secuestrada. La jugabilidad mar saqueando ciudades, barcos y comerciantes, as como descubrir tesoros escondidos. También podía interactuarse sobre la moral de la tripulación, la salud del jugador y la simulación de batallas. 
(2) 


\section{Islands of Kesmai.}

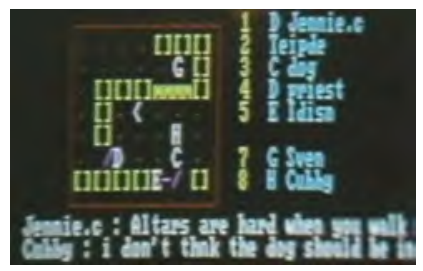

\section{4}

Kelton Flinn y John Taylor. Juego online.

Videojuego de fantasía y MUD (Multi User Dimension o Multi User Domain) considerado el primero de su género e innovador en el uso de pseudo gráficos roguelike. Precursor de los MMORPG actuales. El jugador podía diseñar un personaje que permitía acceder a una sala de chat con el que ingresar en el mundo virtual. La interfaz del juego era bidimensional y su principal mecánica era del estilo Dungeons\&Dragons por turnos a través de una cuadrícula. 

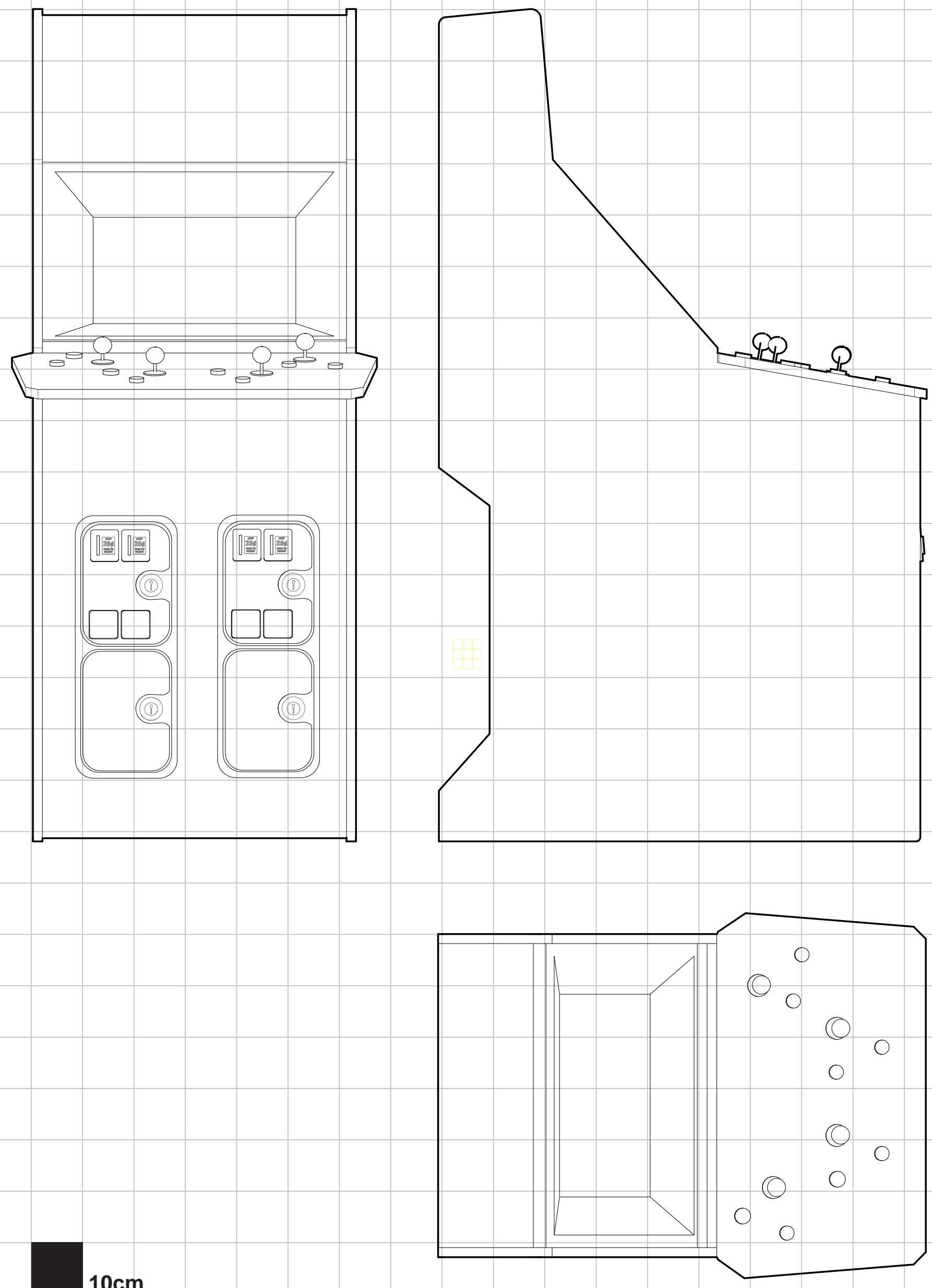


\section{Gauntlet.}

\section{5}

Atari arcade.

Máquina arcade.

Máquina arcade desarrollada por Atari en 1985, este juego fue diseñado por Ed Logg y fue uno de los primeros arcades que contaba con exploración de mazmorras con multijugador.

La máquina disponía de un monitor horizontal CRT de 19 pulgadas que permitía visualizar gráficos ráster en color. Esta máquina contó con dos modelos de cabina ambos clásicos verticales: uno para dos jugadores y otro, el más popular, para cuatro jugadores.

Su panel de control destacaba porque permitía jugar en la misma partida de manera simultánea a cuatro jugadores puesto que dicho panel se dividía en cuatro sectores de diferente color, uno para cada jugador. En cada uno de estos sectores había un joystick que permitía moverse en ocho direcciones y dos botones para disparar hechizos mágicos.

El sistema de juego y el diseño de esta máquina permitía que los jugadores salieran del juego y entraran continuamente (esto supuso que dicha máquina recaudara 4 veces lo que una normal), lo que daba lugar a partidas continuas en las que los 4 jugadores no se conocían necesariamente entre ellos (Kent, 2001).

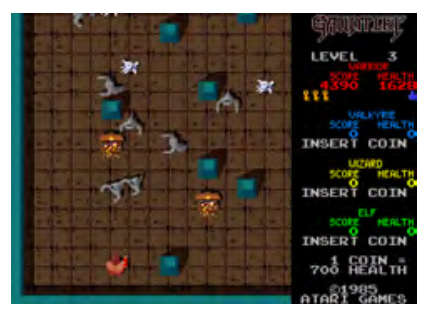

Gauntlet.

1985

Videojuego arcade de fantasía y rol pionero en ser uno de los primeros juegos de exploración de mazmorras multijugador (de 1 a 4 jugadores). El escenario está constituido por una serie de laberintos en perspectiva superior aérea donde el jugador (en tercera persona) debe encontrar la salida, desbloqueando las puertas y destruyendo a todos los enemigos. 

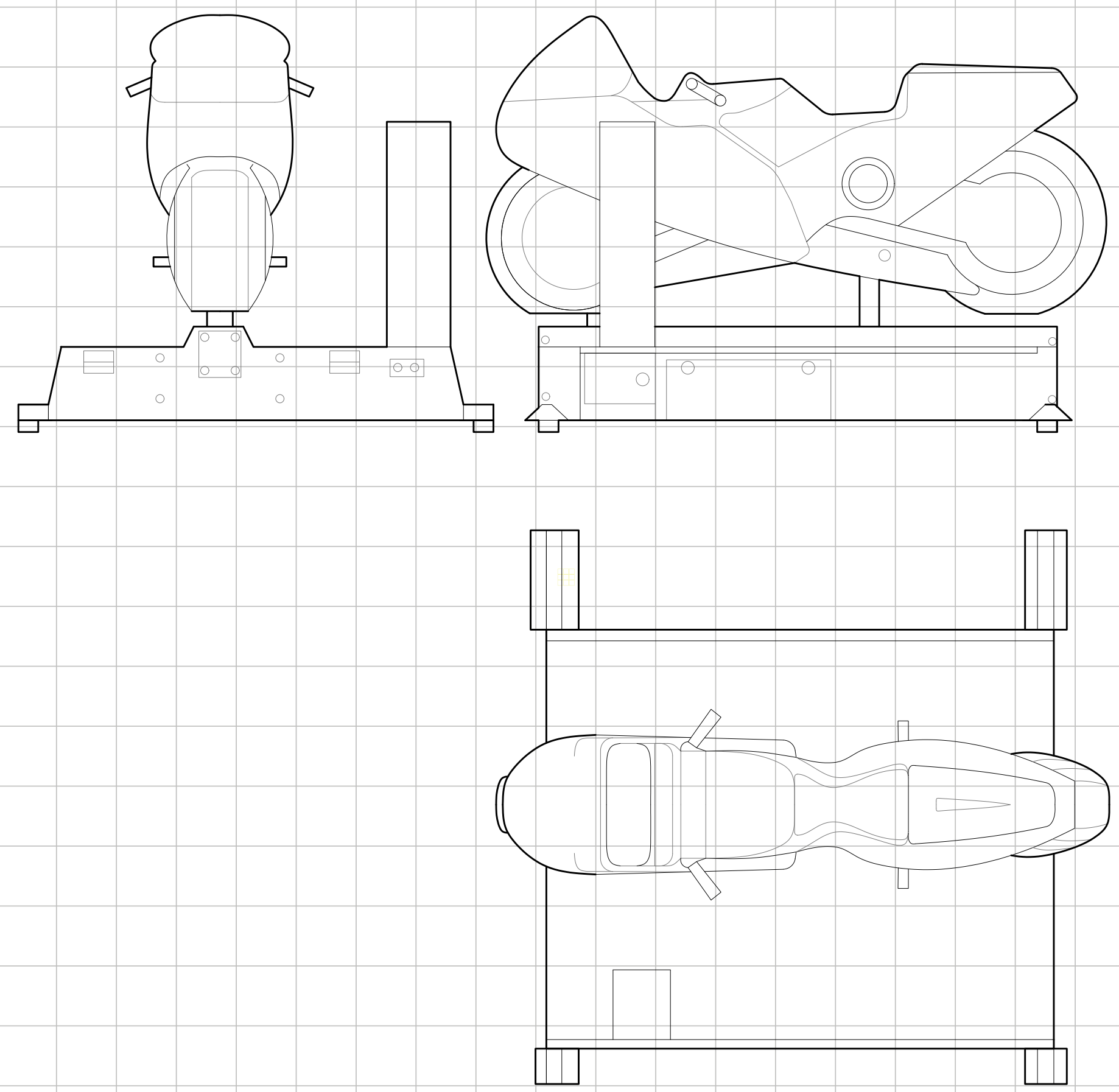


\section{Hang-On.}

1985

AM-2(SEGA) arcade.

Máquina arcade.

Máquina Arcade desarrollado por Sega-AM2 y lanzado al mercado por Sega en 1995. Fue uno de los primeros arcades en incorporar gráficos en 16 bits. Contaba con un monitor horizontal CRT con gráficos ráster en color .

Esta máquina respondía a una investigación de cinco años que su creador, Yu Suzuki, había llevado a cabo combinando videojuegos y elementos propios de los parques recreativos.

El jugador disponía en la parte frontal de la cabina de un manillar de motocicleta (de juguete) construida con fibra de vidrio. El control del juego estaba sujeto al movimiento del jugador con el manillar de la motocicleta y se sincronizaban los movimientos, de modo que, si el jugador inclinaba el manillar hacia los lados o hacia delante, ocurría lo mismo con la motocicleta en la pantalla. Este manillar contaba en sus puños, con las palancas de acelerar y de frenar.

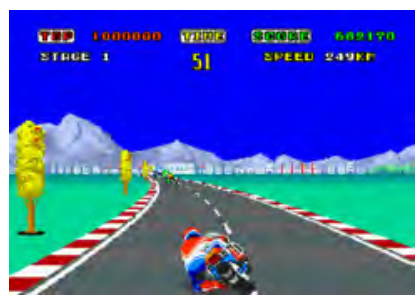

Hang-on.

1985

Videojuego arcade de carreras que fue uno de los primeros en usar gráficos de 16 bits. Incorporaba también la tecnología de Sega "Supe It was one of the first arcade games to use 16-bit graphics and Sega's "super escalador" (en inglés "Super Scaler") que permitía el escalado de sprites pseudo3D a altas velocidades de cuadro. 
$\Xi^{238}$
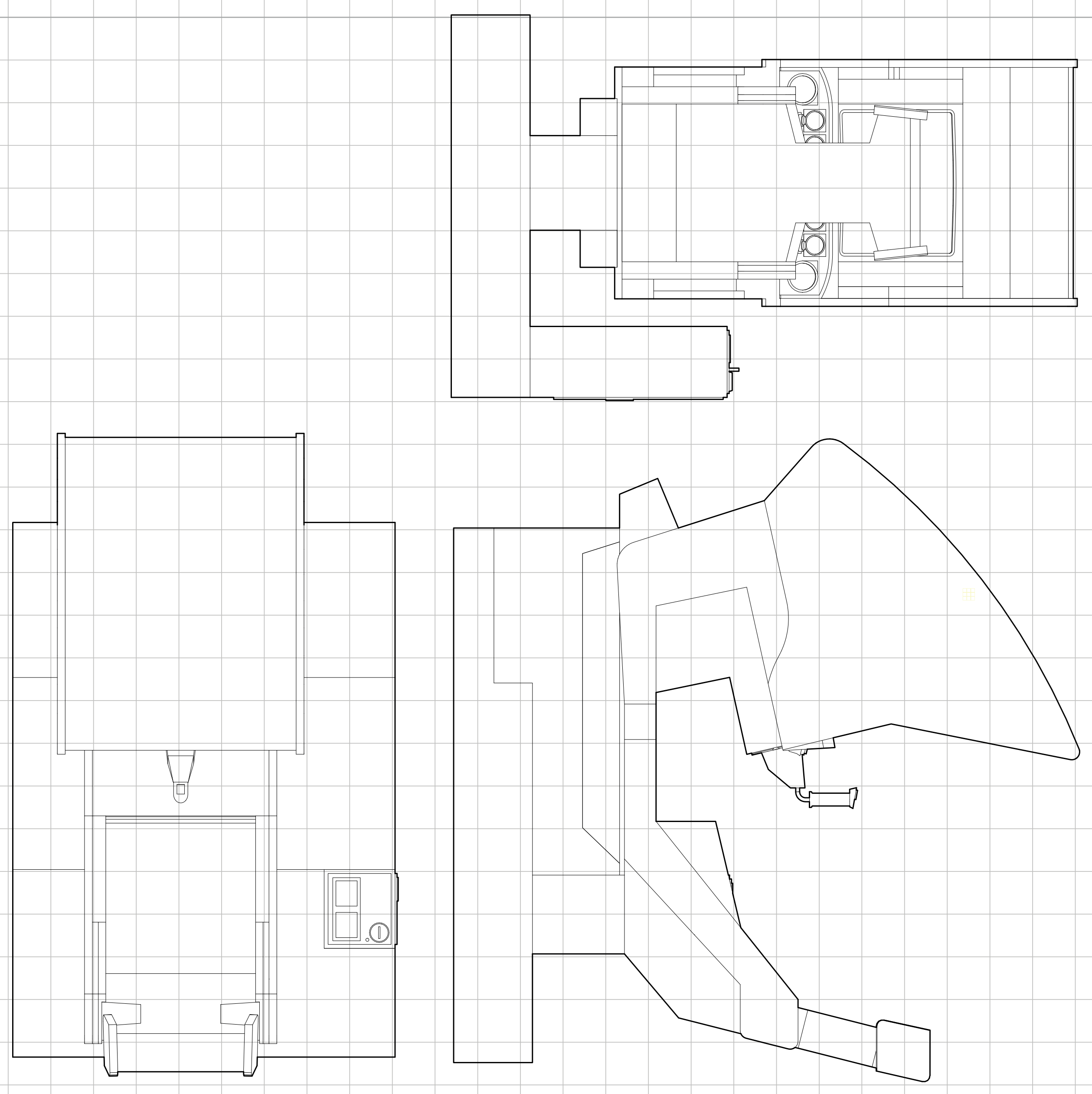


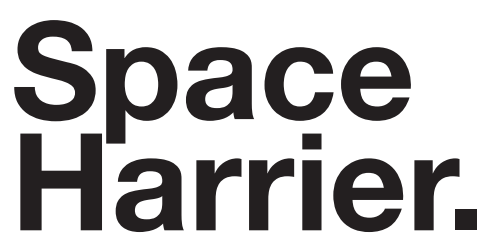

1985

AM-2(SEGA) arcade. Máquina arcade.

Máquina arcade desarrollada por Sega-AM2 y lanzada al mercado por Sega en 1985, diseñada por Yu Suzuki Disponía de un monitor horizontal CRT que permitía visualizar gráficos ráster a color.

La máquina incluía un panel de control con un único joystick analógico que disponía de un gatillo para disparar, y contaba también con un asiento que simulaba el del vehículo del interior del juego. Este arcade contó con esta versión Deluxe con asiento y una versión clásica vertical que carecía de él.

El sistema de juego completo poseía un movimiento propio de un coche en carretera que permitía al jugador una mayor inmersión en la partida.

Tras su arcade, se portó a varias consolas domésticas, entre ellas a la Master System. Contó con varias secuelas Space Harrier 3-D (1988), Space Harrier II (1988) y el spin-off titulado Planet Harriers (2001).

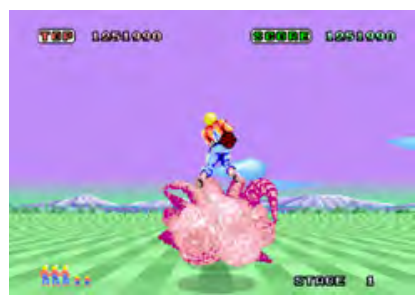

Space Harrier.

1985

Videojuego perteneciente al subgénero shooter sobre raíles que poseía unos escenarios espectaculares para el momento, diseñados en pseudo-3D. Nintendo copió estos diseños para Star Fox. 

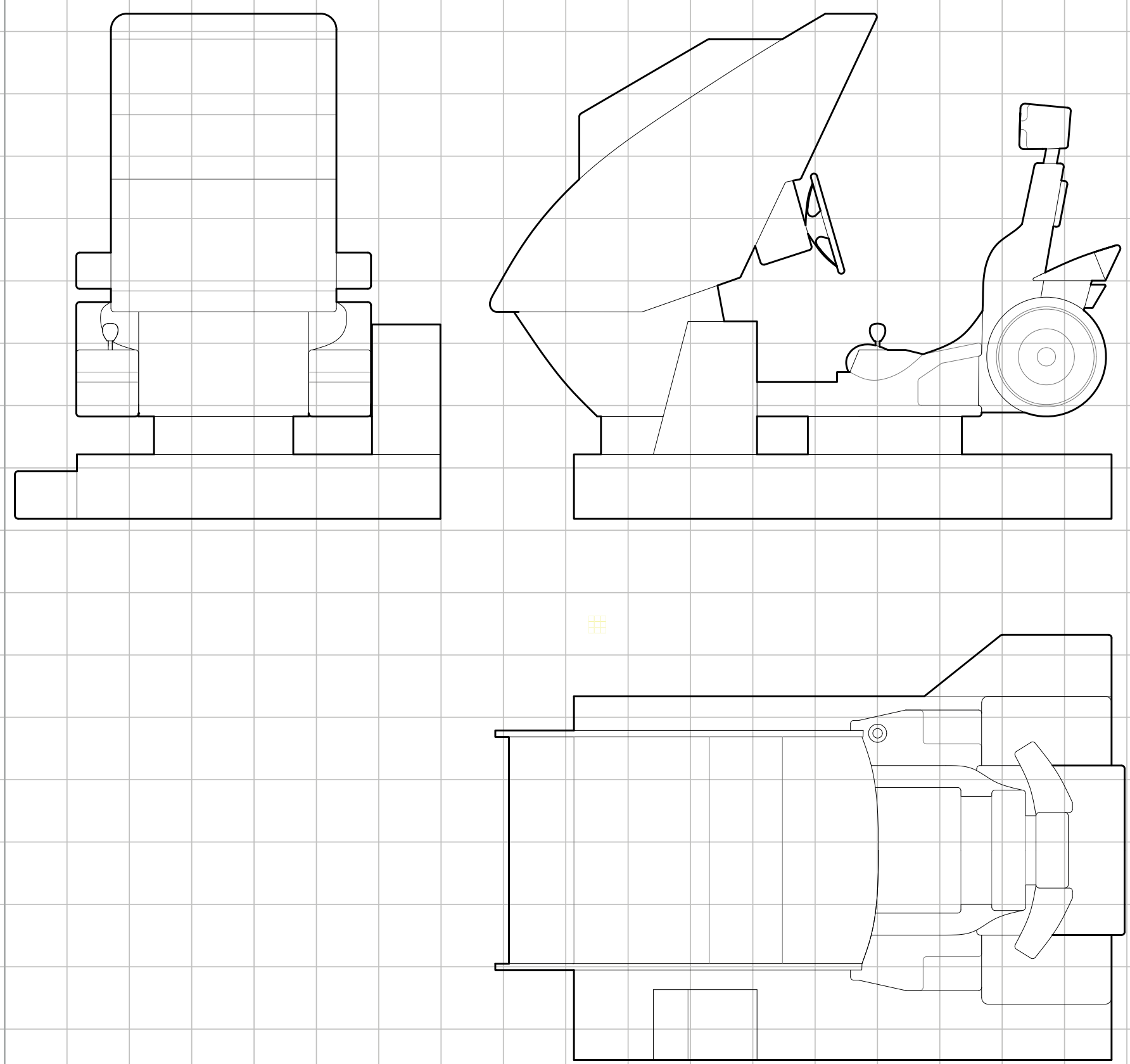
Videojuego de carreras con un hardware y gráficos pioneros que innovó con rasgos como el gameplay lineal.

1986

AM-2(SEGA) arcade.

Máquina arcade.

Máquina arcade desarrollada por Sega-AM2 y lanzada al mercado en 1986. Esta máquina contaba con un monitor horizontal CRT con gráficos de tipo ráster en color. Estaba basada en un microprocesador Motorola 68000.

Out Run poseía un panel de control formado por un volante (que disponía de fuerza de respuesta), una palanca de cambio que permitía dos posiciones (baja y alta) y dos pedales (acelerador y freno).

La versión Deluxe incluía un asiento que imitaba un coche de carreras, incluía las ruedas de este. El asiento de esta versión Deluxe tenía movimiento para simular los giros de acuerdo con la pantalla. Este arcade contó también con un modelo clásico vertical (contaba con volante, pedales y palanca de cambio), un modelo mini y un modelo cocktail. 

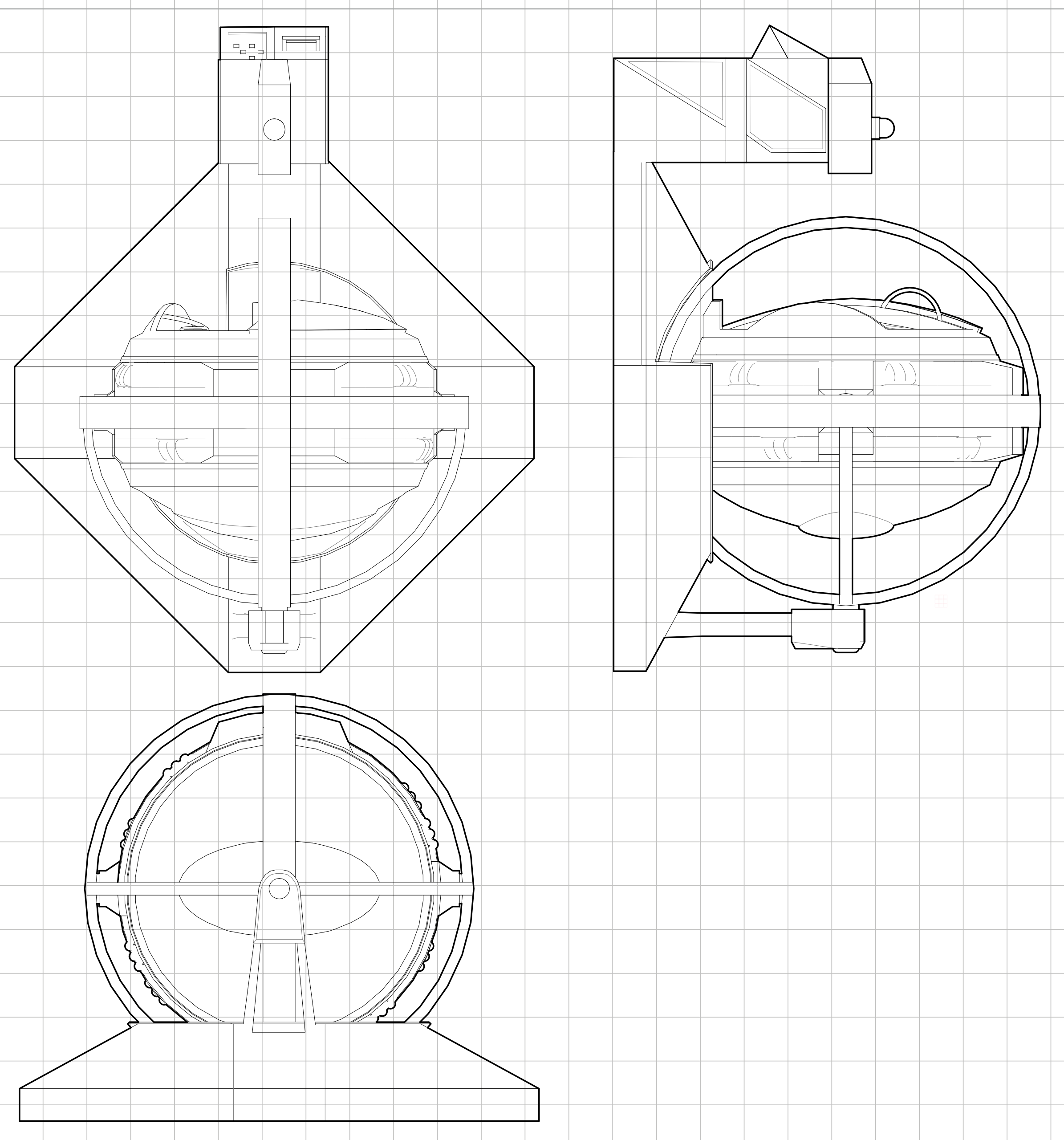


\section{R-360.}

1990

AM-2(SEGA) arcade. Máquina arcade.

Máquina arcade desarrollada por Sega-AM2 y lanzada al mercado por Sega en Japón en 1990 e internacionalmente en 1991.

Esta máquina estaba pensada para que el jugador se sentara frente a la pantalla y viviera una experiencia en tres dimensiones, ya que disponía de un sistema de movimiento en el eje XYZ para rotar por completo su posición. Para garantizar la seguridad del jugador, el asiento incorporaba una barra y un arnés de cuatro puntos.

Disponía de una pantalla horizontal CRT que permitía visualizar gráficos ráster en color. El panel de control poseía un joystick analógico con un botón de disparo y otro botón adicional para que el jugador pudiera detener el movimiento. También disponía de una palanca con un botón en el pulgar (afterburner)

Este arcade es considerado el punto álgido de la investigación entre el juego y el movimiento e integración de dispositivos externos que desarrolló SEGA entre los años 80 y 90 del siglo XX. 
$\theta^{200}$
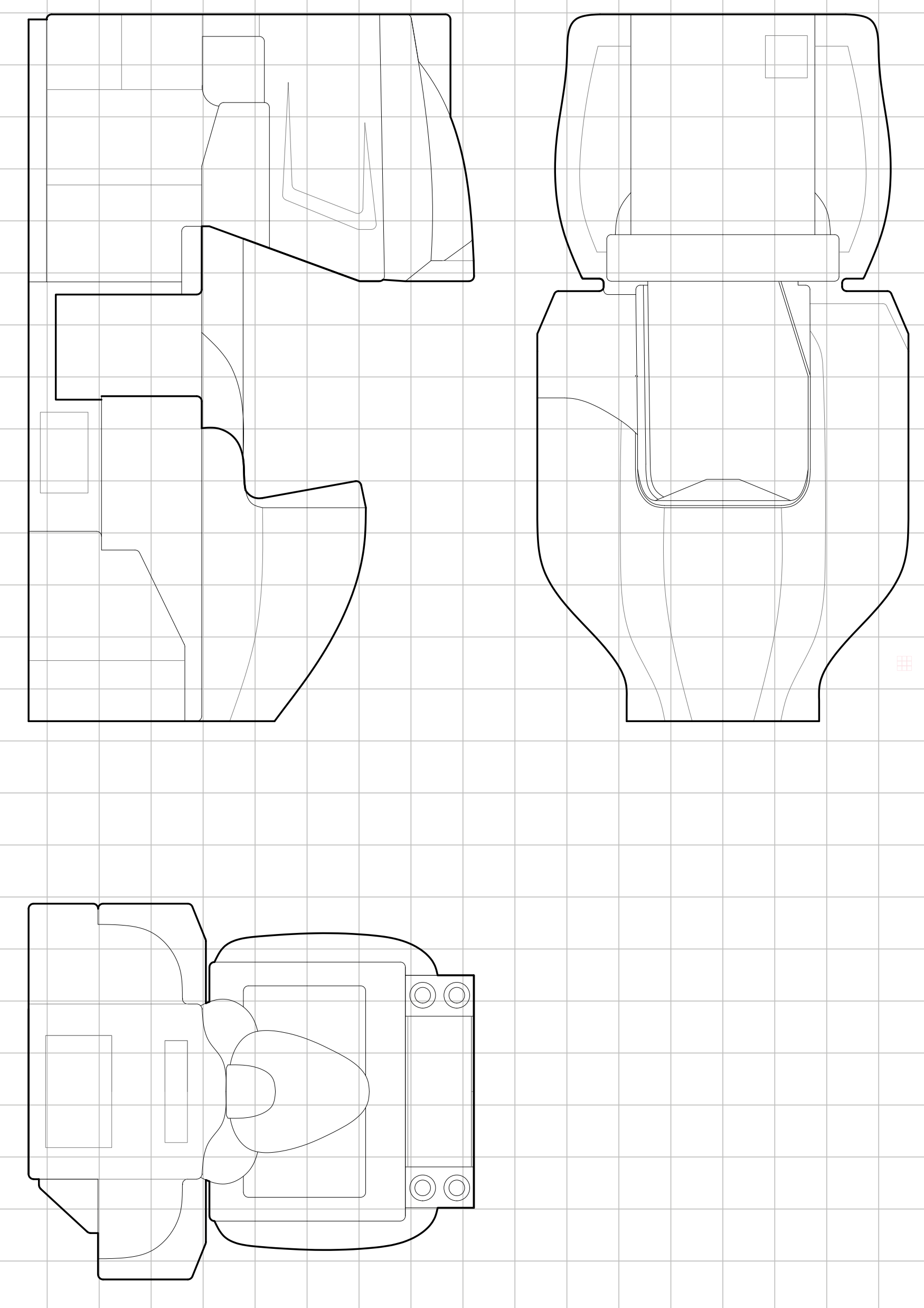


\section{Virtua Racing.}

1992

\section{AM-2(SEGA) arcade. Máquina arcade.}

Máquina de arcade desarrollado por Sega-AM2 (un departamento de desarrollo e investigación de Sega) y lanzado al mercado en 1992.

Esta máquina contaba con dos monitores horizontales CRT con gráficos ráster a color, fue el primer juego de carreras de Sega en utilizar gráficos reales en 3D. Los dos jugadores participaban de manera simultánea en la partida al encontrarse sentados cada uno de ellos en asientos contiguos que simulaban los de un coche de competición de carreras. Cada asiento contaba con uno de estos monitores, un volante que servía a modo de controlador y dos pedales para acelerar y para frenar.

Esta máquina de arcade contó con esta versión Deluxe de dos asientos, pero también tuvo una versión clásica vertical para un único jugador que no disponía de asiento, pero sí contaba con volante y pedales.

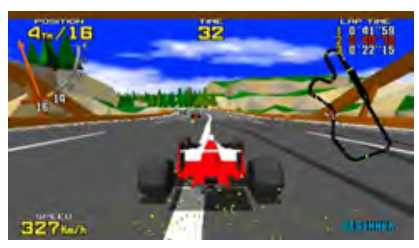

Virtua Racing.

1992

Videojuego de carreras desarrollado para la placa Model1 y que fue uno de los primeros juegos en usar gráficos poligonales en entornos, personajes y automóviles. Incluyendo, además, el View System que permitía al jugador elegir entre cuatro vistas diferentes: cenital, media altura, detrás del coche y primera persona. Siendo también la primera recreativa que utilizó la relación gráfica 16:9. 


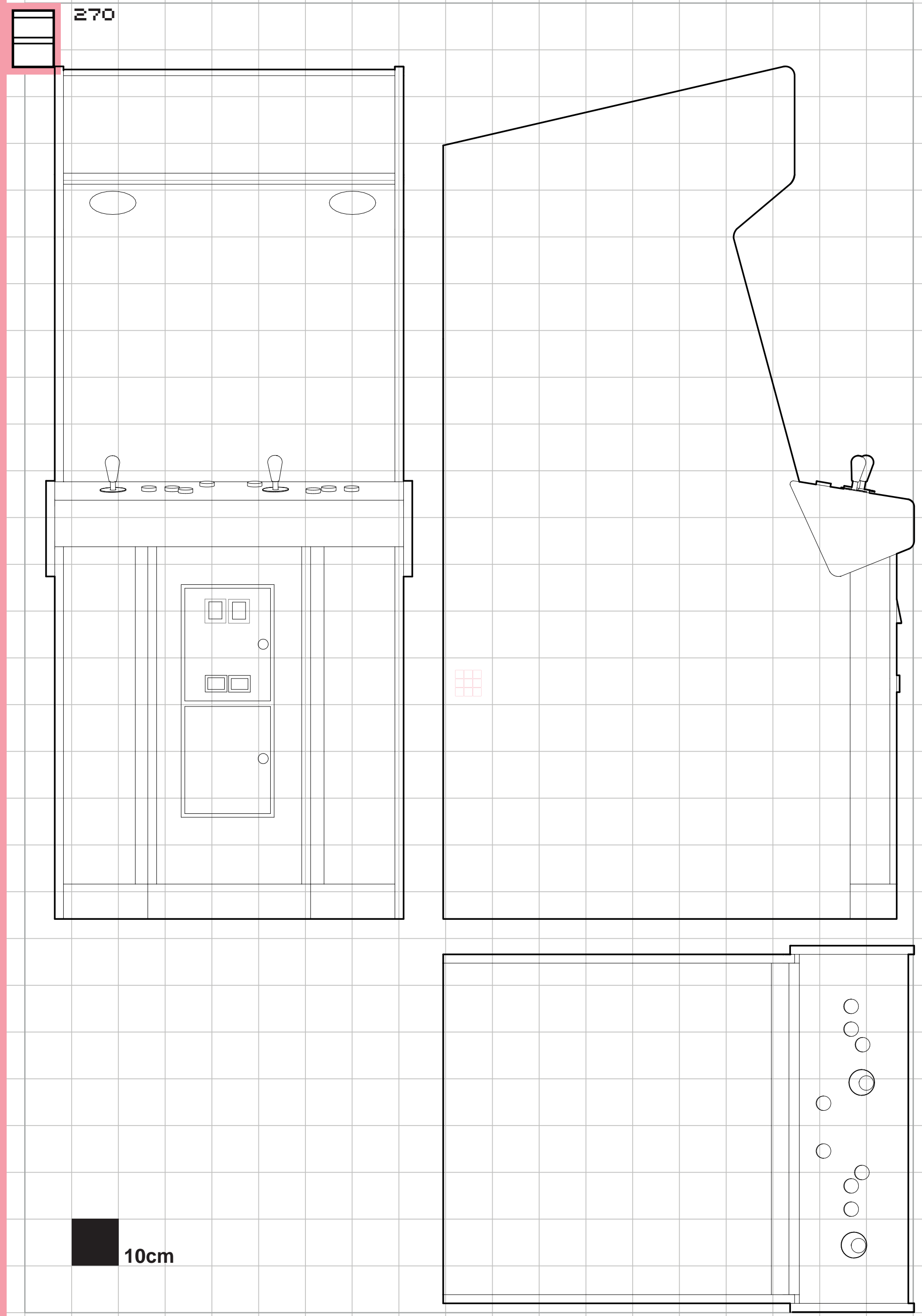




\section{Virtua Fighter.}

1993

AM-2(SEGA) arcade. Máquina arcade.

Máquina arcade desarrollada por Sega-AM2 y lanzada al mercado en 1993, este juego fue diseñado por Yu Suzuki Este fue el primer videojuego de la saga de Virtua Fighter que cuenta con doce juegos que han sido lanzados en consolas como Saturn, PlayStation 2, Dreamcast, Xbox 360, PlayStation 3 e, incluso, en ordenador.

Esta máquina de arcade contaba con un monitor horizontal CRT que permitía visualizar gráficos de tipo ráster en color. Daba la oportunidad de participar de manera simultánea a dos jugadores en la pantalla. Cada jugador disponía de la mitad del panel que, cada mitad, contaba con un joystick que permitía moverse en ocho posiciones y tres botones para propinar puñetazos, golpear y defenderse (punch, kick y guard en inglés).

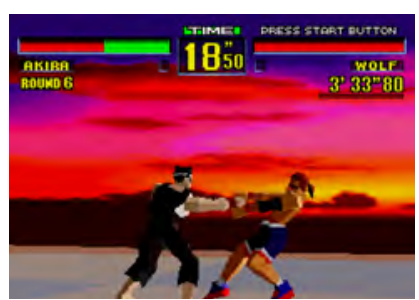

Virtua Fighter.

1993

Videojuego de lucha creador para SEGA Model1 y primer juego de lucha arcade que presentaba gráficos poligonales en 3D. Gozaba de profundidad en las batallas ya que la acción tenía lugar directamente en 3D. 

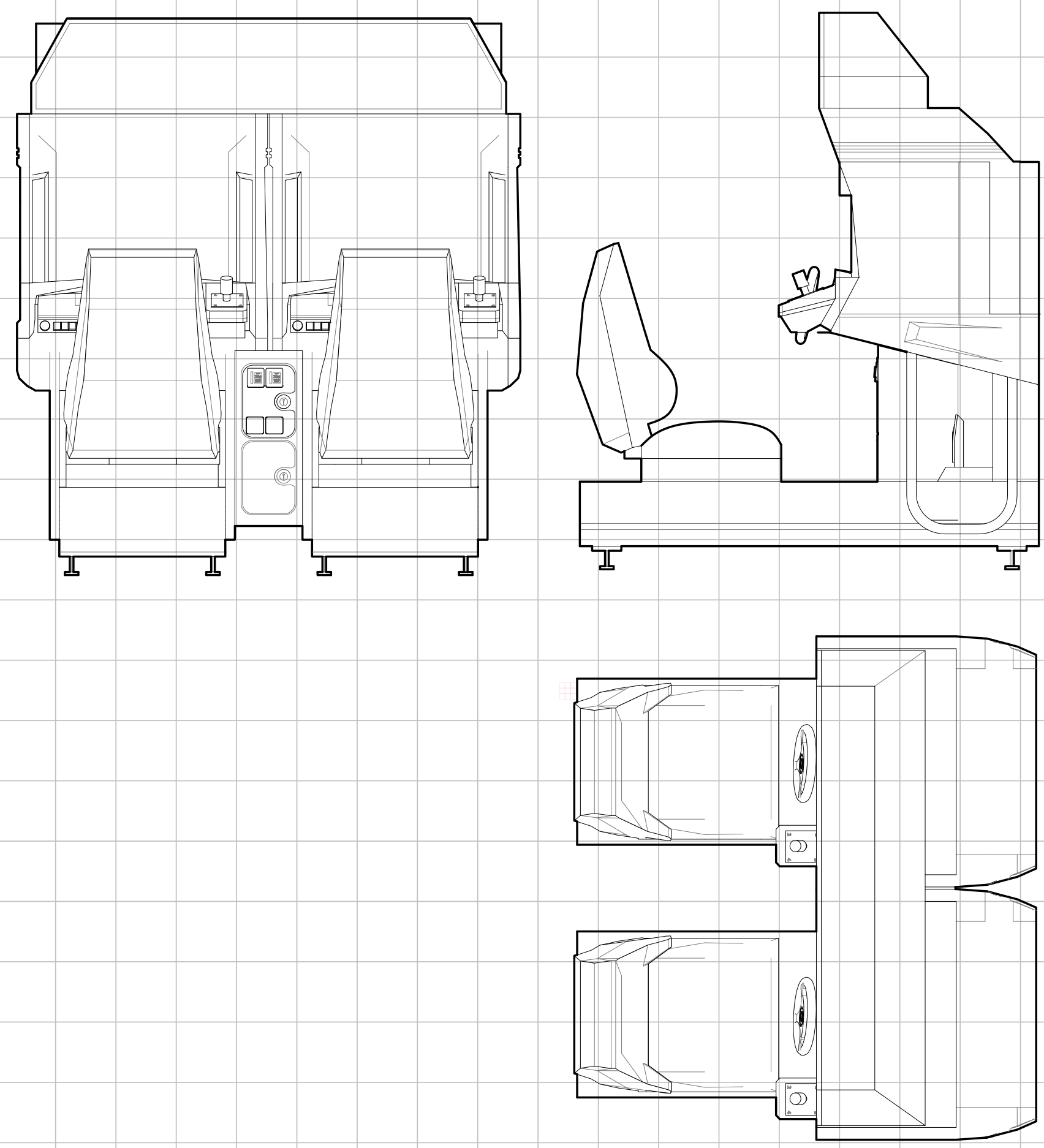


\section{Daytona USA.}

1993

\section{AM-2(SEGA) arcade.}

Máquina arcade.

Máquina de arcade de carreras diseñado y lanzado al mercado por Sega-AM2 en 1993. Esta máquina contaba con dos monitores horizontales CRT de 25 pulgadas que permitía visualizar gráficos ráster en color. Al igual que Virtua Racing, también contaba con un panel de control formado por un volante, una palanca de marchas que tenía cuatro posiciones (marchas: 1, 2, 3 y 4) y dos pedales (acelerador y freno).

Contó con una versión clásica vertical y una versión Deluxe que incluía un asiento integrado que simulaba los coches de NASCAR de Daytona. Aunque el modelo básico era de dos jugadores, existieron unidades de hasta ocho jugadores.

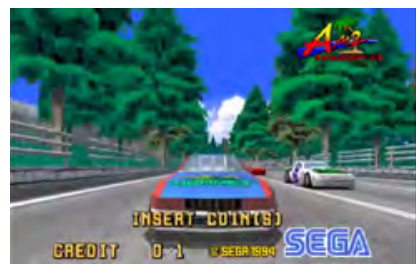

Daytona USA.

1993

Videojuego de carreras y plataformas pionero dentro de SEGA en el uso del Arcade System Board que sitúa al jugador en una carrera de Nascar. Para diseñar el escenario se utilizaron imágenes de satélite y fotografías aéreas, junto a efectos visuales de texturizado para conseguir un mayor realismo. 

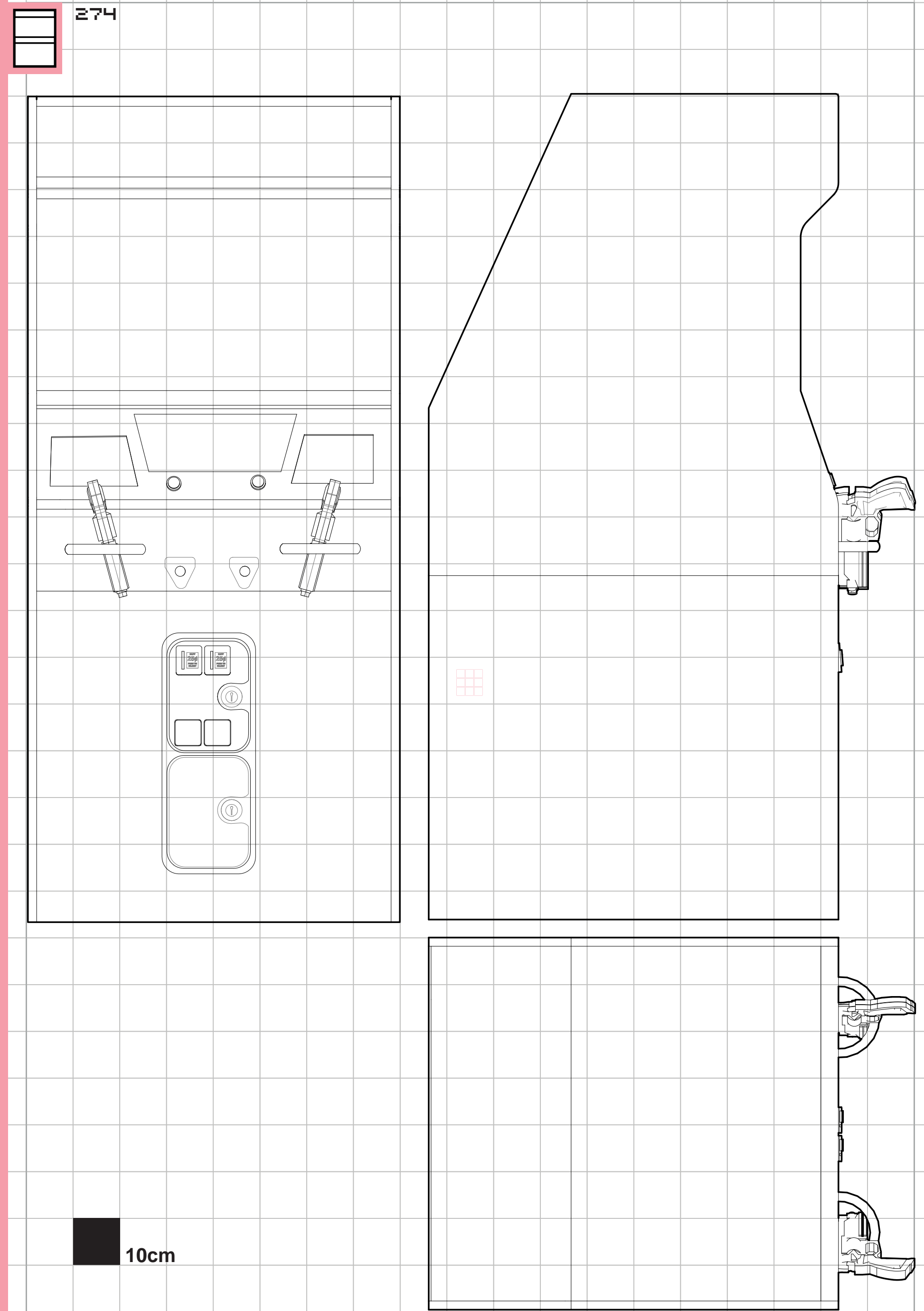


\section{Virtua Cop.}

1994

AM-2(SEGA) arcade.

Máquina arcade.

Máquina de Arcade desarrollada por Sega-AM2 y lanzada al mercado en 1994, cuya versión americana recibió el nombre de Virtua Squad. Esta máquina contaba con un monitor horizontal CRT con gráficos ráster a color, que se reflejaba en un espejo desde el que se visualizaba el juego.

El panel de control estaba constituido por dos pistolas de luz (ópticas), que debían usar dos jugadores diferentes para disparar en el "interior del juego", es decir, apuntando a la pantalla. Tan sólo contó con este modelo vertical clásico.

Este juego contó con una segunda parte, Virtua Cop 2 (1995), y fue portada a otras consolas como la Saturn así como en PC y, años más tarde, incluso el móvil Nokia N-Gage contó en 2004 con una versión.

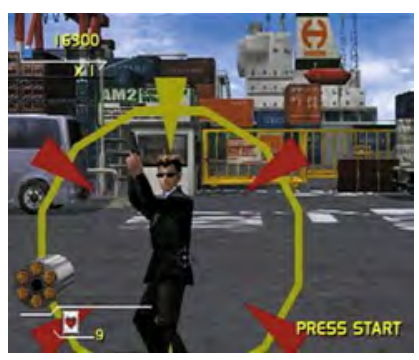

Virtua Cop.

1994

Videojuego del subgénero shooter sobre raíles, en primera persona, en el que el jugador asume el papel de un oficial de policía que debe disparar y detener criminales para avanzar en el juego. Destacó por el uso de gráficos poligonales en tiempo real, siendo uno de los primeros juegos que permitía al jugador disparar a través del cristal de la pantalla con una pistola accesoria. 


\section{$\mathbb{Q}^{207}$}

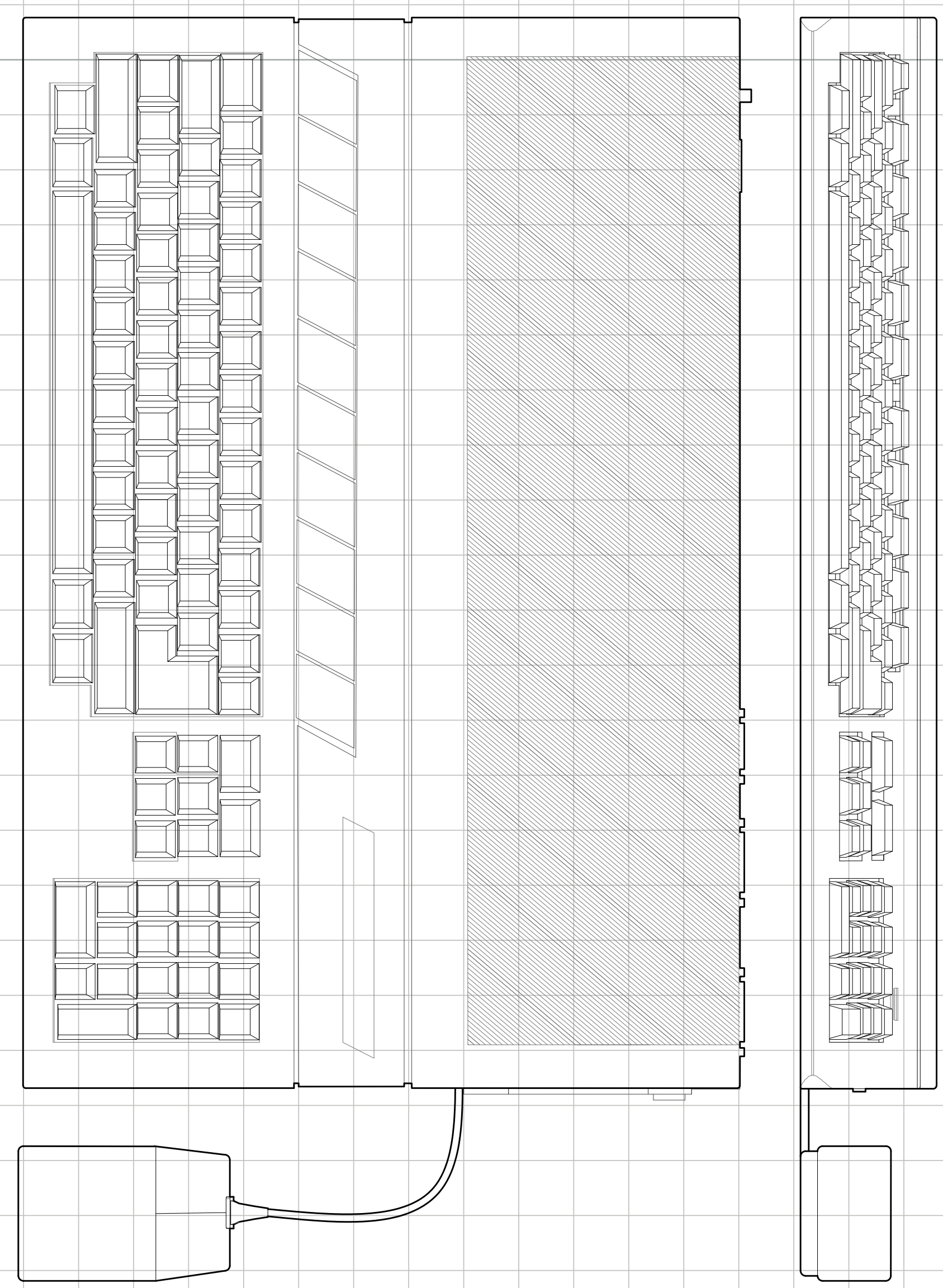

$2 \mathrm{~cm}$

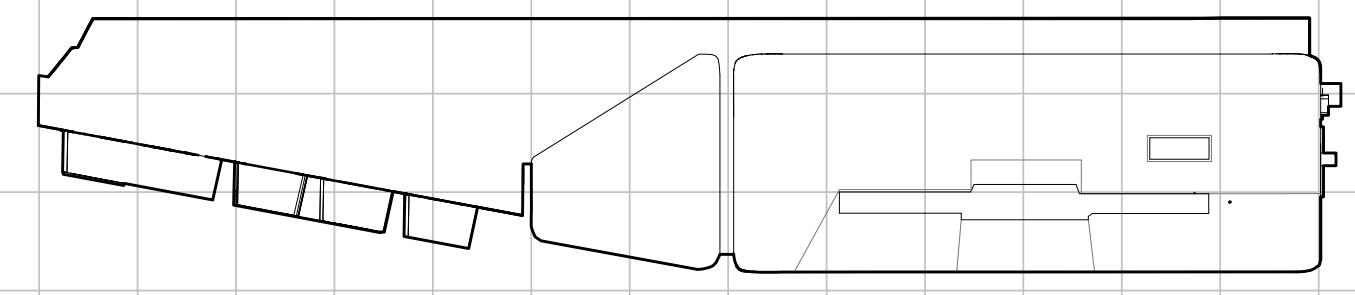




\section{Atari ST.}

\section{5}

Atari.

\section{Ordenador.}

Línea de ordenadores domésticos que sucedieron a la familia Atari 8-Bits. El primer modelo de estos microordenadores, el Atari ST (abreviación de Sixteen/Thirty-two, por sus buses de datos de 32 bits y su microprocesador de 16 bits), salió al mercado 1985.

Este ordenador fue pionero por poseer una interfaz gráfica de mapa de bits en color (GEM de Digital Research). Contó con varios modelos de monitor: dos de doce pulgadas (uno monocromático y otro a color) y otro modelo de 19 pulgadas. Además, disponía de otros periféricos como un teclado y un lector de disquetes. Contaba con un puerto para la conexión del ratón en el que también podían conectarse otros elementos (como joysticks).

"El primer ordenador doméstico compatible con el estándar de música electrónica MIDI [...] El principal rival de Amiga en Europa"

(Donovan, pg 473, 2010/2018)

Este ordenador presentó un éxito inicial, sobre todo en Europa, gracias en parte a su idoneidad para el software de dibujo informatizado CAD, entre otros motivos por su resolución gráfica, los colores que podía mostrar y su interfaz gráfica de usuario (GUI). Se vendieron más de seis millones de copias en el mundo.

La serie Atari ST contó con 17 modelos de 16 bits, tres modelos de portátiles (entre ellos el ST Book) y cinco modelos de 32 bits.

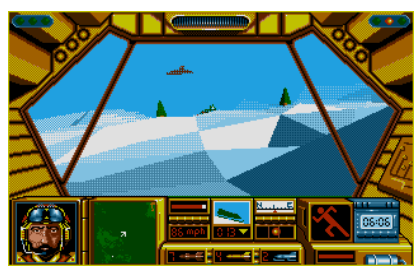

Midwinter.

1989

Videojuego rol de acción en primera persona que sitúa al jugador en un futuro post apocalíptico (2099) en una isla que pasa la mitad del año cubierta de nieve. El juego incluía una novela corta que narraba la historia. El jugador disponía de dos horas para completar una misión de reclutamiento antes de que el tiempo se agotase. Toda la isla se renderizó en polígonos 3D sombreados y la pantalla de juego mostraba, como parte de la interfaz, las gafas de esquí que otorgaba al jugador una mayor inmersión.

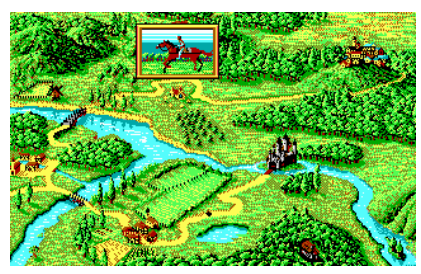

Iron Lord.

\section{0}

Videojuego de aventuras que sitúa al jugador en la Edad Media como víctima de un complot a manos de las fuerzas oscuras, capitaneadas por su propio tío, a las que debe derrotar. En cada etapa del juego el jugador debe responder a preguntas con siete posibles respuestas o interacciones: inventario, discutir, examinar, comprar, dar, bolsillo, salir.

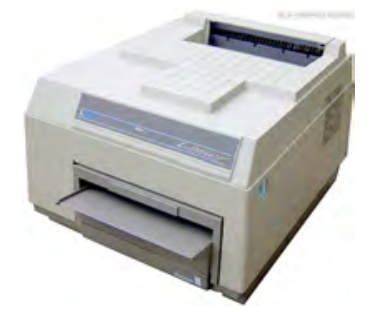

\section{ACCESORIO}

SLM804 Printer.

Impresora laser.

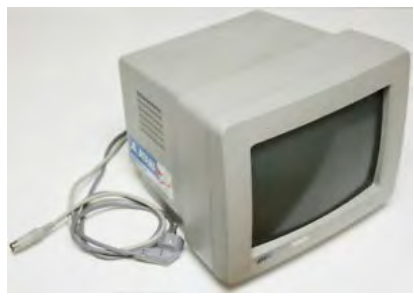

\section{ACCESORIO}

SM124 Monochrome monitor. Monitor que permitía visualizar los juegos en blanco y negro.

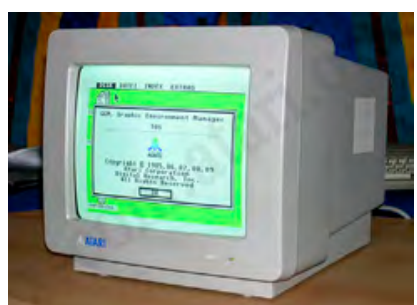

\section{ACCESORIO}

SC1224 Color monitor.

Monitor que permitía visualizar los juegos en color.
Fuente análisis gráfico:

Elaboración propia a partir de los datos contenidos en los documentos originales archivados en archive.org y la consulta a la oficina de patentes de Estados Unidos. №277,795 del 26 de febrero de 1985. 


\section{$\mathbb{Q}^{238}$

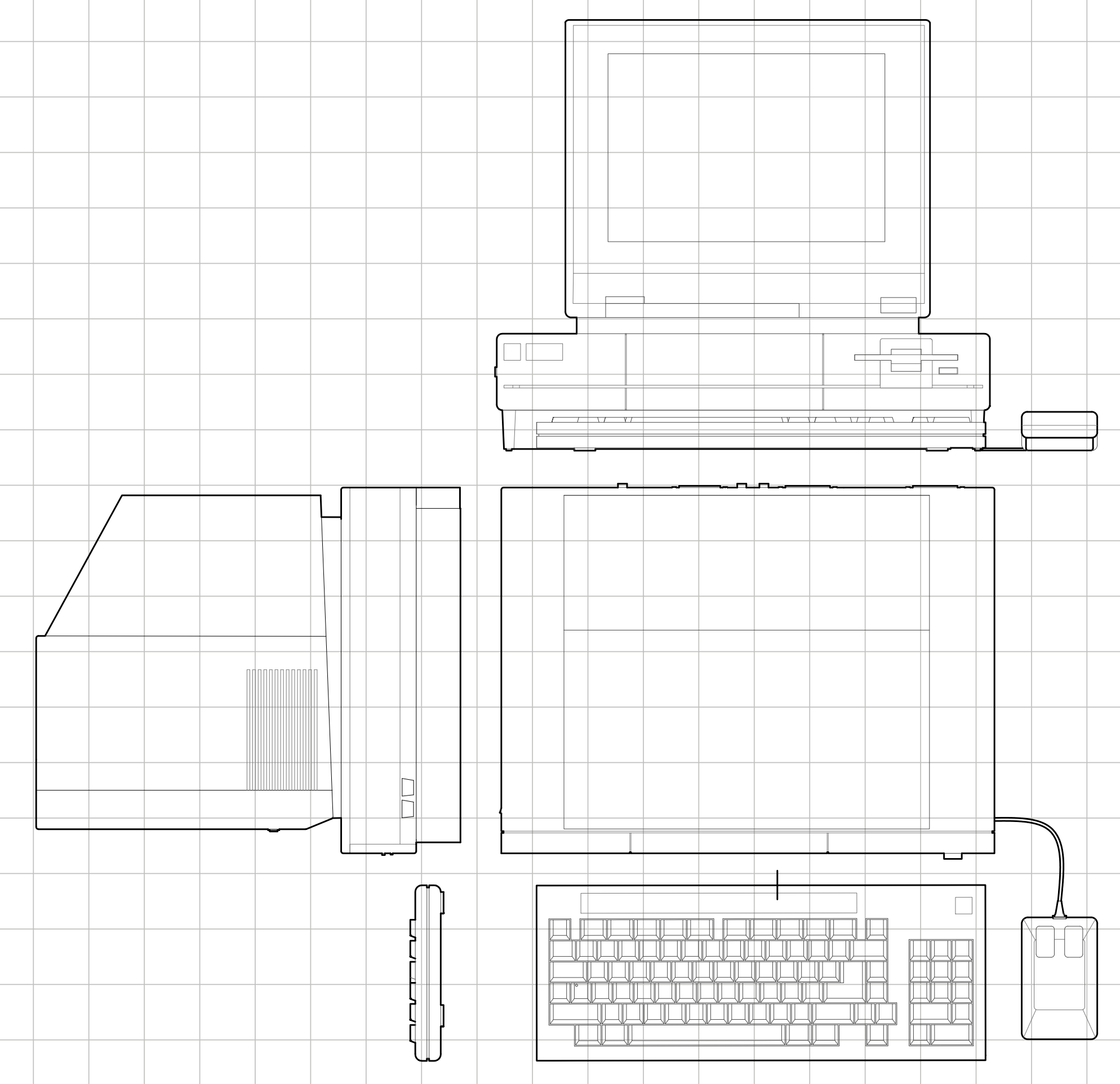



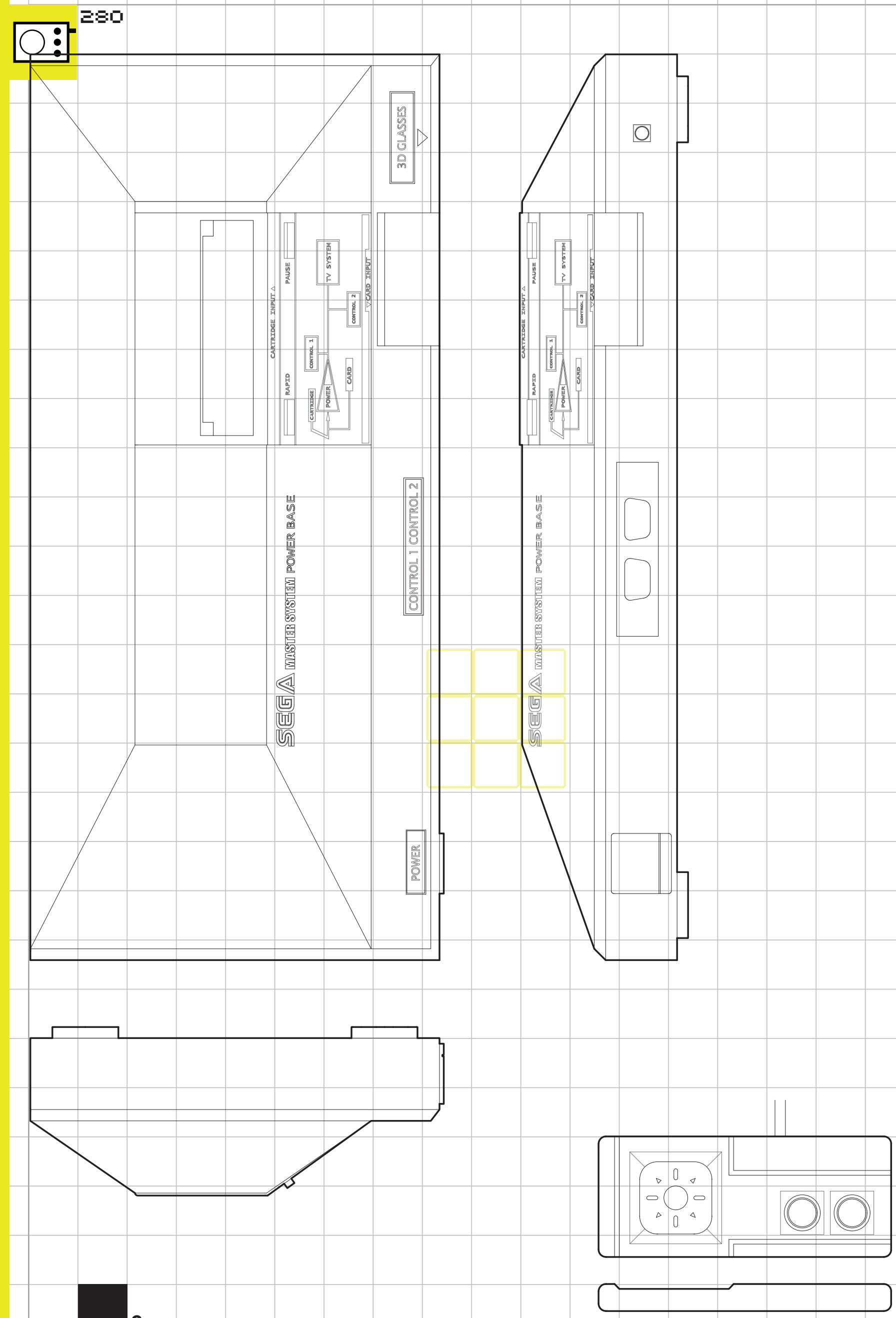


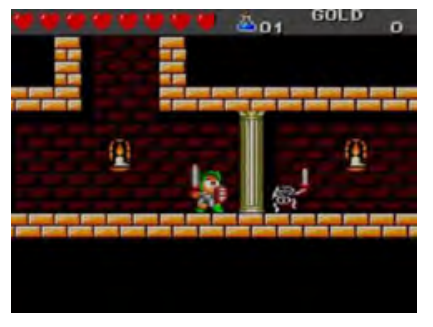

1985

\section{SEGA.}

Videoconsola doméstica.

Consola doméstica de 8 bits lanzada inicialmente en el mercado japonés (bajo el nombre de SEGA Mark III) en 1985, y reestructurada para su venta en América y Europa (donde salió al mercado en 1986 y 1987 respectivamente). Sin embargo, en Estados Unidos no alcanzó demasiada fama comercialmente. Mundialmente se vendieron entre 10 y 13 millones de copias (Harris, 2014).

Su sistema estaba basado en un procesador Zilog Z80A y $128 \mathrm{~Kb}$, casi el doble que la NES (ambas de a tercera generación de consolas). Contaban con chip para los gráficos que permitian una resolución de 256 x 192 pixeles y pudiendo mostrar 64 colores (tan solo 32 colores simultáneos), así como un microprocesado

Esta consola disponía de un sistema de cartuchos y contaba, además, con perifericos como la pistola optica (Sega Light Phaser), unas gafas 3D (SegaScope 3D Glasses) y un trackball para juegos deportivos, entre otros. En Japón, la consola tambien aceptaba juegos en formato de tarjetas de plástico que tenian conectores en el borde y eran mas economicas. Sin embargo, en el modelo de Estados Unidos esto se descartó. El controlador Sega Control Pad tenía una cruceta de PAD y dos botones. Este mando tenía un alcance de 1,55 metros.

"Los controladores [...] eran rectangulares y tenían una cruceta direccional en lugar de un joystick. Sega también fabricó unos pequeños joysticks que se podian acoplar en el centro de las crucetas, en lo que parecía un pequeño homenaje a los sistemas de videojuegos de generaciones anteriores"

(Kent, pg 304, 2001).

Variaciones:

Sega Master system

Segaster system 2 (1987)

Fuente análisis gráfico:

Elaboración propia a partir de los datos contenidos en los documentos originales de la Master System archiva-
dos en The Flyer Arcade Archive. En el caso de la Master System 2, elaboración propia a partir de la consola.
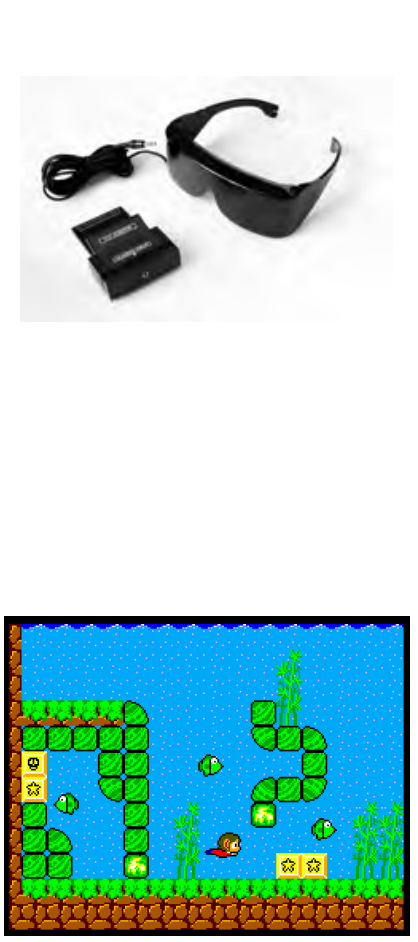

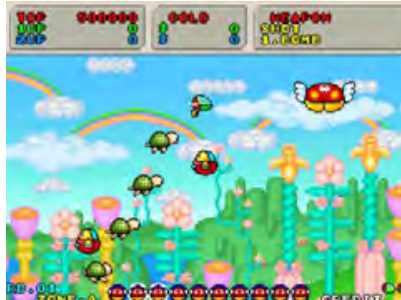

Fantasy Zone II: The tears of Opa Opa.

1987

deojuego de plataformas

desarrollado originalmente

para arcade. La versión para

Master System contiene

niveles amplios y muy dos extra.

uso del color y los sprites.

\section{ACCESORIO}

Periférico que salió

mercado en 1985 cuya

finalidad era convertirse

en una antena que captara

señales de TV y pudiera

mostrarlas en la pantalla.

Debido a las diferencias entre

los canales de entrada de la

TV entre Japon y el resto de

territorios, este accesorio no

pudo distribuirse.

\section{ACCESORIO}

Light Phaser.

Pistola laser que permitía

disparar al interior de la

pantalla desde el exterior. Fue puesto a la venta en 1986.

\section{ACCESORIO}

\section{ACgaScope 3d Glasses.}

Dispositivo en forma de

gafas que el jugador podía

( gráficos de juegos en 3 dimensiones (empleando diferentes velocidades de obturador de forma alterna en lente izquierda y derecha). Fue creado por el diseñador de Marble Madness y lanzado en 1987.

ex Kidd in Miracle World

Videojuego de plataformas protagonizado por Alex Kidd, quien fue la mascota de Sega antes de Sonic, este es su thulo más conocido. Fue un plataformas increible para su época - por el cuidado gráfico, la construcción de Mester System en memoria. System en memoria.

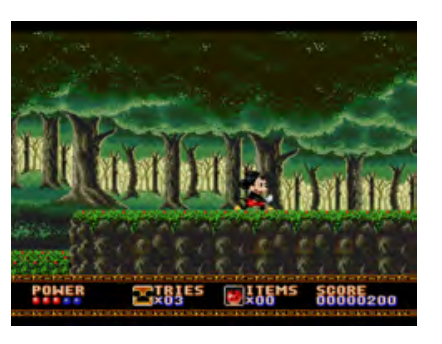

Castle of Illusion Mickey Mouse.

Videojuego de plataformas primero de la saga Illusion de Sega. El jugador controla a Mickey Mouse y debe recorriendo un enorme trampas y jefes finales principal mecánicales. Su en 'rebotar' enemigos. El juego se adaptó a Game Jear sembianó enemigos y gráficos.

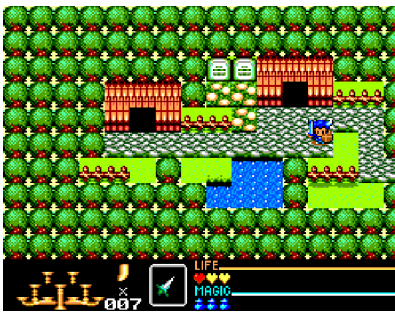

Golden Axe Warrior. 1991

Videojuego de rol y aventura. hacer frente a Zelda de tanto en el que tomo incluso sus diseños en perspectiva egipcia, su mundo mágico abierto y su modo de desplazamiento por el mapa (de pantalla en pantalla).

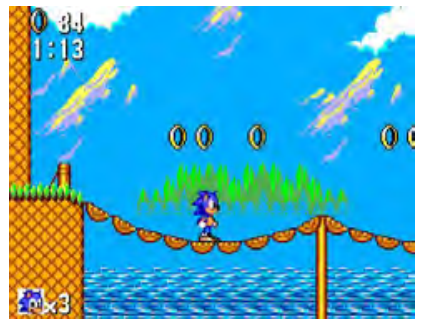

the Hedgehog.

1991

Videojuego de plataformas hedgedog de Megadrive, los niveles originales a las limitaciones técnicas de los 8 bits.

\section{ACCESORIO}

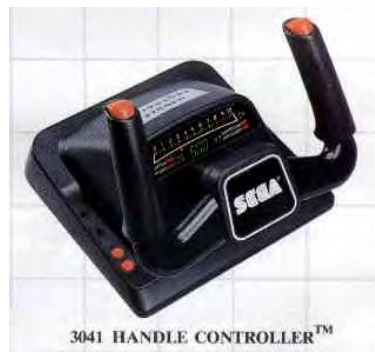

conducción y juegos de

Disponía de dos botones además de un mecanismo de dirección incluyendo a opción de acelerar. Fue publicado en 1989 inicialmente en Japón y solo para Nintendo pero posteriormente fue distribuido por Sega. rescatar a Minnie Mouse Sega lanzo este titulo para Nintendo. Pero se inspiró versión del Sonic the en el cual se adaptaron 

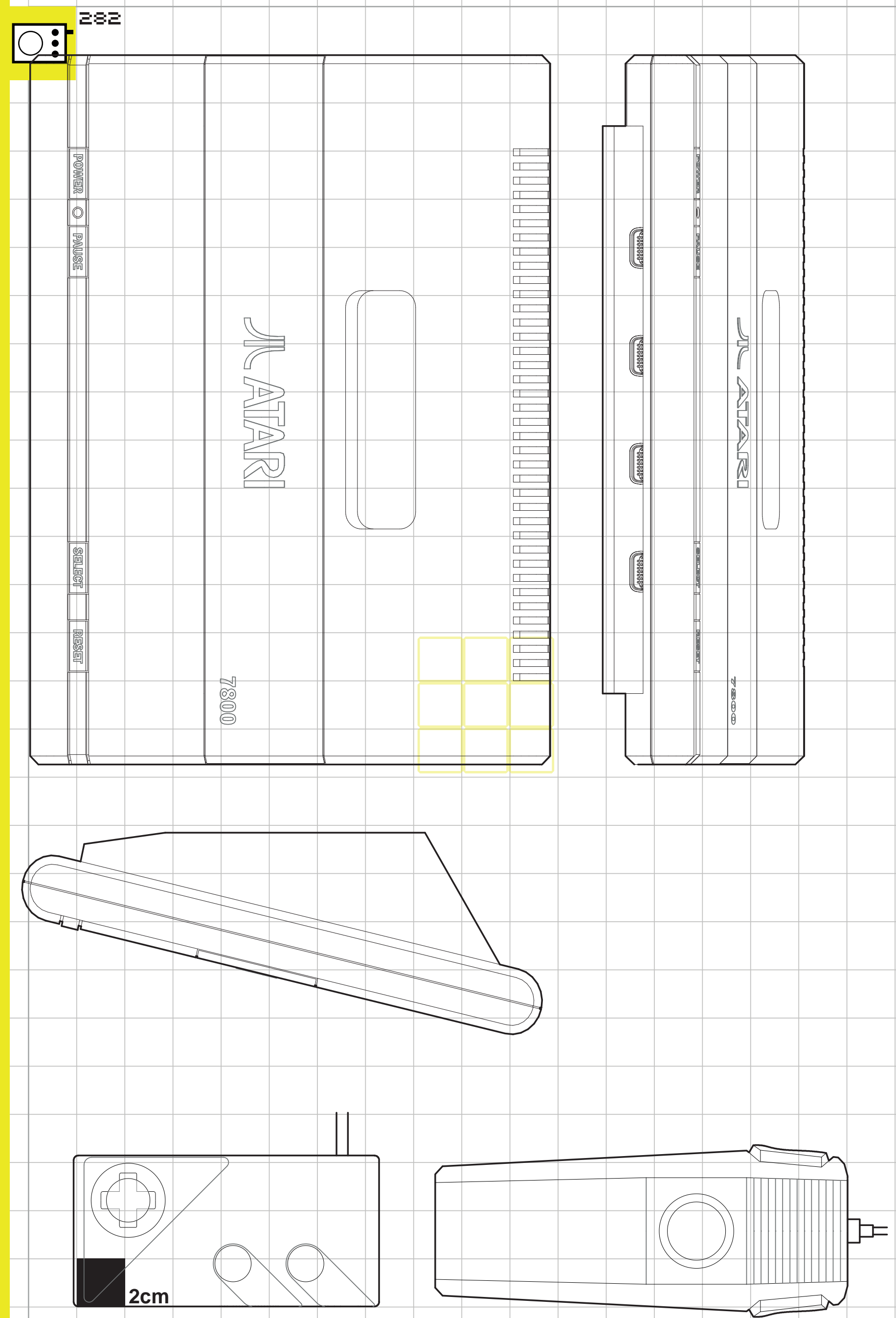


\section{Atari 7800.}

\section{6}

Atari.

\section{Videoconsola doméstica.}

Consola doméstica desarrollada por Atari que se lanzó al mercado en 1984 y en 1986, hasta que fue descontinuada en 1992.

"El primer lanzamiento fue en 1984, pero, cuando Jack Tramiel compró la división de consumo de Atari poco después, la retiraron de la venta. La volvieron a lanzar en 1986 para hacerle la competencia a la NES"

(Donovan, pg 473, 2010/2018)

Esta consola presentaba una mejora significativa en cuanto a hardware respecto a la Atari 2600, aunque mantenía algunas características como por ejemplo el mismo chip de audio.

La 7800 incluía un chip que permitía la retrocompatibilidad con los juegos de la 2600. Incluía un procesador Atari SALLY 6502, contaba con una memoria RAM de 4Kb y dos modos gráficos: el propio de la 7800 (con $320 \times 200,16$ colores de 256) y el modo de compatibilidad con la 2600 (160 x 102, 16 colores de 128).

Los controladores eran de dos tipos: unos que continuaban el diseño tipo joystick y otros que introducían la cruceta direccional tipo PAD. Permitía también conectar un teclado tipo QWERTY.

Pese a la retrocompatibilidad con la 2600 , no se evitó que fuera un fracaso comercial, vendiendo menos de 4 millones de unidades en todo el mundo.

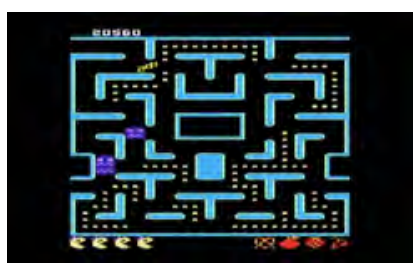

Ms. Pac Man.

1981

Videojuego de tipo laberinto desarrollado originalmente para arcade.

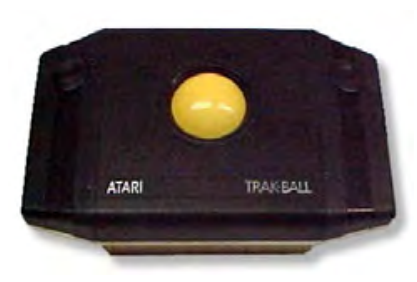

\section{ACCESORIO}

Track Ball.

Controlador con una esfera que servía de botón de giro, permitiendo movimientos de $360^{\circ}$. Seguía la línea de los otros track ball de Atari, tanto en arcade como en videoconsolas domésticas.

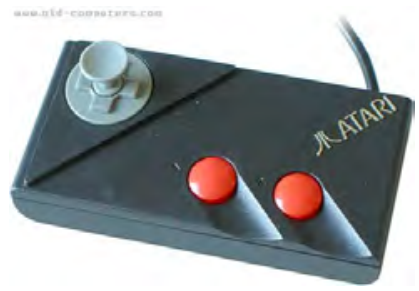

\section{ACCESORIO}

Atari JoyPad.

Controlador en forma de mando con dos botones y un pequeño Joystick que abandonaba el diseño original de Atari, acercándose al propuesto por Nintendo. 

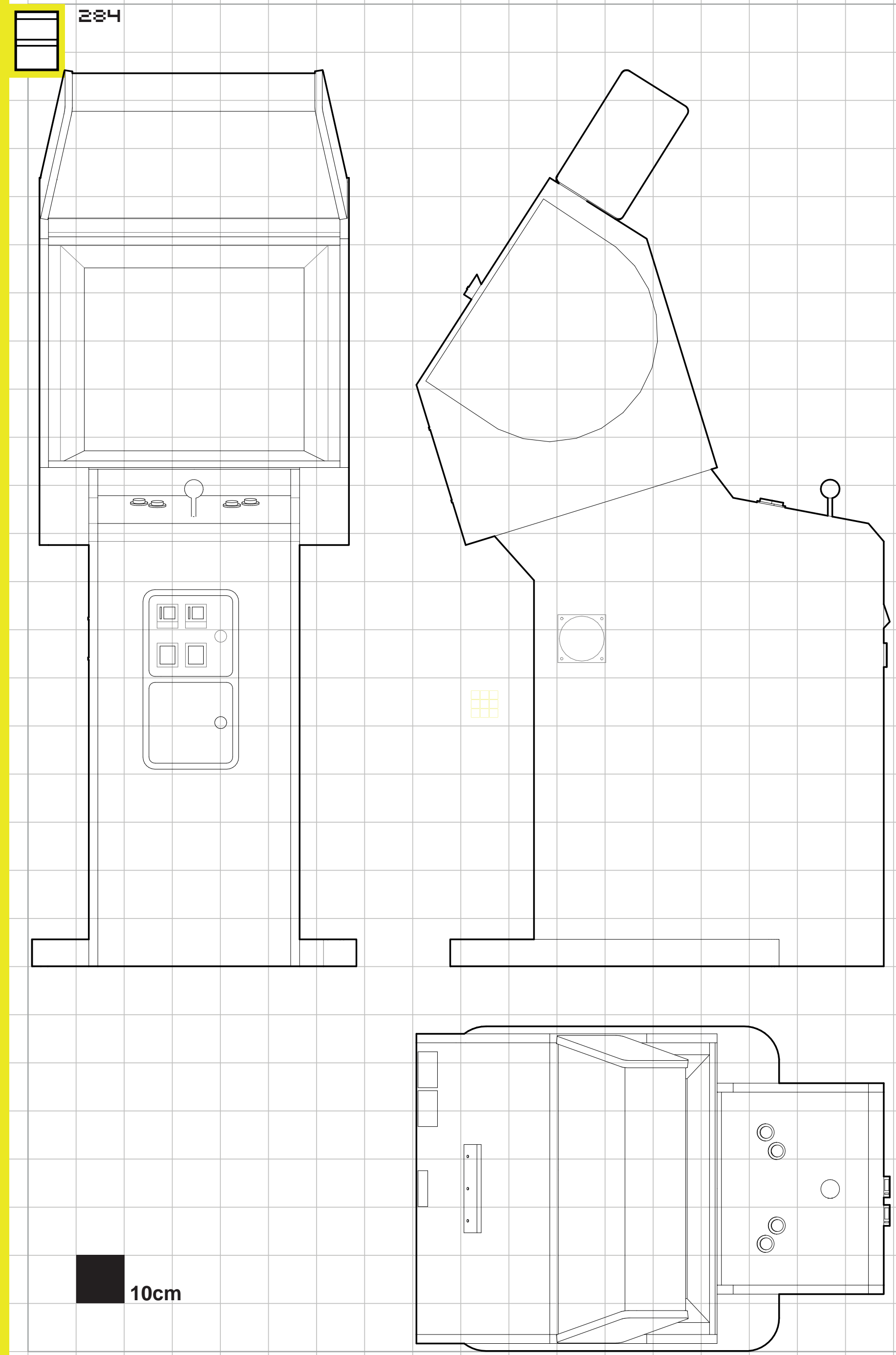


\section{$720^{\circ}$.}

1986

\section{Atari arcade.}

Máquina arcade.

Máquina arcade desarrollada y lanzada al mercado por Atari en 1986. Disponía de un monitor horizontal CRT que permitía visualizar gráficos de tipo ráster en color y una resolución 512 × 384 píxeles. Este arcade contó con un único modelo de cabina vertical (el modelo clásico).

El jugador disponía de un panel de control con un joystick rotatorio circular y dos botones a cada lado (para golpear/patear y saltar). Disponía de un sistema de sonido estéreo gracias a los altavoces montados en la parte superior del frontal de la cabina, similando un boombox.
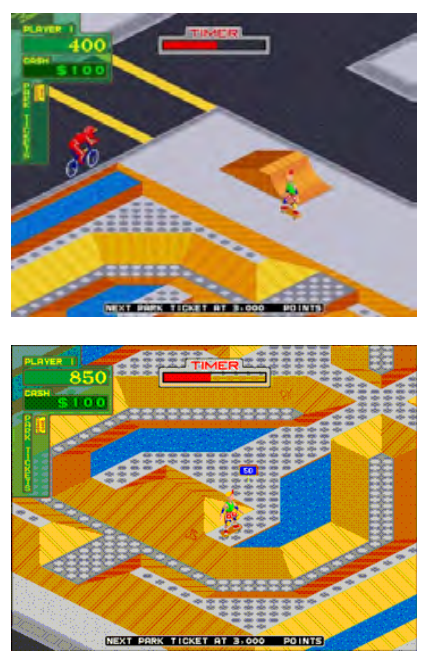

$720^{\circ}$.

1986

Videojuego de arcade deportivo en el que el jugador controla a un skater que patina en una ciudad y que debe conseguir puntos haciendo trucos y saltos. El juego consta de cuatro niveles en un entorno urbano y se considera el primer videojuego de esta disciplina deportiva. 

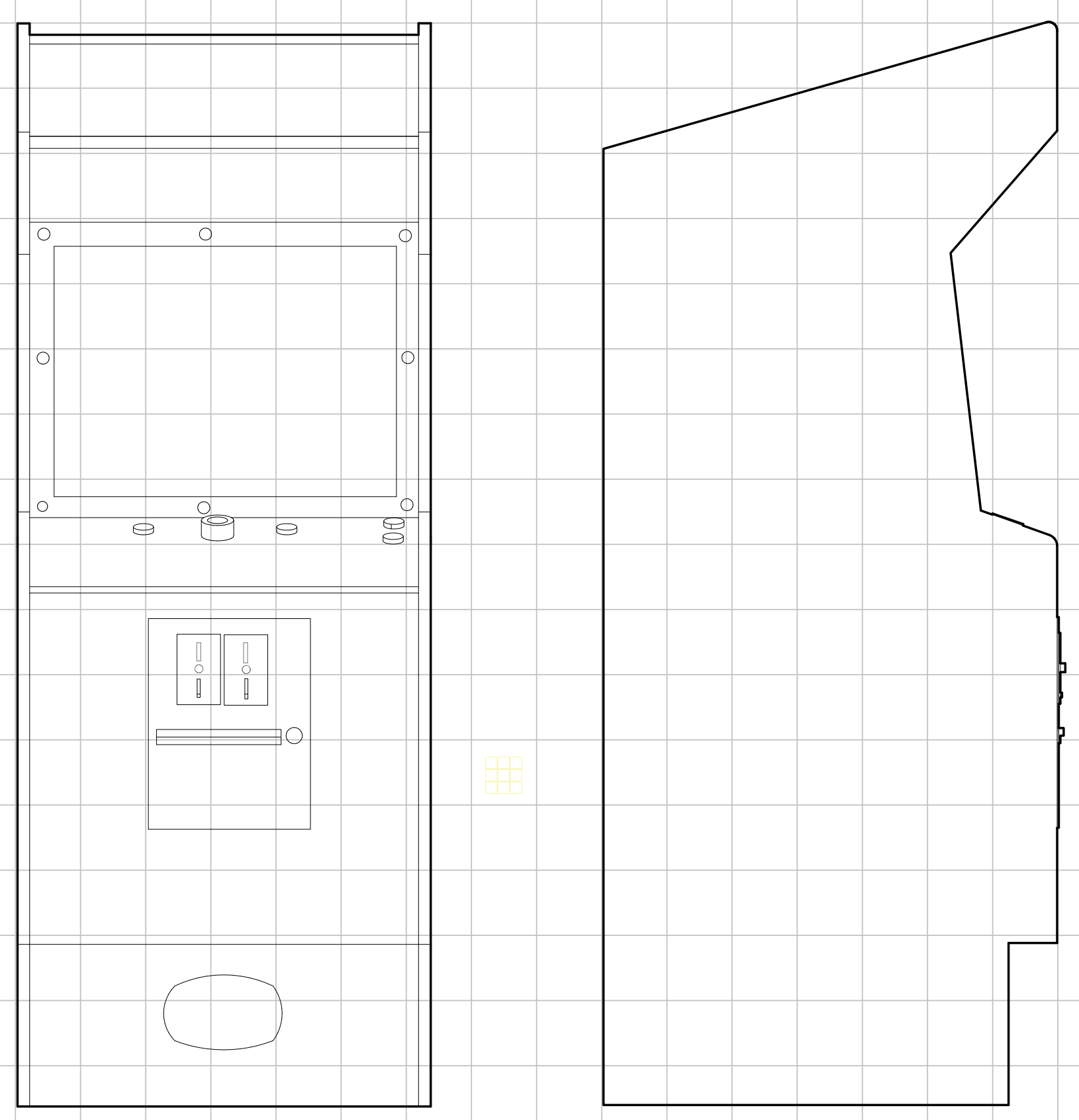


\section{Arkanoid.}

1986

Taito arcade.

Máquina arcade.

Máquina arcade desarrollada por Taito y lanzada al mercado en 1986. Disponía de un monitor vertical CRT que permitía visualizar gráficos ráster en color. Contó con dos modelos de cabina: el clásico vertical y un modelo tipo cocktail.

El jugador disponía de un panel de control formado por un botón rotatorio y un botón a cada lado (para partidas de dos jugadores) con los que podían disparar o soltar la bola. Este juego era una versión actualizada de Breakout de Atari que fue un éxito y terminó siendo una pieza de coleccionista. Debido a su popularidad contó con varias ediciones posteriores: Arkanoid: Revenge of Doh (1987), Arkanoid: Doh It Again (1997), Arkanoid Returns (1997) y Arkanoid DS (2007).

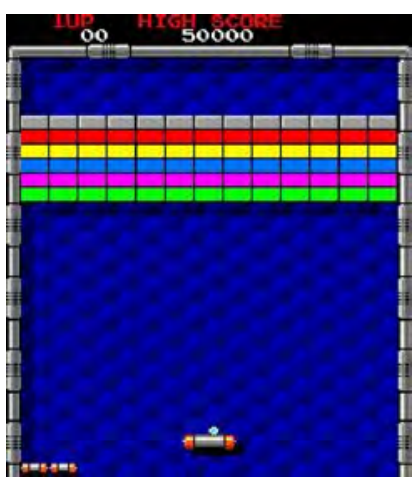

Arkanoid.

1986

Videojuego arcade que expande la idea de Breakout añadiendo potenciadores y diferentes combinaciones de ladrillos, en diseños y capas, que el jugador debe destruir para avanzar al siguiente nivel. 

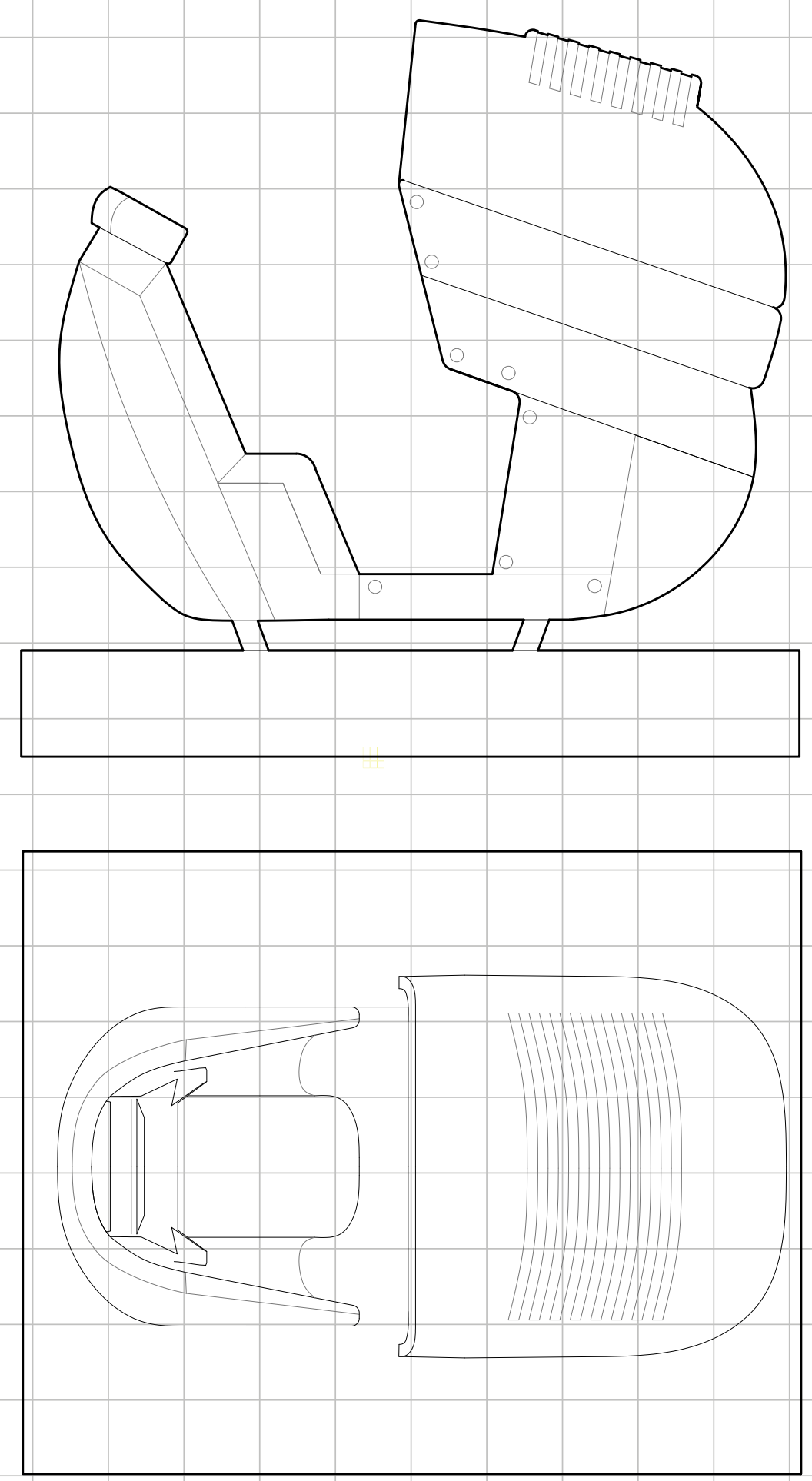
Videojuego de arcade y carreras en primera persona en el que el jugador se convierte en un piloto de

1988

\section{Namco.}

Máquina arcade.

Máquina arcade desarrollada y distribuida por Namco, que llegó al mercado nipón en 1988 y a Europa en 1989. La máquina disponía de un monitor horizontal CRT que permitía visualizar gráficos ráster en color

El jugador disponía de un panel de control formado por un volante, una palanca de cambios que permitía dos posiciones y dos pedales de aceleración y de freno. Esta máquina poseía, además, un asiento integrado que simulaba un coche de carreras. Todo ello se encontraba sujeto a un pedestal a través de una serie de conexión móviles que reproducían el movimiento de la conducción real.

Este arcade cosechó un gran éxito que llevo a dos nuevos juegos: Winning Run Suzuka GP (1989) y Winning Run '91 (1991), ambos títulos lanzados exclusivamente en Japón. 
(2)

$$
\Xi \Xi 0
$$


वाप
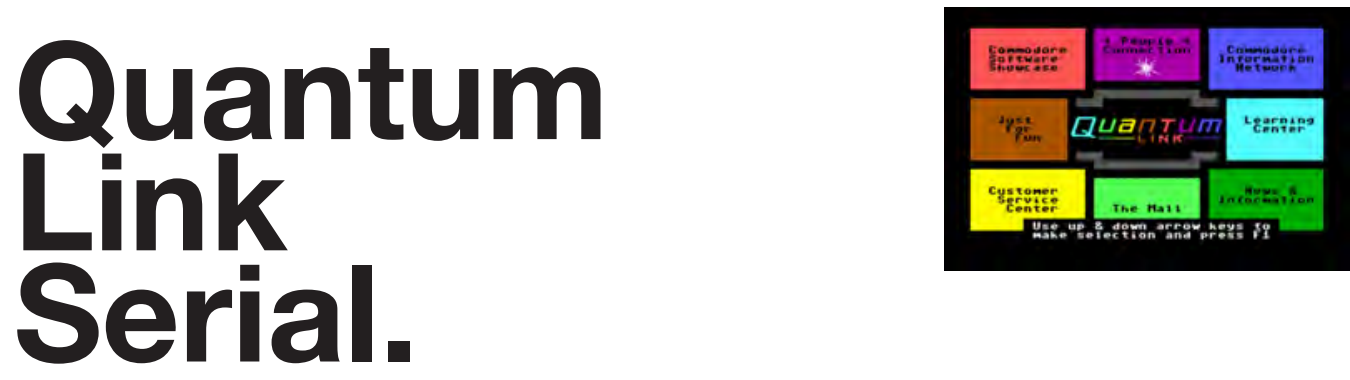

1988

Juego Online.

Obra de ficción por episodios, que podía jugarse a través de chat, correos electrónicos o narrativa tradicional. Después de cada publicación, los usuarios escribían a la autora proponiendo la continuación modificándose las líneas narrativas en cada caso. 


\section{[: ${ }^{232}$}
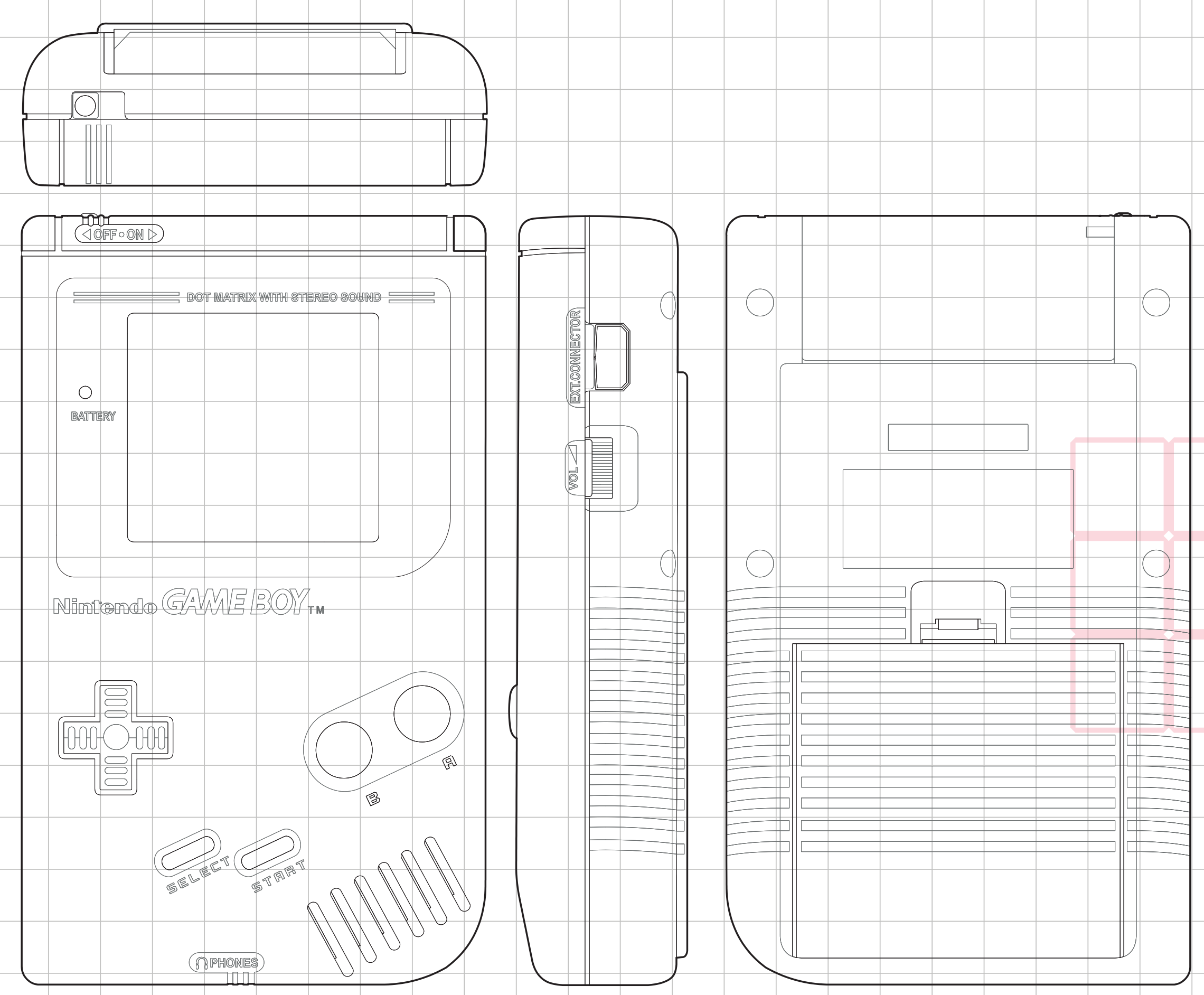

$1 \mathrm{~cm}$ 


\section{Game Boy.} 1989

Juego Online.
Videoconsola portable.

Videoconsola portátili desarrollada y lanzada por
Nintendo y lanzada al mercado japonés y america
no en 1989 , que legaría el resto de los mercados en 1990. Esta consola cosechó un gran éxito, ven-

"Minoru Arakawa, el presidente de Nintendo
of America, realizo una maniobra muy inteligente $y$ decidió usar Tetris como el cartucho
que se lanzo a la venta junto a la Game Boy thy simples que funcionaban muy bien en la pantalla LCD de la consola, y su jugabilididad (Kent, pg 415, 2001)

Esta consola funcionaba por un sistema de video-
juegos en cartuchos (de $2 M B$ ) y poséía una pan-
talla LCD (relación de aspecto 16:9) que tenía una resolución de $160 \times 144$ pixeles y ofrecía cuatro
tonalidades de gris. Disponía de una crucetar direccional de control, dos botones para controlar el

La primera edición, la segunda (Game Boy Light,
sólo en Japón) y la tercera (Game Boy Pocket) eran en blanco y negro (4 tonos de gris). Las siguientes
a partir de la Game Boy Color contaron con gráti-

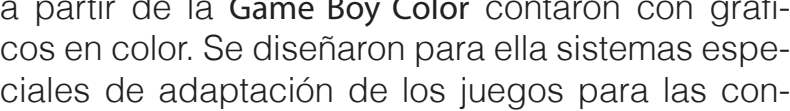
solas domésticas de Nintendo, asi como el cable
Link que permitit conectar varias Game Boy entre
sí para determinados juegos. Destacó también el lanzamiento de la Game Boy
Camera y de la Game Boy Printer que permitian La Game Boy original ten de 15 horas y 30 minutos, la Game Boy Color de 35
horas y 45 minutos, la Game Boy Advance de 29

Game Boy Pocket (1996)
Game Boy Color (1998)

Fuente análisis grático:
Elaborcacion a partir de las consolas fisicas Gameboy,
Game Boy Colory Game Boy Pocket.

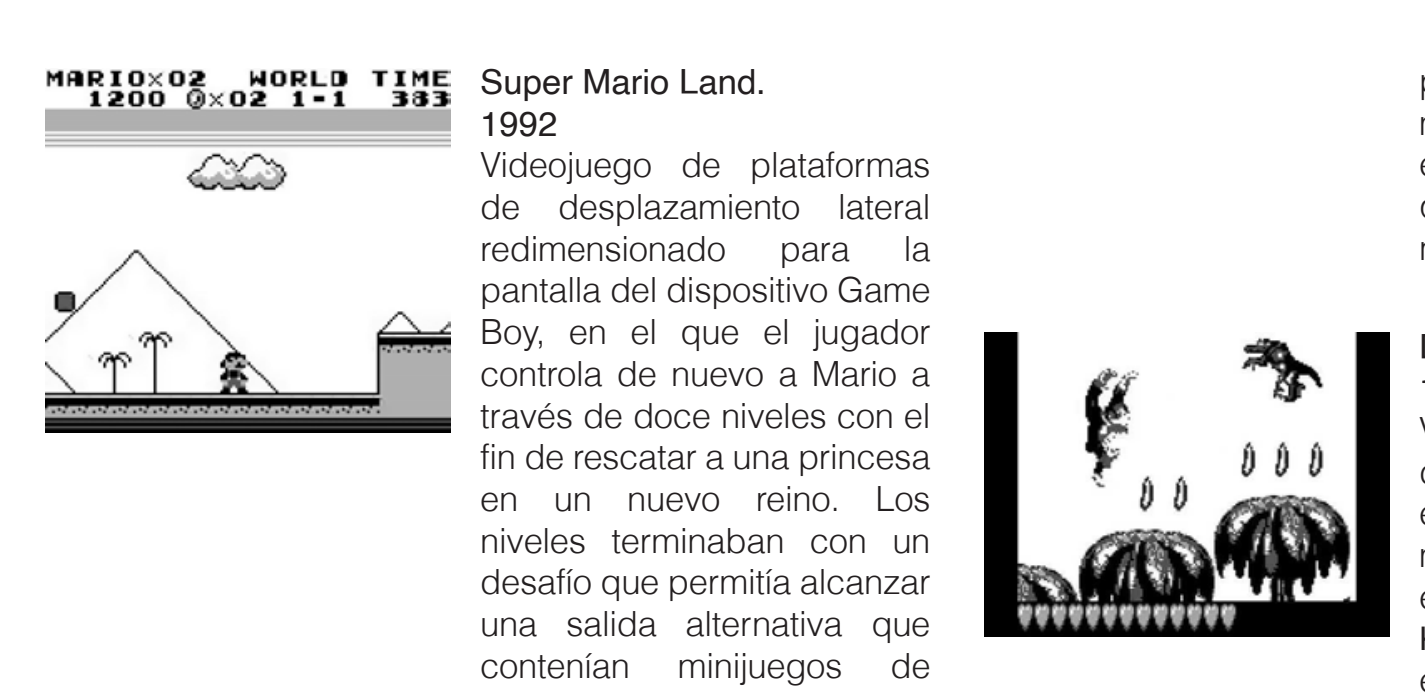

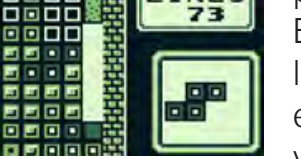

scogido como juego para
vender el kit de lanzamiento un le consola, lo que supuso
un repunte an las ventas de
este software.

$\square+\infty$ \begin{tabular}{l|l} 
ACCESORIO & una salida alternativa \\
Cable Link & contenian minijuegos \\
bonificación extra.
\end{tabular}

astar dos (y posteriormente
hasta 4 ) consolas para que
jugadores pudieran

interactuar, persiguiendo un un cable con nos pouertros de
entrada y salida idénticos. A partir de la Game Boy Pocke adaptador. Salí́ al marcado
con la aparición de la Game

The Legend of Zelda: Link's

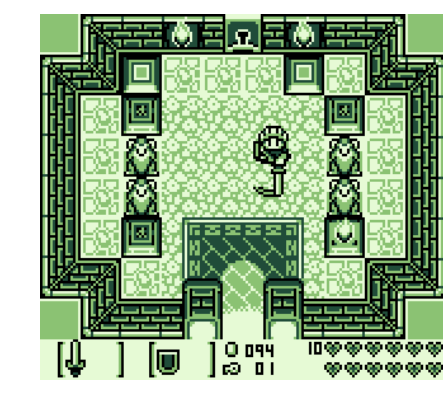

Videojuego de acción y
aventura en el que el jugador,
L nuevo en el papel de Link.

cebe resolver una serie de
uzzles para rescatar ocho
nstrumentos musicales de una isia en la que se nouentra atrapado para
poder escapar. El juego se Hediuk, visualizando los
Heles, en scroll lateral. se incluyeron misiones secundarias que permitian
encontrar zonas ocultas del una referencia especial a aprender el luso de la ocarina
enlazando con el siguiente Durante la promoción de luego, Nintendo America
pago un tren que cruzaba
el pais seleccionando los suberes jugadores para que
subieran a bordo y jugaran. duración de mostrar la las de la
dame Boy.

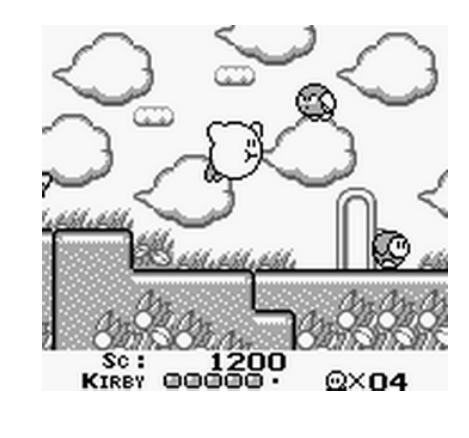
Kirby's Dream Land
1992

Donkey Kong Land.
1995

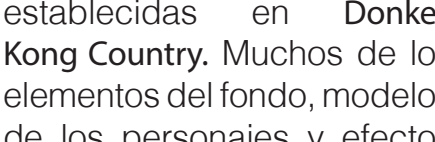
de sonidodo se transsiriereron
la versión de SNES, lo que

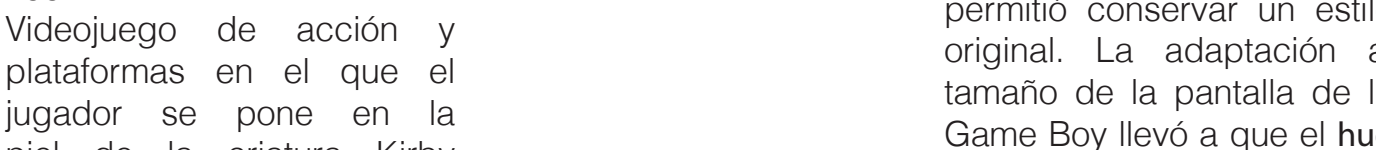
recolectaba
recibía daño

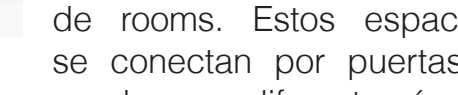

8
8
8
8 Pokémon Azul, Rojo y Amarillo. conducen a difierentes áreas a espacios alternativos.
juego carece de la funcion juego carece de la tunc
de guardado pero una vez
acabado el juego se oftef

deojuego RPG de acción
aventura que pone a
ygador en el papel de un
nno que quiere convertirse un código para aumentar la

en maestro Pokémon y debe
vivir una aventura a través
de un extenso mundo.
elemento thave del pegog es

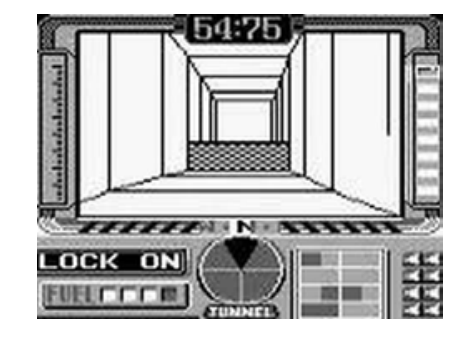

(992

Videojuego de simulación de
combate espacical en primera elemento clave del juego es
la exploración espacial que os Pokemon. El videojuego egipcia y los cartuchas
originales contenian ciertos
glitches que permititian llegar glitches que permitian llege
a espacios no contemplados del juego. de crear un juego en $3 D$
para Game Boy. El jugador
asume el papel de una nave espacial que debe proteger
el planeta Tetanus de una invasión alienigena. Además,
el jugador posera un radare n
la parte inferior de la pantalla que mostraba su ubicación

目

ACCESORIO

Dispositivo térmico au

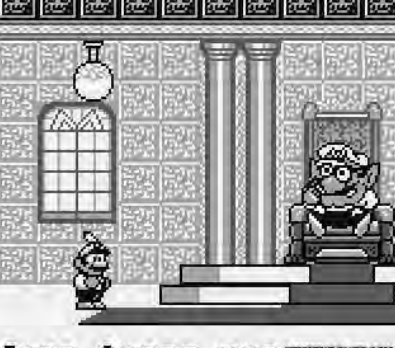
$\begin{array}{lll}\text { Super Mario Land } 2 . & \end{array}$

ACCESORIO

que supone la continuación
de su predecesor y también
la aparición del antagonsita

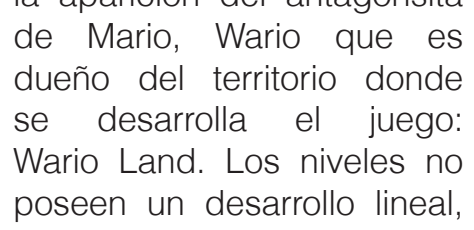

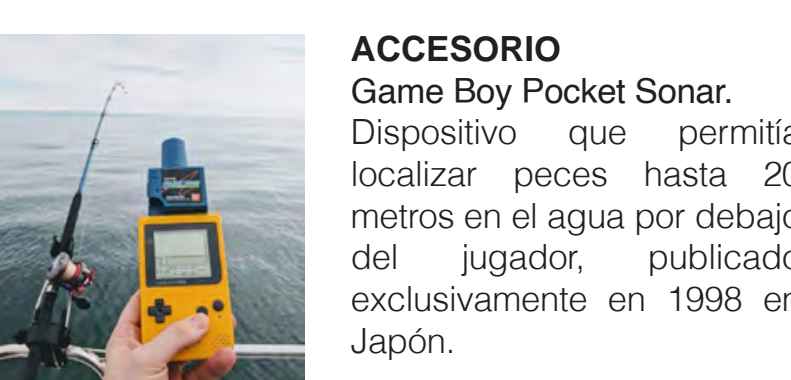
Weojuego de platatorm
desplazamiento later
$2 \mathrm{D}$ que toma prestada
chas de las mecánicics

permitia imprimiri la pantalla
de la Game Boy $y$ fue
publicado en 1998 . permitiendo al jugador
moverse por el mapa y
escoger los niveles cue
quiera (incliyyendo también
niveles ocultos)
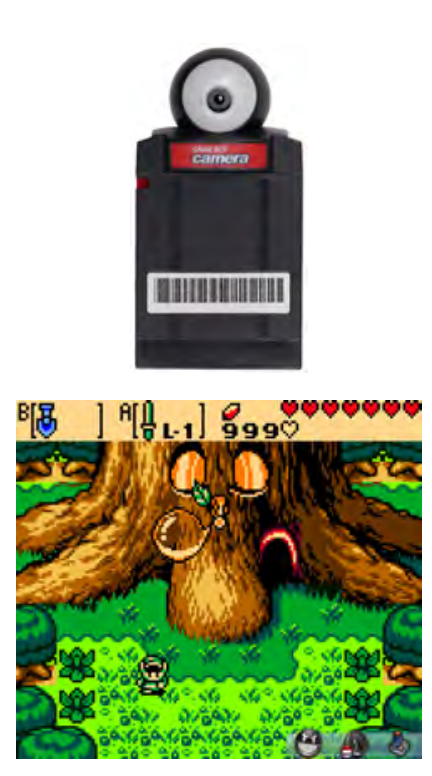

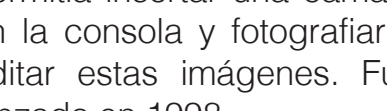

The Legend of Zeltho
Ages \& Seasons.

1998
Videojuegos de acción y
aventura (en perspectiva
egipucia) que interactuaban
entre ellos mediante el cable
link y un sistema de codigos.
Ambos

Ambos juegos presentan
un color mas brillante para

uno de los juegos aparece

un código secreto que

en el otro, desbloqueando

eventos y jugando cont
fees especiales al final

el mundo está compuess
por dos partes: una

unicas por portales.
Oracle of Ages el dualismo
da ente

da entre presente y pasado
conectados por agujeros

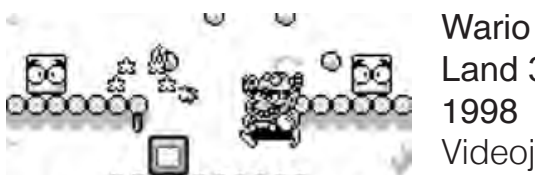

- goroco0008

8.

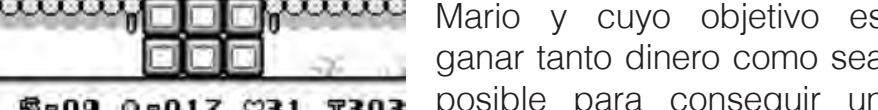

posible para conseguir
gran castillo y competir con
Mario. A diferencia de Mario

Wario posee movimientios
más brutules y contundentes

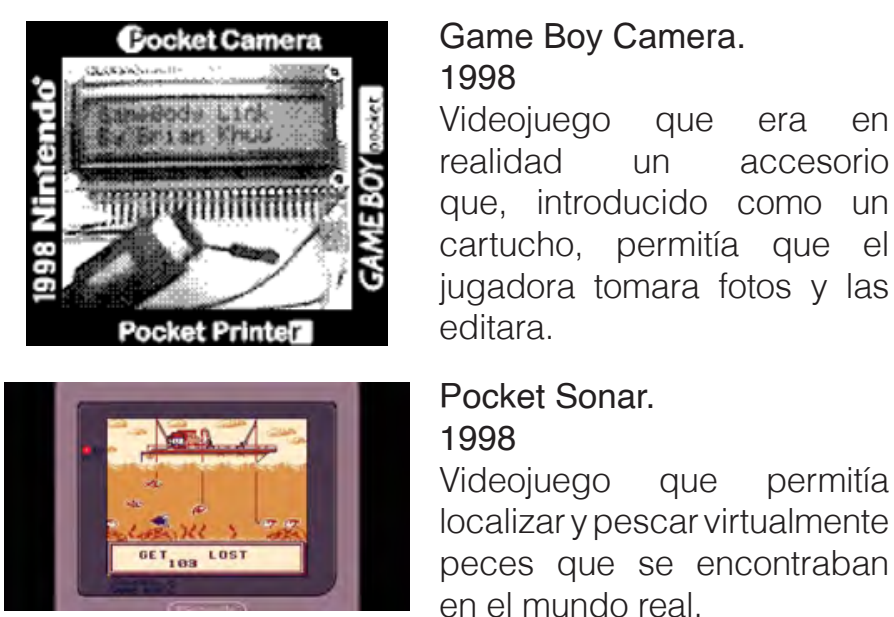

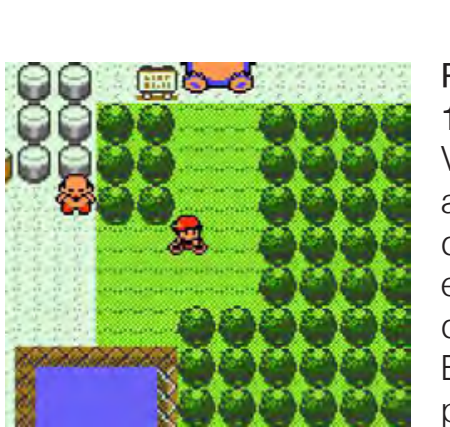

escoger la hora de

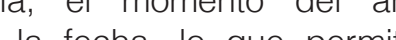

la semana también
partida Pokémon Crista

we el primeror que, permititi

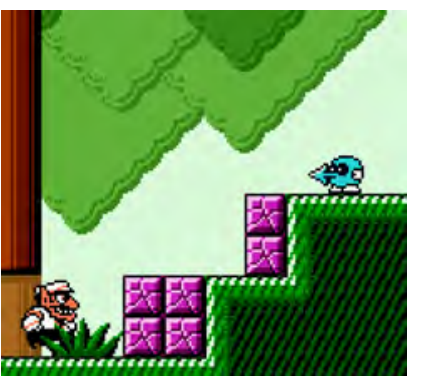

Wario Land 3

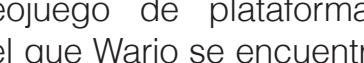

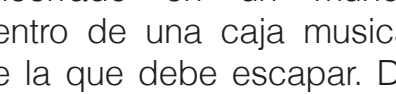

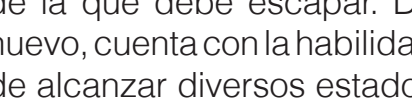

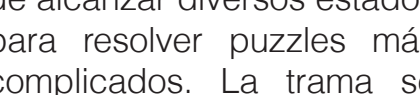

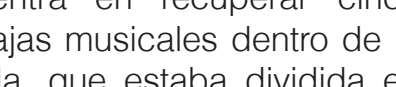

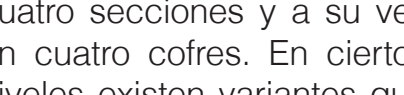
niveles existen variantes que
permitin entrar a z zonas que
antes no se podia 


\section{$0:{ }^{234}$}

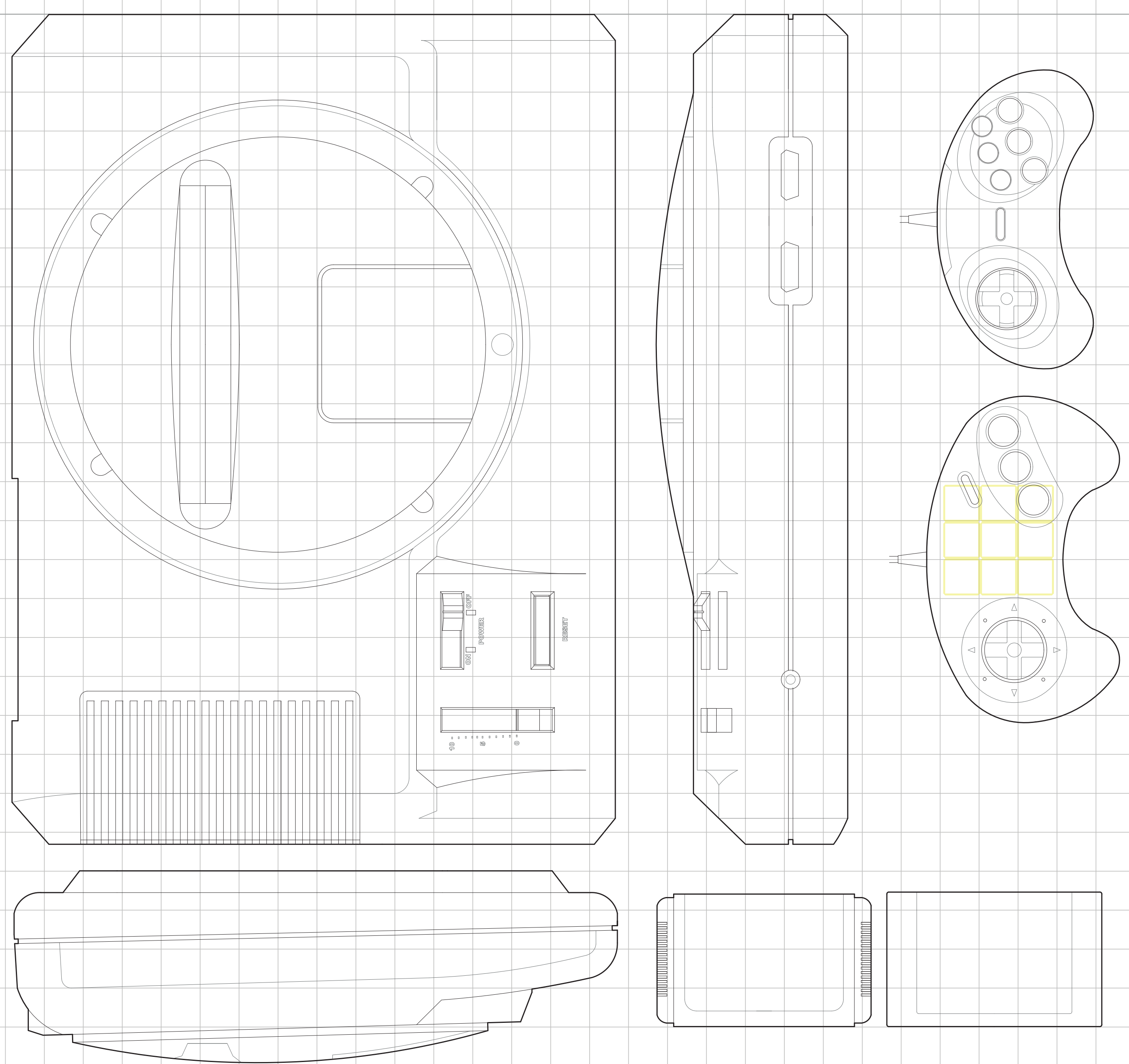




\section{Sega Megadrive.} 1989

Consola doméstica de 16 bits desarrolladay lanzada
al mercado por SEGA. Llego al mercado nipón en

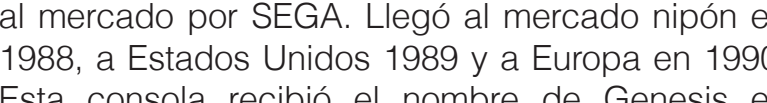
Esta consola recibió el nombre de Genesis en
Estados Unidoso. Pertenecia a la cuartra generación
y compitió con la NES en el mercado (Harris, 2014)

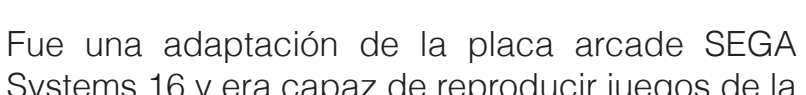
consola Master System a través del Master System
Converter. Esta consola fue la responsable de la guerra entre SEGA y Nintendo, llegó a vender Existieron dos versiones, la segunda de un tamaño
más reducido. Ambas consolas contaban con dos controles con cruceta direccional, uno de ellos

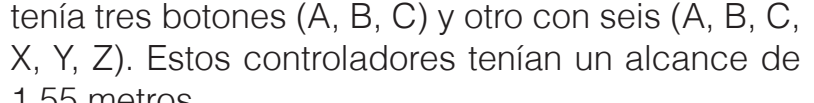

Disponía de un procesador principal Motorola
68000 y uno secundario Zilog Z80. Podia mostrar en un total de 512 . Poseía una memoria RAM de $64 \mathrm{~Kb}$, con una memoria para video y otra para
sonido. La capacidad de los cartuchos varió desde La consola dispuso de un gran número de
accesorios, entre los que destacan la pistola de luzz
Menacer, un joystick propio y dos ampliaciones la

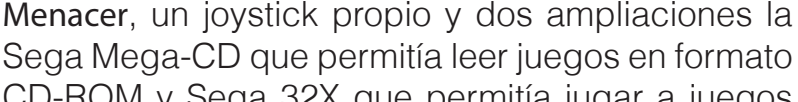
en 3D. Existió una versión portable conocida con el
nombre de Sega Megajet que respondía a una colaboración con Japan Airlines y permitía a los
viajeros emplear juegos trálos dosdde su propia
casa durante el vuelo, seguía requiriendo pantalla, Variaciones:

Sega Megadrive 2 (1993)
Sega Mega Jet (1993-Portable)

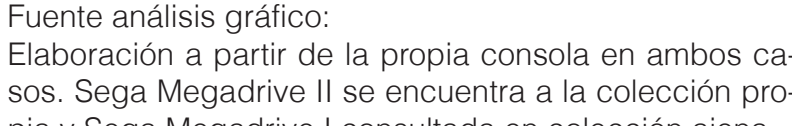

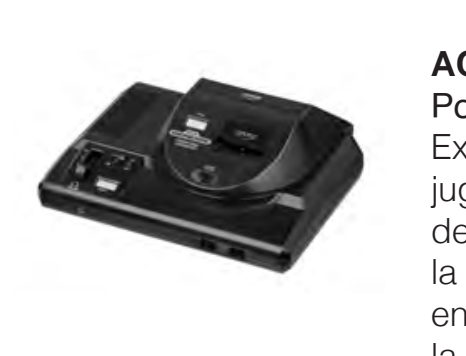

Stensión Conser

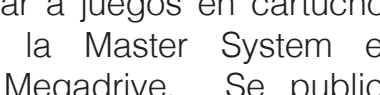
1989 y aprovechaba consolas (la Megadrive es
una version mejorada de la

ACCESORIO

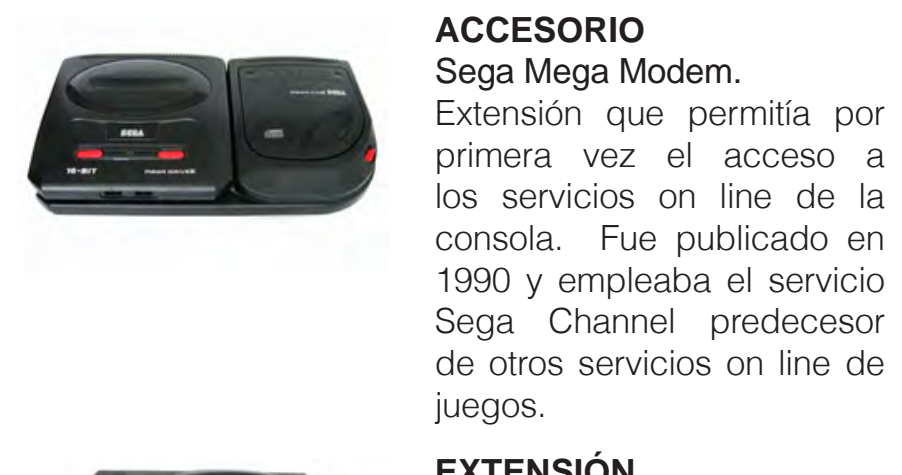

EXTENSIÓN
Sega CD

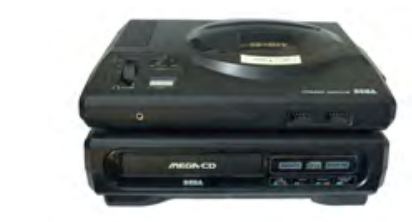

lectura
de
jumegos
almacenados en CD-ROM Fue publicado en 1990 , es
considerado en si mismo una consola por el avance
tecnologico que supuso.
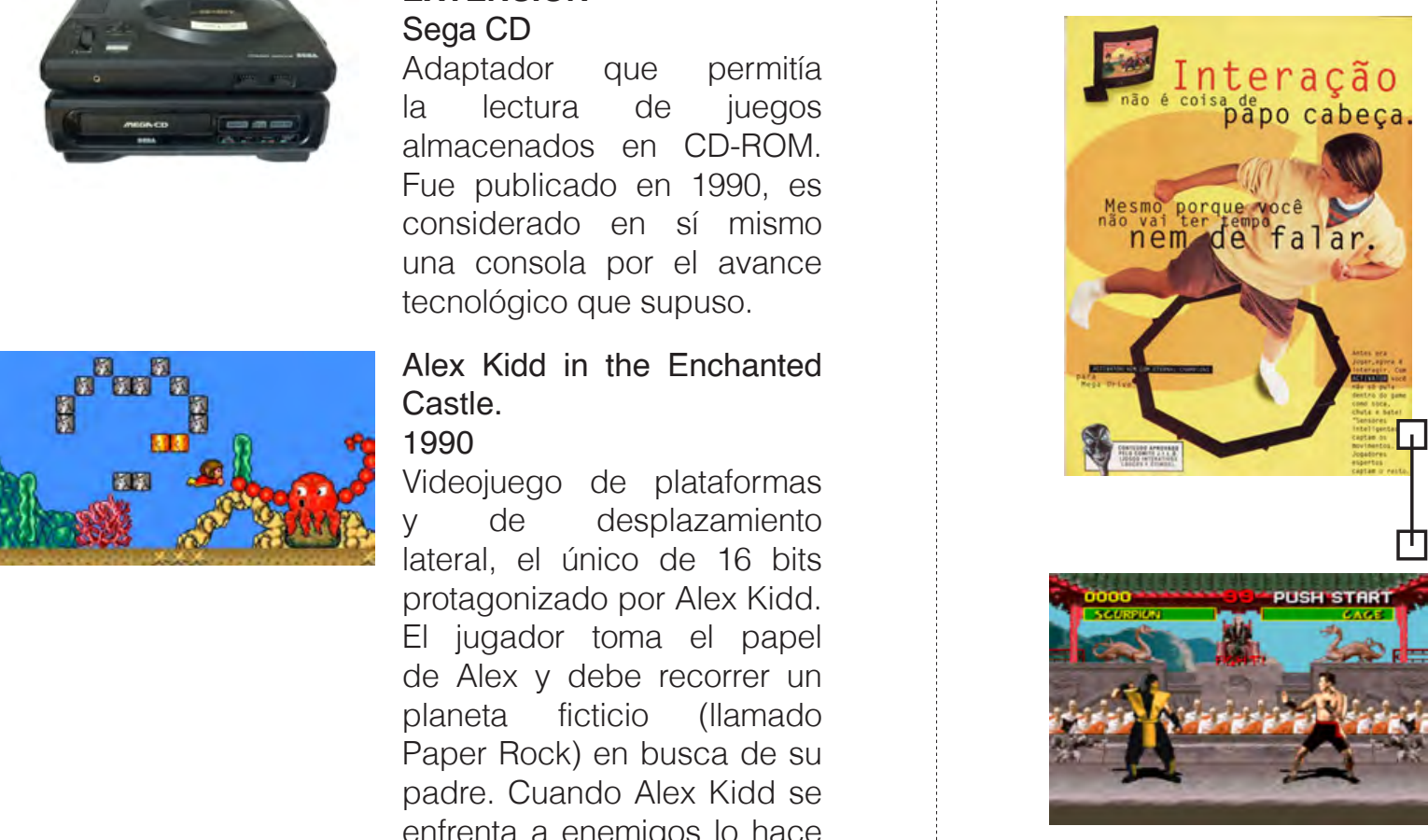

Videojuego de plataformas
de desplazamiento y de desplazamientio
lateral, el unico de 16 bits
protaconizado por Alex Kitd El jugador toma el pape planeta
Paper Rockicio (Ilamado en busca de su enfrenta a enemigos lo hace
través de "piedra, papel Videojuego de platatormas
que istua al jugador en el
ape

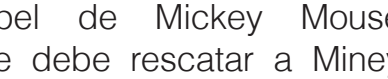
Mouse. Forma parte de una
arga saga de videojuegos,
conocidos como "lllusion".

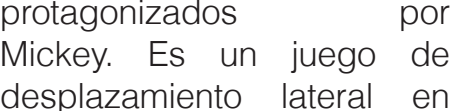
el
encontrar siete gemas dentro
de varios mundos de fantasia.
Sega Activator.
Extensión con forma
corla

octogono de piezas conectadas
que permitia a un juador
colocadons

el interior

ello sensorers de deletección de

movimientio. Fue publicado en
1993 y utilizado en numerososos

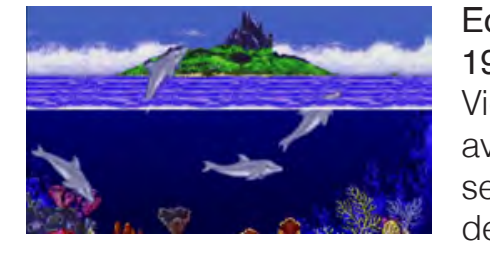
EE juego se fragmentiaba

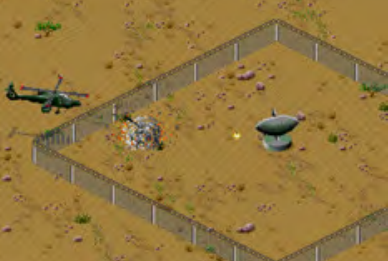
vegos de lucha

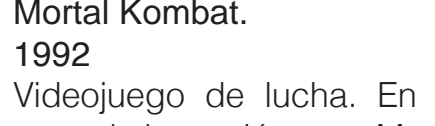

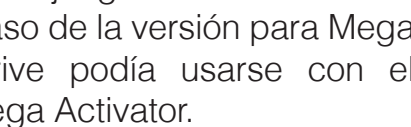

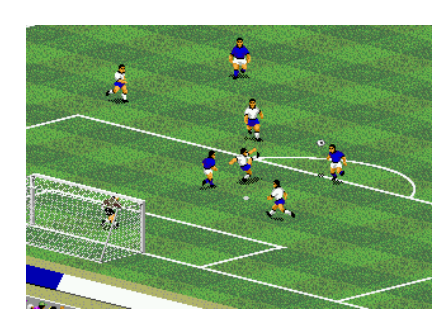

"2010

CCESORIO

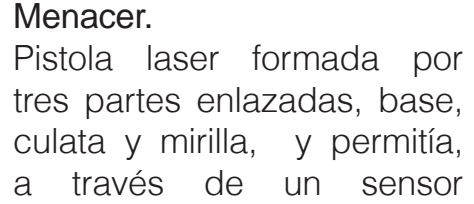

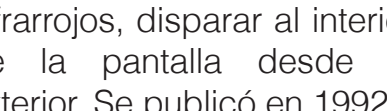

(0) 010
000.
exterior. Se publicó

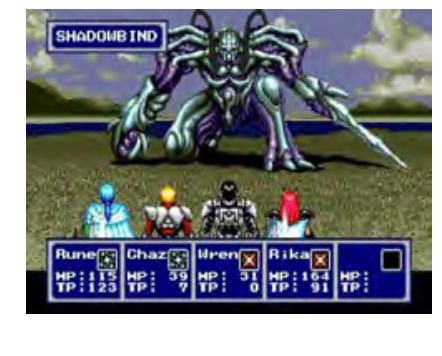

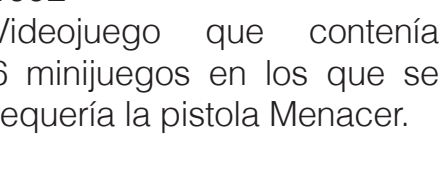

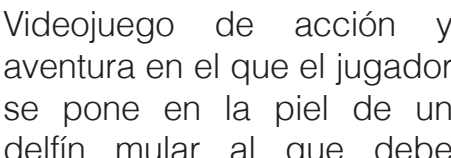

guiar a través de laberintos
horizontales en difierentes

con objetos $y$ personajes.
Contenía acertijios de elevada dificutad ys sestuaba en una
lematica de ciencia ficción.

Desert Strike: Retur to
Gulf. 1992

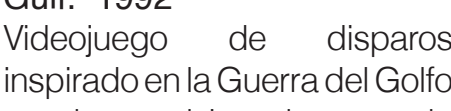

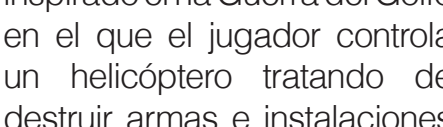

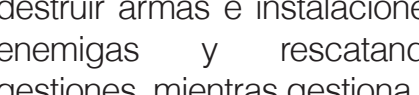

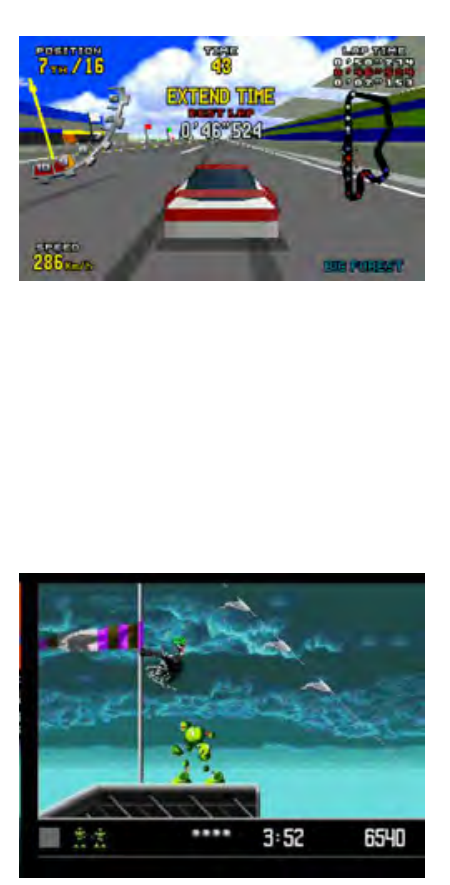

para Megadrive incorporó en
el cartucho un chip gráfico sor que consegula

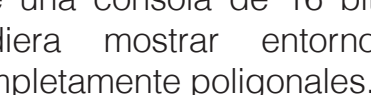

vectorman

Videojuego de platatarmas

embarca en un viaje espacia
en busca de otro planetas
habitables. El juego utiliza

modelos $3 \mathrm{D}$ renderizados

sensación de formas limpias
generadas por ordenador Se trataba de un juego
platatormas en dos

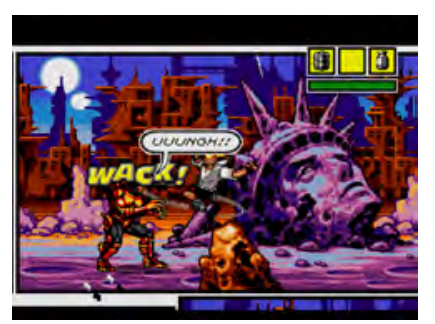

Comix Zor

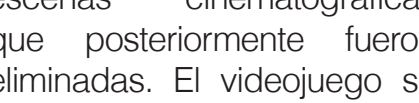
generó una inconsistencia Fifa
1999
Vide
tuito
lat as
su
su
o do que permite emplear un un estilo de dibujo dinámico un dibujante de cómins a
medida aue avanza por las vinetas paraescapar antes de
que sus propias creaciones diferenciaba de los otros
titulos que ofrecian una vista Phantasy Star IV.
1993

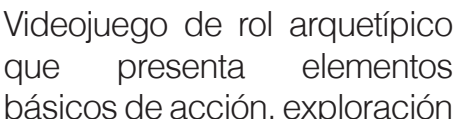
básicos de acción, exploracioín
ys combate por turnos. A ilustraciones de paneles $x$
estilo manga que acompañan astilo manga que acompaña desarorolada guión. El Ijugador
se pone en la piel de un jover se pone en la piel de un joven
cazador que se enfrenta a una
crisis eccológica en en platentat

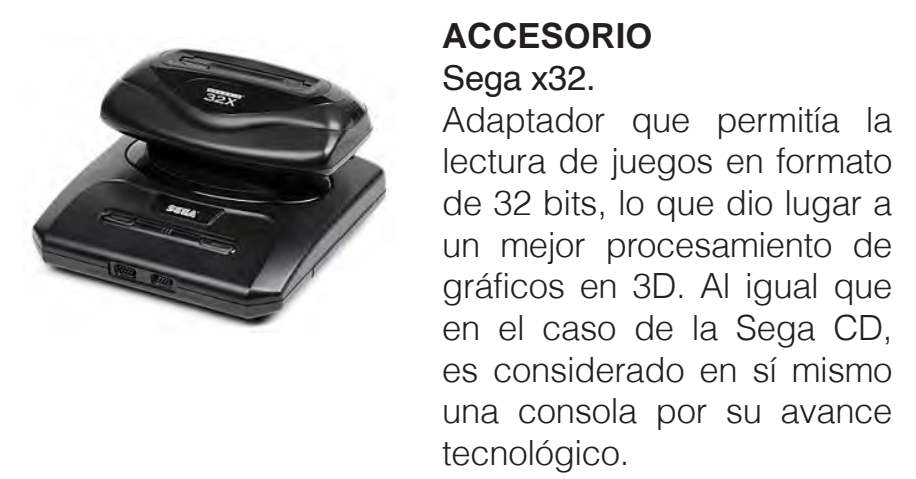

una consola por su avance 


\section{圆 ${ }^{208}$
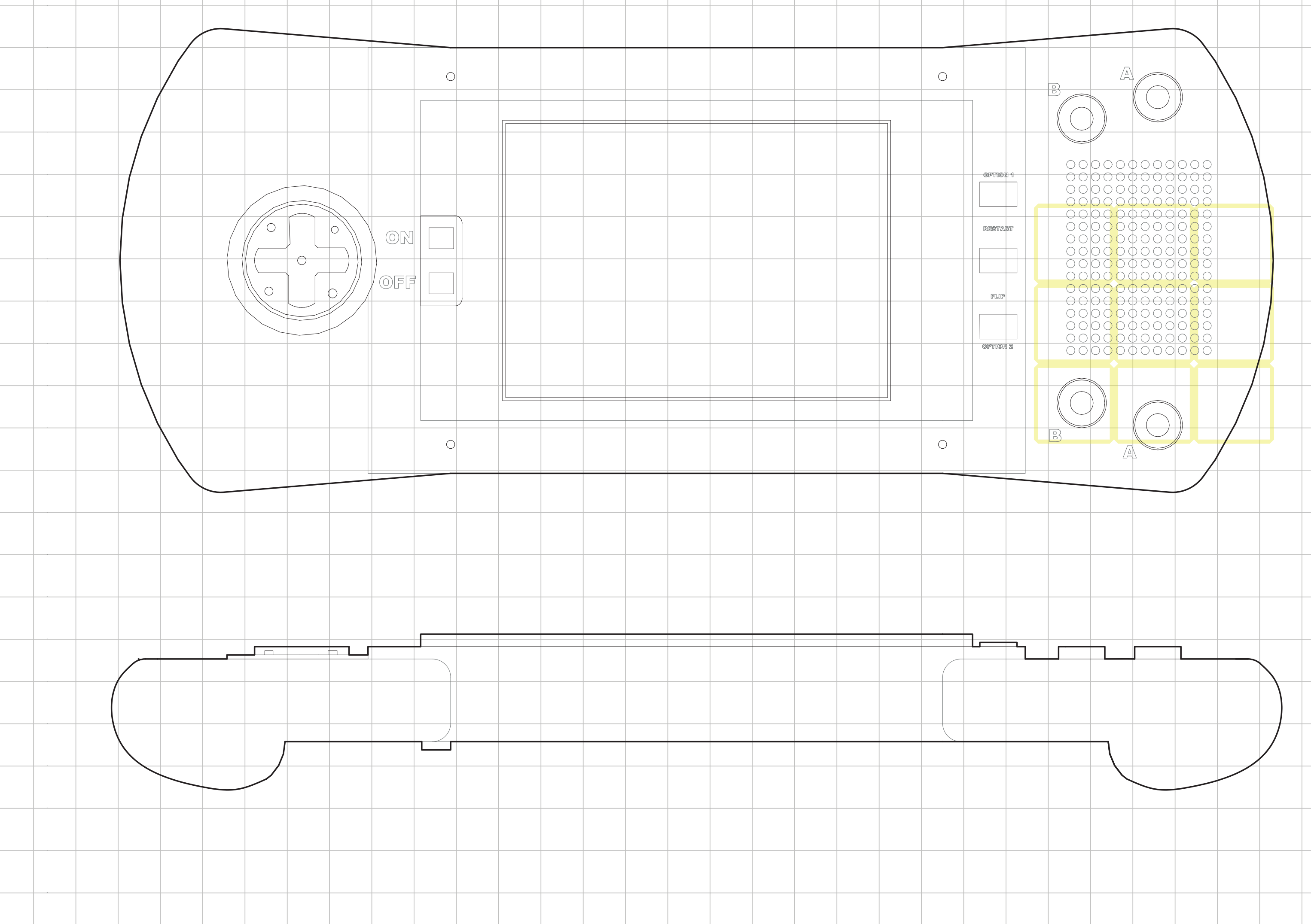


\section{Atari Lynx.}

1989

Atari.

Videoconsola portable.

Videoconsola portátil de 8 bits desarrollada y lanzada al mercado por Atari en 1989, fue pionera en el uso de una pantalla LCD en color. Esta consola estaba basada en la Handy Game diseñada por Epix, de la que Atari adquirió los derechos.

"El diseño de Lynx era compatible con jugadores diestros y zurdos y tenía una de las mejores pantallas LCD de la época. La pantalla de la Game Boy y de las posteriores consolas portátiles tendían a desdibujar los gráficos cuando mostraban imágenes a mucha velocidad. Con la pantalla de la Lynx aquello no pasaba"

(Kent, pg 418, 2001)

Su pantalla LCD tenía una resolución de 160×103 píxeles que permitía mostrar 16 colores de forma simultánea. Una CPU WDC 8-bit 65SC02 y una memoria RAM de 64Kb.

La Atari Lynx poseía un periférico llamado Cable ComLynx que permitía jugar de manera simultánea a 18 jugadores. Era una consola de gran tamaño pese a ser portátil y con una corta duración de las baterías (entre cuatro y cinco horas). Esto limitó su éxito comercial y tan solo se vendieron tres millones de copias.

Contó con una segunda consola, Ilamada Lynx II (1991) de menor tamaño y con una mayor duración de la batería hasta cinco horas.

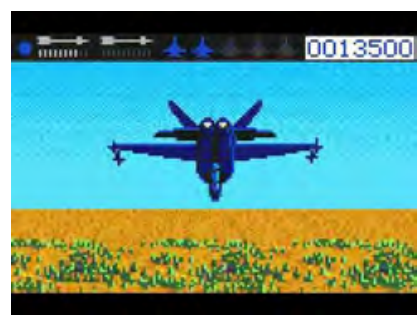

Blue Lightning.

1989

Videojuego de simulación de vuelo de combate en el que el jugador asume el papel de un piloto de avión que trata de penetrar en territorios enemigos para ganar la guerra. Fue ideado como una simulación de vuelo de combate en pseudo 3D en tercera persona, inspirado en gran medida en Super Escaler. El juego utilizaba características propias de la consola como la escala y la rotación de sprites, así como un motor de animación para la secuencia de introducción que se usó para otros títulos.

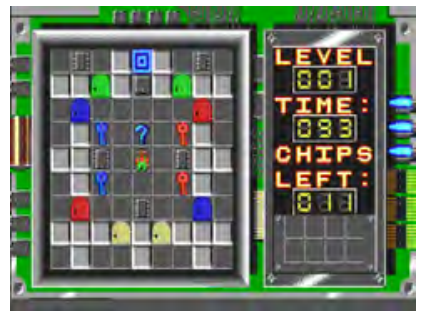

Chip's Challenge. 1989

Videojuego de puzzles en el que el protagonista debe abrirse camino a través de escenarios en los que debe recolectar chips para abrir las barreras que encuentra a

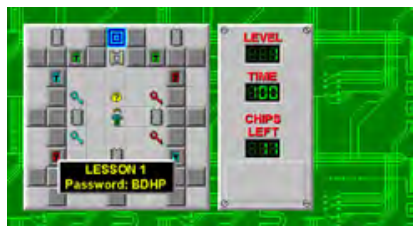
la salida de cada uno. Cada nivel cuenta con un número de chips a recolectar y un tiempo límite. Existen claves ocultas en los niveles 34, 82, 137, 146 y 177 que permiten acceder a niveles extra. Se trata de un videojuego basada en una cuadrícula. 
$\Xi \Xi \Xi$

$$
\text { モョョ }
$$




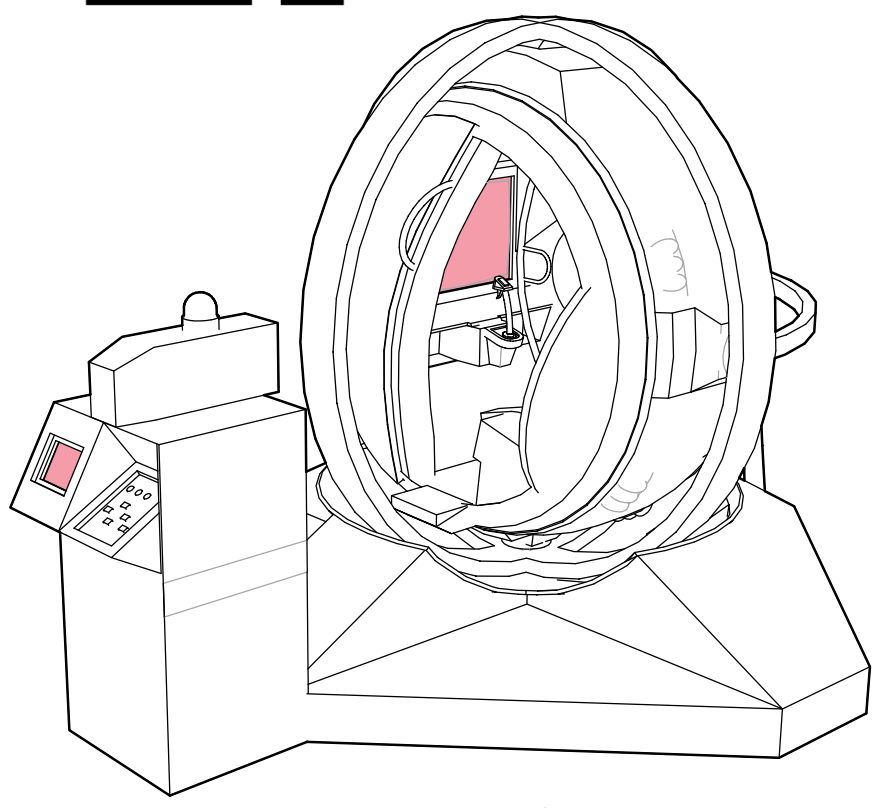

\title{
GENERACIÓN 4
}

\author{
1992 (1990)
}

Aunque podría decirse que la cuarta generación de consolas comenzó con el lanzamiento de la consola estrella de la época, Super Nintendo, en 1990, lo cierto es que lo hizo en 1987 con la Turbograftx 16 (que se adelantó a la competencia). En el campo de las arcade la revolución llegó con Virtua Racing en 1992 (primer juego por completo en 3D) y R-360 (arcade considerado experimental) ambos del grupo de investigación AM-2 de Sega. Fue la época dorada de la Game Boy original en portables y el final de los ordenadores de marcas principalmente de juegos como el Amiga Commodore (posiblemente uno de los sistemas mejor diseñados para gráficos).

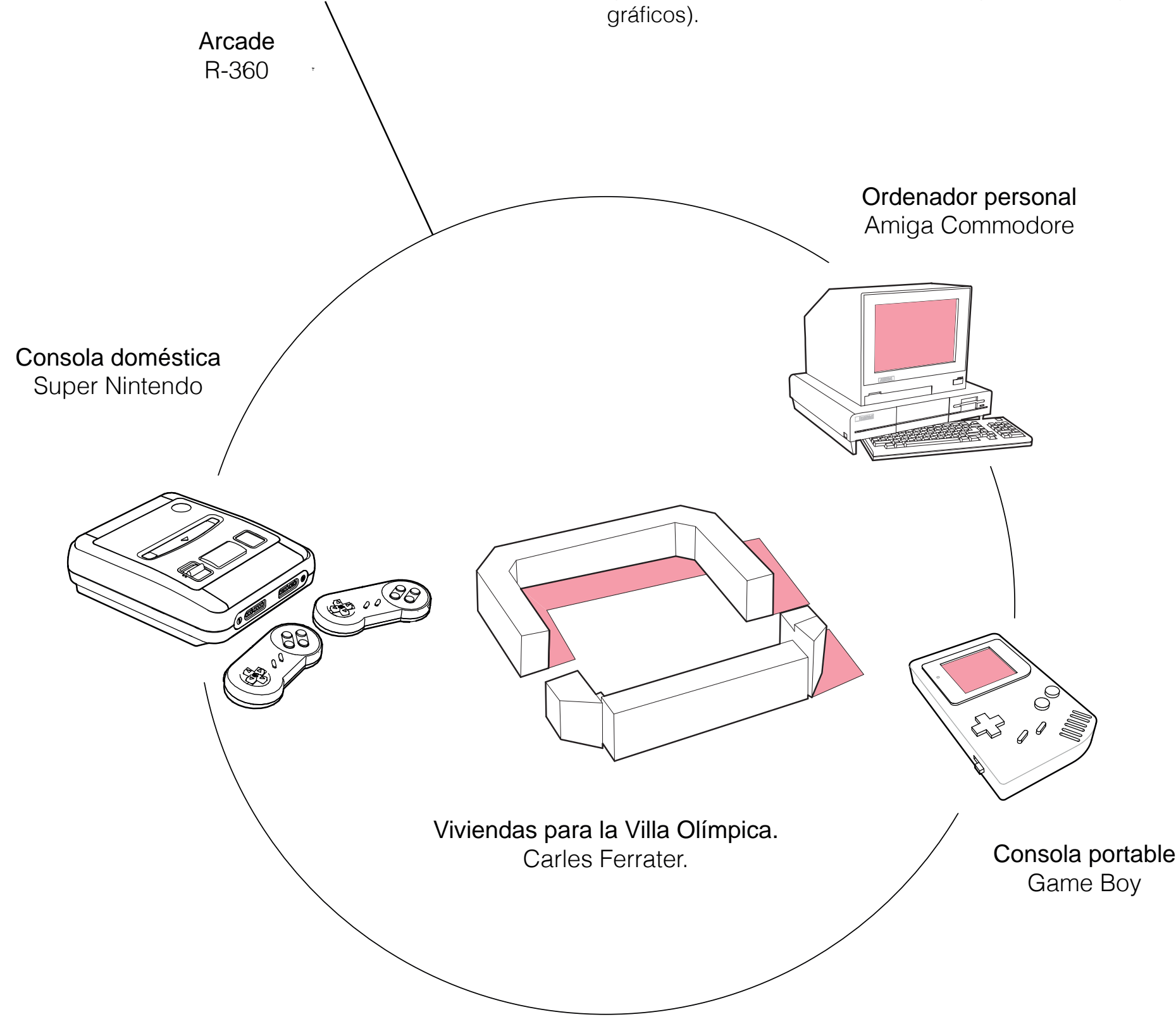




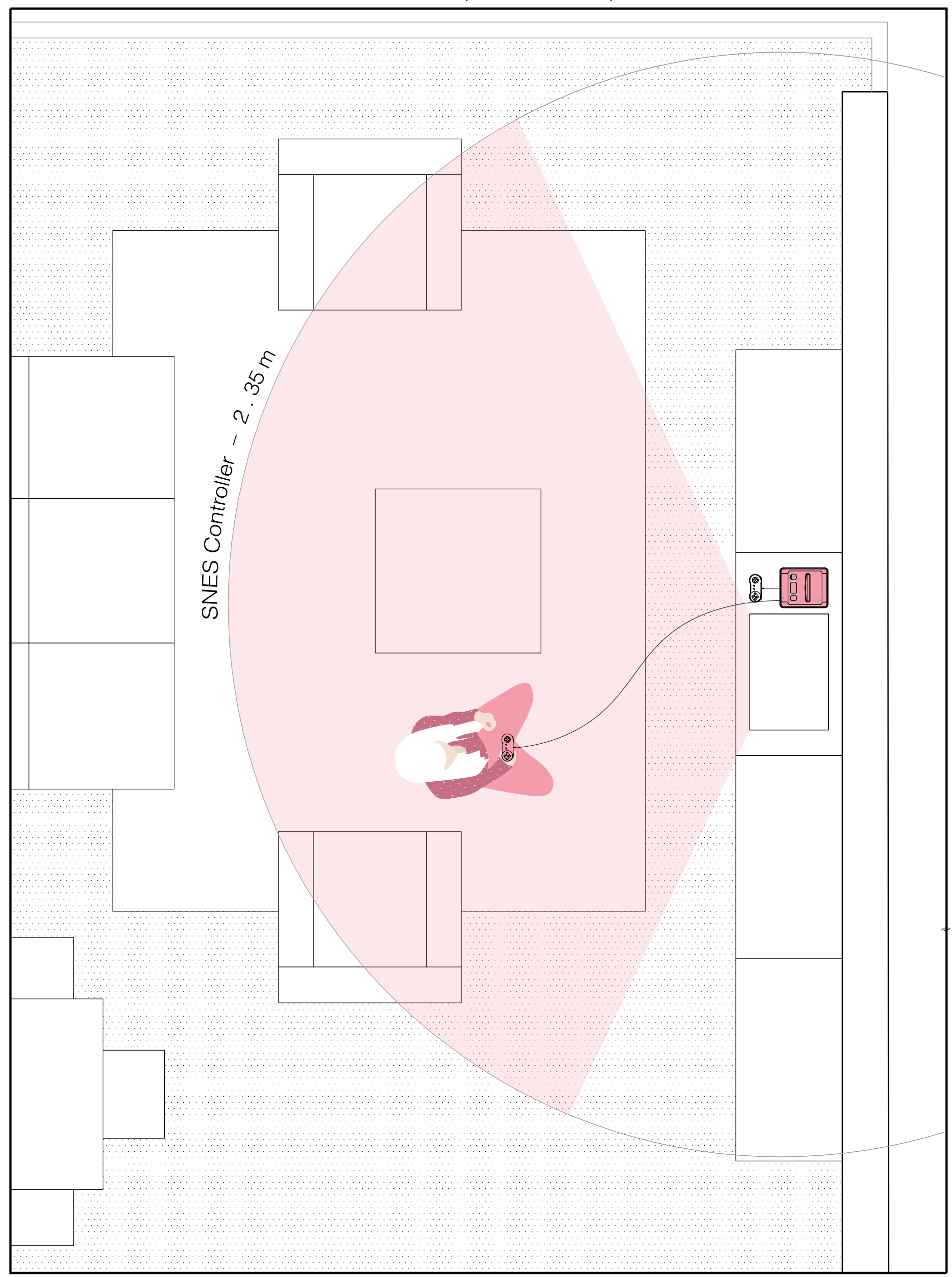




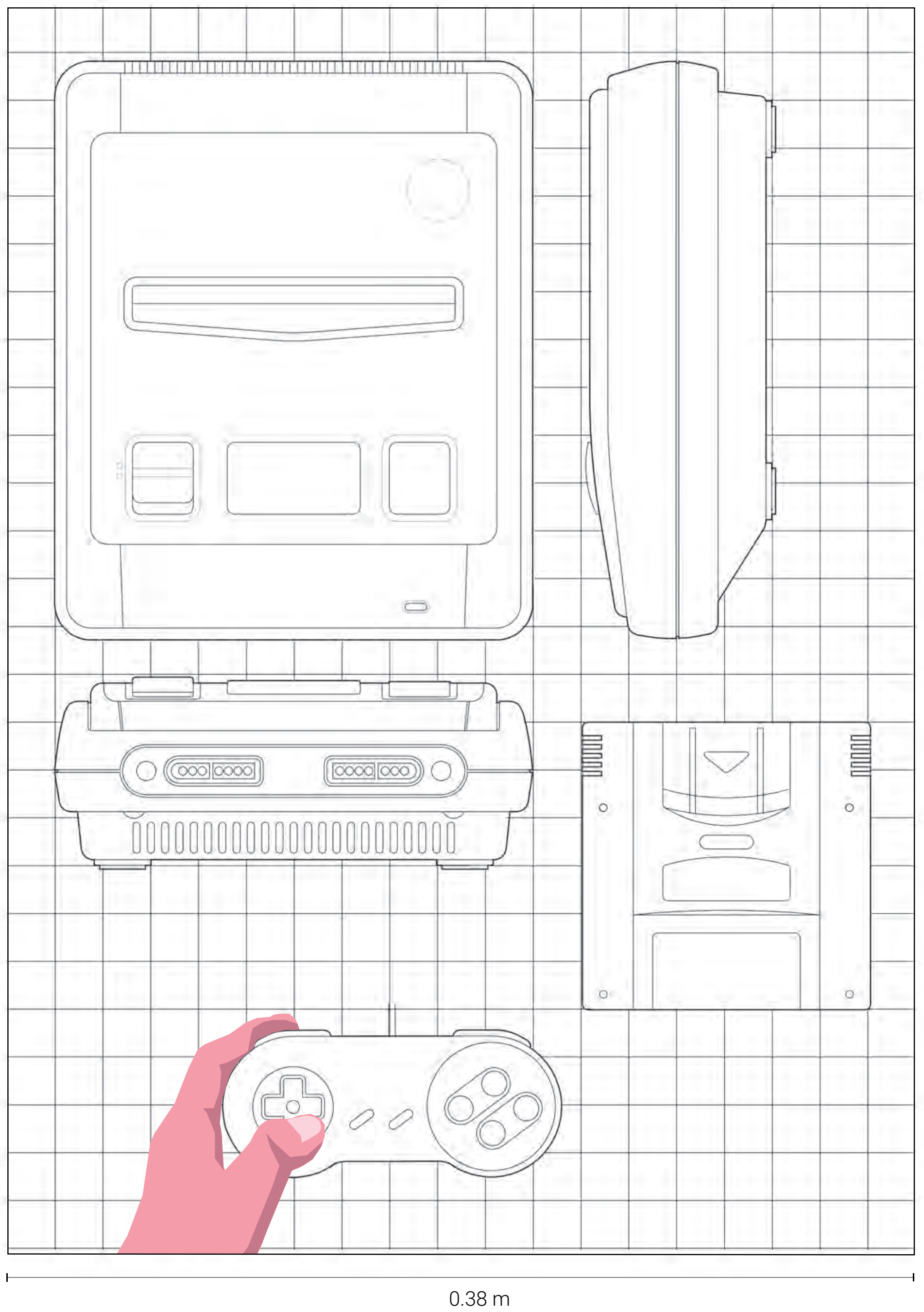


El juego más vendido de la Super Nintendo fue Super Mario World. Permitía acceder, desde las viviendas de Barcelona, a un mundo compuesto por 96 niveles. Cada uno de ellos tenía de media la misma longitud de 3 manzanas que el proyecto completo de la Villa Olímpica.
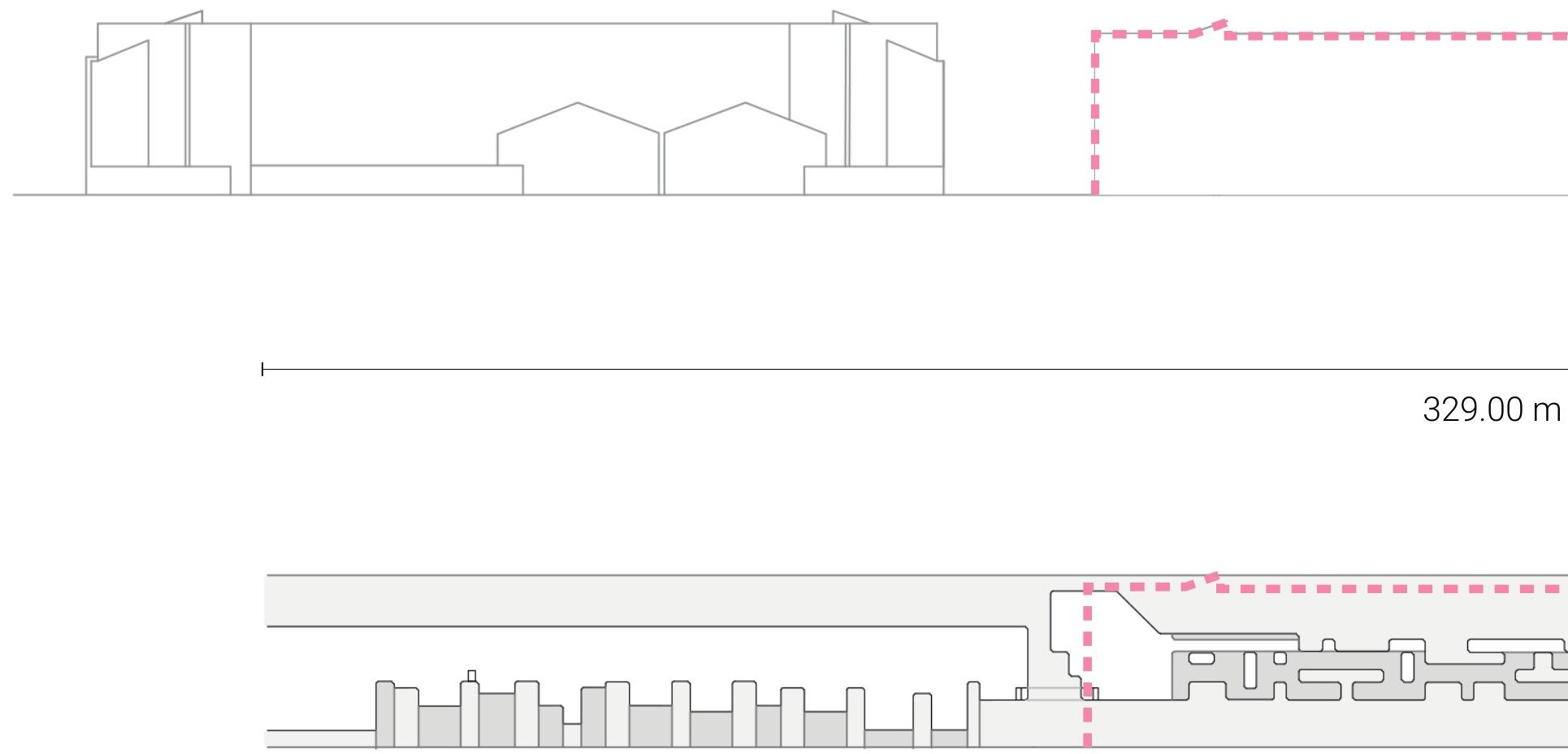
एव

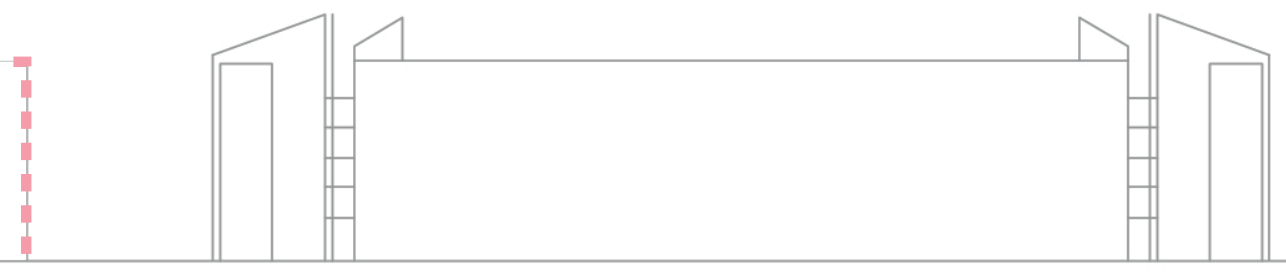

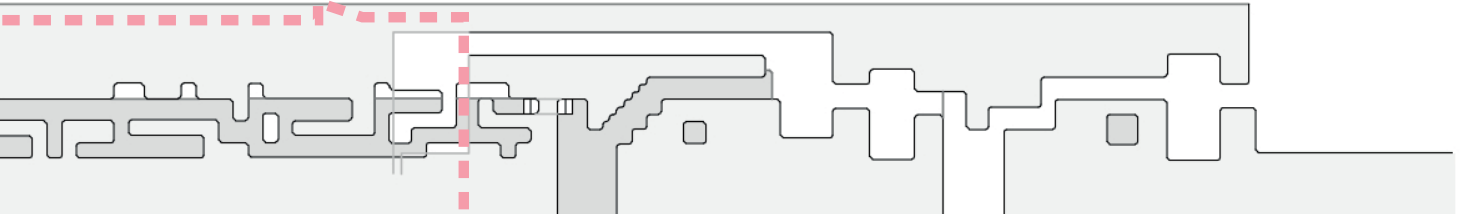


Game Boy paseando por la Villa Olímpica.

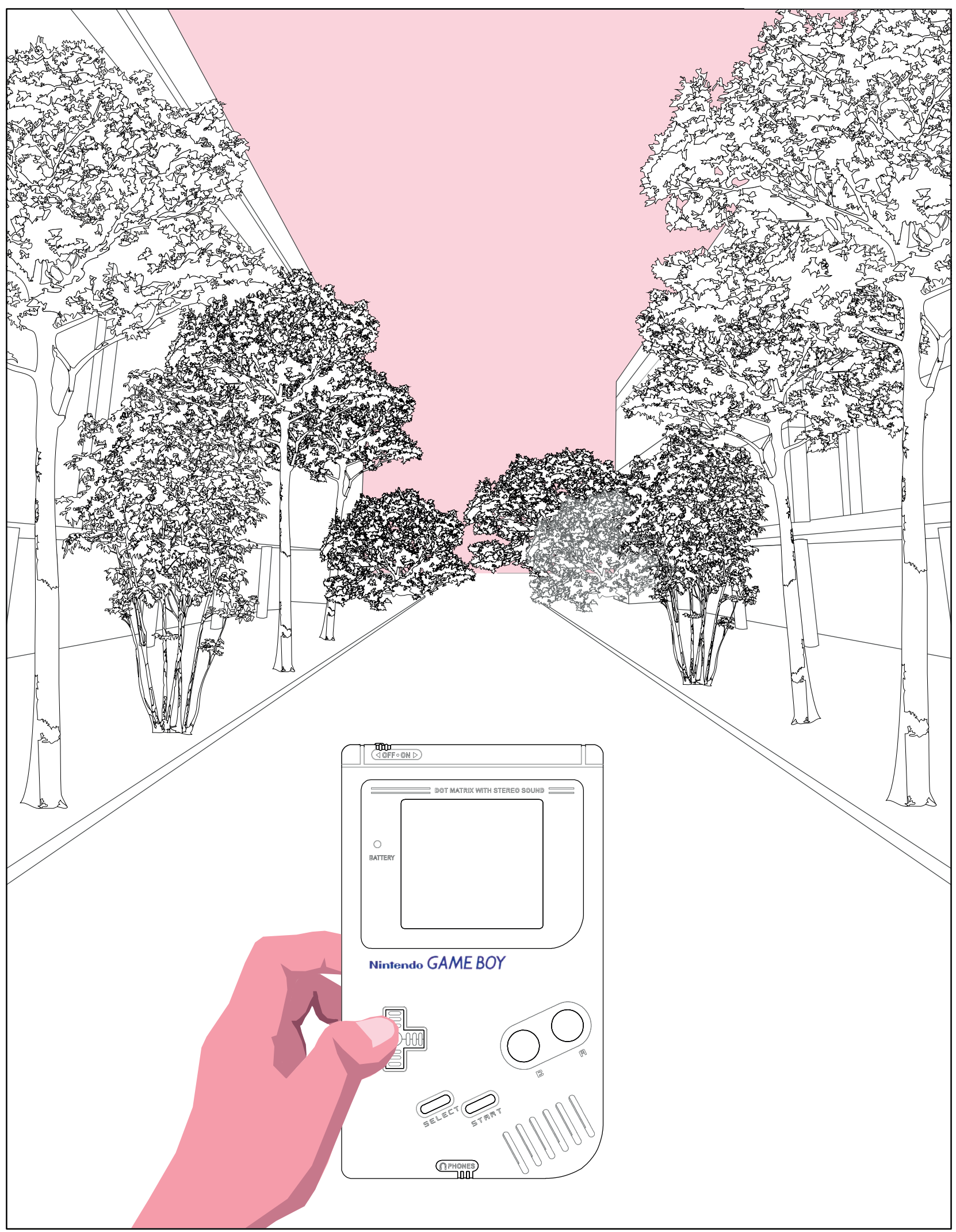

\section{Game Boy}

duración de la bateria 15 horas y 30 minutos pasos jugando 93.000 


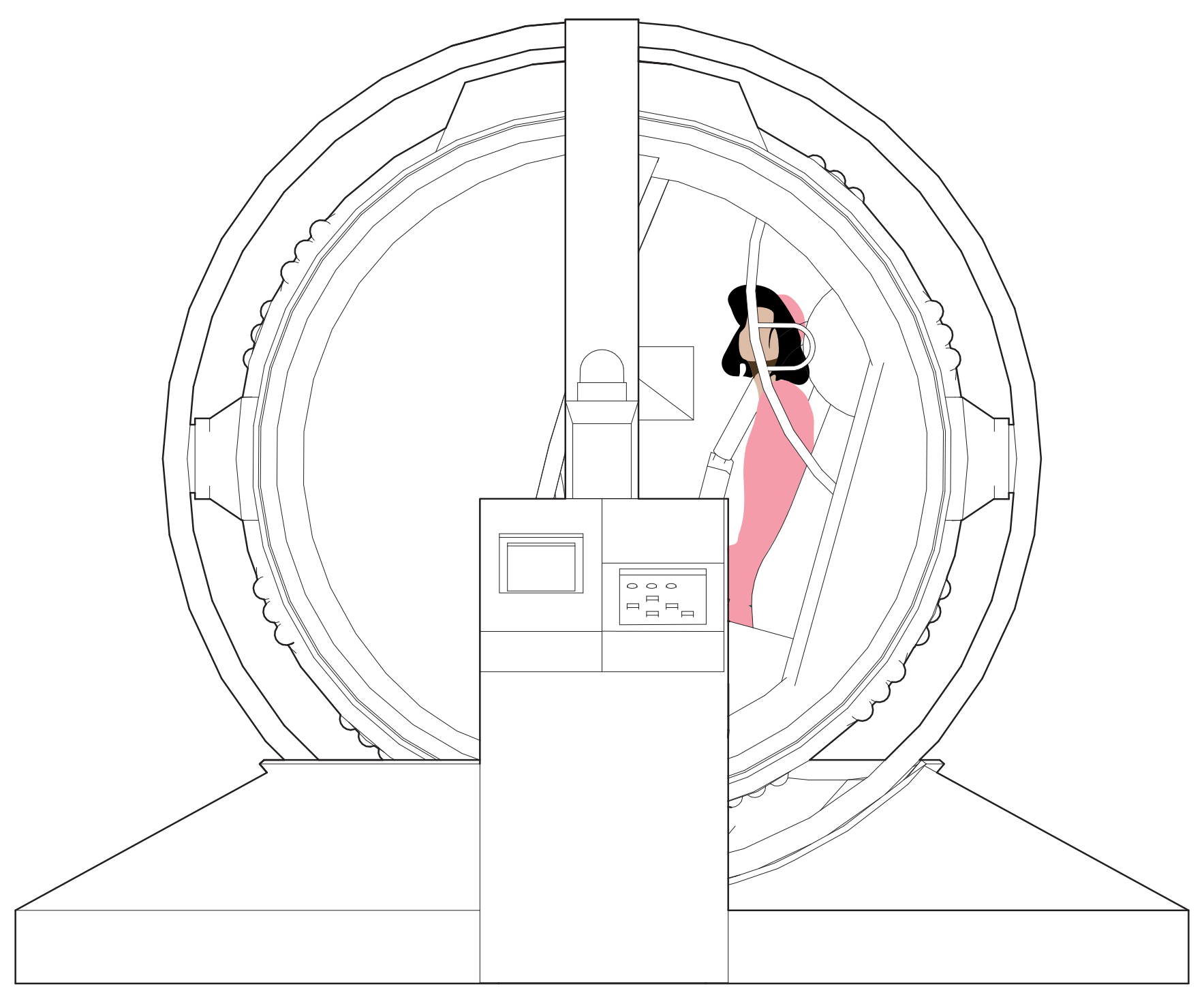




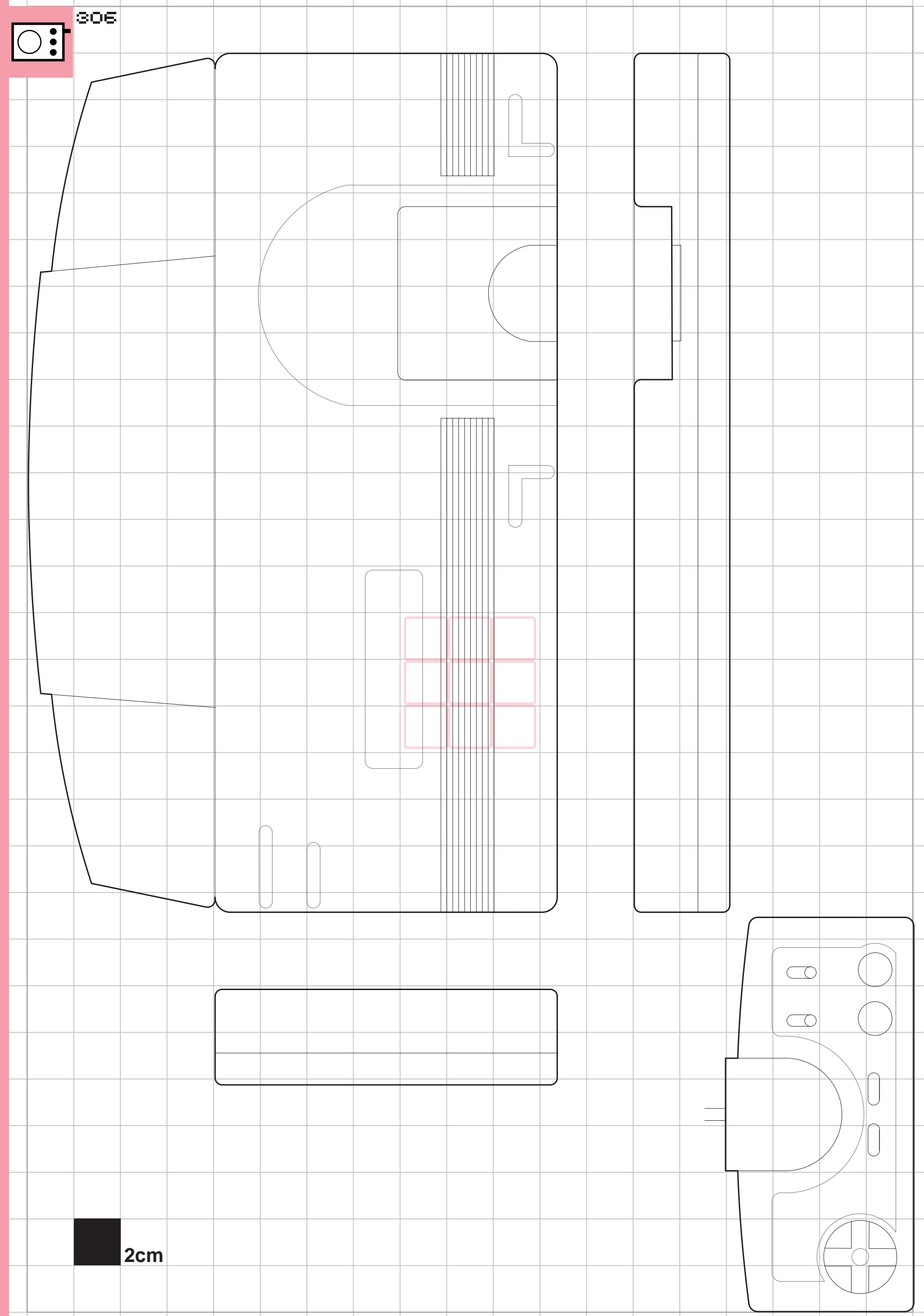




\section{TurboGraftx 16/PC Engine.}

\section{9}

\section{NEC home electronics y Hudson Soft. Videoconsola doméstica.}

Consola doméstica desarrollada por NEC Corporation y lanzada al mercado en Japón en 1987 (bajo el nombre de PC Engine), que llegó al mercado internacional dos años después debido al éxito entre los consumidores nipones y a las compras de importación de estadounidenses. Llegó a vender 10 millones de copias a nivel mundial

Era una consola híbrida entre los 8 y los 16 bits, ya que, aunque estaba basada en un sistema de 8 bits, poseía un chip gráfico de 16 bits y era capaz de mostrar 482 colores en pantalla. Esta consola fue descontinuada en 2004.

"El departamento de marketing de NEC hizo mucho hincapié en que tenía un chip de procesamiento gráfico de 16 bits hecho a medida y otro central también de 16 bits, pero los críticos no dejaban de recordar que ambos sistemas estaban construidos en torno a chips de 8 bits. La TurboGrafx era, sin duda, menos potente que la Genesis, aunque podía mostrar muchos más colores en pantalla"

(Kent, pg 413, 2001).

Fue pionera en implementar la posibilidad de instalarle un lector de CD (en 1988 apareció este primer periférico de la consola) y en popularizar los juegos de hasta 5 jugadores. Posteriormente, NEC lanzó una expansión que aumentaba la RAM de la consola hasta $2048 \mathrm{~Kb}$ lo que permitía mostrar gráficos en 3D pre-renderizados. No disponía de juegos en cartuchos, sino que recurrieron a las tarjetas de plástico (similares a las ya usadas por la Master System), pero con una mayor capacidad de almacenamiento.

Existieron varios modelos de esta consola, siendo los más conocidos los que se distribuyeron inicialmente en Japón, y luego en América y Europa. Ambos tenían un controlador con cruceta direccional, dos botones de control de juego y dos más (de Select y Run), con un alcance de 1,36 metros.

Fuente análisis gráfico:

Elaboración propia a partir de los datos de los manuales originales de la consolas archivados en Archive.org y las propias consolas físicas.

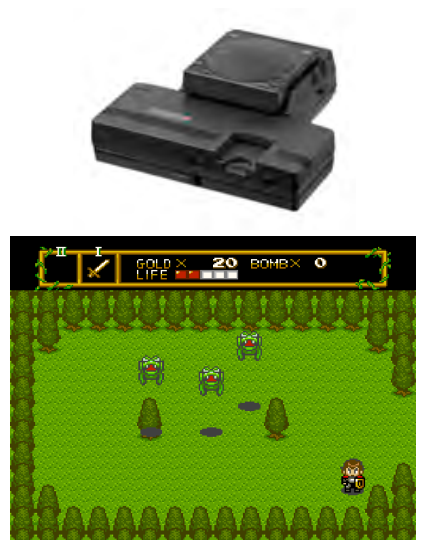

ACCESORIO

Turbografx CD-ROM.

Expansión que permitía la lectura de juegos en CD. Publicado en 1988.

Neutopia.1989

Videojuego de acción y aventura en perspectiva egipcia desarrollado en el mundo fantástico de Neutopía donde una princesa ha sido capturada y ocho medallones robados, misiones que el protagonista debe completar. El juego es considerado un clon de The legend of Zelda.

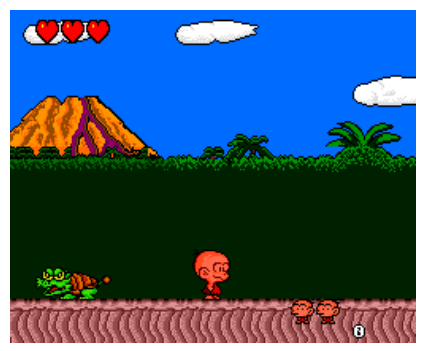

Bonk's Adventure.1989

Videojuego de plataformas en 2Denel que el jugador controlaa un cavernícola que lucha contra dinosaurios antropomórficos. La versión arcade permite al jugador escoger entre 28 niveles diferentes.

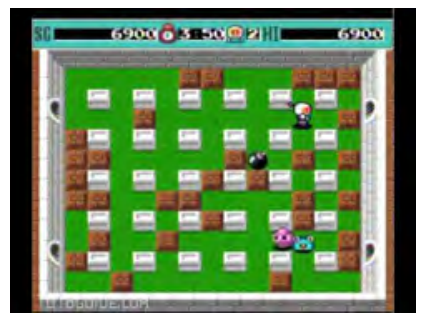

\section{Bomberman.1990}

Videojuego de estrategias y de tipo laberinto en el que el jugador controla al personaje Bomberman a través de un laberinto en el que debe derrotar a los enemigos. Las conexiones entre los diferentes espacios se encuentran debajo de rocas que deben ser destruidas con bombas. Cada juego tiene cincuenta niveles, al final de los que el protagonista llega a la superficie.

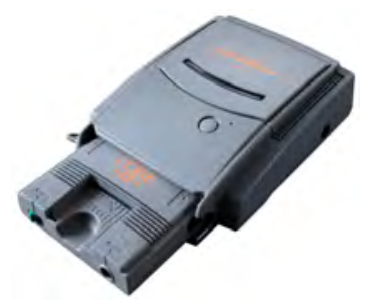

\section{ACCESORIO}

Súper CD-ROM.

Extensión, publicado en 1991, que permitía la lectura de juegos en CD e implementó una actualización del sistema que mostraba gráficos mejorados.

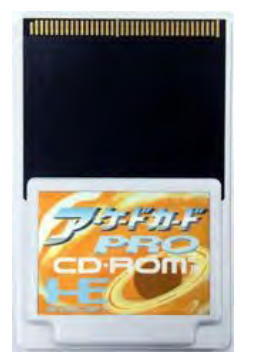

\section{ACCESORIO}

Arcade Card.

Cartucho que, introducido en la consola, permitía la lectura de juegos de hasta 2 megas y también de otros dispositivos como la Neo Geo. Publicado en 1994.

\section{ACCESORIO}

Screen display.

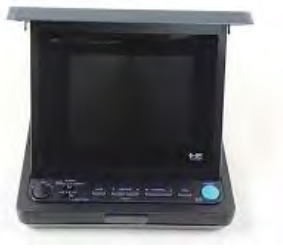

Dispositivo que contenía una pantalla en color que permitía visualizar los juegos sin necesidad de disponer de un monitor. 


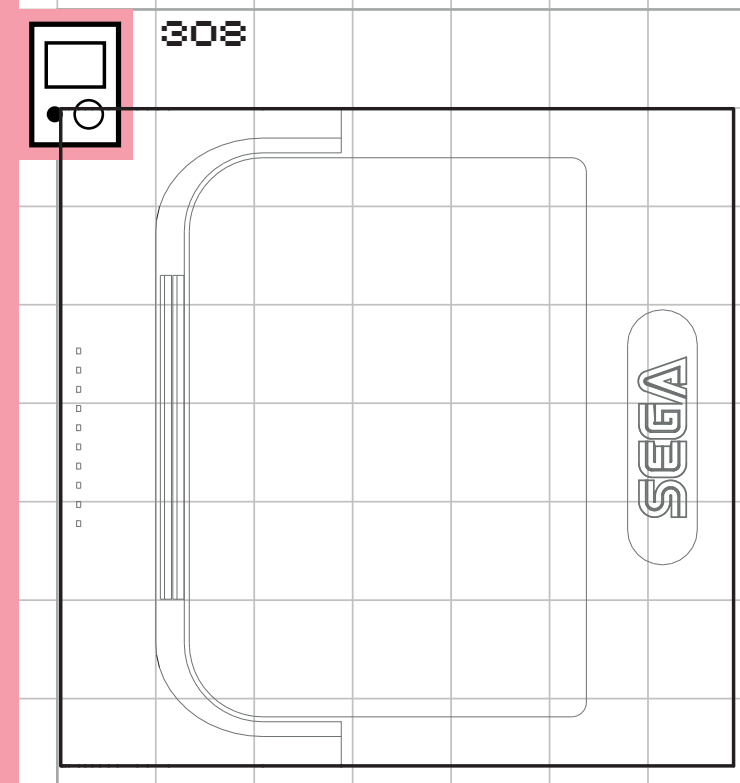

000

00000

00000

00000

00000

00000

00000 


\section{Sega Game Gear.}

1990

SEGA.

Videoconsola portable.

Consola portable desarrollada por SEGA y lanzada al mercado japonés en 1989. Llegaría a Europa y Estados unidos en 1990 y a Australia en 1991. Esta consola perteneció a la cuarta generación y fue la respuesta de SEGA para competir con la popular Game Boy de Nintendo (Harris, 2014).

Era una consola de 8 bits basada en un sistema de juegos en cartuchos, poseía una pantalla de 3,2 pulgadas retroiluminada que ofrecía una resolución de 160x144 píxeles y podía mostrar 32 colores de manera simultánea, de un total de 4096 (algo excepcional para la tecnología de la época).

Sin embargo, poseía una duración de batería bastante limitada, de tan solo entre unas tres y cuatro horas, y requería seis pilas recargables (que SEGA lanzó al mercado para aumentar la duración de la batería). Motivo por el cual fracasó en su intento de liderar el mercado, vendiendo solo 10,6 millones de copias.

Disponía de una cruceta direccional, dos botones de control y uno de Reset. SEGA desarrolló varios accesorios, entre los que destacó el TV Tuner, que permitía ver la televisión en la pantalla, y el cable Gear to Gear, para poder conectar dos consolas.

Fuente análisis gráfico:

Elaboración propia a partir de los datos del manual original de la consola archivado en Archive.org.

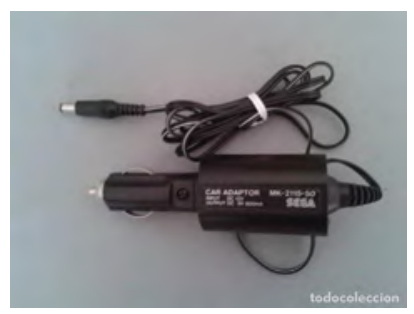

ACCESORIO

Car Gear.

Cargador eléctrico que permitía la conexión de la consola al coche. Fue la consola portátil pionera en disponer de este conector. Salió al mercado a la vez que la misma en 1990.
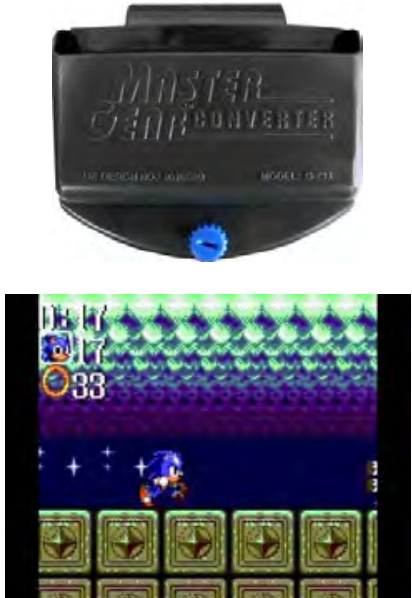

\section{ACCESORIO}

Master Gear.

Adaptador que permitía la reproducción de juegos de Master System en la Game Gear. Salió al mercado en 1992 solo fuera de Japón.

\section{Sonic Chaos.1993}

Videojuego de plataformas que presentó por primera vez a Tales como un personaje jugable, dando al jugador la posibilidad de escoger a Sonic o a Tales y manteniendo las gemas que deben encontrarse en etapas especiales exclusivamente de Sonic. Los niveles se basaron esencialmente en el Sonic II de la Sega Master System.

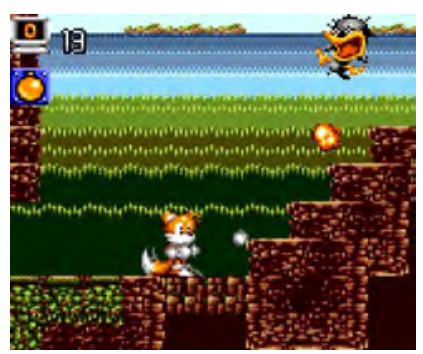

Tales Adventure.1995

Videojuego de plataformas que, por primera vez, se mezcla con elementos de rol y difiere la versión japonesa de la occidental. La característica principal del juego es la estrategia a la hora de analizar que cuatro objetos, como máximo, debe llevar Tales que le ayudarán a superar obstáculos.

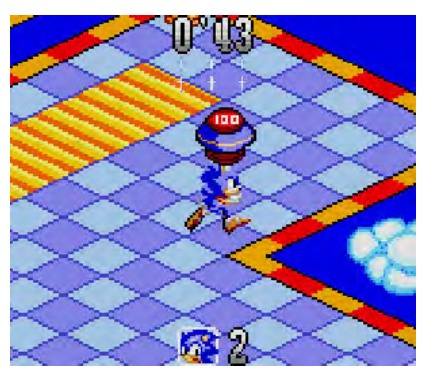

Sonic Labyrinth.1995

Videojuego de plataformas que fue el primer y último juego de Sonic en perspectiva isométrica, representando un laberinto creado por el Doctor Eggman del que el erizo azul debe escapar. La velocidad, que es la gran característica de Sonic, no se refleja en este juego. Sus gráficos han sido comparados con los de Marble Madness.

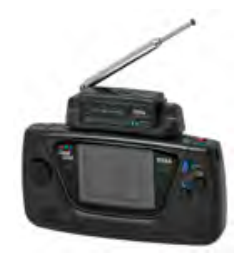

\section{ACCESORIO}

TV Tuner.

Dispositivo que, introducido como un cartucho, permitía sintonizar la TV en la consola.

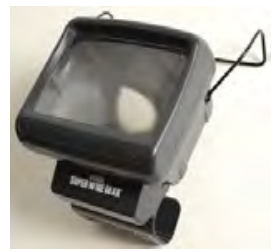

\section{ACCESORIO}

Super Wide Gear.

Dispositivo en forma de sobrepantalla que colocado sobre la consola magnificaba la imagen de ésta. 

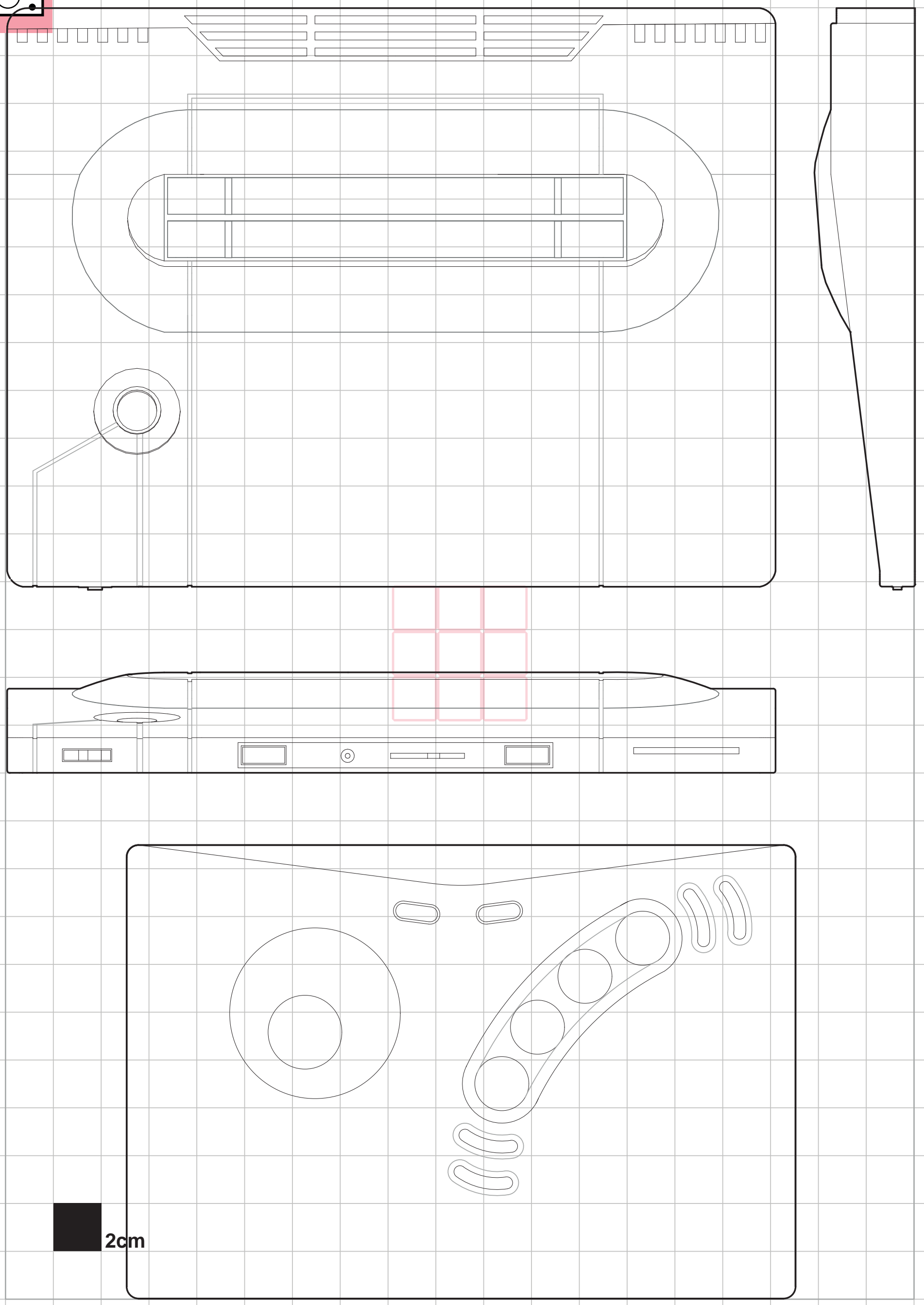


\section{Neo-Geo.}

\section{0}

\section{SNK Corporation.}

Videoconsola doméstica.

Videoconsola doméstica de 16 bits desarrollada por SNK y lanzada al mercado japonés y estadounidense en 1990 y que llegó a Europa en 1991. Esta consola estaba basada en un sistema de juegos en cartuchos, aunque también tuvo un equivalente en máquinas de arcade.

Originalmente, se trataba de un sistema desarrollado para salas recreativas, que permitía mostrar 4095 colores. Su conversión a videoconsola doméstica tuvo como resultado un producto a un precio muy elevado, lo que impidió su éxito, vendiendo tan solo un millón de copias.

Poseía un procesador principal Motorola 68000 y otro secundario tipo Zilog Z80, disponía además de un chip para el sonido. La resolución de la pantalla era de $320 \times 224$ píxeles.

La Neo-Geo disponía de un controlador de gran tamaño que simulaba los de las máquinas recreativas y que contaba con un joysticks y cuatro botones. Se implementó un sistema de tarjetas de memoria que permitía al jugador comenzar la partida en el salón recreativo, guardarla y continuarla en su casa.

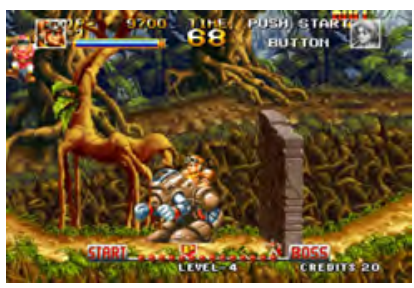

Top Hunter: Roddy \& Cathy. 1994

Videojuego de plataformas de desplazamiento lateral que requería un cartucho de 110 megabytes. El juego se subdivide en cuatro planetas que pueden ser seleccionados acorde con la opinión del jugador y esta decisión condicionará el diseño posterior del juego.

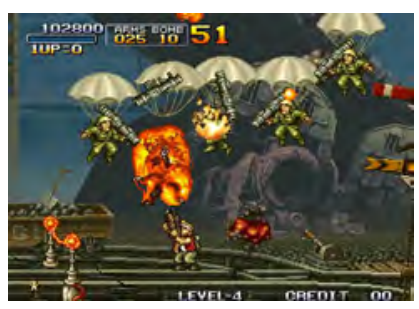

Metal Slug.

1996

Videojuego de disparos de tipo run and gun concebido originalmente para arcade. El juego se centra en un pequeño grupo de soldados que lucha contra el ejército rebelde y otras fuerzas que intentan dominar el mundo. La jugabilidad se centra en el elemento de carreras y disparos e inauguran aquí una saga de videojuegos completa. Todos los juegos de la sala suelen componerse de seis niveles.

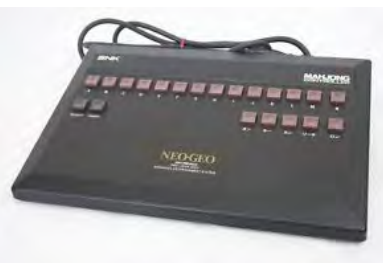

ACCESORIO

SNK Neo Geo Mahjong Controller.

Controlador que disponía de 21 botones, 14 de ellos de letras y resto de símbolos japoneses. Especialmente diseñado para jugar al Mahjong. 


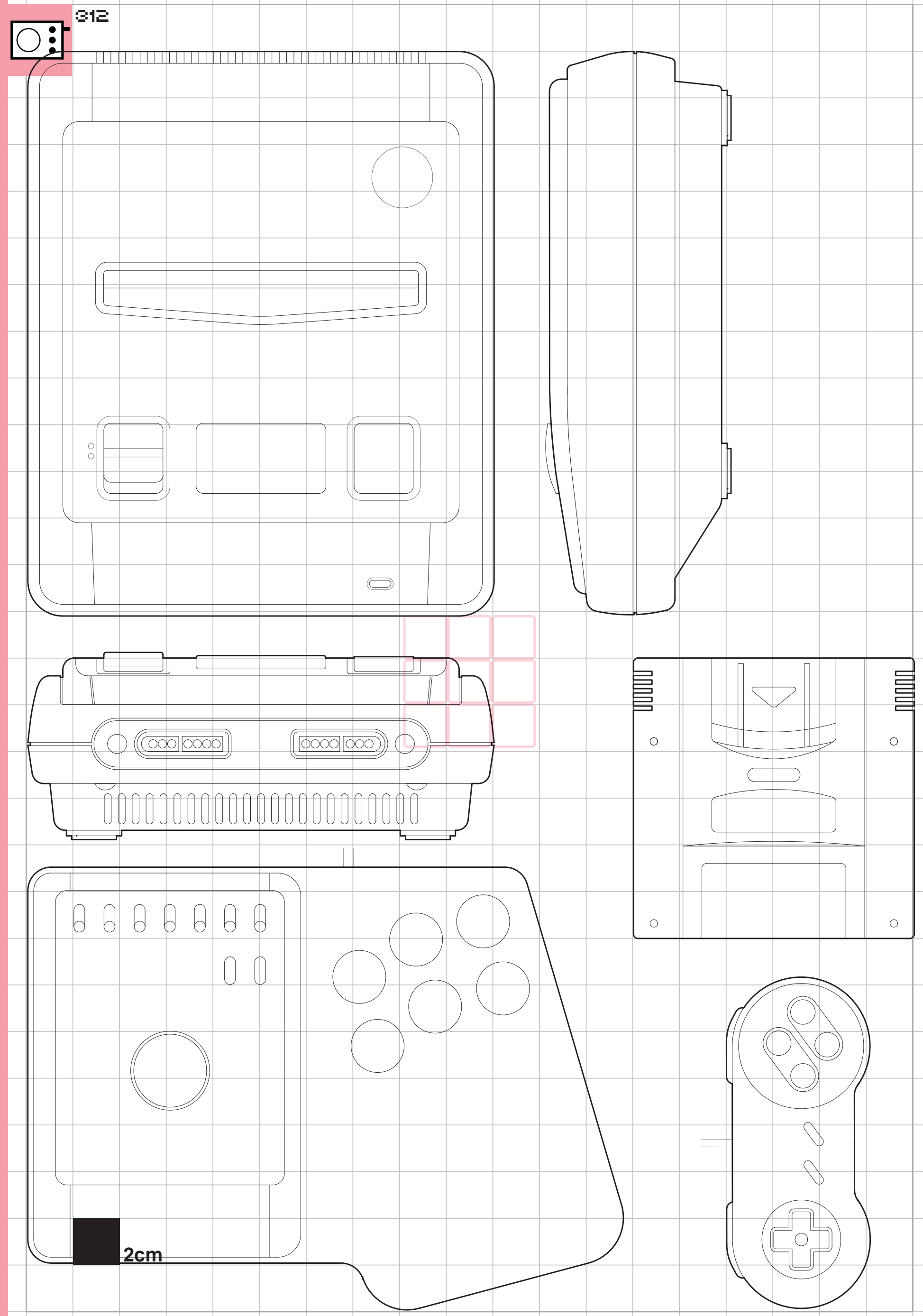




\section{Super \\ Nintendo.}

1990

Nintendo.
Videoconsola doméstica.

Videoconsola doméstica desarrollada por Nintendo
yes considerada como la más exitosa de

generación tras vender 49,1 millones de coppas
Esta consola llegó al mercado japonés en 1990
Idonde se la conocía como Super Famicom).

(donde se la conocia como Super Famicom), un
año después fue lanzada en Estados Unidos y al

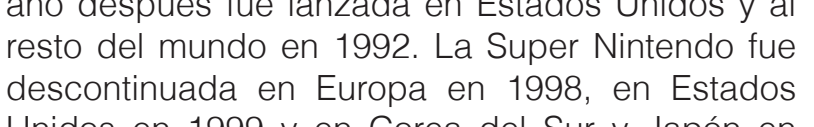
Unidos en 1999 y en
2003 (Gorgues, 2018).

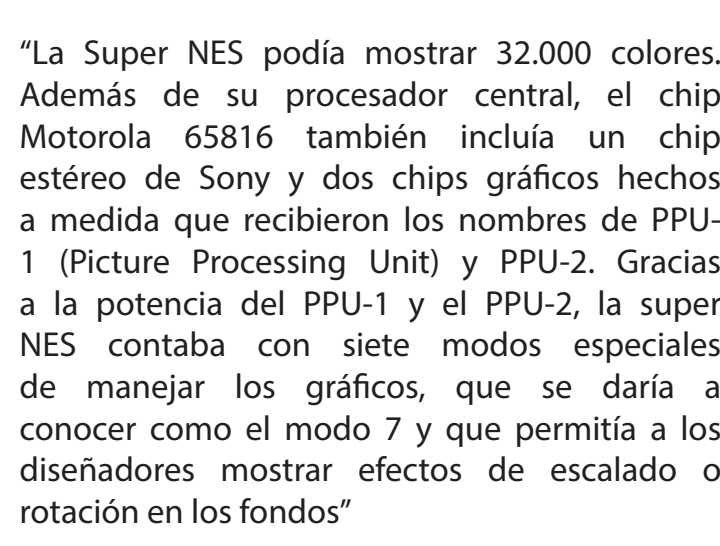

(Kent, pg 431, 2001)

Existieron dos diseños o modelos, uno para Japón
E Europa y otro para Estados Unidos. Ambos y su diseño de botones era idénticos: cruceta dos botones de Select y Sta
botones superiores (LY R).

La Super NES dispuso de mútiples accesorios, entre los que destaca el Super Game Boy que permitía
Igar a los ivegos de la Game Boy el Super Scope,

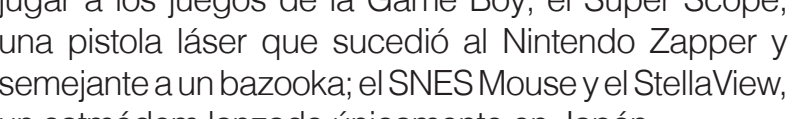
un satmódem lanzado únicamente en Japón

varions

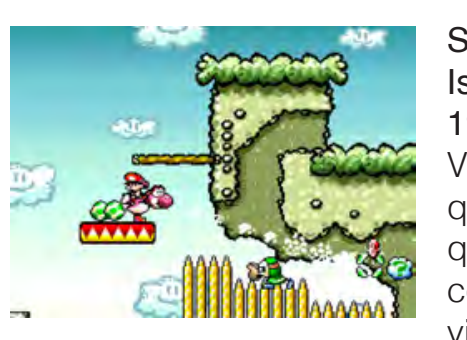

Veejuego de plataformas
une empleaba el chip SFX2
que permitía increibles alores y gráficos, una
colualización de $2 d$ con

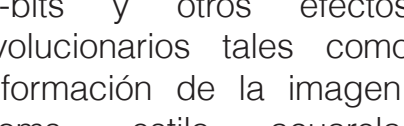
thaciones y diversos efectos

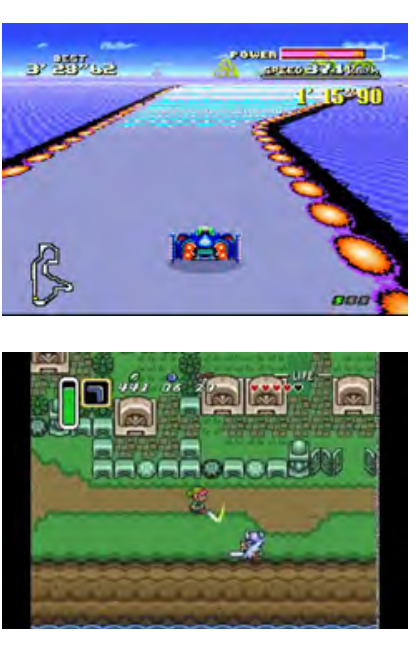

Videojuego de carreras
extremadamente rápido con

extremadamente rápido con
pseudo entornos 3 a traves
de los efectos que permitía la

The Legend of Zelda: A link to

The Legendo
the Past.
1991

deojuego de acción y
aventura que retomal aestela
el primera Zelda en cuanto

al v visualización del mundo
trataba del primer juego

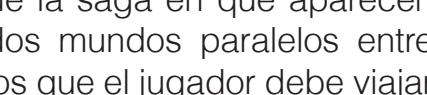

para completar juego. Anivel
de estructura interna estos
mundos eran en realidad el

Mismo, con una variación de
color completa. Pese a todas

La ra dismininuir la dimennsión all juego, el cartucho que le
contenia era de 8 bits y no de $4 \mathrm{~b}$ its lo que permitio crear un
extenso mundo que recorrer.

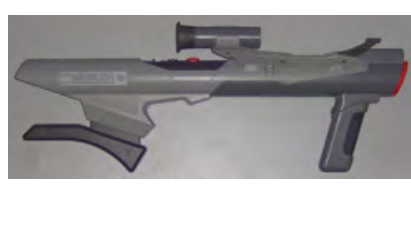

ACCESORIO
Super Scope.

Sistola de luz sucesora del
zapper y diseñada tomando a comolo un bazuca,
la conexion se producía
mediante un receptor conectado al televisor por
lo uue no tenia cableado.
Publicado en 1992 .

Super Nintendo US (1991)
Super Nintendo Jr (1997)

Fuente análisis grático
SNES Europel/Japan

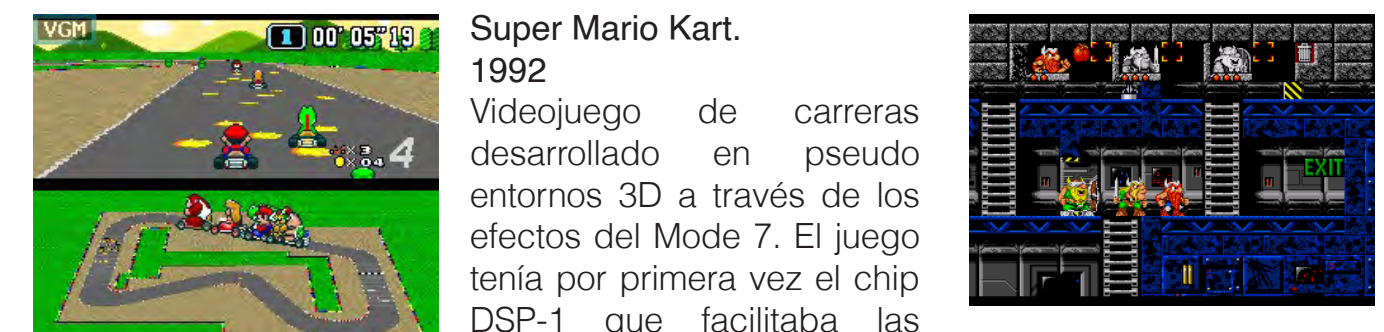

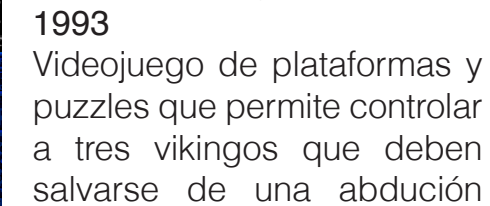

alienigena a traves de 6
niveles. Completar cada nivel

requierell levara lostres- cada
uno con diferentes sabiliades
-vivos hasta el final sino los

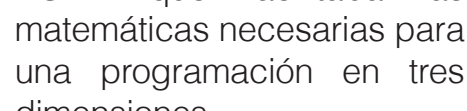

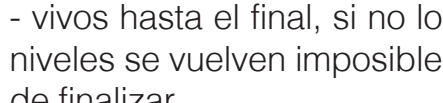

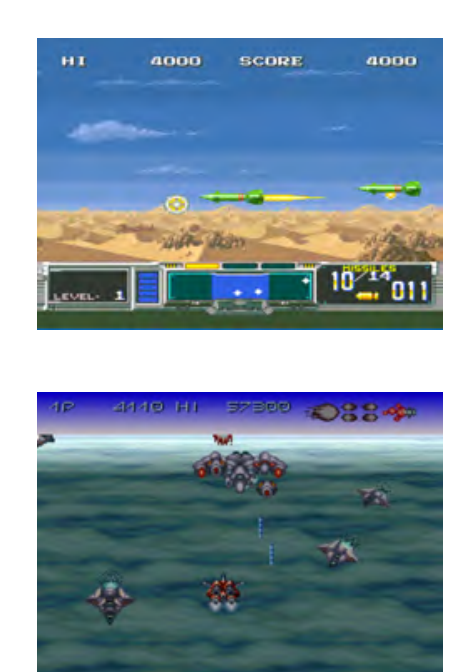

perscope 6-games.

Secret of mana (182).

6 minijuegos en los que
requería del Superscope yse
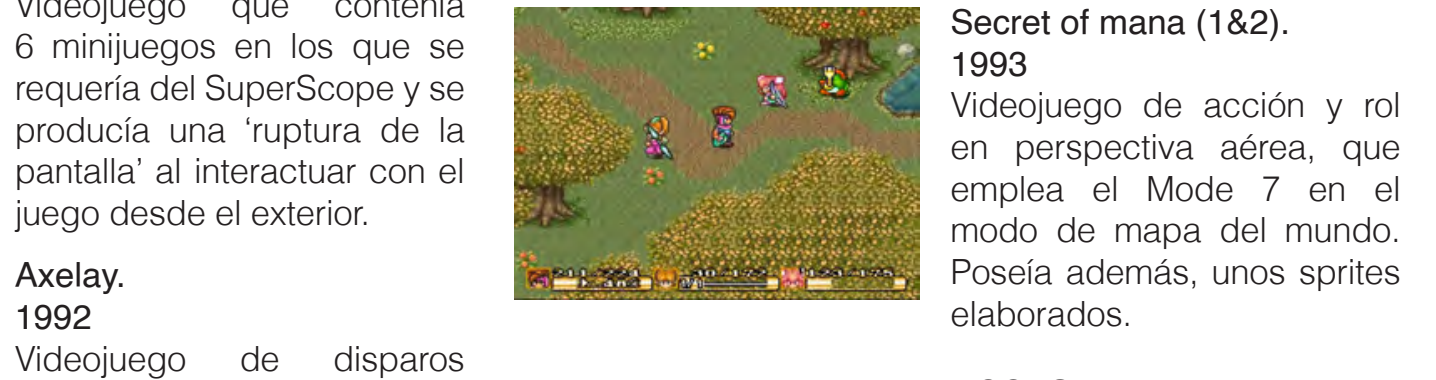

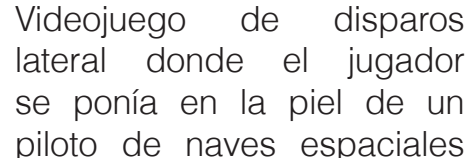

pue trataba de detener una
invasion. Destacaba por sus
jefeses finales y por sus efectos

grálicos que mostraban
ciertos efectios $3 D$ gracias

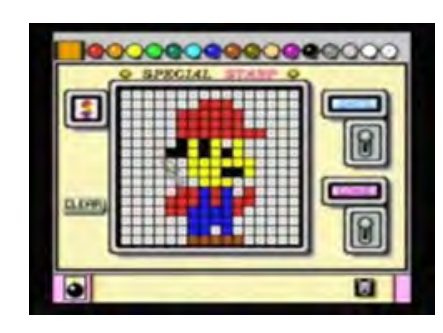

Mario Paint.

Videojuego de arte que
empleaba el ratón y pad de
auper Nintendo para dar

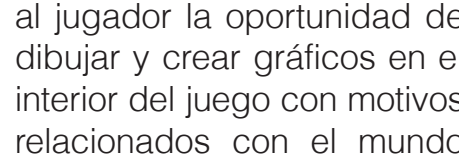

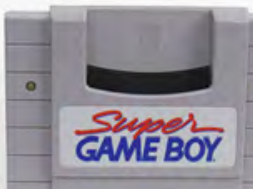

ACCESORIO
Super Game Boy

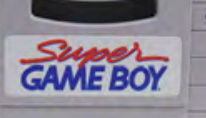

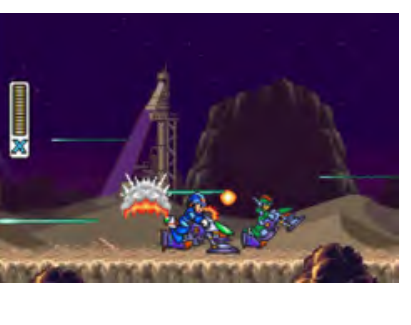

reproducción de dermitiage de
la Game Boy en la Super

Megaman X2 \& X3.

Videa
que
pone
de

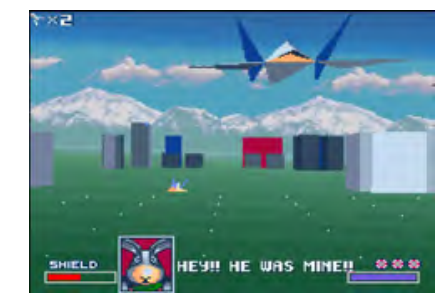

Starfox

deojiuegos de disparos en
rimera persona de temática

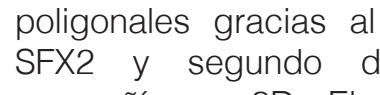

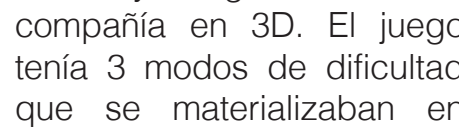

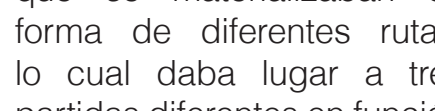

partidas ditier intes
del a e escogida.

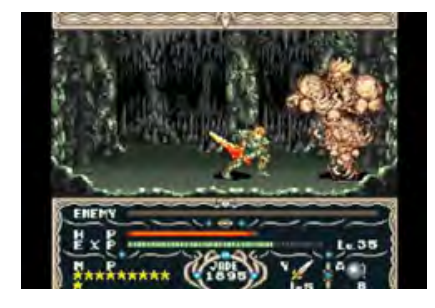

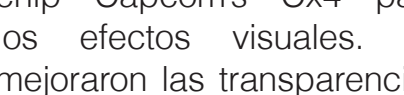

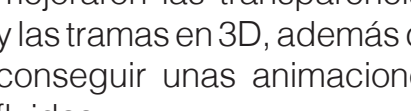
con graficicos politgonales sor
cor

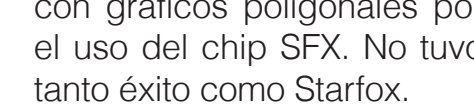

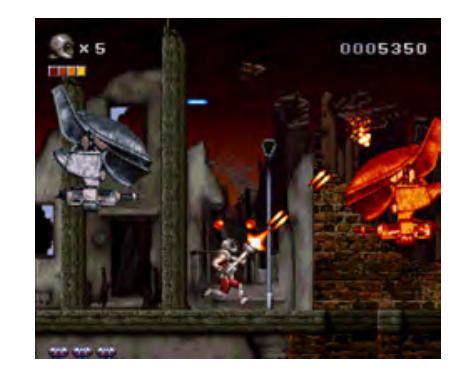

Ranger $\mathrm{R} 2$.

作

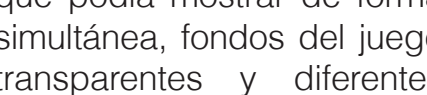

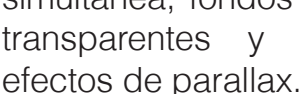

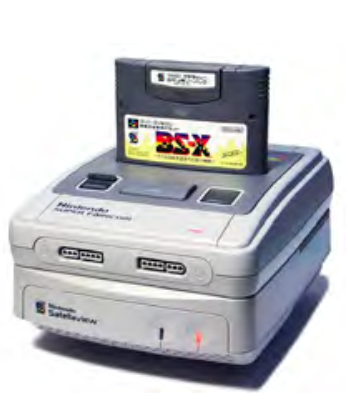

ACCESORIO
Satellaview.

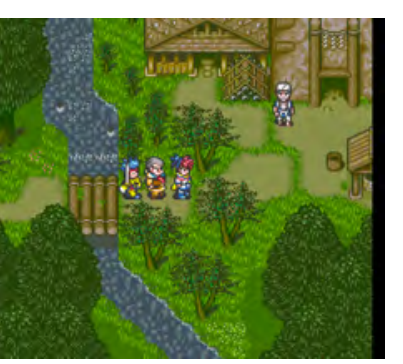

modem que connectada
mosen
base de la super Ninten

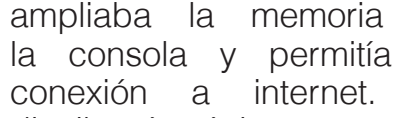
distribuyó únicamente
Japón a partiri de 1995.

Far East of Eden Zero.

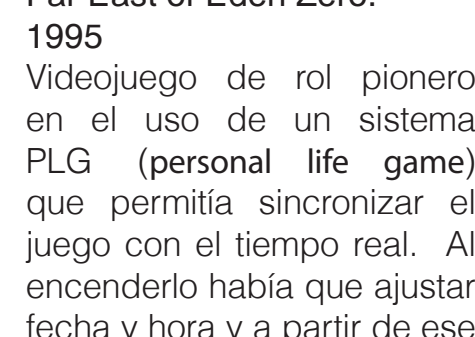

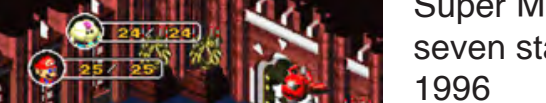

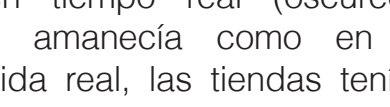

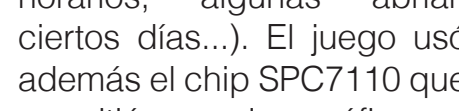
permito manejar rafícicos $y$
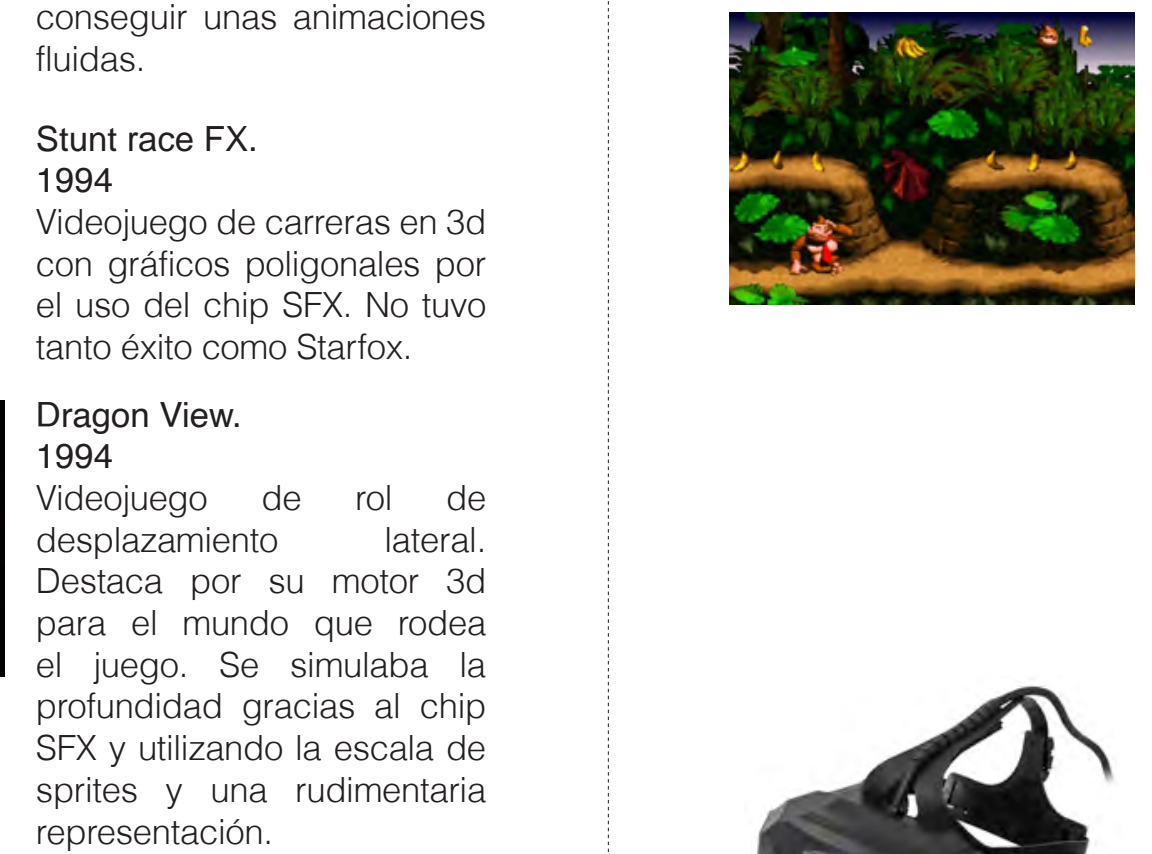

Donkey Kong Country (serie).
1996

Videojiuego de platafarmas
considerado revolucionario
sur lanzamiento Fue el

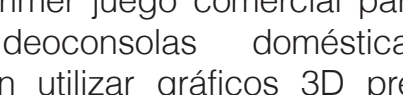

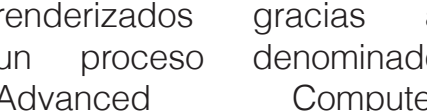
Modelling, lo que Caba lugar
a unos gráitios coloridos ncreibles y unas animaciones
extremadamente fluidas.

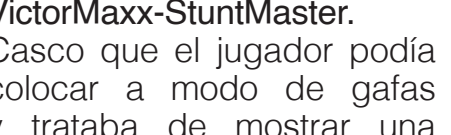

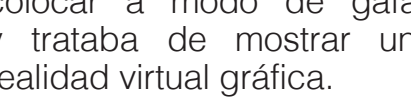




\section{$0:$ \\ :커니}
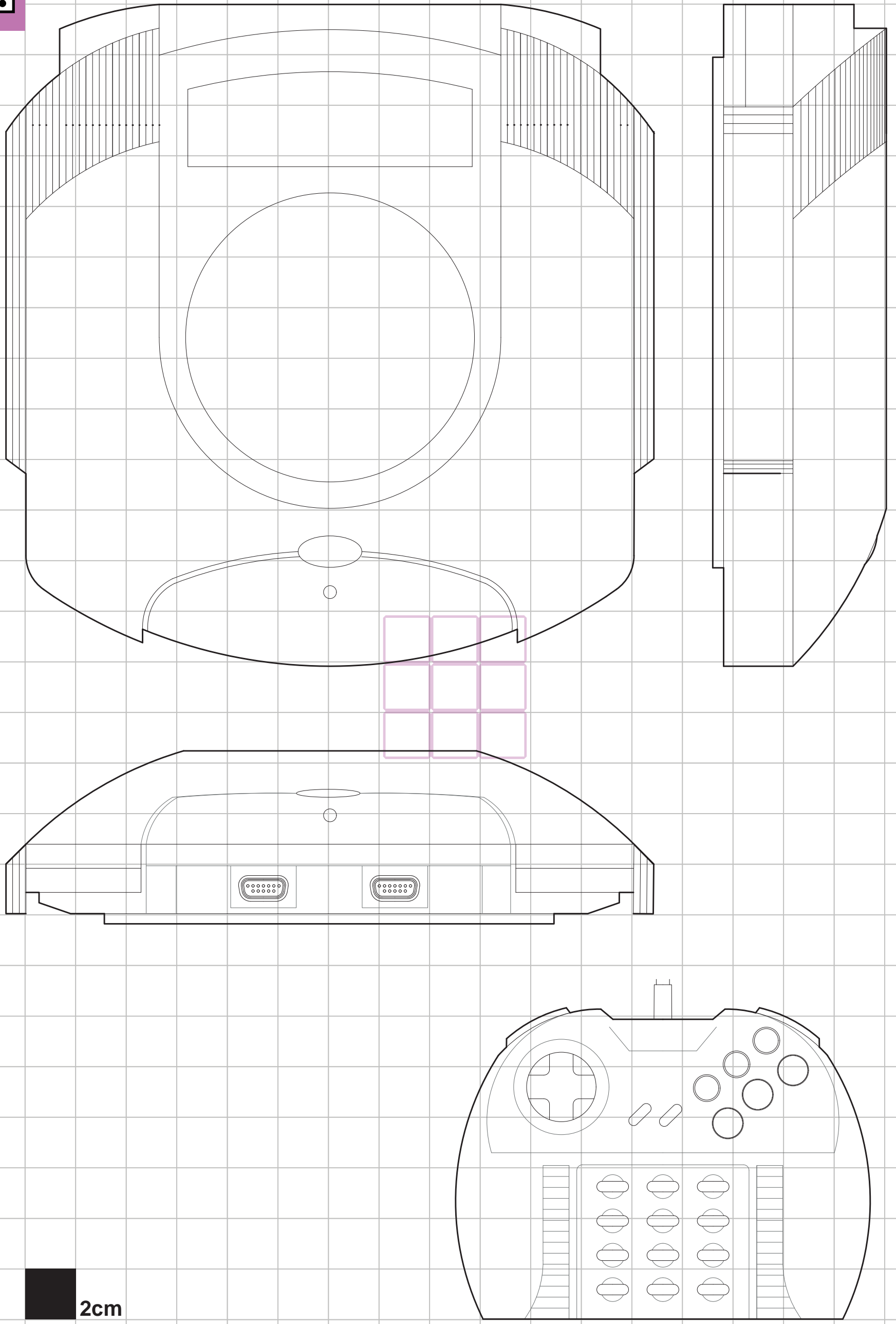


\section{Atari Jaguar.}

1993

Atari.

Videoconsola doméstica.

Videoconsola doméstica de la quinta generación desarrollada por Atari y lanzada al mercado estadounidense en 1993, que llegaría a Europa y Japón en 1994 (a España llegó en 1995). Esta consola estaba basada en un sistema de juegos en cartuchos y fue la última consola lanzada al mercado por Atari antes de su desaparición, y de la que tan solo vendió 250.000 unidades a nivel mundial.

"Aunque la Jaguar solo contaba con 16 megabits de RAM, tenía dos chips de procesamiento gráfico RISC de 64 bits. Atari la publicitó como la primera consola de 64 bits que salió al mercado, pero los competidores afirmaron que, en realidad, se trataba de una consola de 16 bits"

(Kent, pg 488, 2001)

Fue pionera por tratarse de un sistema de 64 bits que conseguía usando cinco procesadores de 32 bits que funcionaban de manera paralela, además de un coprocesador Motorola 68000. Estas características técnicas permitían que podía correr videojuegos en 3D.

Pese a sus características técnicas por encima del resto, los errores en el diseño de hardware, la compleja arquitectura de chips, la falta de herramientas para que empresas third party pudieran desarrollar juegos y la falta de desarrollo interno de Atari llevó a una biblioteca de juegos de sólo 63 títulos.

Posteriormente Atari intentó mejorar el sistema publicando el CD Atari Jaguar que permitía leer juegos en CD. El controlador del Atari poseía un tamaño considerable, una cruceta direccional, tres botones de juego y otros dos más de Pause y Option, además de un teclado de doce botones extras que recordaba a las primeras consolas de la marca.

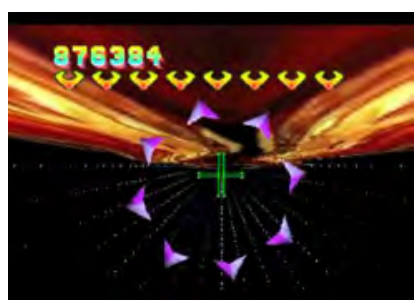

Tempest 2000.

1993

Videojuego de disparos en que el jugador controla una nave espacial - Blaster en forma de garra original. La misión del jugador es sobrevivir y viajar a través de múltiples niveles hasta el final en una guerra intergaláctica, luchando contra una variedad de enemigos que aparecen en el campo de juego. El juego modifica la jugabilidad de su predecesor mediante la adición de potenciadores - que aparecen como objetos poligonales - niveles de bonificación, enemigos más sofisticados y diseños de niveles red tremendamente variables (con un total de 100).

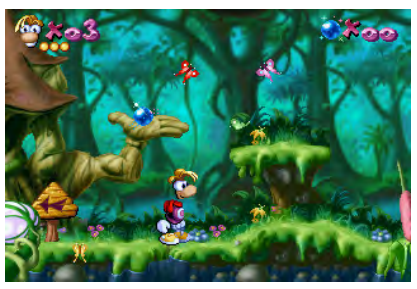

Rayman.

1995

Videojuego de plataformas de desplazamiento lateral en que el protagonista controlado por el jugador - Rayman - debe recorrer 6 mundos - dividido a su vez en varios mapas - para liberar a todos los Electoons enjaulados y enfrentarse al Sr. Dark. Destacó por la calidad de sus gráficos y de su animación.

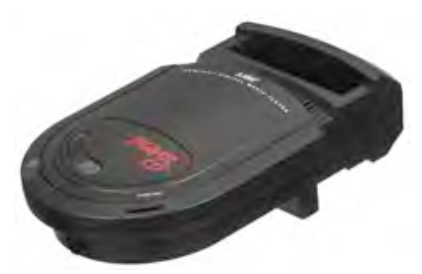

\section{ACCESORIO}

Jaguar CD.

Extensión que permitía reproducir juegos en formato CD Rom, y por tanto de mayor dimensión y calidad gráfica. Publicado en 1995.

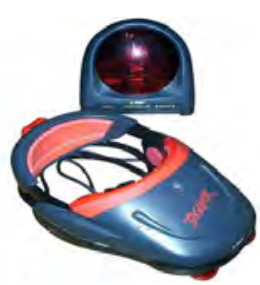

\section{ACCESORIO}

Jaguar VR.

Casco que el jugador podía colocarse a modo de gafas y permitía visualizar los juegos en una realidad virtual inmersiva. Publicado en 1995. 

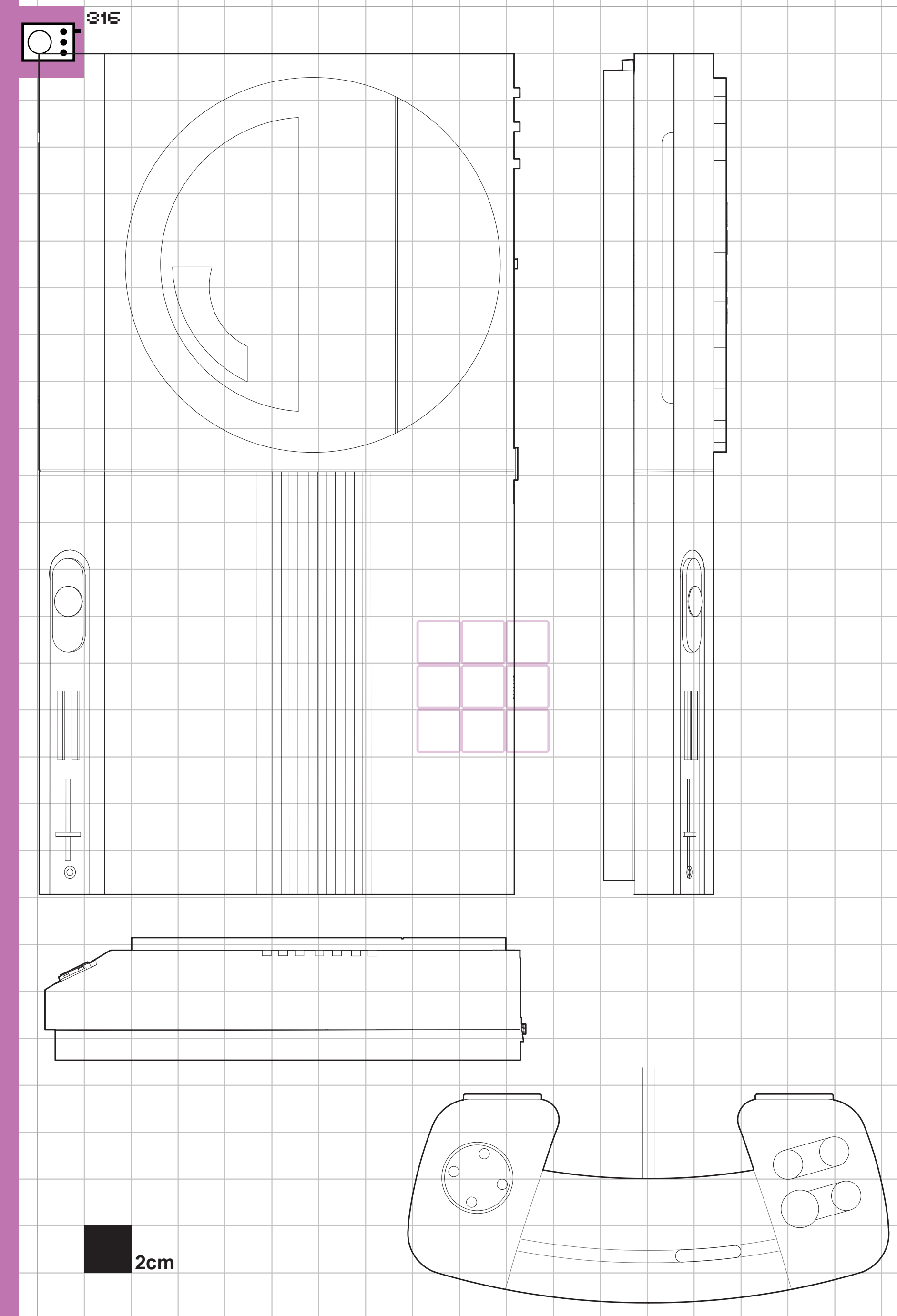


\section{Amiga CD32 \\ Commodore.}

\section{3}

\section{Commodore.}

Videoconsola doméstica.

Videoconsola doméstica de 32 bits, que perteneció a la quinta generación, desarrollada por Commodore International y lanzada al mercado en 1993 y descontinuada en 1994, vendiendo tan solo alrededor de 100.000 unidades.

Forma parte de la familia Amiga de Commodore, siendo muy similar al ordenador amiga de tipo 1200. Estaba basada en un sistema de juegos en CD (Bagnall, 2006) Esta consola tenía un procesador Motorola 68EC020, una memoria RAM de 2MB y su chipset estaba basado en la Arquitectura Gráfica Avanzada de Commodore y contaba con el sistema operativo AmigaOS 3.1, era capaz de mostrar 256 colores en pantalla.

Disponía de un controlador de diseño peculiar con una cruceta direccional y cuatro botones de juego. Se diseñaron dispositivos que permitían ampliar su potencia, como un disco duro, así como un teclado de la marca IBM.

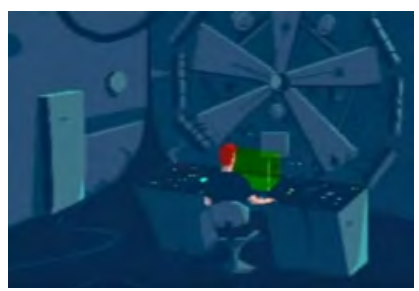

Another World.

1991

Videojuego de acción y aventuras, pionero en el uso de efectos cinematográficos en tiempo real y en escenas de vídeo.

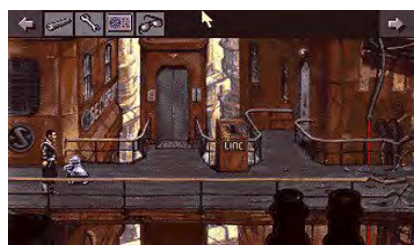

Beneath a steel sky.

1994

Videojuego de aventura gráfica tipo point-and-click de género ciencia ficción cyberpunk que sitúa al jugador en un futuro distópico en que la tierra se ha visto afectada por la contaminación y la lluvia radioactiva. En este juego, a diferencia de otros muchos, la muerte del protagonista es posible. El juego fue desarrollado en 2D y se juega en una perspectiva en tercera persona. El jugador avanza en el juego apuntando y haciendo clic para interactuar con el entorno y los objetos, guiando al protagonista por el mundo. Pueden recogerse objetivos y elementos necesarios para la resolución de puzzles. Las conversaciones con los jugadores controlados por la programación suceden a través de árboles de diálogo.

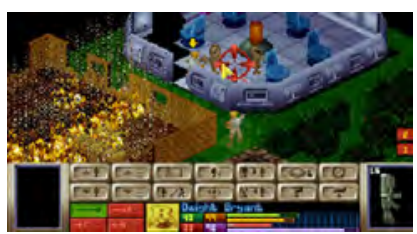

UFO: Enemy Unknown (X-COM:UFO Defense). 1994

Videojuego de ciencia ficción y estrategia que mezcla el juego por turnos con la simulación de gestión y tiempo real. El juego muestra diferentes representaciones globales de la Tierra además de vistas isométricas en mapas generados de forma semialeatoria. El jugador se convierte en una comandante paramilitar que defiende la Tierra de una invasión alienígena. 

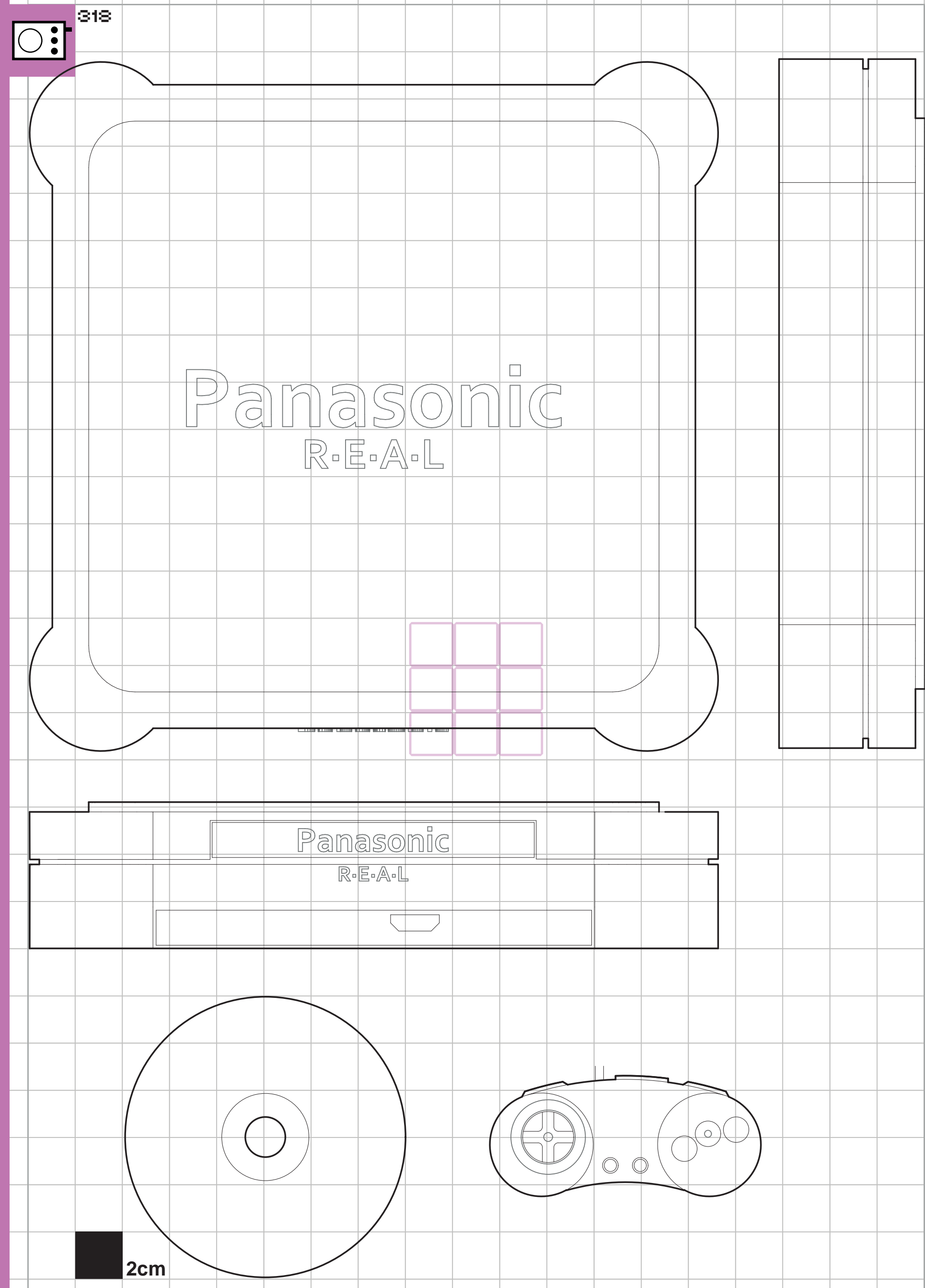


\section{Do.}

\section{3}

Trip Hawkins.

Videoconsola doméstica.

Videoconsola doméstica que fue definida como una línea de dispositivos dentro de la misma tecnología, lo que permitió que Panasonic (el modelo más exitoso), Sanyo y Goldstar lanzaran sus propias versiones basándose en las especificaciones técnicas que definió The 3Do Company. Esta tecnología fue ideada por el fundado de EA Games, Trip Hawkins (Kent, 2001).

El modelo de empresa fue diseñado como un dispositivo CD que podía ser licenciado a diferentes empresas. Sin embargo, su elevado precio en un sobresaturado mercado de consolas, le supuso un fracaso prematuro vendiendo solo un millón de unidades. Esta consola salió al mercado estadounidense en 1993 y llegó un año después a Japón y a Europa; y fue descontinuada en 1996.

Era una consola de 32 bits, que disponía de un microprocesador ARM60 de 32 bits RISC como CPU, así como un coprocesador matemático, la placa base disponía de una memoria RAM de 2MG. Disponía de una resolución en pantalla de 640×480 píxeles y permitía que se pudiesen conectar hasta ocho mandos de manera simultánea. Las especificaciones técnicas variaban en función de la empresa.

Fuente análisis gráfico:

Elaboración propia a partir de los datos del manual original de la consola archivado en manualsdir.com.

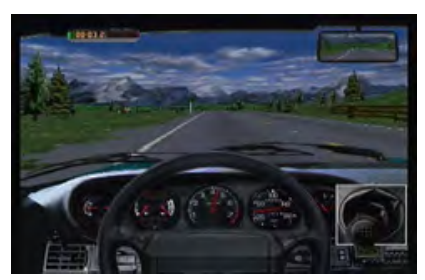

Need for Speed.

1994

Videojuego de carreras que dio lugar a una saga extensa de juegos. Se trata de una simulación realista de los elementos de manejo del automóvil a través de una colaboración directa con revistas de automovilismo americanas, incluyendo cuestiones como el subviraje realista que sigue siendo impresionante décadas después, así como los sonidos emitidos por las palancas de control de los vehículos y otras funciones. El juego contenía datos del vehículo con comentarios hablados, varias imágenes reales de cada automóvil y cortos de vídeo que destacaban los vehículos.

\section{ACCESORIO}

Gamegun.

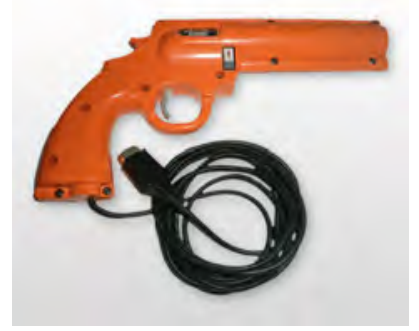

Pistola de luz que permitía disparar desde el exterior al interior de la pantalla.

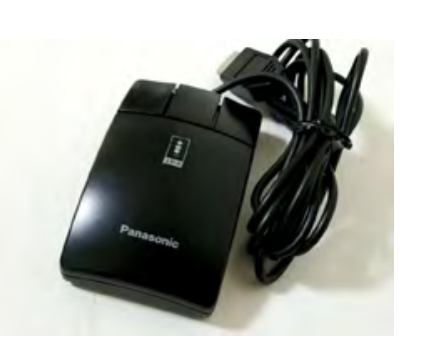

ACCESORIO

Mouse 3do.

Controlador en forma de ratón diseñado para aproximar la consola a un ordenador. 


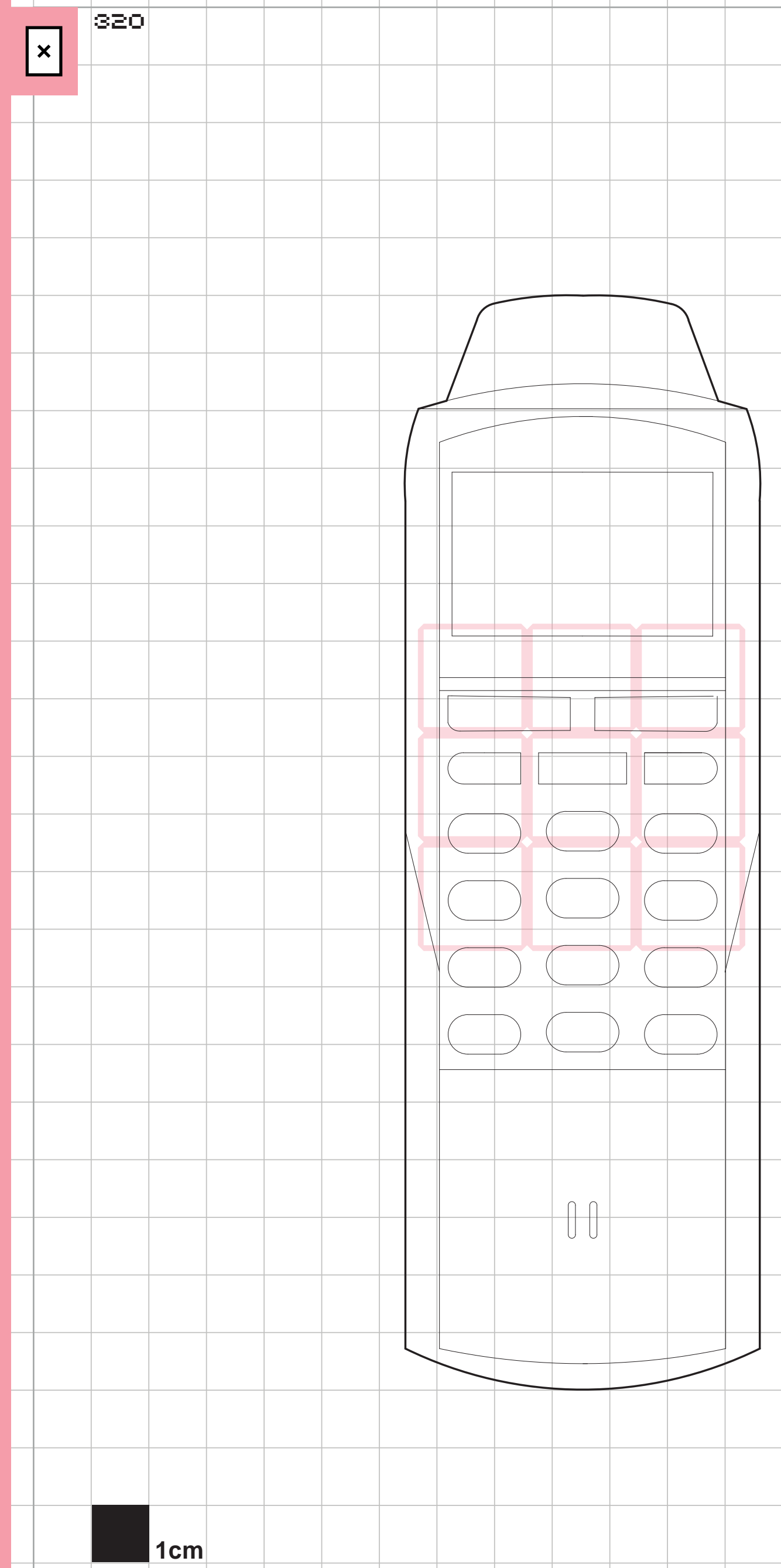




\section{GSM \\ Hagenuk \\ mt-2000.}

\section{4}

\section{Hagenuk.}

Teléfono móvil.

Teléfono móvil desarrollado por Hagenuk y lanzado al mercado en 1994. Destaca por ser el primer teléfono móvil que se vendió con un videojuego incluido en el sistema para poder jugar (Tetris). También fue pionero por tener antena incorporada, dejando de lado las extensibles. 
Aptiva. 1994

Ordenador.

Ordenador doméstico lanzado al mercado por IBM en 1994, fue descontinuado en 20019.
desarrollaron, diferentes modelos siendo
más notables a auellos que incluyeron Pentium (microprocesador) ye listema operativivo Windows
95 . Disponia de pantalla en color e incluía en los

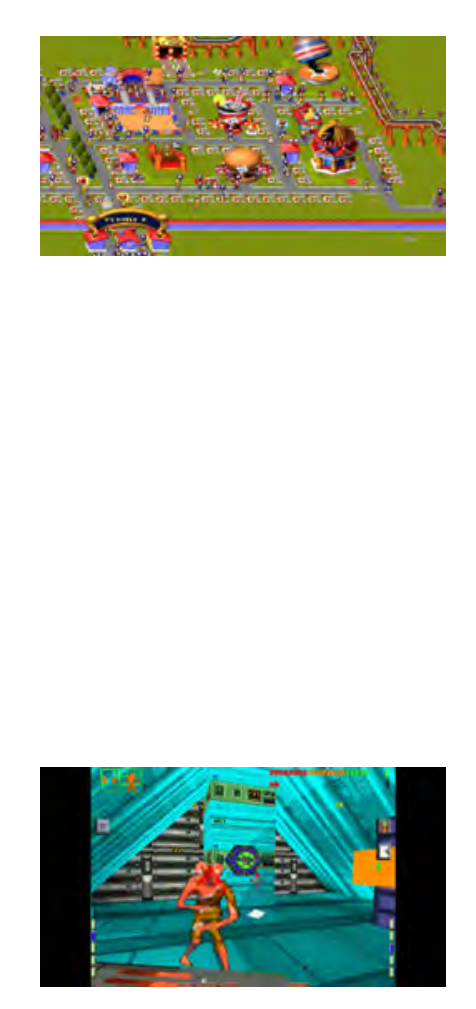

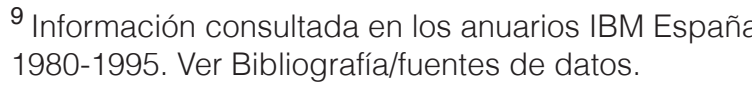
Fuente análisis grático:
Elaboracion propia a artir del propio ordenador y de la
consulta de los manuales de lBM España entre 1980 y
1995 .
Theme Park.

Videojuego de gestión
simulación de construcción de un parque de atracciones y caumentar su valor para expandirse por
mundo. El juego tiene tres

Sagador hasta que progre

The Elder Scrolls. piveles de simulación; así en
ecompleto el iugador debe negociaciones, acsigacionenes en sandbox, el juego campeón prisionero en unas
azmorras de las que debo escapar con ayuda de un
personaje espiritual (Ria) sccatara al rey salvándolo de mago maligno Jagar Than
El juego, en primera persona inmenso que mezcla
intenido generado de contenido generado $d e$
forma procedural y lugares diseñados especificamente lodo tipo de ubicaciones
(posadas, pueblos, elc) contemplada hasta momento. Fue uno de los un ciclo realista día / noch todos los juegos de mundo tiendas y la gente limpia las calles antes de que lleguen
los monstruos y y deambulan los monstruos y
hasta la mañana. Flight Unlimited.
1994

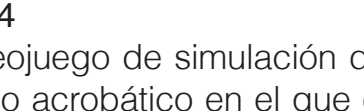

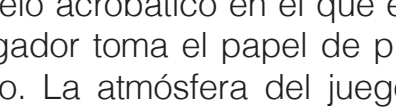
loto. La atmóstera del jueg
está simulada basándose en dinámicac de fluídos. El mur murwe construido en $3 \mathrm{D}$ Studiolo se empleó estereofototorrametria basandose en fotogratias las que se creaban reproducciones de aproximadament

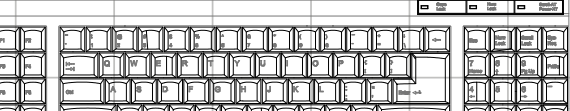

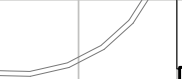

$5 \mathrm{~cm}$
Decent
1995 


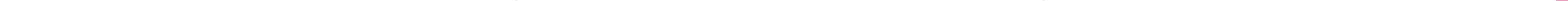


圆 $^{82}$
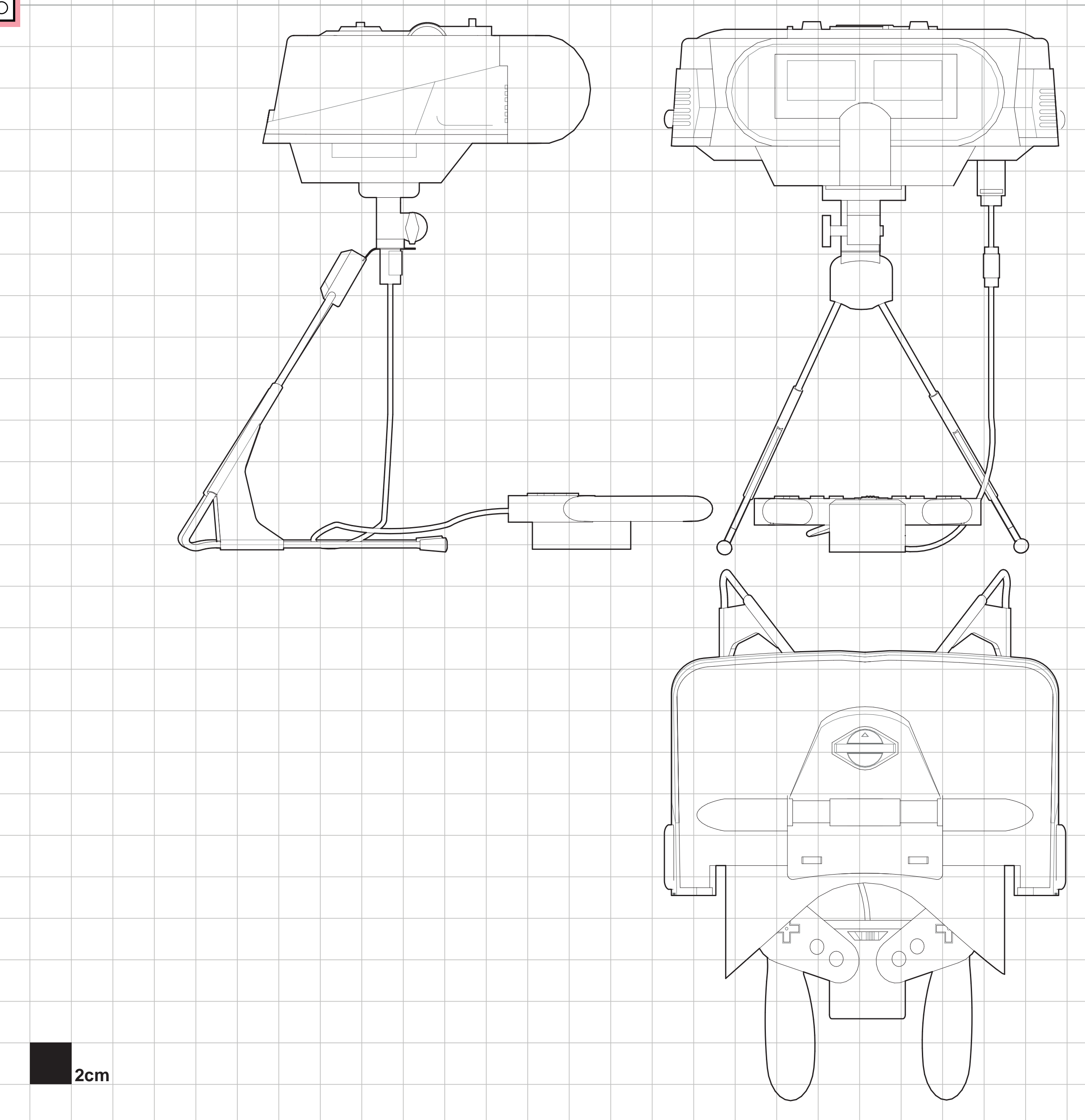